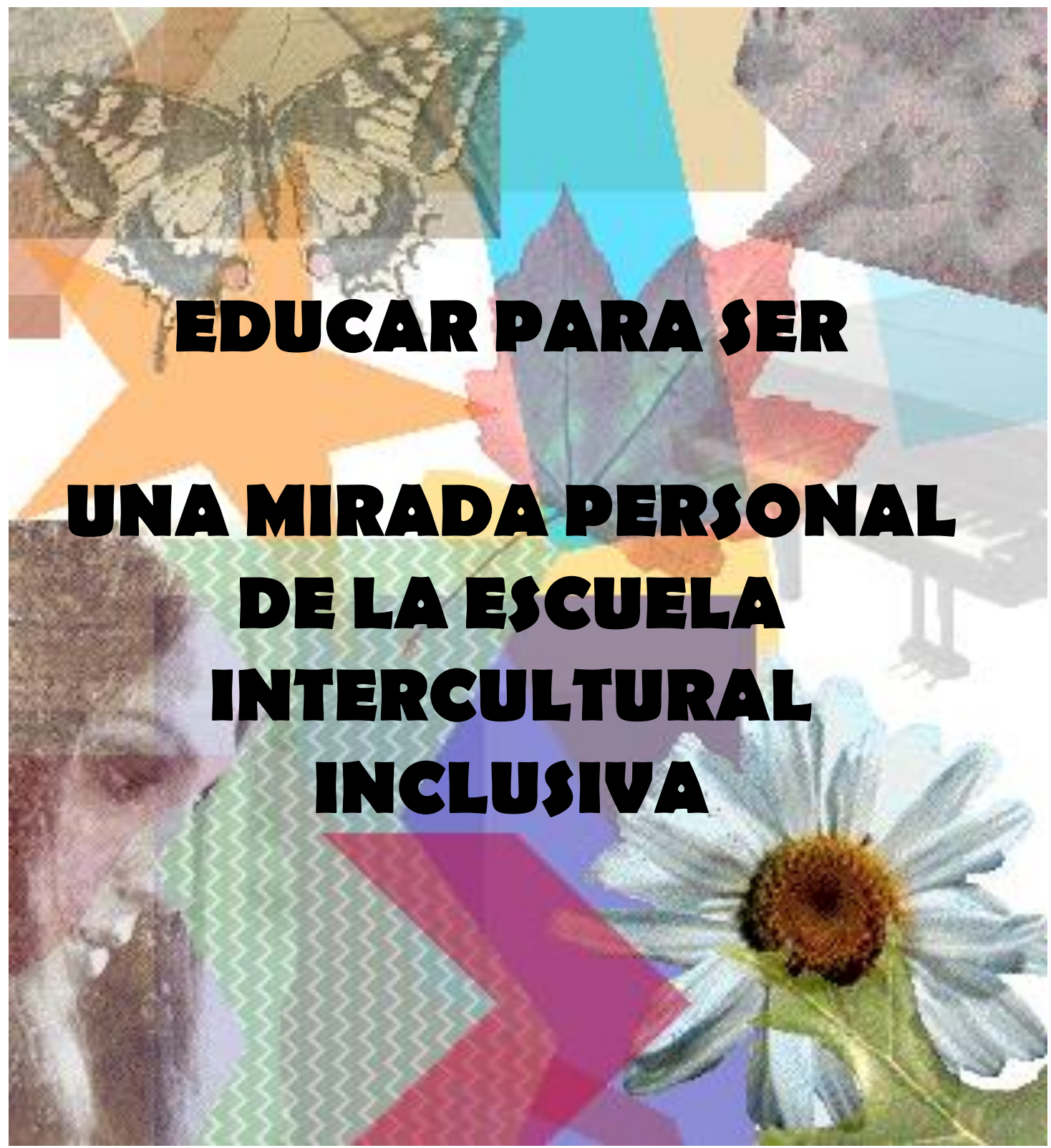

Tesis doctoral

Paula Escobedo Peiro

Dirigida por: Ma Auxiliadora Sales Ciges y Joan A. Traver Martí

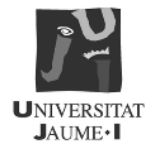

Enero 2016 


\title{
EDUCAR PARA SER
}

\section{UNA MIRADA PERSONAL DE LA ESCUELA INTERCULTURAL INCLUSIVA}

\author{
Tesis doctoral
}

Autora: Paula Escobedo Peiro

Dirigida por: M $^{\mathrm{a}}$ Auxiliadora Sales Ciges y Joan A. Traver Martí

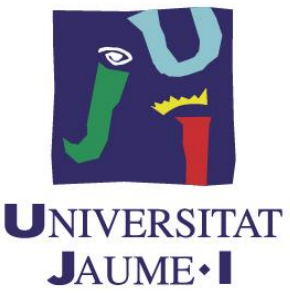

Enero 2016 


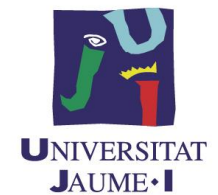

AUTORA: Paula Escobedo Peiro

\section{(c) (i) $(9)$ \\ BY NC ND}

Esta obra está sujeta a una licencia Creative Commons:

Reconocimiento - No comercial - SinObraDerivada (ccby-nc-nd):

Http://creativecommons.org/licences/by-nc-nd/3.0/es

Cualquier parte de esta obra se puede reproducir sin autorización pero con el reconocimiento y atribución de los autores. No se puede hacer uso comercial de la obra y no se puede alterar, transformar o hacer obras derivadas. 


\section{ÍNDICE}

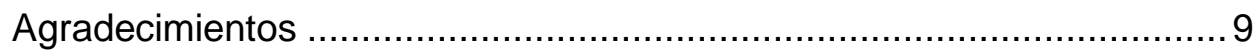

Aquello que no os había contado sobre la tesis................................11

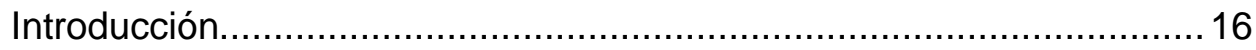

1. El Cambio Educativo hacia La Igualdad De Oportunidades .......21

1.1. Antecedentes. El Cambio Hacia La Mejora Educativa ................24

1.2. La institucionalización del cambio y su dirección hacia una acción

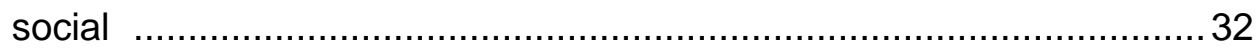

2. La CONSTRUCCIÓN DE LA ESCUELA INTERCULTURAL INCLUSIVA ............41

2.1. Diversidad, Diferencia y Desigualdad ..................................... 45

2.2. Modelo Educativo Intercultural Inclusivo .....................................49

2.2.1. Modelo intercultural ....................................................... 49

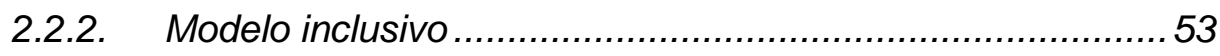

2.2.3. La conjugación entre ambos modelos ...............................55

2.3. La Participación Comunitaria ................................................... 61

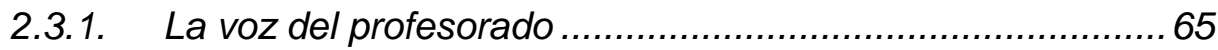

2.3.2. La voz de las familias y otros agentes comunitarios ............ 70

2.3.3. La voz del alumnado...................................................... 76

3. Prácticas INTERCULtURALES E INCLUSIVAS ....................................... 81

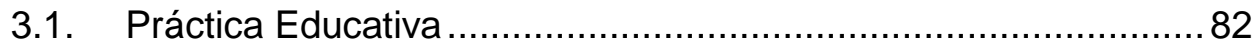

3.2. Prácticas Interculturales Inclusivas en el centro y en el aula.......87

3.2.1. Aprendizaje constructivista: Proyectos de Trabajo............... 88

3.2.2. Aprendizaje cooperativo ............................................... 90

3.2.3. Aprendizaje dialógico...................................................... 94

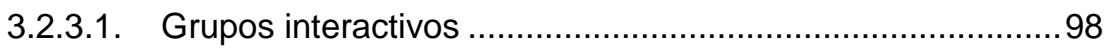

3.2.3.2. Tertulias literarias dialógicas .................................................99

3.2.3.3. Comisiones mixtas ...........................................................102 
3.2.4. Las Asambleas de aula ................................................... 103

3.3. El profesorado en la práctica docente .................................... 106

4. LAS EMOCIONES EN LA EDUCACIÓN....................................................113

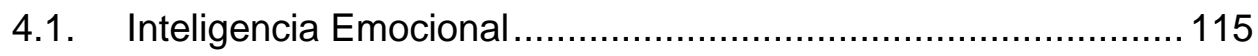

4.1.1. Origen de la IE: Las inteligencias múltiples de Gardner..... 115

4.1.2. Concepto de Inteligencia Emocional.............................. 117

4.2. Educación Emocional ...........................................................122

4.2.1. Objetivos y contenidos de la educación emocional ............ 128

4.2.2. Competencias emocionales......................................... 131

4.3. Educación Holística ........................................................... 135

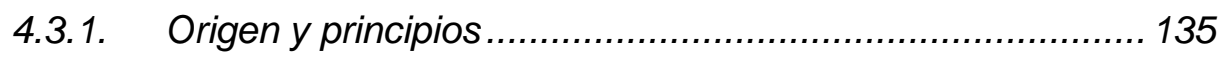

4.3.2. Aprender a ser........................................................... 143

4.4. El educador y su trabajo personal....................................... 146

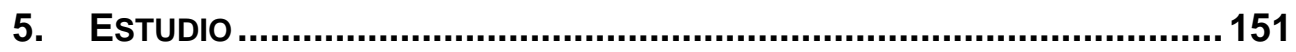

5.1. Historia del centro y contexto ….......................................... 152

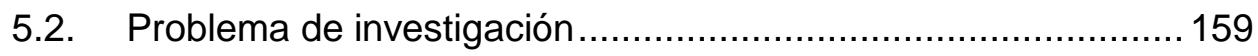

5.3. Preguntas y objetivos de la investigación ............................... 160

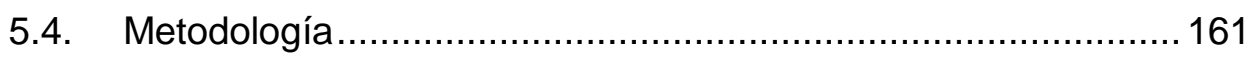

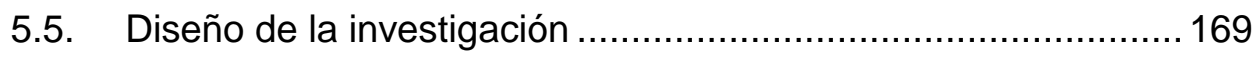

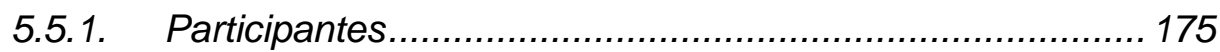

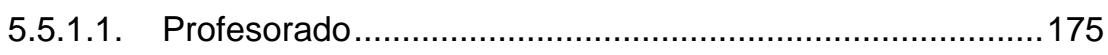

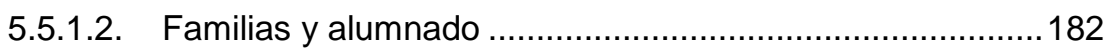

5.5.2. Técnicas de obtención y producción de la información ....... 189

5.5.2.1. Observación participante ..................................................189

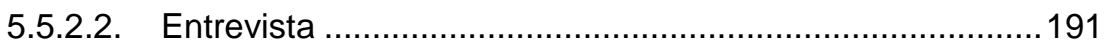

5.5.2.3. Grupos de discusión ........................................................195

5.5.3. Técnicas de registro de la información............................... 196

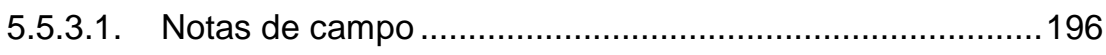


5.5.3.2. Diario de la investigación

5.5.3.3. Vídeos, audios y transcripciones

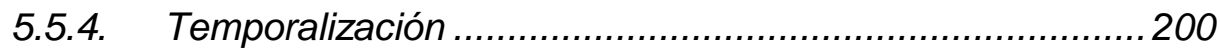

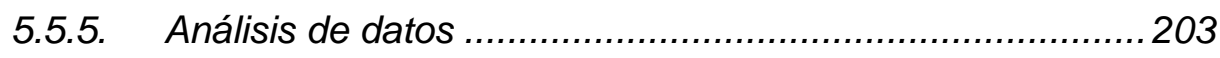

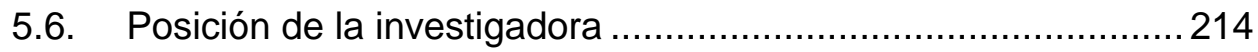

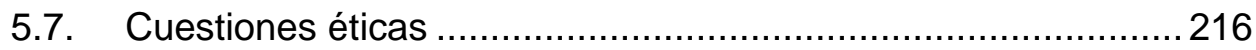

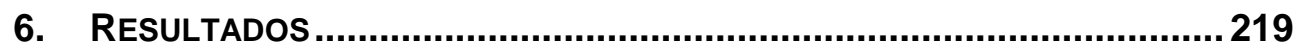

6.1. Las condiciones del cambio ..................................................223

6.1.1. Creencias favorables hacia el cambio .............................224

6.1.1.1. Concepciones pedagógicas …………………….............225

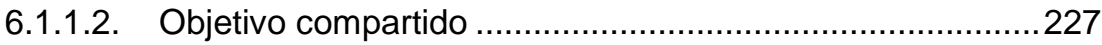

6.1.1.3. Ilusión .............................................................................229

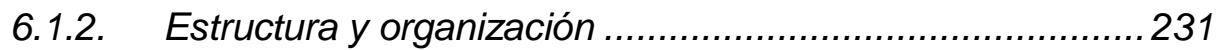

6.1.3. Liderazgo equipo directivo .......................................... 232

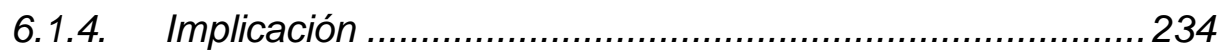

6.1.4.1. Implicación del profesorado …………………………......235

6.1.4.2. Implicación de las familias ………………………….......236

6.1.4.3. Implicación del alumnado..................................................239

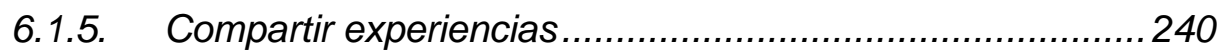

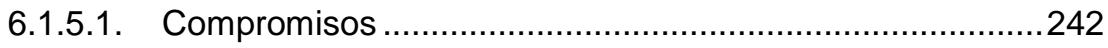

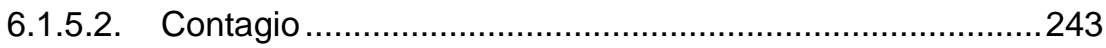

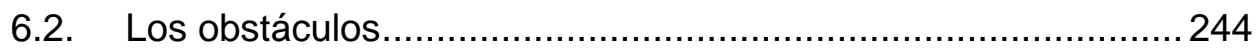

6.2.1. Creencias negativas hacia la diversidad y el cambio .........245

6.2.1.1. Bajas expectativas ..........................................................246

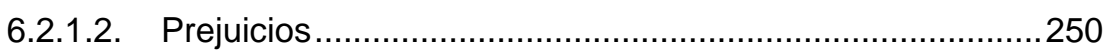

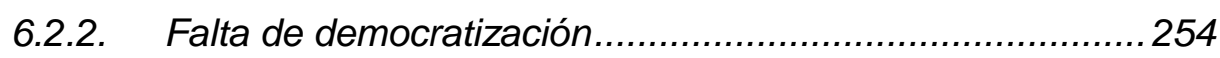

6.2.3. Falta de colaboración docente ..........................................261

6.2.4. Cultura dominante asimilacionista ................................ 265 


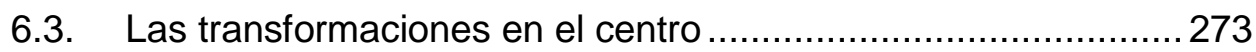

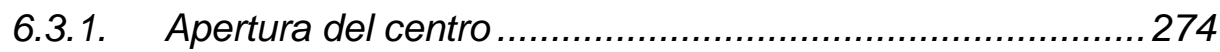

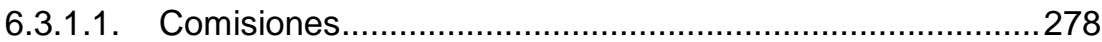

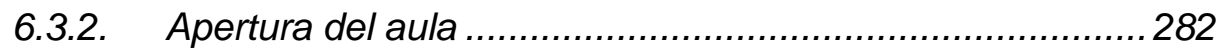

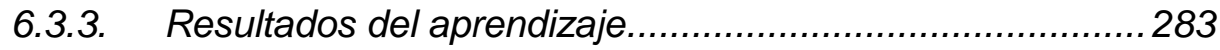

6.3.4. Relación familia - escuela .............................................285

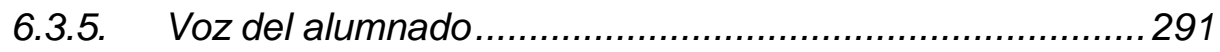

6.3.5.1. Conocimiento del cambio ..................................................291

6.3.5.2. Conocimiento de las prácticas de aula .............................294

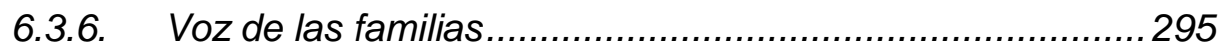

6.3.6.1. Implicación: Entrada en la escuela y en las aulas .............296

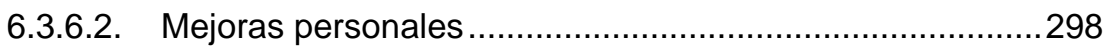

6.4. Las transformaciones en el aula de Estefanía ..........................300

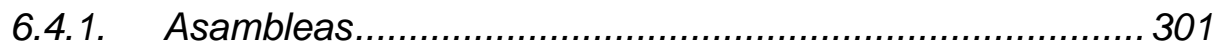

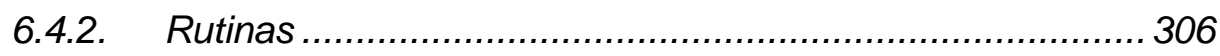

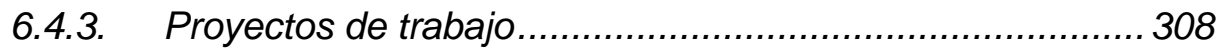

6.4.3.1. Gestión del grupo ............................................................311

6.4.3.2. Cooperación y competitividad ............................................316

6.4.4. Tertulias literarias dialógicas............................................ 317

6.4.4.1. Flexibilidad en la tarea ......................................................319

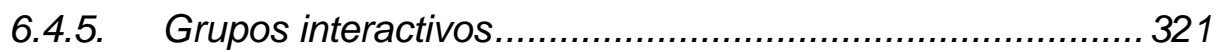

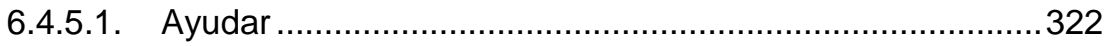

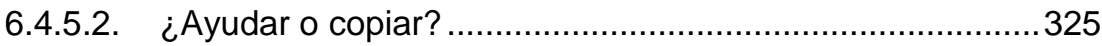

6.4.5.3. Clase magistral: Contraste con la práctica de Grupos

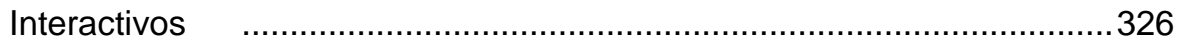

6.4.6. Participación de todo el alumnado .................................. 328

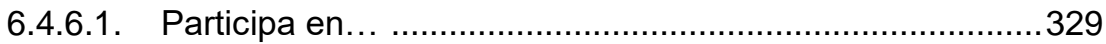

6.4.6.2. Difícilmente participa en... ..............................................332 
6.4.6.3. Motivación del alumnado

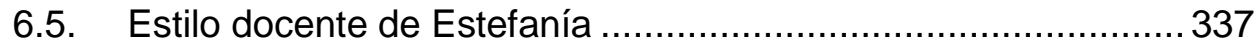

6.5.1. ¿Educar para estar o educar para ser? ........................... 340

6.6. La historia de vida de Estefanía ............................................. 348

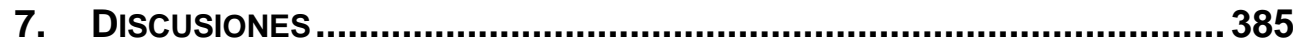

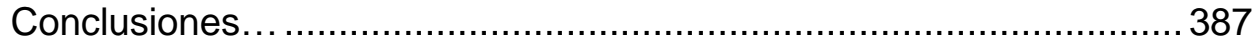

7.1. El cambio educativo: más allá del rol docente .........................391

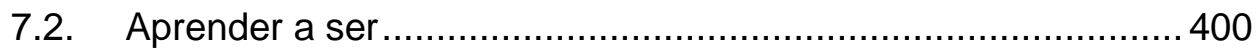

7.3. Educar para ser: el trabajo personal y la historia de vida ..........412 Limitaciones, aportación del estudio y futuras líneas de investigación 415

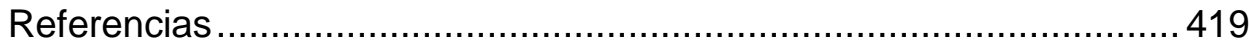

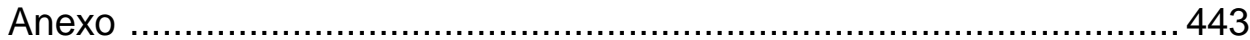





\section{Agradecimientos}

Agradezco a mis compañeros del grupo MEICRI su acompañamiento durante mi proceso en la investigación, gracias por poder compartir mis inquietudes como investigadora y poder aprender al lado de personas que igualmente se plantean la investigación desde la igualdad, la justicia social y el amor por la ciudadanía.

Gracias a los compañeros de la Universidad, especialmente al equipo de prácticas, por vuestra paciencia, apoyo y comprensión en estos últimos meses.

A Isabel, la primera persona que me abrió las puertas del mundo de la investigación, permitiéndome entender la complejidad del mundo educativo desde la academia y también desde las aulas de las escuelas.

Gracias a Auxi y a Joan, amigos y directores. Gracias por confiar en mí y por querer que la tesis no fuera solamente un informe escrito, sino otro camino para empezar a conocerme por dentro. Gracias por mostrarme la investigación como una acción humanista y humanizadora y por ser vosotros un ejemplo en vida de todas las teorías que hablan de compromiso y de equidad.

Gracias Honorio por ser otro maestro en este camino. Gracias por tu paciencia y comprensión, por tu humildad -a pesar de tu gran experiencia y conocimientos- al revisar mis reflexiones, y tu tacto al expresar las tuyas. Gracias por ayudarme a confiar en mí como otra investigadora educativa y por acercarme a la etnografía. Sobre todo, gracias por tu acompañamiento constante y tu ayuda incondicional.

A Gloria, porque nuestro encuentro fue un rayo de luz en medio de una tormenta. Por las conversaciones inspiradoras que tantas veces compartimos y por tu acompañamiento para encontrar el sendero de la tesis y el camino.

Gracias a todos los miembros de la escuela en la que se realizó el estudio. A las familias por confiar en la escuela y permitirnos aprender con ellas, al personal 
de servicio de la institución, especialmente a Javi y a las cocineras por hacer más fácil y agradable la vida en el centro. Gracias al alumnado, por permitirnos aprender la complejidad del mundo educativo y dejarnos fascinar por sus logros en la escuela. Al profesorado del centro, por confiar y dejarse llevar por este proyecto y por ayudarnos a replantearnos las limitaciones del mismo en el campo. A Víctor, a Mar y a Vero, porque todo lo difícil parecía fácil y por abrir las puertas de la escuela a todas las personas que quisieran formar parte de la misma.

Gracias yayos, papá, mamá, Andrea por vuestra paciencia y cariño, por estar a mi lado durante todos estos años, apoyándome en los momentos de desconfianza y ayudándome siempre. Especialmente a ti mamá, por tu ejemplo como maestra comprometida, por tu apoyo como madre y por tu ayuda en este trabajo.

Gracias Víctor por estar ahí, por no decir nada y saber siempre qué decir. Por tu ayuda y compañía en todos los aspectos de mi vida, y sobre todo, por tu paciencia y comprensión durante la realización de este trabajo. Gracias por la paz que has inspirado en mí.

Finalmente quería dar las gracias a Estefanía, investigadora y agente principal de la transformación, maestra, madre, entusiasta de la educación y de la vida. Gracias por dejarme aprender y compartir mi historia con la tuya para crecer humildemente como investigadora y como persona.

Gracias a todos vosotros por vuestro acompañamiento y por compartir conmigo este trabajo. Así ha sido más fácil. 


\section{Aquello que no os había contado sobre la}

\section{tesis}

Para mí la realización de esta tesis ha sido un punto de arranque para conocerme, para indagar en mi mundo y mirarme por dentro. Ha sido una tarea en muchos momentos paralizante, en otros un fuerte motor de autorrealización. Algunas veces ha sacado mis peores pensamientos, mi mayor solitud, y otras, me he sentido la persona más acompañada. Todas estas contradicciones han formado parte del proceso de realización de mi tesis.

Aún recuerdo el curso que realicé en Barcelona en enero del año 2012, cuando al final del curso exprese mi angustia por no saber cómo hallar el problema de investigación. Las respuestas de mis compañeros me sorprendieron, algunos me dijeron que eso era lo más normal y que vendrían muchas otras frustraciones en el proceso de la investigación. En ese momento ya llevaba unos meses estancada, tratando de definir mi problema de investigación. Y digo mi problema, porque entonces no esperaba que el mismo fuera compartido. Mis ganas de que alguien llegara y me diera la solución, despejara cualquier problemática y como si se tratara de una receta de cocina, me dijera los pasos a seguir, parecía ya una utopía. Pero aun esperaba alcanzarla.

También recuerdo aquella tarde en el Café dels sentits, cuando tras una reunión del grupo de investigación Joan y Auxi me dijeron que aprovechara el trabajo de la tesis para crecer también personalmente. Recuerdo mi emoción y mis ganas de realizar este trabajo. También a Joan diciéndome que aunque ahora me mostrara muy dispuesta me vería enfrontada a mis miedos, que era una persona muy "cuadriculada" y la realización de un trabajo más flexible y sin pautas previas de acción me provocaría, al menos, incomodidad. Por otra parte, resuena en mí la 
voz de Auxi alentándome a descubrir ese nuevo mundo que se escondía tras la incertidumbre de la entrada al campo y tras la pasión puesta en la vida, en disfrutar de un buen libro, de una buena película, o como Joan me dijo, de alguna que otra noche loca para descubrir la belleza de la vida más allá de las obligaciones, de la rutina y de nuestros límites. Y ahora desde la lejanía del momento lo entiendo. Y me veo... me veo distinta, pero más fiel a mi manera de ser que nunca antes.

Veo en la lejanía a una muy buena estudiante, que conocía las estrategias para reproducir aquello que el docente esperase de ella. Pero también veo a aquella niña asustada, con miedo de ser creadora de su propia historia, de tomar las riendas de su vida. Y todo eso, ¿iba a ser posible a partir de un acto académico? La teoría me atraía, pero a fin de cuentas no iba a dejar que saliera la persona creadora si eso implicaba la posibilidad de no gustar a la academia y a su público. Seguía necesitando un modelo que copiar y recrear para que la representación fuera tal y como se esperaba de ella.

Sin embargo, las palabras de Joan y Auxi calaron en mí profundamente y creí que era posible sentir la tesis como una oportunidad para crecer interiormente. Creí tanto, que sentí todas las ganas del mundo de ir destapando aquellas capas que estaban inundando mi autenticidad, que no me dejaban mostrarme tal y como soy. Y con todo esto, me dispuse a seguir leyendo teorías sobre educación y "el cambio educativo", pero en esas teorías, me sentía totalmente perdida y no sabía por dónde empezar.

Durante los meses previos a la entrada en el campo, mi relación con Auxi y Joan cada vez era más dependiente. Aunque durante ese proceso quizás nos reunimos dos veces, mi estado de angustia les llegaba, supongo porque toda yo así lo expresaba. Uno de esos días, estaba en el despacho de Auxi para comentarle algo de la tesis. No recuerdo muy bien la conversación pero sí que Joan me miró directamente y me preguntó a qué tenía miedo. ¿Por qué no empezaba con la tesis, qué me estaba paralizando? Me dijo que seguramente la tesis iría bien, pero que podía ser que no, aun así no pasaba nada, tendría que aprender haciendo y ahora era el momento de lanzarse. Aunque desde la distancia veo cuánta razón tenía, en 
aquel momento mi miedo no se iba. En una de las reuniones para sentarnos a discutir sobre el estudio, fue tal el embrollo que me sentí totalmente sola. Parecía que cada vez que me sentaba con ellos para obtener alguna respuesta me iba con más preguntas, y esa era la intención, esa era la manera para poder crecer, aunque en ese momento yo no la compartía. Enfadada, decepcionada con ellos, pero sobretodo y únicamente conmigo misma por sentirme tan bloqueada, decidí empezar.

Con la inicial entrada en el campo mis visitas al despacho de Auxi y Joan se hicieron más constantes. En el colegio ya estaban pasando cosas y yo no quería perderme nada, pero tampoco sabía qué era aquello tan importante que no me podía perder. El problema de investigación seguía escondido. Al final me di cuenta de que lo único que tenía que hacer era dejar a un lado ese miedo que me estaba limitando. Eso lo hice al cabo de unos meses, cuando ante la desesperación llegué al campo dispuesta a equivocarme por no saber cuál era la respuesta ni tampoco la pregunta.

Con la entrada al campo mi inseguridad fue desapareciendo. Todo lo que me habían dicho Auxi y Joan tenía más sentido. Ya no era mi problema de investigación, sino una propuesta dialogada en una comunidad, en función de sus problemáticas y necesidades.

Desde el momento en que empecé el trabajo de campo, el asesoramiento con Auxi y Joan se convirtió en lo que su nombre indica: asesoramiento. Tomé las riendas de la tesis y me sentí totalmente segura de las cosas que iban sucediéndose. No sabía muy bien cuál iba a ser el siguiente paso, las cosas se disponían a una velocidad en la que yo no podía planear con demasiada antelación. Tras una decisión venía otra, pero todo se sucedía con total naturalidad y me sentía tan cómoda en el proceso que se disipó cualquier miedo.

No quiero decir que todas las decisiones fueron acertadas. Cada una de ellas me llevó a un punto distinto, pero todas tenían sentido para mí y pienso que también para las personas con las que iba investigando. 
La angustia vino en verano, cuando tuve que sentarme a profundizar en los datos. Profundización que poco a poco fue disipándose por no saber tampoco cómo realizar el análisis. Pero en septiembre volvía al campo y las preguntas y respuestas sobre la investigación iban a volver a disponerse una tras otra sin demasiado tiempo para pensar.

Mi decisión sobre cómo continuar el trabajo de campo, en función del problema de investigación que se había ido dibujando durante ese curso, se había ido concretando durante el verano. Sin embargo, cuando en septiembre volví al campo las circunstancias del centro habían cambiado y el proceso de la investigación debía adaptarse a la nueva realidad. Me sorprendí a mí misma tomándome este cambio de rumbo con tranquilidad.

Quizá todo la ansiedad y mis resistencias habían cesado y se habían rendido a un proceso flexible y dinámico, un proceso vivo, propio de la investigación. Mirando la vista atrás sigo viéndome y sigo viviendo procesos en los que mis resistencias y limitaciones surgen para retenerme. Pero sin duda la realización de esta tesis ha sido un gran aprendizaje, no solo como investigadora; principalmente ha sido un aprendizaje para la vida, un estudio para vencer los miedos o al menos, algunos de ellos. En mi caso, el miedo a equivocarme, la frustración por no encontrar la respuesta, o la sensación de estar trabajando y no ser productiva, han sido aspectos que he podido experimentar en el transcurso de la tesis.

Al principio, mi motivación para realizar este trabajo era aportar mi granito de arena a la educación, transformar la escuela para que fuera más justa y más accesible para todos. Ahora, me doy cuenta de que el aprendizaje reside en conocerme a mí misma y, en cuanto al tema de la educación que sigue apasionándome, mi pretensión, más que transformar es poder estar ahí: acompañar a los miembros de la comunidad educativa, aprender de la práctica y ver la convergencia entre teoría y práctica desde ambas perspectivas. Fruto de este acompañamiento he experimentado un cambio en mi manera de ver la escuela y de relacionarme con el profesorado. Quizás el tiempo que he compartido junto a ellos me ha convertido en una nativa en el campo. Quizás me he "contaminado" y he 
perdido la perspectiva más académica de la educación. Sin embargo, creo que ahora mi entendimiento de la escuela es más cercano. Entiendo las resistencias del profesorado sin vivirlas desde la cólera. Entiendo el proceso de cambio de esta escuela desde su complejidad. Y solo me queda agradecer esta experiencia por todo aquello que me ha aportado. 


\section{Introducción}

Mis experiencias en el campo de la educación como estudiante y aprendiz, me situaron en el contexto del doctorado. Tengo que decir, que todo vino un poco sin buscarlo. Mis pretensiones al iniciar magisterio musical eran continuar los estudios del conservatorio una vez finalizara la diplomatura. Sin embargo, algunas asignaturas del último curso me hicieron interesarme por el mundo de la educación, como una posibilidad para mejorar la sociedad.

Hasta entonces, conocía algo de la educación puesto que mi madre es maestra y todas las noches compartía en familia algunas de las anécdotas que sucedían en su aula. También nos contaba cada uno de los proyectos que estudiaba con su alumnado y ella misma se fascinaba por los logros de sus estudiantes. Yo también estaba presente en esas conversaciones, pero quizás porque era una adolescente un poco perdida en ese momento, o porque para mí era más mi madre que una maestra, no prestaba demasiada atención a sus explicaciones. Un día, a la hora de la cena, como era habitual, compartíamos cada uno de nosotros aquellas cosas que nos habían pasado durante el día. Esa noche yo estaba emocionada y tenía ganas de contarle a mi madre que una profesora de la universidad nos había hablado sobre proyectos de trabajo, sobre el protagonismo del alumnado en el aula, etc. Mi madre me escuchó atenta y cuando acabé me dijo que eso, los proyectos de trabajo, era lo mismo que hacía ella en clase. Un poco avergonzada y al mismo tiempo sorprendida, empecé a sentir admiración hacia mi madre como maestra. Desde esa noche escuché más activamente sus anécdotas y comencé a enriquecerme de las muestras de su práctica escolar.

Esta escucha, acompañada de algunas asignaturas de la carrera de magisterio que me cambiaron la visión sobre la educación, fueron las que me llevaron a estudiar psicopedagogía. En ese momento, pensaba que al finalizar los estudios 
prepararía oposiciones sobre pedagogía terapéutica y en un futuro quizás optaría a ser psicopedagoga en un centro educativo. Sin embargo, durante los cursos de psicopedagogía pude conocer mejor la investigación y eso me llevó a realizar el doctorado.

Los temas que me interesaban eran los cambios educativos hacia modelos de equidad y justicia social. Estos eran los que trabajaban desde el grupo MEICRI (Mejora Educativa y Ciudadanía Crítica), al que pude vincularme gracias a mis directores del trabajo de fin de master, que posteriormente pasaron a ser mis directores de tesis. Mis motivaciones a la hora de realizar la tesis eran las de conocer mejor estos cambios en los centros y contribuir de algún modo, a realizar estas transformaciones hacia una sociedad más intercultural e inclusiva.

Con estas intenciones aterrizamos en una escuela que quería transformar su dinámica, para acercarse a las familias, mejorar la relación que tenían con ellas hasta ese momento y mejorar también el rendimiento de su alumnado. Nuestra propuesta como equipo de investigación, trataba de posibilitar estos cambios pero situándose en un modelo educativo en concreto, el intercultural e inclusivo. Por eso, tras algunas reuniones con el claustro y el equipo directivo, estos decidieron realizar sesiones de formación para conocer mejor el modelo en el que nos basábamos y decidir si querían emprender este cambio con nuestro acompañamiento.

Después de estas sesiones, la comunidad educativa decidió embarcarse en la transformación del centro y yo podría acompañarles en el camino para realizar un estudio de investigación que diera muestra de su proceso de cambio. Sin embargo, sobre la práctica las pretensiones se convirtieron en acciones y estas no siempre nos llevaron dónde habíamos imaginado. En nuestro caso, nos atrevemos a decir que nos llevaron a un lugar mejor.

En este trabajo, el cambio educativo hacia modelos de mayor justicia social, se investiga junto con la dimensión más personal del mismo. A partir de un trabajo etnográfico y la historia de vida de una maestra presentamos esta investigación que 
trata de integrar la dimensión personal y emocional en la educación intercultural inclusiva.

El informe está dividido en siete capítulos que tratan de acercarnos a este propósito. En los cuatro primeros, realizaremos el marco teórico que nos permite conocer la situación actual y las distintas teorías que nos ayudan a comprender mejor nuestro caso.

En el primer capítulo realizaremos un repaso sobre el cambio educativo hacia la igualdad de oportunidades. Para ello indagaremos en los antecedentes sobre el concepto de cambio educativo y posteriormente nos basaremos en distintos autores que explican cómo se puede institucionalizar el cambio y dirigirse hacia una acción social.

El segundo capítulo trata de sentar las bases sobre la construcción de la escuela intercultural inclusiva. Para ello, explicaremos el concepto de diversidad, diferencia y desigualdad y posteriormente, el modelo educativo intercultural inclusivo; tratando en el último apartado del mismo de hacer una propuesta que conjugue ambas perspectivas. Para finalizar el capítulo hablaremos sobre un eslabón clave en esta construcción, la participación comunitaria. Realizaremos un recorrido por las distintas voces, destacando las dificultades y las potencialidades que encontramos en cada una de las mismas.

Dentro de la construcción de la escuela intercultural inclusiva, encontramos otra pieza clave, que son las prácticas educativas. En el tercer capítulo prácticas interculturales e inclusivas, nos detendremos en el concepto de práctica educativa y posteriormente definiremos algunas de las prácticas que desde la literatura se consideran interculturales e inclusivas. Finalmente, haremos mención a la figura del profesorado como eje vertebrador de las prácticas educativas y concretamente, de las prácticas de aula.

El cuarto capítulo trata de acercarnos a una dimensión más personal, y a nuestro juicio, necesaria en la construcción de una escuela más inclusiva. Las emociones en la educación, que son una parte fundamental para conseguir una inclusión más real en todos los contextos humanos. En este capítulo recorreremos 
distintas teorías, desde la inteligencia emocional, la educación emocional, hasta la educación holística. Finalmente, hablaremos sobre el educador y la necesidad de una formación que le permita trabajar con el alumnado los aspectos emocionales más cercanos a una educación integral del ser.

Una vez finalizado el marco teórico, empezaremos la parte empírica de la investigación. A lo largo de los tres últimos capítulos explicaremos cómo se ha realizado este estudio, los resultados obtenidos y finalmente, las conclusiones a las que hemos llegado.

En el capítulo 5 el estudio, hablaremos sobre la historia del centro y el contexto en el que se realiza el trabajo. Definiremos el problema de investigación, así como las preguntas y los objetivos que nos planteamos. Seguidamente, dedicaremos un apartado a la metodología de la investigación, que responde a una aproximación etnográfica sobre un caso educativo y utiliza herramientas del método biográfico-narrativo. A continuación, explicaremos el diseño de la investigación, haciendo mención de sus participantes; las técnicas de obtención, producción y registro de la información; la temporalización y finalmente el análisis de los datos. Además, en este capítulo explicaremos también cuál es el posicionamiento de la investigadora así como las cuestiones éticas que se han seguido.

Seguidamente, en el sexto capítulo, encontramos los resultados del estudio, que se han estructurado en función de los objetivos planteados y de las categorías emergentes del análisis. En esta parte también podremos diferenciar entre la presentación de datos a partir de categorías, y una última parte en la que narraremos la historia de vida de la maestra.

El último capítulo son las discusiones. Empezaremos esta parte destacando las principales conclusiones que se obtienen en el estudio, para a continuación, pasar a discutir algunas de ellas. Finalmente, el trabajo termina con las limitaciones, la aportación del estudio y las futuras líneas de investigación. 



\title{
1. El Cambio Educativo hacia La Igualdad De Oportunidades
}

\author{
Cuando comenzaba mis prácticas de \\ psiquiatría, uno de los primeros días de trabajo en \\ el hospital vi a una mujer que gateaba por el suelo \\ del pabellón. Por su tablilla supe su nombre y me \\ acerqué a ella, y le pregunté: \\ -Mary, ¿qué estás haciendo? Ella me miró y \\ muy sincera y honestamente, me respondió: \\ -Estoy haciendo lo mejor que puedo. \\ 18). \\ Me quedé sin palabras (Krishnananda, 2012, p.
}

Hablar de cambio educativo nos puede llevar a muchos horizontes, pero el cambio educativo que nosotros divisamos es el que trata de aproximarse a la igualdad de oportunidades. Aunque este es uno de los principales objetivos de la escuela, algunas autoras argumentan que es difícil garantizar el éxito escolar orientado hacia la igualdad (Mata y Ballesteros, 2012), pues como dice Aguado (2010), la escuela se siente impotente para cumplir estas funciones. 
Podemos decir que se realizan muchos intentos o que hay una conciencia entre el profesorado y en la sociedad sobre la importancia de aportar equidad a todas las personas. Sin embargo, a la hora de llevar estos principios a la acción es cuando la escuela en su conjunto, entendiendo la acción del profesorado principalmente, así como la de otros agentes educativos, se siente sin herramientas para poder hacerlo. $\mathrm{Y}$ es que el alcance de la igualdad de oportunidades supone realizar cambios profundos en la estructura educativa y en lo más hondo de las actitudes y creencias del profesorado, las familias y generalmente, de la sociedad. Cambios que no pueden ser impuestos (Fullan, 2002) sino que tienen que nacer de la necesidad vivida en el contexto socio-educativo.

Para conocer el proceso por el que podemos llevar a la acción los valores de enfoques que den una respuesta a las necesidades de la sociedad actual, necesitamos realizar un recorrido por distintas teorías. Por un lado, por las teorías sobre los procesos de cambio educativo y por otro lado, por las teorías sobre el concepto de diversidad que nos acerquen a una atención más adecuada que permita aportar igualdad de oportunidades y justicia social desde el marco educativo.

En principio, nos situamos en los procesos de cambio educativo, porque como muestran Mata y Ballesteros (2012), la preocupación por la superación de las desigualdades y por combatir la exclusión social se sitúa originariamente en el movimiento de mejora de la eficacia escolar (Effective School Improvement). Se trata de una corriente de investigación teórico-práctica que estudia los procesos de cambio escolar que contribuyen a mejorar el rendimiento de los estudiantes e impulsar procesos de innovación en los centros (Reynolds y otros 1997; Creemers y otros, 1998; Stoll y Fink, 1999; Ainscow y otros, 2006; Murillo, 2001; Mac Gilchrist, Myers y Reed, 2004).

Para explicar dicho movimiento tenemos que situarnos también en dos corrientes previas de investigación, una centrada en la eficacia escolar -sobre la que no nos detendremos demasiado por estar tradicionalmente más relacionada con el rendimiento, el liderazgo y la efectividad de los centros- y la otra orientada hacia 
la mejora de la escuela. Ambas tienen en común su búsqueda de la mejora y de la calidad.

En relación al movimiento de eficacia, destacaremos su objetivo que es identificar aquellos factores escolares que influyen positivamente en el rendimiento académico del alumnado y que contribuyen a la obtención de logros superiores a los esperados según el contexto socio-económico del alumnado y de las familias (Murillo, 2002 y 2004).

Por otra parte el movimiento de mejora escolar busca transformar la realidad de una escuela para mejorarla. En este sentido, el esfuerzo se dirige a un cambio en la práctica, realizado por los agentes que forman parte de la comunidad educativa y que toma como referente las transformaciones que se realizan en otras escuelas con el mismo fin: la equidad del alumnado. Las transformaciones pueden verse tanto a nivel estructural del centro como en las prácticas concretas realizadas en las aulas. Desde esta perspectiva, es importante construir entre todas las personas la escuela y hacerlo de una manera democrática, contando con la participación de todas las voces. Para Murillo (2002) dicho proceso implicaría un esfuerzo sistemático y continuo orientado a cambiar las condiciones de aprendizaje y otras condiciones internas de la escuela con la finalidad de alcanzar las metas educativas.

La diferencia entre el primer modelo de eficacia respecto del segundo, radica principalmente en el foco de ambos modelos. Siendo para el primero, el rendimiento del alumnado y para el segundo la transformación de la escuela hacia la equidad.

En nuestro trabajo, hablaremos de los procesos de cambio para comprender sus orígenes, las resistencias y los elementos importantes a tener en cuenta para la institucionalización de los cambios, pero situándonos en la segunda perspectiva desde la mejora basada en la construcción de la escuela. En concreto, pensamos que este proceso tiene que ser compartido y democrático y creemos que es desde esta corriente desde la que podemos realizar una mirada crítica sobre la escuela y sobre los elementos que se conjugan con ella. Como dice Escudero (2006) la mejora educativa debe ser construida colectivamente a través de la participación 
democrática de todos los miembros y debe basarse en principios de justicia, cuidado, critica y responsabilidad. Así lo exponen Fernández Enguita y Terren (2008), cuando indican la necesidad de reflexionar sobre el papel de la escuela y sobre sus funciones básicas de cohesión social, integración política y apoyo al desarrollo personal de todo el alumnado. La calidad en educación se relaciona con los fines, con las políticas educativas pero también con la idea de hombre y de sociedad, y con los valores subyacentes al sistema educativo (Muñoz Repiso, 1996, 1999). Este planteamiento que presentan distintos autores, situando a la institución educativa como un marco para aprender a vivir y a convivir, estaría totalmente entrelazado con un modelo intercultural inclusivo. En concreto, Mata y Ballesteros (2012) destacan que el concepto de cambio orientado hacia la mejora educativa está totalmente relacionado con el modelo educativo intercultural. Además, la definición del modelo intercultural según Gil-Jaurena (2009) también nos acerca a un concepto de interculturalidad relacionado con la equidad educativa y el reconocimiento de la diversidad cultural desde la igualdad de oportunidades y, por otra parte, dirigido al apoyo del cambio social según principios de justicia social.

Por todo lo explicado, iniciaremos el presente capítulo con un breve repaso sobre el concepto de cambio educativo dirigido hacia la mejora escolar. En concreto, nos detendremos en las primeras investigaciones sobre la temática; en las resistencias que podemos encontrar en relación al cambio, así como aquellos factores que facilitarían su institucionalización.

\subsection{Antecedentes. El Cambio Hacia La Mejora Educativa}

El cambio de un modelo educativo hacia otro no es un proceso sencillo ni fácil. Comporta el replanteamiento de un sistema y de un modo de hacer las cosas para ir introduciendo cambios en la práctica educativa. 
Si nos remitimos a la literatura veremos que mayoritariamente se habla del cambio educativo en relación a su reforma. En estas líneas no vamos a entrar en los movimientos de reforma educativa, sino en el cambio educativo hacia la mejora, que se lleva a cabo en los centros a demanda de alguna de las personas vinculadas a él.

En este caso, entendemos que el cambio educativo, se fundamenta en la transformación de una serie de dinámicas hacia otras, en función de una perspectiva educativa determinada. Sin embargo, es cierto que por cambio educativo podemos encontrar términos variados como reforma, cambio/transformación o innovación, que si bien vienen a decir lo mismo, difieren los unos de los otros por los matices que cada uno de estos términos aporta.

Basándonos en Bolívar (1999) entendemos la reforma como un cambio en la estructura, no solo de un centro sino a nivel legislativo. En este sentido el cambio no sería una iniciativa del centro ni de los agentes implicados en él, sino una imposición del gobierno. Así mismo, para González y Escudero (1987) tampoco es lo mismo reforma que innovación; entienden que la reforma implica cambios estructurales mientras que la innovación se acerca a los cambios internos y cualitativos.

En nuestra opinión, al hablar de cambio o la transformación en educación lo entendemos como el proceso por el cual un centro modifica aspectos de su cultura escolar para acercarse a enfoques más acordes con los valores de las personas que forman parte de la institución. El proceso del cambio implica una mirada reflexiva sobre el hecho educativo y dicho replanteamiento sobre las acciones realizadas aparece cuando la situación que tenemos no nos gusta, o algo nos indica que tenemos que cambiarla. Más allá de buscar "culpables" en diferentes agentes que forman parte del contexto educativo (las familias no se implican; el alumnado no respeta las normas de convivencia; la administración no aporta los recursos necesarios; la formación del profesorado no es la adecuada), y un sinfín de quejas, el cambio real se experimenta cuando nos decidimos a cambiar en mayor o menor medida nuestras propias acciones en los centros. Por tanto, para nosotros un 
cambio o una transformación de centro es un proceso complejo que parte de las acciones planteadas y llevadas a cabo por los miembros de la comunidad educativa y que pretende transformar determinados aspectos sobre la educación desarrollada en dicho contexto, y que en mayor o en menor medida va a influir en elementos de la cultura escolar.

Los estudios pioneros sobre el tema del cambio educativo, se sitúan en la segunda mitad del siglo XX. Pero, en ese momento el cambio era entendido más como un concepto técnico que como un proceso de transformación reflexivo, tal y como podemos entenderlo en la actualidad. Por eso, los procesos de cambio se basaban en la adopción de técnicas distintas y modelos establecidos, en lugar de buscar el sentido que podía tener el cambio para quienes lo propiciaban. Distintas obras alrededor de los años 70 nos muestran este hecho: "Tras la puerta del aula" de Goodlad y Klein (1970), "La cultura escolar y el problema del cambio” de Sarason (1971), "Implementar innovaciones en la organización” de Gross y otros (1971) y “Anatomía de la innovación educativa” de Smith y Keith (1971). Es por esto que desde sus inicios, el estudio de cambio educativo viene acompañado por un estudio sobre las resistencias al cambio, o factores que dificultan su institucionalización. Volviendo a la cuestión anteriormente planteada, podemos decir que el sentido que tiene el cambio para los agentes implicados sigue siendo una de las principales cuestiones que facilitan, o por el contrario dificultan, las transformaciones en las escuelas.

Por otra parte, podemos basarnos en las primeras conclusiones de Fullan, en 1972, para explicar algunas de las resistencias al cambio; ya que, aunque ha pasado mucho tiempo, algunas de las dificultades que seguimos encontrando en las transformaciones de los centros (Essomba, 2006; Escobedo, Sales y Traver, 2011) coinciden con estas conclusiones extraídas por Fullan. Conclusiones que vienen a mostrar que a pesar de la gran cantidad de recursos y de las distintas adaptaciones metodológicas, se produce muy poco cambio en la educación.

Una de las principales razones que influyen en que el cambio no acabe realizándose, se explica en el propio proceso seguido para la transformación. 
Fullan (1993) nos mostraba que las innovaciones en el aula no podían conllevar una transformación real en la medida en que estas fueran una adopción de un programa o de un modelo más que un proceso creativo y reflexivo para repensar la práctica educativa. Del mismo modo, si comparamos este hecho con los cambios realizados actualmente en los centros, podemos encontrar programas o modelos cerrados que presuponen que un cambio escolar puede realizarse en la medida en que se reproduzcan las acciones propuestas en el programa, en lugar de pararse a pensar en todos los valores que estarán detrás de dichas propuestas y que pueden facilitar o dificultar la realización de las mismas. En la medida en la que los cambios se desarrollen de este modo, es decir, sin replantear el enfoque desde el que se propone, no habrá una participación activa de aquellos que tratan de implementarlos y nos encontraremos con un "mundo de adoptantes" en lugar de con una sociedad crítica y reflexiva. Como lo expresa Fullan (2002) "en lugar de considerar la innovación como parte de un universo de significados, las escuelas se interpretan como un mundo de adoptantes" (p.4). Centrados en este tipo de innovaciones los valores de los participantes no tendrán influencia en los procesos y la diversidad no estará siendo considerada en la construcción del cambio. En este sentido, tampoco encontraremos nuevos roles o cambios personales o profesionales entre los participantes que forman parte de la transformación; o al menos esa no será la intención del proceso. En contraposición a esta idea, cabe destacar que el cambio debe llevar a un replanteamiento y por tanto, a una transformación del rol que desempeña cualquier participante en el mismo, si entendemos que el proceso de cambio es también un proceso de empoderamiento.

Otra de las conclusiones a la hora de comprender las dificultades del cambio es que las innovaciones propuestas o incluso introducidas, se convierten en alternativas vacías en la medida en que estas no coinciden con los valores de los actores que las llevan a cabo. Quizás este problema ya viene de la "fase de arranque" (Sales, Ferrández y Moliner, 2012) cuando se decide iniciar el proceso de cambio. Es decir, si esta decisión ha sido impuesta y por tanto no se percibe la necesidad de cambio. Como indican diversos autores (Sales, Traver y García, 2011; Sales, Ferrández y Moliner, 2012), desde el primer momento la necesidad del 
cambio debe ser percibida por los miembros de la comunidad educativa (equipo directivo, profesorado, alumnado y familias); pues llevar a cabo una transformación requiere de un proceso participativo que no se puede imponer (topdown), sino que la implicación de la comunidad educativa y sobretodo la del profesorado y el equipo directivo es un aspecto clave. En este sentido, autores como Gather, (2004); Tedesco, (2004) y Essomba, (2006), coinciden en la importancia de invertir en procesos innovadores fundamentados en el cambio del profesorado, más que en la inversión de recursos o la transformación de las estructuras. El cambio es necesario para crear una escuela que se adapte a la comunidad educativa. En este sentido, el cambio no viene de afuera sino del interior de las instituciones, de las personas que trabajan en ellas y de su voluntad y su creencia en una educación más igualitaria. Por ello, un buen elemento para el cambio es la profesionalidad docente (Hargreaves y Fullan, 2014). Para estos autores, dicha profesionalidad potenciada en un contexto de trabajo en equipo que lidere el crecimiento de la escuela sería un elemento primordial para activar cambios en la institución. Como ellos lo llaman, el "capital profesional” del profesorado formando una comunidad profesional de aprendizaje es el principal motor para transformar la enseñanza. O según Wenger (2001), las citadas comunidades de práctica.

Por este motivo, recordamos que los cambios estructurales son necesarios pero no suficientes para provocar un cambio significativo (Fullan, 2002). Esta conclusión nos parece especialmente interesante, pues abre las puertas a otros elementos que influyen en el cambio. Para nosotros uno de esos elementos que es fundamental es la parte personal y humana del cambio. Como decía Fullan (2002) un cambio en la estructura es importante, pero no suficiente y, ¿un cambio individual puede ser suficiente? A nuestro juicio, depende de para qué. Si nuestra intención es que el cambio llegue a toda una institución educativa, con un cambio individual será difícil conseguirlo, requerirá de mucho tiempo y finalmente tendría que ser el cambio colectivo y colaborativo el que podría desembocar en acciones sobre la comunidad. En otras palabras, si nuestra pretensión es que el cambio llegue a transformar aspectos en la estructura del centro, necesitaremos de la 
participación democrática de todas las voces para conseguirlo. Sin embargo, no tenemos que subestimar los cambios individuales ya que pensamos que pueden ser la base para realizar acciones colectivas. En este caso, con las acciones de un maestro o de una familia será difícil llegar a la transformación de la institución, o se requerirá de más tiempo para que se puedan "contagiar" las ganas y contar con la participación de más personas; pero es un inicio, una primera contribución hacia el cambio.

En el párrafo anterior hablábamos del cambio y lo relacionábamos con las ganas de llevarlo a cabo. Es decir, con las creencias sobre el mismo que pueden desembocar en acciones. No obstante, existen distintos elementos que pueden incidir en el cambio, facilitándolo o dificultándolo. Además de los aspectos pedagógicos, podemos encontrar motivos políticos, sociales, etc. (Romero, 2003). Solamente planteándonos si el cambio tiene que ser una necesidad individual o compartida ya podemos abrir un debate.

Desde la literatura se destacan las dos vías como necesarias para realizar el cambio. Por una parte se habla sobre la necesidad de un cambio sentido por el profesorado más allá de reformas e imposiciones administrativas:

En las reformas predomina, pues, una lógica de cambio instituido, frente a la innovación, que tendría una lógica instituyente. De hecho, los profesores y profesoras no suelen confiar en que los cambios en sus prácticas dependen de la llegada de reformas, sino por otro tipo de dinámicas internas [...] Para que una reforma de lugar a innovaciones tiene que afectar al núcleo duro de la enseñanza, entendido como los modos en que los profesores comprenden la naturaleza del conocimiento y se intercambian dichos conocimientos con los colegas, el papel que tienen los alumnos en los procesos de enseñanza, así como estas ideas sobre conocimiento y enseñanza se manifiestan en el aprendizaje en el aula (Fullan, 2002, p. 26 - 27).

Por otra parte, otros estudios nos muestran la necesidad de transformaciones que lleguen a la estructura $\mathrm{y}$, por tanto en las que estén implicados todos los agentes. En estos casos argumentan que cuando no ocurren transformaciones culturales en el centro tampoco las prácticas cambian sustantivamente: son 
relegadas, en el mejor de los casos, a espacios especiales, profesores especiales y medidas especiales (Petrou, Angelides y Leigh, 2009).

Por tanto, es tan importante el trabajo individual y la reflexión personal como el hecho de fomentar una cultura colaborativa que posibilite la expansión del cambio (Fullan, 1993). Es importante situar las dos caras de la moneda, la individualidad del profesor y la cultura escolar del centro como dos partes necesarias para que la transformación sea real y se institucionalice. Aunque, concluimos que no existe un modelo por excelencia para realizar transformaciones reales en los centros. Aquello que tienen de positivo los cambios más individuales es que son más reales, porque todas las personas que los emprenden lo hacen por iniciativa propia. Mientras que en un cambio global del centro puede que haya personas que se sientan "obligadas" o presionadas para llevar a cabo algunas acciones que no coinciden con sus ideales. Por eso, nosotros nos posicionamos más afines a la realidad que implican los cambios individuales. Aunque somos conscientes que, como decían Petrou, Angelides y Leigh (2009), estos cambios se pueden quedar en anécdotas para los centros.

No solo defendemos el cambio desde la necesidad individual, sino que entendemos estos cambios como una necesidad también personal del docente, más allá de su rol como maestro. Como dicen Fullan y Hargreaves (1996), resulta primordial entender al docente en su totalidad, no solo en su rol como maestro o profesor, sino también como persona, entendiendo que su ciclo vital también forma parte del proceso del cambio y también influye en él.

Con todo esto queremos reflexionar sobre las condiciones, los obstáculos, el sentido del cambio y la importancia de la dirección hacia la que se orientan las transformaciones y que debería ser compartida por todos sus miembros. Nos referimos, por ejemplo, a que un cambio en la estructura no es suficiente para que el cambio llegue a la práctica. Ni tampoco un cambio que llega a la práctica será real si se aplica sin creer en él y sin comprenderlo. Por eso, incluso cuando partimos de iniciativas personales en maestros que, a lo largo de los años por el contagio y el trabajo colaborativo con otros docentes realizan innovaciones, estas 
solamente podrán consolidarse en su práctica en la medida en que la adopción de las mismas haya supuesto un proceso de reflexión. Pues el valor reside en el replanteamiento de nuestra propia práctica, desde la reflexión sobre nuestra manera de trabajar, sobre las razones y los valores que guían nuestras acciones, no solo como docentes, sino como personas. Pensamos que dicho replanteamiento, sí que podría llevarnos a transformar nuestra práctica e incluso nuestros propios valores. Por eso, el cambio tiene que ser un proceso sentido y comprendido por aquel que lo implementa para que pueda suponer una transformación real.

Otra cuestión a señalar, es que para hablar de un cambio que suponga una transformación social, que influya en el mayor número de alumnado y de ciudadanía, necesariamente tenemos que tener en cuenta otros agentes del contexto socio-comunitario (Traver, Sales y Moliner, 2010). Por tanto, se deben estructurar radicalmente las relaciones entre la escuela y su entorno. Como dicen Hargreaves y Fullan (1997), las fronteras entre las escuelas y el exterior deben ser transparentes y permeables tanto como puedan hacer los profesores en esta dirección.

La necesidad del cambio puede sentirse en otro colectivo, no necesariamente tiene que ser el profesorado. Aunque anteriormente hemos hablado sobre los cambios individuales que se proponen los docentes, también podemos llegar a motivar estos cambios desde las necesidades que manifiesten otros agentes, como las familias o el alumnado. Desde esta perspectiva, destacamos la teoría del Aprendizaje Organizativo, en la que resaltamos a Senge (1992); Argyris y Schön (1996); Leithwood y Louis (1998) y Bolívar (1999), (2000). Desde esta teoría, se plantea que el cambio no es solo un asunto que afecta al profesorado y al alumnado, sino que el contexto también es quien activa y siente esa necesidad. En cualquier caso, el cambio educativo impulsa a la escuela y a sus agentes, a relacionarse de un modo distinto entre ellos, más colaborativo. Las escuelas se relacionan de forma diferente con los padres/comunidad, la tecnología, debiendo unirse a una variada red de alianzas con otros colegas, las universidades, etc. En el caso de la colaboración de la Universidad, o de otros centros con agentes educativos, puede ser de gran ayuda el papel de un asesor o "amigo crítico" (Hink, 
2005). La falta de experiencia de los centros en estos procesos hace necesario que una persona facilite los recursos para la recogida de pruebas, como si fuera un asesor sobre estrategias de diagnosis participativa y acompañara al centro en la autoevaluación escolar.

Estas nuevas relaciones con los agentes socio-comunitarios implican cambios profundos en la gestión de la escuela, de establecer relaciones horizontales con personas que anteriormente considerábamos fuera de las decisiones educativas del centro. Estos cambios, en la literatura actual (Hargreaves y Fink, 2006) nos muestran que son uno de los caminos para el desarrollo de las escuelas. Suponen una transformación en la formación inicial de los maestros, en la construcción de nuestras ideas y valores como ciudadanos y en la responsabilidad de crear entre todos, escuelas que eduquen a la sociedad. En esta línea, Fullan (2002) expone que, no puede relacionarse la implementación de nuevas acciones y el sentido del cambio sin tomar conciencia de que la profesión de la enseñanza debe ser muy distinta a la del pasado y que las escuelas deben llegar a transformarse tanto que nos parezcan irreconocibles.

\subsection{La institucionalización del cambio y su dirección hacia una acción social}

El cambio es un proceso, no se limita a un hecho puntual. Como proceso podemos distinguir distintas fases que forman parte del mismo y que enunciaremos a continuación basándonos en Murillo y Krichesky (2012, p.28):

Un primer momento de iniciación por el cual algún individuo o grupo, por algún motivo, inicia o promueve un programa o proyecto de cambio, fase que incluye el diagnóstico; seguido por instancias de planificación que definen el sentido y los pasos que se darán; una fase de implementación por el cual se ponen en práctica 
dichas estrategias o acciones; tras el cual será necesario un periodo de reflexión o evaluación; y, como resultado de ello, la extensión o difusión de las innovaciones más exitosas a través de una serie de esfuerzos de institucionalización de aquellas estrategias que han resultado particularmente eficaces.

Todas estas fases suponen un proceso de análisis y reflexión continua. Empezando por la iniciación, en la que normalmente hay algunas personas o colectivos que lideran el cambio, pero que con su iniciativa también pueden movilizar al resto. Después de la fase de inició, y de lograr un consenso que anime a todos a emprender el cambio educativo, vendría la realización de un diagnóstico. En este momento se realiza un balance de la situación del centro. Aunque esta fase es exploratoria aporta las bases para poder emprender acciones en la escuela. Según Murillo y Krichesky (2012), el diagnóstico tiene que centrarse en tres dimensiones: el desarrollo de los estudiantes, la calidad del centro y la adecuación de los procesos de enseñanza en el aula. En tercer lugar, la planificación. A partir de los objetivos que se quieren conseguir con el cambio se planifica el diseño para su posible consecución. A continuación, la fase de implementación, en la que se ponen en marcha las iniciativas propuestas. Después de esta fase se valoraría cómo ha sido el proceso, sería esta la fase de reflexión y evaluación. Este proceso sería en sí mismo una muestra de la investigación - acción, o investigación - acción participativa, que emprenden los centros hacia la mejora educativa (Elliott, 1990; Latorre, 2007).

Finalmente, si los cambios dejan de ser un hecho puntual para convertirse en una forma habitual de proceder en las escuelas, podremos hablar de la institucionalización de los cambios. Esto situaría a la escuela en una cultura escolar de cambio. En la que este no sería visto como un hecho puntual sino como un proceso y un modo de proceder en la institución.

Algunos de los factores que facilitan la institucionalización de una cultura de mejora son (Murillo y Krichesky, 2012, p.40): 
- Los docentes consideran los métodos utilizados eficaces y están satisfechos con el proceso y los resultados. Están motivados a seguir por la senda del cambio.

- La dirección mantiene una visión y apoya con claridad el cambio. Se muestra abierta a las innovaciones, incentiva a los profesores a tomar riesgos e incita a probar cosas nuevas.

- Se avanza hacia la creación de una cultura profesional de aprendizaje, es decir, se crea una cultura que estimula el aprendizaje y el desarrollo profesional continuo, en el marco de una estructura en la cual tenga lugar ese desarrollo a través de la colaboración y el apoyo mutuo.

- Las nuevas prácticas que han sido objeto de valoración positiva se integran en las rutinas escolares, de tal forma que no supongan un esfuerzo añadido a docentes o a estudiantes.

De estos factores destacamos: la satisfacción del profesorado en el cambio, sobre el proceso y los resultados conseguidos. Y por ende, su motivación de seguir. Aunque en este sentido, opinamos que también juegan un papel importante las creencias y valores del profesorado (Essomba, 2006; Lobato, 2001). También es importante el papel del equipo directivo y su apuesta por el cambio y las innovaciones. En la colaboración y el apoyo mutuo del profesorado, como aspectos básicos para contribuir al cambio, serían también el acompañamiento y la cooperación aspectos importantes. Finalmente, la integración de nuevas prácticas como un modo de proceder habitual en el centro.

Un concepto estrechamente vinculado con los procesos de institucionalización del cambio es el de sostenibilidad. Es decir, que el cambio sea posible y un aporte favorecedor de la mejora a lo largo del tiempo.

Para Fullan (2002), la sostenibilidad educativa es la capacidad que tiene el sistema de comprometerse para resolver las complejidades que resultan de la mejora y que es compatible con los valores profundos derivados de las necesidades humanas. Para Hargreaves y Fink (2006) la sostenibilidad se entiende junto con el liderazgo y la mejora educativa, que cuando llegan a institucionalizarse en un 
centro, preservan y desarrollan el aprendizaje profundo de todas las personas que participan en la transformación del mismo. En concreto, estos autores definen una serie de características sobre la sostenibilidad de los cambios en educación. En primer lugar, destacan que el valor del cambio reside en que el aprendizaje realizado por el alumnado sea profundo. Es decir, sin perder de vista que el cambio educativo se realiza hacia la mejora educativa y dicha mejora apuesta por la igualdad de oportunidades, nos encontramos con que el alumnado debería ser el protagonista del cambio o al menos el colectivo más importante sobre el que se plantea toda la transformación. Es por esto que los autores explicitan que el cambio no pretende conseguir una mejora en el rendimiento del estudiantado sin prestar atención a cómo se produce su aprendizaje. Por esto, se pretende que el alumnado alcance un aprendizaje profundo, que no se mida a partir de test, exámenes, o memorizaciones sobre la temática, sino que asegure que ha habido un proceso de aprendizaje. Por otra parte, los valores que guíen el cambio deben encontrarse en la atención y el cuidado que se mantiene hacia los demás y que se propicie entre todos los miembros. De ahí podemos concluir que un cambio de esta envergadura puede suponer un proceso real de mejora educativa, no solo centrándonos en los contenidos sino en la educación de personas de una manera integral.

En segundo lugar, se mantiene la longitud como otro de los aspectos importantes a tener en cuenta (Hargreaves y Fink, 2006). Entendiendo esta longitud durante toda la etapa de educación formal. Es decir, que el cambio que se inicia en la etapa de Educación Infantil tenga una continuidad en la Educación Primaria a lo largo de sus diferentes niveles de enseñanza. Si además, consiguiéramos que dicha longitud se mantuviera en la etapa de Educación Secundaria y en la Educación Superior, los cambios llegarían a transformar los valores y estilos de vida de la ciudadanía. Pero para conseguirlo, los autores mantienen que sería necesario que en los centros se llevara a cabo un proceso de contratación meticuloso del profesorado, con el propósito de seleccionar a aquellos docentes comprometidos con el cambio. 
En tercer lugar, se destaca la anchura del cambio, entendiendo por anchura que el cambio se difunda a través de un liderazgo distribuido en el entorno educativo. El liderazgo distribuido proporciona un nuevo marco conceptual que posibilita reconceptualizar la práctica del liderazgo en las escuelas (Bolívar, 2010; Harris, 2004; Murillo, 2006).

El liderazgo no depende de una cúspide o primera cadena de mando; por el contrario, en una organización que se mueva suele estar ampliamente distribuido, de modo que los docentes, al trabajar conjuntamente, desarrollan competencias y ejercen apoyo mutuo. Por lo demás, el incremento de responsabilidades y, en especial, el rendimiento de cuentas están llevando a que se precisen más personas que el director, si queremos que una organización funcione bien. Se requiere desarrollar la capacidad de liderazgo de los demás, cada uno en la parcela en que tenga mayores competencias o intereses, para fomentar formas de trabajo colaborativo y el compromiso del personal en una organización que pretende aprender a hacerlo mejor cada día (Bolívar, 2010, p. 92-93).

Existen diversos estudios sobre innovación educativa que destacan la importancia del liderazgo en el desarrollo del proceso de cambio (Uribe 2005; Hargreaves y Goodson, 2006). También es importante nombrar que existen distintos tipos de liderazgo. Para nosotros, el distribuido (Lieberman y Miller, 2004) o por otra parte, el compartido, en el que todos los miembros se sienten responsables del cambio, es el que más sentido tiene en procesos de mejora educativa enfocados hacia la equidad y la justicia, ya que entendemos estos procesos desde una participación democrática, como hemos comentado al inicio del capítulo. Es decir, desde la participación igualitaria de las distintas voces.

Para Marcelo y Estebaranz (1999) "el liderazgo compartido es una forma positiva de caminar hacia la colaboración y hacia el desmantelamiento de estructuras jerárquicas que se oponen al cambio real en las escuelas" (p. 54). También dicho liderazgo ha de ser un liderazgo positivo, sensible a las necesidades de la escuela, democrático, que promueva la colaboración, comparta la toma de decisiones y los éxitos, y transmita los valores del centro en las situaciones cotidianas (Ortiz y Lobato, 2003). En definitiva, la importancia de liderar el 
proceso se sitúa en la gestión del propio liderazgo, separándonos de modelos que requieren de liderazgos únicos e individuales, para acercarnos a liderazgos compartidos. Es decir, cuantos más profesores y otros agentes educativos se involucren en el cambio de la escuela, mayor será su potencial para conseguir mejoras (Fink, 2000).

Bolívar (1997) introduce el concepto de liderazgo transformativo como un elemento que contribuye a la transformación de la cultura escolar. En este caso el autor propone la idea del liderazgo en el sentido de transformar las estructuras, refiriéndose a la organización del centro. Es decir, que el liderazgo no esté únicamente en manos de la dirección sino que otros agentes puedan sentirse motor del cambio. Esta transformación en la cultura escolar es la que nos puede acercar a un mayor compromiso por parte de otros agentes y a una implicación mayor en las acciones educativas. Se trata de realizar una mirada crítica hacia las estructuras de poder y transformarlas en acciones colaborativas. Este tipo de liderazgo también influye en la capacidad tanto individual como colectiva, para resolver problemas.

En cuarto lugar, el cambio y la mejora educativa que plantean Hargreaves y Fink (2006), está totalmente relacionada con la justicia. Por justicia entienden la extensión del cambio al contexto más próximo, generando redes de apoyo con otros agentes socio-educativos o con otras instituciones educativas. El propósito es brindar las mismas oportunidades a todas las personas y compartir las posibilidades de mejora. Este aspecto resulta esencial para que la transformación no se quede en el propio centro sino que trascienda a otras esferas como el barrio, el territorio, las familias, etc. Pues sin tener en cuenta el contexto más próximo el cambio no tiene sentido.

En quinto lugar, el cambio trata de fomentar la diversidad en la enseñanza y el aprendizaje. Lejos de crear estructuras estandarizadas trata de generar procesos abiertos a la diversidad. Se entiende esta diversidad junto a la necesidad de crear una red de conexiones entre los distintos componentes. Sobre estos aspectos hablaremos a continuación al plantearnos la dirección del cambio. 
Además, Hargreaves y Fink (2006), defienden que la institucionalización del cambio ayuda a incrementar los recursos no solo materiales sino también humanos; se preocupa porque todas las personas se sientan incluidas en el proceso. Por un lado amplían su red de apoyo al mismo tiempo que tratan de conservar aquello que les funcionaba con el fin de crear un futuro mejor. Se trata de un cambio que recuerda el pasado y lo tiene en cuenta como punto de partida para implementar mejoras.

A modo de conclusión, resaltaremos dos de las conclusiones que Hargreaves y Fink (2006) realizan acerca de los aspectos que se deben considerar en las políticas de cambio para que estos puedan mantenerse a lo largo del tiempo. Por una parte, es importante el hecho de que el cambio sea un proceso compartido en todas sus facetas por las personas de la comunidad educativa. Por otra parte, que se aporte igualdad de oportunidades y se facilite la formación pedagógica a todos sus miembros, con la finalidad de garantizar una educación de calidad para todos los agentes de la comunidad educativa. La sostenibilidad del cambio culmina en mantener una escuela que recoja los valores de todos sus miembros, siempre fomentando que esos valores sean coherentes con la igualdad y con la inclusión.

Con estas consideraciones delimitaremos la importancia de la dirección del cambio. Es decir, se trata de un cambio hacia la mejora educativa para conseguir una escuela que promueva la igualdad de oportunidades, la equidad y la justicia social. En este sentido, tomaremos la referencia del contexto social para situar la dirección del cambio hacia la construcción de una escuela intercultural e inclusiva.

El cambio desde un inicio se ha configurado para aportar una educación mejor, de mayor calidad para el alumnado (Hargreaves y Fink, 2006), pero poco a poco vamos encontrando más trabajos que sitúan la necesidad de un cambio educativo como un aporte social y que trasladan el proceso de cambio visto desde el centro como un proceso de cambio social y comunitario (Gale y Densmore, 2007; Traver, Sales y Moliner, 2010). Eso no significa que el alumnado no sea uno de los principales motivos del cambio; es más, implica que se puedan aportar mejores recursos desde un contexto más amplio. En este sentido, una de las tareas más 
importantes para los educadores es la de ayudar a construir un movimiento social que facilite la puesta en marcha de un sistema educativo no solo público, sino también inclusivo y dinámico en la Sociedad de la Información.

Es por esto que la finalidad del cambio se entiende desde la transformación experimentada en la sociedad en la que vivimos. Pues hemos pasado de la Sociedad Industrial a la Sociedad del Conocimiento o de la Información y los retos que se plantean, tanto para la escuela como para los ciudadanos son distintos. El objetivo para la escuela es preparar a todos los jóvenes para afrontar los retos de una Sociedad del Conocimiento (Hargreaves, 2003) creativa, democrática e inclusiva. Para ello, Hargreaves y Fink (2006), realizan una serie de propuestas a tener en cuenta:

La primera de ellas sería denunciar con valentía las situaciones de injusticia y de exclusión allá donde las veamos. La segunda, para el profesorado, sería reconocer que tienen una responsabilidad profesional no solo con respecto a sí mismos, sino hacia los hijos de otras personas, formando así una cadena que se extiende desde su implicación en la escuela más próxima, a la más lejana. Además, entendiendo el cambio como un proceso social, esta responsabilidad sería un compromiso no solo escolar sino también ciudadano. La tercera de las propuestas es comprender que la educación constituye un bien de interés público, prepara a las generaciones del futuro y sirve al interés de todos. Por todo ello, la propuesta viene a destacar la importancia de crear una red de conexiones entre los centros, de manera que funcionen como comunidades profesionales sólidas y potentes en colaboración con todos los agentes de la comunidad educativa.

Así mismo, nos situamos en el modelo social que opta por la interculturalidad y la inclusión al entender que la diversidad forma parte de la vida humana y que cualquier cambio que pretenda generar igualdad de oportunidades tiene que tener en cuenta la diversidad desde el respeto a la diferencia. Es por esto, que no podemos separar el concepto de cambio del de diversidad y es necesario que el cambio se dirija hacia la construcción de una escuela intercultural inclusiva que adopte los principios del modelo intercultural inclusivo. 



\title{
2. La Construcción De LA ESCUELA INTERCULTURAL
} INCLUSIVA

\begin{abstract}
Mi respeto hacia los niños partía de considerarlos ya, a pesar de sus pocos años, como personas, y no meros proyectos de futuro y se dirigía, sobre todo, a ese fondo misterioso y sagrado que para mí representa todo ser humano. Este respeto se traducía en la convicción profunda de que podían comprender lo que yo les decía y que tenían el derecho a no ser tratados, a pesar de su poca estatura, con ningún tipo de rebajas: ni en mi entrega, ni en la calidad de mi trabajo, ni en los niveles académicos o en los temas de conversación y reflexión. Respeté, como algo realmente venerable, la grandeza que se ocultaba en su pequeñez y cuidé, con todo el esmero que pude, la fragilidad de los pequeños tesoros que la vida me regaló en el cofre que cada niño o niña representaba (José María Toro, 2005, p. 22).
\end{abstract}

En este capítulo vamos a hablar sobre la ideología del cambio, las bases sobre las que definiremos nuestro proyecto de transformación en una escuela, que son las del modelo intercultural inclusivo. Para ello, en primer lugar distinguiremos entre conceptos como diversidad, diferencia y desigualdad. En segundo lugar, nos 
detendremos en el modelo intercultural y el inclusivo y la conjugación entre ambos.

Continuaremos con un apartado sobre la participación comunitaria para hacer posible la construcción de este tipo de escuelas. En esta parte, hablaremos sobre la voz del profesorado; de las familias y del alumnado, como agentes protagonistas en la construcción de una escuela intercultural inclusiva.

Pero antes de iniciar este capítulo queríamos empezar con dos ejemplos que son una muestra sobre cómo vivimos la diversidad en la sociedad. Aunque sobre el concepto de diversidad hablaremos más adelante, queríamos relacionar este concepto -asociado tradicionalmente con la diversidad funcional o con la inmigración y las situaciones de desventaja social- con el de superación y con los valores humanos.

Hasta hace unos años, hablábamos de integración en lugar de inclusión, y con ello nos referíamos a la adaptación social de una minoría con respecto de un grupo social más numeroso. En este sentido, queremos destacar dos ejemplos, de entre los miles que podemos encontrar a diario, para precisamente situar la inclusión y la interculturalidad en otra esfera, la que defenderemos desde el modelo educativo intercultural e inclusivo.

Estos ejemplos que mostraremos a partir de dos vídeos, tratan sobre historias llenas de sentido y que en definitiva vienen a hablar de la igualdad y de la diversidad. No nos hablan desde argumentos sobre equidad, nos muestran vidas y nos lanzan hacia una mirada del ser, de la potencialidad de la persona. Es en esos vídeos donde encontramos la inspiración y la motivación para sentirnos atraídos por todas las historias que si bien no han tenido un comienzo con las mismas oportunidades que la mayoría, han conseguido efectos que tampoco parecerían alcanzables para otras personas en su misma situación.

Ejemplo 1: https://www.youtube.com/watch?v=1Jd4XDM03hI

Uno de esos ejemplos fue el de Jennifer, una niña que al nacer sin piernas fue abandonada en el hospital. Una de las enfermeras al ver que la niña se quedaría sin 
una familia decidió adoptarla. Su marido y ella ya tenían hijos más mayores pero quisieron cuidar también de Jennifer. La única norma que había en su casa es que no existía la palabra no puedo. Con esta condición fue creciendo la niña, que tenía mucho interés por el deporte y que quería convertirse en gimnasta.

Actualmente, Jennifer trabaja como gimnasta, dedicándose profesionalmente a ser acróbata en actuaciones de cantantes famosos o en teatros y auditorios importantes de Estados Unidos. Lleva una vida normalizada e independiente.

Si algo queda por destacar de esta historia es que para Jennifer no hay límites, la capacidad va más allá del cuerpo, pues se extiende entre la mente y el alma y es por esto que ha podido alcanzar sus sueños al creer que ello era posible. Con esta historia queremos situar el proceso de lucha por los Derechos Humanos y la Igualdad de oportunidades, desde lo personal, desde educar en una apertura hacia la vida vista desde una mirada sin límites. La educación para nosotros tiene que explicitar la parte creativa del ser, ayudar a que el alumnado se conozca y sea capaz de crear desde una mirada crítica y solidaria. Educar es amar y transmitir ese amor hacia uno mismo y hacia el otro, para acercarnos a una sociedad más humanizadora.

El ejemplo que encontramos a continuación habla de otra mirada hacia la diversidad. Si con el anterior ejemplo dábamos muestra de una persona sin piernas que consigue realizar todo tipo de actividades físicas llegando a ser campeona de gimnasia, a continuación mostramos el límite que supone a nivel social el prejuicio.

Ejemplo 2: https://www.youtube.com/watch?v=n9DRGdc66VE

Se trata de un experimento en el que unos chicos preguntan a extraños que están comiendo pizza si les pueden dar una porción porque están hambrientos. En casi todos los casos, los extraños les niegan ese trozo de pizza a los chicos, quizás por desconfianza. Con esto queremos mostrar que, generalmente, nuestras limitaciones mentales van más allá de nuestra conciencia de atención a la diversidad o de una serie de valores asumidos pero no sentidos, en los que creemos. 
Después de varios intentos, el experimento se hace de otro modo. Uno de los chicos se acerca a un indigente que está en la calle y le da casi media pizza, le dice que ya no tiene más hambre y que si él la quiere. En este caso, el mendigo la acepta agradecido y al tiempo de estar comiendo, cuando aún le quedaba algún trozo de pizza aparece uno de los chicos del experimento pidiéndole comida. El indigente en este caso no lo duda y le abre el cartón para que coja el trozo de pizza.

Con este ejemplo, vemos personas que niegan la ayuda a un desconocido y a otra persona que vive en la calle sin ninguna pertenencia más que algunos trozos de pizza que le han dado, y no duda en compartirlos. Este ejemplo nos hace pensar en las limitaciones mentales que tenemos, en los prejuicios y estereotipos que tenemos hacia lo desconocido. Por supuesto que se podría realizar un análisis más exhaustivo sobre la situación y sobre las razones que nos impulsan hacia la ayuda en este tipo de casos. Pero no es la pretensión de este estudio. Simplemente, facilitamos este ejemplo para poder abrir nuevas reflexiones acerca de la diversidad y de los valores para la construcción de una sociedad más solidaria, justa y equitativa.

Ambos ejemplos, y tantos miles como podemos encontrar, son una inspiración. Sin embargo, si pensamos en la escuela y en su función parece que vemos más niños y niñas sin saber cómo actuar en sus vidas; más ejemplos de depresiones, de desaliento y desamparo que de empoderamiento. La escuela no es la única palanca para el cambio, pero es una de ellas y puede proponerse mirar la diversidad desde el desarrollo de las máximas potencialidades de cada persona y de la creación de un alumnado solidario, con confianza en él mismo, con seguridad y que pueda sentir verdadero amor por el otro y por la vida. 


\subsection{Diversidad, Diferencia Desigualdad}

Empezaremos por definir el concepto de diversidad y sus implicaciones. Por diversidad, destacamos la definición de Jiménez y Vilá, (1999), por la que se considera la diversidad como "una característica intrínseca a la naturaleza humana y una posibilidad para la mejora y el enriquecimiento de las condiciones y relaciones sociales y culturales entre las personas y entre los grupos sociales" (p. 28). Esta definición nos acerca a lo propio y personal del ser humano. Sin diferenciar entre grados ni establecer comparativas se entiende la diversidad como algo humano, característico de lo individual pero desde un punto de vista de equidad y justicia social. Cada uno es como es y desde el valor de la persona se respeta al otro. Por tanto, la diversidad es indisociable de las características humanas que nos hacen auténticos en nuestra esencia. La diversidad es también la riqueza, al posibilitar distintas opciones y distintas miradas.

Estos planteamientos más enriquecedores, pero que además reclaman una justicia y equidad social para todas las personas, son los que se tienen en cuenta desde un modelo que entienda la diversidad como enriquecimiento, en el que nos detendremos más adelante y hacia el que se quiere avanzar en la escuela que estudiamos.

Siguiendo con el planteamiento de Jiménez y Vilá, la definición de López Melero (1997), también nos aporta claridad al concepto. La diversidad es la identificación de la persona por la que cada uno es como es y no como nos gustaría que fuera (Identidad). De ahí la crítica a la homogeneización en la que trata de educar la escuela y en la cual está inmersa. Pues siguiendo el principio de diversidad desde la igualdad de oportunidades, la escuela tiene que dar una respuesta adecuada, que no será la misma o de la misma manera, para todo el alumnado. Ya que "el derecho a la igualdad de oportunidades no significa tratar a las personas igual, sino dar a cada uno lo que necesita en función de sus características y necesidades individuales” (Blanco, 1999, p. 59). En este sentido, 
la legitimación de la diversidad nos acerca a nuestras potencialidades y a nuestro máximo desarrollo. En lugar de tratar de ser como es el otro nos acercamos a la mejor versión de nosotros mismos (Anónimo).

La diferencia es "la valoración (por tanto subjetiva) de la diversidad y es precisamente en esta valoración donde hay varias manifestaciones ya sean de rechazo (antipatía, xenofobia, racismo, intolerancia,...) como de comprensión (simpatía, xenofilia, tolerancia,...)" (López Melero, 1997, p. 5-6). La diferencia hace una comparativa y un juicio sobre la realidad, para poder separar o unir en función de unos parámetros (etnias, culturas, edad, etc.). Decimos que la diferencia y la diversidad son conceptos fácilmente equiparables, si al entender la diversidad existente podemos darnos cuenta que dicha diversidad lleva implícitas características distintivas de unas personas respecto a otras, características que también dan seña de nuestra autenticidad. Estas características propias son las que hacen que la vida evolucione hacia miradas y caminos distintos. Por otro lado, y centrándonos en el paradigma educativo, dichas diferencias implican maneras de aprender distintas, maneras de hacer y de mostrarse diversas y que requieren de respuestas amplias por parte del profesorado que den cabida a la totalidad de su alumnado para poder generar igualdad de oportunidades.

Siguiendo con el argumento de López Melero (1997), después de la valoración de la diversidad vendría la posible desigualdad si, como dice el autor establecemos jerarquía en esa valoración subjetiva de la diversidad. Si por ejemplo, atribuimos criterios de poder social, político, económico, étnico,... En este sentido, creamos la desigualdad después de crear la diferencia y de valorar como negativa la diversidad de un grupo de personas respecto a otras. En el lado opuesto se sitúa la valoración de la diversidad desde el derecho a la igualdad de oportunidades, sin jerarquías en el que todos somos diversos pero iguales. Se trata de como dice Sales (2007), de conjugar la igualdad de derechos con el derecho a la diferencia.

El concepto de diversidad está ligado al de cultura (Aguado y Ballesteros, 2012). La diversidad cultural está presente en las relaciones humanas y en la interacción. Al relacionarnos construimos, compartimos, modificamos y 
transmitimos significados que dan sentido a lo que sucede o nos sucede. Es decir, que dicha relación es la que aporta el sentido dinámico y móvil a la cultura. Por eso, es necesario adoptar un enfoque intercultural desde el que mirar la diversidad en educación y tratar de vivir la interculturalidad desde el conocimiento y reconocimiento del otro. En este proceso de conocernos, resulta decisivo el papel del profesorado quien puede convertir los enfoques, modelos, creencias y asunciones teóricas en prácticas reales. Así mismo, es también importante entender el concepto de cultura como dinámico y en construcción constante, en lugar de entenderlo como un elemento que encierra en sí mismo la diferenciación entre distintas culturas. Esta cuestión es un aspecto claramente identificado en nuestro estudio, en el que al inicio de un proceso de sensibilización hacia la diversidad y la posibilidad de crear una escuela intercultural inclusiva, aparecían argumentos desde el "nosotros" y el "ellos" para diferenciar entre el profesorado y las familias, entre aquellas personas de una cultura y de otra.

En este sentido entendemos que aunque hemos realizado un intento, al igual que se realiza desde la teoría y desde la práctica, por acercarnos a la diferencia desde una visión igualitaria que sitúa estas diferencias como aspectos propios de la diversidad humana, en muchas ocasiones la diversidad se reconoce desde la categorización de las diferencias de un grupo respecto a otro. Diferencias marcadas por la sociedad y por las personas pertenecientes a ambos grupos que lejos de llevarnos a un diálogo intercultural sentencian las diferencias generando desigualdades.

Aguado (2010) advierte de ello, y de la necesidad entonces de distinguir entre diversidad y diferencia. Como la autora comenta, habitualmente se establecen diferencias y se reconocen grupos culturales a priori, llevando a confusión la diversidad cultural por la distinción social realizada sobre un grupo de personas. Un ejemplo de esta confusión, como señala Aguado (2010), es identificar la diversidad cultural con características como el origen nacional, la lengua materna, el nivel económico, la etnia, la religión, el género, etc.; todas ellas categorías 
construidas que informan sobre grupos sociales a los que los individuos son adscritos; pero no nos dan información sobre las personas.

Por otra parte, cabe acercarnos a las prácticas para entender estos conceptos en vivo. Es decir, si por un lado hemos realizado una aproximación teórica sobre los conceptos de diversidad, diferencia y desigualdad, es de justicia conocer de cerca estos conceptos en la realidad escolar. Para ello, hacemos referencia a estudios recientes del grupo INTER (2010), en los que se describe lo que sucede en las escuelas en relación a la diversidad cultural del alumnado.

Estos estudios, nos alertan sobre cómo las escuelas discriminan al alumnado. Discriminación que se explica por la manera en cómo se vive la diversidad en los centros. En general, los centros muestran una visión problemática de la diversidad que suele verse asociada a deficiencias que deben ser superadas o compensadas. Normalmente, se identifica a un estudiante con un grupo ya establecido (inmigrante, familia desfavorecida, rendimiento bajo, etc.) y solo por pertenecer a ese grupo se aplican el conjunto de prejuicios y estereotipos construidos sobre el mismo. De manera que las expectativas no solo hacia ese grupo, sino también hacia cada uno de sus estudiantes son bajas. Sin darle a cada uno la oportunidad de crecer y salir de la etiqueta que le es asignada. O de darle la oportunidad de desarrollar sus potencialidades que quizás no son las mismas que las de la mayoría o no se desarrollan de la misma manera. Sin embargo, en la escuela no se suele optar por una enseñanza abierta a las necesidades de cada persona, sino que suele haber un modelo único a seguir; un modelo homogéneo que separa al estudiantado por niveles según su edad y que pretende generar el aprendizaje de unos contenidos establecidos por la cultura dominante.

Esta manera de proceder en las escuelas genera discriminación, que influye no solo en los resultados del alumnado sino también en aspectos más personales, debido a las experiencias de discriminación vividas. Como dicen Aguado y Ballesteros (2012), esta visión hace problemática la diversidad y provoca, entre otras consecuencias, la aceptación de procesos de enseñanza-aprendizaje 
homogéneos y rígidos, en los cuales no se reconoce la diversidad de formas de aprender del estudiantado sino la de unos pocos.

Sin embargo, si pensamos que educar en la diversidad es un proceso que se fundamenta en los Derechos Humanos y se basa en el pluralismo democrático que tiene que ver con todo el alumnado, pensaremos en la diversidad como un concepto amplio en el que tienen cabida procesos educativos atentos a la diversidad de necesidades y demandas derivadas de características tales como la cultura, el género, la clase social, las creencias religiosas, la capacidad intelectual, etc. (Moriña, 2008). Como dice Mir (1997), la diversidad vista desde esta mirada no sería una evidencia de una sola condición sino que sería el fruto de combinaciones peculiares y complejas, propias de las condiciones internas y externas que confluyen en cada persona.

Como veremos en el siguiente apartado, la manera de entender la diversidad se ha ido transformando hasta la actualidad, en la que se entiende tal y como la hemos definido, como parte de la condición humana, parte de nuestra identidad y de nuestros rasgos personales y culturales.

\subsection{Modelo Educativo Intercultural Inclusivo}

A continuación definiremos cada uno de estos modelos para posteriormente realizar la conjugación entre ambos.

\subsubsection{Modelo intercultural}

Para empezar, nos preguntaremos qué entendemos por una escuela o una educación intercultural. Para ello, nos basamos en la autora Gil-Jaurena (2012) que 
entiende lo intercultural como un enfoque, una perspectiva, una forma de mirar a la escuela y a los aspectos educativos. Además, en esta manera de mirar la escuela entendiendo que la diversidad cultural forma parte de la realidad, nos parece relevante la definición de la autora, en la que se entiende la interculturalidad como un enfoque educativo holístico e inclusivo que, partiendo del respeto y de la valoración de la diversidad, busca reformar la escuela como totalidad para incrementar la equidad, superar el racismo/discriminación/exclusión, favorecer la comunicación y las competencias interculturales, y apoyar el cambio social según principios de justicia social. Para esta autora, la educación intercultural implica que:

- Se trata de un enfoque educativo, una manera de entender la educación, y supone un proceso continuo (no un programa o una acción ocasional).

- Como enfoque holístico, afecta a todas las dimensiones educativas (no solo al currículo).

- Como enfoque inclusivo, supone la educación de todos (no la de minorías o inmigrantes).

- Percibe la diversidad como un valor (no como una deficiencia).

- Tiene cuatro objetivos generales: la equidad, el antirracismo, la competencia intercultural y la transformación social.

- Pretende reformar la escuela para conseguir una educación de calidad para todos los estudiantes, es un enfoque transformador.

La diferencia entre los supuestos del modelo intercultural respecto de los anteriores es que entiende que cada cultura tiene unas características propias, pero también existen elementos compartidos con otros grupos. La dificultad para la educación intercultural se encuentra precisamente en establecer el equilibrio entre el respeto a la diferencia y la construcción de un marco social y cultural común entre distintos grupos. Además, a diferencia del pluralismo, con el modelo intercultural se trata de que se valore no solo la propia cultura sino la diversidad de cada grupo, sea o no el de pertenencia. De modo que los objetivos principales del 
modelo intercultural se basan en conseguir la igualdad de oportunidades y en la búsqueda de un diálogo cultural y social enriquecedor.

Por otra parte, para el modelo intercultural es importante enriquecer las culturas y no ignorar elementos de estas. Por eso, se defiende el multilingüismo y se apuesta por modelos de educación bilingüe para que los grupos minoritarios no pierdan el conocimiento de su lengua materna, que puedan comunicarse y a ser posible, estar también alfabetizados en su idioma. Aunque esta segunda parte supone un reto que podría ser competencia de toda la comunidad educativa más que una labor únicamente de la escuela. Pero sí que es importante que la escuela se convierta en lo que sería una verdadera democracia vivida activamente, donde toda la comunidad analizara la realidad social y aprendiera habilidades de acción y modos alternativos de compromiso en la transformación de la sociedad, donde se diera una participación plena en la toma de decisiones y en la construcción del conocimiento colectivo. Una escuela que permitiera a todos los grupos culturales valorar su propia cultura, fortaleciendo así su autoconcepto y autoestima, al tiempo que le aporta actitudes y destrezas tanto intelectuales como sociales para enriquecer su identidad con la concepción de un mundo complejo y diverso en el que participar activamente.

Para Osuna (2012, p. 52-53), "la educación intercultural debe entenderse como un enfoque holístico en educación de manera que «intercultural» no sea un adjetivo sino un «todo» que debería permear toda práctica y sistema educativo”. En este enfoque se debería:

- Valorar la diversidad cultural de la sociedad en su conjunto y de la comunidad educativa en particular, teniendo en cuenta a todos sus actores sociales: personal del centro, estudiantes, padres de familia, personas que quieran acercarse al colegio, etc.

- Esto tiene que hacerse así porque el espacio educativo se concibe como un espacio abierto a la comunidad y no restrictivo, en el que la participación y el trabajo colaborativo sean fundamentales para construir un espacio democrático en la escuela. 
- En esta escuela se debe desarrollar y fomentar el pensamiento crítico y reflexivo en torno a la diversidad y las diferencias que se atribuyen.

- De esta manera, la cultura se "desesencializa" y se deja de percibir como algo que se puede cosificar y relacionar equivocadamente con ciertos comportamientos, actitudes, aspiraciones... que clasifican a las personas (en general) y a los estudiantes en el aula y el centro (en particular) en conceptos rígidos de identidad.

- Esto significa una educación en la que se reflexione críticamente sobre cómo se construyen las diferencias y que valor se les atribuye en el contexto socio-histórico y actual.

- De esta manera, se formaran ciudadanos críticos que desarrollen habilidades y competencias para comunicarse y desenvolverse en diferentes contextos, conscientes del juego de relaciones de poder y de privilegios que pueden surgir en espacios que son, por definición, de conflicto (en mayor o menor grado).

El enfoque intercultural contemplaría de manera prioritaria el tratamiento del racismo y la discriminación como un tema transversal del currículo, no con aspiraciones de superarlo -lo cual es, desde el punto de vista de Osuna, utópico-, sino con la finalidad de sensibilizar, debatir y despertar la conciencia sobre el mecanismo racista. Esto se haría desde una postura que evite disfrazar todo tipo de desigualdades y apueste por generar espacios abiertos y de diálogo en los que desde el fomento de la autoestima y del respeto- se ofrezcan herramientas para que los niños sepan "con qué cartas juegan" en el sistema social, político y económico en el que están creciendo y que, dadas las desigualdades estructurales atribuidas a diferencias naturalizadas, les ofrece y les ofrecerá ventajas, desventajas y toda una serie de adscripciones identitarias que no siempre se eligen o aceptan de forma voluntaria. 


\subsubsection{Modelo inclusivo}

Desde la diversidad funcional avanzamos hacia el modelo inclusivo, que nace con la necesidad de dar una respuesta adecuada a la diversidad dejando de excluir o etiquetar al alumnado y tratando de generar su participación democrática en la escuela y en la sociedad. La primera aportación hacia la inclusión la encontramos en "La declaración de Salamanca (1994)", con el objetivo de promover la “Educación para Todos”. Es en la Conferencia organizada por el gobierno español y la colaboración de la UNESCO, en el que se congrega a especialistas de la educación y representantes de Naciones Unidas y otras organizaciones especializadas, así como organizaciones gubernamentales internacionales... En la conferencia se partía del principio de integración desde una visión que consiguiera sentar las bases de lo que podría ser una "escuela para todos":

Para hablar de inclusión a nivel nacional, no podemos sino referirnos a autores que han realizado numerosas aportaciones al respecto, entre ellos destacamos a Arnaiz, Blanco, Echeíta, Parrilla, Moriña, Muntaner, etc.

En primer lugar, con la intención de distinguir el modelo inclusivo del integrador, cabe destacar cómo cada uno de ellos entiende la atención a la diversidad. Mientras que para la integración la atención a la diversidad viene a definirse por la escolarización del alumnado en escuelas ordinarias, para la inclusión este proceso de escolarización tiene un carácter más profundo. No es suficiente con estar escolarizado, sino que se tiene que tener en cuenta a todo el alumnado para que forme parte de manera activa de su propio proceso de aprendizaje. Según Echeíta (2005), en la integración la atención a la diversidad se situaría en la compensación de desigualdades; mientras que para la inclusión no se trata de compensar desigualdades sino de generar equidad. Sin embargo, las diferencias tan notables en su significado pueden pasar desapercibidas al hacer un mal uso del concepto, por eso, es importante que al utilizar un nuevo término no lo confundamos con significados y concepciones previas, que no responden al término en concreto. La inclusión es un concepto más amplio que el de integración y se centra en todo el alumnado, no solo en aquel "diferente", y pretende que 
alumnos y alumnas aprendan juntos independientemente de sus capacidades y habilidades. Según Blanco (1999):

Se trata de lograr una escuela en la que no existan "requisitos de entrada" ni mecanismos de selección o discriminación de ningún tipo; una escuela que modifique substancialmente su estructura, funcionamiento y propuesta pedagógica para dar respuesta a las necesidades educativas de todos y cada uno de los niños y niñas, incluidos aquellos que presentan una discapacidad (p. 62 - 63).

Por tanto, la inclusión es un paso más hacia la igualdad, se pasa del Principio de Normalización a la Declaración de los Derechos Humanos y se plantea la inclusión como un derecho humano basado en la justicia y la igualdad social. En este sentido, Parrilla (2002), destaca que la educación inclusiva supone dos procesos interrelacionados: "el proceso de incrementar la participación de los alumnos en la cultura y el currículum de las comunidades y escuelas ordinarias, y el proceso de reducir la exclusión de los alumnos de las comunidades y culturas normales" (p. 18). Es decir, la inclusión tiene que garantizar la participación activa de todos los miembros de la comunidad en las iniciativas que allí se desarrollan; al mismo tiempo que se es sensible a posibles exclusiones que pueden estar sucediendo en los centros y en la sociedad.

Desde este modelo se pone el énfasis en la transformación de la comunidad escolar, aspecto en el que nos detendremos más adelante, para poder atender a la diversidad del alumnado y conseguir su éxito en la escuela. En el modelo inclusivo la diversidad no es algo que hay que normalizar, sino que es un enriquecimiento. Por eso, consideramos no solo las dificultades sino también las capacidades. Partimos de que todos y todas somos iguales, pero cada uno tiene un modo de aprender y unas motivaciones hacia la educación. Ahora, es el contexto quien se transforma para responder a las necesidades de cada persona, en lugar de ser la persona quien se adapta al contexto. Es decir, el alumnado diagnosticado con diversidad funcional, al igual que el resto de sus compañeros, estará en el aula y el tutor trabajará con él para dar respuesta a sus necesidades. El especialista entrará en el aula, cuando sea conveniente, para trabajar con el estudiante, mientras él interacciona con sus compañeros. El trabajo del especialista es un refuerzo y ayuda 
en las funciones del profesorado. En este contexto de aprendizaje el profesorado debe formarse para ser capaz de atender a la diversidad del aula. De este modo, cabe destacar que la inclusión de todas las personas no distingue entre razones de género, culturales o de capacidades. Contempla que cada persona es diversa y se dará respuesta a sus propias necesidades.

A nivel internacional, otros de los autores referentes que podemos encontrar en dicho ámbito son Porter (1994); Dyson (1999); Stainback y Stainback (1999); Booth y Ainscow (2000), etc. En concreto, desde la mirada de Booth y Ainscow hacemos referencia a su propuesta para generar culturas inclusivas en las escuelas. Con esta finalidad se construye el Índice para la Inclusión o Index for Inclusion (Booth y Ainscow, 2000) que pretende desarrollar las escuelas hacia una educación más inclusiva. El objetivo que resaltan los autores es el de construir comunidades escolares que apoyen el fomento de altos niveles de logro para todos los estudiantes y para ello se promueve un análisis y una reflexión a fondo sobre todo lo que forma parte de la vida de un centro escolar.

Finalmente, la inclusión es una filosofía pero también es acción. Pues para movilizar y promover acciones educativas inclusivas necesitamos creer en ellas, pero después se tienen que poner en marcha siendo coherentes con el modelo en el que se cree, contando con la participación activa de toda la comunidad educativa y facilitando prácticas que no segreguen sino que incluyan y generen equidad. Así mismo, entendemos que la inclusión no se limita al marco educativo, sino que es una manera de entender la vida y la sociedad. Es un posicionamiento individual en la sociedad y constituye un proceso de enriquecimiento cultural y educativo. Además, la inclusión se basa en la igualdad de todas las personas, pero esta igualdad valora la diferencia desde el punto de vista de la diversidad.

\subsubsection{La conjugación entre ambos modelos}

En este apartado queremos conjugar el modelo intercultural y el inclusivo, ya que ambos proceden de tradiciones distintas, pero han llevado un camino paralelo 
desde el que vienen a defender la igualdad de oportunidades, la equidad y la diversidad como riqueza. La fuerza de aunar ambos conceptos en uno mismo viene por el hecho de mirar hacia una misma dirección, hacia el mismo horizonte, pero con particularidades que ponen el acento en aspectos distintos (uno en la diversidad cultural y el otro en la diversidad funcional). En ambos casos se busca una participación democrática de los miembros de la comunidad educativa, el respeto hacia la diversidad en todos los sentidos, la desaprobación de cualquier tipo de exclusión y en última instancia, la transformación socioeducativa para conseguir que estos principios se conviertan en claves educativas en los centros.

Sin embargo, también tenemos que ser cautos, ya que se ha puesto de moda hablar de interculturalidad e inclusión y en algunos casos se identifican prácticas, llamadas interculturales y/o inclusivas por quienes participan de ellas, con prácticas que son meramente segregadoras. Es por esto que, es necesario distinguir entre los principios que aportan equidad y aquellos que no hacen más que reproducir desigualdades, y concienciarnos de aquellas acciones que hacemos en un sentido o en el otro, para promoverlas en el caso de ser buenas prácticas o para poder dejar de hacerlas en el caso contrario. Sin embargo, dejar de hacer algo a lo que estás acostumbrado no siempre suele ser sencillo, y más aún cuando lo que determina que una práctica sea más intercultural e inclusiva son las actitudes y creencias que la envuelven. Es por esto que el profesorado o profesionales de la educación en primer lugar, deben conocer sus "limitaciones mentales" para no reproducirlas. Es decir, ser conscientes de sus valores pero también de sus prejuicios y expectativas bajas hacia el otro. En segundo lugar, es necesario un trabajo de sensibilización y conciencia sobre estos temas a nivel social. "Ser críticos y tomar conciencia de nuestras prácticas segregadoras y racistas es un primer paso para la transformación educativa y social" (Sales, 2007, p. 2). De hecho, en las prácticas que podemos encontrar en las escuelas, todavía tiene un gran peso el modelo compensatorio y asimilacionista, mientras que el inclusivo e intercultural sigue su desarrollo teórico, pero tiene poca presencia en las aulas (Barton, 1998; Lluch, 2003). 
Por todo ello, coincidimos en que la transformación hacia valores y actitudes democráticos de igualdad, respeto, autonomía y solidaridad son aspectos fundamentales para generar una educación intercultural e inclusiva que propicie la construcción de un proyecto sociocultural y educativo que incida tanto en el ámbito de lo macro-social como de lo micro-social (Gairín, 2004; Sales, 2007).

Toda esta teoría social y educativa que se pone de manifiesto en las relaciones humanas también necesita hacerse eco en las instituciones educativas, para de alguna manera, poder transformar la educación hacia una sociedad más intercultural e inclusiva (Carbonell, 2000; Besalú, 2002). Es por ello que nos planteamos la función de la escuela en una sociedad diversa, democrática, plural, multicultural, etc. Para esta sociedad necesitamos de sistemas que formen al alumnado y a las personas hacia políticas de libertad, de mayor conciencia sobre sí mismos, sobre sus intereses y sobre el sistema en el que están inmersos. De ahí que, necesariamente la escuela tenga que definirse como un lugar intercultural e inclusivo, democrático, plural, abierto, dinámico, resolutivo, crítico y dialógico, cuanto menos, para que forme a ciudadanos capaces de convivir y vivir felizmente en sociedad.

Pero, ¿por qué la escuela? La respuesta para nosotros sería que no es únicamente la escuela quien tiene dicha función, pues es una función social. Pero, además de las familias que son otro de los pilares básicos para la educación y la transformación de la ciudadanía, la escuela es el lugar donde las personas pasamos más tiempo durante el período de socialización y enculturación. Es un lugar donde se transmiten valores y creencias que van determinando nuestras actuaciones en la vida. Es también uno de los lugares donde se adquieren competencias y herramientas para la vida. Es por esto que la escuela nos proporciona el marco adecuado para desarrollar una interculturalidad e inclusión real, basada en prácticas que traten de generar igualdad, que traten de desarrollar una cultura escolar democrática. Como diría Sales (2007): “desarrollando una cultura escolar democrática basada en la explicitación de valores e intereses de cada colectivo, desde los órganos de participación escolar, que son el marco legal organizativo que 
permiten desarrollar una dinámica democratizadora y pluralista" (p.14). Una cultura escolar en la que se identificarán todas las voces, no con la pretensión del asimilacionismo, de acallar las voces de las minorías, sino con la de la interculturalidad. Para legitimar esa función globalizadora de la escuela es necesario establecer un diálogo compartido, basado en la participación activa y democrática de toda la comunidad educativa. En esta manera de construir la escuela se tienen que escuchar y tomar decisiones entre todos los agentes implicados, cada uno con sus ideales y sus valores culturales. Esto supone replantearnos no solo aspectos concretos como actividades extraescolares, sino también aspectos estructurales de la institución, o curriculares, entre otros.

Sin embargo, la determinación de querer una escuela intercultural inclusiva no supone per se, que la transformación se lleve a cabo, ya que se trata de transformaciones sociales y educativas que no son fáciles de realizar. En numerosas ocasiones aparecen contradicciones y paradojas entre la teoría y la práctica. Nos podemos encontrar con un discurso que explicite el deseo, por ejemplo del profesorado, de transformar sus prácticas para que sean más interculturales e inclusivas y que al mismo tiempo se estén reproduciendo prácticas desde un modelo segregacionista o asimilacionista, pues existen otros factores, políticos, sociales, culturales, etc. que influyen en la acción. Las dificultades que se encuentran en la práctica, para Escudero (2002), pueden explicarse porque la escuela todavía no se ha replanteado su función como institución para todos los ciudadanos. Es más, sigue sin cuestionar las estructuras socioeconómicas en las que se tratan de llevar a cabo las reformas educativas.

Más allá de este debate, a continuación aportamos siete acciones estratégicas que Essomba (2006) propone para avanzar hacia la construcción de la escuela intercultural inclusiva, y que ya se están llevando a cabo en algunas escuelas:

En relación a la ideología del profesorado, el autor propone la creación de un consejo de actualización curricular. Este consejo tiene la función de reflexionar sobre los acontecimientos sociales del entorno, para tratar de aproximarlos al currículum. 
Con respecto a la dimensión de cultura escolar y profesional, se propone la participación del alumnado no solo en las actividades que diseña el profesorado, sino que replantea esta función, y la amplía a la participación del alumnado también a la planificación de las actividades.

Por otra parte, desde esta dimensión también se plantea la participación de las organizaciones y asociaciones sociales en la vida del centro.

En cuanto a la dimensión de comunidad educativa, se replantean las funciones de todos los miembros de la comunidad y de ahí el establecimiento de un currículum creado por todos: currículum "on line”.

Además, esta dimensión también considera la acción comunitaria como una acción de servicio. Al estar la escuela en un territorio concreto, se nutre y puede aprovecharse de las características contextuales, así como sus miembros pueden realizar una labor de servicio.

Finalmente, en la dimensión del sistema educativo, se realizan dos propuestas: la creación de una red de centros y el observatorio local de la educación. Este último vendría a referirse a una dimensión más política, desde el que se puedan diseñar propuestas concretas para llevarlas a las autoridades competentes.

Por su parte, Sales (2007) indica que los elementos básicos para la construcción de la escuela intercultural inclusiva serían:

- La transformación educativa queda enmarcada dentro de un proceso más amplio de transformación social y cultural.

- La escuela debe entenderse como un espacio de participación democrática.

- La concepción comunicativa de las ciencia sociales da lugar a un aprendizaje dialógico (Freire, 1996).

- La búsqueda del diálogo intercultural.

- La emancipación crítica y la autonomía personal.

- $\quad$ El profesorado como ciudadano e investigador comprometido.

A partir de todos estos principios que contribuyen a la creación de una escuela intercultural e inclusiva, realizamos nuestra propuesta sobre los elementos 
necesarios para la creación de una escuela de estas características, que presentaremos a continuación. Los tres primeros elementos que aparecen están relacionados con el modelo educativo que estamos defendiendo. Sin embargo, el cuarto y el quinto aspecto vendrían a incidir en una dimensión más personal sobre el cambio educativo, sobre la que nos detendremos en el cuarto capítulo.

a) Modelo Intercultural e Inclusivo como referencia para el cambio.

Este aspecto es el que hemos ido estudiando a lo largo del primero y segundo capítulo y que hemos acabado concretando en este apartado. Es por esto que no volveremos a repetir las bases del modelo, aunque destacaremos dos principios fundamentales: la mirada de la diversidad como enriquecimiento y la igualdad de oportunidades como objetivo.

b) Participación democrática de toda la comunidad educativa.

Ya hemos comentado la importancia de que las familias y miembros de la comunidad formen parte del proceso, pues es necesaria la participación de todas las voces para la construcción de una escuela intercultural e inclusiva. Estas ideas las desarrollaremos a lo largo de este capítulo.

c) Prácticas educativas en el centro y en el aula que sean interculturales e inclusivas.

Otro de los elementos en el que aparece un reflejo de la filosofía intercultural inclusiva hacia la que caminan los centros son las prácticas. Por prácticas interculturales e inclusivas nos referimos tanto a aquellas desarrolladas en un nivel más macro del centro, como en un nivel micro o de aula. Este aspecto lo trabajaremos en el siguiente capítulo.

d) El desarrollo personal del alumnado.

Basándonos en la afirmación de Gale y Densmore (2007), en la que se habla de la escuela como un lugar para fomentar la emancipación crítica y la autonomía personal, desde el desarrollo del potencial de cada persona, coincidimos en que la función de la escuela es formar a ciudadanos críticos y también con herramientas para poder gestionar sus vidas de una manera saludable. Es por esto que en el 60 
cuarto capítulo nos detendremos en la educación emocional basada en favorecer el bienestar en las personas y en la educación holística, que entiende la educación desde el desarrollo integral del alumnado.

e) El profesorado como persona.

Al final, uno de los agentes que contribuye de manera decisiva en la transformación de las escuelas es el profesorado, pues todo el tema de la educación emocional o de la educación holística, que se basa en el desarrollo integral del alumnado, no tiene ningún sentido si el propio docente no sabe cómo desplegar en su vida su propio potencial. Las personas somos creadoras de nuestras vidas y el profesorado además, acompaña al alumnado en sus primeros pasos. Sin embargo, se suele centrar en su papel como profesional, dejando a un lado el valor de lo personal tan importante en la educación. La gestión de las emociones y una educación dedicada al desarrollo del ser es la necesidad social de este momento. Una escuela más consciente nos puede ayudar a transformar aspectos tan importantes como el respeto a la diversidad y puede sentar las bases para que se despliegue una convivencia más pacífica y solidaria en la sociedad. Es por esto que dedicaremos un capítulo para comprender la importancia que tiene el docente, como persona, en su papel como maestro para fomentar el desarrollo personal en el alumnado.

\subsection{La Participación Comunitaria}

Como ya veníamos defendiendo en apartados anteriores, para avanzar hacia la mejora educativa y hacia una mejora fundamentada en la interculturalidad e inclusión, es necesario construir la escuela de manera democrática, para conseguir una escuela que dé cuenta de los valores y principios de justicia e igualdad defendidos en la sociedad. 
Además, en una escuela intercultural inclusiva la participación de todos los miembros de la comunidad es un elemento necesario, para que dicha interculturalidad e inclusión sean una realidad, no solo en la escuela sino también en el contexto más próximo del alumnado: sus familias y el barrio. Por eso, la construcción de una escuela igualitaria, de todas y todos, desde la diversidad de cada uno, implica la construcción de una escuela que sea democrática y que se construya contando con la participación activa e igualitaria de todos sus miembros.

¿Pero, qué entendemos por participación comunitaria? Para Reparaz y Naval (2014) la participación significa "tener algo en común” y además, si la comunidad surge de aquellos quienes tienen algo en común, la participación y la comunidad serían dos dimensiones inseparables para las autoras.

Para nosotros, la comunidad y la participación también son dos ejes unidos, y coincidimos en que participación implica "tener algo en común". Aunque creemos que esta es una definición muy amplia y tienen cabida distintos tipos de participación, no todos coincidentes con lo que consideramos una participación democrática. Es decir, aquella en la que los miembros de la comunidad toman decisiones y realizan acciones de manera consensuada. Por otro lado, existe otro tipo de participación, para nosotros "menos democrática" en la que unos pocos deciden y el resto cumple con los objetivos o acciones marcados por una minoría, y que no han sido valorados de manera democrática. Esto sería una "falsa" participación en nuestra manera de entender la educación intercultural e inclusiva, ya que no puede existir una educación basada en la ciudadanía democrática sin la participación de los diferentes agentes de la comunidad educativa en su totalidad.

Actualmente, creemos necesaria esta función de ejercer la participación desde la escuela para que desde el ámbito educativo se prepare a la ciudadanía en un ejercicio que les pertenece y al que quizás estamos poco o nada acostumbrados. Para Freire (1996) la participación es un ejercicio de tener voz, de asumir y de decidir. Este ejercicio está relacionado con los niveles de poder y con el derecho de ciudadanía que se halla en relación directa con la práctica educativo-progresiva. 
Por otra parte, es necesario definir también el concepto de comunidad para comprender lo que implicaría una participación comunitaria. La manera de entender la comunidad, las relaciones entre esta y la escuela y la participación, es un aspecto clave que vendrá a definir la realidad de un centro. Además, las relaciones entre el ámbito comunitario y el escolar pueden adoptar diferentes formas, desde la mera "participación testimonial" de algunos representantes de las familias en los órganos oficiales de gestión y/o representación del centro (consejo escolar, etc.), hasta otras opciones que han explorado fórmulas que fomentan la intervención "real" de la comunidad educativa - entendida en un sentido más amplio e inclusivo-, mediante procesos de participación, negociación y gestión democrática (Traver, Sales y Moliner, 2010, p.116).

Es en este último eslabón en el que nos queremos situar al tratar el tema de la participación. Una participación unida a la democracia, que venga a re-definir la escuela como un lugar donde vivir la democracia de manera participativa (Dewey, 1995; Martínez Bonafé, 1999). Pero no vale cualquier tipo de participación, sino que es necesaria una participación sin exclusiones. Para ello, es necesario favorecer la buena comunicación entre personas de distintas culturas, para evitar el aumento de los estereotipos y prejuicios que bloquean el diálogo igualitario y lo hacen en algunos casos inaccesible, debido a nuestras limitaciones mentales proyectadas sobre el otro. Pues al fin y al cabo, dicha participación comunitaria se asienta sobre las bases de construir juntos un proyecto común, consensuado y basado en principios de igualdad y equidad. Pero ese "construir juntos" no siempre es fácil. Supone traspasar "puertas", como metafóricamente comentan Traver y otros. (2010), o límites tradicionalmente anclados que suponen un replanteamiento de nuestros valores y de nuestra manera de ver al otro y la escuela, como institución. Quizás traspasar esta puerta entre el mundo escolar y el comunitario sea una de las mayores dificultades al inicio, pues supone un cuestionamiento de la cultura escolar; pero sin duda, es la única oportunidad de transformar radicalmente la escuela para dotar de mayores oportunidades al alumnado. Cuando esto sucede, encontramos centros y aulas abiertas a la participación de vecinos, familias, voluntarios, etc. que cuentan con mayores recursos y oportunidades para aprender; 
con una cultura permeable de las vivencias de los miembros que forman parte del centro y con una atención más adecuada a la diversidad.

La participación es la base del compromiso, de la apropiación, de la motivación, de la construcción compartida de significados, etc., que, a su vez, fundamentan cualquier proyecto colectivo de escuela (Guarro, 2005). Además, la participación implica también una nueva construcción personal, desde una perspectiva emancipadora y en base a unos principios particulares que caracterizan algunas prácticas y procesos (Valderrama, 2012). En este sentido la reconstrucción personal va unida a la construcción comunitaria que necesita establecer mínimos comunes desde los que encontrarse.

Por otra parte, no podemos entender la participación sin incluir en ella la toma de decisiones (Fullan, 2002; Elmore, 1996; Senge, 1992). Como dice Guarro, la participación activa y consciente es uno de los pilares de una sociedad democrática, lo que exige tomar decisiones constantemente. Pero además, para poder participar en igualdad de condiciones en dicho proceso de priorización y toma de decisiones, no basta con elegir, sino que es necesario que esa decisión se fundamente desde el entendimiento, es decir, que sea informada.

Por ello, la escuela debe incorporar en su quehacer cotidiano ese tipo de prácticas para que el alumnado las vaya interiorizando y las considere parte esencial de sus comportamientos democráticos. La actitud de búsqueda, es decir, la mente abierta, curiosa, inquisitiva, cuestionadora, etc., es la manifestación de valores como la tolerancia, la apertura, etc., y por tanto exigible tanto en el alumnado, cuando se enfrenta al aprendizaje como el profesorado cuando se plantea la enseñanza (Guarro, 2005, p.28).

Por otra parte, también es necesaria una reorganización de las estructuras, los horarios y el espacio, para que se pueda facilitar la participación de todos los miembros de la comunidad educativa; del mismo modo que su proyecto educativo se debe extender a la comunidad (Guarro, 2005).

Otro de los elementos importantes a tener en cuenta en relación con la participación de la comunidad es la necesidad de que haya un clima de confianza 
entre las personas para promover o motivar la participación (Reparaz y Naval, 2014). Aunque como dice Brisebois (1997, p. 19) "es difícil dar responsabilidad a alguien cuando no se sabe si es capaz de asumirla; pero, por otra parte, nunca será capaz de asumirla si no se le deja, si no se le da responsabilidad". En este sentido, Pinkus (2003) señala que debe haber un consenso en relación con los objetivos que se persiguen y en las funciones de las familias, profesionales y otros miembros que participan en el centro. Con esto, no estamos pensando en delegar responsabilidades de manera autoritaria, sino de establecer una relación colaborativa entre todas las personas basada en la corresponsabilidad (Bolívar, Moya y Luengo, 2008).

En este proceso de participación, vamos a centrarnos en tres agentes principalmente: el profesorado, las familias y el alumnado. Empezaremos por el profesorado, por ser el colectivo que, por su rol, juega un papel privilegiado en cuanto al hecho de participar en la toma de decisiones y en las acciones del centro. Seguiremos con otros miembros de la comunidad, prestando especial atención a las familias, al ser estas unas de las primeras en traspasar la distancia entre la escuela y el barrio y finalizaremos con el alumnado, un colectivo tradicionalmente silenciado.

\subsubsection{La voz del profesorado}

La participación del profesorado para la construcción de una escuela intercultural inclusiva es básica, pues de él dependen una parte de las acciones a realizar en el centro y prácticamente todas las decisiones de aquello que se trabajará en el aula y que por tanto, llega directamente al alumnado. Sin embargo, desde este enfoque que busca una participación democrática de todos los miembros, se requiere de un profesorado que abandone una perspectiva profesionalista sobre el papel docente, que lo convierte en responsable y agente único, especialista de la educación escolar, para convertirse en uno más en la construcción de un proyecto compartido. Se piensa en el profesorado como 
colaborador y dinamizador de una cultura colaborativa. Aunque no siempre resultará fácil establecer relaciones de igualdad entre los distintos colectivos, o pasar de una cultura profesionalista a una cultura colaborativa con la comunidad.

Por cultura profesionalista entendemos aquella que mantiene al profesorado como experto de la educación, excluyendo a otros agentes de la toma de decisiones y de la participación en el marco escolar (Escobedo, Traver, Ortells, 2013). O, tal y como la define Imbernon (2007), desde una concepción neoliberalista de la profesión docente que se atribuye al término profesionalismo; entendiendo la cultura profesional de un modo reduccionista que impide el desarrollo profesional y colectivo del profesorado, tanto a nivel social como educativo. Además, este posicionamiento, puede llevar al docente a adoptar actitudes y comportamientos prepotentes, basados en pretensiones de poder y anclados en un saber técnico específico, patrimonio del propio colectivo.

Siguiendo los trabajos sociológicos clásicos sobre el profesorado de autores como Becker (1953) y Waller (1932), esta forma de entender la docencia y el estatus que asumen como profesionales especializados, hace que perciban a los demás sectores educativos como intrusos e ignorantes en relación a lo que sucede en las aulas. De ahí que no entiendan la necesidad de su participación así como todas las contribuciones que podría aportar su voz. El profesionalismo se basa en relaciones de poder $\mathrm{y}$ en el estatus que se otorga a los docentes, u otros profesionales de la educación, por disponer de conocimientos especializados que otros no tienen.

Contrariamente a este posicionamiento, desde los planteamientos de la escuela intercultural e inclusiva se entiende la profesionalidad del profesorado desde un marco de relaciones sociales justas y democráticas. Desde esta perspectiva su reconocimiento social está más ligado a sus capacidades para desarrollar un liderazgo inclusivo y sostenible (Gale y Densmore, 2007; Hargreaves y Fink, 2008). En este sentido, la mirada del profesorado sobre la comunidad y sobre su papel en ella será fundamental a la hora de acercarnos a procesos más participativos y democráticos. Pues como dice Echeíta (2011) los y las docentes 
"ya no son simplemente conductores de conocimientos, sino guías de los niños" (p.124). Este cambio en el posicionamiento de maestras y maestros, no tiene que ver únicamente con aspectos procedimentales, sino que como señalan Rojas y otros (2012) “conlleva la manifestación de actitudes de respeto y escucha auténtica acerca de los asuntos que los alumnos plantean” (p.93). Es precisamente este cambio de mirada el que puede ser conflictivo para una parte del profesorado, pues no se trata de implementar unas determinadas acciones sino de realizar un cambio de paradigma. Cambio que muchas veces el docente entiende y se plantea por sus propios valores, pero que en otras ocasiones pueden suponerle un conflicto interno.

Como dicen Marcelo y Estebaranz (1999), los cambios en la cultura exigen entender las innovaciones como una actividad no solo individual sino también cooperativa, replanteando el concepto de liderazgo y profesionalización docente. El reto es transformar la cultura docente profesionalista en una cultura docente colaborativa, que cuente con todos los miembros del centro. Sería, en palabras de Imbernón (2007), pasar a una cultura docente basada en un concepto de la profesión docente "más social, más dinámico, más complejo [...] y multidimensional, en el que el proceso de profesionalización se forja en un contexto de democracia, de auge de valores contradictorios entre los individuos y el progreso social" (p.14).

Sin embargo, la literatura nos muestra las dificultades y las resistencias en un intento por pasar de culturas más profesionalistas a otras más colaborativas. En nuestra experiencia con distintas escuelas en proceso de cambio hacia la interculturalidad y la inclusión, hemos observado que no es fácil realizar este cambio entre el profesorado (Traver, Sales y Moliner, 2010; Escobedo, Sales y Traver, 2011); sino que mayoritariamente, prima la visión profesionalista. Esta visión del docente como especialista produce siempre altos grados de exclusión de las propuestas educativas que proceden del resto de agentes comunitarios. Desde este planteamiento las relaciones más intensas entre familia-comunidad-escuela, se suelen limitar a una colaboración armoniosa, dependiente y desigual con algunas familias -las que el profesorado considera más implicadas en el centro-, y la iniciativa educativa siempre viene de la mano, avalada o supervisada por el 
profesorado. Además, en algunos de los estudios realizados se hace visible la actitud de rechazo que el profesorado mantiene hacia algunas familias y el alumnado. Desde esta actitud se resisten a valorar y propiciar la participación de otros agentes; por eso, el profesorado situado en una cultura profesionalista trata de limitar la participación de otros miembros, actuando siempre que es posible como actor único del quehacer escolar. Su percepción estereotipada de la diversidad cultural y de lo que puede esperar del contexto en el que trabaja, dificulta su posicionamiento inclusivo e intercultural a la hora de cambiar su mirada sobre la escuela. Finalmente, el papel protagonista que el profesorado ocupa en el centro condiciona de manera decisiva su relación con el alumnado. Como apunta Guerrero (2007), "El poder del profesor se hace sentir de manera protagonista en la relación pedagógica; bien sea como actividad de imposición e inculcación del arbitrario cultural, en las pedagogías visibles o pasivas; o bien a partir de la posición de ventaja que posee en la negociación de la transmisión cultural en las pedagogías invisibles o activas". Relación que, como describe Guerrero, viene reforzada por la propia institución escolar en la que las características específicas de los espacios de enseñanza formal junto con el uso de un lenguaje docente difícil y alejado de los intereses de la mayoría del grupo clase, provoca un mayor distanciamiento e invisibilización del alumnado.

Por tanto, la voz del profesorado puede situarse en una continua paradoja, al considerar por una parte que debe apostar por una mayor participación comunitaria y democratización de las decisiones en el centro; y al mismo tiempo, al resistirse a abandonar un enfoque profesionalista que le legitima a ser el que tome la última decisión.

Por eso, para transformar dicha cultura hacia un modelo de participación más democrático y basado en la validez del argumento de todos los miembros, es necesario transformar también el liderazgo. Puesto que en la construcción de una escuela abierta a la comunidad el liderazgo no puede recaer únicamente en manos del profesorado, como hemos comentado en el primer capítulo, sino que es necesario que sea compartido. Para ello, en muchas ocasiones necesitaremos 
"romper la seguridad tradicional de las relaciones de poder que se establecen entre profesores y alumnos y redefinir las fronteras de la posibilidad" (Rudduck y Fielding, 2006: 225).

Para Gale y Densmore (2007), existen al menos tres grandes cuestiones que influyen de manera importante en la comprensión y el ejercicio comprometido de la docencia y, por tanto, en la cultura docente: el aislamiento docente -que desde una cultura profesional arborescente nos aboca a un grave problema de individualismo competitivo-, la falta de diálogo y entendimiento -ensombrecida por una profesionalidad rápida, corporativista y una desmedida obsesión por la eficiencia-, y una escasa cultura de participación e implicación social -que lleva a minusvalorar de forma importante y dolorosa el trabajo y la misión que como educadores tenemos encomendada-.

Aceptar esta situación de manera pasiva hace que el profesorado se sienta fácilmente superado por las dimensiones de los problemas a los que debe enfrentarse. No obstante, contamos con buenos ejemplos que muestran algunas claves para afrontar estas cuestiones y ejercer una influencia positiva en las vidas presentes y futuras de nuestro alumnado y la comunidad a la que pertenecemos. Esta orientación colaborativa y comunitaria está presente en los planteamientos educativos de la escuela intercultural e inclusiva: el maestro o la maestra debe considerar la influencia de la familia y del medio y desarrollar los recursos necesarios para hacer extensiva la acción educadora a la familia y a la calle, dado que el destino de su alumnado es la vida social, la acción en una comunidad.

Finalmente, cabe destacar el planteamiento de Gale y Densmore (2007), sobre cómo debe ser la implicación del profesorado para favorecer la construcción de una escuela al servicio de la justicia social a través de medios democráticos:

a. La democracia radical. En primer lugar es necesario entender la escuela como un lugar único para vivir la democracia de manera participativa.

b. La disposición crítica para con la sociedad. Percibir las desigualdades que vemos desde un posicionamiento empoderado nos da posibilidades de cambio. 
c. El activismo político. El activismo político, fruto de la democracia radical y de una disposición socialmente crítica, implica necesariamente una dimensión política colectiva.

\subsubsection{La voz de las familias y otros agentes comunitarios}

Como hemos comentado, es esencial la participación de todos los miembros para la construcción de la escuela intercultural inclusiva. Por esto, destacamos en primer lugar el sentimiento de pertenencia a la comunidad (Soodack y Erwin, 2000) y la necesidad de transformar la individualidad de cada colectivo por una postura de colaboración y cohesión entre todos los miembros (O’Connor, 2008). Para ello, es fundamental la apertura de los centros:

La apertura de los centros al entorno y, especialmente sus relaciones con las familias, debería constituir uno de los pilares fundamentales de su trabajo cotidiano y, más aún, de su reconstrucción democrática. Las relaciones entre el centro y las familias de su alumnado deberían ocupar un lugar predominante en la dinámica de trabajo no solo a través de las estructuras formales (Consejo Escolar, AMPAS, etc.), sino en el día a día (Guarro, 2005, p.23).

La relación entre el contexto y el centro es necesaria e inevitable. La cuestión es si podemos utilizar los recursos del contexto y contar con una participación e implicación total como muestra de un trabajo compartido entre escuela y comunidad o si nos resistimos a ello y limitamos el aprendizaje del alumnado. Ante esta situación la respuesta de los profesionales debería ser rotunda y segura, "apostar por un trabajo colaborativo junto con la comunidad como seña de una escuela intercultural e inclusiva". Sin embargo, lo que parece fácil u obvio no resulta tan evidente por la cultura escolar en la que estamos acostumbrados a crecer en las instituciones educativas. Cualquier replanteamiento sobre la cultura supone procesos de ruptura o transformación con lo anterior para avanzar hacia lo desconocido, y este hecho como mínimo produce un sentimiento de descontrol y 
desconfianza, cuanto menos, al principio. Sin embargo, la literatura nos da muestras de la importancia de la participación comunitaria en los centros (Apple y Beane, 2005; Bolívar, 2000; Flecha y Tortajada, 1999; Jiménez y Pozuelos, 2001; Aubert et al., 2004; Elboj et al., 2002; etc.) e insiste en que la participación comunitaria, basada en procesos de aprendizaje dialógicos y cooperativos, es la base fundamental para generar equidad en educación.

Por otra parte, la participación comunitaria suele concretarse en la de una parte de las familias, las primeras en asistir al centro y también las que más ganas demuestran. Aun así, solemos encontrar una participación de las familias restringida a su ayuda en actos lúdicos, o la asistencia a reuniones para recibir quejas de sus hijos, pero pocas veces se llega a una participación más relacionada con la toma de decisiones (Freire, 1996).

En este sentido, podemos distinguir entre distintas formas de participación; desde niveles básicamente informativos o burocráticos hasta niveles que suponen una participación real y que cuentan con la implicación de las familias y otros miembros de la comunidad en las escuelas. A continuación, realizaremos una clasificación sobre la participación de las familias y la comunidad en la escuela, basándonos en los niveles que se proponen desde diferentes proyectos y estudios (Torres, 2007; INCLUD-ED, 2006- 2011; Epstein, 2001; Sanders y Epstein, 1998):

a) Informativo o burocrático. El primer nivel de participación es el que se limita a la relación entre familia y escuela basada en la transmisión de información. Este tipo de participación se concretaría en las reuniones, convocadas por el profesorado para hablar con las familias e informarles sobre aspectos de la escuela, del aula, o de sus hijos; así como de aspectos puramente burocráticos. En estas reuniones, las familias pueden dar su opinión pero esto no implica que puedan participar en la toma de decisiones. Por otra parte, este nivel respondería a lo que para Epstein (2001) sería ejercer su función como padres, que implica la ayuda entre la familia y la escuela para establecer un entorno en casa que apoye a los 
niños como alumnos y contribuya a las escuelas a comprender a las familias.

b) Consultivo o de apoyo. El profesorado opina que la familia es importante en la educación de sus hijos, pero limita su participación a programas que se planifican desde el centro, para implicarlas en la educación desde la escuela. Desde esta perspectiva se realizan conferencias, programas de escuelas de padres y madres. Algunas familias asisten a estas conferencias y otras propuestas del centro y ayudan a sus hijos en sus tareas escolares, las familias se convierten en voluntarias activas de las tareas que decide exclusivamente el profesorado. Las familias no participan en la toma de decisiones sobre aspectos referentes al centro. Según Torres (2007) este modelo es una de las consecuencias de la cultura del profesionalismo que asume que todas las familias son iguales. Familia estereotipada de clase media, urbana y del propio país. Se trata de un nivel en el que las familias son bienvenidas para organizar, ayudar y apoyar en el aula, el centro y las actividades de los alumnos y al mismo tiempo realizan su función supervisora, reforzando desde casa los contenidos explicados desde la escuela.

c) Ser parte de los procesos de toma de decisiones y de los sistemas de responsabilización. En este nivel, los miembros de la comunidad entrarían a formar parte en la toma de decisiones en los órganos de gobierno de la escuela. Aunque nos encontraríamos con propuestas más abiertas a la comunidad donde esta puede entrar y tomar parte, quizás la diferencia entre este nivel de participación y el posterior es que en este las propuestas siguen viniendo desde la cultura dominante en la escuela, que sería la del profesorado por tradicionalmente ejercer su rol como profesionales de la educación. Alguna de las acciones en las que participarían sería en formar parte del proceso de evaluación del estudiantado; otro tipo de participación más profundo sería entrar a formar parte en las actividades de aprendizaje realizadas en el centro y en el aula. 
d) Relación cívica o ciudadana. Desde este enfoque familias y profesorado trabajan cooperativamente para alcanzar metas comunes. Se fomenta la participación democrática de toda la comunidad educativa. Un objetivo clave sobre la participación de las familias es que estas se sientan escuchadas y que sus opiniones tengan una repercusión en el aprendizaje de sus hijos e hijas. Para ello, es necesario transformar las relaciones de poder por una estructura más abierta, participativa e igualitaria (Flecha, Padrós y Puigdellívol, 2003). Es importante que las familias participen democráticamente en la educación escolar de sus hijos e hijas. Por una parte, porque tienen mucho que aportar y el enriquecimiento es mutuo. Por otra parte, es importante también para mejorar las expectativas familiares. Por eso, si habilitamos los recursos para que las familias tengan mayor igualdad de oportunidades, sus hijos también podrán tenerla, ya que tendrán ayuda desde sus familias (Flecha y Puigvert, 2002). Pero, además de las familias es importante que toda la comunidad educativa se embarque en el aprendizaje, que sea un asunto de todas las personas. En este sentido es importante identificar e integrar recursos y servicios de la comunidad para apoyar a las escuelas, a los alumnos y a sus familias, así como utilizar recursos de las escuelas para apoyar a la comunidad.

Después de distinguir entre los distintos niveles de participación, creemos necesario superar la visión de la participación de las familias o la comunidad desde estructuras menos participativas o clientelistas a niveles mayores de participación, desde los que su participación puede suponer la superación de las desigualdades. Es importante destacar el gran aporte de las familias al disponer de información y recursos privilegiados que pueden optimizar el aprendizaje y la participación del alumnado (Echeíta, Sandoval, Illán, Domingo, Soler, Melero, Luengo, 2010).

Si nos situamos en este cuarto nivel de participación, contando con la participación de toda la comunidad, el centro tiene que cambiar. Es por esto que en escuelas con una relación más estrecha con la ciudadanía, encontraremos estructuras más flexibles, en cuanto a horarios y espacios; además, se ampliarán las 
voces de los actores y se incrementarán las posibilidades de acción hacia una educación más intercultural e inclusiva; y se cuestionará de una manera crítica el currículum (Guarro, 2005; Banks, 1995).

En estos procesos las familias, u otros miembros de la comunidad, entran a formar parte en la toma de decisiones; participan en comisiones generadas para priorizar acciones de mejora y poder llevarlas a cabo; y son protagonistas de aquello que acontece en el centro. Además, la comunicación entre todos los miembros del centro se realiza desde el respeto y el reconocimiento del otro, desde lo que sería un diálogo igualitario, basado en la Teoría de la Acción Comunicativa de Habermas (1987), que viene a resaltar la igualdad de todas las personas en el diálogo y la importancia del argumento por encima del estatus social o rol de quien lo expresa. Esta manera de construir la escuela supone un proceso de empoderamiento, no solo del alumnado sino de todas las personas que participan. $\mathrm{Al}$ establecer relaciones igualitarias en las que se transmite la valía de las personas independientemente de las carreras cursadas, el puesto de trabajo o su nivel económico y al extender el aprendizaje como una cuestión de todos y no solo del alumnado. Como dicen Dunst y Dempsey (2007) el empoderamiento de las familias se desarrolla al sentir que forman parte de acontecimientos que afectan a sus vidas y que les permiten impulsar cambios positivos en las mismas.

Cuando la participación se entiende de este modo, la comunidad participa en la construcción de la escuela desde principios de igualdad y es aquí donde podemos hablar de horizontalidad y democracia vivida en la escuela. Por tanto, sin la participación comunitaria resulta imposible construir una escuela democrática y abierta a la interculturalidad y la inclusión (Guarro, 2005).

Para finalizar, recordaremos los "ingredientes" básicos que nos pueden ayudar a fortalecer la colaboración con las familias (Echeíta et al. 2010).

a) Escuche la voz de las familias. Tener en cuenta la voz de los implicados y, por tanto, preocuparse por la planificación y puesta en marcha de canales efectivos que permitan que sus voces sean escuchadas (Susinos y Parrilla, 
2008) es una de las condiciones para hacer realidad la inclusión en un centro.

b) Sitúe a las familias en el plano que les corresponde. Para poder establecer una verdadera alianza con las familias es necesario reconocer lo que cada uno puede aportar. Valore los recursos que tiene cada familia. Considere a las familias como verdaderos aliados. Si bien los profesionales son los expertos en sus ámbitos correspondientes de competencias, las familias son expertas en "su familia” (Cagigal, 2005; O’Connor, 2008). Para ello, es necesario que el proceso de toma de decisiones se realice desde el "diálogo igualitario" por parte de todos los implicados (Flecha, 1997).

c) Escuche sus necesidades. A la hora de establecer una comunicación y colaboración con las familias y en especial, con las que tienen hijos vulnerables a los procesos de exclusión, marginación o "fracaso escolar" es importante, tener en cuenta sus necesidades, ya que puede ayudarnos a ser más eficaces a la hora de establecer marcos de colaboración y ayuda mutua. Giné (2000) señala algunas de las necesidades de las familias que tienen hijos en situaciones de riesgo y que pueden ser también un reflejo de las que presentan otras muchas familias: ver reconocida su singularidad y respetada su intimidad; sentirse aceptadas, escuchadas y no juzgadas; tener una relación estable y continuada con la escuela; disponibilidad de profesionales preparados; apoyo para mejorar la autoestima y para el fortalecimiento de la pareja y de sus competencias como padres; redes de apoyo social y comunitario; disponibilidad de información y accesibilidad a servicios apropiados de acuerdo con la edad y características de su hijo o hija; asesoramiento familiar y apoyo para la educación de su hijo o hija; orientaciones y apoyo en relación con los hermanos y otros miembros de la familia; orientaciones para promover la educación emocional y la autonomía de su hijo o hija.

d) Piensa globalmente, pero actúa localmente. Cada centro debe analizar sus fortalezas y debilidades y establecer, teniendo en cuenta a los miembros 
del centro líneas de actuación consensuadas. Tenemos que pensar en lo que ocurre en nuestras aulas o centros educativos concretos. Empezar por cambiar ese contexto cercano es la mejor estrategia para avanzar hacia cambios más globales y sistémicos. Para ello, en cada escuela se deben crear las condiciones de tiempo, espacio o asesoramiento que permitan la puesta en marcha de procesos de análisis de su realidad educativa, así como la búsqueda conjunta de soluciones que ayuden a superar las barreras detectas. El papel de los equipos directivos y de las administraciones locales, a través de sus servicios de asesoramiento y supervisión psicopedagógica principalmente, resultan determinantes para movilizar este proceso, y proporcionar a los centros las condiciones necesarias para su puesta en marcha.

e) Propicie una implicación activa de la familia en la vida de la escuela. Es necesario ir más allá de las actividades tradicionales relacionadas con la organización de actividades extraescolares, asistencia a reuniones, etc. Como señala Flecha (2006), la inclusión de la comunidad en la escuela debe hacerse realidad en todos los espacios del centro escolar, incluida el aula, que permita que las familias participen tanto en la gestión del centro como en el establecimiento de objetivos y planificación de actividades.

\subsubsection{La voz del alumnado}

"El alumnado suele ser, paradójicamente, el actor principal y secundario del quehacer escolar" (Traver, Sales y Moliner, 2010, p. 110). Con esta cita tratamos de evidenciar una de las contradicciones educativas más normalizadas en los centros. Como dicen los autores, el alumnado es siempre el motivo que nos lleva a cambiar, a movernos y a buscar prácticas más inclusivas. Sin embargo, de manera natural solemos al mismo tiempo dejarlos fuera del proceso situándolos como meros receptores de un proceso totalmente desconocido para ellos. Esto no deja de ser una práctica exclusora que pasa totalmente desapercibida si no hay una 
conciencia del profesorado o de otros miembros de la comunidad que lo evidencien. De este modo, aparecen como mundos totalmente desconectados el del alumnado, el de las familias y el del profesorado que si bien deberían ir de la mano, suelen encontrarse en la cultura de la queja, sin entender desde su lugar los planteamientos que se hacen desde el otro.

El concepto de "voz del alumnado" es reivindicado y estudiado en los últimos años, tanto a nivel nacional (Rojas, Haya y Lázaro, 2012; Susinos y Ceballos, 2012; Susinos, 2013) como internacional (Ainscow, 2002; Rudduck y Flutter, 2007; Bucknall, 2009; Fielding, 2011; Messiou, 2013). Con él, nos referimos a "todas aquellas iniciativas que emprenden las escuelas y que están dirigidas a aumentar el protagonismo del alumnado en la toma de decisiones sobre el diseño, la gestión y la evaluación de cualquier aspecto de la vida escolar" (Susinos, 2012, p.16). Pero, como destaca Bucknall (2009) en su tesis doctoral, aunque a lo largo de los años ha habido cambios con respecto a la voz de los estudiantes, este aspecto sigue siendo problemático. Ha cambiado el estatus del alumnado en algunos centros, pero puede que su opinión siga sin ser escuchada de manera significativa. A dicha cuestión, Susinos y Ceballos (2012) responden que se puede ir avanzando hacia modelos de voz del alumnado cada vez más comprometidos con una participación real, en la medida en que haya un mayor interés por conocer su punto de vista y se propicie un mayor debate y autonomía.

El último estadio en el que la voz del alumnado estaría más presente sería aquel basado en un proyecto inclusivo. Fielding (2011) denomina a este último estadio "aprendizaje intergeneracional como forma de vida" (p.32). En este estadio el profesorado y el alumnado se sitúan como aprendices e investigadores. Se trata de un aprendizaje compartido entre jóvenes y adultos, alumnado, familias, profesorado y vecindario. Pero, este hecho no tiene que verse como un aspecto puntual sino como una manera habitual de proceder en el centro. Sería la oportunidad para el alumnado de experimentarse como agente de cambio y de aprender que sus acciones pueden influir sobre la realidad (Rojas y otros, 2012). 
Intención que Santos Guerra (2010) destaca como una de las principales funciones de la escuela.

Por otra parte, la participación del alumnado en el currículum es también un aspecto fundamental desde el que ejercer su responsabilidad activa en su aprendizaje. Como dice Guarro (2005, p.16) "solo una organización del currículum que favorezca el tratamiento de problemas cotidianos, tanto sociales como personales, puede facilitar que el alumnado se comprometa con su realidad y le incite a una participación activa, responsable y crítica en ella”. Por otra parte, su participación en la evaluación del currículum y del centro significa un mayor compromiso e implicación, una mayor capacidad de autocrítica y autorreflexión y una mejor comprensión de lo que aprende y cómo lo aprende.

En este sentido, entendemos que la voz del alumnado es importante y está directamente comprometida con el cambio hacia la inclusión y la democracia participativa en los centros (Fielding, 2011; Rudduck y Flutter, 2007; Thompson, 2007, Susinos, 2013). Además, es necesario el uso de estructuras colaborativas, en las que estudiantes y profesionales trabajen juntos (Messiou, 2013). Cuando esta dinámica, entra a formar parte de la cultura de la escuela, algunos autores lo identifican como un progreso hacia lo que se define como una cultura inclusiva (Dyson, Howes y Roberts, 2004). Pero, como comentan Calvo, Rodríguez-Hoyos y García (2012), a la hora de trabajar la participación de los estudiantes encontraremos dificultades por la ausencia de una cultura democrática en los centros, que por el contrario, se irá construyendo en la medida en que cambie tanto el rol del alumnado como del profesorado. "El alumnado necesitará incorporarse al proyecto en un rol poco conocido para él” (Susinos, 2013, p. 129). En este punto es importante destacar que la participación del alumnado no se dirige únicamente a la de unos pocos, sino a la de todos y todas. De manera que, la voz del alumnado estará más presente en la medida en que participe más, y activamente, todo el alumnado en la toma de decisiones sobre distintos aspectos del centro y de su funcionamiento (Susinos y Ceballos, 2012). 
Por otra parte, podemos diferenciar entre distintos niveles de participación del alumnado en las escuelas. Para ello, tomamos como referencia a Hart (1992), Fielding (2001) y a Flutter y Rudduck (2004); aunque cabe destacar, como indica Fielding, que no se trata de niveles excluyentes entre sí, por lo que en un mismo centro y en una misma iniciativa podrían tener cabida diferentes niveles, aunque el nivel más elevado sería también el más deseable.

A continuación mostramos los distintos niveles, presentando en primer lugar aquellos que implican una menor participación de aquellos que suponen la participación más activa y comprometida por parte del alumnado:

a. Ausencia de consulta a los alumnos: no puede observarse ningún aspecto de participación del alumnado.

b. Consulta (se escucha al alumnado): el alumnado representa una mera fuente de datos, y no llega a intervenir en la discusión de resultados ni recibe retroalimentación; es el profesorado quien procesa esa información y actúa en consecuencia.

c. Alumnado como participante activo: el profesorado emprende la indagación e interpreta los datos, pero el alumnado suele recibir retroalimentación de los resultados obtenidos e intervienen de algún modo en la toma de decisiones a partir de los mismos.

d. Alumnado como investigador: el alumnado está implicado en la indagación, habrá retroalimentación, se discutirá con ellos los resultados derivados de los datos y desempeñarán un papel activo en la toma de decisiones.

e. Alumnado como plenos participantes activos y co-investigadores: la iniciativa de la indagación parte conjuntamente de alumnos y profesores; desempeñan un papel activo en la toma de decisiones; junto con los profesores, planifican las acciones que se adoptarán a la luz de la información obtenida e incluso evaluarán su impacto.

Además, añadimos un sexto nivel, nombrado anteriormente, aportado por Fielding (2012); que sería el de aprendizaje intergeneracional como democracia 
vivida, en el que hay un compromiso y responsabilidad compartidos con la finalidad de trabajar por el bien común.

Para finalizar, destacaremos que la voz del alumnado nos permite visibilizar y convertir en un "problema pedagógico" lo que con frecuencia pasa inadvertido. (Susinos, 2013). En este sentido la voz del alumnado nos aporta una mirada crítica sobre aspectos que quizás para el profesorado y otros miembros de la comunidad no tienen importancia. 


\title{
3. Prácticas
}

\section{INTERCULTURALES E}

INCLUSIVAS

\begin{abstract}
La sonrisa de un niño que es feliz en la escuela no tiene precio. La sonrisa de un maestro que es feliz en la escuela... Eso tampoco tiene precio. Dices que no puedo sugerirte nada porque ya llevas 30 años de experiencia. Mas yo diría que llevas 1 año de experiencia y 29 repitiendo lo mismo" (José María Toro, 2005).
\end{abstract}

En este capítulo trataremos de hacer un recorrido por distintos aspectos que forman parte de las prácticas docentes. En primer lugar empezaremos por el concepto de práctica educativa; en segundo lugar nos centraremos en distintas teorías sobre las que se fundamentan las prácticas que se han analizado en el estudio. En este sentido, distinguiremos entre el aprendizaje constructivista y los proyectos de trabajo como práctica de aula; el aprendizaje cooperativo, y sus principios, puesto que no se realiza ninguna técnica de aprendizaje cooperativo en el aula, aunque sí que se basan en sus principios para realizar algunos trabajos grupales. En la teoría sobre el aprendizaje dialógico. En este caso, distinguiremos 
entre las prácticas de aula realizadas que han sido las tertulias dialógicas y los grupos interactivos y explicaremos también las comisiones mixtas de trabajo, como una forma de agrupación para gestionar las prioridades a realizar por la comunidad educativa. Las comisiones mixtas parten de los principios del aprendizaje dialógico, en el que aquello importante es la validez de los argumentos y no las pretensiones de poder que pueden sustentarlos. Finalmente, explicaremos las asambleas de aula, que no se sitúan en las perspectivas teóricas anteriores sino que encontramos sus antecedentes en la Escuela Nueva, de la mano de Freinet (1972).

Para concluir el capítulo, realizamos un breve repaso sobre el posicionamiento que puede tener el profesorado en la práctica docente. Es decir, traspasaremos el umbral de la técnica definida por la literatura para conocer la influencia que puede tener el profesorado en el desarrollo de la práctica, ya que en última instancia los valores y las creencias del profesorado están presentes en la puesta en práctica de cada una de las estrategias que él utiliza.

\subsection{Práctica Educativa}

Para construir una escuela intercultural inclusiva, uno de los ingredientes a tener en cuenta son las prácticas educativas. Para nosotros este es un elemento fundamental donde también se posibilita el cambio, pues es el plano de la acción el que viene a mostrarnos las transformaciones fruto de la reflexión compartida en la comunidad. En esta acción se da muestra de cómo se posibilita esa construcción compartida basada en principios interculturales e inclusivos.

Es en las prácticas del centro dónde podemos abrir la participación a los agentes comunitarios; y en las prácticas de aula en las que podremos comprobar que el cambio explicitado y deseado por el profesorado también llega al alumnado en sus respectivas clases. Además, es donde aparecen también las contradicciones 
entre el discurso y la acción (Freire, 1979). Por eso la práctica es un indicador fundamental para poder conocer el punto de vista de los participantes.

Por práctica o praxis, Gómez Mendoza (1999) se refiere al actuar responsable, independiente y guiado por las ideas del hombre. Para Romero y cool. (2006, p. 7):

La praxis es la secuencia de actos o hechos sociales, y acorde con tal significado la praxis educativa es la cristalización en modalidades de actividades y estas en tipos de actos, de carácter educativo. Por eso quienes pretendan investigar la praxis de ciertos actores sociales institucionales tienen que partir de su cristalización en actosactividades. En el caso de la educación, la praxis se presenta como una variedad y variación de actos, como los actos pedagógicos, la investigación formativa o investigación en general, la extensión, actos administrativos (toma de decisiones y tareas de gestión), actos de bienestar estamental (lúdicos como los artísticos, recreacionales y deportivos y de salud física y mental) y actos de trabajo social.

Pero la característica esencial de la praxis docente para estos autores, es que no implica un acto de naturaleza técnica, sino que se fundamenta en su naturaleza viva y subjetiva al establecer el intercambio constante con el alumnado u otras personas que forman parte de la acción pero que no son un instrumento ni un objeto más de la práctica. Es decir, se pone el valor en la naturaleza humana entre las personas que forman parte de la práctica.

Para Freire (1975), la praxis es la reflexión y la acción de los hombres sobre el mundo para transformarlo. Además, distingue entre la praxis, como la acción realizada y la praxis teórica, refiriéndose a esta última cuando tomamos distancia respecto de la práctica realizada para poder analizarla. Aun así, identifica la práctica como un proceso completo que tiene que ver tanto con la acción como con la reflexión. Aunque apunta que durante la fase de la acción, la práctica no puede ser interrumpida, sino que es constantemente retroalimentada por el movimiento dialéctico entre la propia praxis y la siguiente acción realizada en el campo.

Para Giné y Parcerisa (2003), pensar en la práctica educativa desde una perspectiva a priori significa prever, planificar o diseñar qué deseamos o pretendemos y por dónde queremos que discurra el proceso de enseñanza - 
aprendizaje. Esto requiere la toma de decisiones para planificar la práctica, teniendo en cuenta múltiples factores como las intenciones, los medios, los tiempos, etc. Por otra parte, la práctica en su desarrollo implica la toma de decisiones constante $\mathrm{y}$ en ocasiones sin tiempo para reflexionar. Aunque coincidiendo con Freire (1975), los autores indican que la práctica necesita también de una reflexión sobre todo lo sucedido para poder mejorarla.

Además, la práctica educativa puede entenderse como un resultado o como un proceso en sí mismo. Para nosotros una práctica educativa tiene más sentido como proceso que como un resultado concreto y estático. Como dicen Giné y Parcerisa (2003), "la concepción procesual responde mejor a la idea de evolución y de construcción progresiva de los aprendizajes y focaliza la atención en la persona y no en un producto final" (p. 15). Estos autores también señalan la importancia de la parte reflexiva sobre la práctica ya realizada, e indican que esta parte es igual de importante o más que la práctica en sí. De hecho, cuando analizamos las prácticas para poder mejorarlas estamos haciendo una reflexión sobre aspectos que in situ, difícilmente se podrían cambiar. Para ello hubiera sido necesaria la consciencia de aquellos elementos que no estaban funcionando, pero que bajo el punto de vista de quien participa en la acción pueden fácilmente pasar desapercibidos. Por esta razón contar con un compañero, amigo crítico, u otra persona que nos pueda devolver una mirada sobre la práctica es una manera de poder mejorarla; también el escribir en un diario nuestras percepciones nos ayudará a reflexionar sobre la misma; o el hecho de grabarla nos puede ayudar a observar aspectos que no habíamos podido detectar en la acción, aunque en este caso puede que al principio, el alumnado esté pendiente de la cámara y no actúe de un modo natural.

Cabe destacar que al hablar de prácticas también entra en debate el concepto de buenas prácticas. Coincidimos con Duran, Giné y Marchesi (2010) en que este concepto puede resultar confuso al mismo tiempo que limitador. En el sentido de que al hablar de buenas prácticas estamos trazando una línea entre lo que consideramos buenas prácticas y aquellas que no lo son. Por otra parte, se puede entender que las buenas prácticas son deseables, pero al mismo tiempo, difíciles de 
alcanzar. Además, aquello que en un contexto funciona puede que en otro no, por eso se podría afirmar que no hay buenas prácticas en términos universales, sino que la buena práctica inclusiva tiene que entenderse como una actuación situada que adquiere sentido y es viable a partir de una realidad concreta, con unos condicionantes estructurales que la hacen única e irrepetible. En otras palabras, no se trata de comparar o de imitar lo que hacen otros profesionales en otros centros o en otras aulas, sino de reflexionar sobre la situación de cada centro, de cada aula, y de hacerse las preguntas que nos permitan identificar los pasos que necesitamos seguir para crear aulas que den respuesta a nuestro posicionamiento docente. En nuestro caso, se trata de un posicionamiento intercultural e inclusivo, desde el que se valore de manera positiva la diversidad, que facilite la participación de todas y todos y que promueva la igualdad de oportunidades.

En este sentido, las buenas prácticas nos pueden servir como ejemplos y serán de ayuda para conocer cómo otras personas han dado respuestas a problemas parecidos a los que encontramos en nuestra realidad, sin que eso suponga la necesidad de imitar la práctica. De este modo, Durán, Giné y Marchesi (2010) definen por buena práctica toda aquella actuación que, inmersa en la realidad de un centro a partir del compromiso del profesorado, alumnado y las familias, se oriente a promover la presencia, la participación y el éxito de todo el alumnado.

Algunos de los indicadores que aparecen en la "Guia per a l'anàlisi, la reflexió i la valoració de pràctiques inclusives" (2010) son:

- En el aula se trabaja deliberadamente la comprensión de las diferencias.

- Las actividades que se hacen en el aula recorren sistemáticamente el aprendizaje cooperativo.

- El profesorado facilita que el alumnado que ayuda a sus compañeros tome consciencia de que también está aprendiendo.

- El profesorado colabora, los unos con los otros, en las prácticas inclusivas.

Finalmente, para que las prácticas sean sostenibles, es fundamental que todo el centro conozca las innovaciones y las sienta como propias. Además, también es un 
aspecto importante que el centro comparta con otras escuelas las prácticas que llevan a cabo para fomentar la inclusión. Finalmente, la evaluación es otro aspecto clave para que las prácticas puedan mejorarse.

Otro indicador que tenemos en cuenta a la hora de revisar una práctica realizada con toda la comunidad educativa es si se ha realizado de manera democrática, si han participado representantes de distintos colectivos, no solo en la acción sino también en la toma de decisiones.

Por otra parte, la práctica educativa pretende en última instancia el alcance de una serie de aprendizajes. En este sentido, el aprendizaje necesariamente comporta transformación o cambio en las competencias de la persona. "Si no se ha producido un cambio no podemos hablar de que se haya dado aprendizaje ni, por tanto, proceso formativo ni educativo" (Giné y Parcerisa, 2003, p. 15). Sin embargo, hacia qué tipo de aprendizajes se orienta la práctica es otro de los aspectos importantes a definir. En este caso, nuestro marco de referencia sería también el enfoque intercultural inclusivo.

Si nos basamos en la interculturalidad y la inclusión, los valores que el maestro tendrá que transmitir estarán relacionados con una concepción social de respeto y acercamiento a la diversidad. Esto implicará también utilizar estrategias de trabajo cooperativo y de ayuda entre el alumnado y entre distintos agentes sociales, y comunicarnos e interactuar desde el respeto y una base dialógica. Además, los distintos contenidos del currículum también tendrían que ser un reflejo de un modelo intercultural e inclusivo, favoreciendo el aprendizaje de otras culturas, tradiciones, etc. desde una mirada que promueva la equidad y la valoración de la diversidad.

Pero para poder construir una escuela intercultural e inclusiva, es necesario que los valores del profesorado coincidan con los del modelo. El papel del docente también debe cambiar, de un rol de experto pasa al de aprendiz, junto con otros miembros de la comunidad. Las antiguas estructuras que generan exclusión se deben transformar en otros formatos para atender a la diversidad. La función de la escuela también cambia y de ser instructora pasa a ser socializadora $y$ 
emancipadora. En definitiva, los cambios en determinados aspectos generarán tensiones o transformaciones en todo lo relacionado con la escuela. Sin embargo, para que el profesorado pueda participar de estos cambios, favoreciendo la puesta en marcha de prácticas más inclusivas, necesariamente tiene que creer en los principios de la inclusión y la interculturalidad. Más allá del replanteamiento de la organización, lo que supone una mirada intercultural e inclusiva es la reflexión personal sobre el hecho educativo, sobre nuestra misión como agentes educadores y en nuestro propio proceso de aprendizaje. Por eso pensamos que las actitudes y las creencias personales del profesorado son aspectos fundamentales que influyen en la práctica docente. Pero sobre este aspecto nos detendremos en el último apartado del capítulo.

\subsection{Prácticas Interculturales Inclusivas en el centro y en el aula}

A continuación, explicaremos las que se realizan en el estudio y que han sido analizadas. En primer lugar, nos centraremos en el aprendizaje significativo y el constructivismo como base de los proyectos de trabajo; en segundo lugar, nos detendremos sobre el aprendizaje cooperativo para conocer las bases de la cooperación necesarias para realizar un trabajo en equipo y que además sea cooperativo. En tercer lugar, destacaremos el aprendizaje dialógico, y en concreto dos tipos de prácticas que se basan en el diálogo igualitario para construir conocimiento, como son los grupos interactivos y las tertulias literarias dialógicas. Seguidamente, hablaremos sobre las comisiones mixtas como una agrupación basada en el aprendizaje dialógico para fomentar la realización de acciones en los centros. Para finalizar hablaremos de las asambleas, como un tipo de práctica que nos permite acercarnos a las vivencias del alumnado. 


\subsubsection{Aprendizaje constructivista: Proyectos de Trabajo}

Los proyectos de trabajo son una práctica que facilita atender a la diversidad y por tanto fomenta la inclusión en el aula. Es una práctica en la que el alumnado, con diferente ritmo de aprendizaje, puede trabajar de manera cooperativa en un proyecto común. Por otra parte, aunque permite el trabajo desde diferentes ritmos, en todos los casos se apuesta por un aprendizaje de máximos, en el que el alumnado con la ayuda de sus compañeros y/o del maestro trata de crear su propio aprendizaje. Además es una práctica que no requiere de una respuesta concreta y cerrada sino que permite que el alumnado desarrolle su creatividad sobre la creación del proyecto, siendo válidas distintas respuestas. Por otra parte, los proyectos de trabajo no solo se centran en la adquisición de contenidos académicos, sino también en aprendizajes para la vida. De este modo, es una parte importante la adquisición de habilidades sociales y comunicativas, así como la resolución de conflictos que se pueden trabajar con este tipo de prácticas. Aunque esto no significa que siempre que realicemos un proyecto de trabajo estaremos trabajando las habilidades sociales, comunicativas, la resolución de conflictos, etc., sino que esto va a depender del trabajo que el maestro realice con el alumnado. Si el maestro se lo propone, la dinámica de los proyectos lo facilitará.

Los proyectos de trabajo se desarrollan en distintas fases: en primer lugar se decide el tema; después el alumnado expone aquello que sabe sobre ese tema, que serían sus conocimientos previos la fase ¿qué sabemos?; seguidamente viene la fase de ¿qué queremos saber?, en la que el alumnado expresa sus inquietudes; después necesitamos organizarnos, sería una fase de planificación; a continuación vendría una fase en la que el alumnado investiga, lee, reflexiona y va confeccionando su proyecto (Hernández y Ventura, 1992). Una vez finalizado el proyecto quedan dos cuestiones más que atender, una sería ¿cómo mostramos aquello aprendido? Sería una fase de difusión, y finalmente, la última parte sería realizar una evaluación sobre cómo ha ido el proyecto. 
Si echamos la vista atrás y realizamos una mirada global sobre la práctica de proyectos de trabajo, podemos decir que en principio estas se inscriben en una perspectiva renovadora de la educación en el marco pedagógico que se deriva del Movimiento de Educación Nueva en Europa, expresado en la Pedagogía activa con Decroly y Freinet como precursores, y del Movimiento progresista y pragmatista, en Estados Unidos con Dewey y H. Kilpatrick como sus máximos exponentes (Offir, 2012). En cambio, las propuestas recientes sobre proyectos de trabajo se basan principalmente en teorías de aprendizaje y en el constructivismo, que comprende desde la perspectiva de Piaget (1969) hasta las propuestas de Vygotski (1996); desde la concepción de aprendizaje significativo de Ausubel, hasta la concepción de Enseñanza para la Comprensión de la Escuela de Graduados en Educación de Harvard, entre otros (Offir, 2012).

Sin embargo, los proyectos de trabajo no se centran en la mirada individual del alumnado, sino que más allá de una perspectiva cognitiva, social y cultural los proyectos de trabajo son una respuesta a la diversidad; en la que el alumnado es el protagonista de su aprendizaje:

La propuesta pedagógica de los proyectos plantea la construcción de planes conjuntos entre maestros y estudiantes en los que se "negocia" la temática o el problema a abordar en el aula de clase. El diseño de actividades, los tiempos, los lugares, los participantes, la evaluación, los temas que serán incorporados y, en general, todo lo concerniente al proyecto aparece como objeto de concertación y de responsabilidad de los participantes del proyecto. Muchas veces son incluidos los padres de familia y otras personas de la comunidad educativa, que a propósito del objeto de saber pueden aportar a la propuesta (Offir, 2012, p. 688).

Finalmente, destacamos que en los proyectos de trabajo obtenemos una participación del alumnado a la hora de organizar el trabajo del aula y de su propio aprendizaje, plena (Fernández-Batanero, 2010). El alumnado, al organizar el trabajo del aula en relación a sus intereses se siente motivado con la elaboración del proyecto. Aunque la participación que tome el alumnado va a depender de la que le ofrezca el maestro, en principio el alumnado podrá participar en todas las fases del proyecto, en la elección del tema; en la elaboración del guión que sirve 
como eje del trabajo; en la búsqueda de información; en la aportación de documentos; en la elaboración del producto, en la difusión final y en la evaluación del proyecto. El papel del maestro durante todo el proceso es sobre todo de guía o mediador.

\subsubsection{Aprendizaje cooperativo}

Otra de las prácticas que favorecen la atención a la diversidad, son todas aquellas que tienen como base fundamental el aprendizaje cooperativo. La idea del trabajo cooperativo data de finales del siglo XVIII con trabajos de Lancaster y Bell (Vera, 2009). Sin embargo, es a partir del siglo XIX cuando en EEUU se empieza a expandir el aprendizaje cooperativo como una respuesta al aprendizaje individualista y competitivo, predominante hasta el momento. A partir de los años 70 el aprendizaje cooperativo y sus técnicas empiezan a realizarse en otros países.

Para situarnos en aquello que entendemos por aprendizaje cooperativo, nos conviene diferenciar entre lo que no es. Aprendizaje cooperativo no es trabajo en equipo. En primer lugar, no es trabajo en grupo o en equipo, porque aunque la formación sí que sería la misma, la intención y por tanto el proceso a seguir en un proyecto realizado de manera cooperativa y en uno realizado en equipo serían distintos. Los elementos básicos del aprendizaje cooperativo, en los que nos detendremos más adelante no serían necesarios para realizar un trabajo en grupo, puesto que la máxima de cooperar no es un objetivo en los trabajos grupales. En segundo lugar, no es equivalente a un trabajo colaborativo porque a diferencia de la cooperación, la colaboración se refiere a colaborar para realizar juntos una actividad y aprender en grupo, pero desde una mayor homogeneidad. Por eso, aspectos que son básicos en el aprendizaje cooperativo, como es el impulso de la solidaridad, el interés por el otro y la creación de igualdad de oportunidades, es mucho menor en un trabajo meramente colaborativo (Damon y Phelps, 1989; Pujolàs, 2009; Gozálvez, García y Traver, 2011). 
Como dicen Traver y Rodríguez (2010), podemos entender el aprendizaje cooperativo como:

La organización intencional de la estructura de aprendizaje que pretende conseguir distintos y complementarios objetivos educativos, desde la facilitación de los aprendizajes del alumnado y el intento de aumentar su rendimiento escolar, hasta la enseñanza de estrategias y habilidades de cooperación en el aula y con los compañeros y compañeras, pasando por fomentar actitudes de respeto $\mathrm{y}$ colaboración (p. 19).

Cuando el alumnado aprende cooperativamente, no solo aprende de manera más eficaz y con un mayor sentido, sino que además aprende a colaborar con los otros, a compartir proyectos, a convivir y a desarrollar el sentimiento de pertenencia a un grupo (Traver y Rodríguez, 2010). Pero esto también debe trabajarse en el aula. Por ejemplo, para crear un sentimiento de pertenencia al otro necesitamos conocernos, reconocernos y vincularnos a un proyecto compartido, de grupo. Además, también necesitamos aprender a cooperar, puesto que estas habilidades no son innatas. Las habilidades cooperativas y comunicativas que podemos desarrollar trabajando de manera cooperativa también necesitan hacerse conscientes y trabajarlas explícitamente, ya que además de no ser innatas, son habilidades que en nuestra sociedad tampoco están integradas.

Ser más hábil en las relaciones con los otros, aprender a construir en compañía, comprometerse y exigir a los otros a decir las cosas bien, escuchar, pedir y dar ayuda son, entre otros, los aprendizajes que constituyen la riqueza de la cooperación (Traver y Rodríguez, 2010, p. 21 -22).

Por otra parte, para que el aprendizaje sea cooperativo un primer requisito es que la formación de los grupos responda a criterios de heterogeneidad. De este modo se acrecenta la posibilidad de que aparezcan conflictos sociocognitivos o sociomorales y que puedan resolverse entre los miembros del grupo. En un grupo homogéneo las posibilidades de que se dé el conflicto o la discusión son menores (Gozálvez, García y Traver, 2011). Una vez disponemos de grupos heterogéneos las cuestiones a tener en cuenta para saber si un trabajo está siendo cooperativo es que todo el alumnado participe activamente $y$ desempeñe un rol con 
responsabilidades sobre la actividad. En el modelo de Johnson, Johnson y Holubec (1999) se destacan cinco elementos clave en el aprendizaje cooperativo, que son: interdependencia positiva; responsabilidad individual; interacción promotora cara a cara; desarrollo de habilidades interpersonales o grupales y el procesamiento grupal.

La interdependencia positiva está vinculada al valor de solidaridad, tal y como defienden Gozálvez, García y Traver (2011). Y, según estos autores, es quizás el elemento más decisivo entre los miembros del grupo cooperativo. La interdependencia positiva nos dice que para poder adquirir el objetivo grupal cada uno de sus miembros tiene que adquirir tanto los objetivos individuales como los grupales. Por eso, conseguir éxito en el grupo depende de todos y cada uno de los miembros.

La responsabilidad individual consiste en que cada uno de los miembros tiene responsabilidades individuales. Todo el equipo tiene una serie de tareas que necesita realizar para poder aportar al trabajo cooperativo.

En el caso de la interacción promotora cara a cara se señala que para poder cooperar es necesario interaccionar. Para ello se tiene que compartir un tiempo para trabajar entre todos los miembros.

Por otra parte, el desarrollo de habilidades sociales es un elemento que estará presente en cualquier trabajo cooperativo. Aunque quizás al principio el alumnado necesite una mayor orientación para poder resolver sus conflictos, poco a poco cada grupo se irá gestionando consiguiendo una convivencia pacífica y de ayuda entre todos los miembros.

Finalmente, el procesamiento grupal es necesario para poder aprender sobre aquellas actuaciones que funcionan y por otra parte, detectar los aspectos que se pueden mejorar como grupo. Este procesamiento grupal permite reflexionar conjuntamente sobre el proceso del trabajo cooperativo y tomar decisiones que ayuden a mejorarlo. 
Estos elementos son básicos para poder decir que el alumnado está realizando un trabajo cooperativo. Además, existen distintas técnicas consideradas de aprendizaje cooperativo, que tienen cada una de ellas unas características, y fases distintas, pero que en definitiva, facilitan que se realice el trabajo de manera cooperativa. Algunas de estas técnicas son: el Puzzle de Aronson; los grupos de investigación; la técnica TAI; el concurso de De Vries; etc.

A continuación, argumentaremos porque el aprendizaje cooperativo es una práctica que facilita el desarrollo de la democracia y la inclusión (Gozálvez, García y Traver, 2011). En primer lugar en relación a la democracia, es una práctica que asume que todos y todas deben participar de manera activa durante todo el proceso. Además, la construcción compartida del trabajo se basa en la escucha respetuosa y en la crítica razonable y argumental. Toma también fuerza un diálogo compartido e igualitario en el que los miembros del grupo, desde la madurez intelectual y dialógica abandonan o modifican sus puntos de vista al entrar en contacto con otros argumentos de sus compañeros. Es por esto que el aprendizaje cooperativo también se fundamenta en una escucha respetuosa del otro.

En segundo lugar, queremos destacar que el aprendizaje cooperativo es una práctica que facilita la inclusión de todo el alumnado. Puesto que da respuesta a las necesidades de todos y no solo a las de unos pocos (Johnson y Johnson, 1987; Gillis, 2007; Kagan, 1994; Lara, 2001; Pujolás, 2008; Slavin, 1983; Traver, 2009; Moriña, 2011).

En concreto, de las características que propone Moriña (2011, p.200) que pueden ayudar a comprender qué es una práctica inclusiva, se cumplen todas ellas con el aprendizaje cooperativo. Siempre y cuando la puesta en práctica del AC sea la adecuada y no se confunda con otras prácticas que, si bien responden a lo que sería un trabajo grupal o colaborativo, no cumplen con los elementos básicos del AC. Estas características son:

- Todos los niños y niñas tienen derecho a recibir una educación de calidad en un sistema único y en su propio entorno. 
- El propósito debe ser buscar mecanismos que eliminen las barreras para la participación y el aprendizaje de todo el alumnado.

- No hay un único camino para hacer educación inclusiva, sino distintas formas de recorrerlo.

- Es necesario reconocer la diversidad como una oportunidad, haciendo visible a todo el alumnado.

- El currículum común debe ser el hilo conductor del proceso educativo, planificando para todos y todas.

\subsubsection{Aprendizaje dialógico}

El aprendizaje dialógico se fundamenta en distintas teorías sobre el poder del diálogo y la interacción desde la igualdad. Estas teorías son una muestra del cambio social que lejos de estar situado en la violencia se sitúa cada vez más en el diálogo y la fuerza del argumento. Esta perspectiva transforma los valores sociales, otorgando poder al argumento en lugar de a las relaciones de poder por las que la fuerza se centra en quién emite el argumento. Estas teorías que comentaremos a continuación nos muestran que esta sociedad ya no asienta sus bases en la Sociedad Industrial, sino que se ha producido un giro dialógico (Beck, 1998; Flecha, Gómez y Puigvert, 2001; Giddens 1995; Habermas, 1987).

En primer lugar hablaremos de la teoría de la acción dialógica de Freire (1975), el autor defendía que la naturaleza del ser humano es dialógica. Las personas al estar continuamente en diálogo con el otro se crean y se recrean en el discurso. El diálogo es así, visto como una fuente de liberación y como una oportunidad para llegar a construir entre todos, una sociedad más igualitaria. El diálogo nos acerca a una mayor comprensión del mundo, del otro y de mí mismo, y a una acción con sentido desde la reflexión alcanzada.

Además, en su teoría, Freire (1975) distingue entre acciones dialógicas, las que promueven el entendimiento, la creación cultural y la liberación; y las que no son 
acciones dialógicas; es decir, las que niegan la posibilidad del diálogo, distorsionan la comunicación y reproducen poder (Aubert y cool., 2008).

Por otra parte, desde la teoría de la acción comunicativa, Habermas (1987) explica que el pensamiento o la conciencia de una persona provienen de las interacciones sociales que ha tenido con otros. Además, Habermas explica cómo lo subjetivo responde a un proceso de interiorización de las relaciones sociales que han tenido lugar en el mundo externo y opina que no hay mente sin un lenguaje previo.

Otras de las aportaciones en las que se basa el aprendizaje dialógico es en Mead (1973) que desde el ámbito de la psicología y desde la teoría del interaccionismo simbólico, desarrolla el concepto de persona dialógica. También son importantes las aportaciones de Vygotski (1996) y las de la teoría histórico cultural que indican cómo el desarrollo cognitivo siempre tiene lugar en la interacción social, en la que el lenguaje desempeña un papel central como herramienta de mediación entre la mente y la cultura. Por su parte Rogoff (1993) explica que el pensamiento se aprende en la participación guiada. Por otra parte Wells (2001) habla de comunidades de indagación dialógica como contextos dialógicos de aprendizaje. Wenger (1988) indaga en cómo el aprendizaje siempre tiene lugar en comunidades de práctica. Lave y Wenger (1991) enfatizan que el aprendizaje está siempre situado en el contexto social y cultural. Scribner (1986) estudia el desarrollo de la inteligencia en contextos de trabajo práctico y Bruner (1996), propone convertir las aulas en foros de discusión y comunidades de aprendices mutuos, y argumenta que el reto de la psicología del siglo XXI debe ser el estudio de la intersubjetividad (Aubert, García y Racionero, 2009).

Fruto del análisis de cómo el giro dialógico también está afectando al modo en que las personas aprenden, siendo más necesaria que nunca la "dialogicidad" de la persona como base para el proceso de enseñanza - aprendizaje, surge el aprendizaje dialógico (Aubert, García y Racionero, 2009). En concreto,

El aprendizaje dialógico es producto de procesos de creación de significados desde interacciones que se dirigen a alcanzar mejores aprendizajes. El conocimiento se 
crea y recrea a través de un diálogo orientado por pretensiones de entendimiento, por la intención de alcanzar la mayor comprensión y acuerdo posibles en torno a un aspecto de la realidad, en torno a los contenidos de aprendizaje que se enseñan y sobre el centro educativo mismo (Aubert y cool. 2008, p. 80).

El aprendizaje dialógico se basa en siete principios que definiremos a continuación (Aubert, García y Racionero, 2009): diálogo igualitario; inteligencia cultural; transformación; dimensión instrumental; creación de sentido; solidaridad e igualdad de diferencias.

En primer lugar hablaremos del diálogo igualitario, este se refiere a la importancia del argumento y no de la voz de quien lo emite. Con el diálogo igualitario se quiere poner sobre la mesa la igualdad de todas las personas por encima de todo. Para que cada uno pueda dar su opinión basada en argumentos.

En segundo lugar la inteligencia cultural. Se pone de manifiesto que no solo existe la inteligencia académica y que todas las personas poseemos las habilidades para poder ser competentes en la vida cotidiana. En este sentido la inteligencia cultural se suma a las teorías que resaltan el valor de otras inteligencias. En concreto, la inteligencia cultural está formada por la inteligencia académica, la inteligencia práctica y la inteligencia comunicativa, siendo esta última de especial relevancia.

En tercer lugar, el aprendizaje dialógico destaca la transformación como un aspecto fundamental. Es por esto que cualquier práctica de aprendizaje dialógico está orientada al cambio o la transformación del contexto socio-cultural. La transformación se basa también en la teoría socio-cultural de Vygotski (1996), por la que se defiende que el desarrollo cognitivo siempre está vinculado al contexto socio-cultural. Des de esta teoría se explica que para poder favorecer el desarrollo cognitivo se tiene que intervenir en el contexto y transformarlo.

En cuarto lugar definiremos la dimensión instrumental. Esta dimensión pone el énfasis en el currículum y en los conocimientos instrumentales a adquirir en las escuelas. Además, hace un llamamiento a lo que llaman currículum de la felicidad y se comenta que no se pueden descuidar los aprendizajes instrumentales porque en 
ese caso las consecuencias nos pueden llevar a escuelas con absentismo escolar, etiquetaje, descalificación del alumnado y de las familias, desmotivación, problemas de convivencia y de fracaso escolar (Aubert y cool., 2008).

En quinto lugar, la creación de sentido se refiere a que los proyectos desarrollados tengan sentido para el alumnado. Se entiende también que estos sean coherentes con sus vidas y entiendan sus situaciones particulares, para que un proyecto no carezca de sentido para el alumnado. También la creación de sentido, se refiere a que la educación y la asistencia a la escuela tienen que ser importantes para los niños y las niñas y también para el profesorado y las familias.

En sexto lugar hablaremos de la solidaridad, orientada a compartir los procesos de aprendizaje en lugar de favorecer la competitividad entre el alumnado. La solidaridad también se refiere a la creación de un clima de convivencia en el aula y en el centro. Además, implica la inclusión en las aulas de interacciones entre toda la diversidad del alumnado (Aubert, García y Racionero, 2009).

Finalmente, el séptimo principio es el de igualdad de diferencias. Este principio está directamente relacionado con la teoría de la inclusión por la que se entiende la diversidad como una riqueza. Desde el mismo, se defiende que todos tenemos derecho a una educación de calidad y que la diversidad no es un obstáculo para los aprendizajes. La manera de plantear una mejora tanto en el centro como en el aula desde este principio es abrir las puertas a la entrada de las personas de la comunidad, para que el centro sea un reflejo de la diversidad.

Algunas de las técnicas que se proponen desde el aprendizaje dialógico son los grupos interactivos y las tertulias literarias dialógicas. Tanto los grupos interactivos como las tertulias son prácticas que desde el proyecto INCLUD-ED se identifican como acciones educativas de éxito y que son una propuesta para facilitar la inclusión en el aula. En ambas propuestas el eje de las prácticas gira en torno al diálogo igualitario y a los principios del aprendizaje dialógico. 


\subsubsection{Grupos interactivos}

Esta forma de agrupación consiste en la formación de pequeños grupos heterogéneos distribuidos en la misma aula. Cada uno de estos grupos cuenta con la participación de una persona voluntaria que facilita las interacciones entre el alumnado. La riqueza de los grupos interactivos es precisamente propiciar las interacciones desde los principios del aprendizaje dialógico y ampliar las interacciones del alumnado al poder interactuar con vecinos del barrio y familias que cuentan con una riqueza cultural, en muchos casos, distinta a la suya (Molina, 2007).

Además, la dinámica de los GI (grupos interactivos) se basa en la rotación de diversas actividades en un tiempo limitado, durante una sesión. Cada cierto tiempo el alumnado cambia de actividad, pero cada una de las actividades está basada en asignaturas instrumentales.

Por otra parte explicaremos aquello que desde el CREA (Centre Especial de Recerca en Teories i Pràctiques Superadores de Desigualtats) se define como lo que son y lo que no GI:

Los GI es una forma de organización del aula, pero no es una metodología; son grupos reducidos de alumnado agrupados de forma heterogénea tanto por niveles de aprendizajes, cultura, género, etc.; no son grupos cooperativos; son grupos en los que se establecen relaciones entre el alumnado que forma parte del grupo por medio del diálogo igualitario; no son agrupaciones flexibles; cada grupo cuenta con el apoyo de un adulto que facilita el aprendizaje y aumenta la motivación del alumnado; no se considera GI si sale del aula el alumnado con un nivel bajo de aprendizaje; es un GI si todo el alumnado del aula trabaja sobre la misma tarea, pero no es un GI si dentro del grupo se asignan tareas distintas al alumnado en función de su nivel de aprendizaje; finalmente, en un GI tanto el profesorado como el voluntariado deben mantener unas expectativas altas hacia el alumnado; y no se considera un GI si no hay interacción entre el alumnado mientras se resuelve la tarea planteada (Véase en http://utopiadream.info/ca/presentacion/\%C2\%BFquees-y-que-no-es/). 
Desde la literatura, se explica que la riqueza de interacciones que se consiguen en el aula potencian la solidaridad entre el alumnado, la autoestima y las altas expectativas, y esto repercute en la mejora de los resultados académicos de todo el alumnado (INCLUD-ED Consortium, 2009). Sin embargo tanto estas afirmaciones como el fomento de la inclusión que se atribuye a la técnica, son aspectos que contrastaremos en los resultados y en las discusiones, basándonos en estudios como el de Muntaner, Piña y De la Iglesia, (2015). En este estudio en concreto, se apunta que no todas las sesiones en las que se llevan a cabo GI pueden ser inclusivas, sino que para que un GI sea inclusivo se tiene que tener en cuenta toda la diversidad.

Los grupos interactivos son actos comunicativos dialógicos en los que predominan las interacciones dialógicas sobre las de poder. Aunque Oliger y Gatt (2010) también comentan que la práctica no puede estar exenta de interacciones de poder ya que está influida por el contexto y la estructura en la que pueden darse este tipo de relaciones. En definitiva, “cuantas más interacciones dialógicas existan en estos actos comunicativos dialógicos, entre los niños y niñas y los diferentes miembros de la comunidad educativa, más aumentará el éxito escolar de todos y todas" (Oliger y Gatt, 2010, p.290). Finalmente, para que los actos comunicativos dialógicos tengan lugar, los diferentes agentes sociales que intervienen en el aula tienen que adoptar una actitud activa en la generación del máximo de interacciones dialógicas.

\subsubsection{Tertulias literarias dialógicas}

Esta actuación de éxito, surgió en los años 80 en el barrio de la Verneda Sant Martí, de Barcelona, como una actividad educativa y cultural basada en la lectura realizada desde principios dialógicos (Soler, 2001; Aguilar, Alonso, Padrós y Pulido, 2010). Como dicen Pulido y Zepa (2010):

En las tertulias literarias dialógicas se demuestra que la interpretación de los textos no es monopolio de unos pocos expertos sino el resultado del diálogo entre personas diversas. Las personas participantes transforman sus conocimientos culturales a través de las interacciones dialógicas que se generan y el uso del lenguaje que 
realizan. Tanto el desarrollo lingüístico como la elaboración de discursos críticos profundos son resultado de la predominancia de actos comunicativos dialógicos en estas tertulias (p. 296).

La dinámica que se sigue en esta práctica es: en primer lugar, escoger entre todos los participantes un libro de la literatura clásica universal. Una vez elegida la obra, se decide en el grupo cuántos capítulos o páginas se realizarán para la siguiente sesión. En casa, cada participante lee las páginas acordadas y selecciona aquellos párrafos que más le hayan gustado. En la siguiente sesión, la persona moderadora va dando el turno de palabra, siguiendo el orden de los capítulos o partes del mismo, para que cada uno de los participantes pueda compartir el párrafo que ha seleccionado, aportando sus razones. Seguidamente, se abre un turno de palabra, para que todas las personas puedan aportar su opinión respecto al párrafo mencionado. Se repite esta misma secuencia a lo largo de la sesión, hasta que todos los participantes hayan podido expresar su opinión y dar sus argumentos sobre los párrafos trabajados.

La intención en las tertulias literarias dialógicas (TLD) no es buscar el consenso sobre una interpretación del texto, aunque sí que se consensua cómo se deben comunicar en la sesión. Los criterios que se utilizan son los principios del aprendizaje dialógico. Además, se intenta que nadie monopolice la palabra y se anima a aquellas personas que no suelen intervenir a participar. (Pulido y Zepa, 2010).

Al igual que en la acción anterior, a continuación distinguiremos entre lo que para el CREA es o no es una Tertulia Literaria Dialógica.

(Véase http://utopiadream.info/ca/presentacion/\%C2\%BFque-es-y-que-no-es/).

Las tertulias se basan en la lectura dialógica de libros únicamente de la literatura clásica universal, e implican un proceso de lectura e interpretación colectiva y dialógica de textos en un contexto donde prima la validez de los argumentos en lugar de las pretensiones de poder. Desde este procedimiento, cada persona y el grupo da un nuevo sentido a la lectura de los clásicos y se alcanzan comprensiones muy profundas y críticas que hubiesen sido imposibles en solitario. 
Se trata de un proceso de interpretación colectiva que está mediado por el diálogo igualitario entre todas las personas participantes en la tertulia.

Como hemos comentado, la participación en la tertulia implica asistir a la sesión con la lectura de las páginas acordadas realizada. En la sesión, cada uno de los participantes expone un párrafo que por algún motivo le ha llamado la atención y lo comparte con el grupo, explicando también el sentido que tiene ese párrafo para él. Posteriormente se abre un turno de palabras y los participantes aportan sus opiniones respecto el mismo párrafo o reinterpretan el sentido aportado por sus compañeros, de manera que se construye de forma dialógica un nuevo sentido.

En las tertulias también hay una persona que ejerce de moderadora y tiene la función de favorecer la participación igualitaria de todos los miembros. Así mismo, una tertulia se puede llevar a cabo con familiares, personas de la comunidad, profesorado, voluntariado y estudiantes desde Educación Infantil hasta el bachillerato, pasando también por la educación de adultos. Además se defiende que el diálogo igualitario promueve el desarrollo de valores como la convivencia, el respeto y la solidaridad.

Por otra parte, no se considera TLD si no se realiza la lectura de libros; si no se leen libros de la literatura clásica universal; y si el diálogo está basado en pretensiones de poder y no de validez, siendo las personas con mayor estatus académico las que monopolizan el debate o imponen sus interpretaciones.

Al igual que en los grupos interactivos, Pulido y Zepa (2010) nos recuerdan que las tertulias se basan en actos comunicativos dialógicos que "permiten que los sujetos no estén condicionados por coacciones y puedan expresen desde su visión cuál es su aportación al texto" (p.303). Además, las autoras destacan que las personas aprenden las unas de las otras $y$, conjuntamente, van creando una interpretación interactiva y profunda del texto leído, sin que haya ninguna persona que ejerza de experta y dirija cuál debería ser la interpretación adecuada del texto. Más allá de una interpretación individual se apuesta por una colectiva que nos permite profundizar más en la obra. 


\subsubsection{Comisiones mixtas}

Para que las prácticas sean una realidad en el centro también tienen que tener en cuenta a todas las voces de la comunidad educativa. En este sentido destacamos uno de los primeros descubrimientos del proyecto IQEA (Lipman, 1997), en el que se afirma que la mejora de la escuela funciona de manera óptima cuando existe un centro de atención claro y práctico para su desarrollo, ligado al trabajo simultáneo sobre las condiciones internas del centro. En este sentido destacamos las comisiones mixtas como un modo de organización para llevar a la práctica las decisiones de la comunidad.

Estas comisiones consisten en la participación de una representación de todos los colectivos (familias, alumnado, maestro, asociaciones) -de ahí que se llamen mixtas- para organizar las acciones que se realizarán sobre el centro. De este modo, la formación en comisiones surge para dar respuesta a los cambios que se quieren realizar en los centros (Traver, Sales y Moliner, 2010).

En las comisiones se parte de un trabajo colaborativo entre los miembros de la comunidad. Pero antes de la formación de las comisiones, se realizaría un diagnóstico sobre las necesidades del centro, y posteriormente se pasaría a priorizar las necesidades detectadas (Aguirre, Sales y Escobedo, 2014). El trabajo de los participantes podría ser realizar dicha categorización y priorización conjuntamente y posteriormente, dividirse en grupos de trabajo por temáticas. Estos grupos, formados por personas de los distintos colectivos, vendrían a conformar las comisiones mixtas de trabajo.

La formación de estas comisiones pretende llevar a cabo la construcción de una escuela intercultural inclusiva de manera democrática, contando con la participación de las distintas voces para organizar los cambios que se quieren realizar.

El nombre de comisiones mixtas también lo utilizan en las CdA (Comunidades de Aprendizaje) (Flecha, Padrós y Puigdellívol, 2003) para referirse a grupos formados por alumnado, familias, voluntariado, profesorado, miembros de 
asociaciones, etc. En el caso de las CdA, las comisiones mixtas se crean una vez se ha realizado la fase del sueño, para trabajar sobre las prioridades propuestas entre toda la comunidad (Flecha, Padrós, y Puigdellívol, 2003).

\subsubsection{Las Asambleas de aula}

Una de las prácticas que también consideramos que facilita la atención a la diversidad es la asamblea de aula, que como hemos comentado, tiene su origen en la Pedagogía Freinet (1972).

En el estudio que realizamos, esta práctica se realiza diariamente, antes de empezar con las rutinas y las asignaturas instrumentales. La asamblea es la asociación de un grupo de iguales para debatir sobre diversos aspectos de la vida en el centro o en el aula y sacar conclusiones (Gómez Rosado, 2007). Algunas de las ventajas que destaca Gómez Rosado (2007, p. 4-5), son las siguientes:

- Las personas participantes se expresan libremente, por tanto, se fomenta la capacidad de reflexión sobre los problemas y la creación de la opinión propia.

- Se debaten temas de interés y les resultan muy motivadoras. Se sienten importantes cuando se les escucha y se tienen en cuenta sus propuestas y opiniones, su autoestima sube y su interés por el colegio aumenta.

- Invita a la observación, la reflexión y el contraste de pareceres. Aprenden a sistematizar el proceso completo de observación-análisis-tesis.

- Aprenden a respetarse. Escuchar y sentir que se les escucha, les hace valorar la importancia de las opiniones ajenas. Descubrir que lo que alguien propuso se lleva a cabo en la escuela y da resultados, les sirve para aprender a valorar las opiniones y propuestas ajenas y respetar a todas las personas, libres de prejuicios.

- Exige seguir una actitud disciplinada, escuchar y respetar unas normas.

- Les ayuda a desinhibirse y pierden el miedo escénico a expresarse en público. Desde infantil, asumen que cuando hablan se les escucha y se les tiene en 
cuenta, en un elevado grupo de personas menores diversas. Poco a poco, se van afianzando en el espacio y en sus dinámicas y participan cada vez más activamente, superando el miedo escénico que suelen impedir a muchas personas adultas aportar sus interesantes opiniones y propuestas.

- Nos da gran cantidad de información sobre la vida en el centro que desconocíamos. Cuentan la vida en el colegio desde su perspectiva, que no es la nuestra, y nos descubren una realidad distinta del colegio, que nos sirve para plantear alternativas o afianzar aciertos para mejorar la vida en el centro.

- Nos muestran deficiencias y necesidades que han pasado desapercibidas. Desde nuestra mirada elevada de personas adultas, a veces no vemos cómo experimentan las situaciones o cómo se sienten. Cuando encuentra un ambiente propicio en el que se les da la oportunidad de expresarse cuentan todo lo que observan y sienten, lo que ayuda a buscar soluciones a problemas que, de otro modo, no conoceríamos.

- Nos dan soluciones efectivas y fáciles de llevar a cabo, ante pequeños problemas. Las propuestas y soluciones a problemas que plantean, suelen tener en común su facilidad de ejecución y su pragmatismo, por lo que suele ser muy efectivo seguir sus recomendaciones.

- Les motiva a implicarse activamente en la puesta en práctica de sus propuestas. Cuando es el grupo de iguales el que decide, se implican más intensamente porque lo consideran algo propio, que deben cuidar y proteger.

Además las asambleas son un puente entre el mundo interior del alumnado y la realidad del aula; es un espacio donde el alumnado puede expresar aquello que le preocupa, más allá de las cuestiones puramente académicas (Lara, 2002). Para el profesorado es una oportunidad para conocer más de cerca a su alumnado y empatizar con algunas situaciones de su vida o poder ayudarle y guiarle en su proceso de crecimiento personal. Como dicen Poveda, Sebastián y Moreno (2003), la ronda (o asamblea) es un espacio afectivo en el que se pueden discutir temas familiares "delicados". Además, el hecho de compartir este tipo de información 
posibilita también la construcción de biografías públicas de los miembros de la clase.

Por otra parte, desde las asambleas se trabajan distintas competencias que a continuación explicaremos (Gómez, 2007), como por ejemplo, la competencia en Comunicación Lingüística. A partir de las asambleas el alumnado puede expresar pensamientos, emociones, vivencias y opiniones. Se propicia también el uso de códigos lingüísticos y no lingüísticos y de las reglas propias del intercambio comunicativo. Se utiliza el diálogo como herramienta para mejorar colectivamente la comprensión de la realidad.

Otra de las competencias que se desarrolla es la competencia social $y$ ciudadana; entre otros aspectos, se utiliza el diálogo como herramienta para expresarnos y comprender mejor la realidad; se alcanzan habilidades sociales que nos permiten resolver de una manera constructiva los conflictos, etc.

Además, también se trabaja la competencia en Autonomía e iniciativa personal. Esta competencia se refiere a alcanzar la capacidad para elegir con criterio propio y llevar adelante las acciones necesarias para desarrollar las opciones y planes personales. Tener capacidad para transformar las ideas en acciones o para afrontar los problemas y encontrar soluciones en cada uno de los proyectos vitales que se emprenden.

La asamblea también se constituye como un espacio normativo, como indican Poveda, Sebastián y Moreno (2003), ya que en el diálogo que se construye en la misma aparecen hábitos de vida y normas de conducta deseables en el alumnado; hábitos de higiene y alimentación, etc. La figura del profesorado en esta dinámica también juega un papel importante. Trata de situarse en un plano horizontal al del alumnado, y por eso, en algunas ocasiones siente su responsabilidad hacia el grupo si en algún momento le piden su participación. Por otra parte, es también el que anima al alumnado a participar, si no lo ha hecho ya.

Finalmente, cabe destacar que aunque la asamblea no sea una actividad instruccional eso no significa que no sea educativa, ya que la multitud de temáticas 
abordadas desde un sentido tan ligado al contexto del alumnado, hacen que esta dinámica tenga un carácter fuertemente educativo.

\subsection{El profesorado en la práctica docente}

Más allá de las prácticas en sí, existe otro aspecto fundamental que es el profesorado. En función de su visión sobre la educación estará dando ejemplos sobre distintos modos de aprender y de posicionarse en la vida. En este sentido, hablar de inclusión y no tener en cuenta el estilo docente, o los valores y actitudes que le acompañan en su práctica, es estar dejándonos una parte importante de la práctica educativa.

De manera quizás inconsciente se nos pueden escapar comentarios o actuaciones que no ayudan a incluir a todo el alumnado en el aula, sino que separan e incluso pueden llegar a estigmatizar. Es por esto que, no tiene ningún sentido realizar un trabajo de manera cooperativa tratando de que todo el alumnado participe activamente al máximo de sus posibilidades y al mismo tiempo tener una actitud de desprecio hacia uno de nuestros alumnos. Por eso decimos que, en última instancia es el aprecio y la estima que sentimos por nuestro alumnado la base para poder favorecer la inclusión. En palabras de la doctora Pérez de Lara (1998, p.91);

Si bien se ha abandonado en gran medida los supuestos médicos biologicistas y psicologistas, ha aparecido una nueva tecnificación pedagogista, basada en el enfoque curricular anglosajón que sigue olvidando lo fundamental: que el eje de la educación, de la socialización, de la inclusión y la integración está en la relación amorosa de aceptación plena junto a mí del otro, de la otra, distintos de mí, distintos entre sí, pues esa relación amorosa es la única que puede mediar saber y convivencia, conocimiento y vida. 
Así mismo, Pérez Gómez (1985), haciendo referencia a los planteamientos de Doyle, entiende que la escuela es un "nicho pedagógico", donde lo que se aprende proviene más del contexto, del clima emotivo y del escenario ambiental, que de los programas. Evidentemente, el escenario ambiental depende también de las decisiones y acciones de quien desempeña el rol de maestro, de animador o de educador. Por esto, a continuación hablaremos de las creencias y actitudes del profesorado como un aspecto clave a la hora de plantearnos la interculturalidad y la inclusión en las aulas.

Es cierto que existen prácticas que, como hemos visto anteriormente, favorecen la inclusión de todo el alumnado apostando por estructuras abiertas y flexibles que dan respuesta a la diversidad. Sin embargo, más allá de la técnica, de la receta, está el profesorado con su complejidad como persona. Es decir, además de su identificación como maestro está "Teresa, Paco, Andrea,..." con toda su historia, sus experiencias, sus creencias, valores... y su modo de entender la educación y la vida. Esto es muy importante porque viene a mostrarnos que toda la filosofía sobre interculturalidad, inclusión, justicia social, equidad, etc. de la que hemos hablado anteriormente es también interpretada y vivida por una persona en su totalidad. En otras palabras, si anteriormente hemos mostrado algunos tipos de prácticas que pueden favorecer la inclusión del alumnado, como los proyectos de trabajo, las tertulias o las asambleas, todas estas técnicas puede que no sean más que recetas carentes de sentido si no se realizan bajo los principios de la inclusión. Pero para ello, necesariamente el profesorado tiene que vivir la inclusión y la interculturalidad. No se puede limitar a leerla en textos sino que tiene que interpretarla en la vida. No puede ser un trabajo forzado, porque en nosotros hay una serie de creencias que de manera consciente o no, están en nuestro pensamiento y limitan nuestra mirada sobre el mundo. Con esto no nos referimos a que si alguien tiene unas creencias que le llevan a actitudes racistas nunca las podrá cambiar. Pero es cierto que, en principio estas creencias van a limitar nuestra mirada o por el contrario, nos van a permitir ampliarla. De ahí que a veces se hable de resistencias y de la dificultad de llevar a la práctica los principios de la inclusión, pues uno de los elementos fundamentales a abordar son las creencias. 
Para que los cambios hacia la interculturalidad y la inclusión también penetren en las aulas es necesario que el profesorado crea en este modelo. Las creencias y los pensamientos son al fin de cuentas, la base para una inclusión real y auténtica. Si nuestras creencias muestran esa sensibilidad hacia el alumnado, la parte más pedagógica de la práctica la podremos aprender y mejorar día a día, con la experiencia y la formación, pero no nos llevará a incoherencias. Hacer lo contrario es más difícil, si no imposible.

Distintos autores (Domingo, 2001; Carreres y Arnáiz, 2010) muestran el tema de las creencias y las actitudes como un pilar básico a trabajar para poder acercarnos a la interculturalidad y la inclusión. También la autora Gil-Jaurena (2012, p. 106), sitúa a la práctica educativa como fruto de los pensamientos y creencias del profesorado. Por su parte Fernández Batanero (2013) explica que el éxito de poner en marcha cualquier política educativa sobre atención a la diversidad, depende de muchos factores, pero en concreto hay dos que son clave: La formación del profesorado, y la actitud. En relación a la actitud, otro de los aspectos que tenemos que tener en cuenta son las expectativas que tenemos hacia el alumnado. Es fundamental mantener unas expectativas altas sobre ellos y también explicitarlas. Por eso, es importante tomar conciencia sobre cuáles son nuestras expectativas y revisar las creencias que tienen que ver con estas.

Al igual que Aguado, Gil-Jaurena y Mata (2008), pensamos que la revisión de creencias es un punto inicial y también un elemento recurrente en la práctica docente que puede complementarse con la formación y la innovación metodológica, pero siempre que esté sustentada en un esquema basado en la I-A (Investigación - Acción). La formación basada únicamente en metodologías, pautas o técnicas cerradas, no nos parece suficiente ni para responder de manera contextualizada a las necesidades en escenarios educativos concretos, ni para considerar que con ello ya estamos formando en el enfoque intercultural.

Para poder revisar las creencias y las prácticas podemos hacerlo de manera individual, con lecturas planteadas para la reflexión individual; o en colaboración, con compañeros que observen nuestra práctica y que nos ayuden a analizarla; en 
foros virtuales; en redes específicas de intercambio; etc. Esta segunda mirada nos puede aportar una visión más completa de la práctica así como de las actitudes detectadas por el otro. Por otra parte, la formación centrada únicamente en metodologías (aprendizaje cooperativo, etc.) implica una visión restrictiva si no hay un cuestionamiento de los principios que guían la propia práctica y una revisión sistemática en términos de igualdad/desigualdad y de calidad de los aprendizajes de todo el alumnado (Aguado, Gil-Jaurena y Mata, 2008). Además, una formación restringida a mostrar prácticas sitúa al profesorado como un técnico que tiene que aplicar una estrategia, más que como un pensador:

La formación centrada o focalizada en la introducción de técnicas de enseñanza, de trabajo en el aula, o de atención a colectivos específicos (enseñanza de español, educación compensatoria), conciben al profesorado como un técnico, un aplicador de métodos, y no como un pensador, intelectual, diseñador y desarrollador de estrategias contextualizadas y fundamentadas a partir de sus conocimientos, adquiridos y repensados a partir de su formación inicial, de la propia práctica, del intercambio con otros profesores, etc. (Aguado, Gil-Jaurena y Mata, 2008, p. 286).

En este sentido, las autoras señalan que el profesorado prefiere situarse en procesos de I-A en los que su práctica vaya cambiando con su reflexión a partir también de la discusión con sus compañeros, que el tener que aplicar de manera poco reflexiva determinados programas y paquetes. Cabe destacar que este posicionamiento sitúa al profesorado en un rol más activo, podríamos incluso decir, menos cómodo. Pero es la única manera de poder ser coherentes con el planteamiento de estas técnicas, ya que lo importante es comprender la filosofía en la que se fundamentan y en base a la misma reflexionar sobre la puesta en práctica.

Por otro lado, la mirada del profesorado sobre la diversidad no siempre es la que cabría esperar de profesionales de la educación. Pero como hemos dicho, son ante todo personas, con vivencias que les llevan a mantener una percepción determinada sobre la realidad. En general, la diversidad es vista por el profesorado más como una situación problemática y deficitaria que como un enriquecimiento (Aguado, Gil-Jaurena y Mata, 2008). Como dicen las autoras, la diversidad se asocia con la falta de requisitos lingüísticos o académicos, pautas culturales que 
dificultan el proceso de enseñanza-aprendizaje, aumento de conflictividad en los centros, relaciones difíciles con las familias, etc. Esta visión produce una situación de confusión e impotencia en el profesorado que en ocasiones se traduce en una demanda de técnicas o soluciones concretas, requeridas como "recetas" para afrontar estas situaciones, "y que a menudo tienen un marcado carácter compensatorio”. (Aguado, Gil-Jaurena y Mata, 2008, p. 278).

Como señala Jordán (2004), se requieren cambios pero en la personalidad profesional que la diversidad cultural exige al profesorado. Es decir, se necesita transformar la visión problematizadora por otra que reconozca la diversidad como enriquecimiento y al mismo tiempo como una situación normalizada. Además, es necesario tomar consciencia sobre algunas rutinas e inercias que se desarrollan en los centros y que sin saberlo o pretenderlo, están excluyendo al alumnado. Algunas de las cuestiones sobre las que Jordán nos invita a reflexionar es replantearse la tarea docente como algo más educativo que instructivo; asumir una responsabilidad ético-profesional, un compromiso; y disponerse al trabajo conjunto y cooperativo con otros profesionales. Al mismo tiempo el autor plantea que conseguir hoy en día estas transformaciones es un reto porque las instituciones de formación inicial y permanente son tan conservadoras y lentas para cambiar como lo son los centros de enseñanza primaria y secundaria.

Desde un enfoque intercultural inclusivo, la formación del profesorado debe basarse en una mirada crítica que trate siempre de favorecer la equidad, la igualdad de oportunidades, y que sitúe en el centro al alumnado como persona. Además, la formación continua es una necesidad, y desde esa formación es importante que se atienda a aptitudes y actitudes como nos dicen Aguado, Gil-Jaurena y Mata (2008); no solo se debe atender al "saber" y al "saber hacer" sino que es un aspecto muy importante atender a la dimensión más personal, atender al “ser”. En este sentido el reconocimiento del otro vendría de la mano de la mirada intercultural e inclusiva y dicho reconocimiento nos podría llevar a aunar caminos en lugar de basarnos en las diferencias para crear separación entre distintos grupos. Clasificar a determinados grupos como "los otros" nos lleva a la necesidad de tomar conciencia de cómo nos 
posicionamos respecto del otro y de tratar de conocerle, de acercarme a él para poder cambiar mis prejuicios por conocimiento (Aguado, Gil-Jaurena y Mata, 2008).

Esto nos sitúa en una realidad en la que el profesorado, para poder ser coherente con el modelo y tratar de incluir en todas las circunstancias al alumnado en la práctica del aula, necesita reflexionar sobre la misma y poner especial atención a sus creencias y actitudes. Como dicen Giné y Parcerisa (2003, p. 26). "A menudo los educadores y educadoras no somos suficientemente sensibles a la necesidad de reflexionar sobre nuestra práctica y sobre qué «currículo oculto» se está transmitiendo con ella” (p.26). Es importante tener en cuenta que toda acción educativa se basa en un modelo socioeducativo, explícito o implícito. Por eso, pensamos que es necesario que el modelo sea explícito y que al planificar la acción educativa así como a la hora de reflexionar sobre ella, lo hagamos siguiendo las bases del mismo, que en cualquier caso debería ser un modelo que facilite la inclusión de todo el alumnado. 



\title{
4. LAS EMOCIONES EN LA EDUCACIÓN
}

\author{
La verdadera entrega significa soltar \\ completamente esta manera de ver. Cuando \\ entregamos nuestra percepción por completo, \\ abandonando todo juicio, toda la situación se \\ transfigura y vemos que la persona es digna de \\ amor (David Hawkins, 2014, p.177)
}

A lo largo de los capítulos anteriores, hemos visto que la atención a la diversidad y la necesidad de una escuela intercultural e inclusiva es una necesidad hoy en día. La sociedad y la escuela necesitan ahondar en cuestiones sobre igualdad y diversidad e incorporar mecanismos o procesos que ayuden a los ciudadanos a realizar una mirada crítica sobre la cuestión.

Sin embargo, nos planteamos una atención a la diversidad más profunda. Como hemos dicho, la diversidad es intrínseca a la naturaleza humana y no se restringe a las personas con diversidad funcional, con dificultades de aprendizaje o inmigrantes. Es por esto que en el presente capítulo hablaremos de otro de los aspectos que pensamos que se debe responder desde el modelo intercultural inclusivo: las competencias emocionales. 
Actualmente, la generación de jóvenes muestra más conflictos emocionales y una mayor tendencia a estar deprimidos que en épocas anteriores (Goleman, 1995). Inmersos en una sociedad que nos invade con anuncios publicitarios relacionados con fármacos para ayudarnos a estar más “despiertos” con mayor vitalidad y menos agotamiento, que nos invita a combatir el estrés o la tristeza con pastillas... la escuela sigue resistiéndose a indagar en la perspectiva emocional. Lo que venimos a destacar desde este capítulo es la necesidad de una escuela intercultural inclusiva que también se plantee el tratamiento emocional en los centros. Nos planteamos la necesidad de una educación más abierta a las necesidades humanas y personales. Una educación que se atreva a formar a sus ciudadanos para que sean capaces de gestionar sus conflictos también emocionales. Una educación que entienda a la persona en su complejidad, de manera integral.

Es hora de mirar la sociedad que tenemos, en la que hay alumnos que sufren y se revelan en contra de la educación. Algunos dejándola porque no le encuentran sentido, otros hiriendo a compañeros o al profesorado. Es por esto que creemos necesario que en la escuela se adopten otras miradas que nos permitan realizar una lectura más profunda sobre la sociedad y sobre nosotros mismos.

El reto está en conseguir una educación que indague en cuestiones del corazón. Una educación del sentir, de la emoción. En definitiva una educación en la que la atención a la diversidad sea una necesidad para todas las personas. La educación para el bienestar y la felicidad, basada en un camino de autoconocimiento que nos permita superar nuestras limitaciones y desarrollar nuestras potencialidades.

Con esta pretensión iniciamos el presente capítulo, en el que realizaremos un recorrido desde la inteligencia emocional hasta la educación emocional, pasando por las competencias emocionales. A continuación, explicaremos el origen y los principios de la educación holística, como una apuesta por una educación integral del ser humano. Nos detendremos en la importancia de aprender a ser, y de centrarnos en el alumnado desde su persona. Finalmente, hablaremos sobre el papel del educador y la importancia de que realice su propio proceso de autoconocimiento y trabajo personal, para poder realizarlo con el alumnado. 


\subsection{Inteligencia Emocional}

El estudio de las emociones siempre se ha mantenido al margen de los avances de la ciencia. Hasta mediados del siglo XX, no se empezó a poner especial atención en este tema. Es a partir de entonces, de la mano de la psicología Humanista, con Carl Rogers, que se presta atención a la importancia de las emociones. Posteriormente, otros pensadores, filósofos y científicos continuaron escribiendo al respecto. Sin embargo, hasta finales de los años ochenta no se produce ese énfasis sobre el estudio de las emociones.

El concepto de inteligencia emocional aparece por primera vez en un artículo de Peter Salovey y John Mayer, Emotional Intelligence (1990). Sin embargo, no fue hasta cinco años después que cobró relevancia a partir del libro publicado por Daniel Goleman con este mismo título, Inteligencia Emocional (1995).

El concepto de inteligencia emocional (IE), trata de traspasar el concepto de inteligencia defendido hasta el momento, situando a las emociones como una parte importante en nuestra vida. Este concepto tiene sus antecesores en las inteligencias múltiples de Gardner. En concreto, en la inteligencia interpersonal y en la intrapersonal.

\subsubsection{Origen de la IE: Las inteligencias múltiples de Gardner}

Entre 1979 y 1983, Howard Gardner realizó un estudio sobre la naturaleza del potencial humano y la realización del hombre. En este estudio, que tuvo como resultado el libro Frames of mind, el autor puso en cuestión el cociente intelectual (CI), resaltando que la inteligencia, tal y como se entendía hasta el momento, estaba muy limitada a dos ramas de conocimiento principalmente, la lógico matemática y la del léxico y la literatura. En este sentido, el concepto de inteligencia no hacía justicia sobre el potencial humano, ni tampoco era un 
predictor de la autorrealización que podía alcanzar una persona, en función de sus capacidades intelectuales.

Como alternativa al concepto de inteligencia establecido hasta el momento, Gardner propuso la teoría de las inteligencias múltiples. Fruto de esta teoría publicó el libro, Multiple intelligences. The theory in practice (1993), destacando 7 tipos de inteligencias: musical, cinético-corporal, lógico-matemática, lingüística, espacial, interpersonal e intrapersonal. Posteriormente (en el año 1995 y en el 1998) añade la inteligencia naturalista y la inteligencia existencial. La naturalista se refiere a la conciencia ecológica; la inteligencia existencial también es conocida como la inteligencia espiritual o filosófica, se plantea cuestiones sobre la realidad y la propia existencia, como por ejemplo, aspectos relacionados con la vida y la muerte.

Cabe destacar que este estudio nos traslada a otra manera de entender la educación, quizás, como indican algunos autores (Bisquerra, 2003) a la escuela del futuro, ya que estas propuestas son una apuesta mejor para dar una respuesta más adecuada a la diversidad.

De todas las inteligencias propuestas por Gardner (1993), nos centraremos en la inter y la intrapersonal, como las bases que fundamentan el concepto de inteligencia emocional.

La inteligencia interpersonal es aquella relacionada con la capacidad de ponerse en el lugar del otro. Por eso, algunos de los indicadores de este tipo de inteligencia son la empatía, las relaciones con los otros o relaciones interpersonales y las responsabilidades sociales. Este tipo de inteligencia está muy relacionada con el concepto de Inteligencia Social, de Thorndike (1920), y con el trabajo en las aulas de las habilidades sociales.

Este tipo de inteligencia es sumamente importante a la hora de relacionarnos con el mundo y con el otro. Cobra también especial importancia en los trabajo de carácter cooperativo. Así mismo, este tipo de inteligencia es necesaria para que una persona se sienta integrada entre sus iguales. También para resolver los conflictos 
de una manera más adecuada, teniendo en cuenta nuestros intereses y los del otro. En cierto modo, es una inteligencia relacionada con el concepto de empatía.

En cuanto a la inteligencia intrapersonal es la que se refiere al conocimiento de uno mismo, de sus propias emociones y sentimientos. La inteligencia intrapersonal o el autoconocimiento es un aspecto básico para que una persona sea feliz, y también para que pueda empatizar y comprender al otro. Esta inteligencia es la que se asocia a todo el trabajo emocional y la que nos permite desarrollarnos en nuestra vida de una manera más coherente con nuestro sentir. Es también la que facilita que nos acerquemos y desarrollemos nuestro proyecto vital.

A partir de ambas propuestas, Salovey y Mayer desarrollan en 1990 el concepto de Inteligencia Emocional. No obstante, Trujillo y Rivas (2005) destacan a Thorndike, como un antecesor tanto de la teoría de Salovey y Mayer como de Gardner, con su aportación en 1920 sobre la inteligencia social, íntimamente relacionada con las inteligencias inter e intra-personal. La inteligencia emocional, se basa en los dos términos.

\subsubsection{Concepto de Inteligencia Emocional}

Para conocer las bases de la inteligencia emocional tenemos que indagar en el concepto de inteligencia, del que hemos hablado anteriormente al explicar la teoría de las inteligencias múltiples, y del concepto emocional, basado como su nombre indica, en las emociones. En relación a este último, cabe mencionar que la educación a lo largo del siglo XX se ha centrado en el desarrollo cognitivo. Así queda de manifiesto en los grandes referentes teóricos como la psicología cognitiva en sus orígenes, las teorías del desarrollo cognitivo, el constructivismo, etc. Es a partir de la psicología humanista en la que encontramos las primeras aportaciones en cuanto al componente emocional. No obstante, el máximo desarrollo de la inteligencia emocional aparece a partir de la segunda mitad de los años noventa. Se produce una "revolución emocional", siendo sus más claros exponentes Gardner, Salovey, Mayer, Caruso, Elias, Tobias, Friedlander, Lantieri, Bracket, etc. Entre 
estos autores destaca precisamente Goleman, y su "best seller" Inteligencia emocional.

Aunque se resalta la figura de Goleman como su principal precursor, como ya hemos nombrado, fueron Salovey y Mayer quienes acuñaron el término y cinco años más tarde fue difundido por Goleman, con algunos matices distintos.

Por inteligencia emocional (IE), entendemos la habilidad de tomar conciencia de las propias emociones, de las emociones de las demás personas, así como de la capacidad para regular las nuestras. Es por esto que se habla de la conciencia emocional como un requisito indispensable para poder pasar a la autorregulación emocional, de la que hablaremos más adelante. La finalidad última de la inteligencia emocional radica en el bienestar personal y social del individuo (Bisquerra, 2011).

Sin embargo, se habla de dos modelos de IE: los modelos mixtos y el modelo de habilidad, de Salovey y Mayer. En nuestro contexto educativo el modelo más difundido es el de Goleman, que estaría dentro de los modelos mixtos. Los modelos mixtos se centran en dimensiones de personalidad como son el optimismo, la automotivación, habilidades emocionales, etc. Por su parte, el modelo de habilidad se centra en el procesamiento emocional de la información y en el estudio de las capacidades relacionadas con ese procesamiento (Extremera y Fernández-Berrocal, 2004). Desde esta perspectiva la IE se define como la habilidad para atender y percibir los sentimientos, asimilarlos y comprenderlos de manera adecuada, así como regularlos y modificar nuestro estado de ánimo o el de los demás.

La IE no es un rasgo de la personalidad, sino nuestra manera de gestionar las emociones. Tampoco es lo mismo que la inteligencia social, sino que en la IE se tienen en cuenta las emociones internas que necesariamente debemos comprender y saber regular para nuestro crecimiento personal.

Desde el modelo de habilidad de Salovey y Mayer, se diferencia entre cuatro aspectos clave para poder gestionar nuestras emociones: la percepción y la 
expresión emocional; la facilitación emocional; la comprensión emocional y la regulación emocional.

La percepción y la expresión emocional, se refiere a ser conscientes de nuestras emociones, identificarlas para posteriormente poder expresarlas de una forma adecuada. Esto implica escuchar nuestro cuerpo y reconocer los sentimientos que me provocan las emociones. Sería de alguna manera poner nombre a la emoción que siento, identificarla, para posteriormente dar una respuesta.

Por otra parte, la facilitación emocional se refiere a la relación que existe entre las emociones y los pensamientos. Nuestra manera de percibir la realidad en función de nuestras creencias da pie en cada uno de nosotros, a unas emociones, y esas emociones a su vez, alimentan los pensamientos que tenemos y los juicios que hacemos. Por eso, Extremera y Fernández Berrocal (2004), destacan a continuación la influencia que tienen las emociones en los pensamientos y cómo eso influye en el alumnado:

Por otra parte, el «cómo nos sentimos» guiará nuestros pensamientos posteriores, influirá en la creatividad en el trabajo, dirigirá nuestra forma de razonar y afectará a nuestra capacidad diaria de deducción lógica. En efecto, que nuestros alumnos estén felices o tristes, enfadados o eufóricos o hagan o no un uso apropiado de su IE para regular y comprender sus emociones puede, incluso, determinar el resultado final de sus notas escolares y su posterior dedicación profesional (p. 4).

Otro de los aspectos clave, es la comprensión emocional. Consiste en comprender, de una manera más profunda, nuestras respuestas emocionales y las situaciones o pensamientos que las causan. Además de nuestras respuestas al efecto. Es decir, la comprensión emocional lo que significa es una mayor escucha y conciencia emocional, que es básica para poder estar bien con uno mismo, y también para poder comprender al otro. La comprensión emocional implica conocernos mejor, identificar nuestras emociones, conocer nuestros deseos, nuestra manera de sentir, etc. e integrarlo. Además, también es comprender la complejidad de los cambios emocionales en uno mismo y en el otro. 
Finalmente, el último aspecto sería la regulación emocional. Pero para llegar a regular las emociones en primer lugar cabe identificarlas, sentirlas y comprenderlas. Una vez hemos hecho esto vendría la respuesta que le damos a la situación, o a la emoción. Es decir, después de sentir la emoción, la misma nos suele llevar a una respuesta u otra, de forma casi automática. Por ejemplo, ante una muy buena noticia, la emoción suele ser la alegría, que normalmente se expresa con reacciones de euforia. Por el contrario, si sentimos tristeza la reacción puede ser muy variada pero no sería la misma que la que nos provoca la alegría. Por eso, en situaciones en las que sentimos ira es necesaria la regulación emocional para que nuestra respuesta pueda ser adecuada y adaptativa para nosotros.

Diríamos que conviene aplicar la regulación emocional para dar respuestas adaptadas a emociones intensas. Para ello, entre la emoción y la acción tenemos que contemplar un espacio, una pausa que tiene por objetivo liberar la tensión emocional y facilitar posteriormente, la construcción de una respuesta adaptada (Bach y Darder, 2002). Esa pausa, que algunas veces puede ser simplemente tomar aire, y lo más calmadamente posible reflexionar, es la que nos puede llevar a una reacción más adaptada. El tiempo de la pausa es muy diferente para cada uno, hay quien en unos segundos se calma, toma conciencia de la emoción y trata de dar una respuesta adaptada. Para otras personas lo difícil puede ser tomar conciencia de la emoción y no dejarse dominar por ella a la hora de expresarse, si la respuesta no es adaptativa.

En este sentido, identificar nuestras emociones y saber cómo gestionarlas no es un aprendizaje innato, sino que también requiere de entrenamiento. Por eso, es tan importante que desde la escuela se enseñe al alumnado a identificar sus propias emociones; a expresarlas en lugar de reprimirlas y a regularlas, para dar la mejor respuesta posible ante la situación.

Desde el modelo de Goleman (1995), aparecen también algunos de los elementos del modelo anterior y se identifican aspectos nuevos. Para Goleman la IE consiste en: conocer las propias emociones; manejar las emociones; motivarse a uno mismo; reconocer las emociones de los demás y establecer relaciones. 
En cuanto a conocer las propias emociones, se refiere a tomar conciencia sobre las emociones que estamos sintiendo.

El segundo aspecto, manejar las emociones, requiere de la habilidad para manejar los sentimientos para expresar nuestras emociones de una manera adecuada. Para ello es necesario en primer lugar tomar conciencia sobre la emoción y posteriormente poseer o desarrollar estrategias para reflexionar, hacer una pausa, y expresarnos.

El tercer paso sería motivarse a uno mismo. Puesto que la emoción motiva a la acción, el concepto de emoción y motivación están íntimamente relacionados. En este sentido, dirigir la emoción y la motivación hacia el logro de un objetivo es esencial para conseguirlo. Para ello es necesario también el autocontrol emocional.

En cuarto lugar, es necesario también reconocer las emociones de los demás. Esto sería sentir empatía.

Finalmente, establecer relaciones sería el último elemento del modelo. Las relaciones con el otro son también una fuente de enriquecimiento. De hecho, la felicidad depende de la relación con uno mismo, pero también de cómo vivimos la relación con el otro.

Posteriormente, Goleman (1998), modifica su modelo que pasa a definirse de la siguiente manera:

- Autoconciencia

- Autorregulación

- Automotivación

- Empatía

- Habilidades sociales

Además de estos modelos existen otros, como el de Bar-On (1980), anterior al de Salovey y Mayer; el de Cooper y Sawaf (1997); el de Weisinger (1998); el de Epstein (1998), etc. En definitiva, podemos afirmar que no existe un consenso en cuanto a la definición de inteligencia emocional, y en cuanto a si se trata de un concepto con entidad propia o a un rasgo de la personalidad (McCrae, 2000). 
En definitiva, la inteligencia emocional es un constructo hipotético, propio del campo de la psicología, que ha sido propuesto y defendido por los autores que anteriormente hemos destacado. Cabe señalar, que este concepto ha sido cuestionado, pero aquello que no se pone en tela de juicio es la importancia y necesidad de adquirir competencias emocionales (Bar-On y Parker, 2000; Cohen, 1999; Elias, Tobias y Friedlander, 2000; Elias y otros, 1997; Goleman, 1995; Saarni, 2000; etc.). Las competencias emocionales, de las que hablaremos más adelante, se centran en la interacción entre persona y ambiente y le dan importancia al aprendizaje y al desarrollo. Este tipo de competencias tienen unas implicaciones psicopedagógicas inmediatas y ayudan a mejorar el bienestar cotidiano. Las competencias emocionales son también el objetivo principal de la educación emocional, de la que hablaremos a continuación. Para ello, desde la educación emocional se analizan las necesidades individuales o grupales, se formulan objetivos, se diseñan programas, se aplican actividades, técnicas y estrategias metodológicas, etc. con la finalidad de que se adquieran las competencias emocionales (Bisquerra, 2009).

\subsection{Educación Emocional}

La educación emocional es una de las innovaciones psicopedagógicas de los últimos años y responde a las necesidades sociales que no quedan suficientemente atendidas en las materias académicas ordinarias (Bisquerra, 2009). Fruto de esta necesidad de aportar una educación para la vida, aparece este concepto basado, en parte, en la inteligencia emocional. Además, la educación emocional toma como referencia otros elementos. Por ejemplo, la teoría de las inteligencias múltiples, las habilidades sociales, las habilidades para la vida, el bienestar, la neurociencia, etc. 
Cabe destacar que es un concepto amplio, y por eso no es fácil de delimitar. No obstante, basándonos en la propuesta de Bisquerra (2000, p. 243), podemos decir que se trata de un:

Proceso educativo, continuo y presente, que pretende potenciar el desarrollo emocional como complemento indispensable del desarrollo cognitivo, constituyendo ambos los elementos esenciales del desarrollo de la personalidad integral. Para ello se propone el desarrollo de conocimientos y habilidades sobre las emociones con objeto de capacitar al individuo para afrontar mejor los retos que se plantean en la vida cotidiana. Todo ello tiene como finalidad aumentar el bienestar personal y social.

La educación emocional pretende ser una educación que capacita para la vida. Una educación que tiene como propósito el desarrollo integral de las personas y como base el conocimiento de las emociones, desde un punto de vista experiencial y práctico. Para ello, se propone el autoconocimiento como el vehículo necesario para poder comprender las emociones en uno mismo y en los demás. Todo ello, para contribuir al bienestar personal y social, ya comentado anteriormente.

Pero, para comprender mejor en qué consiste la educación emocional necesitamos conocer qué son las emociones. La palabra emoción proviene del latín movere, que significa mover. Esto indica que el significado de una emoción ya nos predispone hacia un movimiento, hacia la acción. Basándonos en Mora (2013), definimos la emoción como una energía codificada en la actividad de ciertos circuitos del cerebro que nos mantiene vivos. Sin la emoción, sin esa energía base, nos encontraríamos deprimidos, apagados y por tanto, no podríamos estar atentos a los estímulos de nuestro alrededor y aportar además, una respuesta adaptada a los mismos.

Para Bisquerra (2011), el proceso de vivencia emocional se puede esquematizar de la siguiente manera: evento $\rightarrow$ valoración $\rightarrow$ cambios fisiológicos $\rightarrow$ predisposición a la acción.

En un primer momento la persona evalúa un evento como relevante respecto a un objetivo personal que es valorado como importante. En segundo lugar, se 
predispone a actuar. Algunas veces de forma urgente, si se siente amenazado. En tercer lugar, la vivencia de la emoción tiende a ir acompañada de reacciones involuntarias, como pueden ser cambios corporales de carácter fisiológico y/o voluntarias, como las expresiones faciales, verbales, comportamientos y acciones (Bisquerra, 2011).

Otro de los conceptos que en muchas ocasiones se usa indistintamente junto con el concepto de emoción es el de sentimiento. La diferencia para Bach y Darder (2002), es que la emoción alcanza el proceso completo y engloba el componente fisiológico-corporal, el evaluativo-cognitivo y el conductual-social, mientras que el sentimiento tiene un radio más restringido y se refiere solo a una de las partes del proceso, la valorativo-cognitiva. Por tanto, un sentimiento es una emoción hecha consciente, que identificamos, clasificamos y valoramos gracias al dominio que poseemos del lenguaje. Sería como una emoción analizada por la razón. Así mismo, la emoción tiene un sentido más amplio y engloba la vivencia. Por eso, estos autores explican que una emoción siempre es más que lo que podemos llegar a conocer o a expresar sobre aquella emoción después de haberla experimentado.

Sin embargo, es importante destacar que no siempre somos conscientes de nuestras emociones, aunque estas, siendo nosotros más o menos conscientes, nos impulsan a alcanzar unos fines $\mathrm{u}$ otros. Conocer nuestras emociones significa conocer sus causas; descubrir nuestras necesidades; analizar la funcionalidad de los esquemas emocionales que normalmente utilizamos para interpretar la realidad; reconocer y poner un nombre a las emociones que sentimos; gestionarlas y finalmente, expresarlas de manera adecuada.

Para identificar las emociones en nosotros mismos, en primer lugar tenemos que conocerlas. Como la lista de emociones sería interminable y no hay un consenso entre todos los autores sobre qué emociones se consideran básicas, a continuación definiremos de manera resumida, algunas de ellas. Aquellas que consideramos esenciales en nuestro día a día. 
Amor: el amor es el afecto que sentimos hacia nosotros mismos y hacia los otros. Se manifiesta en una sensación de bienestar y placer y se corresponde con la aceptación incondicional de uno mismo o de otra persona.

Alegría: es la emoción que produce una situación o suceso agradable para la persona.

Felicidad: es la forma de valorar la vida en su conjunto (Bisquerra, 2011). Por eso, el concepto de felicidad se refiere más a un estado o un sentimiento que a una emoción. La felicidad suele asociarse con la emoción del amor y de la alegría.

Ira: sentimos ira cuando tenemos la sensación de haber sido perjudicados de alguna manera. La reacción que desencadena es el enojo, furia o cólera.

Miedo: es la sensación que experimentamos ante un peligro, que puede ser real, como por ejemplo, tener delante a un animal salvaje que puede atacarnos; o inducido, por ejemplo, el miedo o el estrés que puede provocar un examen en el alumnado. El miedo se activa cuando sentimos amenazado nuestro bienestar.

Tristeza: la tristeza se desencadena por la pérdida de algo que se valora como importante. Está relacionada con la emoción del miedo, siendo el miedo un estado transitorio y la tristeza un estado que puede mantenerse durante más tiempo (días, meses, etc.).

Compasión: la compasión es también más un estado que una emoción. Podemos sentir amor y puede desembocar en compasión. Este es un sentimiento de amor incondicional hacia el otro, implica también empatía, ponerse en el lugar del otro para comprender su situación y sentir compasión por una persona. La compasión no significa sentir lástima, sino comprender y sentir aprecio por los demás, más allá de sus conductas. La compasión está relacionada con el perdón, hacia uno mismo y hacia los demás.

Sorpresa: la sorpresa está provocada por una situación imprevista, por eso es una emoción que puede desencadenar en alegría o en tristeza, en función del tipo de suceso. 
Vergüenza: es un sentimiento de pérdida de dignidad por alguna situación cometida. También se puede sentir vergüenza delante de una humillación. En cualquier caso, la sentimos cuando pensamos que somos culpables (Bisquerra, 2011).

Humor: el humor es una emoción que nos remite a una situación de abandono y relajación, delante de un acontecimiento. El humor también se considera un estado de ánimo. En cualquier caso, el humor nos aporta experiencias positivas.

"El humor y la risa contrarrestan las experiencias de emociones negativas; intensifican la confianza entre las personas; preparan al organismo para experimentar placer sensorial; amortiguan el estrés, reducen el malestar y el dolor; bajan la tensión" (Bisquerra, 2011, p. 106).

Aversión: es una familia de emociones que implica el rechazo de algo o alguien. Algunas de las emociones que se incluyen son: desprecio, rechazo y asco.

Además de saber qué estamos sintiendo, es muy importante permitirnos vivir esa emoción. Con esto venimos a referirnos a que no es adecuado reprimirla. Algunas emociones son más aceptadas que otras socialmente. Por ejemplo, el amor o la alegría, son emociones que generalmente, solemos expresar desde la niñez y que las personas adultas aceptan con agrado. Sin embargo, la ira o la tristeza no siempre son emociones que sabemos gestionar porque desde bien pequeños quizás, las hemos reprimido. Por eso, es importante durante todas las etapas de la vida, pero sobre todo llegados a la edad adulta, saber identificar nuestras emociones y gestionarlas.

En algunos casos, como hemos comentado, reprimimos la emoción, en otros casos podemos quedarnos enganchados en una emoción sin saber muy bien cómo salir del sentimiento que nos provoca. En esos momentos, también es importante tomar conciencia de la emoción y permitirnos experimentarla para poder soltarla. Por ejemplo, la ira y la tristeza son emociones que necesitan también vivenciarse. Una persona que no se permite sentir la tristeza, quizás no llega nunca a sentir la crisis a la que lleva esta emoción, pero tampoco aprenderá de ella y cada vez la sensación de vacío que experimente, podría ser más grande. Es decir, sentir las 
emociones es esencial para poder vivir felizmente. Vivir la alegría sería permitirnos sentir la alegría, la sensación de agradecimiento, o aquello que supone para cada uno de nosotros. De igual manera, vivir la tristeza sería permitirnos sentir lo que en cada uno de nosotros provoca.

Sentir la emoción nos permite estar en una mayor coherencia con nosotros mismos y esto es esencial para tener bienestar. Por eso, no podemos hablar de emociones positivas y emociones negativas, sino de reacciones que son más positivas para nosotros o más negativas. En este sentido, la emoción en sí, el tomar conciencia de ella, permitirnos sentirla y soltarla, es siempre necesario y positivo, sea una emoción que nos provoque un sentimiento de tristeza o de alegría.

El hecho de no expresar las emociones conlleva consecuencias, sentimientos de frustración y enfado con uno mismo, y pensamientos negativos hacia sí mismo. Desde un estado emocional en el que no realizamos esa integración entre lo que sentimos y lo que expresamos la persona se encuentra desconectada de sí misma y de su vida, y puede tener la sensación de estar constantemente en una emoción de amargura de la que no sabe muy bien cómo salir. Por otra parte, la represión de las emociones puede también conllevar una respuesta explosiva ante situaciones que no tendrían demasiada importancia.

Además, la visión de la realidad para una persona que no ha aprendido a expresarse en coherencia con su sentir, puede estar también distorsionada. En algunos casos, el hecho de no expresar las emociones puede afectar también en las relaciones sociales. Algunas de las personas que tienden a reprimir sus emociones lo hacen por no sentirse valoradas o aceptadas tal y como son. Estas personas pueden sentirse poco amadas por ellas mismas, y puede que busquen reconocimiento y afecto en el otro. Sin embargo, al ser incapaces de darse ese amor a sí mismas, también puede que piensen que los demás no las aprecian y sus relaciones sociales no sean satisfactorias. Por eso es tan importante desarrollar la capacidad de sentir y manifestar afecto y compasión hacia uno mismo y hacia los demás. 
Nuestra manera de vivir las emociones, también contribuirá a nuestro carácter. Se forjará en base a nuestras experiencias y, estas serán de un modo u otro en función de nuestros esquemas emocionales (Bach y Darder, 2002; Bisquerra, 2011). Por eso, en última instancia todas las respuestas que aportamos en la vida están delimitadas por nuestras creencias y nuestra manera de vivir las emociones.

Como hemos visto, nuestra vida social está altamente condicionada por nuestra inteligencia emocional y por la manera en la que vivimos nuestras emociones. Pero es importante destacar que la relación con el otro es siempre una fuente de enriquecimiento para poder explorar nuestras propias emociones y conocer nuestras limitaciones. Es decir, en la relación con el otro aparecen situaciones que nos gustan y que nos molestan. El ser consciente de aquello que el otro genera en mí es lo que nos va a hacer crecer personalmente y nos va a permitir conocernos mejor.

En la educación emocional es importante que tanto la escuela como las familias se impliquen y le enseñen al alumnado a ponerse en contacto con sus emociones, a sentirlas, gestionarlas y expresarlas.

Finalmente, el trabajo emocional desde la niñez desemboca en adultos más competentes, que se sienten más capaces para vivir felizmente su vida y con una autoestima más adecuada. Ya que la base de la autoestima está en las emociones.

\subsubsection{Objetivos y contenidos de la educación emocional}

El trabajo emocional es necesario para aceptarnos tal y como somos y querernos. Para acercarnos a nuestro sentir y dirigir nuestro proyecto de vida hacia una mayor coherencia con nuestras necesidades y deseos. También es esencial para aceptar a los demás y poder crecer conjuntamente.

En educación, el trabajo emocional es necesario porque sin él, el resto de aprendizajes tienen menos sentido (Bach y Darder, 2002). Es decir, un alumno que 
no posea competencias emocionales, por más que aprenda matemáticas y el resto de asignaturas, no será feliz. Nuestro estado emocional influye en la adquisición de otros conocimientos. Desde la neurociencia también se defiende la importancia de las emociones incluso por encima de la racionalidad: "La naturaleza parece haber construido el aparato de la racionalidad no solo encima del aparato de la regulación biológica, sino también a partir de éste y con éste" (Damasio, 2001, p.126).

No obstante, aunque cada vez hay más programas de educación emocional para infantil, primaria y secundaria (Repetto, Pena, Mudarra y Uribarri, 2007), pensamos que todavía no se da un trabajo emocional en la mayoría de los centros. Consideramos que en las primeras etapas y niveles de la educación formal, esto sería en la etapa de infantil y el primer ciclo de primaria, sí que se contempla más la dimensión emocional en la clase. A lo largo de los diferentes cursos se va prescindiendo de ella, y sin embargo, las emociones, lo queramos o no, forman parte de nuestra manera de vivir la vida. Incluso existe cierto paralelismo entre la educación emocional y el fracaso escolar (Bach y Darder, 2002). El fracaso escolar, no es del alumno, sino del sistema, que prescinde de las emociones, cuando en nuestra vida es imposible prescindir de ellas. Como hemos nombrado en distintas ocasiones, el alumnado lo que desea es vivir y compartir y sobre todo, ser felices.

Desde esta perspectiva, se hace necesario trabajar la educación emocional desde las aulas. A continuación, nombraremos los objetivos que persigue la educación emocional que tratan de acercarse a un mayor bienestar en el alumnado.

El objetivo principal de la educación emocional es el desarrollo de competencias emocionales, que son básicas para vivir con el mayor bienestar posible nuestra vida. Además de este objetivo principal del que hablaremos en el siguiente apartado, existen algunos objetivos generales que podemos resumir de la siguiente manera (Bisquerra, 2011; p. 244):

- Adquirir un mejor conocimiento de las propias emociones

- Identificar las emociones de los demás

- Desarrollar la habilidad para regular las propias emociones 
- Prevenir los efectos nocivos de las emociones negativas

- Desarrollar la habilidad para generar emociones positivas

- Desarrollar una mayor competencia emocional

- Desarrollar la habilidad de automotivarse

- Adoptar una actitud positiva ante la vida y aprender a fluir

De estos objetivos generales se derivan otros específicos como por ejemplo, desarrollar la capacidad para controlar la ansiedad y el estrés; potenciar la capacidad de ser feliz; ser más conscientes de nuestros pensamientos internos y poco a poco tratar de eliminar aquellos que son destructivos, etc.

Además de los objetivos, la educación emocional se plantea una serie de contenidos, estos se centrarían en el marco teórico de la educación emocional, de las competencias emocionales y en aspectos en los que nos hemos detenido en el apartado anterior, sobre el significado de las emociones, la definición de cada una de ellas, etc. Pero sobre todo, se centrarían en ayudar al individuo a tener un mayor bienestar y a ser más feliz.

En este sentido, para aumentar la felicidad se pueden mejorar las relaciones sociales, realizar un trabajo en el que la persona se sienta realizada, aprovechar el tiempo libre de forma satisfactoria y gozar de una buena salud. Como señala Bisquerra (2011), las habilidades de vida, necesarias para que estos temas estén equilibrados en nuestra vida, y las habilidades para afrontar situaciones de conflicto deben considerarse como recursos que todas las personas deberían desarrollar y dominar. Es por esto que, entre los componentes de la inteligencia emocional que deberían estar presentes en un programa de educación emocional, deberíamos encontrar las siguientes temáticas (Goleman, 1995): dinámica de grupos; conexión personal; prevención de conflictos y análisis social o empatía.

En definitiva, pensamos que es necesario un currículum sobre educación emocional, para abordar desde el aula aquellos aspectos que forman parte e inciden en la vida del alumnado. Además de este trabajo más explícito, no dejamos de lado el trabajo emocional desde la transversalidad. Y aprovechamos para destacar que 
desde las asambleas de aula se puede indagar sobre las emociones de nuestro alumnado (Bisquerra, 2011).

\subsubsection{Competencias emocionales}

La educación emocional tiene como objetivo el desarrollo de las competencias emocionales en todos los contextos en los que nos desarrollamos. Las competencias son las capacidades que tenemos en distintos ámbitos para ser capaces de realizar una tarea o para desarrollarnos de manera adecuada en nuestra vida.

Según Bisquerra y Pérez (2007), una competencia es la capacidad para movilizar de la manera adecuada, un conjunto de conocimientos, capacidades, habilidades y actitudes, necesarias para realizar determinadas actividades con calidad y eficacia. Por tanto, poseer competencias emocionales, es ser capaces de desarrollarnos adecuadamente en nuestra vida en todo aquello relacionado con aspectos emocionales.

Las competencias emocionales también se basan, en parte, en la inteligencia emocional. Pero además incluyen otros aspectos que provienen de otras teorías. La inteligencia emocional es un constructo teórico realizado desde la teoría y sin embargo, las competencias emocionales también tienen un componente educativo. La diferencia entre ambos es que el concepto construido desde la psicología tiene un carácter más restrictivo y teórico, mientras que desde la educación su carácter es más amplio e integrador. Por tanto, la mayoría de propuestas sobre competencias emocionales cuentan con una base sobre la inteligencia emocional, pero además, incluyen otros aspectos sociales y emocionales como el trabajo de la autoestima, las habilidades sociales, el bienestar, etc.

No obstante, el concepto de competencias emocionales está en proceso de construcción y reformulación. Existen diversos planteamientos respecto al mismo, pero en definitiva, se apunta a que las competencias emocionales son un concepto más amplio que el de inteligencia emocional. 
Uno de los modelos de competencias emocionales es el de Bisquerra y Pérez (2007), que definen las competencias emocionales como "el conjunto de conocimientos, capacidades, habilidades y actitudes necesarias para tomar conciencia, comprender, expresar y regular de forma apropiada los fenómenos emocionales" (p. 8).

Desde este modelo, las competencias emocionales se estructuran en cinco grandes competencias o bloques: conciencia emocional, regulación emocional, autonomía personal, competencia social y habilidades de vida para el bienestar. A continuación hablaremos de cada una de estas competencias y de las microcompetencias que se incluyen en las mismas, según los autores.

Algunas de estas competencias, ya han sido definidas anteriormente, al ser también aspectos de los modelos de inteligencia emocional presentados en el primer apartado del capítulo. Como por ejemplo, la conciencia y la regulación emocional. No obstante, volveremos a ellos para delimitar las microcompetencias que aparecen en cada caso.

Empezamos por la conciencia emocional. Como hemos dicho es ser consciente de las propias emociones y de las de los demás. También implica la habilidad para captar el clima emocional de un contexto determinado. Las microcompetencias que distinguimos en esta parte son:

- Tomar conciencia de las propias emociones. Poner atención a las emociones y ver qué nos generan. Darnos cuenta que a veces no estamos siendo conscientes de nuestros sentimientos porque no les prestamos atención

- Dar nombre a las emociones.

- Comprensión de las emociones de los demás. Ser empáticos con las demás personas y situaciones.

- Tomar conciencia de la interacción entre emoción, cognición y comportamiento.

La regulación emocional, que ya ha sido explicada desde la inteligencia emocional, tiene que ver con el hecho de auto-gestionar las propias emociones. 
Pero además, también con nuestra capacidad para generar en nosotros emociones que nos devuelvan a un estado de mayor conciencia y estima hacia nosotros mismos.

En este caso, las microcompetencias que destacamos serían:

- Expresión emocional apropiada. Es la capacidad para expresar las emociones de forma adecuada. Aunque nosotros preferimos decir, de forma adaptada al contexto, porque quizás aquello que se espera como lo adecuado para la situación no es lo adecuado para la persona.

- Regulación de emociones y sentimientos.

- Habilidades de afrontamiento. Son las habilidades para afrontar las situaciones de conflicto o los retos que encontramos en la vida.

En tercer lugar, la autonomía emocional. Sería la capacidad para autogestionar nuestra propia vida, y la manera en la que vivimos nuestra realidad. Algunas de las microcompetencias que incluye son:

- Autoestima. La autoestima tiene que ver con el amor y estima que uno tiene de sí mismo.

- Automotivación. Es la capacidad para motivarse a uno mismo y lograr los objetivos que nos hayamos propuesto.

- Autoeficacia emocional. Es la percepción que se tiene sobre uno mismo relacionada con el "ser capaces de". También es la competencia para percibirse a uno mismo como se desea y para generar las emociones que necesita. Es por esto que la autoeficacia emocional significa aceptar la propia experiencia emocional.

- Responsabilidad. Es la capacidad para dirigir nuestra vida, desde nuestro sentir, desde comportamientos que nos aportan bienestar. Asumir nuestra responsabilidad en la toma de decisiones también es asumir la responsabilidad de nuestra vida.

- Resiliencia. Es la capacidad para aceptar la adversidad y fortalecerse de ella. 
La cuarta, es la competencia social. Es la capacidad para mantener buenas relaciones con otras personas. Para ello es necesario desarrollar las habilidades sociales y las habilidades comunicativas. Las microcompetencias que se contemplan son:

- Dominar las habilidades sociales.

- Respeto hacia los demás.

- Practicar la comunicación receptiva y expresiva.

- Compartir las emociones.

- Tener un comportamiento prosocial y cooperativo.

- Asertividad.

- Prevención y resolución de conflictos.

- Capacidad para gestionar situaciones emocionales.

Finalmente, es necesario poseer competencias para la vida y el bienestar. Esto sería la capacidad para adoptar comportamientos apropiados y responsables para vivir con el mayor bienestar posible. Las microcompetencias que destacamos son:

- Fijar objetivos adaptativos.

- Tomar decisiones desde la responsabilidad.

- Buscar ayuda y recursos.

- Ciudadanía activa, participativa, crítica, responsable y comprometida.

- Bienestar emocional.

- Fluir.

En definitiva, en las escuelas está entrando el currículum de la educación emocional. No es un currículum que ignora los contenidos de las asignaturas instrumentales, pero sí que incluye el desarrollo de aspectos necesarios para adaptarnos y ser felices en la vida. Es un nuevo concepto de escuela el que se demanda para el presente y el futuro. Es una escuela que pretende conseguir transformar la sociedad desde el corazón, desde la superación de los miedos individuales hacia una ciudadanía más implicada, más respetuosa y también más amorosa. 


\subsection{Educación Holística}

Hasta ahora hemos visto el estudio de las emociones y cómo se trabaja actualmente mediante la educación emocional. Sin embargo, existen también otras perspectivas que caminan en la misma dirección, aunque con distintos matices. A continuación explicaremos algunas cuestiones sobre la educación holística. Empezaremos por sus orígenes y finalmente hablaremos sobre un aprendizaje centrado en el Ser.

\subsubsection{Origen y principios}

Como dice Gallegos (2001), durante más de trescientos años la ciencia mecanicista impuso una visión de la realidad, arrojando luz en determinados aspectos, al mismo tiempo que ensombrecía otros. En este intento por eliminar cualquier pensamiento supersticioso también se le negó al hombre de su genuina espiritualidad. La concepción del hombre se acercó a su entendimiento como autómata u hombre robot.

Esta deshumanización nos ha llevado a la larga, a la pérdida de sentido y a una desvalorización de los recursos naturales del planeta. Estos problemas causados por el paradigma científico mecanicista, son el punto opuesto de lo que sería la visión holística del mundo, que desde sus orígenes se ha basado en un mirada completa del hombre.

En estos momentos, para varios autores (Wilber, 1982; Yus Ramos, 2001; Gallegos, 2001) nos encontramos en un cambio de paradigma. Del modelo mecanicista, que no da respuesta a las necesidades actuales, avanzamos hacia un modelo holístico que comprende nuestra realidad compleja y profunda y trata de dar respuesta a la sociedad. Dicha visión holista incluye una nueva ciencia y una nueva espiritualidad integradas en un marco ampliado de la experiencia humana (Gallegos, 2001). 
El paradigma holista tiene sus bases en la Filosofía Perenne. Desde este enfoque Wilber (1991) defiende que existen "tres ojos del conocimiento". El "ojo de la carne", el "ojo de la razón" y el "ojo de la contemplación o espiritual".

El ojo de la carne está orientado al mundo externo, el tiempo y los objetos. Es el mundo que podemos percibir por los cinco sentidos, un mundo sensorial. Es la forma de conocimiento más elemental, basada en nuestros sentidos físicos. En segundo lugar el ojo de la razón, ya participa en el mundo de las ideas, de la lógica y de los conceptos. Finalmente, estaría el ojo de la contemplación, que no se limita a un conocimiento racional sino que llega a plantearse al hombre desde un conocimiento transpersonal, más allá de lo observable.

Cada uno de los ojos es inclusivo de la visión del ojo anterior. Pero el primero, el de la carne, no puede ver la realidad que ve el ojo de la razón ni este la que ve el espiritual. Es imposible situarse en el mundo solo desde la visión de un ojo, pues nos estaremos perdiendo la realidad que estamos viviendo. Por estas razones, se argumenta que el paradigma científico no nos sirve para ver la realidad de manera completa. Pues se está dejando fuera aspectos que no puede valorar, porque los ve desde una visión limitada. En este sentido, la educación holística trata de ver el alumno o el hombre, desde una visión integral y completa, desde una visión también contemplativa y comprensiva.

Para Yus Ramos (2001), la Educación Holística es también una respuesta al reto de la transversalidad, por su especial énfasis en una educación de todas y cada una de las potencialidades humanas conocidas, y no exclusivamente de la dimensión racional-analítica. La educación holista surge de educadores convencidos de la necesidad de restaurar la fragmentación percibida en todas las esferas de la vida humana. Puesto que desde la Revolución Industrial se ha fomentado la compartimentación y la estandarización, dando como resultado esta fragmentación. Una fragmentación que afecta a las diferentes facetas humanas. Por otra parte, la educación holística siendo crítica con esta fragmentación pretende restablecer las conexiones en todas las esferas. Por esto, Miller (1996) indica que el centro de atención de la educación holística está en todo tipo de relaciones: 
Relaciones entre pensamiento lineal e intuición. Un currículum en el que se intenta restablecer un equilibrio entre el pensamiento lineal y la intuición. Técnicas como la visualización pueden utilizarse en la escuela para el equilibrio entre ambos ejes.

Relaciones entre mente y cuerpo. Un currículum holístico explora la relación entre la mente y el cuerpo, de forma que el estudiante sienta la conexión entre ambos. La relación puede ser explorada por el movimiento, la dramatización y ejercicios de concentración y de relajación.

Relaciones entre dominios de conocimiento. Hay muchas formas distintas de conectar las disciplinas académicas y los temas escolares. Por ejemplo, las aproximaciones interdisciplinares al pensamiento y las aproximaciones centradas en el tema, el lenguaje global, etc. pueden conectar varias disciplinas.

Relaciones entre el yo y la comunidad. Un currículum holístico ve al estudiante en relación con la comunidad (tanto la escolar como la del vecindario o la ciudad, la de la propia nación o incluso la planetaria). El estudiante desarrolla destrezas interpersonales, destrezas de servicio comunitario y destrezas de acción social.

Relaciones entre el yo y el Yo. En última instancia, un currículum holístico nos lleva a conectar con la parte más profunda de nosotros mismos que llamamos Yo (Yo superior, super-consciente, etc.). Un vehículo para trabajar esta parte son las artes (danza, música, poesía, pintura y el drama).

Más allá de esta aproximación a la Educación Holística, no existe una definición universalmente aceptada. Sin embargo, podemos a partir de su significado etimológico, comprender a qué se refiere una educación de estas características. El holismo viene del griego holos, que hace referencia a un todo formado a su vez por partes, las cuales influyen unas en otras. Por eso, el todo no puede ser entendido como la suma de sus partes, sino que existe una interrelación entre todas ellas a su vez. La visión holística se basa en la integración del conocimiento desde la ciencia, el arte, la espiritualidad, las tradiciones, etc. Esta concepción de una mirada integradora es también la que se defiende desde la 
pedagogía sistémica, que reconoce los vínculos que existen entre las diversas materias de estudio (Senge y otros, 2002).

El concepto de Educación Holística fue propuesto por Miller (1997) para referirse al conjunto de liberales, humanistas y románticos que tienen en común la convicción de que la personalidad global de cada niño debe ser considerada en la educación. Teniendo en cuenta todas las facetas de la experiencia humana, no solo el intelecto racional sino también aspectos físicos, emocionales, sociales, estéticos, creativos, intuitivos y espirituales innatos en el ser humano (Yus Ramos, 2001). Aunque la Educación Holística, como tal, empieza a nombrarse a partir de la Declaración de Chicago, en la que se toman importantes acuerdos internacionales entre educadores holísticos de distintas ciudades y tendencias, es en la Octava Conferencia Internacional de Educadores Holísticos en Chicago (1990), en la que se llevó a cabo la fundación del GATE (Global Alliance for Transforming Education). En esta conferencia se elaboró un documento aglutinador de las principales inquietudes de todos los educadores holísticos del mundo; denominado Educación 2000: una perspectiva holística.

Los diez principios que se recogen en el documento son los que citamos a continuación (Yus Ramos, 2001):

\section{Principio I: Educar para el Desarrollo Humano.}

Aunque hubo pioneros en el ámbito de la educación que apostaban por un desarrollo integral del alumnado (Pestalozzi, Froebel, Dewey, Montessori; Steiner; etc.) la literatura histórica muestra que los sistemas escolares fueron organizados para aumentar la productividad nacional, inculcando la obediencia, la fidelidad y la disciplina como máximos a adquirir en la educación formal. Este origen sigue siendo una constante en la filosofía de éxito que se persigue desde algunos centros educativos que con este objetivo siguen apostando por el desarrollo económico por encima del desarrollo humano.

Desde este principio se reclama un reconocimiento de los valores humanos como la armonía, la paz, la cooperación, el comunitarismo, la honestidad, la 
justicia, la igualdad, la compasión, la comprensión y el amor. Se busca una visión del ser humano más allá de su papel como trabajador o ciudadano. Esta visión es además esencial, puesto que si nos centramos únicamente en la formación de la persona basada en la economía y en su papel como ciudadano nos encontraremos con una crisis moral en la sociedad. Crisis que ya se escucha en la actualidad.

Esta falta de humanidad es la raíz de algunos problemas adictivos, en busca de la felicidad en el exterior; también de problemas de crimen, corrupción y casos de suicidio y violencia. Por tanto, el objetivo de una educación holística no debería verse como una apuesta más en la educación, sino como uno de los caminos que ponen de relieve la importancia de las personas como seres completos. Permitirnos una educación tan integradora como la que se demanda nos puede acercar a la inclusión social de las personas, la estima hacia uno mismo y hacia el otro. Nos lleva a una sociedad realmente feliz, desde un sentido profundo y hondo del ser.

\section{Principio II. Respetar a los alumnos como individuos.}

El respeto a cada persona con la que nos encontramos no solo por el respeto hacia el otro, sino también hacia nosotros mismos. Pero la educación debe enseñarnos este respeto reconociendo a cada uno de sus aprendices. Esto significa aceptar la diversidad y apreciarla. Pues como se viene a recoger desde este principio, cada individuo es inherentemente creativo, tiene necesidades y habilidades físicas, emocionales, intelectuales y espirituales únicas, y posee una capacidad ilimitada para aprender.

\section{Principio III. El papel central de la existencia.}

Desde este principio se viene a afirmar que la educación es un asunto de experiencia. El aprendizaje es un engarce activo y multisensorial entre un individuo y el mundo, un contacto mutuo que potencia al aprendiz y revela la rica significatividad del mundo. Otro de los aspectos que se recogen en este principio es que, el objetivo de la educación debe ser nutrir natural y saludablemente el crecimiento a través de la experiencia, y no presentar un "currículum" limitado y fragmentado como el camino para el conocimiento y la sabiduría. 
Por esto, la educación debería conectar al aprendiz con las maravillas del mundo natural a través de aproximaciones experienciales que sumerjan al alumno en la vida y la naturaleza. La educación debería conectar al alumnado con personas que trabajan para conocer de manera real la vida económica y social. También, debería ponerle en contacto con su propio mundo interior, a partir de la expresión artística, momentos de reflexión, etc. Sin llegar a un conocimiento verdadero interior, todo conocimiento es superficial y sin propósito.

\section{Principio IV. Educación holística.}

Desde este principio se reclama la globalidad de los procesos educativos y la transformación de las instituciones educativas y las normativas requeridas para conseguirlo. La globalidad de la educación implica que cada disciplina académica proporciona una perspectiva distinta sobre el fenómeno de la vida. Esto supone construir el conocimiento sobre aspectos intelectuales y vocacionales pero también sobre aspectos físicos, sociales, morales, estéticos, creativos y espirituales.

Como se aporta desde el documento, el holismo está enraizado en la asunción de que el universo es un conjunto integrado en el que todas las cosas están conectadas. Esta asunción de globalidad y unicidad está en directa oposición con el paradigma de la separación y fragmentación que prevalece en el mundo contemporáneo.

\section{Principio V. Nuevo papel de los educadores.}

Tal y como se señala en el documento, se reclama una nueva comprensión del papel del profesorado. Se hace una crítica a muchos de los educadores que en la actualidad creen en la educación desde una perspectiva competitiva y profesionalista y que abordan con frialdad los temas espirituales, morales y emocionales.

Según este principio, los educadores deben ser facilitadores del aprendizaje, entendiendo este como un proceso orgánico y natural, no como un producto cerrado. El profesorado requiere de autonomía para el diseño e implementación de 
entornos de aprendizaje que sean apropiados para las necesidades particulares de su alumnado.

En este sentido, no solo se reclama una nueva manera de entender la vocación docente sino nuevos modelos de formación del profesorado que incluyan el cultivo del propio interior y de su despertar creativo. Cuando los educadores están abiertos a su propio ser, logran un co-aprendizaje y unos procesos de co-creación con el alumnado. En estos procesos el profesorado se sitúa como aprendiz de su alumnado; entiende que su relación con él es una oportunidad para aprender. Es por esto que se reclaman profesionales centrados en el alumnado, que muestren respeto por ellos y que hayan realizado un trabajo personal para poder comprender el valor que eso supone y trasladarlo a la escuela.

Además, se buscan educadores que faciliten la comprensión significativa del mundo para los jóvenes. Por otra parte, se pide la desburocratización de los sistemas escolares, de manera que las escuelas, así como otros espacios sociales, puedan ser lugares de encuentro humano genuino.

\section{Principio VI. Libertad de Elección.}

La libertad de investigación, de expresión y de crecimiento personal es totalmente requerida. Se debería permitir que el alumnado realice elecciones auténticas sobre su aprendizaje. Ellos deberían tener una voz significativa en la determinación del currículum y de los procedimientos disciplinarios, de acuerdo con su habilidad para asumir tal responsabilidad. Las familias deberían tener acceso a un espectro diverso de opciones educativas en los sistemas de escuela pública.

\section{Principio VII. Educar para una democracia participativa.}

La democracia debería ser otro de los aspectos en la vida de las escuelas. El poder participar de forma significativa en la comunidad y en el mundo. El concepto de democracia desde su sentido verdadero, que va mucho más allá que el hecho de votar a unos líderes. La democracia desde el tomar parte en los asuntos de la comunidad. Una verdadera sociedad democrática es más que la "regla de la 
mayoría", es una comunidad en la que las voces desaparecidas son oídas y los asuntos humanos son atendidos. Es una sociedad abierta al cambio constructivo. Además, debe haber un reconocimiento de las necesidades humanas entendido desde un compromiso hacia la justicia.

\section{Principio VIII. Educar para una ciudadanía global.}

La diversidad entendida en su sentido más amplio se acerca al concepto de globalidad. Por este se entiende que, la educación global está basada en una aproximación ecológica que enfatiza la conectividad e interdependencia de la naturaleza y la vida humana y su cultura. La educación global facilita la toma de conciencia del papel de un individuo en la ecología global.

La educación global nos recuerda que toda educación y actividad humana necesita descansar sobre principios que gobiernen exitosamente los sistemas ecológicos. Estos principios incluyen el valor de la cooperación y el equilibrio, las necesidades y los derechos de los participantes.

Por otra parte, también es importante la comprensión de las causas de los conflictos y la experimentación de métodos para su resolución. Al hilo de este tema, vendrían también a explicarse otros, como los derechos humanos, la justicia, las presiones populares y el desarrollo, las causas de la guerra y las condiciones para la paz.

Además, desde la educación global se anima a la comprensión y apreciación de valores universales y de la comprensión del significado del amor, la compasión, la sabiduría, la verdad y la armonía.

\section{Principio IX. Educar para la alfabetización de la Tierra.}

Necesitamos de un planeta sano en el que vivir y aprender. Desde este principio se reclama una educación que promueva la alfabetización de la tierra para incluir una conciencia de la interdependencia planetaria, la congruencia del bienestar personal y global y las responsabilidades del ser humano hacia el planeta 
en el que vive. La educación de la Tierra implica una valoración holística de nuestro planeta y de los procesos que sostienen toda vida.

\section{Principio X. Espiritualidad y Educación.}

La espiritualidad no es una opción ideológica. Todas las personas son seres espirituales que expresan su individualidad a través de sus talentos, habilidades, intuiciones e inteligencias. Así como nos desarrollamos física, emocional e intelectualmente, también lo hacemos espiritualmente.

Desde este principio se destaca que la experiencia y el desarrollo espiritual manifiestan una profunda conexión con uno mismo y con los demás, un sentido de significado y propósito en la vida diaria, una experiencia de globalidad e interdependencia. La parte más importante y válida de la persona es su interior, su vida subjetiva o su alma. En contraposición, la ausencia de la dimensión espiritual es un factor crucial en el comportamiento autodestructivo.

Como se recoge en estos principios, fomentando un sentido profundo de conexión hacia los demás y hacia la Tierra en todas sus dimensiones, la educación holística promueve un sentido de responsabilidad hacia uno mismo, hacia los demás y hacia el planeta. Esta responsabilidad individual, grupal y global se desarrolla fomentando la compasión, instalando la convicción de que el cambio es posible y ofreciendo herramientas para hacerlo viable.

\subsubsection{Aprender a ser}

Es importante destacar uno de los aportes de la educación holística, el aprender a ser. Hasta ahora hemos visto como cada vez, la educación ha ido acercándose desde distintas perspectivas a un mayor conocimiento de la persona, más allá de aspectos que tienen que ver con las relaciones sociales.

En este sentido, el gran aporte de la educación holística pensamos que es la vuelta a lo humano y desde una perspectiva más completa. Como hemos visto en el apartado anterior, hasta 1997 no se acuñó el término de educación holística. Sin 
embargo, ya en la Octava Conferencia Internacional de Educadores Holísticos en Chicago (1990) se hablaba sobre principios de una educación integral. También fue en 1990, cuando Salovey y Mayer dieron a conocer el concepto de educación emocional, y en 1995 cuando Goleman lo difundió. Y otro dato más, el Informe de Delors, que en 1996 destacó los cuatro pilares básicos para la educación del siglo.

Lo que queremos mostrar es que, tanto desde una perspectiva más academicista como puede ser el trabajo de la inteligencia emocional y la educación emocional, como desde la educación holística, se apunta hacia las cuestiones destacadas en el Informe para la Unesco de Delors.

El primer aspecto que defendemos y que está presente durante todo nuestro trabajo, es la visión de la educación y de la escuela como una fuente de enriquecimiento para el individuo. Pero no solo desde el punto de vista de los conocimientos instrumentales, sino del desarrollo vital del ser. Por eso, destacamos del informe para la Unesco "la Educación Encierra un Tesoro" (1996), la misión de la escuela de hacer fructificar los talentos de todo el alumnado y todas sus capacidades de creación para que puedan responsabilizarse de su vida y realizar su proyecto vital.

Desde este informe se hace hincapié en la educación a lo largo de la vida, y se centra en cuatro pilares básicos sobre los que educar: aprender a conocer, aprender a hacer, aprender a vivir juntos y aprender a ser.

Aprender a conocer, se destaca la importancia de conocer la cultura, en un marco amplio y general y además, de conocer en profundidad un número reducido de materias. Estas podrían ser la lengua, las matemáticas, las ciencias, etc. Con este concepto de aprender a conocer se relaciona también el aprender a aprender, haciendo referencia a la capacidad por la que uno se hace responsable de su propio aprendizaje. En este sentido la formación permanente y el saber dónde buscar el conocimiento serían aspectos que nos ayudarían a desarrollar esta capacidad de aprendizaje que está relacionada con una conciencia más científica.

El aprender a hacer, está relacionado con un aprendizaje más orientado al trabajo. Por eso, algunas de las propuestas destacan la importancia de combinar los 
aprendizajes más orientados al conocimiento teórico con aprendizajes más prácticos. Este tipo de aprendizaje se basa en la acción. Sería aquel aprendizaje que necesitamos adquirir para el desempeño de una profesión. También se entiende la capacidad de realizar trabajos en equipo como parte del aprender a hacer. Por eso, este tipo de aprendizaje se relaciona con la conciencia social.

Por su parte, el aprender a vivir juntos, implica responsabilidad, respeto y cooperación entre los seres humanos u otros organismos del planeta. También es importante para vivir juntos la capacidad empática, la resolución de conflictos y una conciencia hacia el respeto de los valores y la búsqueda de la paz.

Finalmente, uno de los pilares que para nosotros cobra fuerza a medida que realizamos un trabajo más completo como personas, es el aprender a ser. Este aspecto también era el pilar en el informe de publicado en 1972 por la comisión internacional para el desarrollo de la educación, establecido por la UNESCO. Es importante hacer esta mención para destacar que ya en ese momento estaba la mirada puesta en la potencialidad del individuo más allá de una educación para el saber o el hacer. No obstante, incluso en la actualidad parece difícil encontrar una escuela que eduque principalmente para el ser. Aunque quizás es el objetivo de muchos docentes, se ven desbordados por un currículum para el saber y el hacer.

Llegados a este punto y considerando todo el recorrido realizado por la educación emocional y la educación holística, es importante situar el aprender a ser en el lugar que se merece. El de una escuela y una educación preocupadas por el bienestar, la ciudadanía, las relaciones sociales y la vida de cada una de las personas que viven en ella.

El aprender a ser nos transporta a una relación más profunda con uno mismo, a una preocupación por nuestro desarrollo en sus máximas potencialidades. Para Gallegos (2001), significa el encuentro con la esencia de uno mismo, que va más allá de pensamientos e incluso de emociones. El trabajo profundo con uno mismo es el único que nos puede acercar a la responsabilidad real sobre nuestras vidas y sobre la sociedad. Es aquel que nos puede aportar libertad y autonomía, porque sin llegar a conocernos por dentro es difícil saber dónde está para cada uno de 
nosotros, la libertad. Es un aprendizaje que no limita, que no piensa que la libertad de uno termina donde empieza la del otro, sino que cada uno es dueño de la suya sin tener que invadir en ningún momento al otro. El aprender a ser es la manera de acercar el autoconocimiento a la educación y a la escuela y desde ahí, fomentar una sociedad auténtica, autosuficiente y feliz.

\subsection{El educador y su trabajo personal}

Hasta ahora hemos visto que la escuela necesita acercarse a las emociones, crear espacios para indagar en el mundo interior del alumnado. Sin embargo, no siempre es fácil, y para nosotros una cuestión clave es la manera en la que el propio maestro realiza este trabajo consigo mismo.

Hemos visto que ya en 1972 se apuntaba a la necesidad de realizar un aprendizaje del ser, y en la actualidad todavía los adultos, entre ellos maestros y profesores, y formadores de futuros maestros, no lo estamos haciendo. Se podría decir que igual que ocurre en la teoría del cambio, si no crees en él no se puede llevar a la acción. En este caso, más que creer o no, se trata de saber cómo realizar este trabajo con nosotros mismos.

Pensamos que si en la actualidad, en las escuelas y en el resto de instituciones educativas no se realiza un trabajo emocional con el alumnado es porque los mismos formadores no se sienten preparados para realizar este trabajo interior desde su propia experiencia. Si no sabemos cómo gestionar nuestros conflictos emocionales ¿cómo podemos enseñar al alumnado a hacerlo? Como esta pregunta podemos hacernos más... ¿si no nos permitimos sentir la tristeza, cómo podemos enseñar a nuestros alumnos a gestionar esa emoción? O, ¿si nos molesta su rabia y su ira, cómo les vamos a dar las herramientas para que en lugar de reprimirla la expresen de un modo adecuado? 
Nosotros tampoco tenemos la respuesta a todas estas preguntas, pero sí que planteamos como una necesidad la formación del profesorado en aspectos emocionales. Aún más, pensamos que esta formación debe ser sobre su propia experiencia. Por esto, nos parece tan importante que cada maestro se haya trabajado interiormente, y continúe haciéndolo.

Escuchar nuestras emociones día a día es necesario para saber qué podemos hacer con ellas. Pero también nuestro pasado ejerce una influencia en nuestra manera de vivir el presente y los acontecimientos actuales. Por eso, consideramos que una herramienta para iniciar un proceso de crecimiento personal con el profesorado puede ser que trabajen su historia de vida.

En el estudio que presentamos, la historia de vida con la maestra se vuelve un instrumento indispensable para organizar los sentimientos presentes y para comprender la sensación del vacío y de plenitud. Según Burkhard (2009), el trabajo sobre la historia de vida nos acerca a una mayor comprensión del presente, pero además, los acontecimientos de nuestra vida son los que finalmente nos impulsan hacia un desarrollo del ser y de nuestras potencialidades, o hacia la decadencia. Por eso, es importante trabajar nuestra biografía y estar atentos a todas las cuestiones que hemos de alguna forma "enterrado". En su libro, la filósofa Escudero (2015) también nos habla sobre su reencuentro y su despertar espiritual a partir de su propia biografía. Generalmente, en los talleres sobre crecimiento personal, el trabajo sobre la biografía es una parte fundamental para iniciar un proceso de autoconocimiento. Pero no solo desde el ámbito del desarrollo personal y de las emociones, sino que metodológicamente también existen teorías que fundamentan el trabajo sobre la historia de vida como una fuente de enriquecimiento y de indagación sobre el perfil personal y profesional de una persona. El método biográfico - narrativo, sobre el que nos detendremos en el apartado de la metodología, nos permite precisamente dotar de sentido en investigación, el trabajo más personal y profundo sobre cuestiones humanas.

En nuestro caso, realizamos la historia de vida de una maestra. Nuestra primera pretensión a la hora de conocer su historia, estaba más relacionada con su 
faceta profesional que con la personal. Sin embargo, puesto que no se pueden separar la una de la otra, como ya han apuntado algunos autores (Bolívar, Domingo y Fernández, 2001), nos encontramos de frente con las emociones, los sentimientos y las vivencias más profundas de la maestra. En nuestro caso, la herramienta metodológica nos permitió conectar un trabajo centrado en los cambios del centro con un trabajo más personal, centrado en las emociones.

Por todo le expuesto, pensamos que para trabajar las emociones con nuestro alumnado, el profesorado tiene que trabajarlas primero consigo mismo. Bisquerra (2009), habla de dos tipos de formación, la inicial y la permanente. Respecto a la formación inicial sería necesario incluir en la formación de futuros docentes una asignatura sobre educación emocional, aunque en la actualidad estas asignaturas están más presentes en los másteres de especialización que en los grados de maestro. Por otra parte, es necesario también que la formación permanente opte por estos temas. Pero sobretodo, que los docentes sientan la necesidad de trabajarse emocionalmente por iniciativa propia, para mejorar su bienestar y contribuir al bienestar de su alumnado.

Según Bach y Darder (2002, p. 37), educar con una actitud emocionalmente sana implica adoptar una actitud vital:

- Relajada y receptiva

- Cálida y cercana

- Honesta y dignificante

- Responsable y comprometida

- Voluntariosa y flexible.

Esto implica que no solo es importante educar las emociones, sino que además tenemos que hacerlo desde las propias emociones. Por eso es necesario hacerlo desde una actitud vital que favorezca este tipo de trabajo con el alumnado. Desde una mirada y un estar en el aula relajado y receptivo. Mostrando al alumnado nuestra cercanía y proximidad. Permitirnos hacerlo también desde la honestidad hacia nosotros mismos. Es decir, ser honestos con nosotros mismos en cuanto al propio trabajo emocional que realizamos. Ser también responsables y acompañar al 
alumnado en su desarrollo personal. Por supuesto, hacerlo desde la propia voluntad y siendo flexibles con nosotros y con ellos.

El trabajo emocional con el alumnado, además de favorecer un mayor autoconocimiento de la persona y por tanto, más bienestar, es importante también para afrontar las dificultades que encuentran en otros trabajos basados en el aprender a conocer, o el aprender a hacer. Así mismo, el hecho de que el profesorado enseñe desde las emociones también favorece la creación de una mejor autoestima en el alumnado. Es decir, la actitud que tanto el alumnado como el profesorado tengan puede favorecer que por ejemplo, la resolución incorrecta de problemas de matemáticas, no mengüen afecto, valor ni consideración hacia la persona del alumno y no lastimen su autoestima, su ilusión ni su entusiasmo por la vida (Bach y Darder, 2002).

En otras palabras, pensamos que para trabajar la educación emocional no necesariamente se tienen que realizar actividades de este tipo. Como dinámicas para valorar las cualidades del alumnado, o de reconocimiento, etc. Aunque pensamos que sí que es importante realizarlas. Sin embargo, aquello que es imprescindible es situar la dimensión humana y personal por encima de la dimensión profesional.

Como dicen Extremera y Fernández- Berrocal (2004), para que las relaciones familiares, escolares y sociales sean cada vez más equilibradas, debemos llegar al alumnado y mostrarles a través de nuestro ejemplo, una manera adecuada de gestionar nuestras emociones y de relacionarnos los unos con los otros.

Se trata de ir introduciendo las competencias emocionales en la educación, pero de la mano de un profesorado emocionalmente competente y concienciado de la importancia de este trabajo con el alumnado y para la sociedad:

En este momento de fuerte debate sobre los cambios educativos, sería una buena ocasión para reflexionar sobre la inclusión de las habilidades emocionales de forma explícita en el sistema escolar. Porque el profesor ideal para este nuevo siglo tendrá que ser capaz de enseñar la aritmética del corazón y la gramática de las relaciones sociales. Si la escuela y la administración asumen este reto, dotando de la formación 
pertinente a los educadores, hará que la convivencia en este milenio sea más fácil para todos y que nuestro corazón no sufra más de lo necesario (Extremera y Fernández-Berrocal, 2004, p.6). 


\section{EstUdIO}

De hecho, sentí una sensación de profunda libertad, porque ahora podía dejar que las cosas ocurrieran en lugar de hacer que ocurrieran (Renard, 2009, p. 277).

Este capítulo está organizado en siete apartados, a partir de los cuales entenderemos mejor cómo se ha realizado esta investigación.

El primer apartado que encontramos es la historia del centro y el contexto en el que se realiza la investigación. En esta parte explicaremos aspectos contextuales que nos ayuden a definir el lugar en el que se realiza el trabajo de campo. En el segundo apartado, una vez ya conozcamos el contexto, formularemos el problema de investigación. En el tercer apartado encontraremos las preguntas de investigación realizadas a partir del problema, así como los objetivos que perseguimos con este estudio y que tratan de responder a las preguntas de investigación.

El cuarto apartado es la metodología utilizada a la hora de realizar el trabajo. En este caso se trata de un trabajo etnográfico con una parte en la que se utilizan técnicas propias del método biográfico-narrativo. 
A partir del quinto apartado explicaremos el diseño de la investigación. En esta parte hablaremos sobre los participantes; las técnicas de obtención y producción de la información empleadas; las técnicas que se han utilizado para registrar la información; la temporalización del trabajo de campo y el modo en el que se ha realizado el análisis de los datos. Otro de los apartados, es la posición de la investigadora en este estudio y finalmente, las cuestiones éticas que se han tenido en cuenta.

Con toda esta información trataremos de explicar minuciosamente en qué ha consistido el trabajo para llegar al capítulo siguiente, sobre los resultados, con una visión clara del estudio.

\subsection{Historia del centro y contexto donde se desarrolla la investigación}

A la hora de realizar este apartado, nos basamos en las características de la escuela durante el inicio del estudio. Es decir, su situación y contexto en septiembre del año 2011. Se trata de una escuela pública de educación infantil y primaria situada en una ciudad costera de la provincia de Castellón. Esta ciudad ha ido creciendo demográficamente a lo largo de los años, hasta alcanzar una población de 34.700 habitantes en el año 2013. Casi 10.000 habitantes más que en el año 2001, en el que contaba con 26.700 habitantes. Esta, ha sido la causa de los cambios acontecidos en el centro en relación a las familias y el alumnado que ha asistido a la escuela en los últimos 10 años.

La mayoría de la inmigración que acoge la ciudad se sitúa en la periferia, siendo el barrio donde está situada la escuela uno de los que cuenta con el mayor índice de inmigración. Tradicionalmente, el barrio ha sido conocido como una zona marginal de la ciudad en el que han vivido siempre personas inmigrantes o con 
pocos recursos económicos. Hacia la década de los años 60 los vecinos eran mayoritariamente andaluces, que llegaban a la ciudad en busca de trabajo. En la actualidad, aún siguen viviendo estas familias, pero mayoritariamente residen familias árabes que también buscan un futuro mejor para ellas y sus hijos. En este sentido, la historia del centro se ha visto afectada a lo largo de los últimos años por numerosos cambios respecto al alumnado de la escuela. Siendo en la actualidad un 90\% el alumnado árabe y el resto familias de origen extranjero o de la localidad, pero en todos los casos con un nivel socio-económico bajo.

Además, la situación de la escuela y su distrito resulta estratégica para la ciudad, en el sentido de que en él se concentran los espacios destinados a las personas dependientes en el barrio, mientras que no se dispone de otros más lúdicos o culturales en esta zona. Por eso, se han construido edificios subvencionados donde residen personas principalmente del norte de África, y otras personas procedentes del barrio con un nivel socioeconómico por debajo de la media de la ciudad. Podemos encontrar Oficinas de Servicios Sociales y Asociaciones para personas Dependientes, enfrente de la escuela; así como un instituto cercano al que asiste el alumnado del centro. Otros espacios cercanos son bares, cafeterías y una carnicería Halal. Por otra parte, no hay ninguna asociación cultural, teatro, zona de comercio o biblioteca cercana, sino que están situadas en el centro de la ciudad.

Año tras año el profesorado se ve desbordado por la diversidad, principalmente por las dificultades que muestran no solo las familias árabes, sino también el propio alumnado en relación a la adquisición de la lengua. Además, el hecho de que la mayoría del alumnado hable el mismo idioma y que este sea diferente al del profesorado también afecta a que el proceso de adquisición de la lengua sea más lento. En el caso de las familias, los padres suelen ser quienes trabajan y tienen un mayor dominio del idioma. Sin embargo, como están trabajando tampoco suelen acercarse a la escuela para hablar con el profesorado, lo hacen las madres pero no entienden casi nada del castellano o del valenciano. Ellas tienen todos los recursos que necesitan sin salir del barrio. Aunque encuentran más 
dificultad por ejemplo, si tienen que asistir al médico o, si tienen que hablar con el profesorado.

Por otro lado, esta limitación afecta también al rendimiento del alumnado. Como explica el profesorado, el alumnado que inicia la etapa de infantil en la escuela no llega a una perfecta adquisición del valenciano y el español hasta el segundo ciclo de primaria. Según el profesorado, su falta de comprensión sobre elementos lingüísticos afecta también a su comprensión sobre los contenidos del currículum. Según el equipo directivo, aproximadamente un $30 \%$ del alumnado tiene un rendimiento apto y un $70 \%$ un bajo rendimiento académico hasta llegar al segundo ciclo, en el que ya podemos diferenciar entre un rendimiento alto, bajo y medio.

Otro de los principales problemas en la escuela es la relación entre el profesorado y las familias. Como dice el profesorado, con las familias inmigrantes apenas existe comunicación y esto se atribuye al desconocimiento que tienen de la lengua. En el caso de las familias españolas, generalmente existe una mala relación, que el profesorado atribuye a que las familias no confían en ellos y en muchas ocasiones aprovechan cualquier incidencia para denunciar a la escuela. Por ejemplo, en el caso de una canasta de baloncesto que estaba en mal estado y un niño se lastimó, la madre denunció a la escuela. Este hecho es, para el profesorado, bastante habitual en algunas familias que, si no siempre llegan a denunciarles les amenazan con hacerlo.

Delante de esta perspectiva, una parte del profesorado trata de implementar mejoras en el centro o desarrollar programas que favorezcan la educación del alumnado. Por eso, han realizado distintos proyectos, de los que destacamos el MUS-E, de la Fundación Yehudi Menuhin de Madrid, como uno de los que contribuyó a la atención a la diversidad, aunque no se logró la mejora en la relación con las familias.

Finalmente en el año 2004/2005, la escuela se convierte en un CAES (Centro Educativo de Acción Singular). Aunque por una parte, había cierto rechazo entre el profesorado por la imagen negativa que tenían de estos centros -puesto que suelen 
verse como guetos con mayores problemas de convivencia y con un bajo rendimiento del alumnado- se decidieron a dar el paso, principalmente, por la compensación económica que como centro recibirían y que podría favorecer principalmente al alumnado. Es decir, para disponer de ayudas en libros de texto, etc. y así no depender de las familias a la hora de aportar estos materiales.

Aunque todo el profesorado decidió optar por esta opción, les preocupaba la imagen que se podía tener de la escuela. Sobre todo la imagen que se tuviera en el pueblo. En ocasiones habían escuchado habladurías, en las que se afirmaba que algunos estudiantes del centro asistían con navajas a la escuela. Esto no era verdad, pero las familias del pueblo evitaban que sus hijos asistieran a este colegio e incluso preferían que no pasearan por esa zona.

En general, todavía hay un notable prejuicio hacia la escuela y el barrio, ambos son vistos como un gueto. Por otra parte, la situación de la escuela es de desventaja respecto a otros centros de la localidad. La escuela no está adaptada a las necesidades de un centro de infantil y de primaria y el profesorado no goza de los mismos servicios que hay en otros colegios de la localidad. Por ejemplo, no hay un edificio de infantil y el alumnado de cuatro y cinco años tienen que subir todos los días las escaleras para acceder a su clase o para salir al patio. Por otra parte, el edificio no cuenta con un gimnasio ni tampoco con una zona de estacionamiento para el profesorado, a diferencia de otros centros educativos de la ciudad.

Además de estas características, la escuela tiene un total de 215 alumnos y 28 profesores. Entre ellos, hay 3 hombres y 25 mujeres entre educación infantil y primaria. Hay también una maestra especialista en música, una maestra y un maestro de educación física y un maestro especialista en inglés a tiempo completo y otro a media jornada. Además, en la escuela se cuenta con una maestra de PT (pedagogía terapéutica) y una maestra de AL (Audición y lenguaje).

El centro tiene también un aula de Educación Compensatoria a la que asiste el alumnado recién llegado en la etapa de primaria y aquellos que, aunque llevan más tiempo en la escuela pueden tener alguna dificultad en la adquisición de la lengua. En casos excepcionales, también asistían alumnos de Educación Infantil de 5 años, 
si tenían serias dificultades para seguir las clases. Aunque el aula de compensatoria se mantiene, anteriormente -cuando el porcentaje de inmigración era mucho más bajo-, tenía más sentido para el profesorado. Pensaban que pasar por el aula de compensatoria era una adaptación básica a realizar para que el alumnado fuera incorporándose a las aulas a medida que comprendiera mejor la lengua. En la actualidad, puesto que en todas las clases de infantil el alumnado inmigrante es el 90\% de la clase, no tiene demasiado sentido realizar esta adaptación fuera del aula, puesto que es prácticamente todo el alumnado el que no entiende la lengua. Actualmente, al aula de educación compensatoria asiste el alumnado con dificultades en la lengua en la etapa de primaria. Además de esta aula, en el centro encontramos también un aula para el trabajo con la maestra de PT y de AL, aunque normalmente suele estar vacía porque estas maestras intentan ir a las clases ordinarias para ayudar a todo el alumnado.

Para finalizar, cabe destacar que la plantilla del profesorado del centro es muy cambiante. Existe un bajo porcentaje del profesorado que lleva más de diez años en la escuela. Podemos decir que la mitad de la plantilla está compuesta por este profesorado con plaza definitiva, del cual la mayoría son maestros y maestras de la localidad y la otra mitad de la plantilla suele ser profesorado itinerante o docentes con plaza definitiva pero con expectativas de cambiar de centro para acercarse a su lugar de procedencia. Según los docentes, la principal razón por la que el profesorado cambia tanto es que al ser un CAES, algunas personas lo solicitan para poder conseguir más puntuación y poder acercarse antes a su casa. Por otra parte, la percepción del profesorado es que para otros maestros de la localidad no es un destino deseable. En definitiva, el cambio en la plantilla del profesorado del centro, supone una dificultad a la hora de emprender proyectos de innovación educativa; de hacer una planificación a largo plazo o de establecer compromisos, porque como hemos visto, las creencias del profesorado son un aspecto fundamental, y en este centro cada dos años cambia la mitad de la plantilla. 
Con toda esta perspectiva, el profesorado del centro se pone en contacto con el equipo de investigación MEICRI (Mejora Educativa y Ciudadanía Crítica) ${ }^{1}$ del que formamos parte, para pedir asesoramiento y formación con la finalidad de conseguir mejorar el rendimiento del alumnado, la relación con las familias y la imagen que se tiene del centro en el resto de la localidad. Después de una primera sesión conjunta (el 29 de junio del 2011) entre docentes y el equipo de investigación, la propuesta de asesoramiento que desde el equipo MEICRI realizamos es la transformación de la escuela hacia un modelo de todas y todos, el modelo intercultural e inclusivo. Con esta transformación se pretende acceder también a la perspectiva que tienen de la escuela otros agentes, ya que en este momento conocemos únicamente el posicionamiento del profesorado y para conseguir un enfoque intercultural e inclusivo necesitamos de un trabajo colaborativo entre las personas de los distintos colectivos.

Por eso, antes de tomar la decisión sobre si desean transformar la escuela o no hacia dicha perspectiva, se les propone realizar unas sesiones de formación dirigidas al profesorado y a las familias principalmente. En estas sesiones se sientan las bases sobre la educación intercultural e inclusiva y se les facilitan ejemplos sobre experiencias realizadas en otras escuelas en las que se realizan prácticas más interculturales e inclusivas, tanto a nivel del centro, como del aula.

Las sesiones de formación se realizaron durante las dos primeras semanas de septiembre del curso escolar 2011 - 2012. Se realizaron un total de seis sesiones a las que asistieron, principalmente, el profesorado y algunas familias. También asistió una parte del alumnado, aunque las sesiones no estaban bien planteadas para captar su atención y se solían aburrir al no entender las dinámicas realizadas ni la finalidad de las mismas.

La temática de las sesiones trataba sobre el modelo de educación intercultural inclusivo, se intentó hacer reflexionar a todos los asistentes acerca de principios como la igualdad de oportunidades; la atención a la diversidad; la participación socio-comunitaria; la justicia social; etc. Estas sesiones fueron el inicio de la

\footnotetext{
${ }^{1}$ http://meicri.uji.es/
} 
transformación del centro, y a lo largo de las mismas, aunque solo duraron dos semanas, pudimos detectar la situación que existía entre las familias y entrever un cambio en las actitudes de algunas de ellas.

Generalmente, la relación entre las familias era prácticamente nula. Sobre todo entre las familias de origen distinto; existía una separación entre las españolas y las familias inmigrantes. Las españolas se referían a las inmigrantes como familias separadas del colectivo. Utilizando el pronombre "ellos", para referirse a estas y el "nosotros" al referirse a las españolas. Cabe destacar que tanto en el caso de las familias españolas como en el de las familias inmigrantes, existían discrepancias. Sin embargo, a la hora de manifestar sus preocupaciones y los conflictos que tenían en relación con la escuela y el profesorado, era cuando se sentían reconocidas en otras familias de su misma procedencia y separadas de aquellas de distinto lugar de origen. Como hemos comentado anteriormente, las familias inmigrantes sentían una gran dificultad para comunicarse con el profesorado, puesto que no disponían de intérpretes que les ayudaran a entenderse, a excepción de algunos casos en los que el alumnado realizaba el papel de mediador lingüístico. No obstante, esta tampoco era la mejor solución para el profesorado y las familias, puesto que preferían que el alumnado no fuera conocedor de alguna información.

Para las familias españolas, los conflictos estaban más relacionados con la convivencia escolar del centro. En muchas ocasiones las quejas del profesorado eran que las familias no se implicaban en la educación de sus hijos, mientras que la visión de las familias era que el profesorado no se preocupaba por sus hijos y percibían la escuela como un lugar ajeno a ellos.

A lo largo de la formación algunas de estas creencias cambiaron, y así se mostraba en el discurso de algunas madres y padres. Como por ejemplo, en el caso de Pepe. Este padre, al iniciar las sesiones mantenía una actitud de rechazo hacia las familias inmigrantes, que se detectaba principalmente en su discurso - por ejemplo, en la diferenciación entre el "ellos" y el "nosotros"-, y que después de las seis sesiones cambió. En general, tenía una actitud más dialogante con las familias 
inmigrantes y no repetía la separación -el "ellos"- entre las familias de una procedencia o de otra.

Después de estas sesiones de formación, el profesorado y las familias decidieron emprender un proceso de cambio y reflexión sobre su escuela, con el acompañamiento de nuestro grupo de investigación. En este marco es donde se realiza el estudio para la tesis doctoral.

\subsection{Problema de investigación}

Nuestra pretensión al inicio del estudio, era poder indagar y entender mejor los procesos de cambio en los centros educativos hacia la escuela intercultural inclusiva. Por eso, al aparecer la oportunidad de intervención formativa en una escuela con ganas de emprender esta transformación, decidimos acompañarles en su proceso de cambio.

En ese momento, queríamos conocer cuáles eran los elementos que facilitan estas transformaciones en un centro escolar. Elementos como el cambio en las prácticas de aula, la colaboración entre el profesorado, la relación con las familias, etc. eran algunas de las categorías teóricas que teníamos en mente.

Para poder responder a nuestro problema de investigación entramos en el centro y empezamos a analizar las prácticas que allí se realizaban. Pero debido al cambio de la plantilla docente en la entrada del nuevo curso escolar, acotamos nuestra mirada al trabajo de una maestra altamente implicada en las transformaciones del centro. Nuestro objetivo seguía siendo conocer el proceso del cambio escolar. Sin embargo, a partir de la historia de vida que realizamos con esta maestra para conocer mejor su posicionamiento como docente, empezamos a interesarnos por el trabajo emocional tanto con el alumnado como con el profesorado. Por eso, nos planteamos la necesidad de integrar la dimensión 
personal y emocional como una parte más en la construcción de la escuela intercultural e inclusiva.

Por tanto, el problema de investigación se sitúa en una escuela en proceso de transformación hacia el modelo intercultural e inclusivo y trata de comprender cómo es ese proceso y cómo se puede integrar la dimensión personal y emocional en dicho modelo, para favorecer una educación basada en el desarrollo integral del alumnado.

\subsection{Preguntas y objetivos de la investigación}

El problema de investigación nos sitúa en el proceso del cambio desde sus dimensiones pedagógica y personal. Las preguntas de investigación que nos planteamos al respecto son:

¿Cómo es el proceso de cambio de la escuela hacia el modelo intercultural inclusivo?

¿Cómo se puede integrar la dimensión personal y emocional en la escuela intercultural inclusiva?

Los objetivos que queremos abordar con la investigación para responder a la primera pregunta y de este modo, conocer cómo es el proceso de cambio hacia el modelo intercultural inclusivo son los siguientes:

1. Conocer las condiciones que existen para que se realice el cambio en el centro hacia el modelo intercultural inclusivo.

2. Conocer los obstáculos que se encuentran a lo largo del proceso.

3. Conocer las transformaciones que se realizan en el centro y en las aulas, en concreto en el aula de Estefanía. 
En el caso de la segunda pregunta de investigación, nos acercamos a un enfoque más personal sobre el cambio, sobre el quehacer docente y la construcción de una educación intercultural e inclusiva que contribuya al desarrollo integral del alumnado. Para ello nos centraremos en una maestra: en su estilo docente y en su historia de vida como una herramienta de autoconocimiento, para contribuir a ese tipo de escuela orientada al desarrollo del ser. Los objetivos en este caso son:

4. Analizar el estilo docente de Estefanía para conocer cómo trabaja la dimensión personal de su alumnado en el aula.

5. Trabajar la historia de vida de Estefanía como una herramienta de autoconocimiento para poder aportar una educación integral al alumnado.

Finalmente, cabe destacar que nos planteamos un objetivo transversal a lo largo de nuestro trabajo en la institución, que es:

6. Fomentar la reflexión y el cambio en la escuela.

Este objetivo pensamos que podremos conseguirlo a partir de reuniones y sesiones compartidas con la comunidad educativa. Especialmente con el profesorado, que en este estudio se sitúa como el principal agente de cambio.

\subsection{Metodología}

La metodología utilizada en el estudio se inscribe en el marco de la investigación cualitativa, en la que generalmente, la aproximación a la realidad se lleva a cabo desde dentro del campo, junto con las personas implicadas en esa realidad. La metodología cualitativa está orientada a la comprensión profunda de una situación concreta. Como dice Sandín (2003) la metodología cualitativa se basa en la comprensión en profundidad de fenómenos educativos y sociales, la 
transformación de prácticas y escenarios socioeducativos, la toma de decisiones y el descubrimiento y desarrollo de un cuerpo organizado de conocimiento. No obstante, podemos distinguir dos aportaciones en este tipo de metodología, aquella dedicada a la comprensión y producción de información y que por tanto tiene el objetivo de describir e informar y, por otra parte, aquella dedicada a la acción y el cambio, cuyo principal objetivo es la transformación.

Según Dorio, Sabariego y Massot (2009), la investigación cualitativa orientada a la comprensión está fundamentada en la fenomenología y señala al sujeto como productor de conocimiento que se construye a partir de aquello que subjetivamente percibe. Algunas de las principales dimensiones que se estudian desde esta perspectiva son: los procesos sociales, la relación entre sociedad/persona; los patrones culturales de un grupo; los patrones de interacción social entre miembros de un grupo cultural, etc. (Bartolomé, 1992).

Por su parte, la investigación cualitativa dirigida al cambio, se centra en la transformación social y la emancipación humana. Esta perspectiva se fundamenta en la teoría crítica, cuyos precursores en el ámbito de la educación fueron Carr y Kemmis (1988). En nuestro estudio, además de describir la realidad estudiada, también se pretenden generar cambios y contribuir a la transformación de una escuela hacia un modelo determinado para dar respuesta a la diversidad. Por eso, lo enmarcamos en esta perspectiva transformadora.

Desde esta posición, la teoría se genera a partir del análisis autocrítico de la práctica, localizada en un contexto social y cultural, y desarrollada por sus propios protagonistas. Se construye mediante una forma de investigación impregnada por los valores sociales emergentes en el contexto y consensuada por sus propios participantes. Mediante el ejercicio autocrítico, “en” y "desde” la práctica, éstos toman conciencia de las posibilidades del cambio y mejora de su práctica (Dorio, Sabariego y Massot, 2009, p. 283)

Desde cada uno de estos ámbitos, ya sea el descriptivo o el orientado al cambio, se identifican distintos métodos de investigación. Como por ejemplo, el estudio de casos más relacionado con la investigación orientada a la comprensión; 
o la investigación-acción, en el caso de la orientada al cambio. Sin embargo, aparecen otros métodos como el etnográfico o el biográfico-narrativo, que podrían situarse en las dos perspectivas, en función del problema y los objetivos de la propia investigación.

En nuestro estudio, realizamos una aproximación etnográfica para analizar el caso de una escuela y posteriormente, el caso de una maestra. Sobre la escuela, realizamos esta aproximación a partir de técnicas y estrategias típicas de la etnografía, como son las entrevistas, los grupos de discusión, y principalmente la observación participante. Perseguimos también el mismo objetivo que se trata de abordar en estudios etnográficos, conocer la cultura del lugar estudiado. En nuestro caso, tratamos de conocer el proceso de cambio en el que está inmersa la escuela.

En cuanto a la maestra, concretamos el caso en su historia de vida, las prácticas de aula, y todas aquellas acciones que se desarrollan en el centro en las que está implicada. Por todo esto, argumentamos que para realizar el estudio nos basamos en distintos enfoques. Es decir, realizamos una aproximación etnográfica para conocer el proceso de cambio de la escuela y nos basamos en herramientas del método biográfico-narrativo, para poder trabajar la historia de vida de la maestra.

\section{ETNOGRAFÍA}

Basándonos en Woods (1987) y en Velasco y Díaz de Rada (1997), empezaremos por definir la etnografía como un modo marcadamente peculiar de investigación social y principalmente descriptivo. Con esto, los autores se refieren a que la etnografía es un método particular de investigación. Aunque cuenta con una serie de técnicas y de estrategias de recogida y de producción de datos, el uso de estas técnicas no viene a definir que la investigación sea o no etnográfica. Este hecho viene determinado principalmente por el objeto de estudio y también por el papel que adopta el investigador. En la etnografía se trata de conocer y comprender la vida y cultura de un contexto en particular; en nuestro caso, como primer paso para su transformación y mejora. 
El rol del investigador también es importante, puesto que para conocer la cultura de un contexto desconocido para el investigador, este tiene que adentrarse y relacionarse con sus miembros para poder obtener una mirada más real del objeto de estudio. La relación del etnógrafo con las personas que forman parte de la investigación es un aspecto fundamental, ya que la confianza que los informantes depositen en el investigador va a resultar un aspecto clave. En este sentido, la relación no se puede limitar a la del etnógrafo desde su rol investigador, ni por otra parte, en el caso de investigar una institución, a la de sus informantes en el rol más relacionado con su papel en la institución. Sino que en ambos casos, la relación que se establece va más allá de roles. Es una relación de persona a persona.

Aunque en nuestro caso, no se trata de un estudio etnográfico como el que se pueda hacer desde la antropología, ya que como hemos mencionado, realizamos una aproximación a la etnografía escolar. Cuando la etnografía se utiliza para estudiar la cultura educativa, también se denomina etnografía educativa, y su objetivo es aportar datos descriptivos de los medios o contextos, de las actividades y las creencias de los participantes en el contexto educativo (Del Rincón, 1997).

La etnografía escolar se centra en explorar la realidad cotidiana de la escuela, aportando datos significativos de la forma más descriptiva posible para poder comprender e intervenir del modo más adecuado en la realidad educativa (Goetz y Le Compte, 1988). Algunos de los usos pedagógicos que se le ha dado a la etnografía son estudios basados en los efectos de las estructuras organizativas y los cambios que se producen en ellas, sobre sus individuos y grupos; las culturas de grupos particulares así como las subculturas de maestros; aquello que se "hace" en las escuelas; las actitudes, opiniones y creencias de las personas; cómo influyen algunas situaciones determinadas en las opiniones y comportamientos, etc. (Dorio, Sabariego y Massot, 2009).

La etnografía supone también un constante tránsito entre la cultura del campo y la del mundo académico, que está presente desde el principio de la investigación. Desde el inicio, el etnógrafo realiza un "balanceo" entre su mesa de trabajo, en la que estudiará documentos extraídos del campo así como del proyecto de la 
investigación, y el espacio del campo del que extrae los datos y convive con los informantes (Velasco y Díaz de Rada, 1997).

Algunos términos clave de la etnografía para Velasco y Díaz de Rada (1997), son: el extrañamiento, este se refiere a la curiosidad e ingenuidad del etnógrafo durante su estancia en el campo. La intersubjetividad, puesto que el objeto de estudio en la etnografía suelen ser discursos y acciones sociales realizadas por personas, la etnografía redefine la objetividad por intersubjetividad. La descripción densa, refiriéndose a la pretensión propia de la etnografía de reflejar la trama de la cultura, tal y como aparecen en una forma de vida. La localización, puesto que la descripción densa implica también un proceso de localización de los datos en situaciones concretas, así como un proceso de encarnación. Este último se refiere a que los datos aparecen encarnados en personajes. La triangulación de la información analizada, a partir de la contrastación y su localización en distintas fuentes. La presentación de datos multirreferenciales, que se refieren al mismo tiempo a distintos factores. La ironía y la intertextualidad, se refiere a la intención que se busca en etnografía de que unos datos se dirijan hacia otros, serían los puentes de sentido que se establecen en relación a diferentes parcelas de la realidad.

Para finalizar, destacamos algunas características que enumera Rockwell (2008) en relación a la etnografía. En primer lugar, se requiere de una estancia relativamente prolongada en una localidad o en un grupo, que a su vez, sea relativamente pequeño. De manera que el investigador pueda construir relaciones de confianza con los habitantes. En segundo lugar, el etnógrafo intenta aproximarse a los discursos y lenguajes locales, para poder comprender el sentido que tienen para los nativos los distintos acontecimientos y para captar la esencia de la cultura. En tercer lugar, la autora nos alerta de que la etnografía no termina con el trabajo de campo, sino con la producción de textos. Éstos, deben conservar la realidad observada y analizada. El sentido último de la etnografía es producir un conocimiento nuevo y una mayor comprensión de procesos que han sido estudiados de otro modo. Para lograrlo, el etnógrafo debe dejar el campo 
transformado en otro ser humano. "Si no hay una transformación profunda de sus marcos de interpretación y de comprensión de la localidad en la que realizó el estudio, el arduo trabajo de campo y de análisis cualitativo no vale la pena" (Rockwell, 2008, p. 91). En nuestro estudio, la inmersión en el campo nos acercó a un nuevo entendimiento de la escuela y a una comprensión más humana, en relación a la que se tenía antes de acceder al campo. Allí, fue donde cobraron importancia las emociones y la dimensión más personal del cambio, ya que lo estudiáramos o no, no podíamos negar que el cambio estaba motivado por personas, por sus valores y sus creencias, sus relaciones, etc. Del mismo modo que el cambio estaba teniendo un efecto en la vida personal de aquellos que convivían en la escuela.

En este sentido, la propia etnografía nos trasladó a otros escenarios, como fue el caso de la maestra. Desde esa perspectiva se hacía necesaria la utilización de otros métodos que nos acercaran más a la persona. Optamos por la comprensión de la vida de Estefanía, una de las maestras más comprometidas con el cambio, que al iniciar el proceso de transformación quería quedarse al margen por su situación personal, pero que poco a poco se fue implicando en el proceso.

\section{MÉTODO BIOGRÁFICO-NARRATIVO}

En nuestro estudio se introduce el método biográfico narrativo para poder acceder a la biografía de la maestra, con la intención de conocer no solo su rol como docente, o su práctica de aula; sino su historia de vida enfocada también a sus vivencias personales (Pujadas, 2000). La opción por la narrativa nos lleva a un marco más emotivo que engloba infinidad de experiencias de vida.

Si nos remitimos a la literatura, la narrativa biográfica se fue introduciendo en el campo de la educación en estudios que indagaban sobre la dimensión personal como un factor crucial en los modos en como los profesores construyen y desarrollan su trabajo. A finales de los setenta, con el movimiento llamado pensamiento del profesor y más adelante, sobre el conocimiento práctico del profesor, se indagó sobre las teorías y creencias del profesorado (Schön, 1983; 
Pérez Gómez, 1987; Marcelo, 1987; Clark y Peterson, 1990), resaltándose la dimensión biográfica y narrativa del docente.

En nuestro caso, el uso de la narrativa también está relacionado con el propio contexto en el que esta se inscribe. Por una parte, para situar la historia en unos marcos sociales y temporales concretos, y por otra parte, para comprender las actuaciones del presente en relación con la historia de vida. Es decir, "entender ampliamente las experiencias del pasado puede posibilitar comprender qué nicho pedagógico ha arbitrado una persona entre todo este cúmulo de influencias, intenciones y sentimientos con respecto a la enseñanza" (Bolívar, Domingo y Fernández, 2001, p. 85-86). Pues la parte personal que en ocasiones queda separada de lo profesional nos da el guión, desde donde podemos entender la manera de actuar del profesorado.

Algunos de los elementos a tener en cuenta para conocer con mayor profundidad la historia de vida individual, son los que nos muestran Bolívar, Domingo y Fernández (2001): comprender a la "persona", otorgando la debida dedicación a conocer la trayectoria de vida; los sentimientos y vivencias a lo largo de su vida y los proyectos futuros; y comprender el "entorno".

A partir de la investigación biográfico narrativa podemos conocer desde dentro (emic), lo que los profesores piensan, sienten o hacen (el significado subjetivo que otorgan a su trabajo), como base para cualquier posible cambio. Ignorar la dimensión emotiva del cambio educativo -dice Hargreaves- es querer introducirlo por la puerta falsa (Bolívar, Domingo y Fernández, 2001, p. 58).

Bajo la perspectiva del método biográfico podemos distinguir entre los relatos biográficos y las historias de vida. Según Pujadas (2000), por relato biográfico (life story) entendemos el registro literal de las sesiones de entrevista que realiza el investigador con el informante. Por historia de vida (life history), se entiende el texto final, una vez editado por el investigador y aprobado por el informante. En nuestro caso, a partir de las entrevistas accedimos al relato de su vida, que posteriormente se convirtió en la narrativa de una historia de vida. 
Además, existen varias modalidades de historias de vida. Aunque nosotros hemos realizado un relato único destacamos también la modalidad de relatos múltiples, en los que podemos distinguir entre relatos cruzados y paralelos. En el caso de las historias de vida de relato único, se consideran menos frecuentes, ya que es más probable poder elaborar la teoría a partir de varios relatos que de uno solo.

Finalmente, destacaremos algunas de las características para poder llegar a realizar historias de vida, basándonos en Cortés y Nuñez (2012):

Se requiere de compromiso, puesto que este tipo de trabajos implican el estar dispuesto a repensar nuestra propia vida, analizarla y exponernos. Como dicen los autores, implica la "no renuncia a ponerme en juego", desvelar quiénes somos en frente de con quién estamos trabajando para entrar en una dimensión interpretativa por ambas partes. Este hecho implica también un principio moral de ética, responsabilidad y honestidad social y epistemológica, principalmente hacia aquellas personas que comparten con nosotros su historia personal.

Por otra parte, se trata de un trabajo colaborativo, de diálogo entre el investigador y el informante, en el que aparecen relaciones que tratan de establecerse desde la horizontalidad y que en algunos casos tratarán de fomentar la transformación y en otros, tan solo con el repensar de la historia de vida, ya se estará contribuyendo a ello.

Para concluir, destacamos las palabras de Moriña, Perea y Molina (2013), que recalcan la importancia de las historias de vida, precisamente otorgando valor a la subjetividad. A partir de esta metodología se permite que las personas hablen de ellas mismas sin silenciar su subjetividad, desde su propia voz. 


\subsection{Diseño de la investigación}

Este trabajo es un estudio de caso, que se enmarca dentro de una perspectiva cualitativa con un diseño de investigación emergente. Se trata de un estudio de caso, porque como hemos comentado anteriormente, estudiamos el caso de un centro y posteriormente, el de una maestra. Cuando definimos un estudio desde esta perspectiva, la pretensión no es alcanzar resultados generalizables a otros casos, sino que, como señala Stake (2007), nos interesa la particularidad y la complejidad del mismo, ya que por ese motivo ha sido seleccionado. En concreto, seleccionamos esta escuela por el proceso de transformación que se iba a emprender en la misma, y tras unos meses de trabajo en el centro, seleccionamos a una maestra por su situación personal y su compromiso con la transformación.

También decimos que el diseño es emergente, ya que los datos van definiendo el proceso que sigue la propia investigación. Como destaca Flick (2007), la elección correcta de métodos y teorías apropiados, el análisis de perspectivas diferentes, las reflexiones de los investigadores sobre su investigación como parte del proceso de producción de conocimiento, y la variedad de enfoques y métodos forman parte de lo que significa una investigación cualitativa.

A continuación diferenciaremos distintas fases en relación al trabajo realizado en el campo. Una primera fase exploratoria sería la que conlleva desde la primera reunión entre el claustro y algunos miembros del equipo MEICRI hasta la decisión que toma la comunidad educativa -a partir de la asamblea-, de querer realizar una transformación orientada hacia la escuela intercultural inclusiva. Es decir, desde junio hasta diciembre del 2011. A partir de enero, después de que el centro explicite su deseo de transformar sus prácticas y su filosofía hacia un modelo intercultural inclusivo, iniciamos nuestra entrada en el centro para definir el problema de investigación y realizar el trabajo de campo de la tesis. Este período lo dividimos en dos fases, una primera que comprendería desde enero hasta julio del 2012 y la segunda, desde septiembre a diciembre de ese mismo año. Esta última, la diferenciamos de la fase anterior porque debido a los cambios en el 
equipo del profesorado necesitamos ajustar la investigación, que acabó acotándose al trabajo focalizado desde la mirada de una maestra. En esta fase, además de realizar una aproximación etnográfica se utilizaron estrategias propias de la metodología biográfico-narrativa.

A continuación aportamos más datos sobre cada una de estas etapas de la investigación:

\section{FASE 0. EXPLORATORIA}

Nombramos fase exploratoria a aquella en la que se lleva a cabo la primera aproximación con la escuela. Durante esta fase se realiza el primer contacto entre el equipo de investigación y los miembros del profesorado, para conocer la perspectiva de este colectivo y sus necesidades. Después de una primera reunión, y tras la propuesta del equipo de investigación de realizar una transformación en la escuela hacia un modelo más intercultural e inclusivo, se realizan sesiones de formación y sensibilización los días 6, 7, 13 y 14 de septiembre del 2011, en horario de 9.00 a $13.00 \mathrm{~h}$ y de 15.00 a $17.00 \mathrm{~h}$. Tras las sesiones de formación, el profesorado y las familias manifiestaron su intención de emprender un proceso de cambio educativo en la dirección planteada durante la formación. Unos meses después, el día 2 de diciembre del 2011, el profesorado junto con el alumnado y las familias, prepararon una asamblea para dar a conocer a todas las familias, vecinos y asociaciones del barrio, el proyecto de transformación hacia la construcción de una escuela inclusiva, que estaban dispuestos a emprender. En esta asamblea se pidió la implicación de las familias en el proyecto y de todas las instituciones que desearan hacerlo. Además, se dejó un buzón en la entrada del colegio donde cada persona podría depositar su sueño, enfocado a la escuela que le gustaría tener.

Después de esta asamblea, en la que se explicitó la intención de realizar un proceso de cambio en el centro de la mano del profesorado, el alumnado y las

familias -principalmente-, decidimos iniciar el trabajo de campo para nuestro estudio de tesis doctoral, con la intención de conocer el proceso de cambio de la escuela y las transformaciones realizadas. 


\section{FASE 1. ETNOGRAFÍA EN LA ESCUELA.}

A partir de enero del 2012 se desarrolló la primera fase de análisis del proceso de cambio en la escuela, concretada en la observación participante; grupos de discusión y entrevistas.

Durante este período tratamos de definir el problema de la investigación junto con el profesorado, al ser estos quienes empezaron a liderar el cambio. Tras varias reuniones, el profesorado concluyó que aunque se estaban realizando algunas acciones en el centro, los cambios en las aulas no tenían el impacto que ellos esperaban. Se habían empezado a realizar acciones en el primer ciclo pero el resto de docentes se sentía sin herramientas para poder implementar prácticas más interculturales e inclusivas -acordes con el proyecto de transformación-, en sus clases. Llegados a abril de ese mismo curso, centramos el problema de investigación en tratar de fomentar cambios en las aulas. En concreto, el profesorado manifestó la necesidad de formarse en nuevas estrategias que posibilitaran la realización de prácticas más interculturales e inclusivas. A partir de esa demanda, entre todos los asistentes a las reuniones, diseñamos un seminario de formación para el profesorado. Este seminario al que asistió todo el profesorado del centro, se impartió por las propias maestras que durante ese mismo curso, o incluso en cursos anteriores, habían implementado prácticas definidas por la literatura como prácticas interculturales e inclusivas. Se realizaron tres sesiones de formación sobre proyectos de trabajo, grupos interactivos y tertulias literarias dialógicas. Además, en estas sesiones, después de que las maestras compartieran sus experiencias sobre la realización de las técnicas, se dedicó un tiempo para el diálogo y la reflexión compartida. De modo que el seminario de formación se convirtió en la excusa para movilizar al profesorado del centro. A partir de esas tres sesiones, el profesorado que no realizaba esas técnicas, empezó a "probarlas" en sus prácticas de aula, y se realizaron dos sesiones más del seminario para compartir las experiencias y llegar a establecer compromisos. Los compromisos que se acordaron entre todo el profesorado se establecieron como una medida para no 
abandonar la innovación en las aulas y tratar de mantenerla en el siguiente curso y posteriores.

Además de la realización del seminario, otras de las acciones desarrolladas durante la primera fase fueron: reuniones con el equipo directivo, reuniones con el claustro, observación de aula, realización de grupos de discusión y entrevistas.

\section{FASE 2. ETNOGRAFÍA E HISTORIA DE VIDA}

Después de una primera fase en la que el proceso de transformación del centro era el foco principal del estudio, tuvimos que adaptar nuestra investigación a las circunstancias. Con el cambio de la mitad de la plantilla del profesorado, el claustro planteó que la formación interna realizada durante el curso anterior a todo el profesorado debería limitarse al trabajo en los distintos ciclos. De ese modo ofrecerían un acompañamiento a los docentes nuevos, a cada uno desde su ciclo, y pensaban que así la adaptación de estos sería más personalizada y favorecería la implantación de las prácticas inclusivas en todas las aulas.

Por esta razón, nos centramos en uno de los ciclos, seleccionamos a Estefanía, una maestra del primer ciclo que durante el curso anterior se había implicado mucho en el proceso de transformación del centro. Entre los distintos tipos de técnicas de obtención de datos utilizadas, durante esta fase de la investigación, realizamos entrevistas en profundidad para conocer la historia de vida de esta maestra, con el objetivo de entender mejor su posicionamiento como docente. A partir del trabajo biográfico, nuestra pretensión sobre la investigación se amplió a la parte más personal y emocional de la educación.

Desde septiembre hasta diciembre del 2012, el trabajo de campo se concretó principalmente en la mirada de Estefanía. Además de conocer su historia de vida, analizamos la realidad del centro desde sus acciones en la escuela. Es decir, observamos sus prácticas de aula; las reuniones de coordinación del primer ciclo, del que formaba parte; y las sesiones que se realizaron en la comisión mixta del comedor, en la que participaba activamente. Además, puesto que estábamos dentro 
de la escuela, inevitablemente obteníamos información desde otros ámbitos, como eran el despacho de dirección, los pasillos del centro, etc. En estos casos, registrábamos los acontecimientos, junto con nuestras reflexiones en el diario de la investigación. Cabe destacar también la creación del consejo social en esta segunda fase, para compartir el proyecto de investigación con la comunidad educativa y poder acercarnos a las necesidades del contexto estudiado.

El consejo social se creó con la finalidad de abrir un espacio comunitario en el que valorar y discutir la propia investigación, ya que creemos que es necesario realizar investigaciones que tengan sentido también para las personas de ese contexto. La visión de las familias y de otras personas que formaban parte del consejo social y que no estaban tan ligadas a la investigación como Estefanía y yo, nos facilitaba no perdernos en los marcos del estudio. Así mismo, pretendíamos que el trabajo se realizara de un modo horizontal. Que las voces de todas las personas que formaban parte de ese consejo fueran escuchadas por igual, puesto que todas las aportaciones eran siempre oportunidades de aprendizaje. Por eso, determinamos en la primera reunión que cualquier persona que formara parte del consejo podía convocar una reunión, siempre y que hubiera un propósito claro por el que realizarla y se contara con material de antemano para poder llegar a la reunión con un conocimiento sobre el tema a tratar. Puesto que el acceso a la información escrita no resultaba claro para todas las personas del consejo, en el caso de las familias y del alumnado este material se trabajó en sesiones tutorizadas con la investigadora, unos días antes de la reunión del consejo. Se realizaron dos sesiones del consejo social, una primera para dar a conocer el tema de la investigación y recoger aportaciones para definir tanto el problema como el propio diseño de la investigación y, una segunda reunión en la que se dieron a conocer los primeros resultados del estudio y se discutieron con los miembros del consejo.

Las personas que formaron parte del consejo social eran por un lado, aquellas implicadas directa, o indirectamente en la escuela y por otro lado, personas interesadas en la educación intercultural inclusiva. En relación a las personas implicadas en la escuela, se seleccionó a un padre y a una madre implicados en la 
escuela; a una maestra con un estilo democrático en el aula y con un posicionamiento educativo intercultural e inclusivo; a dos miembros del equipo directivo (aunque se acordó que participara solo una persona, dos de los miembros insistieron en que les interesaba mucho estar presentes en estas sesiones y poder participar); al conserje, como personal de servicios; a una representación del alumnado; a Estefanía y a la investigadora. De las personas que no tenían una relación directa en la escuela pero que estaban interesadas en la educación intercultural inclusiva y en los procesos de cambio escolares, se seleccionó a Empar, trabajadora del CEFIRE y responsable de la formación en educación intercultural e inclusiva y a Paloma, miembro del equipo de investigación MEICRI.

De las personas que no estaban implicadas en la escuela pero que indirectamente tenían un vínculo con la misma o con el contexto en el que estaba situada, se invitó a participar a dos trabajadoras de servicios sociales que ejercían como tal en una oficina del barrio y a la concejal de educación de la localidad. En relación a las trabajadoras sociales, habían realizado algunos trabajos con el alumnado durante ese mismo curso; sin embargo, tras la primera sesión decidieron que el estudio no estaba relacionado con su trabajo y no quisieron volver a la siguiente reunión. En cuanto a la concejal de Educación del ayuntamiento, se le invitó a participar en las dos sesiones con suficiente antelación e informándole sobre el proyecto. Esta persona manifestó su interés sobre el mismo, pero en las dos reuniones excusó su asistencia unas horas antes de la reunión. Más adelante, explicaremos más detalladamente la situación de cada una de las personas que forman parte del consejo, para comprender los motivos por los que son relevantes y se han seleccionado.

En los siguientes apartados, mostraremos los participantes en el estudio; las técnicas de obtención de datos y de registro de la información empleadas. También, la temporalización y los procedimientos utilizados para el análisis de los datos. 


\subsubsection{Participantes}

Los participantes en el estudio son el profesorado, las familias, el alumnado y otros agentes que colaboran en las acciones desarrolladas en la escuela. En primer lugar, definiremos la participación del profesorado, que además es la que está más presente en el estudio.

\subsubsection{Profesorado}

A la hora de definir a los participantes del equipo de docentes, señalamos que todo el profesorado participó en el estudio. Principalmente porque entre las reuniones observadas también se registraban aquellas en las que estaba convocado todo el profesorado para tratar cuestiones sobre el proyecto de transformación. No obstante, en lugar de describir a cada uno de los docentes, nos detendremos en aquellos que por algún motivo, participan en más ocasiones en las acciones registradas para el estudio y que aportan información relevante para comprender el proceso de cambio del centro.

A continuación diferenciamos entre el profesorado que participó durante el curso 2011 - 2012 y el que lo hizo durante el curso 2012 - 2013, ya que no es el mismo.

En relación al profesorado que participó durante el curso 2011 - 2012, destacamos que casi todos asistieron al seminario de formación. Además, realizamos observaciones en las aulas de la mayoría de los asistentes al seminario. Sin embargo, a la hora de explicar qué docentes participaron en el estudio, hablaremos de aquellas personas que fueron seleccionadas para realizar entrevistas, puesto que fueron las que de algún modo podían aportar información relevante al mismo. No nos detendremos en el profesorado que participó en el grupo de discusión, puesto que fueron todos los que asistían al seminario de formación. Para la realización de entrevistas se trató de seleccionar una muestra más representativa para hallar datos que nos ayudaran a comprender mejor la complejidad del cambio, desde el punto de vista del profesorado. 
Cabe destacar que aunque en un principio se pensó en una muestra representativa de unas tres o cuatro personas, una vez iniciado este proceso, y viendo que las declaraciones aportadas por los entrevistados nos acercaban a un conocimiento mayor de la realidad, se realizaron entrevistas con prácticamente todo el profesorado. Es por esto, que a la hora de analizar los datos, descartamos el análisis del grupo de discusión del profesorado, ya que tras haberlo realizado, empezamos las entrevistas y los datos obtenidos aportaban una realidad más contrastada que la detectada anteriormente en las observaciones del seminario de formación o en el grupo de discusión.

Adjuntamos un esquema para clarificar la participación del profesorado en el estudio, durante el curso 2011 - 2012:

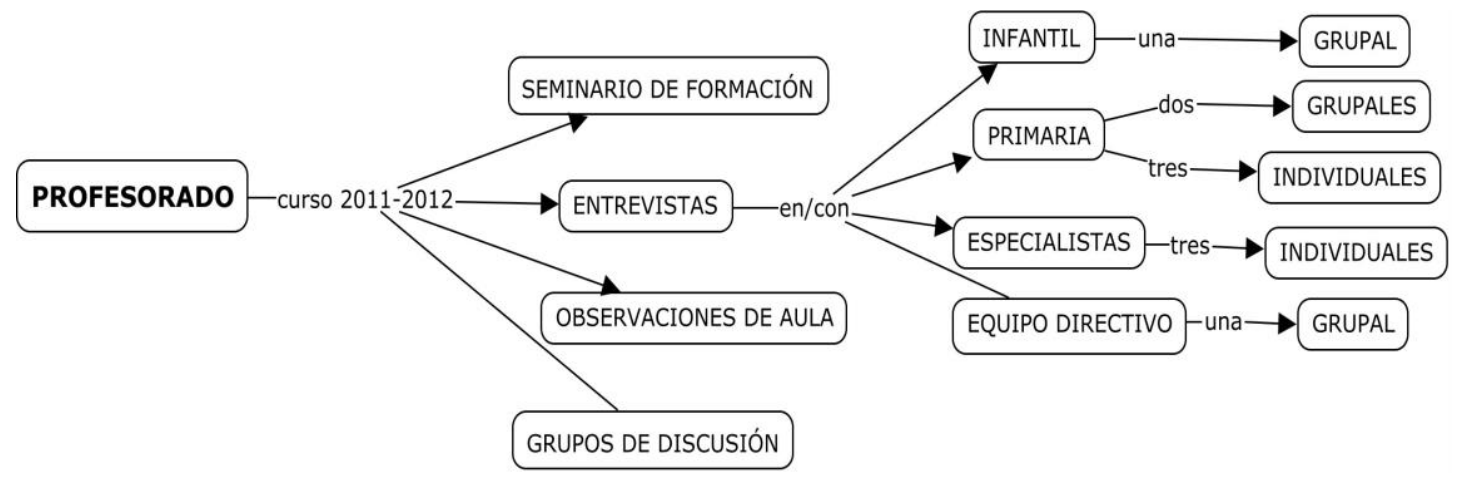

Figura 1. Participación profesorado 2011 - 2012.

A continuación definiremos el perfil de las personas entrevistadas. Empezaremos por las entrevistas realizadas en la etapa de educación Infantil. En esta etapa se realizó una entrevista grupal con todas las maestras que durante el siguiente curso estarían en el colegio, y que además, tenían una trayectoria en el centro. En esta entrevista pudimos contrastar la opinión de Luna, una maestra con un estilo docente democrático (sus prácticas se basaban en la participación y la toma de decisiones del alumnado) y que en las distintas reuniones recordaba el tener presente al alumnado y a las familias en la toma de decisiones del centro, con otras compañeras de Infantil, que sin embargo, tenían una opinión distinta. En este caso, la entrevista grupal aporta información importante para comprender una parte de la cultura escolar del centro, en concreto la relación entre el profesorado; las 
expectativas de estas maestras sobre las familias y otros aspectos relacionados con la cohesión del profesorado en el centro.

En el primer ciclo de educación primaria, se optó por realizar una entrevista a Estefanía, una de las maestras más implicadas en el cambio, que según ella, lo vivió como "una vía de escape" (según sus palabras), que le ayudó a afrontar su situación personal. Además de esta entrevista realizamos otra grupal con las tres maestras del primer ciclo. Aunque estas dos compañeras de Estefanía no estarían al curso siguiente, se seleccionaron por el compromiso que habían mantenido respecto a la transformación del centro desde el inicio del curso y el trabajo que habían realizado con el alumnado y las familias. Además, otro aspecto a destacar en este ciclo era la colaboración docente que había nacido a partir de compartir su mirada pedagógica sobre aspectos del aula, y posteriormente, realizar de manera colaborativa distintas prácticas más interculturales e inclusivas.

En el segundo ciclo, también se realizó una entrevista grupal con tres maestras María, Silvia y Nuria; y una individual con el cuarto maestro que formaba parte del mismo ciclo; Carlos. La razón por la que les agrupamos de este modo fue porque en el caso del maestro, se mantenía al margen y no participaba demasiado en ninguna de las reuniones a las que asistía. Además, su relación con algunas de sus compañeras del ciclo no era muy buena, por eso pensamos que realizar la entrevista de manera individual nos podía ayudar a obtener una opinión más real sobre lo que pensaba acerca del cambio educativo.

En el caso de las otras tres maestras, se escogieron porque su posicionamiento sobre el cambio fue cambiando a lo largo del proceso. Desde el inicio se situaron al margen de la transformación y manifestaron sus discrepancias hacia el cambio. Sin embargo, a lo largo del seminario de formación fueron planteando sus dudas de manera abierta y finalmente cada una de ellas, por iniciativa propia, realizó alguna de las prácticas presentadas en el seminario en su aula. Por esta razón, por su posicionamiento de resistencia pero la posterior realización de innovaciones en el aula "para probar" como ellas decían, las entrevistamos, después de haber observado en cada caso la práctica que habían implementado. 
En el tercer ciclo, entrevistamos a cuatro personas, entre ellas a una de las tutoras de las cuatro que formaban parte del ciclo, y a los especialistas en inglés, música y educación física. Cabe destacar que en este ciclo, ninguna de las tutoras continuaba el curso siguiente, quizás por este motivo asistían poco a las sesiones del seminario y no planteaban sus dudas ni compartían las prácticas que ellas realizaban en su clase. Hasta el final del curso el equipo directivo y el resto del profesorado pensaban que en este ciclo no se estaban implementando las prácticas presentadas en el seminario, pero en la última sesión del mismo, una de las maestras, la que entrevistamos posteriormente, nos explicó todo aquello que se hacía en su aula, incluidas las prácticas presentadas en el seminario. Es por esto que, seleccionamos a esta maestra para que nos comentara su percepción del cambio y su posicionamiento en el mismo.

Por otra parte, entre los especialistas, contamos con Lucía, una persona reacia a introducir transformaciones en sus prácticas y con unas expectativas bajas hacia el alumnado y las familias. También entrevistamos a Xavi que, si bien no se mostraba reacio, tampoco se decidía a implementar mejoras en su clase, aunque asistía a observar las prácticas de sus compañeros que realizaban innovaciones y era una persona muy participativa en el seminario de formación. En su caso, como nos comentó en las entrevistas, sí que le gustaría transformar sus prácticas, pero no sabía muy bien cómo hacerlo, ya que encontraba dificultades por las características de la asignatura que impartía. Finalmente Iris, otra de las personas especialistas seleccionadas, estaba muy implicada en el cambio. Aunque en su asignatura no introducía las prácticas mostradas en el seminario, también por las características de su materia, siempre que podía realizaba un trabajo colaborativo y cooperativo con el alumnado. En su caso, las expectativas tanto hacia el alumnado como hacia las familias eran más altas que las de la mayoría del profesorado, en su caso, las bajas expectativas estaban más relacionadas con la participación e implicación del profesorado sobre el cambio.

Finalmente, entrevistamos a los tres miembros del equipo directivo que estaba compuesto por Rafa, el director; Sonia, la jefa de estudios y Mónica, la secretaria. 
La relación entre el equipo directivo y el resto de maestros era buena. Así mismo, su implicación en la transformación del centro también fue un aspecto clave del cambio, que destacaron no solo ellos, sino también algunas maestras. Con el equipo directivo mantuvimos bastantes reuniones y muchas conversaciones en el despacho para comentar los cambios del centro y para organizar las sesiones de formación.

Hasta ahora hemos nombrado la participación del profesorado durante el primer curso observado. Durante el segundo curso, 2012 - 2013, el estudio se centró más en el trabajo de Estefanía: en su aula, en su historia de vida y en las acciones en las que participaba en el centro. Adjuntamos un esquema con la participación del profesorado durante este curso.

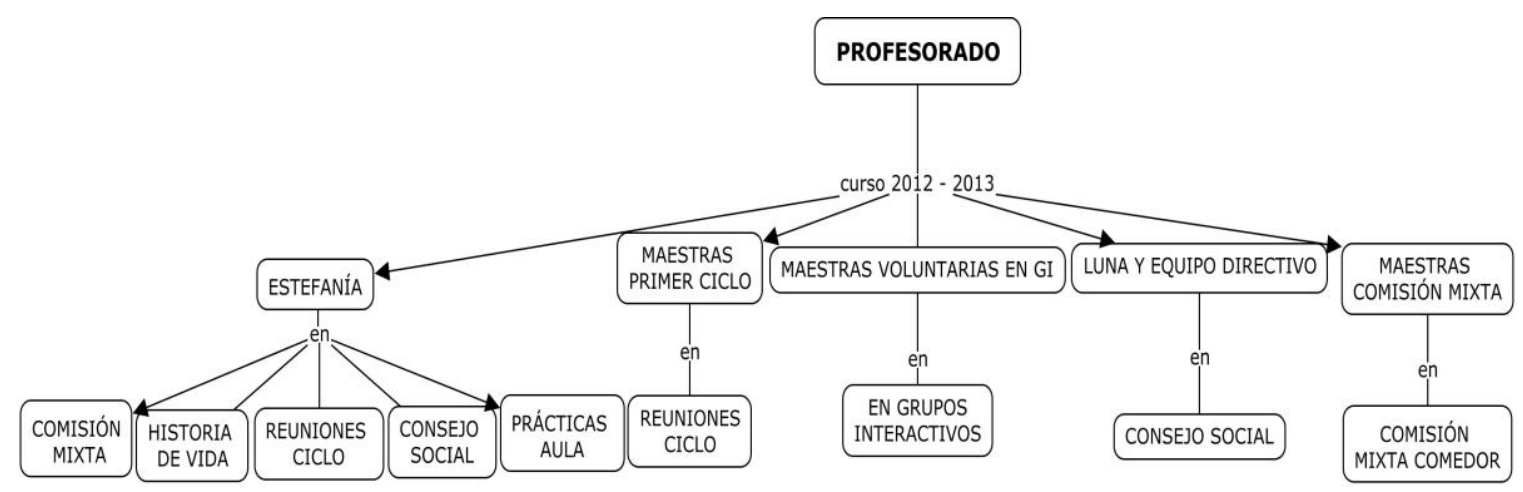

Figura 2. Participación profesorado $2012-2013$.

Estefanía es una maestra de 39 años, muy responsable, apasionada y emotiva. Disfruta de ser maestra y le encanta el teatro, el baile, leer, escribir y conversar. Se preocupa mucho por las personas a las que quiere y trata de cuidarlas día a día. Aunque en algunos momentos se siente poco acompañada y sola, por la situación personal que está viviendo, nunca "tira la toalla", es una luchadora nata. Además del tiempo que emplea en ser maestra y en participar en actividades de ocio como el teatro, dedica todo el tiempo posible a estar con su hija y su hijo.

Mantiene una buena relación con las personas de su trabajo, siendo también una gran amiga de algunas de ellas. Por sus experiencias vitales y su modo de 
entender la educación trata de fomentar la inclusión de todo su alumnado en las prácticas diarias. Le da mucha importancia a la vida del alumnado y dedica espacios en los que se fomenta la expresión de los niños y las niñas. Además, es una persona a la que le gusta mucho introducir novedades en su aula y en su práctica y se siente cómoda haciéndolo. Como profesional no le gusta relajarse, o como ella dice, acomodarse, sino que intenta estar siempre actualizada en relación a los conocimientos pedagógicos y a las acciones emprendidas en su aula. Aunque no siempre se sienta acompañada por las personas de su ciclo, trata de llevar a cabo aquellas ilusiones que se despiertan en ella en relación con su manera de ser docente.

\section{Maestras que entran como voluntarias en el aula.}

A continuación definiremos el estilo docente de las maestras que entraban como voluntarias en su aula para realizar los grupos interactivos.

A la hora de realizar los grupos interactivos en el aula cuentan con cuatro maestras más.

Entre estas maestras encontramos a Sara, con un estilo más autoritario que el resto, normalmente se dirige al alumnado alzando la voz. Por otra parte, Lila es una maestra que al inicio se mostraba muy directiva con el alumnado, pero poco a poco va dejando más espacio para la ayuda e iniciativa del estudiantado. Otra de las maestras es Virtudes, a la que le pone nerviosa atender a alumnos a los que les cuesta más realizar la tarea y finalmente, Pascuala, una maestra con un tono más amable, pero que también tiende a dirigir al alumnado y dar la respuesta ante alguna pregunta que le puedan hacer, en lugar de tratar de que sea el alumnado quien piense e interactúe para llegar a una solución.

\section{Maestras de primer ciclo.}

Las reuniones en el primer ciclo contaban con dos maestras de primero (Carmen y Virtudes), dos maestras de segundo (Carla y Estefanía), una maestra especialista de Educación Física y la jefa de estudios y tutora de la clase de compensatoria. 
Cabe destacar que, del profesorado del primer ciclo tan solo Estefanía y la jefa de estudios, llevaban más años en la escuela. Las otras maestras eran nuevas y una de ellas interina e iba a estar en el centro unos meses, sustituyendo a una compañera que no había llegado a incorporarse.

En cada ciclo, los compromisos que se habían tomado en el curso anterior en el seminario de formación se tenían que ir introduciendo en las tutorías. En el caso de este ciclo, puesto que Estefanía era la única tutora que estaba durante el curso pasado, era la responsable de dar a conocer estas prácticas al resto de tutoras. Esta función le interesaba mucho a ella, que estaba encantada con las nuevas prácticas que estaba aplicando y veía los buenos resultados de las mismas en su alumnado. Sin embargo, la predisposición de las otras tres tutoras no era la misma que la de Estefanía. En el caso de Carla, no conocía estas técnicas y tampoco estaba demasiado interesada en aplicar innovaciones, aunque cuando Estefanía les propuso hacerlo ella fue la única que no mostró resistencia y aceptó entrar a su clase para poder conocer mejor algunas de estas prácticas, como fueron las asambleas y las tertulias dialógicas.

Por otra parte, la realización de grupos interactivos era prácticamente una imposición para el profesorado, puesto que se partía del compromiso tomado por el equipo de docentes del curso anterior y por parte del equipo directivo se facilitaban los recursos humanos (el profesorado hacía de voluntario) para llevar la práctica a la acción. Es por esto, que todas las maestras del ciclo también realizaban grupos interactivos en su clase.

En el caso de las dos maestras de segundo nivel, su motivación hacia las innovaciones dentro del aula era escasa. Este hecho no facilitaba que en las reuniones del ciclo se trataran temas pedagógicos y por eso, los temas a tratar solían estar relacionados con la organización para preparar las fiestas.

En otras de las acciones en las que participaron algunos maestros, fueron en el consejo social, sobre el que explicaremos su composición en el siguiente apartado y en la comisión mixta del comedor, en la misma que participaba Estefanía. 


\subsubsection{Familias y alumnado}

Las familias también son otro de los agentes que participan activamente en el estudio y en el proceso de cambio de la escuela. En este caso podemos destacar la participación de las familias durante el curso 2011 - 2012, en la entrada en las aulas como voluntariado, en su participación en las comisiones, y finalmente en el grupo de discusión realizado para conocer su experiencia. Durante el curso 2012 2013, se limita la participación de las familias a las comisiones, sin proponerles que entren como voluntarias a las aulas, como lo hicieron algunas maestras durante el curso anterior. Sin embargo, otra de las acciones de las que forman parte una representación de ellas (un padre y una madre) es en el consejo social. A continuación explicaremos qué personas participaron en cada una de las acciones mencionadas. Adjuntamos un esquema para sintetizar en qué aspectos participan tanto las familias como el alumnado:

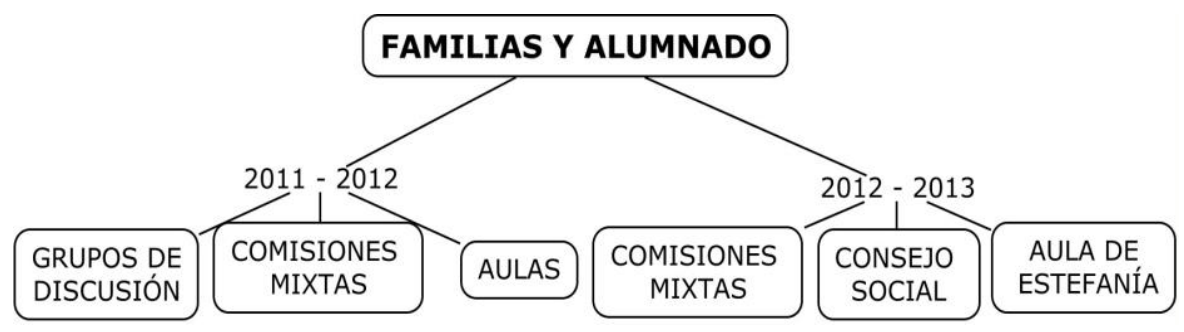

Figura 3. Participación familias y alumnado.

\section{Comisión del comedor}

La comisión del comedor está compuesta por distintos miembros durante los dos cursos. En el curso 2011 - 2012, la comisión del comedor se compone por dos madres, tres maestras, entre ellas Estefanía, y dos alumnos, un niño y una niña del tercer ciclo.

Durante el curso 2012 - 2013, la comisión se compone de varias madres, aunque a las reuniones realizadas asisten dos. El modo de proceder para las madres que quieren formar parte de la comisión como voluntarias, es apuntarse en un panel 
que publica Estefanía. En ese panel, se apuntan las madres y después Estefanía las va llamando para que puedan asistir a la escuela, con la suficiente antelación para que tengan la cita prevista, para asistir a la escuela en el horario del comedor y encargarse del aula de estudio. Si alguna de ellas no puede asistir avisa a la escuela y con tiempo se contacta con la siguiente madre del listado. Además, también forman parte de la comisión otras dos maestras, aparte de Estefanía; dos alumnos y tres alumnas del tercer ciclo. Excepto en el caso de Estefanía, el resto de participantes son distintos a los del curso anterior.

\section{Grupo de discusión con las familias}

En el grupo de discusión de las familias participaron cuatro madres árabes y dos madres y un padre españoles. Todas estas personas estaban interesadas en entrar en las aulas, pero por diferentes motivos no todas se decidieron a hacerlo (sobre todo, debido al desconocimiento de la lengua). De las personas que sí que participaron, lo hicieron para contribuir a la mejora de la educación de sus hijos, para poder ayudarles mejor a realizar los deberes. La valoración de la experiencia, de todas las personas que entraron, fue muy gratificante.

También participaron en el grupo de discusión de las madres dos, de las tres maestras del primer ciclo y la jefa de estudios, que también se mostraba muy interesada en la participación de las familias.

En el grupo de discusión se les preguntó por su participación en las aulas y en las comisiones, si era su caso. Se les preguntó también sobre sus conocimientos acerca del proceso de cambio del centro. Pero sobre todo, se dio bastante importancia a la experiencia que cada uno de ellos quiso compartir a partir de lo que había supuesto para ellos entrar en las aulas y/o en el centro.

\section{Miembros del Consejo Social}

Entre las familias se seleccionó a Pepe y a Fátima. Pepe es el padre de una alumna de segundo curso de primaria y miembro del AMPA. Este padre ha estado muy implicado en la escuela desde que se empezó el proceso de cambio en la sensibilización (septiembre del 2011). El proceso personal que se ha visto en él nos 
sorprende, al ser una persona que expresaba su resistencia hacia la participación de las familias árabes en la escuela (como hemos nombrado, distinguía oralmente entre las familias españolas, a las que se refería como "nosotros", y las inmigrantes que nombraba como "ellos"). A lo largo del curso 2011 - 2012 dejó de hacer referencia a la separación que tanto manifestaba en la formación inicial de septiembre, siendo el padre que más se implicó en los cambios que se querían realizar en el aula. Además participaba en algunas comisiones, que casi lideraba él. También entraba (igual que su mujer) en las aulas del primer ciclo, durante el curso 2011 - 2012, como voluntario. Su alta participación en el centro y su cambio de actitud en la relación con las familias árabes nos llevó a interesarnos por este padre para que participara en el consejo social.

Por otra parte, Fátima, es la madre de una niña de tres años, que en el curso 2012 - 2013 ha iniciado educación infantil. Además, esta madre árabe, había sido exalumna de la escuela. A diferencia de Pepe, Fátima no había estado en la sensibilización durante el curso anterior, por tanto nos interesaba también su mirada ya que conocía los cambios desde el presente curso (como cualquier familia nueva en el centro) y había manifestado su interés por colaborar e implicarse en todo lo que pudiera en la escuela. Además, Fátima asistía al taller de lengua para aprender valenciano y mejorar el castellano, dirigido a las familias e impartido por voluntariado universitario. La realización de ese taller de lengua en castellano, era una de las peticiones que habían hecho las familias árabes al profesorado al inicio del curso anterior para poder aprender el idioma. Cuando el voluntariado en el mes de noviembre dejó de realizar el taller, Fátima se dedicó a preparar las clases de castellano para enseñarles al resto de madres y así continuar con el mismo. Ella había cursado el instituto en la localidad y dominaba la lengua.

El sueño de esta madre era escribir un libro y que su hija fuera a la universidad, el primero de ellos lo consiguió a lo largo de ese mismo curso, contando con el apoyo de las madres y maestras de la escuela.

Seguidamente explicaremos también la participación del resto de miembros del consejo social. Seleccionamos a otra maestra, Luna, de la que ya hemos 
hablado anteriormente. Ella, durante el curso anterior nos hacía replantearnos aspectos fundamentales sobre los cambios educativos, como eran los valores personales y profesionales y la importancia de tener siempre en cuenta la voz del alumnado. Esta maestra le aportaba mucho sentido a las discusiones sobre las prácticas de aula. Ella planteaba el cómo hacer la práctica sin ligarla a ninguna receta, sino a tu manera de ver la educación y trataba de que el alumnado, aun siendo de infantil, fuera cada vez más autónomo y tomara decisiones. Trataba de generar prácticas democráticas y respetaba las decisiones argumentadas tomadas por sus alumnos, incluso cuando ella no estaba de acuerdo con ellos. Defendía los proyectos de trabajo porque observaba que el alumnado era quien iba construyendo su aprendizaje y por la alta motivación que mostraban, y las asambleas, como un espacio democrático en el que el alumnado puede expresarse y mostrar sus inquietudes, preocupaciones, etc.

Del equipo directivo seleccionamos también a dos personas, Rafa, el director y Sonia, la jefa de estudios. Aunque como hemos comentado, al inicio queríamos que participara tan solo una persona del equipo directivo, nos pareció bien que participaran dos. Por una parte, porque en casi todos los colectivos tratábamos de escuchar dos voces, y por otra, porque estas dos personas nos insistieron mucho en que querían participar. Cabe destacar que todo el equipo directivo estaba muy interesado en la mejora del centro y se preocupaban por el bienestar de las familias y el alumnado. Además, mantenían una relación de amistad con Estefanía, la protagonista de la historia y estaban muy contentos de que la investigación se centrara en un trabajo más directo con esta maestra.

Del personal administrativo y de servicios, seleccionamos a Jorge, el conserje. Él compartía despacho con los miembros del equipo directivo y con la coordinadora del comedor, que era Estefanía. Por tanto, aunque no se le había propuesto participar de los cambios durante el curso anterior, era una de las personas que más conocimiento tenía sobre la situación del centro ya que además de participar en algún momento en las conversaciones mantenidas sobre los cambios del centro entre el equipo directivo, Estefanía y la investigadora, estaba 
presente cuando entraban las familias o el alumnado en el despacho de dirección y podía constatar los cambios en las relaciones personales que habían aparecido.

Por otra parte, con la intención de contar con la opinión de personas interesadas en la educación intercultural inclusiva, y de dar a conocer la situación de la escuela y los cambios que se estaban realizando en ella, nos pusimos en contacto con Empar, una asesora del CEFIRE de Castellón que conocía a la escuela y estaba preocupada por la formación del profesorado en temas de inclusión. La mirada de Empar aportaba información sobre los cambios en la percepción del profesorado sobre la escuela, puesto que ella les conocía desde antes de empezar la transformación y les repetía que veía muchas mejoras, sobre todo en el entusiasmo y la motivación que tenían en ese momento.

Por otra parte, formaba parte del consejo social Paloma, otra persona del equipo de investigación MEICRI. Puesto que pretendíamos que hubiera una representación de distintas voces y esta persona podría aportar una mirada desde lo académico, como doctora en educación.

Cabe destacar que en una primera reunión no contamos con el alumnado, pues creíamos que este tipo de reuniones podrían ser aburridas para ellos. Pero Luna insistió en que no podíamos estar hablando de la importancia de la voz del alumnado y volverlos a dejar fuera. Por eso, entre Estefanía y yo, tratamos de seleccionar a cuatro alumnos del tercer ciclo. Esta vez, nuestra pretensión era dar protagonismo a algunos de los niños que solían estar expulsados de la escuela por mal comportamiento. También queríamos que se dieran cuenta de que a las personas que estábamos trabajando en la escuela nos importaba su bienestar. Por eso, pensamos que era conveniente contar con la opinión de Francisco y Román. Además, seleccionamos también a Cristian, un estudiante con un alto rendimiento, que participaba también en una comisión y que le gustaba dar su opinión; y Cecilia, una alumna que no estaba muy motivada por los estudios.

Aunque desde la primera reunión se manifestó que cualquier persona del consejo podía convocar una reunión con el orden del día de la sesión y el material necesario para debatirlo, tan solo se realizaron dos reuniones que preparamos entre 
Estefanía y la investigadora. Pero ambas sesiones, sobre todo la segunda, fueron muy fructíferas para comprender mejor los cambios del centro.

Finalmente, otro de los agentes implicados en la transformación de la escuela fue el alumnado. Durante el curso 2011 - 2012, se recogió información de las aulas, y posteriormente se realizaron tres grupos de discusión, como hemos comentado anteriormente. Uno de ellos con el alumnado de educación Infantil, otro con el de primero a tercer nivel de educación primaria y otro con el de cuarto a sexto. Además, una parte del alumnado participaba en las comisiones mixtas y/o en el consejo social.

\section{Grupos de discusión con el alumnado}

A la hora de realizar los grupos de discusión con el alumnado, se les pidió opinión a las maestras del primer ciclo y entre todas decidimos realizar una sesión con todo el profesorado que quisiera participar para elaborar las preguntas del grupo de discusión y plantear los criterios para seleccionar al alumnado. En algunos casos, puesto que se había realizado una observación de aula, sí que se les comentaba a las tutoras la conveniencia de que algún alumno determinado participara en la sesión, sobre todo en el caso de aquellos alumnos que tenían dificultad para trabajar en equipo o no acababan de engancharse a la práctica. En esos casos, mi propuesta y la de las tutoras coincidían. Los criterios a seguir para seleccionar al alumnado fueron escoger un alumno o una alumna que hubiera comprendido bastante bien la práctica realizada, y uno que hubiese tenido dificultades o manifestara algún comportamiento destacable, bien por su disconformidad sobre la práctica, por sus dificultades, etc. Con estas indicaciones cada tutora realizó sus propuestas. Aunque la indicación era seleccionar a dos estudiantes, puesto que las maestras decidieron que sería mejor separar al alumnado y realizar distintos grupos de discusión para que se sintieran mejor y pudieran aportar más, acabaron seleccionando entre tres y cuatro alumnos de cada clase. De manera que, se realizaron tres grupos de discusión, uno con el alumnado de infantil de las clases de Luna y su paralela, que realizaban proyectos de trabajo. Este grupo estaba formado por 11 alumnos, 5 niños y 6 niñas. Se realizó otro grupo 
de discusión formado por un total de 13 alumnos, entre ellos 7 niños y 6 niñas, de primero a tercero de educación primaria. Finalmente, se realizó un grupo de discusión con 13 alumnos de cuarto a sexto de primaria, de ocho niños y cinco niñas.

Por otra parte, cabe destacar que el profesorado se implicó mucho tanto a la hora de seleccionar a su alumnado como a la hora de plantear los temas a tratar en la discusión. Las preguntas de los grupos de discusión se concretaron con las maestras.

\section{Alumnado de la clase de Estefanía en el curso 2012 - 2013 ( $\left.1^{\circ} \mathrm{A}\right)$}

La clase de primero A del curso 2012 - 2013, estaba formada por un total de 15 alumnos, entre ellos 8 niños y 7 niñas. Era una clase que contaba con un alto porcentaje de inmigración, tan solo tres niñas y un niño eran españoles, el resto eran árabes que residían en el pueblo desde bien pequeños, habiendo asistido a la escuela desde los 3 años. Por lo tanto, aunque no tenían el mismo dominio de la lengua que el resto de niños se expresaban bien, comprendían el idioma y se les entendía perfectamente cuando hablaban en castellano. En relación al valenciano, tan solo era la lengua materna de una niña, por tanto, el alumnado tenía más dificultades para expresarse en esta, que en castellano. Sin embargo, en la clase la maestra destinaba muchos momentos a la expresión oral en valenciano y pronto apareció una mejora en la expresión oral de todo el alumnado del aula.

En relación al nivel socio-económico, el alumnado pertenecía a familias de un estatus económico bajo. No obstante, solían ser niños que estaban bien alimentados y tenían una higiene adecuada. Además, una parte de las familias de esta clase estaba interesada en el aprendizaje académico de sus hijos y por eso, mantenían una relación fluida con la maestra para conocer el funcionamiento de sus hijos en el aula.

En relación al rendimiento del alumnado, 5 de ellos tenían dificultades de aprendizaje y dos dificultades de atención. Otro de los niños tenía Síndrome de Down y no siempre estaba incluido en las actividades del aula, sin embargo, a nivel 
social estaba muy integrado en el grupo, ya que era compañero de estos niños desde hacía dos años. El resto del alumnado tenía un ritmo parecido y solían entender los conceptos trabajados en clase. Podríamos destacar que algunos de estos niños tenían una alta capacidad, sin embargo, los resultados alcanzados en general, se situaban por debajo de los esperados según la media, en relación a otros niños de esta misma edad.

\subsubsection{Técnicas de obtención y producción de la información}

Las técnicas utilizadas para la obtención y producción de los datos han sido la observación participante; la entrevista semiestructurada y en profundidad y los grupos de discusión. Además, la información se ha registrado en notas de campo y en archivos de audio y vídeo. Posteriormente, una parte de estos archivos se han transcrito y se han completado con las notas de campo. Por otra parte, también se ha utilizado un diario de investigación en una parte del estudio.

\subsubsection{Observación participante}

Empezaremos por definir la observación participante. Como su nombre indica, esta técnica se basa en la observación de la realidad estudiada y en la participación e intervención de la persona que investiga, en los casos que se cree conveniente. El investigador no se sitúa en un extremo del aula o de la sala para observar y tomar notas, sino que es partícipe de la situación. Aunque, en algunas ocasiones, como por ejemplo en el seminario de formación o en las reuniones del profesorado, la participación de la investigadora era más notable que en otras. Por ejemplo, en la observación sobre las prácticas de aula se requería de una menor presencia de la investigadora y en este caso se mantenía más al margen, aunque si lo consideraba podía participar. 
La observación ha sido de gran ayuda a la hora de comprender la vida del centro. Pues así como la entrevista permite al entrevistado repensar su oralidad, reflexionar sobre aquello que va a expresar y hacerlo de la manera que crea más conveniente, la observación rescata escenas auténticas, donde la toma de decisiones en la acción supera a la reflexión. Es por esto que a la hora de registrar procesos y cambios en la actitud de algunas familias, y del propio profesorado, nos ha sido de gran ayuda observar. También es importante destacar que para un mayor beneficio en el uso de esta técnica es imprescindible que los informantes confíen en la investigadora. Pues, aunque podemos observar situaciones naturales, el grado de confianza que se deposite en nosotros también favorece que los informantes se sientan más a gusto y cómodos y no traten de "maquillar" la realidad a la hora de expresarse. La confianza es un ingrediente necesario a la hora de hacer investigaciones en las que tratamos de conocer la vida de una institución. Sin embargo, dicha confianza se labra con el tiempo y con la permanencia del investigador en el contexto. Es compartiendo vivencias y acompañando en el proceso como se puede generar un clima de igual a igual, en el que el investigador ya no se siente como un extraño sino como un nativo (Velasco y Díaz de Rada, 1997). La observación muchas veces se da en sesiones pautadas, pero muchas otras en situaciones espontáneas, como podían ser conversaciones en el pasillo o la asistencia a celebraciones y festivales de la escuela. Es también en estas sesiones en las que se obtenía información relevante. Por eso, es necesario que el observador mantenga un rol activo y una reflexión permanente, que esté pendiente de los detalles, de las distintas situaciones y de las interacciones entre los miembros (Cohen y Manion, 1990).

En nuestra investigación, la observación fue una técnica utilizada a lo largo de todo el trabajo de campo. Además de mantenernos atentos a todo lo que acontecía en el centro, utilizamos la observación participante en las reuniones con el claustro y con el equipo directivo; en las comisiones mixtas; en las sesiones del seminario de formación; en las reuniones del primer ciclo y en las aulas. En estos casos la observación se acompañó de las notas de campo y de la grabación en audio y en vídeo. En estas sesiones se obtuvo mucha información sobre la vida del centro, que 
pudimos contrastar con la información obtenida mediante otras técnicas, como la entrevista. A diferencia de esta última, en la observación obteníamos una imagen de la escuela más real. Es decir, aparecían las resistencias, las dificultades... En definitiva, podíamos observar una realidad creíble, que en pocas ocasiones creemos que podía estar condicionada por la presencia de la investigadora o de las cámaras de vídeo o grabadoras. Por otra parte la entrevista, en la que nos detendremos más adelante, posibilitaba entrar en reflexiones individuales. El profesorado se permitía expresar cuestiones que con todo el grupo no expresaba verbalmente.

Aunque la observación participante es una técnica, creemos que la potencialidad de la misma reside en la actitud observadora que acoge el investigador. Es decir, cuando el investigador entra en el campo para realizar un estudio etnográfico, es necesaria una actitud de apertura a todos los acontecimientos. Nos referimos a que quizás cuando menos nos imaginamos aparece información importante.

\subsubsection{Entrevista}

En relación a la entrevista, podemos destacar que es una técnica que nos permite obtener información más concreta sobre el punto de vista de un informante. Además, permite establecer una relación más cercana con la persona entrevistada y acercarnos a sus intereses y preocupaciones.

La entrevista es una técnica en la que una persona entrevistadora solicita información de otra o de un grupo de entrevistados (informantes), para obtener datos sobre un problema determinado. Presupone, pues, la existencia al menos de dos personas y la posibilidad de interacción verbal. Las entrevistas se pueden clasificar de diferentes formas y una de ellas está en función del grado de apertura y de si ha sido más o menos dirigida. Según esto, los diferentes tipos de entrevista que se pueden utilizar en la investigación son la entrevista estructurada, la semiestructurada y no estructurada o en profundidad (Albert, 2007). 
En nuestro caso, se utilizaron las entrevistas en distintos momentos con intenciones también distintas. En un primer momento, se utilizaron las entrevistas semiestructuradas con el equipo del profesorado para conocer su punto de vista sobre el proceso de cambio del centro (finales de junio y principios de julio del 2012). Aunque hablamos de entrevistas semiestructuradas porque había una serie de temas que se querían abordar, el procedimiento que seguimos en las distintas ocasiones era bastante abierto.

Se realizó una selección del profesorado que por algún motivo podía aportar datos al estudio, bien por su alta implicación; por las innovaciones introducidas en el aula; pon no haber introducido ninguna innovación; por su actitud de resistencia mostrada en las reuniones; etc. Como hemos comentado anteriormente, a medida que fuimos realizando las entrevistas, creímos más conveniente ampliar la muestra de entrevistados y por ese motivo, en algunos casos realizamos entrevistas grupales entre personas del mismo ciclo o etapa educativa. También queremos destacar que se seleccionó a una maestra de PT (Pedagogía Terapéutica) que había entrado en distintas clases en las que se habían realizado innovaciones. Sin embargo, en este caso, tras posponer en distintos momentos la entrevista a petición de la maestra, se terminó el curso y ya no se pudo realizar la misma. También la maestra pidió a la investigadora realizar la entrevista online, pero aunque se le enviaron las preguntas nunca llegó a responderlas y enviarlas.

Los temas que se trataron en las entrevistas estaban relacionados con el proceso del cambio emprendido en el centro, con las distintas acciones realizadas, con la relación entre las familias y la escuela y con la valoración personal que cada profesional hacía sobre su experiencia. Es por esto que en cada caso, se trató de ahondar en unos aspectos más concretos que otros. Por ejemplo, en el caso del profesorado que no había realizado cambios en sus aulas se trató de conocer sus razones; en el caso de las maestras que en un principio se mostraban más resistentes a los cambios y que después habían realizado algunas innovaciones se indagó también en aquello que les podía haber hecho cambiar de idea,... En el caso de las personas que sí que habían implementado cambios antes de realizar el 
seminario de formación también se les preguntó por las transformaciones que habían observado en el aula, en la relación con las familias, etc. En definitiva, en cada caso se trató de adaptar los temas a indagar en relación a las personas entrevistadas.

Las entrevistas realizadas aportaron muchos datos para el estudio. Algunos de estos podían intuirse por la actitud que mostraban algunos docentes en las sesiones conjuntas, sin embargo, a partir de las entrevistas obtuvimos una explicación más detallada y argumentada de cada informante. También cabe destacar que, aunque en ningún caso los participantes se negaron a responder a las preguntas de las entrevistas, en una ocasión se realizó una entrevista que no aportó ningún dato sobre aquello que se quería indagar y por ese motivo no se procedió a realizar un análisis en profundidad sobre la misma. En este caso, la maestra fue seleccionada por su actitud reacia hacia las prácticas y el cambio del centro, también por sus bajas expectativas sobre el alumnado y las familias. Sin embargo, en la entrevista no manifestó tanto esta actitud y una vez apagada la grabadora expuso su opinión que expresamente dijo que no quería que quedara registrada en el estudio.

Se realizaron también entrevistas colectivas, o entrevistas grupales, como hemos dicho anteriormente. En este caso, se realizaron con la misma intención que en el de las individuales, pero para conocer la valoración de un conjunto de personas, en una situación parecida. Por ejemplo, se realizaron entrevistas colectivas entre las maestras de distintos ciclos y con el equipo directivo. En el caso del primero, el segundo ciclo y el equipo directivo, participaron tres docentes. En la entrevista a Infantil cuatro.

En otra ocasión en la que se utilizó la entrevista fue en el trabajo biográfico con Estefanía, durante la segunda fase de la investigación. En este caso se realizaron entrevistas en profundidad o entrevistas biográficas, puesto que la temática a tratar era su propia vida. Como destacan Bolívar, Domingo y Fernández (2001), la entrevista biográfica consiste en reflexionar y rememorar episodios de la vida, donde la persona cuenta cosas a propósito de su biografía, en el marco de un intercambio abierto, que permita profundizar en su vida y al entrevistador, realizar 
una escucha activa de la misma. Se trata de un proceso compartido entre entrevistado y entrevistador. La narración de aquello vivido supone un proceso reflexivo, de reconstrucción y autodescubrimiento del significado que han tenido ciertas experiencias en nuestra vida.

Los temas que se suelen recoger en las entrevistas biográficas son los que muestran Bolívar, Domingo y Fernández (2001, p. 166), citando a Atkinson (1998):

Nacimiento y familia de origen. Particulares circunstancias en que se ha nacido: edad, familia, contexto; Factores sociales y culturales en la niñez. Tradiciones culturales y contexto social en que se ha vivido de niño; Escuela $y$ educación. Entrada, estancia, relaciones, maestros y profesores, niveles educativos, intereses, acontecimientos a destacar, etc.; Amor y trabajo. En el proceso de ser independiente, desempeña un lugar importante todo lo referido a la formación de una familia y a la búsqueda, decisión y sentimientos en el trabajo; Grandes etapas en la vida, acontecimientos críticos. Estructurar la propia vida, directamente o a instancias del investigador, es importante. A veces se realiza en función de acontecimientos críticos externos o internos; Principales preocupaciones a lo largo del tiempo. Aunque suelen aparecer, conviene incidir en lo que han sido los grandes temas en la vida; Visión de futuro, cuestiones abiertas. La reconstrucción de la vida cobra sentido en función de su proyección en el futuro. Por eso, la parte final suele dedicarse a aquellas cuestiones abiertas que quiera plantear y a dibujar el horizonte más inmediato o lejano.

Tanto en el caso de las entrevistas semiestructuradas, como en el de las entrevistas en profundidad, el guión era totalmente abierto. En las entrevistas semiestructuradas la conversación giraba en torno a temas concretos, que como hemos explicado estaban relacionados con el proceso de transformación del centro. En las entrevistas en profundidad los temas que se trataban eran los de la biografía de Estefanía, relacionados con su pasado o su presente, y en algunos casos, sobre sus expectativas futuras. 


\subsubsection{Grupos de discusión}

En cuanto a los grupos de discusión, se definen como reuniones planificadas, para hablar acerca de un tema. Gutiérrez (2008), especifica que estos grupos “están formados por un número limitado de participantes cuyo objeto es hablar sobre un tema de interés para la investigación, bajo la supervisión de un investigador que hace las funciones de moderador en un espacio y tiempo limitado" (p. 16). Según Peinado y Gutiérrez (1994), el grupo de discusión reúne en sí diversas modalidades de grupos:

- Su dinámica, simula la de un equipo de trabajo. Se trabaja en el sentido de que se orienta a producir algo y existe por y para ese objetivo.

- $\quad$ El grupo de discusión instaura un espacio de «opinión grupal». (...) En él, los participantes hacen uso de un derecho al habla -emitir opiniones- que queda regulada en el intercambio grupal.

En nuestra investigación, se realizaron seis grupos de discusión durante el tercer trimestre del curso 2011 -2012. Tres de los grupos se realizaron con el alumnado, uno de primero a tercer curso, otro de cuarto a sexto curso de la etapa de educación primaria. El tercer grupo se realizó con el alumnado de educación infantil. En este caso, debido a la edad del estudiantado, la maestra planteó una sesión previa al grupo de discusión para tratar con su alumnado algunas de las cuestiones que se planteaban en el grupo, aunque el trabajo realizado por la maestra fue muy valioso los datos aportados no fueron relevantes para la investigación y por ese motivo no se procedió a realizar un análisis en profundidad sobre los mismos. Otro grupo se realizó con la comisión del comedor, que era la que estaba más activa en el curso 2011 - 2012. Finalmente se realizó un grupo con las familias y otro con el profesorado. En todos los casos, la intención era indagar sobre la percepción de los miembros sobre la transformación del centro. Pero, en función del grupo, se realizaron también preguntas más concretas.

En el caso de los grupos de discusión del alumnado de primaria, de las familias y de la comisión del comedor, se procedió a un análisis en profundidad sobre los 
datos una vez finalizada la investigación. Respecto al alumnado, la semana siguiente de realizar el grupo de discusión nos volvimos a reunir con ellos para realizar una devolución sobre los temas que habían aparecido y en caso necesario indagar más sobre los mismos, aunque consideramos que no era necesario.

En cuanto al profesorado, se realizó una devolución de las temáticas que se habían tratado en el grupo de discusión, pero no se analizaron los datos en profundidad una vez finalizada la investigación, porque se había obtenido una información más completa sobre su valoración en las sesiones de formación observadas y en las entrevistas realizadas. Estos datos sí que fueron analizados en profundidad una vez finalizado el trabajo de campo.

La diferencia entre el grupo de discusión y las entrevistas grupales fue principalmente, el número de personas que participaron. Siendo los grupos de discusión más numerosos que las entrevistas colectivas.

\subsubsection{Técnicas de registro de la información}

Además de utilizar técnicas para obtener la información, se emplearon una serie de estrategias para su registro. A continuación definiremos brevemente las técnicas sobre el registro de la información que se utilizaron en el estudio.

\subsubsection{Notas de campo}

Las notas de campo se realizan para registrar la información a la vez que se observa o se accede a ella a través de otras técnicas como los grupos de discusión o las entrevistas. Son apuntes realizados durante el día para refrescar la memoria acerca de lo que se ha visto y se desea registrar, y notas más extensas escritas cuando se dispone de más tiempo para ampliarlas (Woods, 1987). En la investigación, tomamos notas de campo durante el transcurso de todo el estudio realizado en el campo y registramos no solo la información observada sino también 
los puntos de vista y las reflexiones personales surgidas durante la observación de una situación determinada (Dorio, Sabariego y Massot, 2009).

\subsubsection{Diario de la investigación}

El diario de la investigación, se utiliza para registrar las reflexiones de la investigadora durante el proceso de la investigación. En el estudio, empezamos a utilizar esta herramienta a partir de junio del 2012. Hasta ese momento, algunas de las reflexiones las íbamos recogiendo en las notas de campo. Sin embargo, pensamos que sería más conveniente utilizar un diario expresamente para poder recoger aquellas percepciones más personales. En el diario, más que registrar sesiones concretas, se recogen las actitudes, los sentimientos y las emociones que emergen durante la investigación. Las anécdotas, pensamientos y cuestiones personales que nos permiten seguir el hilo de la investigación y no perder detalle sobre la realidad.

En nuestro diario, anotábamos información que mostraba nuestras impresiones sobre las actitudes del profesorado, acerca de las interacciones que mantenían entre ellos y que nos daban pistas sobre sus relaciones personales. Esta información nos permitía acceder a una cultura que no se hacía explicita pero que sin embargo, influía en el trabajo que se realizaba en el centro. Sobre el tipo de colaboración entre el profesorado y en sus iniciativas a la hora de implementar nuevas prácticas en el aula.

Además, también nos servía para reflexionar sobre el proceso. En ocasiones nos planteábamos preguntas que nos surgían en el campo y que en otro momento tendríamos que resolver. Otras veces, registrábamos información general sobre cuestiones que nos llamaban la atención. Pero siempre, el diario era un recurso para poder comprender el transcurso de la investigación que avanzaba día a día. Es por esto que el uso del diario fue muy útil en la investigación y lo utilizamos hasta enero del 2013, una vez finalizada la estancia en el campo. 
Como dice Zabalza (2004), los diarios constituyen narraciones sobre los acontecimientos vividos en el campo y permiten mejorar la práctica realizada a partir de la reflexión que supone repensar el proceso de la acción. Son, en sí mismo, un recurso orientado a la investigación y evaluación de los procesos didácticos.

\subsubsection{Vídeos, audios y transcripciones}

Los vídeos y audios son un soporte en el que queda registrada la información, sin que haya una manipulación de la misma. Sin embargo, para poder operar con los datos es necesaria la manipulación y tratamiento del investigador para reducir y organizar los mismos y poder hacer un uso estructurado y ordenado de la información.

Si bien no consideramos el uso del vídeo o del audio como una técnica propia de la investigación cualitativa, hemos querido nombrarlos en este apartado para resaltar algunos aspectos relacionados con este tipo de soporte. Destacamos las posibilidades que brinda, ya que nos permite registrar gran cantidad de datos y conservarlos en su estado natural, captando las expresiones de los informantes, etc. De este modo, es más accesible llegar a algún tipo de información que sin estos medios resultaría más dificultosa. Por ejemplo, en la observación de un aula, si mientras que el observador se centra en un grupo de trabajo deja la cámara en otro de los grupos, podrá a posteriori rescatar información que de otro modo no habría sido posible.

Sin embargo, la gran cantidad de datos que se recoge mediante estos soportes también hace más compleja la tarea del investigador que dispone de más información para conocer una misma realidad.

Por otra parte, las transcripciones se utilizan en algunos casos, antes de realizar el análisis de los datos, para contener toda la información obtenida mediante otros formatos por escrito. En nuestro caso se realizaron transcripciones de las sesiones de la segunda fase de la investigación. Puesto que durante la primera fase se realizó 
un análisis de los datos en menor profundidad y más adelante, una vez finalizado el análisis de la segunda fase en profundidad, volvimos a los datos obtenidos durante la primera fase.

Pensamos que no es necesario realizar una transcripción literal de todos los datos y que de hacerlo no significa que haya un mejor tratamiento de la información. La realización de transcripciones alarga mucho el proceso de la investigación sin llegar a suponer una mejora en el tratamiento de los datos. Por eso, en el análisis en profundidad realizado posteriormente sobre la primera fase, se optó por volver al material registrado en vídeo y transcribir únicamente aquellas partes más relevantes. 


\subsubsection{Temporalización}

A continuación presentamos una temporalización de las acciones realizadas, la intención con la que se realizaron las mismas, las personas que estaban implicadas y las técnicas de obtención de información utilizadas.

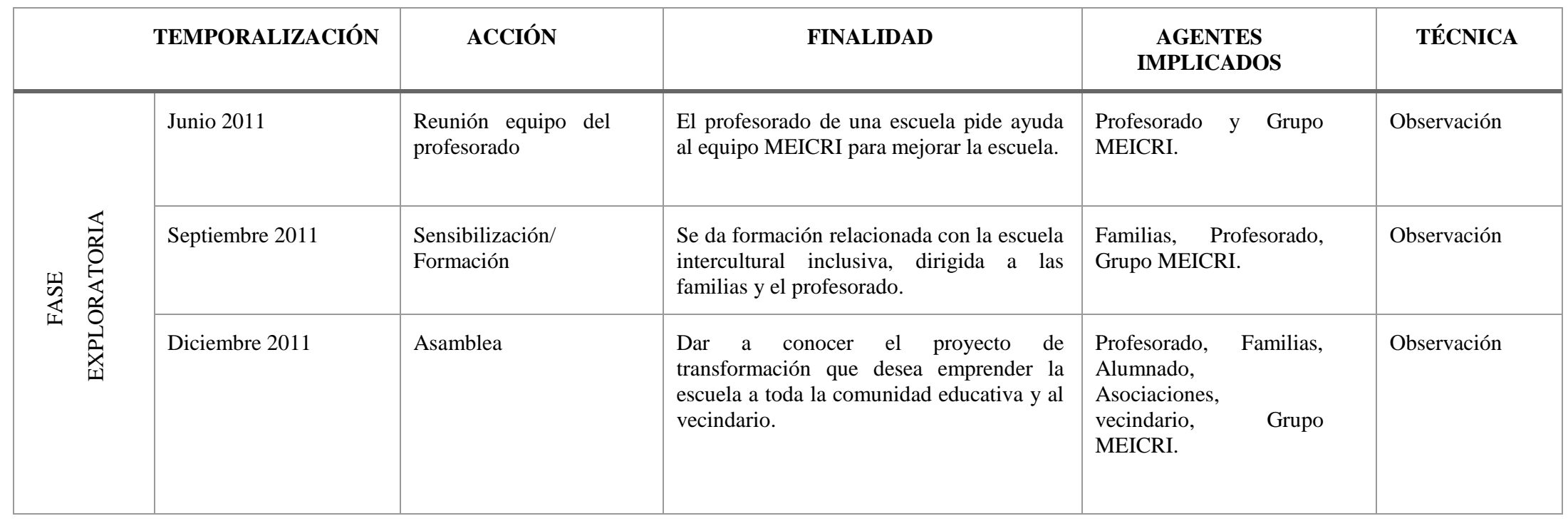




\begin{tabular}{|c|c|c|c|c|c|}
\hline \multicolumn{2}{|c|}{ TEMPORALIZACIÓN } & ACCIÓN & FINALIDAD & AGENTES IMPLICADOS & TÉCNICA \\
\hline \multirow{4}{*}{ 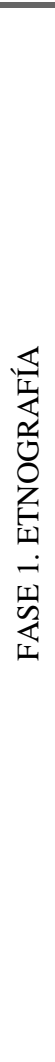 } & $\begin{array}{l}\text { De enero a junio } \\
2012\end{array}$ & Reuniones & $\begin{array}{l}\text { Realización de nueve reuniones para: analizar } \\
\text { los sueños, formar comisiones, plantear las } \\
\text { necesidades del centro y definir el proyecto de } \\
\text { tesis doctoral. }\end{array}$ & $\begin{array}{l}\text { Profesorado e Investigadora. } \\
\text { (Las familias también participan } \\
\text { en el análisis de los sueños y la } \\
\text { formación de comisiones). }\end{array}$ & $\begin{array}{l}\text { Observación y notas } \\
\text { de campo. }\end{array}$ \\
\hline & Abril - julio 2012 & $\begin{array}{l}\text { Seminario } \quad \text { de } \\
\text { formación }\end{array}$ & $\begin{array}{l}\text { Realización de cinco sesiones de formación } \\
\text { interna entre el profesorado, para dar respuesta } \\
\text { a las necesidades planteadas. }\end{array}$ & $\begin{array}{l}\text { Profesorado e investigadora (a } \\
\text { una de las sesiones se invita a } \\
\text { las familias). }\end{array}$ & $\begin{array}{l}\text { Observación y notas } \\
\text { de campo. } \\
\text { Grupo de discusión } \\
\text { profesorado. } \\
\text { Entrevistas. }\end{array}$ \\
\hline & Abril - julio 2012 & Entrada a las aulas & $\begin{array}{l}\text { Para conocer las prácticas interculturales e } \\
\text { inclusivas que se realizaban, antes, durante o } \\
\text { después del seminario de formación. } \\
\text { Para conocer la participación de las familias y } \\
\text { el alumnado. }\end{array}$ & $\begin{array}{l}\text { Profesorado, alumnado y } \\
\text { familias. }\end{array}$ & $\begin{array}{l}\text { Observación y notas } \\
\text { de campo. } \\
\text { Grupo de discusión } \\
\text { familias y alumnado. } \\
\text { Entrevistas docentes } \\
\text { (julio). }\end{array}$ \\
\hline & Junio - julio 2012 & $\begin{array}{l}\text { Conocimiento de } \\
\text { cambios en el centro }\end{array}$ & $\begin{array}{l}\text { Para conocer los cambios en el centro y la } \\
\text { valoración que hacen los miembros. }\end{array}$ & $\begin{array}{l}\text { Familias, alumnado, profesorado de } \\
\text { la comisión. }\end{array}$ & $\begin{array}{l}\text { Grupos de discusión: } \\
\text { comisión comedor, } \\
\text { familias y alumnado. } \\
\text { Diario de la } \\
\text { investigación. } \\
\text { Entrevistas. }\end{array}$ \\
\hline
\end{tabular}




\begin{tabular}{|c|c|c|c|c|c|}
\hline \multicolumn{2}{|c|}{ TEMPORALIZACIÓN } & ACCIÓN & FINALIDAD & AGENTES IMPLICADOS & TÉCNICA \\
\hline \multirow{9}{*}{ 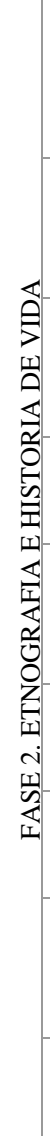 } & Octubre -2012 & Reunión Claustro & $\begin{array}{l}\text { Tras el cambio en la plantilla del profesorado, decidimos } \\
\text { acotar el estudio en el caso de una maestra. Realizamos una } \\
\text { sesión para compartir esta decisión y discutirla con el } \\
\text { profesorado. }\end{array}$ & Profesorado e investigadora & $\begin{array}{l}\text { Observación, diario de la } \\
\text { investigación y notas de } \\
\text { campo. }\end{array}$ \\
\hline & Noviembre 2012 & Tres reuniones de ciclo & Conocer el trabajo realizado desde el ciclo. & $\begin{array}{l}\text { Maestras del primer ciclo } \\
\text { investigadora }\end{array}$ & $\begin{array}{l}\text { Observación, diario de la } \\
\text { investigación y notas de } \\
\text { campo. }\end{array}$ \\
\hline & Diciembre 2012 & Reunión claustro & $\begin{array}{l}\text { Conocer el trabajo realizado por el profesorado, en relación } \\
\text { al proyecto. }\end{array}$ & Profesorado e investigadora & $\begin{array}{l}\text { Observación, diario de la } \\
\text { investigación y notas de } \\
\text { campo. }\end{array}$ \\
\hline & Diciembre 2012 & Sesión de evaluación & $\begin{array}{l}\text { Conocer la valoración final de la evaluación del alumnado } \\
\text { de la clase de Estefanía }\end{array}$ & $\begin{array}{l}\text { Profesorado de primer ciclo e } \\
\text { investigadora }\end{array}$ & $\begin{array}{l}\text { Observación y notas de } \\
\text { campo. }\end{array}$ \\
\hline & Diciembre 2012 & COCOPE & $\begin{array}{l}\text { Para tratar la convivencia y los conflictos de una clase del } \\
\text { tercer ciclo con muchas expulsiones del alumnado. }\end{array}$ & $\begin{array}{l}\text { Miembros de la COCOPE e } \\
\text { investigadora. }\end{array}$ & $\begin{array}{l}\text { Observación, diario de la } \\
\text { investigación y notas de } \\
\text { campo. }\end{array}$ \\
\hline & $\begin{array}{l}\text { Noviembre } \\
\text { diciembre } 2012\end{array}$ & $\begin{array}{l}\text { Reunión con la Comisión } \\
\text { Mixta del comedor }\end{array}$ & $\begin{array}{l}\text { Conocer el trabajo realizado desde la comisión del } \\
\text { comedor. }\end{array}$ & $\begin{array}{l}\text { Miembros de la comisión e } \\
\text { investigadora }\end{array}$ & $\begin{array}{l}\text { Observación y notas de } \\
\text { campo. }\end{array}$ \\
\hline & $\begin{array}{l}\text { Octubre y Diciembre } \\
2012\end{array}$ & $\begin{array}{l}\text { Dos sesiones del Consejo } \\
\text { Social }\end{array}$ & $\begin{array}{l}\text { Compartir y discutir el estudio con miembros de la } \\
\text { comunidad educativa o profesionales de la temática. }\end{array}$ & Miembros del consejo social & $\begin{array}{l}\text { Observación y notas de } \\
\text { campo. }\end{array}$ \\
\hline & Octubre - Diciembre & Prácticas de Aula* & Conocer las prácticas de aula realizadas por Estefanía. & $\begin{array}{l}\text { Estefanía, alumnado e investigadora. } \\
\text { (En ciertas sesiones, voluntariado). }\end{array}$ & $\begin{array}{l}\text { Observación, diario de la } \\
\text { investigación y notas de } \\
\text { campo. }\end{array}$ \\
\hline & Octubre - Diciembre & $\begin{array}{l}\text { Historia de vida de } \\
\text { Estefanía** }\end{array}$ & $\begin{array}{l}\text { Conocer la historia de vida de Estefanía para comprender } \\
\text { mejor su rol de maestra. }\end{array}$ & Estefanía e investigadora. & $\begin{array}{l}\text { Entrevistas } \\
\text { profundidad. }\end{array}$ \\
\hline
\end{tabular}

Tabla 1. Relación entre fases de la investigación y temporalización, acciones realizadas, agentes implicados y técnicas empleadas. 
*El trabajo sobre las prácticas de aula se concretó en dieciocho sesiones de observación. De estas, en siete sesiones se observaron las asambleas y las rutinas. Se dedicaron cuatro sesiones a observar la práctica de los proyectos de trabajo. Dos sesiones a observar el trabajo sobre la lectura, concretamente, a partir de tertulias literarias, y cuatro sesiones a observar el trabajo mediante grupos interactivos. De estas cuatro sesiones, la última práctica se pudo utilizar como contraste sobre las tres anteriores. Puesto que ese día, por falta de voluntariado no se pudieron realizar los grupos interactivos y se realizó el trabajo de matemáticas de manera individual. Finalmente, la última práctica registrada pertenece al día 21 de diciembre, el último día de clase del primer trimestre, en la que el alumnado de la clase, realizó una valoración sobre el tipo de prácticas realizadas en el aula.

** Para acceder a la historia de vida de la maestra mantuvimos 9 sesiones individuales con ella. De estas nueve, cinco se centraron en un trabajo biográfico. El resto las dedicamos a compartir nuestras valoraciones sobre el trabajo que se estaba realizando en el aula y en el centro.

En relación al trabajo biográfico, las dos primeras entrevistas se centraron en el pasado de la maestra, en su historia. Para la tercera entrevista, pensamos que sería interesante situarnos en un plano más horizontal con la protagonista. Por eso, la investigadora compartió también su historia de vida con este fin, el de compartir sentimientos y vivencias personales desde ambas partes En la cuarta y la quinta entrevista, fuimos analizando su vida actual, poniendo especial atención en aquellos acontecimientos que le ayudaban a ser feliz y en aquellos que le producían sufrimiento.

\subsubsection{Análisis de datos}

El proceso de análisis es el procedimiento seguido para tratar los datos y convertirlos en resultados de la investigación (Bolívar, Domingo y Fernández, 2001, p. 192). Este, se puede realizar de modo distintito en función del tratamiento que se le quiera dar a los datos y del objetivo mismo que se tenga a la hora de 
recabarlos. Por eso, en este apartado distinguiremos entre el análisis realizado para el tratamiento de los datos etnográficos que fue un análisis de contenido, y por otro lado, del tratamiento de los datos biográficos que fue un análisis narrativo. Sin embargo, las primeras fases que explicaremos a continuación son las mismas en ambos casos (Álvarez-Gayou, 2005; Miles y Huberman, 1994; Rubin y Rubin, 1995):

1. En primer lugar, obtener la información.

2. En segundo lugar, capturar, transcribir y ordenar la información.

En el caso de la primera fase de la investigación, realizamos una transcripción únicamente de aquellos datos relevantes, a partir de los que formábamos nuestras categorías. En la segunda fase de la investigación se transcribió toda la información recogida.

3. En tercer lugar, codificamos la información.

Para Rubin y Rubin (1995), codificar es el proceso mediante el cual se agrupa la información obtenida en categorías que concentran las ideas, conceptos o temas similares descubiertos por el investigador.

En este caso, para analizar los datos etnográficos se procedió a la reducción sistemática en categorías; mientras que en los datos biográficos identificamos los acontecimientos clave que aparecían a lo largo de las entrevistas, sin llegar a reducir los mismos en categorías.

En los datos etnográficos el proceso de categorización fue principalmente inductivo, ya que las categorías emergieron del propio análisis. Por una parte, construimos las categorías a partir de los datos, y por otra, tomamos como referencia la literatura, para establecer diferencias entre unas categorías u otras, e identificar aquellos datos que podrían formar parte de cada una de ellas.

En concreto, el proceso seguido consistió en: una vez recogidos los datos, leerlos detenidamente para garantizar su óptima comprensión. Después de tenerlos claros y el sentido que estos podían tener, escribimos a modo de "memos", pequeñas anotaciones interpretativas sobre los mismos, para poder comprender 
mejor el significado que el dato podía contener. Posteriormente, comparamos sistemáticamente la información obtenida desde distintas técnicas y distintos informantes y reducimos los datos en categorías.

También en este análisis diferenciamos entre los datos analizados manualmente y aquellos para los que utilizamos un programa informático (NVivo Versión 10) que facilitara la agrupación de los mismos en categorías. En ambos casos el procedimiento seguido fue el mismo, pero por cuestiones de tiempo, empezamos con un análisis manual para analizar la segunda fase de la investigación, e incorporamos la herramienta informática para analizar los datos de la primera fase, analizados posteriormente.

En el caso del análisis manual, asignamos códigos a cada dato que formaría parte de una categoría, con el fin de poder identificar posteriormente la fuente de la que procedía y su informante. En el caso de la utilización del programa informático, este código lo asignaba el programa al seleccionar la información escrita de cada una de las fuentes e introducirla en la categoría.

Las categorías que emergieron en el análisis de la segunda fase fueron un total de 69. En el caso de la primera fase emergieron 51 categorías. Posteriormente, mantuvimos aquellas categorías que nos permitían responder a nuestras preguntas de investigación, siguiendo el principio de pertinencia de Mucchielli (1988) y que además facilitarían la realización de un relato sujeto a algunos de los criterios de calidad de la investigación cualitativa, que según Guba y Lincoln (1985, p. 85) son: el valor de verdad/credibilidad, la aplicabilidad/transferencia, la consistencia/dependencia y la neutralidad/confirmabilidad. Sobre estos principios hablaremos más adelante, en este mismo apartado.

Las categorías que vienen a responder a nuestras preguntas y objetivos de la investigación son un total de 40. En la tabla 2, aparecen las categorías de manera sintetizada en función de las preguntas de investigación; de los objetivos a los que responden; de las técnicas que se utilizaron y de los informantes que participaron.

4. En cuarto lugar, integramos la información. 
Para ello, relacionamos las categorías obtenidas, en función de aquello que nos mostraban los datos y de las aportaciones teóricas escritas al respecto. En el caso de los datos etnográficos, realizamos mapas conceptuales mediante la herramienta informática Cmap Tools, que nos ayudaron a organizar las categorías entre sí (estos mapas aparecen en los resultados).

El proceso de codificación fragmenta las transcripciones en categorías separadas de temas, conceptos, eventos o estados. La codificación fuerza al investigador a ver cada detalle, cada cita textual, para determinar qué aporta al análisis. Una vez que se han encontrado esos conceptos y temas individuales, se deben relacionar entre sí para poder elaborar una explicación integrada. Al pensar en los datos se sigue un proceso en dos fases. Primero, el material se analiza, examina y compara dentro de cada categoría. Luego, el material se compara entre las diferentes categorías, buscando los vínculos que puedan existir entre ellas (Fernández Núñez, 2006, p.4).

5. En quinto lugar, vendría el momento de la obtención de resultados y la verificación de las conclusiones.

A partir de la información de las categorías, establecimos una descripción de toda la información que aparecía en cada una de ellas y en algunos casos, dotamos de significado estas afirmaciones -todas ellas extraídas de los datos-, a partir de las citas textuales de los informantes.

Para verificar las conclusiones extraídas del estudio, volvemos a los criterios de calidad nombrados anteriormente. A continuación, explicaremos en que consiste cada uno de ellos y las estrategias empleadas para asegurar dicha calidad (Rodríguez, Lorenzo y Herrera, 2005).

El primero de ellos, la credibilidad, se refiere a la veracidad que ofrecen los resultados de la investigación. Es decir, si el relato elaborado, basándonos en los datos muestra la realidad observada. Para ello, las estrategias que utilizamos, son la observación persistente, el hecho de estar el tiempo suficiente en el campo para poder obtener una mirada más real y amplia sobre el contexto; la triangulación, en nuestro caso la realizamos sobre la información aportada por distintos informantes y desde distintas técnicas; las comprobaciones de los participantes, a partir del 
consejo social en el que expusimos una primera aproximación a los resultados, pudimos contrastar nuestra mirada con la de las personas que participaban en el proceso; finalmente, la recogida de material de adecuación referencial, en el estudio utilizamos videos y grabaciones en audio para poder tener un acceso más directo a los datos.

El segundo criterio es el de la transferencia de los datos. Se refiere a la posibilidad de transferir los resultados obtenidos en el estudio a otros contextos similares. Aunque realizamos una amplia recogida de datos, que es una de las estrategias empleadas para asegurar la transferencia, nuestra pretensión en el estudio no era la generalización, sino la comprensión del caso.

La consistencia o dependencia, se refiere a la posibilidad de replicar el estudio y obtener los mismos hallazgos. Para ello, las estrategias que utilizamos es el establecer pistas de revisión. Es decir, dejar constancia de cómo se recogieron los datos, cómo se seleccionaron los informantes, qué papel desempeñó el investigador, cómo se analizaron los datos, etc.

Finalmente, el criterio de confirmabilidad, se refiere a la independencia entre los resultados y los intereses personales o concepciones teóricas del investigador. Es decir, que los resultados no corresponden a lo que al investigador le gustaría sino a aquella realidad que se muestra en el campo y que es registrada mediante distintas técnicas y desde distintos informantes. Por eso, en nuestro estudio, los resultados han sido siempre explicados con los datos. A partir de la información transcrita, de citas textuales o referencias directas.

En relación al tratamiento de los datos desde el método biográfico narrativo, el proceso seguido fue distinto, se realizó una narrativa de la historia de vida. En el análisis narrativo no se busca la reducción de los datos en categorías, sino destacar aquellos elementos singulares que configuran la historia.

En este caso, la tarea del investigador es configurar los elementos de los datos en una historia que unifica y da significado a los datos, con el fin de expresar de modo auténtico la vida individual, sin manipular la voz de los participantes. (...) El objetivo último es, a diferencia del modo paradigmático, revelar el carácter único de 
un caso individual y proporcionar una comprensión de su particular complejidad o idiosincrasia (Bolívar, Domingo y Fernández, 2001, p. 109-110).

En este sentido, en lugar de separar los datos en categorías, se trata de integrarlos para la elaboración coherente de la historia de vida narrada por el informante. Según Bolívar, Domingo y Fernández, (2001), nunca se pueden atrapar los matices de la narrativización de una vida bajo una categoría temática, porque en estos análisis no se capta la dimensión personal-afectiva. Cuando desaparece el carácter narrativo en el informe por un fuerte tratamiento categorial o analítico, la investigación deja de ser narrativa.

Siguiendo estos parámetros, el procedimiento seguido para realizar el análisis y posterior elaboración del informe, fue el siguiente: en primer lugar, transcribimos las entrevistas realizadas sobre la historia de vida de Estefanía. Posteriormente, ordenamos la información tratando de seguir el orden cronológico que marcaba su biografía, al mismo tiempo que tratamos de presentarla en relación a los acontecimientos más importantes de su vida. De este modo realizamos un primer borrador de la historia de vida, ciñéndonos al máximo a las palabras utilizadas por la protagonista. Una vez elaborado este borrador, lo compartimos con la protagonista de la historia, quien cambió alguna expresión por no expresar el sentido que ella quería, y resumió algunas ideas que se habían abordado más ampliamente a lo largo de las entrevistas. Finalmente, la protagonista eligió una canción significativa para poder encabezar cada una de las etapas de su vida y tras una lectura compartida del informe, se dio por finalizada la redacción de la historia de vida.

La redacción, fue un trabajo laborioso y compartido entre investigadora y protagonista, si bien el trabajo de la investigadora se dedicó a ordenar las ideas fue la narrativa colaborativa de la investigadora y de la protagonista, la que aportó vitalidad y sentido a la historia de vida. 


\begin{tabular}{|c|c|c|c|c|c|}
\hline & OBJETIVOS & CATEGORÍAS & ACCIONES & TÉCNICAS & INFORMANTES \\
\hline$\dot{0}$ & \multicolumn{5}{|c|}{ ¿Cómo es el proceso de cambio de la escuela hacia el modelo intercultural inclusivo? } \\
\hline & $\begin{array}{l}\text { 1. Conocer las } \\
\text { condiciones que existen } \\
\text { para que se realice el } \\
\text { cambio en el centro } \\
\text { hacia el modelo } \\
\text { intercultural inclusivo. }\end{array}$ & $\begin{array}{l}\text { 1. Implicación } \\
\text { 2. Objetivo compartido. } \\
\text { 3. Ilusión. } \\
\text { 4. } \\
\text { 5. } \\
\text { 6. Compartir experiencias. } \\
\text { 7. Concepciones pedagógicas. } \\
\text { 8. Contagio. } \\
\text { 9. Estructura y organización } \\
\text { 10. Liderazgo equipo directivo }\end{array}$ & $\begin{array}{l}\text { Reuniones fase } 1 . \\
\text { Seminario de } \\
\text { formación } \\
\text { Reuniones de ciclo } \\
\text { Reunión claustro fase } \\
2 . \\
\text { Observaciones aula. } \\
\text { Reuniones Consejo } \\
\text { Social }\end{array}$ & $\begin{array}{l}\text { Observación } \\
\text { Grupos de } \\
\text { discusión } \\
\text { Entrevistas }\end{array}$ & $\begin{array}{l}\text { Profesorado } \\
\text { Familias } \\
\text { Alumnado }\end{array}$ \\
\hline
\end{tabular}




\begin{tabular}{|c|c|c|c|c|c|}
\hline & OBJETIVOS & CATEGORÍAS & ACCIONES & TÉCNICAS & INFORMANTES \\
\hline$\stackrel{\square}{\oplus}$ & \multicolumn{5}{|c|}{ ¿Cómo es el proceso de cambio de la escuela hacia el modelo intercultural inclusivo? } \\
\hline & $\begin{array}{l}\text { 2. Conocer los obstáculos } \\
\text { que se encuentran a lo } \\
\text { largo del proceso. }\end{array}$ & $\begin{array}{l}\text { 11. Creencias del profesorado. } \\
\text { 12. Prejuicios profesorado. } \\
\text { 13. Bajas expectativas. } \\
\text { 14. Cultura profesionalista. } \\
\text { 15. Democratización (falta de). } \\
\text { 16. Colaboración docente (falta de). } \\
\text { 17. Cultura dominante } \\
\text { 18. Conflictos interculturales. }\end{array}$ & $\begin{array}{l}\text { Reuniones fase } 1 . \\
\text { Seminario de } \\
\text { formación } \\
\text { Reuniones de ciclo } \\
\text { Reunión claustro } \\
\text { fase } 2 . \\
\text { Prácticas aula } \\
\text { Comisión del } \\
\text { comedor } \\
\text { Sesión de } \\
\text { tutorización para el } \\
\text { Consejo Social }\end{array}$ & $\begin{array}{l}\text { Observación } \\
\text { Grupos de } \\
\text { discusión } \\
\text { Entrevistas }\end{array}$ & $\begin{array}{l}\text { Profesorado } \\
\text { Familias } \\
\text { Alumnado }\end{array}$ \\
\hline
\end{tabular}




\begin{tabular}{|c|c|c|c|c|c|}
\hline & OBJETIVOS & CATEGORÍAS & ACCIONES & TÉCNICAS & INFORMANTES \\
\hline 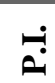 & \multicolumn{5}{|c|}{ ¿Cómo es el proceso de cambio de la escuela hacia el modelo intercultural inclusivo? } \\
\hline & $\begin{array}{l}\text { 3. Conocer las } \\
\text { transformaciones } \\
\text { que se realizan en } \\
\text { el centro y en las } \\
\text { aulas, en concreto } \\
\text { en un aula de } \\
\text { primero de primaria. }\end{array}$ & $\begin{array}{l}\text { CENTRO } \\
\text { 19. Apertura centro. } \\
\text { 20. Comisiones. } \\
\text { 21. Apertura aulas. } \\
\text { 22. Resultados aprendizaje. } \\
\text { 23. Relación familia - escuela. } \\
\text { 24. Voz del alumnado. } \\
\text { 25. Conocimiento del cambio. } \\
\text { 26. Conocimiento de las prácticas de aula. } \\
\text { 27. Voz familias. } \\
\text { 28. Mejoras personales. } \\
\text { 29. Implicación en las aulas. }\end{array}$ & $\begin{array}{l}\text { Reuniones fase } 1 . \\
\text { Seminario de } \\
\text { formación } \\
\text { Comisión del } \\
\text { comedor } \\
\text { Sesiones de } \\
\text { Consejo Social } \\
\text { Observaciones } \\
\text { aulas } \\
\text { Sesión de } \\
\text { tutorización para el } \\
\text { Consejo Social }\end{array}$ & $\begin{array}{l}\text { Observación } \\
\text { Grupos de } \\
\text { discusión } \\
\text { Entrevistas }\end{array}$ & $\begin{array}{l}\text { Profesorado } \\
\text { Familias } \\
\text { Alumnado }\end{array}$ \\
\hline
\end{tabular}




\begin{tabular}{|c|c|c|c|c|c|}
\hline & OBJETIVOS & CATEGORÍAS & ACCIONES & TÉCNICAS & INFORMANTES \\
\hline 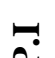 & \multicolumn{5}{|c|}{ ¿Cómo es el proceso de cambio de la escuela hacia el modelo intercultural inclusivo? } \\
\hline & $\begin{array}{l}\text { 3. Conocer las } \\
\text { transformaciones que } \\
\text { se realizan en el centro } \\
\text { y en las aulas, en } \\
\text { concreto en el aula de } \\
\text { Estefanía. }\end{array}$ & $\begin{array}{l}\text { AULA (Estefanía) } \\
\text { 30. Prácticas aula. } \\
\text { 31. Diversidad. } \\
\text { 32. Gestión del grupo. } \\
\text { 33. Coop./ Competición. } \\
\text { 34. Flexibilidad tarea. } \\
\text { 35. Ayudar (interacciones entre iguales). } \\
\text { 36. Copiar. } \\
\text { 37. Participación alumnado. }\end{array}$ & $\begin{array}{l}\text { Realización de } \\
\text { prácticas clase } \\
\text { Estefanía }\end{array}$ & $\begin{array}{l}\text { Observación } \\
\text { Grupos de } \\
\text { discusión } \\
\text { Entrevistas }\end{array}$ & $\begin{array}{l}\text { Profesorado } \\
\text { Familias } \\
\text { Alumnado }\end{array}$ \\
\hline
\end{tabular}




\begin{tabular}{|c|c|c|c|c|c|}
\hline \multirow{2}{*}{$\sim^{\circ}$} & OBJETIVOS & CATEGORÍAS & ACCIONES & TÉCNICAS & INFORMANTES \\
\hline & ¿Cómo se puede intę & dimensión personal y emocional e & la? & & \\
\hline & $\begin{array}{l}\text { 4. Analizar el estilo } \\
\text { docente de Estefanía } \\
\text { para conocer cómo } \\
\text { trabaja la dimensión } \\
\text { personal de su alumnado } \\
\text { en el aula. }\end{array}$ & $\begin{array}{l}\text { 38. Estilo docente. } \\
\text { 39. Educar en saber estar. } \\
\text { 40. Emociones. }\end{array}$ & $\begin{array}{l}\text { Realización de } \\
\text { prácticas clase } \\
\text { Estefanía } \\
\text { Reuniones de primer } \\
\text { ciclo }\end{array}$ & $\begin{array}{l}\text { Observación } \\
\text { Entrevista a } \\
\text { Estefanía. }\end{array}$ & $\begin{array}{l}\text { Alumnado y } \\
\text { Estefanía }\end{array}$ \\
\hline & $\begin{array}{l}\text { 5. Trabajar la historia } \\
\text { de vida de Estefanía } \\
\text { como una herramienta } \\
\text { de autoconocimiento } \\
\text { para poder aportar una } \\
\text { educación integral al } \\
\text { alumnado. }\end{array}$ & Construcción del relato narrativo. & Historia de vida & $\begin{array}{l}\text { Entrevistas en } \\
\text { profundidad a } \\
\text { Estefanía }\end{array}$ & Estefanía \\
\hline
\end{tabular}

*El sexto objetivo de la investigación "Fomentar la reflexión y el cambio en la escuela", no aparece en la tabla, ya que pensamos que es un propósito transversal del estudio y se tiene en cuenta a lo largo de las distintas sesiones realizadas. 


\subsection{Posición de la investigadora}

Cabe destacar que la entrada en el campo supuso una transformación en mí como persona e investigadora. Quizás por mi manera de ser, una persona bastante perfeccionista y con ideas poco flexibles, el hecho de embarcarme -animada por mis directores- en este tipo de investigación cualitativa fue un reto para superar algunas limitaciones mentales, como son la necesidad de control y la exigencia que estaban y siguen estando, aunque quizás en menor medida, dentro de mí.

En este sentido, el de la exigencia, la investigación etnográfica ha supuesto una revolución en la manera de relacionarme y de comprender al profesorado. Aunque en mi vida estoy rodeada de maestros (antiguos compañeros de la carrera de magisterio, amigos, mi pareja y mi madre), y siento una gran admiración hacia estas personas y su trabajo, también me había posicionado hasta el momento con un cierto recelo hacia las creencias de este colectivo en su conjunto. El hecho de que la educación sea un lugar para soñar y para construir una realidad más justa me llevaba en muchos casos al juicio hacia los maestros y las maestras que no emprendían estas acciones más interculturales e inclusivas. Estos juicios se fueron disipando en la medida en la que pude conocer la realidad de la escuela, la cotidianidad de las aulas y sobre todo, a partir de la relación que se creó con todo el colectivo del profesorado.

En mis primeras sesiones la relación se inició con el equipo directivo, quienes desde el primer momento me permitieron sentirme tranquila por mi inexperiencia y me hicieron sentir que aunque estaba realizando mi tesis en la escuela, el proceso del cambio era un proyecto compartido, que sobre todo, era del centro y de sus gentes. En las siguientes sesiones, ya con el claustro, pude observar la multitud de actitudes hacia el cambio. En ese momento yo desaprobaba aquellas que valoraba como resistentes a la innovación. Poco a poco, a partir de la confianza que tuvimos 
unos con otros, la comprensión de la vida en la escuela me resultaba muy interesante y pude empezar a apreciarla con una mirada nueva, menos juiciosa y más curiosa. Esta parte pienso que fue posible debido al tiempo que pasé en el centro, que me permitió establecer una relación cercana con casi todo el profesorado. También la entrada a las aulas fue un aspecto clave a la hora de establecer esa relación más horizontal entre investigadora y profesorado.

Por otra parte, el control también es una característica que he podido trabajar en la investigación. En la entrada al centro no tenía demasiado claro cuál sería el problema de investigación, aunque estaba relacionado con el proceso de cambio que iba a emprender el centro. Por eso, nunca me sentía preparada para poder entrar a trabajar con un colectivo de profesionales de la educación, con un grado de experiencia y con altas expectativas sobre el cambio. Finalmente, empujada de nuevo por mis directores, me decidí a entrar en la escuela, sin tenerlo todo controlado. Sin saber demasiado bien en qué consistiría mi tesis, y sobre todo, sin estar segura de si sería capaz de acompañar a la escuela y de hacerlo bien. Pero es precisamente en esta parte en la que tiene riqueza la investigación. Creo que gracias a ese soltar el control, la investigación pudo ser un proyecto compartido y tener sentido para el profesorado y para mí.

Por todo lo expuesto, quizás esta investigación rompió una parte de mis esquemas mentales, o limitaciones. Los transformó, y esto es debido al tipo de investigación empleada, que siempre ha tratado de estar conectada a la vida del centro, de sus gentes y a la relación entre personas.

El trabajo etnográfico me acercó a los maestros, a las familias, al conserje, la cocinera, una parte del alumnado... me acercó a una parte más personal de la investigación. Del mismo modo, el trabajo biográfico con Estefanía me llevó como investigadora a un autodescubrimiento interior. Su manera de explicitar su historia de vida me ayudó a ser consciente de algunos aspectos emocionales que no estaban trabajados en mi vida. También me ayudó a reflexionar sobre cómo situaciones 
vividas con dolor y sufrimiento, vistas desde otro ángulo tomaban un rumbo distinto.

Para mí el trabajo biográfico fue un regalo, que me permitió mirarme por dentro desde el reflejo de otra persona. El encuentro del personaje, de los momentos de luz y de sombra que podemos descubrir en nuestra biografía, los he podido observar desde mi acompañamiento a otra persona, que sin saberlo, me estaba acompañando a mí.

En base a estos principios personales y a nuestra manera de entender la educación, los maestros y la comunidad educativa en general, nos planteamos las siguientes cuestiones éticas a la hora de investigar.

\subsection{Cuestiones éticas}

La ética de la investigación es un aspecto básico a tener en cuenta en todas las investigaciones. Aunque en España no exista una institucionalización sobre cuestiones éticas, sí que hay una preocupación sobre el uso de la información, el tratamiento de los datos y en las relaciones establecidas entre informantes e investigador en las investigaciones realizadas.

A continuación, destacaremos algunos de los códigos éticos a tener en cuenta en relación a los participantes de la investigación, basándonos en Sandín (2003):

- El consentimiento informado. Implica que los participantes en la investigación hayan sido informados sobre el estudio y estén al corriente de aquello que va a ser investigado y las implicaciones que ello tiene. Además, este principio ético también pone de manifiesto que los sujetos deben aceptar voluntariamente participar en la investigación, a sabiendas de todo lo que esto supondría. 
En nuestra investigación, desde el inicio se realizó una reunión con el equipo directivo y posteriormente con el claustro, para informar al profesorado de la realización del estudio en el centro. Aunque ya desde el principio se sentaron las bases de lo que suponía realizar una investigación en el contexto, a medida que se fue definiendo el problema e iban apareciendo nuevas acciones, estas eran consensuadas con el profesorado. Además, en el caso de que participaran otros agentes además del profesorado, se volvía a informar de las implicaciones de la investigación, del posterior tratamiento de datos y de la difusión de los mismos, y con toda la información se pedía el consentimiento a todas las personas que participaban de determinada acción.

- La privacidad y la confidencialidad. Desde este principio se trata de proteger la identidad de los informantes.

En nuestro caso, hemos mantenido el anonimato de los informantes, utilizando pseudónimos. En el caso de la historia de vida, los nombres utilizados son los que decidió Estefanía.

- La estancia en el campo. Se refiere a adoptar una postura de investigación abierta o encubierta. Es decir, si se hace o no explícito el objeto a investigar.

En nuestro caso, el hecho de definir acotar el problema de investigación junto con el profesorado nos ayudó a que en todo momento este colectivo estuviera informado sobre el objeto de estudio. Así mismo, también se planificaron otras acciones de manera conjunta, como la realización del seminario, así como los criterios establecidos para seleccionar al alumnado en los grupos de discusión o las temáticas propuestas en relación a las preguntas de los grupos de discusión. Por otra parte el consejo social fue un órgano de gran ayuda para poder establecer ese vínculo entre el contexto y el marco de la investigación. En los distintos encuentros realizados, tanto para preparar las sesiones, como para presentar los temas y discutirlos, se realizó un trabajo colaborativo con otros colectivos. Por eso 
pensamos que durante todo el proceso hubo sinceridad en relación a los temas investigados y se plantearon las propuestas y las acciones sin tratar de encubrir información.

En relación a los códigos éticos del desarrollo del trabajo de campo y la difusión de los resultados, destacamos los siguientes (Dorio, Sabriego y Massot, 2009):

- No plagiar o apropiarse de los resultados de otros compañeros.

- No encubrir información o tratar de informar erróneamente sobre las fuentes o inventando los resultados.

- $\quad$ No destruir fuentes y datos, para los que vengan después.

Finalmente, algunas consideraciones que destacan Dorio, Sabriego y Massot (2009), en relación a una comunicación ética de los resultados son, que aquellos investigadores responsables no presentan datos de los que dudan sobre su veracidad y que no ocultan las objeciones que no pueden rebatir. Además, es importante que, una vez obtenidos los resultados y las conclusiones, se consensue su veracidad con los informantes. De lo contrario, se puede realizar un uso indebido de la información.

En nuestro caso, como hemos comentado, los resultados de la primera fase de la investigación fueron compartidos en poco tiempo con los informantes de cada una de las acciones realizadas, por si no se había entendido bien la información o se quería matizar algún aspecto. En el caso de la segunda fase, el análisis de la historia de vida y de las prácticas de aula fue consensuado con Estefanía. Además, una vez escrito el informe también le fue devuelto a la maestra para que pudiera discutir todos los aspectos que considerase. En relación a la observación y resultados sobre el proceso de cambio de la escuela, fue valorado, junto con las prácticas de aula y la historia de vida de Estefanía en el consejo social. 


\section{Resultados}

El privilegio del faraón de vivir en compañía de su alma, debía de estar ligado a una especial sabiduría: saber del origen, de dónde venía y a dónde habría de retornar; vivir a la manera de un viajero que conoce y a memoria de su ruta desde el lugar de partida $y$, por ello sabe en verdad el sentido de cada acontecimiento (María Zambrano, 1973, p. 104).

A la hora de redactar los resultados seguiremos el orden que marcan las preguntas de investigación y los objetivos que tratan de responder a las mismas. Por eso, empezaremos por responder a la primera pregunta de investigación:

¿Cómo es el proceso de cambio de la escuela hacia el modelo intercultural inclusivo?

En primer lugar, explicaremos las condiciones que existen para que se realice el cambio en el centro, hacia el modelo intercultural inclusivo. En segundo lugar, indagaremos en los obstáculos que aparecen en la escuela y que dificultan su transformación hacia dicho modelo educativo. En tercer lugar, para saber si el cambio se ha realizado y en qué medida se han conseguido las transformaciones, nos detendremos en cada una de ellas, distinguiendo entre aquellas que se han 
realizado en el centro y las que hemos detectado en las aulas, más concretamente en el aula de Estefanía.

En el caso de la segunda pregunta de investigación:

¿Cómo se puede integrar la dimensión personal y emocional en la escuela intercultural inclusiva?

La respuesta a la pregunta nos la dan los objetivos de la investigación que se centran en la maestra, para conocer cómo trabaja ella la dimensión personal del alumnado en el aula. En primer lugar, analizaremos su estilo docente y su propósito sobre su manera de educar al alumnado. En esta parte, los resultados nos llevan a la cuestión de si se educa al alumnado para estar, para "saber comportarse", o para ser.

En segundo lugar, trabajaremos la historia de vida, que a su vez la consideramos una herramienta fundamental en el camino del autoconocimiento, imprescindible para posteriormente, trabajar esta dimensión más personal con el alumnado.

En cuanto a los resultados agrupados en categorías, expondremos en un primer momento los mapas conceptuales realizados, con el fin de facilitar la lectura de los datos. Estos mapas, están al mismo tiempo, descompuestos en mapas "más pequeños", con menos conceptos, con el fin de situar al lector en cada una de las categorías que se vayan a tratar en ese apartado.

El primer mapa que aportaremos es para clarificar cómo se exponen los resultados. En él aparecen tanto las preguntas como los objetivos de la investigación. El segundo tipo de mapas que encontraremos, serán aquellos que sitúen en el encabezado los objetivos de la investigación y en un segundo y tercer nivel, las principales categorías extraídas. Sin embargo, aportamos también un tercer mapa, que nos permita explicar mejora las categorías anteriores.

En el caso de la historia de vida, narraremos el relato pasando por sus diferentes etapas hasta el momento en el que se realizaron las entrevistas. Después, nos acercaremos a su presente y mostraremos la información de las entrevistas a 
modo de diálogo. Un diálogo horizontal entre Estefanía y la investigadora, en el que, desde conversaciones entre amigas mostraremos cómo se realizó el trabajo emocional y de autoconocimiento. Esta historia finaliza con el testimonio de Estefanía desde la actualidad, tres años después de las entrevistas.

Otra de las consideraciones a tener en cuenta en este apartado, es la codificación que se ha utilizado para cada una de las citas extraídas, en función de la fuente y los informantes. Para ello, adjuntamos una tabla (Ver anexo) con la referencia que citamos en los resultados y el código equivalente según la fuente a la que se refiere. Además, destacamos que todas las citas textuales aparecen en cursiva. Así mismo, también resaltamos en cursiva aquellas palabras que nos ayudan a comprender mejor los resultados, para conseguir visibilizar los conceptos importantes en cada una de las categorías.

Antes de empezar con la exposición de los datos, recordamos el último objetivo de nuestra investigación, que como hemos mencionado, lo consideramos transversal en el estudio: "Fomentar la reflexión y el cambio en la escuela". Este objetivo está presente a lo largo del trabajo, en las reuniones y sesiones compartidas con la comunidad educativa. Especialmente, se fomenta la reflexión y el cambio en la escuela, en las reuniones desde enero hasta abril del curso 2011 2012, para hablar sobre el proceso de transformación y reflexionar sobre las acciones que se realizaban o se pensaban realizar desde el centro. Por otra parte, el seminario de formación es otro de los espacios en los que el profesorado reflexiona sobre las prácticas para mejorarlas.

Durante el curso 2012 - 2013, esta reflexión se da entre la investigadora y Estefanía, en las prácticas de aula que ella realiza y en las entrevistas sobre el trabajo biográfico. Además, también se reflexiona sobre los cambios a nivel de centro, a partir de las reuniones del ciclo, de las sesiones del claustro, de las reuniones con la comisión del comedor y de las sesiones con el Consejo Social. Por 
eso, pensamos que es un objetivo que se mantiene a lo largo del estudio, gracias a la participación e implicación del alumnado, el profesorado y de las familias.

A continuación, adjuntamos el primer mapa conceptual:

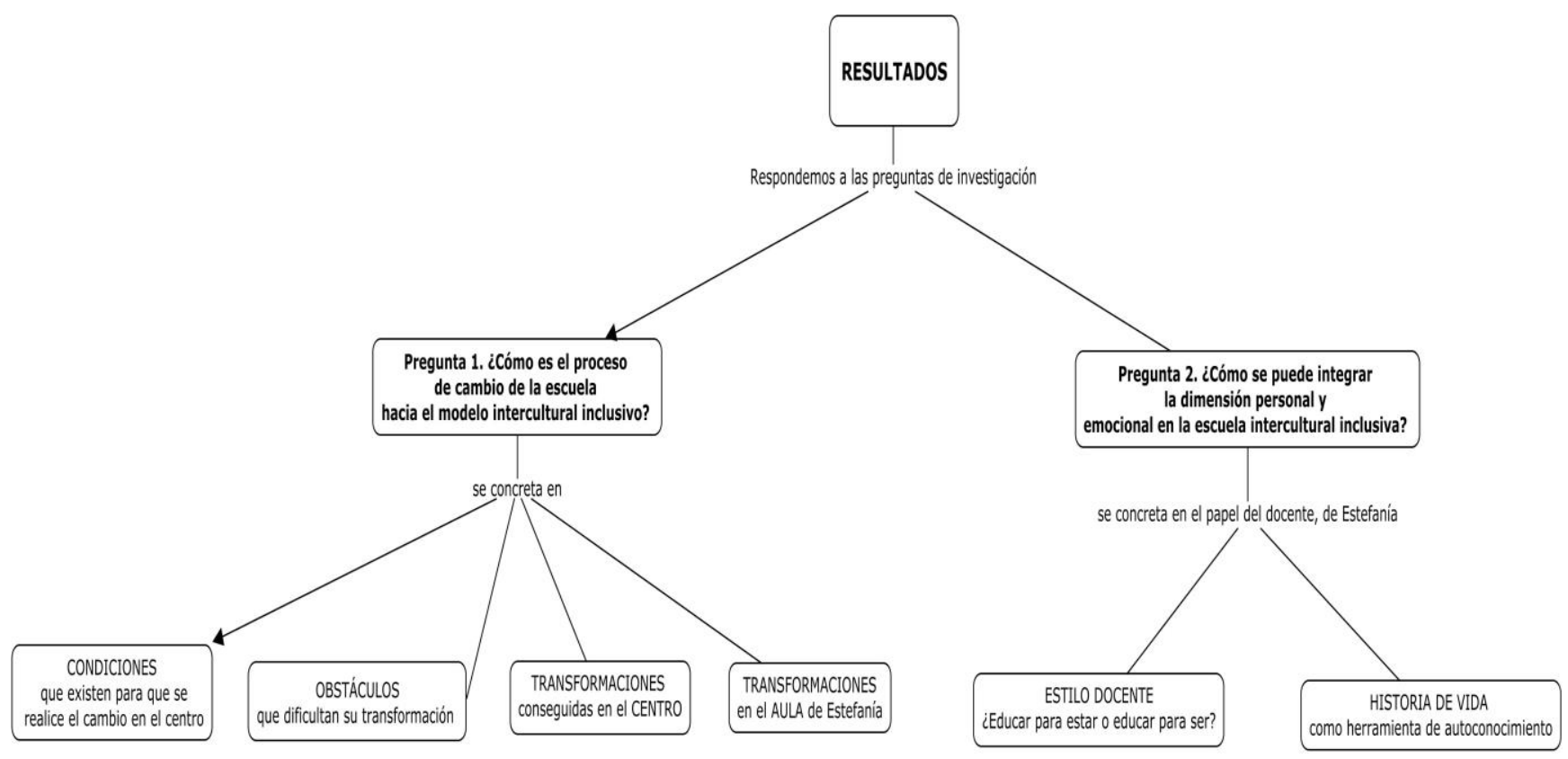

Figura 4. Mapa conceptual resultados 


\subsection{Las condiciones del cambio}

En primer lugar hablaremos sobre las creencias del profesorado respecto el cambio, basándonos en el hecho de si existe un objetivo compartido y sobre las concepciones pedagógicas, así como la ilusión que suscita el cambio en sus agentes.

En segundo lugar nos detendremos en la estructura y la organización del centro como aspectos favorables para la realización de transformaciones. En tercer lugar, hablaremos sobre el liderazgo y concretamente el liderazgo que ejerce sobre el cambio el equipo directivo.

En cuarto lugar, encontramos categorías sobre la implicación como un factor primordial para que el cambio sea posible. Finalmente, otra de las categorías que aparecen es el compartir experiencias, favoreciendo el contagio y el establecimiento de compromisos hacia el cambio.

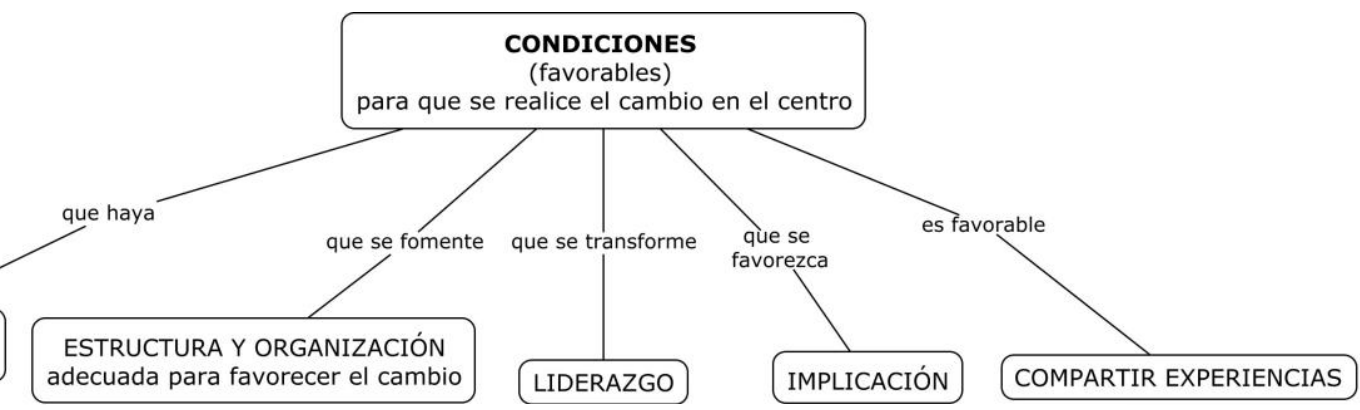

Figura 5. Categorías condiciones para que se realice el cambio. 


\subsubsection{Creencias favorables hacia el cambio}

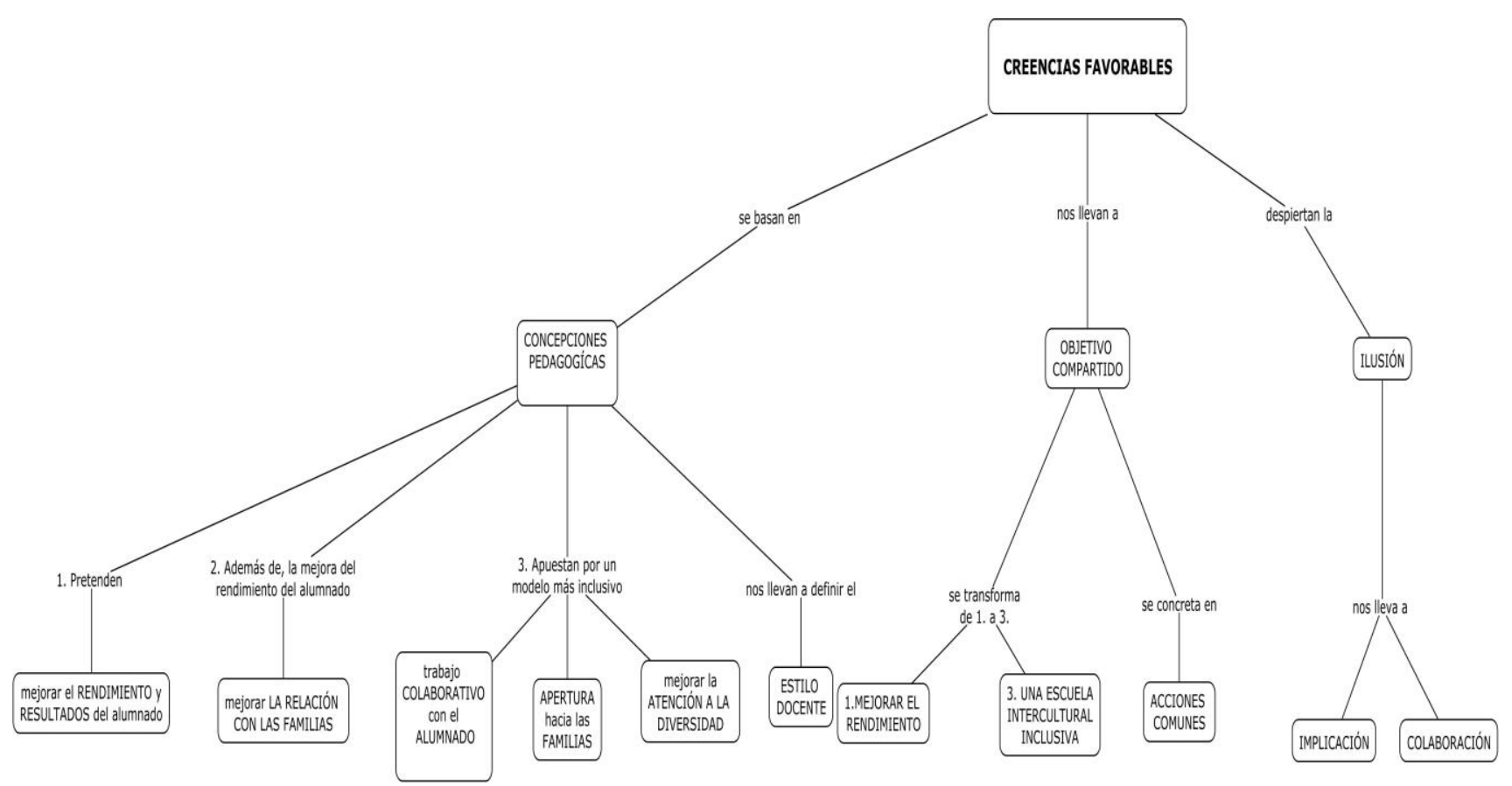

Figura 6. Categorías creencias favorables.

Empezaremos hablando de las creencias positivas sobre el cambio, en concreto de las creencias del profesorado, ya que en este caso es el colectivo que actúa como motor de la transformación. Antes de empezar, queremos destacar que las creencias son tanto una condición fundamental para el cambio, como al mismo tiempo un obstáculo. Con esto queremos decir que, si no se cree en el cambio -al menos una parte de las personas implicadas-, y en el modelo educativo que desde él se promueve, este no llegará a realizarse. Sin embargo, como veremos más adelante, la misma palanca de arranque es a la vez, en los casos de aquellos que no creen en el cambio, un elemento limitador para que se produzca el cambio.

En este apartado hablaremos sobre las creencias del profesorado a partir de las siguientes categorías: las concepciones pedagógicas y el objetivo compartido. Además de la ilusión hacia el cambio, que también es fruto de cómo nos posicionamos respecto al mismo, y de este modo, de nuestras creencias. 


\subsubsection{Concepciones pedagógicas}

Por eso, en primer lugar nos situamos en las concepciones pedagógicas del profesorado. Esta es una de las categorías claves, a la hora de comprender el cambio así como las innovaciones introducidas en el aula.

En relación a las concepciones pedagógicas podemos diferenciar entre aquellas que están encaminadas a mejorar el rendimiento y el resultado del alumnado; aquellas que, además de esto, quieren mejorar la relación con las familias; y finalmente, las que pretenden hacerlo desde un modelo que valore la diversidad.

Podríamos decir que la intención fundamental por la que se pretenden cambiar las acciones del centro es para mejorar el rendimiento del alumnado. Como hemos comentado, por las características socio-culturales de las familias, el alumnado tiene dificultades en alcanzar los resultados académicos esperados según su edad. Por esa razón, en la escuela han buscado y han implementado distintos programas que les ayudarán a mejorar el rendimiento. Sin embargo, en general siguen sin estar satisfechos con los resultados alcanzados. Por eso deciden emprender este proyecto que trata de conseguir cambios y transformaciones, basadas en un modelo de igualdad de oportunidades.

Las razones por las que deciden implicarse como colectivo es para mejorar el rendimiento. Sin embargo, no todos entienden de la misma manera este proceso. Para algunos es una posibilidad para mejorar, para otros es algo más que probar pero no tiene demasiado sentido en sí mismo.

Maestra de primer ciclo: Estamos buscando algo que nos ayude, porque a mí me cuesta con estos niños, que mantengan la atención. Siempre estamos buscando alguna cosa que les enganche. Ver allí tantas técnicas que estaban funcionando era como ver que estábamos salvados.

Estefanía: Era totalmente diferente, el ver allí a las familias, al alumnado... era ver que las familias podían entrar,... Cuando nos lo explicaron era todo muy 
utópico, pero cuando lo vimos fue ver que era posible. (Entrevista a primer ciclo. Referencia 1.)

En este caso, las dos maestras de primer ciclo hacen referencia a una escuela que también había iniciado un proceso de transformación hacia un modelo intercultural inclusivo. Esta escuela está en Terrassa (Tarragona). Aunque está en otra comunidad autónoma, el profesorado de la escuela se organizó en dos viajes para conocer las acciones que realizaban y que les permitían obtener buenos resultados con el alumnado y una buena relación con las familias. En este caso, al igual que al de otros maestros que fueron a visitar esa escuela, se asocia el ver con el creer. Pero tengamos en cuenta que, todas las personas que fueron a visitar la escuela tenían esta predisposición hacia un tipo de escuela distinto al que conocían. Creían que era posible que el alumnado mejorara sus resultados y que las familias participaran en las acciones del centro. Para ellos el cambio sí que tenía sentido.

Los motivos por los que existía esa predisposición, los asociamos precisamente a las concepciones pedagógicas (sus creencias pedagógicas) y al estilo docente del profesorado (su manera de hacer docencia). El hecho de que sean personas que busquen algo distinto, si no se sienten satisfechos con los resultados conseguidos como expresaba la maestra de primer ciclo, les lleva a buscar acciones distintas. También su carácter inquieto, en busca de innovaciones.

Como nos comenta Estefanía, en su caso siempre ha sido una maestra a la que le ha gustado innovar en el aula. Pero no conocía algunas de las prácticas que favorecían un trabajo más colaborativo entre el alumnado, una apertura hacia las familias y una atención más adecuada hacia la diversidad. Por eso, en su caso, ella asocia la innovación que ha ido introduciendo en sus prácticas como una ayuda para ir definiendo un estilo docente más acorde con sus creencias pedagógicas.

Estefanía: ¿Mi estilo? Siempre me ha gustado innovar con el alumnado. Pero no aplicaba estas técnicas y en algunas asignaturas acababa haciendo cosas de las que no era partidaria (como el utilizar demasiado el libro de texto). En otras asignaturas sí que hacía cosas distintas, aunque no le pusiera nombre. (Entrevista a Estefanía. Referencia 3). 
Estefanía: Las técnicas van cambiando el estilo docente, en mi caso sí. Porque cambia la figura del maestro, ya no es quién da la clase magistral. El maestro es un observador, cambias tu perfil y para una persona que quiere innovar eso es fundamental. (Entrevista a Estefanía. Referencia 4).

Es por esto que, en el caso del profesorado de esta escuela, podemos afirmar que existe una predisposición hacia el cambio, en aquellas personas con un estilo más dispuesto a innovar y con una sensibilidad hacia la diversidad.

Si nos centramos en la dirección del cambio, en esta escuela está orientado hacia la interculturalidad y la inclusión. Por eso, creer en el cambio implica también creer en la inclusión y en la interculturalidad.

En este sentido, para que el cambio sea un proceso compartido es necesario que las concepciones pedagógicas del profesorado se acerquen a este objetivo: la innovación educativa en busca de favorecer y dar una respuesta adecuada a la diversidad. Por eso, llegados a este punto hablaremos de la importancia de establecer un objetivo compartido.

\subsubsection{Objetivo compartido}

Como hemos comentado, para caminar juntos y transformar, necesitamos un objetivo compartido que nos dirija hacia acciones comunes. Esto es una condición necesaria que ha favorecido el cambio en esta escuela. Sin embargo, tratando de hacer explícito el proceso del cambio, nos encontramos en que el objetivo compartido se ha ido redefiniendo para el profesorado.

Desde el inicio del proceso, el conjunto del profesorado compartía la necesidad de mejorar el rendimiento del alumnado y las relaciones con las familias. No obstante, la mayor preocupación era que el alumnado llegara satisfactoriamente al instituto y que las familias se implicaran en la educación de sus hijos. Sin embargo, la mirada de una parte del profesorado hacia las familias no buscaba una 
relación colaborativa con ellos. A las familias se las veía, y una parte del profesorado las sigue viendo a lo largo del estudio, como una parte importante de la educación del alumnado, pero ajenas a la escuela. Para otra parte del profesorado que coincide con unas concepciones docentes más acordes con la inclusión y la interculturalidad, la mirada sobre las familias cambia. Ahora se ven como compañeras en el proceso para conseguir una mejora educativa en la escuela. Fruto de estas creencias y esta nueva manera de hacer escuela, se transforman las relaciones y se transforma también el objetivo que comparten. Ahora este no se limita a mejorar el rendimiento del alumnado, sino que una parte fundamental del cambio es que sea compartido. Entonces, cambian las expectativas hacia las familias y hacia el alumnado y el objetivo que se comparte, el de la mejora del rendimiento y la relación con las familias, tiene una base inclusiva e intercultural. Tiene una base colaborativa y de respeto hacia las otras personas que forman parte de la escuela.

Jefa Estudios: El objetivo ahora es que entren las familias. A mí el contacto me ha gustado y en muchos casos ha mejorado. Que entren las familias para el rendimiento también es bueno.

Director: Para mí también, ahora es incluso más importante, porque el rendimiento lo están trabajando también los maestros. Pero con las familias han pasado muchas cosas impresionantes, muy bonitas.

Jefa de Estudios: Yo salí encantadísima del grupo de discusión de las familias. (Entrevista equipo directivo. Referencia 1).

Para otra parte del profesorado, el objetivo también es que las familias se impliquen, pero no las sitúan como compañeras en el cambio. Su manera de verlas es distinta, opinan que no se interesan por la educación de sus hijos. Algunas maestras opinan que debido a las diferencias culturales, otras que debido a su situación personal:

Dos maestras de segundo ciclo explican que las situaciones de las familias son distintas, por eso tienen otras preocupaciones. Sus preocupaciones, según estas maestras, son comer y vivir. (Entrevista a segundo ciclo. Referencia 1). 
Sin embargo, la realidad que se muestra en la escuela es que el profesorado tiene dificultad a la hora de realizar un camino compartido con otros agentes, en este caso, con las familias.

Maestra de infantil: Mirar, yo pienso que, sinceramente, en esta forma que es la escuela intercultural inclusiva... la escuela, que somos todos, la escuela como institución tiene que aprender. No vale que yo haga proyectos, que aquella tal..., si no hay una metodología en la que todos vamos a una, ¿vale? (Sesión 1, seminario de formación. Referencia 1).

En este sentido lo que la maestra trata de remarcar es que más allá de las técnicas y estrategias utilizadas tienen que existir puntos en común desde aquello que pensamos. En cierto modo la maestra habla de discutir entre todos la escuela que quieren y creer en ella, ya que lo que se observa en la sesión es un debate sobre los aspectos técnicos de la práctica más que una discusión pedagógica acerca del papel de la escuela y el rol del maestro.

\subsubsection{Ilusión}

Finalmente, una condición para que se produzca el cambio relacionada con las anteriores es la ilusión hacia el mismo. En esta escuela la ilusión de una parte del profesorado al ver que otra manera de hacer escuela era posible, ha posibilitado la puesta en marcha de acciones. Este entusiasmo y fuerza en el cambio favoreció otros aspectos como la implicación y la colaboración que veremos más adelante.

En relación a la ilusión, cabe destacar que siendo un punto de partida está también presente a lo largo del proceso y es vivida por las personas que conviven en la escuela y por aquellas que en algunos momentos participamos en la transformación de la misma. Por ejemplo, en el caso de una asesora externa que tenía contacto con el colegio desde hacía muchos años, en el segundo consejo social planteó precisamente este cambio observado en una parte importante del profesorado. 
Asesora del CEFIRE: Però, jo per exemple, és el que vos dic, ja fa uns quants anys que vinc al centre $i$ estàveu molt despagats. $O$ siga, dels problemes que havíeu tingut $i$ ara esteu pagats, esteu satisfets. I això és important. Això fa que quan tu arribes al centre arribes en una intenció $i$ una actitud, que són diferents a si, buf, vaig a treballar. El que vull dir és que sou un CAES que està pagat, i això no és comú.

Maestra de infantil: Sí que és veritat.

Asesora: D’alguna manera jo lo que duc és una visió dels centres d'aquestes característiques. I normalment, tu li preguntes a algú, "tu en quin centre estàs, jo en el CAES de..." (con la mano en la cabeza y un tono de decaimiento) clar... si un mestre d'aci diu, "jo estic en -nombre de la escuela-” (lo dice con un tono de Seguridad y orgullo)...

Jefa de estudios: Si això ho dic jo pel poble, quan me miren en mala cara, "jo al -nombre de la escuela-!” ¡Y ahí voy a jubilarme! (Ríen todos). (2ºnsejo Social).

Lo que aparece en este fragmento es que, aunque no todos tienen las mismas creencias sobre el cambio, el entusiasmo y la ilusión de las personas que creen en él les ha llevado a la realización de acciones muy bonitas, que ha acabado por devolverles la ilusión en su trabajo. Ni son todos los maestros ni todas las familias las que lo viven así, pero ha habido un cambio en la escuela que provoca que la gente tenga otro ánimo. Como dice la asesora del CEFIRE, lo que lleva a responder con orgullo en lugar de con pesimismo al preguntarles por la escuela en la que trabajan. 


\subsubsection{Estructura y organización}

Otro aspecto necesario para poder realizar transformaciones en la escuela, es que haya una estructura que lo facilite.

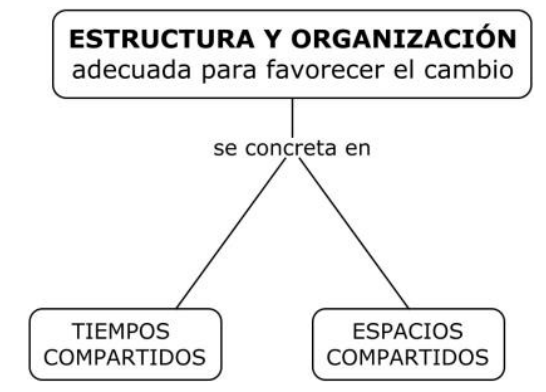

Figura 7. Categorías estructura y organización.

En primer lugar, hablaremos sobre la estructura y la organización en el centro. Pensamos que en esta escuela se favorecen tiempos y espacios compartidos para tratar aspectos de la transformación. Un ejemplo de ello son las reuniones realizadas durante los meses de enero hasta abril (en concreto, siete reuniones para tratar aspectos relacionados con el proceso de transformación de la escuela). Otro ejemplo sería el seminario de formación interna, que pide el profesorado para poder formarse y realizar prácticas más interculturales e inclusivas en las aulas. Este seminario se realiza a lo largo de cinco sesiones desde abril hasta junio. Ambos son ejemplos de las acciones realizadas a favor de que se produzca el cambio. Con esto queremos destacar que existen tiempos y espacios para la reflexión compartida sobre el proceso de transformación de la escuela.

Otro aspecto a resaltar es que, durante el curso 2011 - 2012 se replantearon los apoyos en las aulas, para poder implementar algunas de las prácticas. En concreto, se decidió que el curso siguiente en todas las clases se realizarían grupos interactivos, pero el profesorado opinaba que realizar todas las semanas en todas las aulas este tipo de práctica, requería de muchos voluntarios y pensaban que no sería posible. Por eso, propusieron que fuera el profesorado quién entrara a otras clases como voluntario, para poder realizar todas las semanas estas prácticas. Para 
ello, el equipo directivo organizó los horarios del curso 2012 - 2013, de manera que a las clases de matemáticas de todos los cursos asistieran cuatro docentes como voluntarios para hacer grupos interactivos. Con esto, los apoyos y desdobles del centro se reubicaron para poder realizar un tipo de práctica que el profesorado consideraba adecuada para mejorar el rendimiento del alumnado.

\subsubsection{Liderazgo equipo directivo}

Pensamos que el liderazgo del equipo directivo es importante para que se realicen acciones en el centro, puesto que es el primer motor que activa los cambios.

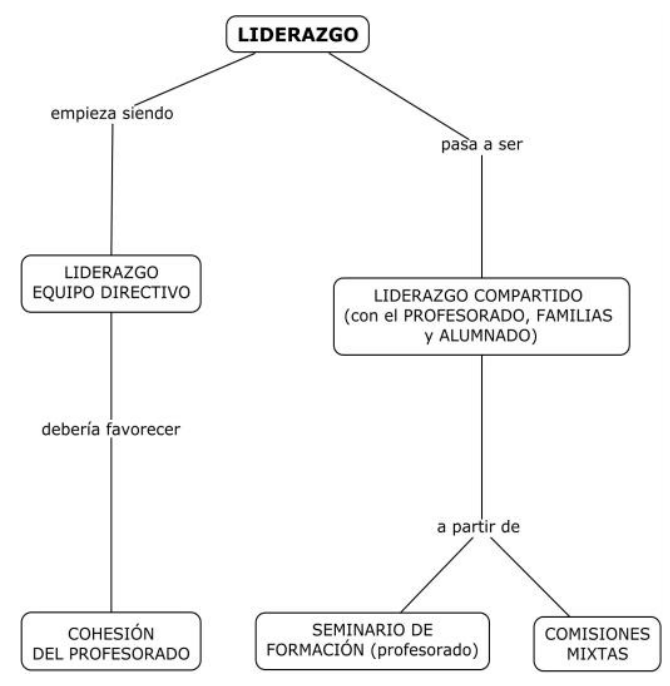

Figura 8. Categorías liderazgo.

Es el equipo directivo el primero que abre el buzón de los sueños para analizarlos y se reúne con distintos agentes para planificar acciones y llevar a cabo los sueños. Por eso, pensamos que desde el inicio, el liderazgo del equipo directivo ha sido un punto a favor para conseguir transformaciones en la escuela.

Sin embargo, el equipo directivo no siempre se ha sentido cómodo en su papel de líder, lo han asumido porque a su parecer, se veían con la obligación de ponerse delante de los cambios, pero cuando no sentían el apoyo del profesorado el mismo 
proceso pesaba más. Es decir, al inicio, cuando desde el profesorado y las familias se decidió emprender el proceso de transformación, el director comenta que notaba como si el cambio fuese una imposición para algunos maestros. No veían el proceso como un proyecto suyo. Es por esto que quién impulsó las primeras acciones fue el equipo directivo. Sin embargo, una vez empezamos a problematizar lo que preocupaba al profesorado y a buscar soluciones a sus necesidades es cuando el profesorado empezó a implicarse.

Como dice Mónica (secretaria del equipo directivo), al principio se sentía hasta mal, de ver que era un proceso que estaban liderando prácticamente ellos.

Secretaria: Me he visto casi hasta final del curso, como el motor. En el curso este de formación del final (seminario), me he visto más como igual. Hasta ahí tirábamos mucho del carro, éramos el motor. Pero ahí hemos conseguido que la gente hable y al hablar nos ha permitido quedarnos más como iguales. Porque estar por arriba es incómodo, porque somos todos maestros (Entrevista equipo directivo).

En las reuniones de trabajo, el profesorado explicitó que les gustaría introducir cambios en las aulas, pero se sentía sin herramientas para hacerlo. Es por esto que decidimos realizar un seminario de formación, pero dinamizado por el propio profesorado, ya que había maestras que realizaban ese tipo de prácticas en sus aulas. Es en este punto en el que el liderazgo empieza a ser compartido entre el profesorado, y en algunos casos, entre las familias y el alumnado. En el caso de las familias y el alumnado también forman parte del cambio y lo lideran a partir de su participación activa en las comisiones mixtas.

En el caso del profesorado, empieza a formar parte del proceso y a liderarlo en el seminario de formación. Una parte del profesorado es quien dinamiza estas sesiones y otra parte, está activa en las mismas y termina por realizar las prácticas mostradas en la formación en su propia aula. O en otros casos, entran en las aulas de sus compañeros para conocer estas dinámicas. No obstante, el papel del equipo 
directivo sigue siendo importante, ya que es quién trata de que el profesorado se implique en el cambio, a partir de los compromisos, de los que hablaremos más adelante.

Por otra parte, algunos maestros destacan que el equipo directivo debería favorecer que hubiese más cohesión entre el profesorado, ya que en la actualidad apenas tienen relación unos maestros con otros y eso antes no sucedía. Años atrás, las maestras conocían parte de la vida de sus compañeros y compartían vivencias. Una de las quejas de una parte del profesorado es esa falta de cohesión, que influye en que el profesorado esté a gusto en la escuela y piensan que el equipo directivo debería favorecer esa unión. Por ejemplo, para una parte de los maestros sería bueno que se fomentara desde el equipo directivo el trabajo inter-ciclos, más allá del trabajo que se realiza desde cada ciclo. También es cierto que años atrás se realizaban estas reuniones y durante el curso 2011 - 2012 dejaron de realizarse porque las sesiones del seminario ya cubrían esa función.

\subsubsection{Implicación}

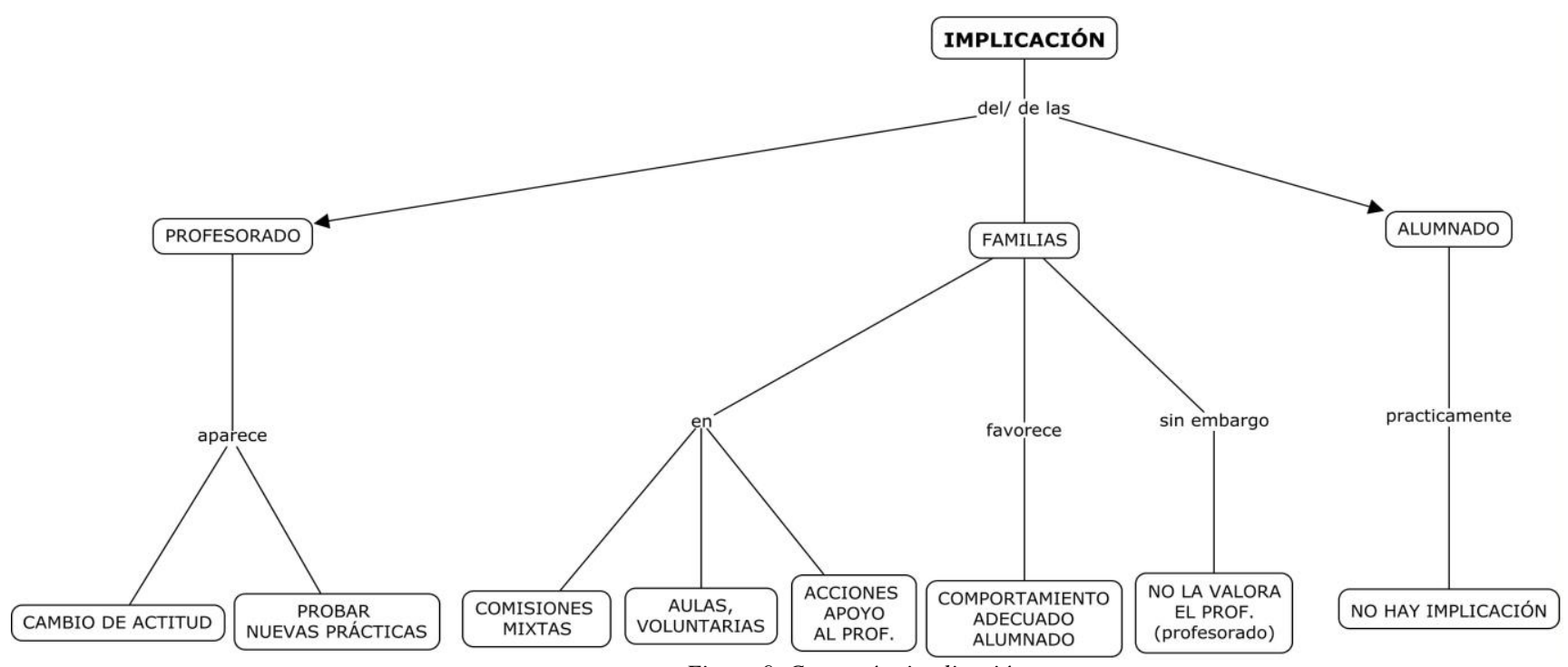

Figura 9. Categorías implicación. 
Como hemos comentado, las condiciones para que se produzcan cambios son: creer en ellos, o que al menos una masa crítica lo haga; tener las condiciones que lo favorezcan, como en el apartado anterior hemos comentado, pero finalmente es necesario actuar, llevar a cabo las acciones para que se puedan realizar los cambios. En este estudio aparecen dos categorías, que han sido claves para realizar las acciones en esta escuela: la implicación y el hecho de compartir experiencias. A continuación, hablaremos sobre la implicación y distinguiremos entre la implicación del profesorado, la de las familias y la del alumnado en el cambio.

\subsubsection{Implicación del profesorado}

Durante el primer curso el profesorado cambió bastante su actitud y su posicionamiento en relación a la transformación. Aunque es el colectivo que decidió iniciar este proceso, parecía que se sentía "obligado" a realizar cambios. Esto lo dice el equipo directivo en la entrevista de final de curso. Pero también lo contrastamos en las actuaciones del profesorado al inicio del proceso, empezando por la primera acción: escribir su sueño sobre algún aspecto que le gustaría cambiar o mejorar del alumnado. Aunque el propio profesorado se quejaba de la poca implicación de las familias en esta acción, escribir los sueños, a la hora de analizar la información comprobamos que era el colectivo que menos papeles había escrito. Algunos comentaron que era porque el sueño era el mismo para todo el profesorado: mejorar el rendimiento del alumnado. Sin embargo, la falta de implicación del profesorado fue una realidad hasta el momento de iniciar el seminario de formación. A partir de ese momento, a nivel general, empezamos a detectar cambios positivos en cuanto a su implicación en el centro, que favorecieron la transformación de las prácticas de aula.

Este cambio de actitud a lo largo del proceso lo detectamos en las reuniones con el claustro que se realizaron desde febrero hasta abril. Posteriormente, también observamos un cambio importante en la actitud del profesorado en las sesiones del 
seminario de formación. En estas, el profesorado que se había mantenido resistente a las transformaciones y mostraba una visión negativa sobre la entrada de las familias y las prácticas inclusivas realizadas por sus compañeros, empezaron a interesarse por estas prácticas, hasta que en las últimas sesiones del seminario se decidieron a "probar" algunas de las técnicas presentadas en el seminario, en sus aulas.

En las entrevistas realizadas con el profesorado al final del primer curso de transformación, aparece precisamente este aspecto. Para todos ellos, la implicación del equipo docente ha sido una de las mayores sorpresas en el proceso de cambio. La implicación por ejemplo, de las maestras del primer ciclo fue un ejemplo a seguir para el resto del profesorado de primaria. Sin embargo, la realización de este tipo de prácticas en el segundo ciclo fue una sorpresa para todo el claustro que no confiaba en esta predisposición hacia el cambio por parte de estas maestras. Puesto que en el segundo ciclo las docentes se habían mantenido con una postura resistente a las innovaciones realizadas por sus compañeras. Generalmente, no participaban en las comisiones y no realizaban prácticas inclusivas. Fue durante las sesiones del seminario, en las que se animaron a probar algunas de las prácticas mostradas para conocer mejor su funcionamiento.

Por tanto, la implicación del profesorado ha sido un aspecto fundamental para iniciar las transformaciones. En concreto, los cambios en las prácticas de aula. Sin embargo, como comenta una maestra del primer ciclo, no es suficiente con probar, sino que es necesario incorporar las buenas prácticas en la programación de aula.

\subsubsection{Implicación de las familias}

En cuanto a la implicación de las familias, es otra de las condiciones que facilita la posibilidad de transformar la escuela y hacerla de todos. Más adelante, en el apartado 6.3.2.1., hablaremos también sobre la implicación de las familias, al hablar sobre su voz en la escuela. Sin embargo, hemos querido mostrar en qué aspectos la implicación de las familias ha supuesto una condición favorable para 
realizar cambios en el centro, por eso, en esta parte aportamos también datos al respecto.

Las familias, es el colectivo más culpabilizado por el profesorado. Sin embargo, a la hora de implicarse en el centro, son los primeros que se unen a la iniciativa que empieza liderando una parte del profesorado. Aunque la implicación de las familias no se amplía a la participación de todas o casi todas, sino que es un colectivo reducido el que se implica, los cambios que suceden en el centro tienen un gran potencial.

Algunas de las acciones que realizan es, participar en las comisiones mixtas y movilizar varias las propuestas que se habían hecho a partir de los sueños. Como por ejemplo, hablar con el alcalde para mejorar las condiciones del centro; hablar con otras escuelas para conseguir la jornada intensiva en las escuelas de la localidad; etc. También participan como voluntarias en las clases del primer ciclo, durante el curso 2011 -2012. Puesto que las maestras de este ciclo les piden su ayuda en algunas prácticas. Durante el curso 2012 - 2013 no entran en las clases porque el profesorado, al organizar los apoyos para contar con voluntarios para los grupos interactivos, no pide su colaboración. No obstante, las familias siguen ofreciéndose como voluntarias para entrar en las aulas (Sesiones del consejo social) e insisten en que les gustaría poder entrar tal y como lo hacían el curso pasado.

Finalmente, otra de las acciones en las que se implican, es en apoyar al profesorado asistiendo a las manifestaciones convocadas a nivel estatal por las condiciones educativas y la desvalorización del colectivo del profesorado. En este caso, el equipo directivo de la escuela manifiesta también su agradecimiento al ser el único colegio que contó con la presencia de las familias en la concentración local que se realizó.

No obstante, esta implicación de las familias en la escuela no siempre es correspondida con la implicación del profesorado en acciones que proponen las familias. O por ejemplo, en actividades propuestas por el AMPA (Asociación de 
Madres y Padres del Alumnado). Esta es una de las quejas que las familias les transmitió al profesorado al final del curso 2011- 2012, porque no asistió ningún maestro a la cena de final de curso que organizaron.

De ahí la afirmación del director al mostrar que realmente, aunque la implicación de las familias sea la de una parte de ellas, las acciones en las que se implican a veces supera la implicación que tiene el profesorado en el proyecto de transformación hacia una escuela más intercultural e inclusiva.

Director: Hay una serie de padres, que la verdad, hasta incluso nos supera porque a veces hacen algunos papeles que les tienes que decir que lo vuelvan a hacer porque eso. Pero están ahí, y están haciendo cosas muy bonitas. Y es una lástima, porque las estoy viendo yo en el despacho y los otros todavía no ( $8^{a}$ Reunión).

Sin embargo, estos cambios no siempre son apreciados por el profesorado, únicamente los agradecen y son conscientes de ellos las personas que mantienen una relación con las familias. En este caso son los miembros del equipo directivo, las maestras del primer ciclo que cuentan con las familias como voluntarias durante el curso 2011 - 2012, una parte de las maestras de infantil, que desde antes de iniciar el proyecto ya mantenían una relación colaborativa con las familias y algunos maestros que conocen la implicación que las familias están teniendo en el centro.

Por eso, contrasta esta información con la obtenida en las entrevistas de final de curso, en la que una parte del profesorado destaca que ha fallado la implicación de las familias. Algunos de los docentes que lo expresan en algún momento sí que han pedido la participación de las familias en el aula y estas no han asistido, pero en la mayoría de los casos no ha sido así. Es decir, la mayoría del profesorado dice que falla la implicación con las familias, pero ellos en ningún momento les han pedido su participación en aspectos de aula o del centro. En el caso del profesorado que sí que ha pedido su ayuda, la valoración es más positiva, incluso manifiestan que se ha dado más implicación por parte de estas familias que del profesorado. 
Sienten agradecimiento hacia estas familias y piensan que poco a poco se irán implicando otras.

Estefanía: Esas familias, seguramente contagiaran a las otras (Entrevista a Estefanía).

Por otra parte, la implicación de las familias favorece el buen comportamiento del alumnado. Como dicen las maestras de primer ciclo en la entrevista, no solo cambia el comportamiento sino también la actitud de los niños hacia la escuela y su comportamiento en clase. Les gusta que sus familias entren y por su parte, las familias quieren seguir entrando (Grupo de discusión familias).

Jefa de estudios: Para nosotros es importante que las familias vengan a la escuela, que tengan la confianza. Si ellas vienen sus hijos se sienten más importantes y valorados (Grupo de discusión familias. Referencia 3).

\subsubsection{Implicación del alumnado}

Finalmente, la implicación del alumnado es la menos notable durante el proceso del cambio, porque como veremos más adelante, el alumnado, ha sido uno de los agentes olvidados en el centro. Su implicación en la escuela se ha visto en aquellos niños y niñas que han participado en comisiones. Sin embargo, no todos conocían las comisiones ni su función en la escuela.

A nivel del aula, el alumnado participaba en prácticas más interculturales e inclusivas en el caso de que sus maestras las pusieran en marcha.

Sin embargo, sobre estos aspectos nos detendremos cuando abordemos el tercer objetivo de la investigación, sobre las transformaciones del centro. En concreto, en esta parte hablaremos sobre la voz del alumnado y explicaremos su conocimiento sobre los cambios escolares y sobre las prácticas de aula. 


\subsubsection{Compartir experiencias}

Otro de los elementos que facilitó que el cambio se llevara a cabo y que se implicara en él el profesorado, fue el hecho de compartir experiencias. Esto fue posible en el seminario de formación, tras conocer cómo algunas compañeras ponían en práctica algunas de las técnicas identificadas como prácticas que favorecen la atención a la diversidad (Entrevista a segundo ciclo).

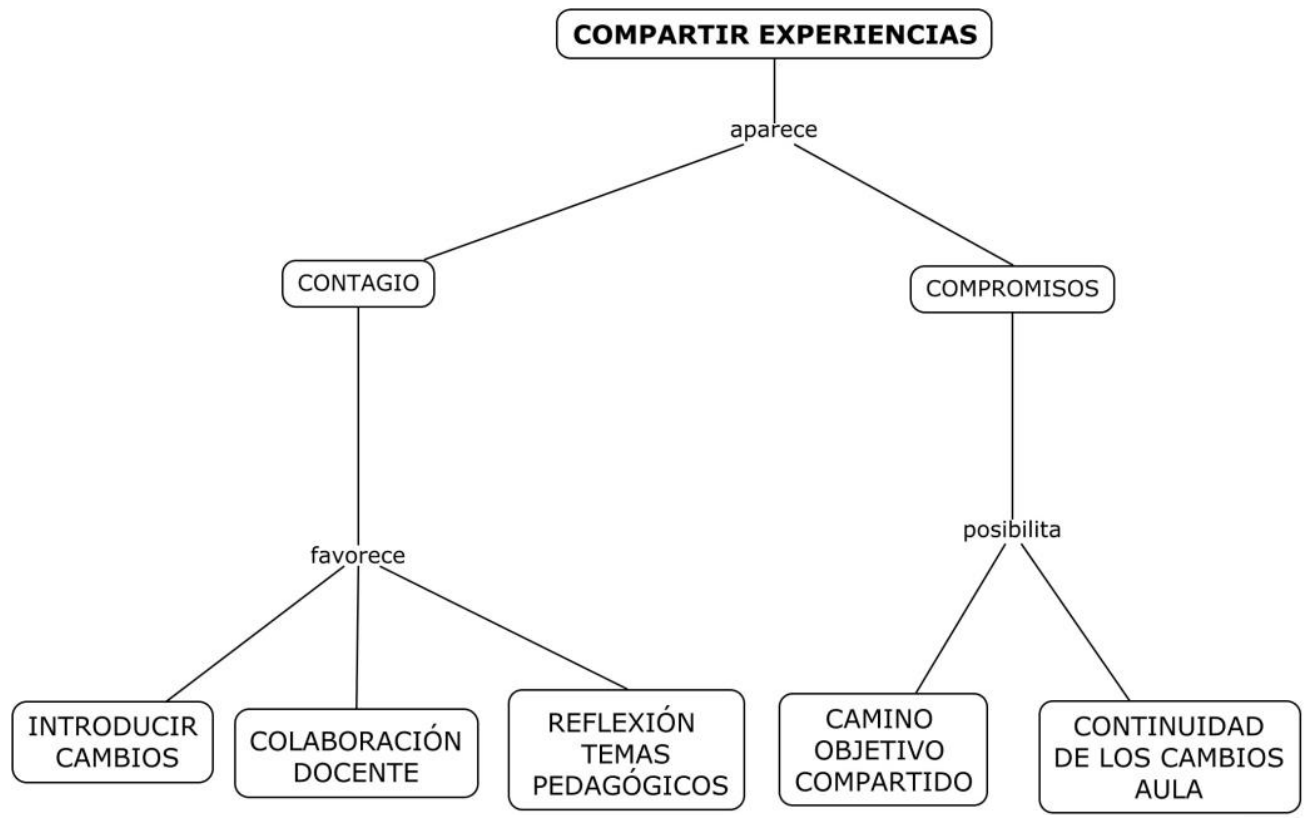

Figura 10. Categorías compartir experiencias.

Hasta el momento algunos docentes se habían implicado en los cambios del centro participando en las comisiones, y otros habían empezado a realizar prácticas más inclusivas contando con las familias. Sin embargo, el terreno en el que el profesorado se sentía más implicado era el de su aula, por eso, gracias al hecho de compartir experiencias aparecieron unas actitudes más cercanas al cambio y una mayor predisposición del profesorado a implicarse en el mismo.

Algunos docentes, antes de empezar el seminario manifestaban sus ganas de realizar prácticas para atender a la diversidad, sin embargo, no sabían cómo realizarlas. Es por esto que al ver que otros maestros de su misma escuela, con sus mismas familias, eran capaces de realizar este tipo de prácticas, su actitud cambió. 
Maestro especialista: Cree que el seminario ha ayudado mucho. Ve cercano que sean compañeras de infantil las que explican este tipo de prácticas. Y además, lo aplican en su mismo colegio con sus alumnos. Él explica que cuando ve que otras personas en circunstancias parecidas lo hacen, se anima, y piensa que estas prácticas, con las familias y el alumnado, pueden realizarse. (Entrevista a maestro especialista 2. Referencia 1).

En este sentido, el seminario de formación posibilitó la colaboración entre docentes. Por una parte, empezaron a compartir sus ganas de probar algunas técnicas para sentirse de este modo, más acompañados (Sesión 2, seminario de formación). Por otra parte, compartían sus inquietudes con el resto del profesorado:

Un maestro especialista, dice que en los grupos interactivos también se pretende no dirigir tanto la sesión. El docente tiene un rol menos directivo. Él dice que a los maestros eso les cuesta pero es un trabajo que tratan de conseguir poco a poco (Sesión 3, seminario de formación. Referencia 3).

Incluso planteaban nuevas propuestas a partir de la reflexión en base al diálogo pedagógico que mantenían:

Una mestra d'Infantil que fins ara no havia fet cap intervenció, proposa, per apropar a les famílies a l'escola, recuperar la dinàmica "el protagonista de la setmana”. Diu que ho feien abans i van deixar de fer-ho. Consisteix en que durant una setmana un xiquet és el protagonista $i$ al final de la setmana va algun familiar seu a contar alguna cosa (Sesión 3, seminario de formación. Referencia 5).

Por todo esto, el seminario más allá de ser un espacio dónde compartir las técnicas, favoreció la reflexión sobre temas pedagógicos que hasta el momento no se estaban abordando en la escuela (Entrevista a maestras de infantil). Y este diálogo pedagógico ha servido también para trazar juntos un camino hacia el objetivo compartido (Entrevista a primer ciclo). 


\subsubsection{Compromisos}

El intercambio de acciones posibilitó cambios en las aulas y en el centro. Pero para que estos cambios no quedaran en una anécdota, el equipo directivo insistió en llegar a unos compromisos mínimos para que durante el siguiente curso continuaran con estas prácticas. El equipo de profesores estuvo de acuerdo, aunque querían que la incorporación de nuevas técnicas en el aula fuera un proceso progresivo, debido a la nueva incorporación de maestros para el siguiente curso.

El seminario de formación finalizó con el compromiso del profesorado de ir incorporando durante el siguiente curso las nuevas prácticas mostradas durante la formación. No obstante, en el curso 2012 - 2013, debido al gran cambio entre el profesorado resultó dificultoso llevar a cabo los compromisos. En el caso del primer ciclo, que es el que observamos con más detenimiento, las nuevas maestras no tenían una predisposición sobre el cambio y no lo sentían como propio. Por eso, aunque Estefanía -la maestra que continuaba en el ciclo, de las del curso anteriortrataba de compartir sus prácticas, tenía dificultades para que las maestras se animaran a ponerlas en práctica en sus clases.

Estefanía: Podem fer una altra cosa, a veure, voleu vindre cada dia una classe a les tertúlies literàries $i$ ho veieu? $\left(3^{a}\right.$ Reunión de ciclo $)$.

Aunque la maestra en varias ocasiones animaba a sus compañeras, dos de ellas se mantuvieron al margen y la tercera asistió un día a la clase de Estefanía con su alumnado para conocer la práctica y poder planificarla en su aula.

Por otra parte, algunos docentes destacan que la posibilidad de compartir las prácticas también ha favorecido el nacimiento de una cultura distinta en la escuela. Las clases se han abierto, no solo para que entren las familias, sino también para que entren otros maestros a observar. Algunas maestras dicen que no todos tienen esa predisposición a abrir las clases ya que es una situación que puede incomodar al profesorado (Entrevista primer ciclo). 


\subsubsection{Contagio}

En definitiva, el intercambio de experiencias en este centro ha llevado a los maestros a probar nuevas maneras de hacer. El propio profesorado identifica también el hecho de compartir experiencias con el contagio, que se ha producido en el centro. Algunos dicen que quieren hacer por probar, otros porque observan que estos cambios ya son una realidad en la escuela y no quieren quedarse atrás (Entrevistas a maestros). Por eso, no en todos los casos podemos decir que el contagio haya supuesto también un cambio en las concepciones pedagógicas, pero sí que existe una apertura y una mayor predisposición a otra manera de realizar las prácticas en la escuela.

Este contagio en las prácticas de aula ha provocado que distintos maestros introduzcan cambios en sus clases. Por ejemplo, una maestra de educación infantil realizó una tertulia con su alumnado; una maestra de primer ciclo realizó asambleas de aula; en el segundo ciclo que no habían realizado ninguna de las técnicas comentadas en el seminario se decidieron por las tertulias y los grupos interactivos. En el tercer ciclo, las tutoras se habían mantenido al margen en las sesiones del seminario, asistían pero no dialogaban con el resto de sus compañeros. En este caso, al ver que sus compañeros empezaron a compartir sus prácticas, ellas contaron todo lo que habían hecho durante el curso; durante el primer trimestre realizaron tertulias literarias y grupos interactivos, pero a partir del segundo trimestre se centraron en el trabajo emocional que habían iniciado al empezar el curso con el alumnado.

En conclusión, el contagio, el compartir experiencias y dicha apertura hacia lo desconocido, ha situado al docente de esta escuela de un modo distinto con sus compañeros. Ha aparecido una mayor colaboración docente que hasta el momento se echaba en falta para algunos.

Maestra especialista: Lo que mejor ha estado es el seminario. Porque han visto que si lo han hecho compañeros del centro ellos también pueden. También ha 
estado bien porque han conocido cómo trabajan el resto cosas de las que no tenían ni idea. Saben a quién dirigirse si necesitan hacer un proyecto y saben que estas personas les ayudaran. (Entrevista a maestra especialista 1. Referencia 1).

Sin embargo, aunque se han podido comprobar acciones en las que ha habido esta colaboración entre el profesorado, una parte del colectivo sigue opinando que no hay cohesión entre el profesorado. Por eso, esta categoría la explicaremos cuando conozcamos los obstáculos encontrados durante el proceso de transformación.

\subsection{Los obstáculos}

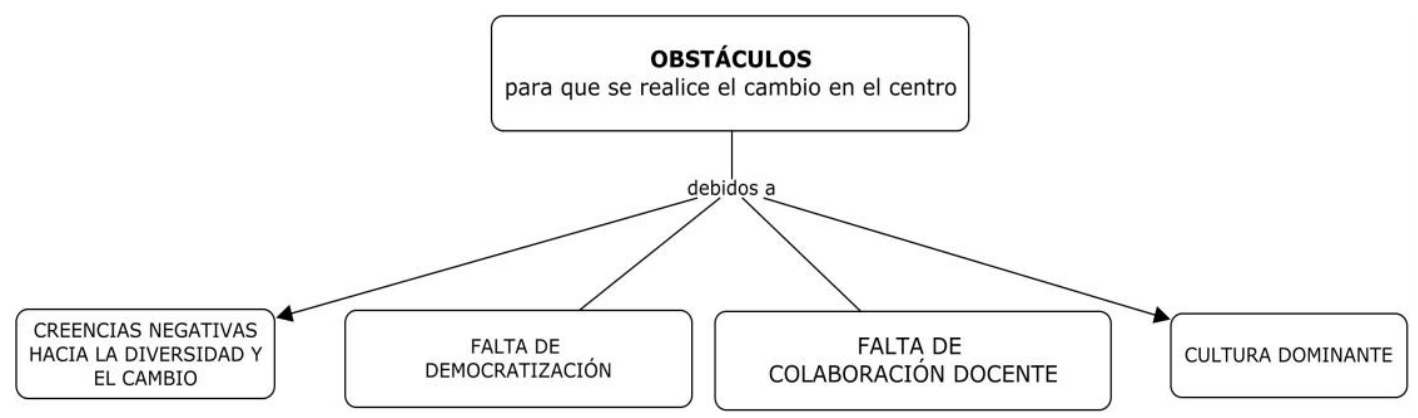

Figura 11. Categorías obstáculos del cambio.

Como hemos visto, existen unas condiciones que han facilitado el cambio en esta escuela. Pero también aparecen algunos obstáculos que dificultan la realización de acciones y finalmente, que el cambio se vaya produciendo en la institución.

Los obstáculos que hemos encontrado en este estudio están asociados por una parte a las creencias negativas hacia la diversidad y hacia el cambio, esencialmente del profesorado; a la falta de democratización debida a la cultura 
dominante, en la que se sitúa tanto el profesorado como las familias españolas. Otro de los conflictos que también aparece es el idioma como una dificultad para comunicarse entre las familias árabes y el profesorado. Además, aparece también la falta de colaboración docente, que en algunos casos es identificada también como falta de cohesión entre el profesorado de la escuela.

\subsubsection{Creencias negativas hacia la diversidad y el cambio}

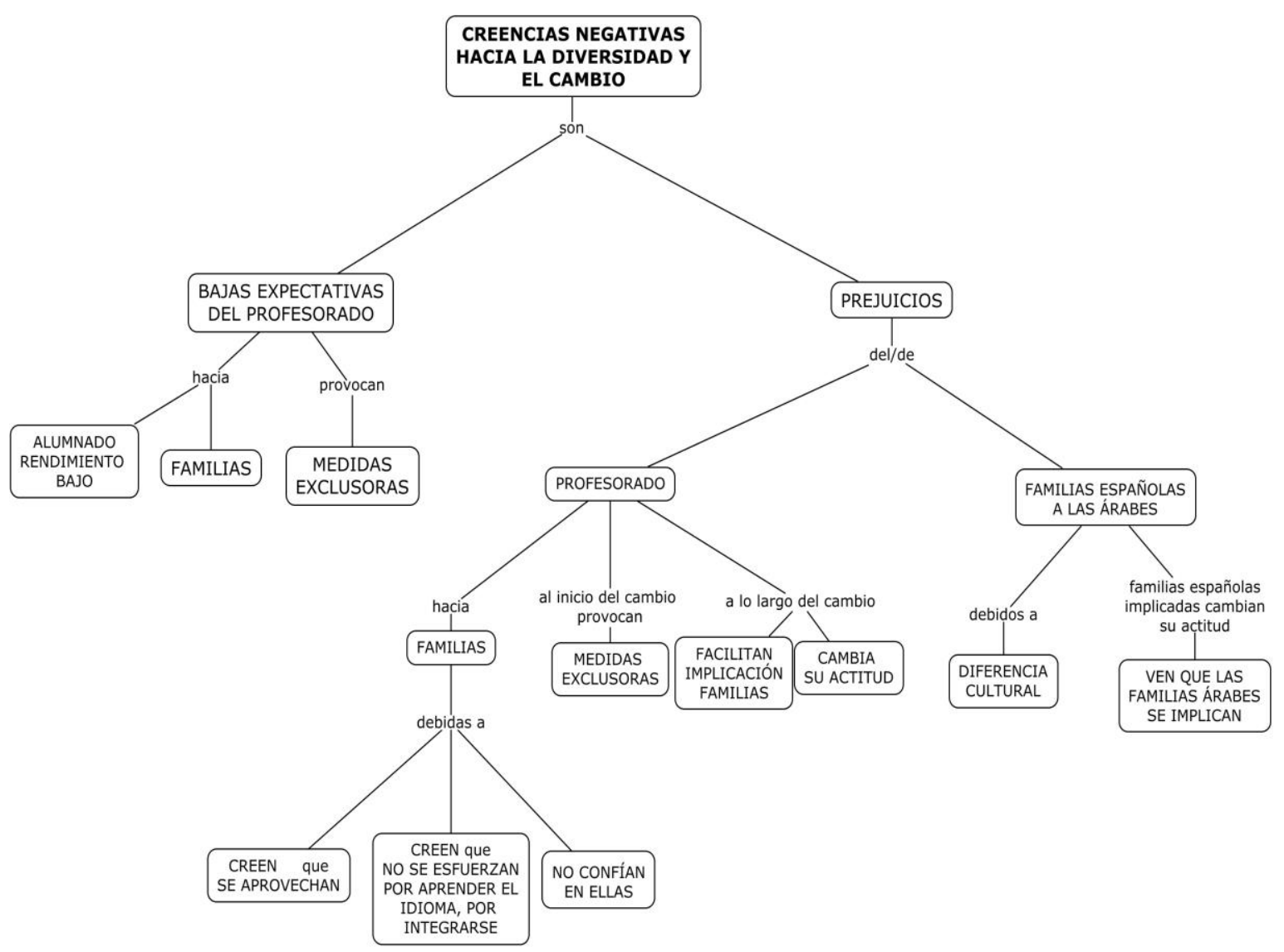

Figura 12. Categorías creencias negativas hacia la diversidad y el cambio. 
Para empezar, nos centraremos en las creencias. Como hemos visto en el objetivo anterior, es necesario creer en el cambio para poder alcanzarlo. Sin embargo, el no creer en el cambio, o tener una actitud negativa hacia las familias y el alumnado del centro va a dificultar la creación de una escuela de todas y todos.

En primer lugar hablaremos sobre las bajas expectativas y los prejuicios del profesorado hacia las familias y el alumnado.

\subsubsection{Bajas expectativas}

Aunque el modelo educativo al que quieren acercarse parte de altas expectativas hacia todas las personas, el profesorado de esta escuela por lo general, muestra bajas expectativas hacia el alumnado y hacia las familias. Y también hacia el propio proceso de cambio, puesto que al principio no confiaban en que el profesorado se implicara en el mismo. A lo largo de este apartado, haremos un recorrido sobre las bajas expectativas mostradas tanto al alumnado como a las familias.

Las bajas expectativas del profesorado hacia el alumnado, se sitúan especialmente hacia el alumnado con un rendimiento más bajo del esperado. Sobre estos alumnos, se habla de sus dificultades en las reuniones de coordinación de ciclo. Por ejemplo, tratando de obtener algún beneficio o ayuda para la maestra y el alumnado, como puede ser el hecho de que el niño salga del aula. En este sentido, teniendo en cuenta el modelo intercultural inclusivo, no se está dando una respuesta adecuada a la diversidad, sin embargo, para algunas maestras esto sería un alivio, como veremos a continuación:

Maestra de primer ciclo: Eixe xiquet és que m'hauria de dedicar única $i$ totalment a ell. Almenys una hora cada dia que el traguen a compensatòria, que jo crec que és...

Estefanía: No, una hora cada dia no el trauran.

Maestra de primer ciclo: No? Pues un reforç o un... el que siga. Quantes hores poden traure'l de classe a la setmana? ( $3^{a}$ Reunión de ciclo). 
Esto sería una forma de mostrar las bajas expectativas que tienen hacia algunos alumnos y las propuestas, en este caso exclusoras que proponen al respecto.

En otros casos, las bajas expectativas hacia el alumnado también se expresan en clase, delante del resto de alumnos. En los casos en los que las maestras desvalorizan a un niño, no es solo la maestra la que tiene esa opinión sobre el estudiante, sino que se acaba estigmatizando al niño y el resto de compañeros tienen las mismas expectativas bajas sobre él. Por eso, al final no son solo las maestras las que esperan un menor rendimiento de estos niños, sino también sus propios compañeros.

En algunos casos, incluso podemos encontrar que a un niño, sus propios compañeros le excluyan de la tarea. En el caso que mostraremos a continuación en el que están realizando un trabajo cooperativo, una alumna limita la participación de su compañero y expresa sus bajas expectativas hacia sus capacidades. En este caso en concreto, la maestra se acerca a ese grupo al detectar esto, tratando de que le acepten por igual. Sin embargo, en muchas ocasiones estas etiquetas ya han sido impuestas y cuestan de quitar.

Adán també vol dir-li alguna cosa i Laia s'alça de la cadira, i fent que no amb la mà, s'arrima a la fulla que té Adán en la mà, li la baixa i li diu, tu no saps llegir.

Estefanía. Per què no sap llegir? (4ª sesión, proyecto de Trabajo).

En este caso no nos referimos a que la maestra le haya dicho en voz alta que no saber leer. Pero sí que encontramos que, de distintas maneras las maestras suelen llamar la atención a estos niños. En concreto, a Adán se le nombra muchas veces en clase para regañarle, separarle del resto por estar hablando o se le dice que atienda que después no sabrá hacer el ejercicio. En todos los casos, son llamadas de atención enfocadas hacia un comportamiento poco adecuado según la maestra. Por eso, el resto del alumnado que escucha este tipo de respuestas, casi a diario, también entiende que estos alumnos "tienen más dificultades hacia la tarea" o su 
comportamiento no es el adecuado. Además, otro aspecto que entienden es que realizar bien las tareas es un modo que tiene el profesorado de medir aquello que el alumno sabe (Observación de aula, $4^{\circ}$ sesión proyecto de trabajo).

En algunos casos, también se felicita a estos niños, aunque suelen ser pocos. Pero incluso en estos casos, se marca la diferenciación de estos niños en la manera de felicitarles, ya que lo hacen explicitando su asombro porque tenían unas expectativas bajas sobre ellos. Para mostrar esto nos basamos en el caso de Waldo, un niño que tiene dificultades para enfrentarse solo a la tarea y cuando recibe la ayuda de algún compañero puede avanzar más.

Ese día, Waldo estaba trabajando en los grupos interactivos, pero a diferencia de otras clases en las que era él quién pedía la ayuda, empieza a explicarles la actividad a sus compañeros. La ficha de Waldo sigue vacía, no ha respondido ninguno de los ejercicios. Sin embargo, se los explica a la perfección a su compañero Juan. La maestra voluntaria que estaba en su grupo se sorprende y lo felicita, pero es tanta su sorpresa que empieza a comunicarlo a otras maestras. Otros niños de grupos distintos lo escuchan e imitan la sorpresa de las maestras. Aunque por un lado las maestras quieren felicitar a este alumno, el modo de hacerlo es una muestra más de las bajas expectativas que tenían sobre él, al pensar que no era capaz de resolver la tarea sin ayuda. A continuación adjuntamos un pequeño fragmento con la sorpresa de una alumna y dos maestras que estaban en la clase y también escuchan la noticia.

Ivana (alumna): Waldo ja ha acabat?

Maestra voluntaria en otro grupo: Què ho explica Waldo?

Otra maestra voluntaria en otro grupo: Dis-li-ho a la mestra que tampoc s'ho creurà! ( $3^{a}$ sesión GI).

Pensamos que la manera de felicitar a niños con dificultades hacia la tarea en estos casos y otros similares, les da poco ánimo y no propicia que lleguen a confiar en sus capacidades. Como por ejemplo, en el caso que mostramos a continuación. Aunque por otra parte, sin tratar de justificar estas actuaciones pero sí tratando de 
entenderlas, queremos destacar que algunas maestras también se agotan delante de las dificultades que muestran estos niños. Ya que en un modelo de escuela que tradicionalmente busca la homogeneidad, las dificultades de aquellos que no llegan a entender las tareas y a resolverlas, también provoca cierta frustración en las maestras.

Estefania: Molt bé Juan, ja t’has adonat d'alguna cosa (1 ${ }^{a}$ sesión GI).

No obstante, en la mayoría de las clases observadas, las expectativas del profesorado hacia el alumnado en general, no suelen ser bajas. Sino que estas bajas expectativas se focalizan más hacia el alumnado con dificultades hacia tareas académicas, como hemos visto, y por otra parte, hacia las familias. Sin embargo, sí que aparecen algunos casos de maestros con bajas expectativas hacia el colectivo del alumnado en general. Aunque suelen ser los casos más aislados hemos querido adjuntar un fragmento que muestra a qué nos referimos.

Maestra anónima: A ver! A ver, yo hablo por mí. Yo pienso que si por ejemplo los míos de quinto y sexto, borregos incluidos, porque son borregos. A ver: “¿Qué os apetece saber sobre este tema?" No me traerian nada, porque lo he hecho y no me trajeron nada a la clase (Sesión 1, seminario de formación).

Finalmente, las expectativas hacia las familias por parte de casi todo el profesorado al inicio del curso 2011 -2012, eran bajas. Por una parte, no pensaban que se fueran a implicar en el cambio y por la otra, pensaban que en la mayoría de los casos la educación de sus hijos no les importaba demasiado (4ª Reunión).

Durante el curso 2012 - 2013, las expectativas de una parte del profesorado que ha estado en contacto con las familias cambia. Unas cuantas familias se han implicado mucho, más de lo que se esperaba y confían en ellas a la hora de pedirles ayuda o de realizar un trabajo colaborativo. Sin embargo, no todo el profesorado piensa de la misma manera.

Algunos opinan que en general no responden a las demandas de la escuela: 
Maestra de primer ciclo: No..., sí, de folios sí que han dut, és de la única cosa que han respost. ( $1^{a}$ Reunión ciclo).

Aunque tampoco se plantean si estas demandas tienen sentido para las familias y el alumnado, o si están adaptadas a sus necesidades.

En relación a las bajas expectativas hacia las familias, encontramos los prejuicios hacia las mismas, que están explicados en la siguiente categoría.

\subsubsection{Prejuicios}

Aunque no existen demasiados datos en esta categoría, pensamos que es importante incluirla en el trabajo ya que nos muestra algunas incoherencias entre el modelo de escuela que se persigue y algunas actitudes y pensamientos que expresa el profesorado.

Por ejemplo, detectamos prejuicios del profesorado hacia las familias árabes. En el caso de una maestra, nos comenta que el idioma es una barrera para que haya una buena comunicación y una implicación de las familias, pero además del idioma piensa que las familias árabes en algunos momentos intentan aprovecharse de la predisposición que existe actualmente en el centro para obtener un mayor provecho y no para poder ayudar o implicarse en el proceso de cambio. En el fragmento que mostramos a continuación, esta maestra explica que las familias sí que se acercan para pedir pero no para dar ayuda. Estas afirmaciones están basadas en su experiencia con las familias, pero cabe destacar que en el caso de las familias que sí que se implican la realidad es bastante distinta. Aportan mucho para el centro porque el hecho de hacerlo ya es reconfortante para ellas (Grupo de discusión de familias).

Maestra de infantil: Jo continue pensant que l'idioma es una barrera molt gran. Elles parlen entre elles en àrab, no saps si estan dient que eres guapa, que eres lletja, o que estan parlant del que parlem. Després al final de tot, el que comentaven elles, demanar sí, "querían un repaso para los alumnos" això ho va 
saber escriure. Me va cridar per a saber si ho havia escrit bé. Però li vam dir, noo!! ¿Tú tienes una hora libre? Comprométete una hora a la semana.

Maestra de infantil (II): ¡Quieren los libros gratis y el repaso!

Maestra de infantil: Es que si fora el primer any, pues dius, vale. Però és que porten 8 anys ací. Jo pense que venen un poc a veure el que trauen. No sé qui demanava berenar, que "la fiesta dónde estaba..." (Entrevista a maestras de infantil. Referencia 6).

El hecho de que no hablen el mismo idioma que los maestros dificulta la relación, por una parte se sienten incapaces de comunicarse con las familias y por la otra también opinan que llevan muchos años en el pueblo y, como dice una maestra "no se han «molestado» en aprender el idioma" (Entrevista a infantil). También se sienten ofendidas en algunas ocasiones si las madres hablan entre ellas en árabe porque no las entienden.

Otras maestras opinan que las familias no han aprendido el idioma porque sus preocupaciones son distintas, y piensan que se preocupan por el día a día, por poder comer y por vivir, más allá de replantearse el futuro de sus hijos. Sin embargo, al preguntarles a las madres que no hablan el idioma pero que están interesadas en asistir al centro, por qué no participan, comentan que no entran en las clases ni participan en las reuniones porque les da vergüenza hablar en un idioma en el que no se expresan bien (Grupo de discusión familias). Algunas madres, aun así, entran en las clases y van mejorando su vocabulario y su pronunciación mientras asisten de voluntarias. Las madres que prefieren mantenerse al margen, además de sentirse avergonzadas por no entender ni poder comunicarse en otro idioma, temen que el alumnado se ría de ellas.

Además de la barrera del idioma, al inicio de la transformación eran una mayoría del profesorado, los que tenían dudas sobre la entrada de las familias en la escuela. No acababan de confiar en ellas. 
Jefa de Estudios: Nosotros también hemos tenido muchas dudas de que entraran los padres porque no sabíamos cómo sería, pero la valoración es muy positiva. (...) Igual que vosotros tenéis el reparo de entrar, nosotros también de que entrarais (Grupo discusión comisión del comedor. Referencia 1).

La entrada de algunas familias a la escuela es la manera de romper con estos prejuicios de una parte del profesorado hacia las familias. El primer sorprendido fue el equipo directivo que temía bastante lo que pudiera ocurrir. Sin embargo, se implicaron mucho para que entraran las familias y trataron de facilitarles todo lo que pudieron su participación en el centro, favoreciendo su implicación en las comisiones y la puesta en marcha de un taller para aprender el castellano.

No obstante, para otra parte del profesorado sigue siendo complicada la relación con las familias de la escuela. Aunque a lo largo del proceso cada vez se escuchan menos resistencias y menos prejuicios, continúan estando presentes.

Sin embargo, el director destaca la actitud de algunos maestros, cuando a veces afirman que acabarán ellos llevando pañuelos. Incluso delante de mí ha hecho alguna maestra el comentario. Que parece que lo digan de broma, pero que lleva un tono de malestar y desagrado con las personas árabes (Notas de campo, también lo explica el director en una sesión de APS con el alumnado universitario).

No obstante, cabe destacar que al finalizar el curso 2011 - 2012, algunas de estas actitudes negativas hacia las familias van cambiando. Por ejemplo, una de las maestras del segundo ciclo comenta en la entrevista que existe una distancia entre el profesorado y las familias. Pero, a diferencia de cuando se inició el proceso de cambio, ahora su discurso no se sitúa en culpabilizar a las familias, sino que atribuye esa distancia a la comunicación y a la manera de educar al alumnado debido a las diferencias culturales y socio-económicas entre unos y otros.

En relación a otros discursos del profesorado que se mantenían con más prejuicios hacia las familias, no hay un cambio radical. Es decir, al final del curso, en algunas entrevistas siguen apareciendo prejuicios. Pero sí que podemos destacar pequeños cambios en la actitud general del profesorado. Por ejemplo, algunos 
docentes en las reuniones anteriores al seminario se negaban a que las familias entraran en sus aulas y en las últimas sesiones del seminario alguna de estas maestras propone recuperar una actividad que se hacía antiguamente en la escuela que propiciaba la cercanía entre las familias y la escuela.

Además de estos, existen también prejuicios de una parte de las familias hacia las otras. Como hemos comentado anteriormente, desde las familias españolas hacia las árabes. Sin embargo, estos prejuicios los detectamos en la fase exploratoria de la investigación, cuando asistimos al centro para realizar sesiones de sensibilización. A lo largo del trabajo, la relación entre estas familias que tenían prejuicios hacia las árabes cambia.

Estos cambios los atribuimos a que la información que obtenemos de las familias es acerca de las que se implican en el centro, y en estos casos, las familias españolas son una minoría. Mayoritariamente se implican las madres árabes. No obstante, precisamente uno de los padres que más manifestaba sus resistencias hacia las familias árabes al inicio del cambio era Pepe. Al finalizar el primer curso la relación de Pepe con las madres árabes que asistían a la escuela era totalmente distinta. Agradecía su implicación porque veía que gracias a ellas el alumnado -y entre ellos su hija-, gozaba de una mayor atención al contar con más voluntarios en el centro. 


\subsubsection{Falta de democratización}

El proceso de cambio a lo largo de los dos cursos se ha caracterizado por una falta de democratización en cuanto a la participación y la toma de decisiones de las familias y el alumnado en cuestiones del centro. Este hecho está también fomentado por una cultura profesionalista, la del profesorado, acostumbrado a tomar decisiones y a liderar los proyectos de la escuela. Estos aspectos que aparecen en los datos están documentados en el marco teórico, al hablar sobre la participación comunitaria. En concreto, en esta categoría hablaremos sobre la falta de democratización de la participación de otros agentes en el centro y en las aulas. También mencionaremos la falta de democratización en la toma de decisiones del alumnado sobre aspectos escolares.

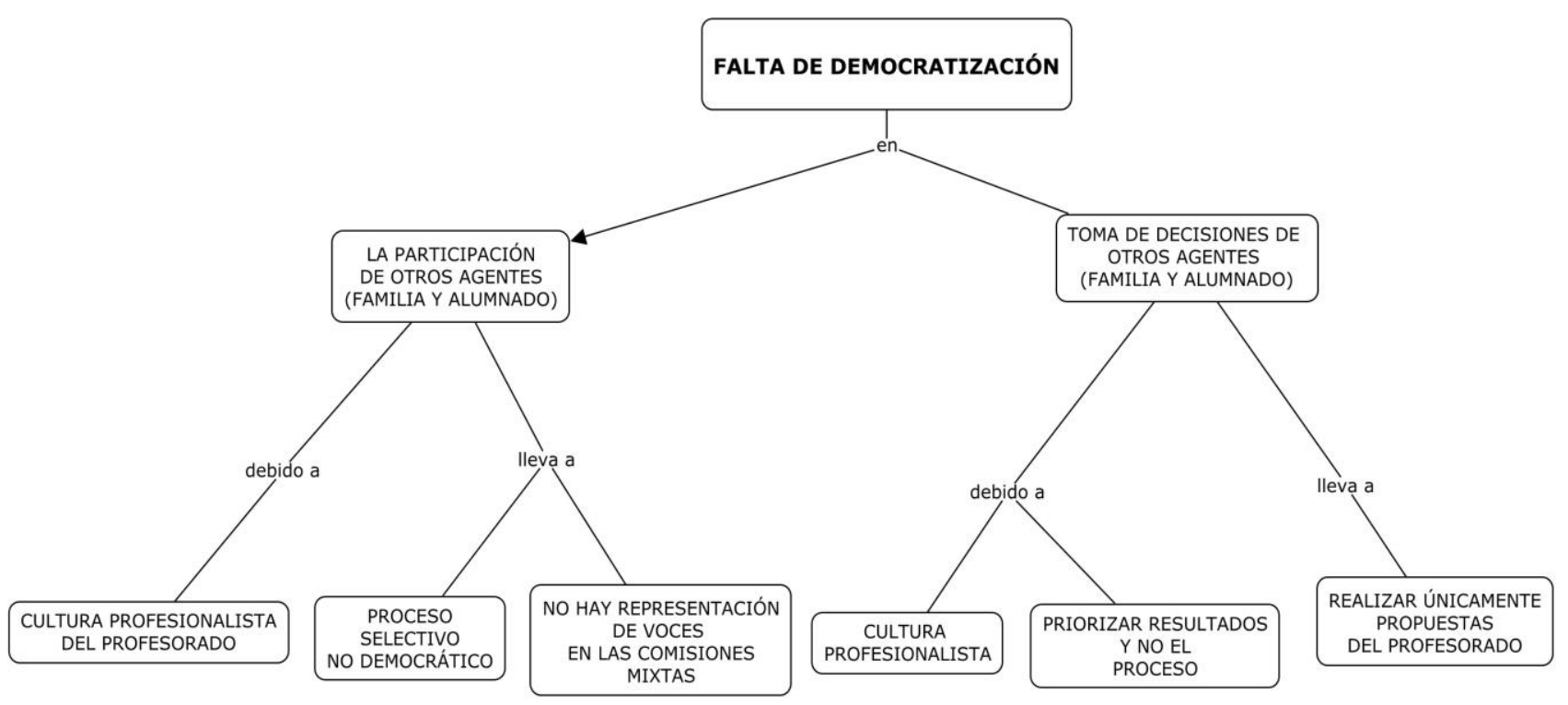

Figura 13. Categorías falta de democratización.

En relación a la entrada de las familias en el centro, empezaremos por ilustrar la falta de democratización en la participación al inicio del cambio, a la hora de analizar los sueños, exponerlos y organizarse en comisiones. 
Durante el curso 2011 - 2012, una vez las familias, el alumnado y el profesorado depositaron sus sueños en el buzón, el equipo directivo los analizó. En primer lugar los clasificó por temas y en segundo lugar, trasladó estos temas a la comisión gestora que se había formado para liderar el proyecto. Una comisión formada principalmente por el profesorado.

Desde esta comisión, se propusieron nuevas comisiones de trabajo para poder realizar algunos de los sueños propuestos, y se decidió deshacer la gestora para que sus miembros también pudieran involucrar-se en otras comisiones. Se realizó una reunión de todo el claustro en la que se presentaron los sueños y se pidió al profesorado que participara en alguna de las comisiones formadas. También se informó en esa reunión, de que la comunidad tenía que participar democráticamente y que tenían que estar representadas todas las voces (alumnado, familias y profesorado) en las distintas comisiones. Sin embargo, a la hora de hacer una llamada a las familias y al alumnado el proceso empezó a desvirtuarse y a ser liderado prácticamente por el profesorado.

El equipo directivo era consciente de que seleccionar a unas familias en concreto, es decir llamarlas por teléfono, para que formaran parte de la comisión, no era la manera correcta de proceder. De este modo no se estaba fomentando una cultura participativa ya que las familias y el alumnado no estaban participando con las mismas oportunidades que el profesorado. Aun así, el equipo directivo insistió en que se llamara a algunas familias que pensaban que podían tener una mayor predisposición para participar.

El primer momento en el que se pidió su participación fue para elaborar un mural en el que aparecieran los sueños de toda la comunidad educativa. En ese mural se pretendía que participaran las familias, pero no en pensar cómo podían presentar los sueños, de eso se encargaría el profesorado.

No todo el profesorado pensaba igual, algunas maestras opinaban que las familias debían participar en el proceso desde el inicio y decidir entre todos si 
hacer un mural o no, y cómo hacerlo. El equipo directivo se mantenía un poco resistente a esta idea porque quería que el proceso empezara lo antes posible y opinaba que si llamaban a las familias o abrían desde el inicio la participación a otros agentes, tardarían más en iniciarlo (Reuniones $3^{\mathrm{a}}$ y $4^{\mathrm{a}}$ ).

El director prefiere hacer el mural antes de realizar una reunión con las familias. Yo les digo que quizás se están “cargando” de trabajo y quizás hay algunas familias que también quieren participar en ese mural. Algunas maestras y maestros, dicen que ellos esperarían a hacer el mural y que los padres pudieran ayudar. El director dice que no quedaría tan chulo y que a veces te retrasan más el trabajo. Estefanía dice que aunque no quede tan bonito ellos pueden sentirse más útiles y más cercanos al proyecto si contribuyen también en esos aspectos. Incluso una maestra dice que les pueden preguntar que cómo lo harían ellos, sin decirles que ellos han pensado en hacer un mural con un zeppelín. Por ejemplo, otra maestra de infantil dice que un padre es fotógrafo y quizás él tenga otra idea de cómo hacerlo que también les puede gustar. Otra maestra dice que es buena idea, que los padres también tienen que pensar, que no se lo tienen que dar todo. Ella había propuesto que realizaran las familias una reunión entre ellas para que plantearan cómo organizarse, pero al final la secretaria del equipo directivo, propone hacer una reunión con todas las familias que quieran asistir para comentarles los sueños que han aparecido, y decirles en qué punto están del proyecto para ver su opinión y cómo van a continuar (Reunión $3^{a}$. Referencia 1).

Aunque la propuesta de la secretaria era más democrática, finalmente se acabó convocando a unas cuantas familias -las que el profesorado consideraba que podían estar más interesadas en participar en el proyecto- a una reunión para formar comisiones y empezar a priorizar los sueños.

Juntaron los sueños por temas y ahora querrían organizar comisiones, por eso pedían la ayuda de los padres que pudieran ir. Para ver qué sueños podrían hacer ya y empezar a trabajar con ellos; los que no se pudieran hacer ya, se harían más poco a poco (Reunión $4^{a}$. Referencia 1). 
En esta reunión también vuelven a plantear cómo organizarse. Es decir, si llaman a todas las familias y convocan también al alumnado para entre todos decidir cómo continuar.

Maestra de infantil: Yo es que primero daría un tiempo para que la gente se apunte.

Director: Bueno, una cosa es los que estamos aquí primero, y después si alguien de fuera quiere apuntarse (Reunión $4^{a}$. Referencia 2).

Para algunos maestros el cambio ya no estaba realizándose de un modo democrático. Pero en este caso, el director insistía en ponerse "manos a la obra" lo antes posible. Por otra parte, el equipo directivo y algunos docentes, tampoco estaban muy convencidos de empezar el proceso contando con la participación de aquellas familias que quisieran unirse. Sino que preferían que poco a poco se fueran implicando.

No obstante, desde la postura de amigos críticos, sí que mostramos nuestro parecer sobre el proceso e indicamos que no estaba siendo un proceso democrático y abierto a todas las voces. Aun así, se decidió empezar con los que estaban en ese momento presentes.

Entre las acciones que priorizaron se decidió también realizar el mural para exponer los sueños y que todas las personas que hubieran escrito el suyo pudieran verse reconocidas en él. Sin embargo, el modo de organizarse para realizarlo seguía siendo una cuestión del profesorado, sin contar con la opinión de todos $\left(6^{\mathrm{a}}\right.$ Reunión).

Además, tampoco se acaba de entender la finalidad de las comisiones en el proyecto, ya que aunque participan tanto el alumnado como las familias no lo hacen con las mismas condiciones que el profesorado. Se les llama para que realicen las acciones que decide y planifica el profesorado, pero no hay un trabajo compartido y horizontal. 
En general, el proceso del cambio durante el primer curso desde que se inició la transformación fue poco democrático. En algunos casos en los que la participación fue más democrática fue en la comisión del comedor. En la que se procedió de modo diferente desde el inicio. Estefanía fue por las clases informando sobre los sueños, y la necesidad de que hubiera una comisión para priorizarlos y que se pudieran ir consiguiendo.

Después, el alumnado que quiso se apuntó a la comisión y contaron también con la participación de algunas madres. Desde la comisión se decidía aquello que se quería mejorar y se realizaban propuestas para llevar a cabo las acciones.

Durante el segundo curso, 2012 - 2013, el trabajo en las comisiones seguía sin ser democrático, a excepción de la comisión del comedor, que continuaba con la dinámica del curso anterior y con una mayor participación de las familias. En relación al resto de comisiones, Estefanía planteó la cuestión en una reunión de ciclo:

Estefanía: Com veieu les comissions? Com les porteu?

Maestra de primer ciclo: En la meua... jo he citat a un pare, però bé, encara no...

Estefanía: És que açò deuríeu de comentar-ho en les vostres comissions. En el tema del projecte escolar en el que estem, en totes les comissions han d'estar les tres parts representades: mestres, alumnes i pares.

Maestra de primer ciclo: Sí, alumnes també estan citats per al divendres, per a pintar i fer cosetes ( $3^{a}$ Reunión de ciclo).

Como podemos observar, el profesorado es quien las gestiona y "cita" a las familias o al alumnado en el horario que él considera para organizar aquellos aspectos que cree necesarios.

Otro de los temas que aparece al inicio de la transformación es la entrada de las familias en las aulas. En el primer ciclo, en febrero llamaron a las familias y una vez entraron en este ciclo, el resto del profesorado se planteó que pudieran entrar también las familias en su aula. 
Realmente la situación fue delicada. Después de haber realizado la sensibilización en septiembre del 2011, las maestras del primer ciclo que ya habían empezado a realizar algunas innovaciones en sus aulas, se plantearon que era el momento de que las familias también pudieran entrar. Esperaban que el profesorado se lanzara también a la piscina, pero puesto que estaban en febrero y durante esos meses las iniciativas sobre el cambio todavía no eran muy notables, realizaron por su cuenta una reunión con las familias en las que se les pidió su ayuda para entrar como voluntarias en algunas de las prácticas realizadas en sus aulas.

Las maestras del primer ciclo, comunicaron al equipo directivo, a la persona investigadora y a otros docentes que también impartían clase a sus alumnos, su intención de favorecer estas entradas. Pero no todo el claustro estaba informado y en la siguiente reunión del profesorado -una semana después de la entrada de las familias- los docentes a los que no les habían comentado nada explicitaron su malestar.

Las maestras del primer ciclo también se molestaron. Ellas explicaban que tras varios meses después de la formación, no habían visto ningún cambio en el centro. Pensaban que si esperaban a que todos estuvieran decididos a llamar a las familias, acabaría el curso y estas no habrían entrado. La situación provocó cierto malestar, tanto en las maestras implicadas como en aquellas que se habían ofendido. Sin embargo, fue una palanca para activar cambios. Fue el primer momento en el que una parte del profesorado empezó a replantearse la posibilidad de que entraran las familias en el centro.

No obstante, algunos docentes no estaban muy de acuerdo en que pudiera entrar cualquier familia y se plantearon de nuevo, el poder seleccionarlas.

Maestra de infantil: Teníamos que dejar muy claro los criterios para seleccionar a los padres. ¿Ahora cómo lo haremos? Porque si a cada padre, según el ciclo tenemos que ponerle unas condiciones... 
Director: Yo entendí que si un padre estaba haciendo una mala acción se le decía que saliera de la clase.

Maestra de infantil: Se trataba de hacer una criba. Para seleccionar a las familias que pudieran entrar y a las que no, sin que nadie se sintiera violento.

Estefanía: Yo ofrezco a las familias que vengan. Si alguien tiene una mala acción, fuera. Si por ejemplo Paula consigue voluntarios, o yo traigo a otras personas que no son familias y en algún momento hacen algo que no es adecuado se les dice. Pero sea quien sea. (5ª Reunión. Referencia 1).

Hasta ese momento, al hablar sobre voluntarios una parte del profesorado pensaba en estudiantes universitarios que desde el grupo de investigación pudiéramos conocer. Aunque se les insistía sobre las ventajas de que fueran personas del barrio las que entraran en las aulas, preferían contar con personas cualificadas y con un bagaje cultural parecido al del profesorado. No todo el profesorado pensaba así, porque no todos tenían prejuicios y bajas expectativas hacia las familias.

Por eso, la propuesta de seleccionar a las familias, de decir si podían entrar o no en las aulas, no se llevó a cabo. Aunque tampoco llegaron a entrar otras familias en ciclos que no fueran el primero o alguna aula de infantil.

Otro ámbito en el que se observa la falta de democratización de las acciones y la cultura profesionalista del profesorado es en el trabajo que realiza el alumnado en las aulas. En los datos del curso 2012 - 2013, vemos que el alumnado queda en un plano secundario de la acción docente. Es el que realiza las acciones que decide el profesorado. Por ejemplo, en el caso de la decoración de Navidad que es decidida por el profesorado, se acuerda hasta qué dibujos, de los motivos navideños propuestos por la comisión de fiestas, pintarán en cada clase los alumnos ( $3^{\mathrm{a}}$ Reunión de ciclo). En el aula difícilmente encontramos que el alumnado tome decisiones. De todas las observaciones de aula realizadas, el alumnado toma decisiones en una clase de infantil; en algunos momentos en la clase de Estefanía, y en las tres clases del primer ciclo durante el curso 2011 -2012. 


\subsubsection{Falta de colaboración docente}

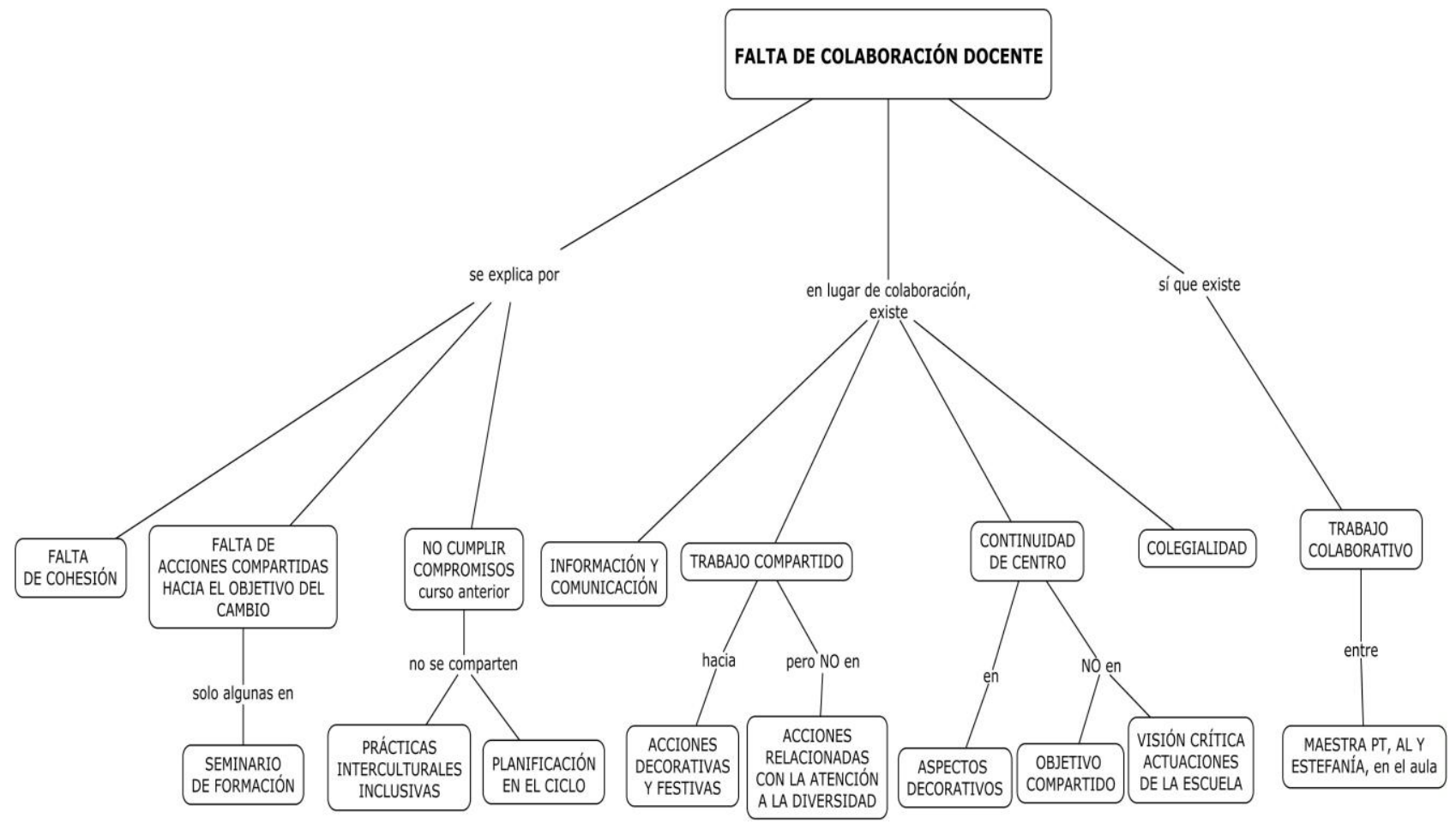

Figura 14. Categorías falta de colaboración docente.

En este apartado nos basamos en los datos de los dos cursos analizados, para describir cómo es la colaboración del profesorado y para mostrar aquellos casos en los que se identifica una falta de colaboración.

Aunque la colaboración entre el profesorado es uno de los aspectos fundamentales para la construcción de un proyecto compartido, nos encontramos en que en esta escuela el profesorado destaca que no hay suficiente colaboración.

Si bien en el seminario de formación se detectó una mejora en la relación entre el profesorado y entre ellos se animaron y se ayudaron a poner en práctica algunas de las acciones presentadas, en las entrevistas una parte del profesorado destacó 
que faltaba una mayor cohesión entre maestros así como más colaboración docente.

La gente no es sincera. La gente habla de que hay mucha colaboración y eso es mentira. ¿Colaboración aquí? Yo no la he visto. Lo bueno de este proyecto es que ahora sí o sí, nos tenemos que sentar y tenemos que hablar las cosas... Pero... yo no digo que sea mentira, pero yo no la veo. Pero lo que pasó del mal rollo, es que ellas empezaron el proyecto sin decir nada a nadie (las maestras del primer ciclo). Nosotros veíamos que los padres entraban por la puerta sin saber lo que estaba pasando, y eso tampoco es. Rollos de estos hay y habrán. Pero hay veces que cuando tú preguntas las cosas, te lo dicen de manera que parece que aquí se esté haciendo, y no es así (Entrevista a maestra especialista 1. Referencia 1).

Por otra parte, el acercamiento que detectamos en el profesorado a partir del seminario no continuó durante el siguiente curso, ya que dejaron de realizar reuniones para compartir las prácticas a nivel de centro. Es por esto que más que hablar de colaboración podríamos hablar de que existe una información y comunicación entre las iniciativas que se llevan a cabo desde cada ciclo. A diferencia del curso anterior (2011 - 2012), en el que el profesorado de toda la escuela se formó conjuntamente sobre aquellas prácticas valoradas como más interculturales e inclusivas.

No obstante, en el curso 2012 - 2013 también aparecen casos puntuales en los que se podría dar dicha colaboración. Por ejemplo, en una reunión del primer ciclo en la que Estefanía comenta a sus compañeros que le han pedido que realice un seminario para hablar sobre las prácticas que se realizan en el centro y les pregunta si quieren participar ( $1^{\mathrm{a}}$ Reunión ciclo). $\mathrm{O}$ en un claustro en el que la jefa de estudios le pregunta al profesorado si existe algún tema en relación a las prácticas de aula, sobre el que quieran formarse conjuntamente (Reunión claustro, segundo curso transformación).

En definitiva, la colaboración del profesorado durante el curso 2012 - 2013, se concreta en acciones festivas y decorativas de la escuela, más allá de un trabajo compartido sobre aspectos pedagógicos del aula. En relación a los actos festivos y 
a la decoración del centro, se suelen acordar en la comisión de fiestas. El trabajo colaborativo en este sentido queda lejos de un trabajo compartido para conseguir una escuela más intercultural e inclusiva, puesto que no se abordan aspectos relacionados con la atención a la diversidad, sino aquellos relacionados con las fiestas. Incluso en las reuniones del ciclo, también predomina el trabajo colaborativo en relación a acciones poco pedagógicas, como serían la decoración de los pasillos o de las puertas y el tipo de felicitación navideña que puede confeccionar el alumnado para llevársela a casa.

También nos llama la atención que se identifica la continuidad del centro (en palabras del profesorado), o el hecho de que haya un proyecto compartido, con la toma de decisiones sobre aspectos también decorativos y en los que no se realiza una visión crítica sobre las actuaciones realizadas en la escuela. Es decir, en una reunión de ciclo dicen que van a ponerse de acuerdo en realizar el mismo tipo de árbol de Navidad para que haya una continuidad en el ciclo ( $2^{\mathrm{a}}$ Reunión de ciclo). En relación a la felicitación navideña, también se coordinan dentro del mismo nivel para que el alumnado realice el mismo trabajo ( $3^{\mathrm{a}}$ Reunión de ciclo).

Sin embargo, las prácticas consensuadas durante el curso anterior y los acuerdos realizados sobre la implementación de prácticas más inclusivas no son generalmente compartidos o reflexionados conjuntamente, ni tampoco planificados en el ciclo, aunque esta era una propuesta realizada en el curso 2011 - 2012 y tiene que ver con el modelo de escuela que se plantean construir. No obstante, sí que se inician algunas acciones para realizar prácticas interculturales e inclusivas de manera colaborativa, tanto en su planificación como en la puesta en acción.

En primer lugar, la preparación del material para los grupos interactivos es compartida entre las maestras del mismo nivel, en primer curso. Sin embargo, no se da una reflexión compartida sobre cómo ha ido la sesión una vez finalizada ( $1^{\text {a }}$ Reunión ciclo). Es cierto que aparecen propuestas interesantes para realizar un trabajo colaborativo relacionado con la práctica. Por ejemplo, una maestra que acepta ir a la clase de Estefanía, su compañera de nivel, para conocer una práctica 
de aula y acaban planificando y realizando una sesión compartida con el alumnado de las dos clases.

Pensamos que sí que se realiza un trabajo más colaborativo entre la maestra de AL, la de PT y la tutora, en la clase de Estefanía. Normalmente, la maestra de PT asiste todos los días unas horas a la clase de esta maestra para hacer el refuerzo del alumnado diagnosticado con diversidad funcional o con dificultades de aprendizaje. Sin embargo, tanto el trabajo de la maestra de PT como el de la de AL, las horas que están en la clase, es un refuerzo global a todo el alumnado. Es decir, estas dos maestras especialistas participan de la práctica dinamizada principalmente por la maestra y ayudan a diferentes niños del mismo grupo en el que se sientan a trabajar; o participan como una persona más en la asamblea favoreciendo la participación de todo el alumnado. Es tal el conocimiento que estas maestras tienen de la clase, que en una sesión de evaluación a la que no podía asistir la tutora, la maestra de PT aportó todos los datos sobre el alumnado de la clase (Evaluación final trimestre, clase Estefanía).

Finalmente, más allá de una colaboración relacionada con la toma de decisiones y el trabajo compartido, existe la colegialidad y el compañerismo entre el profesorado. Por ejemplo, un día que no realizan los GI, dos de las maestras que asisten como voluntarias acuden a la clase para preguntarle a Estefanía si quiere que se queden como maestras de refuerzo ( $4^{\mathrm{a}}$ sesión, contraste con GI).

Por todo lo explicado, destacamos que aunque aparecen algunas iniciativas para realizar un trabajo compartido o colaborativo entre el profesorado, generalmente el profesorado realiza un trabajo bastante individualizado. 


\subsubsection{Cultura dominante asimilacionista: conflictos interculturales}

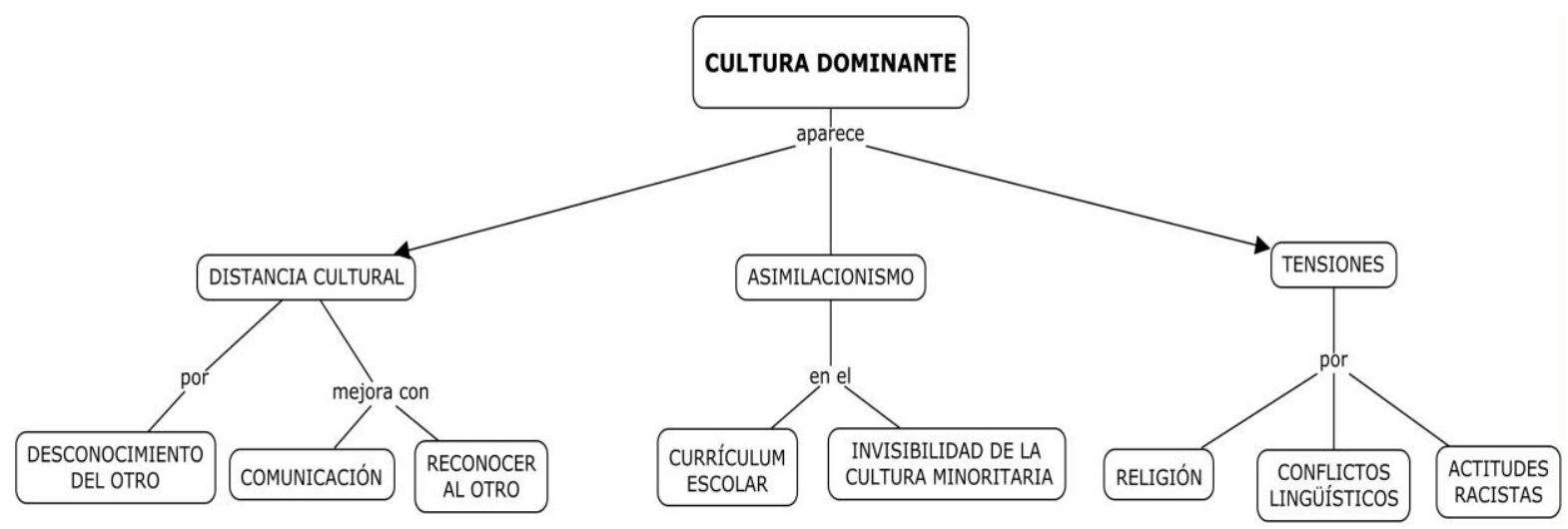

Figura 15. Categorías cultura dominante.

Entre los obstáculos que encontramos, algunos vienen asociados a la distancia cultural que existe entre las personas árabes y las de origen español. Muchos de estos conflictos se sitúan en el desconocimiento del otro, por eso rescatamos una de las afirmaciones de una de las madres más implicadas en la escuela durante el curso 2012 - 2013. Ella, después de la sesión en la que las madres árabes prepararon comida típica para agradecerle al alumnado de la universidad su participación en el taller de lengua, propuso que las madres españolas también realizaran una sesión en la que les enseñaran la comida típica española a las madres árabes, para compartir un espacio y poder conocerse y relacionarse unas con otras.

La madre, insiste en que es importante romper barreras y estar juntas. Dice que en el instituto había compañeras que no les hablaban y en algunas asignaturas el profesor les hacía trabajar juntas y se hacían amigas (Sesión tutorización a las familias para el $2^{\circ} \mathrm{CS}$ ). 
Pensamos que la distancia entre culturas es una distancia entre personas, una distancia de tú a tú, al menos en los casos que veremos a continuación. Por eso, destacamos el valor de conocer y reconocer al otro. A continuación mostraremos algunos de los momentos en los que detectamos ese distanciamiento o conflicto; hablaremos también sobre la cultura dominante y el currículum escolar, como muestra de esa cultura asimilacionista. También sobre la invisibilización de la cultura minoritaria y finalmente, sobre algunos conflictos culturales.

El primero de los conflictos que destacamos no implica una discusión o desencuentro entre las partes, pero sí que nos interesa por el malestar que genera. Este malestar, o tensión, que detectamos lo asociamos precisamente al desconocimiento del otro y en concreto al desconocimiento de la cultura de personas con las que día a día se encuentran en la escuela.

En este caso, en la clase de Estefanía están realizando un "proyecto de Trabajo" del pueblo en el que viven. Uno de los aspectos que estudian es la comida típica y para explicar en qué consiste y cómo se elabora llaman a la cocinera de la escuela para que se lo cuente. Ese día asiste una madre árabe a la clase de Estefanía, ya que le pregunta por el rendimiento de su hijo y la maestra la invita a quedarse. Esta madre está muy atenta a todas las explicaciones y toma nota también sobre cómo se prepara una paella. Pero, llegados al ingrediente de la carne de cerdo, la cocinera se incomoda y trata de evitar nombrarlo, ya que conoce que muchos niños de la escuela no se la comen porque en la cultura árabe no les está permitido.

Cuando la cocinera empieza a nombrar los ingredientes enumera todo los tipos de carne y cuando llega a las costillas de cerdo se para y le pregunta a las maestras si lo puede decir. La maestra le dice que sí, pero ella no lo nombra. Dice simplemente que se añaden costillas. Por eso, la madre cuando se da cuenta de que no sabe qué tipo de carne tiene que poner, le pregunta: ¿de qué carne tienen que ser las costillas? y la cocinera esta vez, con una expresión de incomodidad,frunciendo las cejas- le dice que de cerdo. Entonces la madre dice, ah, vale y se 
ríe. La cocinera le lanza una mirada curiosa y al mismo tiempo trata de excusarse, pero la madre le dice que no pasa nada (Diario, $1^{a}$ sesión de proyectos de trabajo).

Para la cocinera era violento hablar sobre aspectos que en la cultura de la madre árabe están "prohibidos" pero cuando posteriormente la madre le pregunta, se da una conversación con toda naturalidad. Parece que si no conocemos al otro, las diferencias nos pueden separar, pero una vez nos comunicamos y nos conocemos estas barreras pueden desaparecer.

En otra sesión de este mismo proyecto, la maestra le pregunta al alumnado si alguna vez han probado una paella. Al responderles que no, la maestra les propone bajar un día a la cocina para que la cocinera les muestre los ingredientes. Un niño de la clase, pregunta con curiosidad cuándo van a comer la paella. Y la maestra entre risas (sorprendida por la propuesta de su alumno), le responde que si les parece bien le pedirá a la cocinera que un día que haga paella les guarde un plato y catorce cucharillas para que todos puedan probarla. Un niño le responde que a él no le parece bien porque su madre no le deja:

Alumno: Jo no, ma mare no vol.

Estefanía: Tranquil, no hi haurà carn de porc (cerdo), no hi haurà carn de porc. Hi haurà pollastre.

Alumno: Però tampoc puc pollastre.

Estefanía: Pues mengeu l'arròs.

Niños de la clase: A mi tampoc em deixen.

Estefanía: Pues mengeu l'arròs, l'arròs no passa res (2 $2^{a}$ Asamblea clase Estefanía).

En este ejemplo vemos que hay una distancia cultural. Las madres no se acaban de fiar sobre la comida que se prepara en el centro, aunque nunca han tratado este aspecto con las maestras.

Otro de los aspectos que aparece en el mismo proyecto de trabajo es que aunque estudian el pueblo en el que viven y sus tradiciones, estas son poco 
significativas para ellos porque ni ellos ni sus familias conocen la historia. Es una oportunidad para poder aprender aspectos de la ciudad, aunque en algunos casos, los contenidos a trabajar también son estudiados desde el currículum de una cultura dominante y también, asimilacionista. Por ejemplo, al estudiar la historia de la ciudad se habla de la expulsión de los árabes realzando la figura de Jaume I. La historia en las escuelas se explica desde un punto de vista subjetivo, que en este caso es el de la cultura mayoritaria. En estas explicaciones acerca de cómo se conquistó la ciudad, no se entra a detallar aspectos como por ejemplo, cómo fueron expulsados los antepasados de los niños árabes que vivían allí, viéndose obligados a abandonar todas sus pertenencias o a convertirse a una religión que no era la suya. No se para a reflexionar sobre la ética, o falta de ética, de ese hecho; la situación de injusticia que pudieron vivir y que se sigue viviendo en muchos países por cuestiones políticas o religiosas principalmente.

Quizás es importante en este centro en el que la mayoría de las personas del barrio tiene una actitud despectiva hacia las familias árabes recordar un poco la historia, al menos si forma parte de los contenidos que se están estudiando en clase. En lugar de estudiarla desde el punto de vista de los que se quedaron.

Enlazando con la historia, existen otras tradiciones de carácter racista que son vistas con total naturalidad en la ciudad y también en la escuela, como es la celebración del día de "Sant Nicolau", el día 5 de diciembre. En concreto, esta tradición celebra la expulsión de los moriscos por los cristianos y para conmemorarlo ese día se comen un bocadillo de longanizas de cerdo, ya que dice la tradición que a los moriscos que se quedaron les obligaron a comer carne de cerdo para celebrar la expulsión de la mayoría de sus parientes.

Esta tradición se sigue celebrando por los maestros en la escuela, aunque con algunas adaptaciones. En el caso del alumnado, son las madres las que compran la carne y la llevan a la escuela. Dicen que durante los primeros años en los que el centro empezó a acoger al alumnado árabe, se les decía a las familias que la carne la compraban ellos, el profesorado, y que podían estar tranquilas porque no sería carne de cerdo. Pero según un maestro, algunos niños lloraban y no querían 
comerse el bocadillo; otros los escondían por el patio. Por eso, durante los siguientes años fueron las familias las que llevaban la carne a la escuela y la compraban en una carnicería "Halal". Actualmente, el alumnado come esos bocadillos de longanizas celebrando la expulsión de los moriscos, siendo estos sus antepasados. Pero el profesorado no se plantea quitar la tradición. Ellos celebran también esta comida en la escuela con carne o verduras. Además, en otras escuelas de la ciudad se canta también una canción que entona una de las maestras para que conozca la letra, y el alumnado confecciona también sus espadas típicas en la tradición del día de Sant Nicolau. En esta escuela, me dicen que no se canta la canción ni se diseñan las espadas, aunque sí que se continúa con la tradición (Sesión Sant Nicolau).

La letra de la canción es la siguiente:

"Sant Nicolau, sant beneït confessor de Jesucrist.

Visca el rei! Muira el gall! Quatre-cents per al cavall.

Tris-tras! Llonganissa menjaràs!

Tris-tras! O en l'espasa moriràs!"

Otro de los conflictos culturales que detectamos en la escuela es la invisibilidad de las culturas minoritarias en algunas celebraciones del colegio. No nos referimos solo al hecho de que no sean visibles las tradiciones de la cultura árabe, siendo un $90 \%$ del alumnado del colegio, sino a que en las celebraciones de la cultura dominante tampoco se tiene muy presente la diversidad cultural. Por ejemplo, en la decoración del centro para las fiestas Navideñas, se decidió pegar en la escuela felicitaciones en todos los idiomas. Pero cuando fueron a colocar las felicitaciones se dieron cuenta de que no había ninguna felicitación en árabe ni en chino o rumano, lenguas de una parte del alumnado de la escuela. Sin embargo, sí que aparecían en inglés e italiano y no había ningún alumno que hablara estos idiomas. Cabe destacar que no fue un acto realizado a propósito, pero es un indicador más de la falta de presencia de la cultura minoritaria en el currículum. No 
sólo en el currículum sino también en la cotidianidad del centro. En este caso, en el que la cultura árabe es predominante, no se le asigna un espacio en una actividad como es la preparación de la felicitación de la Navidad, ni tampoco a aquellas culturas minoritarias, representadas por el alumnado del colegio, a diferencia de la española, que como hemos comentado en este centro actúa como la cultura asimilacionista. También planteamos que este hecho aparece al mismo tiempo que observamos la falta de presencia del alumnado en las actividades del colegio. En una postal navideña pensada por alumnos árabes quizás se replantearían la lengua a utilizar en la misma.

Otro de los aspectos es que, las familias árabes, siendo una mayoría de las familias de la escuela, asisten a al centro para celebrar tradiciones del cristianismo. Aunque tan solo un 10 o un 15\% del alumnado puede que sea cristiano, se "monta" el Belén en la entrada del centro, y las familias árabes participan en su elaboración; una muestra más de la cultura asimilacionista en la escuela.

Por otra parte, en relación a la multiculturalidad, aparecen algunas tensiones por el tema religioso. En una sesión en la que estoy con Fátima y con Pepe, para mostrarles de antemano los resultados que se aportarán en la siguiente reunión del Consejo Social, para que así que puedan comprender mejor los datos aportados el día del consejo, aparecen algunas discusiones entre ambos en relación a temas tanto culturales como religiosos. Todo empieza porque el padre le dice a la madre que antiguamente los hombres llevaban sombrero y cuando entraban en las casas o en lugares de reunión se lo quitaban, por eso mismo dice que en "nuestra cultura" quitarse el sombrero o la gorra cuando vas a reunirte con alguien es un gesto de educación. De ahí, le comenta que quizás en algunos casos algún profesor le ha podido pedir que se quitara el pañuelo a lo que la madre responde:

Los profesores son más cultos y no he tenido problemas con nadie. Ellos entienden que es un tema religioso y por eso lo comprenden... El mundo debería ser como en América, en el sentido de poder ir vestido como quieras y que nadie te diga nada, que cada uno pueda ir como quiera (Sesión tutorización a las familias para el $\left.2^{\circ} \mathrm{CS}\right)$. 
Al respecto el padre le dice que hay dos cosas que no le gustan de su cultura:

A mi hay dos cosas que no me gustan, que se hagan tatuajes en el cuerpo (refiriéndose a la gena) y que tapen a las mujeres. El pañuelo aún, pero eso que van todas tapadas no me gusta (Sesión tutorización a las familias para el $2^{\circ} \mathrm{CS}$ ).

Estos temas aparecen en la reunión por parte del padre, que sin estar hablando sobre dichas cuestiones las comparte con nosotras. Quizás desde la "ignorancia” o el atrevimiento el padre manifiesta una opinión desagradable para una persona de la cultura árabe. Además, continúa diciéndole que en su cultura los hombres tienen anuladas a las mujeres, a lo que la madre le responde que no es del todo cierto. La madre le dice que este caso no es una cuestión de religión, puesto que su profeta hablaba de que las mujeres podían estudiar, tener cargos,... igual que los hombres. Pero el problema para ella reside en la interpretación que se hace de los textos islamistas. De hecho esta madre está divorciada y ella sola se ocupa de la crianza y mantenimiento de su hija.

La conversación continúa y el padre sigue haciendo énfasis en sus ropas y su manera de vestir. Le dice que si una persona española fuera a su país le harían ir vestida de otra manera, aunque ella responde que si visitara el país como turista podría ir vestida como quisiera. Poco a poco van tratando de dejar la conversación que la concluye el padre diciendo que no le importa si le reza a Alá o a Dios, que para él Dios es amor y nada más y lo importante es respetarse y tratarse con amor, en lo que ambos coinciden.

Aunque se dan momentos de tensión, es una conversación que desde el diálogo permite conocer otra cultura, e incluso romper con los prejuicios que se tienen hacia lo desconocido. Aunque quizás esta no fuera la pretensión primera de la conversación. En cualquier caso, es un diálogo entre personas con creencias distintas que tratan de comunicarse y compartir sus distintos puntos de vista.

Finalmente, se producen también algunos conflictos lingüísticos. El primero que mostraremos está relacionado con la valoración de un padre (Pepe), sobre el 
hecho de que la mayoría del alumnado que asiste a la misma clase de su hija sea de origen árabe. En principio se plantea el tema de la lengua porque incluso para las familias españolas la adquisición del valenciano resulta dificultosa y a partir de algunas prácticas de aula, se facilita su uso y su comprensión. En relación a este tema, el padre muestra su descontento al pensar que en la clase de su hija se habla más el árabe que el castellano. En el siguiente fragmento apreciamos esto, aunque también podemos observar que la predisposición de este padre es que se mantenga la lengua de origen del alumnado, al menos en casa. En este sentido, al inicio del proceso del cambio, las familias árabes también pidieron que en horas extraescolares se pudiera realizar un taller de árabe para que sus hijos aprendieran a escribirlo para no perderlo, pero finalmente no se realizó.

Sobre el tema de la lengua, les presento los resultados de la evaluación y les comento que en la clase de Estefanía, el alumnado va mejor en valenciano que en castellano y este hecho lo atribuimos a que las asambleas y las tertulias las realizan en valenciano. El padre, me dice que su hija habla en castellano pero que cree que al menos un $60 \%$ del alumnado son árabes y que hablaran en árabe en clase. La madre dice que ella en su casa le suele hablar el árabe a su hija, aunque a veces también le habla un poco de valenciano y un poco de castellano, porque ella quiere que aprenda los tres idiomas. Yo le digo que también soy partidaria de que en casa hablen su lengua materna, que es el árabe. El padre dice que también cree que es importante porque si no lo hacen lo perderán, a lo que la madre responde que en un futuro su hija necesitará también saber el árabe. Además, cuando va en vacaciones a Marruecos a ver a su familia necesita hablar en árabe para comunicarse con sus primas y con su familia. (Sesión tutorización a las familias para el $\left.2^{\circ} \mathrm{CS}\right)$.

Para finalizar este apartado podemos concluir que existe una mayor apertura en el centro, en relación a su situación antes de iniciar el proceso de cambio. Sin embargo, también existen actitudes racistas. Aunque, se aprecia un intento por parte de algunas familias de cambiar su percepción sobre las familias de origen árabe que asisten al centro. 
En el caso de Pepe, hemos podido observar un cambio en su actitud. En las primeras sesiones se manifestaba en contra de las familias árabes, y al finalizar el curso 2012 ha trabajado en numerosas ocasiones con ella. Él comenta que algunas personas le dicen que es racista y él les responde que para cosas de la escuela no. Que él defiende a uña y carne a todas las personas del centro (Sesión tutorización a las familias para el $2^{\circ} \mathrm{CS}$ ).

\subsection{Las transformaciones en el centro}

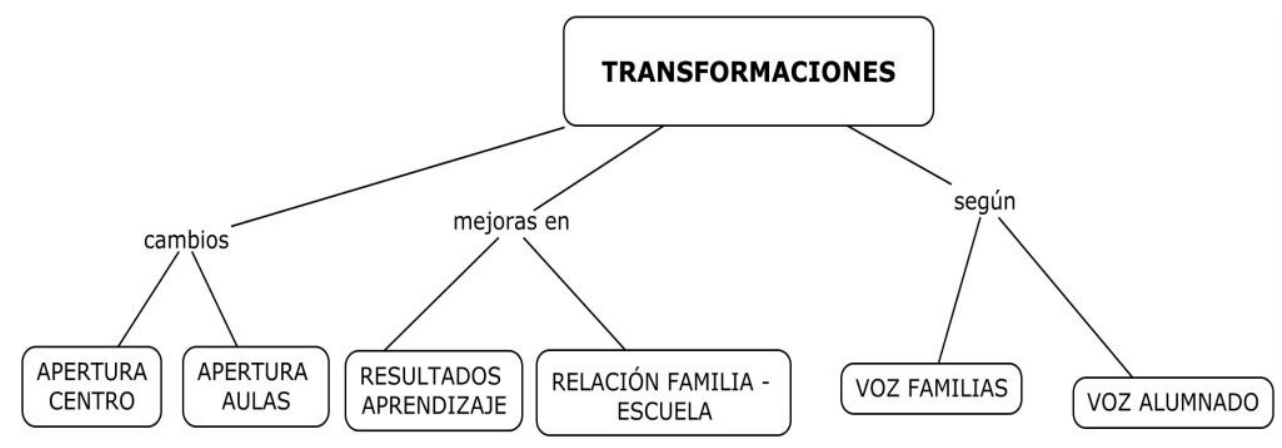

Figura 16. Categorías transformaciones.

Puesto que se ha recogido información sobre las transformaciones a nivel de centro y de las aulas en general de la escuela, y por otra parte del aula de Estefanía, en primer lugar hablaremos de aquellas categorías relacionadas con los cambios en el centro y en las aulas. Posteriormente nos centraremos en las transformaciones llevadas a cabo en el aula de Estefanía. 


\subsubsection{Apertura del centro}

Una de las transformaciones de la escuela es su mayor apertura hacia la comunidad, y especialmente hacia las familias.

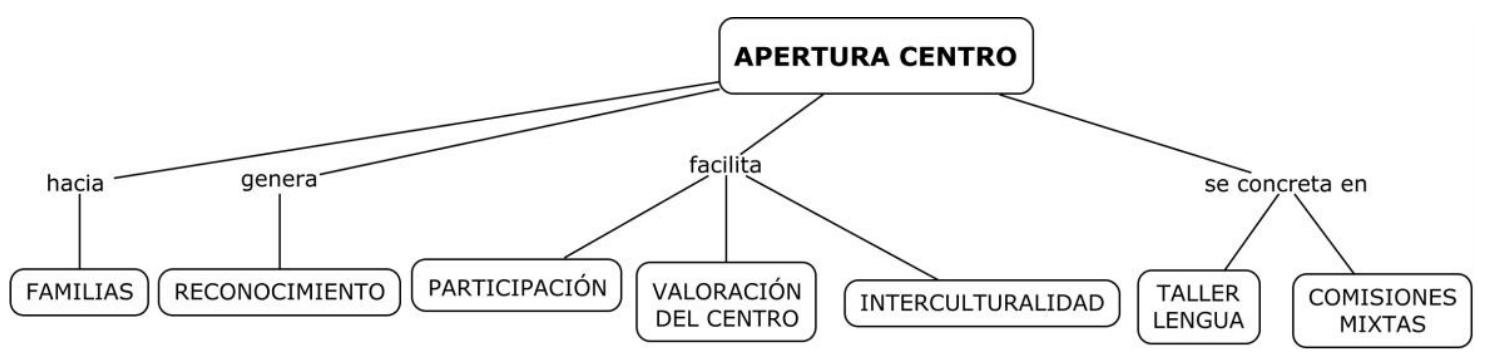

Figura 17. Categorías apertura centro.

Antes de iniciar el cambio, el centro se sentía menos abierto a que llegaran las familias y estas entraban para temas muy concretos, como para hablar sobre los resultados de sus hijos o en caso de que el profesorado requiriese de su atención.

A partir del inicio del cambio esta situación se transforma. A continuación expondremos algunos fragmentos que muestran cómo ha cambiado la escuela en este sentido.

No, jo no sé si ho noteu però abans venia un pare i nosaltres diem és el pare de... El pare de Marta, no ara és Pepe ( $2^{\circ}$ CS. Director).

Uno de los principales hechos que se destaca, es precisamente el reconocimiento del otro. El poder llamar a las familias por sus nombres en lugar de referirse a ellos como "el familiar de". Pero además, existen otros cambios relacionados con la entrada de otras personas a la escuela. El proceso iniciado transforma el posicionamiento del centro, ahora es una escuela que se llena cada día de las visitas de gente del barrio y de otros agentes.

Director: Es bonito lo que se está haciendo en el centro, que en este mismo instante en la escuela haya madres haciendo un taller para aprender el castellano, alumnado de la Universidad haciendo APS, personas del centro de Drogodependencia que se ofrecieron para hacerle un taller al alumnado, la 
asociación de minusválidos con la que también se realizan talleres. No todas las escuelas pueden estar haciendo eso, si incluso es difícil que se haga a lo largo de un trimestre, ya ni decir a lo largo de un día.

Hay bastante interacción entre la escuela y el mundo que la rodea, aunque es cierto que la implicación de las familias o la entrada del barrio a la escuela es algo que se va haciendo poco a poco, pero ya se da un acercamiento. (Fragmento del diario de campo de la investigadora; sesión de APS. Comentario de la investigadora y del director).

Esta apertura que es vista con alegría desde el equipo directivo también se reconoce desde las familias:

Pero por eso hablamos de que el colegio que estaba abierto a las familias. $Y$ creo que como yo hay unos cuantos padres más, igracias a Dios! Y creo que este año se... hay mucha gente que ha venido con ganas. Falta pues eso, que nos dirijan un poquito, yo estoy desde el año pasado, entonces a mí también me hace ilusión todo lo que estábamos hablando de... a mi me parece perfecto $\left(2{ }^{\circ} \mathrm{CS}\right.$. Padre).

Además, la apertura del centro hacia las familias facilita que ellas se sientan partícipes de los cambios y con la libertad de aportar ideas y propuestas.

Sí, igual que yo también quería comentar que también he hablado con uno, ya de paso ya lo digo, que es pintor, que es descendiente de las Liras y le he pedido si podría venir aqui a hacer clases de pintura o de... lo que sea, como voluntario. $Y$ también, cuando yo hablo del colegio, siempre pienso que yo tengo la plena libertad que si yo dijera, oye hacemos tal, que lo tenemos el colegio abierto. ¿Vale? Que, o sea, que cuando lo digo en los demás colegios, enseguida "uy, es que mi director no sé qué, no sé cuantos... "Y yo creo que le digo al director nuestro, "hacemos esto" y lo tenemos abierto. Es una cosa que sí que pienso $\left(2^{\circ} \mathrm{CS}\right.$. Padre). 
También valoran como positiva esta apertura, que en comparación con otras escuelas no es la habitual.

Yo tengo amigas que les cuento lo que estamos haciendo y dicen qué envidia, nosotras para entrar tenemos las horas de atención del maestro y ya está, ya no puedo estar más tiempo en ese colegio $\left(2^{\circ} \mathrm{CS}\right.$. Madre $)$.

No obstante, en algunos casos las familias reconocen que no todo el profesorado se implica de la misma manera o les atienden con esa misma predisposición. Aunque creen que generalmente, tienen una actitud muy positiva sobre la entrada de las familias en la escuela.

Yo te puedo garantizar que la profesora que tiene mi hija, la que está de sustituta, la verdad es que la ves un poco (hace gestos con las manos y pone cara de que no le convence) que dices, ¿cuándo tengo que ir a protestar...? Y la ves en estado de preocupación. Y la verdad, cuando le pedí que quería ir a hablar con ella le dije que quería ir ya, no me podía esperar por el horario. Ella me dijo lo del horario y yo le dije, mira, yo vengo sin horario, vengo hablo y tengo esa libertad. Si me dicen que no pueden yo me espero o... Pero sí que es verdad que como tú tienes una predisposición de cara al colegio, creo que los profesores también tienen una hacia mí, por lo menos los veteranos $\left(2^{\circ} \mathrm{CS}\right.$. Padre).

Por otra parte, la situación que se propicia desde el centro es envidiable para algunas escuelas y por eso, una trabajadora del CEFIRE dedicada a la formación del profesorado sobre temas de interculturalidad e inclusión, les pide al profesorado y a las familias si podrían ir a otras escuelas a contar su experiencia.

Profesional del CEFIRE: Jo el que sí que vull és demanar una cosa, ja que hi ha pares que estan actius, hi ha centres en esta població $i$ al voltant, que s'estan pensant apuntar-se a coses d'estes i si en un cas donat vos demanara si podeu acompanyar-me a un centre a explicar-los com vos sentiu vosaltres, com ho veieu vosaltres, si estaríeu disposats?

La madre y el padre asienten. 
Padre: Sí, hombre claro, siempre. Aquí han venido padres a ayudarnos ¿no los vamos a ayudar ahora nosotros?

Madre: Sí, sería bueno hacer eso porque es lo mínimo que se merece todo este colegio, la verdad.

Profesional del CEFIRE: Jo als mestres sí que sé que si els ho demane vindran (...), però m'agradaria també tindre un banc de pares, un personal, perquè me pareix que és important conèixer quina és l'opinió de tota la comunitat educativa $\left(2^{\circ} \mathrm{CS}\right)$.

Por otra parte, la apertura del centro está presente también en su manera de vivir la interculturalidad.

Este colegio, pues la verdad, nos ha abierto una puerta enorme tanto para sentirnos, pues, integrados (lo dice con afirmación- asiente con la cabeza) y tener confianza entre nosotros, que no haya esa barrera entre extranjero o no. A ver, nos hemos sentido ya gente normal $\left(2^{\circ} \mathrm{CS}\right.$. Madre $)$.

La distancia que existía en un primer momento entre el "ellos" y el "nosotros" poco a poco se va borrando a partir del conocimiento del otro.

Padre: Pero fue algo curioso porque eso es gracias a una asamblea. Fue a partir de esa asamblea. Yo creo que eso creó una unión. Y creo que esa unión hay que hacerse de vez en cuando. Entre padres era casi hola y adiós, y con ellos (mira a la madre árabe)... Ellos (refiriéndose a las personas inmigrantes) a nosotros nos miraban como bichos raros y nosotros a ellos los mirábamos así también, como bichos raros. ¿Es así o no es así? (Se dirige a la madre, y esta asiente). Y sin embargo...

Jefa de estudios: No, es que piensas que eres diferente, pero es que tienes todo en común.

Padre: Todo, correcto. Y la ventaja que hemos tenido es que gracias a que se hizo algo en común pues se pudo más... Claro que hay peleas entre nosotros y 
ellos, porque si entre nosotros ya las hay, ¿entre todos no las vamos a tener? Pero yo sí que he pedido más colaboración de los españoles que no la hay. Somos más reacios los españoles, somos más cómodos que incluso que ellas, que no necesitan nada, enseguida ellas se acoplan $\left(2^{\circ} \mathrm{CS}\right)$.

Algunas de las acciones que se realizan para conseguir una mayor apertura en el centro es por ejemplo, la realización de un taller de lengua en castellano para familias árabes. Esta acción se inicia a partir del sueño de algunas familias árabes de aprender uno de los idiomas. El valenciano, también tienen la intención de aprenderlo, aunque en primer lugar prefieren el castellano porque es la lengua predominante en el barrio y aunque no sea la lengua vehicular de la escuela los maestros igual las entenderían. Las madres árabes, que son las que manifiestan la necesidad de aprender la lengua, tienen dificultad en asistir a cursos de lenguas que se ofrecen por ejemplo en la "Escuela para Adultos". Por eso, la iniciativa puesta en marcha durante ese curso fue uno de los aspectos que favoreció su entrada en la escuela y también en las aulas. Este taller lo empezó un grupo de alumnas y alumnos de la Universidad que estudiaban magisterio, y lo continuó una de las madres asistentes al taller y exalumna de la escuela, que tenía dominio de la lengua.

Por otra parte, se está organizando un taller de francés que también era otro de los sueños de las familias árabes, al que puede asistir todo el alumnado del centro por orden de inscripción. Este taller es impartido por una madre de habla francesa y como el anterior, su participación es como voluntaria y no supone coste alguno para los participantes.

\subsubsection{Comisiones}

La participación de las familias en la escuela también se concreta en su implicación en las comisiones mixtas de trabajo. En esta apartado comentaremos 
aspectos sobre la composición de las mismas, su funcionamiento y la valoración que se hace sobre su utilidad.

En relación a la composición, las comisiones deben contar con la participación de las personas de distintos colectivos: alumnado, familias y profesorado principalmente y asociaciones del barrio y vecinos. No obstante, como ya ha aparecido en los datos, no en todas las comisiones aparece una representación de todos.

Durante el curso 2011 - 2012 el profesorado se agrupó en distintas comisiones, pero de todas ellas las únicas que llegaron a contar con la presencia de las familias y/o del alumnado fueron la comisión de infraestructuras y la del comedor. En alguna otra comisión como en la de rendimiento, también se contaba con la participación de las familias pero no llegaron a tomar ninguna decisión porque la mayoría de sus miembros eran docentes y las familias apenas participaban. En el caso de la comisión de infraestructuras y del comedor sí que realizaron acciones y tanto las familias como el alumnado participaron activamente.

Durante el segundo año desde que se inició la transformación, se hizo un mayor hincapié respecto al funcionamiento de las comisiones. Sin embargo, a nivel general siguieron sin ser suficientemente democráticas, como hemos explicado anteriormente, y no contaron con la participación de todos los colectivos en la toma de decisiones.

Las comisiones del curso 2012 - 2013, son: el rincón solidario; infraestructura; talleres; fiestas; relaciones con la comunidad; biblioteca y comedor. A modo de resumen explicitaremos características de cada una de ellas (Información de la sesión 23.11.12. Jefa de estudios).

La comisión del rincón solidario es una comisión que propuso el profesorado para poder aportar información de interés a las familias. A modo de tablón de anuncios, en esta comisión se encargan de comunicar a las familias sobre las becas 
u otras oportunidades de las que pueden obtener algún beneficio social. En esta comisión se llamó a las familias para que participaran, pero tras una primera reunión informativa en la que el profesorado les contó en qué consistía esa comisión, las familias se fueron y ya no volvieron a participar en la misma.

En la comisión de infraestructura se cuenta con un padre, que es el principal representante de la escuela a la hora de hablar con el ayuntamiento. A este padre le gusta esta tarea, aunque en general no sabemos si las decisiones que se toman en la comisión son o no democráticas, porque no hemos podido participar en ninguna de las reuniones.

La comisión de los talleres consiste en la coordinación de los talleres propuestos por las familias, en algunos casos son talleres de lengua y en otros de cocina, ejercicio físico, u otros, en función de las propuestas de las madres que participan en los mismos. En esta comisión participan algunos docentes y algunas madres, principalmente árabes. La primera acción de la comisión fue la puesta en marcha del taller de lengua en castellano para madres árabes, que lideró un grupo de alumnos de la Universidad, como hemos comentado anteriormente. Aunque las madres de esta comisión están muy activas, no podemos decir lo mismo de todo el profesorado que forma parte de la misma. Algunos de ellos no saben cómo funcionan estos talleres e incluso no comprenden porque es necesario hacer esta clase de actividades desde el centro. Como dice la jefa de estudios, algunos pueden sentir que les están dando un lugar que no era necesario ofrecerles a las familias.

La comisión de fiestas es una comisión que está activa pero que es muy poco democrática. Esta comisión la podemos encontrar en varias escuelas, sin por ello contar con un proyecto de cambio hacia la interculturalidad y la inclusión. En esta escuela, podemos decir que el funcionamiento de esta comisión sería parecido al que cabría esperar en una escuela que no ha hecho ninguna reflexión sobre dicho modelo. En definitiva, no cuenta con la participación ni de las familias ni del profesorado. Se limita a tomar decisiones sobre la realización de celebraciones, así como la decoración y el material necesario para celebrar las fiestas. No se escuchan 
las voces de otros colectivos para poder introducir otras celebraciones importantes para el alumnado o las familias.

Otra de las comisiones que estaba presente desde el curso anterior era la de relaciones con la comunidad. Según nos comenta la jefa de estudios, esta comisión durante el curso 2012 - 2013 está totalmente parada. La función de la misma era acercar la escuela a las actividades de la ciudad. Sí que existen algunas acciones que realiza la escuela con el barrio, como son los talleres que prepararon las trabajadoras sociales desde la Oficina de Dependencia. Sin embargo, estos fueron una iniciativa de estas trabajadoras que no formaban parte de la comisión. La formación de la comisión cuenta únicamente con tres maestras.

La comisión de la biblioteca está muy ligada a la del comedor, puesto que la sala de la biblioteca funciona sobre todo en las horas del comedor. Aunque todavía no se ha puesto en marcha el sistema de préstamos de libros y materiales de lectura, es una de las propuestas del profesorado.

La comisión del comedor es una de las más activas durante los dos cursos escolares. En este caso, tanto la implicación de las familias como del alumnado se realiza de un modo más democrático, abriendo la posibilidad de participar a todo el colegio, en lugar de llamar a algunas familias en concreto. Por eso cuenta con una participación bastante alta de las madres, siendo 20 las que se apuntaron para participar en el curso 2012 - 2013. Las funciones que realizan las madres en esta comisión, además de tomar decisiones junto con otros miembros y priorizar acciones, es la de abrir la sala de estudio y hacerse cargo del buen funcionamiento de la misma. Al contar con tanta participación de las madres, la propuesta del profesorado fue elaborar una tabla con la disponibilidad de cada una y establecer entre todas unos horarios con distintos turnos para que cada día se hicieran cargo unas madres de la sala. 


\subsubsection{Apertura del aula}

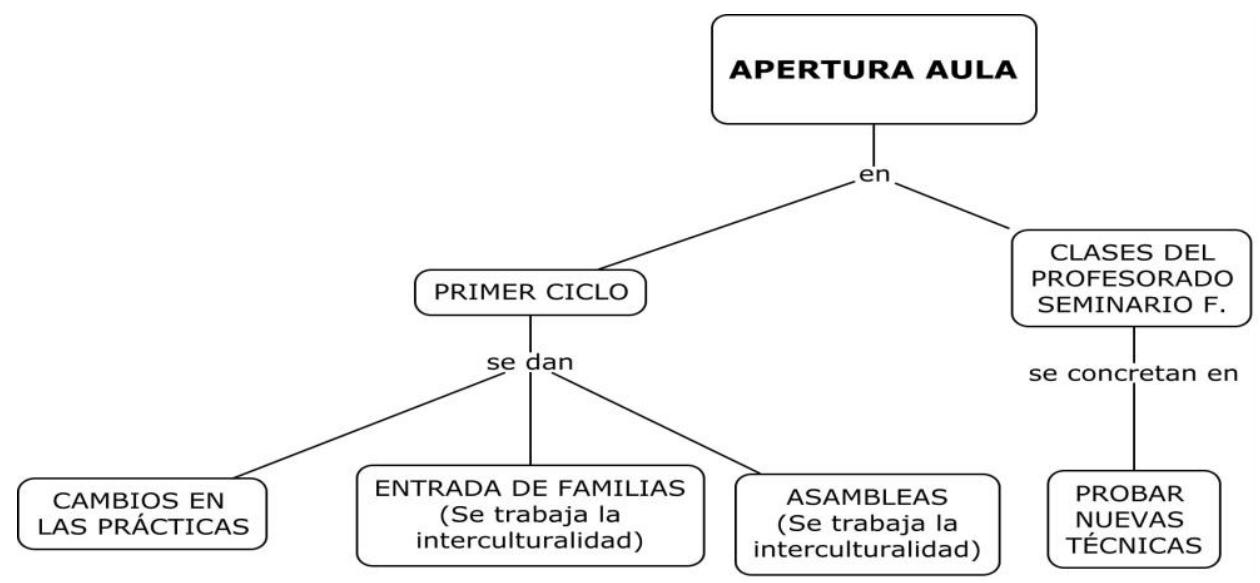

Figura 18. Categorías apertura aula.

En el aula, también se intenta conseguir una mayor apertura. Durante el curso 2011 - 2012 observamos esa apertura en las aulas del primer ciclo, en las que las maestras de estas clases llamaron a las familias y cambiaron algunas de las dinámicas realizadas en clase (incorporan técnicas distintas a las realizadas). Otros cambios en las prácticas de aula aparecen en los maestros que asisten al seminario de formación, aunque no hablamos de cambios introducidos en la programación de las clases, sino de pequeños cambios para probar cómo son las técnicas y cómo funcionan en el aula. Sin embargo, fruto de esas "pruebas" el profesorado del centro se comprometió a incorporar dichas dinámicas en su programación para el siguiente curso, que se concretarían en los compromisos tomados, de los que ya hemos hablado anteriormente.

Esta apertura del aula también la observamos durante el curso 2012 - 2013 en la clase de Estefanía, a la que en determinados momentos asiste alguna madre para conocer cómo trabaja su hijo. A partir de la participación de esta madre en la sesión, se introducen aspectos típicos de otras culturas (interculturalidad). Por ejemplo, cuando en clase están hablando de la paella como el plato típico del pueblo, la maestra le pregunta a la madre si tienen también algún "plato" en el que el componente principal sea el arroz. O ese mismo día, en el que felicitan a un 
niño, y al contar con la presencia de la madre, les enseña la canción de “cumpleaños feliz" en árabe, y algunos niños de esa misma cultura la desconocían ( $1^{a}$ Sesión proyectos de trabajo).

Otra de las situaciones en las que se trabaja la interculturalidad en el aula es en la asamblea. En este espacio el alumnado muestra aspectos relacionados con sus vivencias y por eso aparecen también tradiciones o celebraciones asociadas a la cultura. En uno de los días, uno de los alumnos explicó que el día anterior habían tenido una fiesta en casa de otra compañera, y otra de las niñas de la clase explicó que el día anterior había sido el día de Navidad para los árabes $\left(2^{a}\right.$ Asamblea clase Estefanía).

En definitiva, la apertura de las aulas no se concreta en la participación de las familias voluntarias, sino que también se entiende una apertura en todos los ámbitos posibles. Esto lo facilita la maestra y también el tipo de interacciones que establece con su alumnado, que en muchas ocasiones tratan de acercarse a sus vivencias fuera del mundo escolar.

\subsubsection{Resultados del aprendizaje}

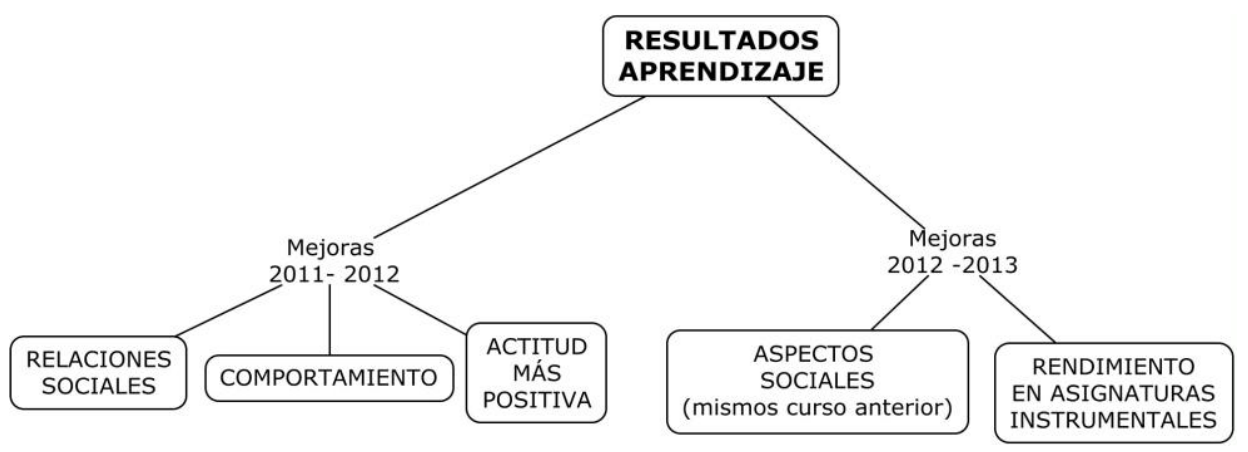

Figura 19. Categorías resultados aprendizaje. 
Respecto al aprendizaje del alumnado, el profesorado destaca que ha habido transformaciones a partir de las prácticas realizadas en el aula (lo comentan en sus sesiones de evaluación del final del trimestre y Estefanía y el equipo directivo me lo dicen).

En relación al primer curso en el que se iniciaron las transformaciones, las maestras que habían empezado a poner en uso las prácticas a partir de febrero, destacaron que a nivel de aprendizajes instrumentales no podían hablar de grandes diferencias puesto que pensaban que era poco tiempo para poder comprobar cambios. No obstante, durante ese primer curso ya destacaron que hubo una mejora en cuanto a las relaciones sociales de la clase (Entrevistas 1er ciclo). El alumnado estaba más integrado y mejoraba su comportamiento y tenía una actitud más positiva hacia la tarea cuando entraban las familias en el aula.

En cuanto al rendimiento y el aprendizaje en las asignaturas instrumentales, en la clase de primer ciclo que analizamos durante el curso 2012 - 2013, la maestra sí que destaca una mejora en cuanto a la adquisición de la lengua valenciana. Su expresión tanto oral como escrita mejora notablemente respecto a la adquisición del español. Cabe destacar que el valenciano se trabaja todos los días en la asamblea y todas las semanas en las tertulias dialógicas.

No obstante, la maestra continúa viendo que el alumnado de su clase, se situaría por debajo de los resultados esperados en otros alumnos de su mismo curso. Por eso, en la evaluación los resultados generales del alumnado son bajos, aunque en lengua valenciana y en matemáticas son mejores que en otras asignaturas (evaluación final trimestre, clase Estefanía). En matemáticas, también se asocia la mejora de esta asignatura a la realización de grupos interactivos, puesto que el alumnado realiza más trabajo y está más motivado hacia la tarea en esta práctica que en una clase en la que tienen que realizar igualmente fichas de matemáticas, pero no a partir de los grupos interactivos. Esto también lo comprobamos a lo largo de las sesiones de grupos interactivos y en otra sesión en la que no se realizan los grupos interactivos pero se trabajan las matemáticas 
(Cuatro sesiones observadas, tres de grupos interactivos y la última sesión como contraste de las anteriores).

\subsubsection{Relación familia - escuela}

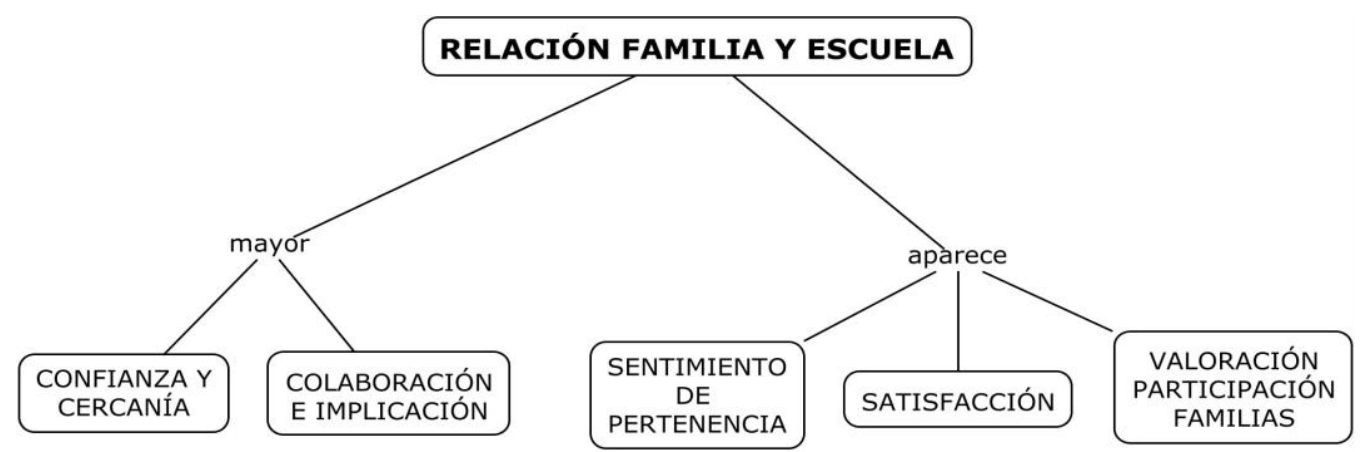

Figura 20. Categorías relación familia y escuela.

La relación entre las familias y la escuela ha cambiado mucho a lo largo de los dos cursos. Como destacan tanto el profesorado, como las propias familias, algunas de las madres que se acercaban al centro con amenazas e incluso con alguna denuncia ahora están colaborando como voluntarias en alguna comisión o entrando a formar parte del AMPA.

Este cambio en la relación con las familias también sitúa al profesorado en un lugar distinto. Las familias, en lugar de verlos como "enemigos" los ven como compañeros, como personas en las que confiar una parte de la educación de sus hijos (Grupo de discusión del comedor). Este cambio también influye en el profesorado, sobre todo en aquellos que por sus funciones en el centro (equipo directivo) pasan más tiempo con las familias y cada día se sienten más cercanos a ellas. 
Es que a los maestros en un principio se nos ve como lejanos. Como otras personas, como si viviéramos en otro mundo y nosotros lo vemos así incluso también, pero al fin y al cabo, somos iguales, tenemos hijos y tenemos las mismas preocupaciones por nuestros hijos, porque yo soy madre. Tú tienes, ... yo me doy cuenta de que vosotros tenéis las mismas preocupaciones que yo y que en casa tenéis los mismos problemas que yo y que todo es lo mismo y compartido es mucho más fácil $\left(2^{\circ} \mathrm{CS}\right.$. Jefa de estudios).

De esta manera, la demanda inicial del claustro que venía a reclamar una mayor colaboración e implicación de las familias en la educación de sus hijos, es poco a poco correspondida en el caso de algunas familias. Pero para ello, tanto las familias como el profesorado destacan que ha sido muy importante el hecho de acortar las distancias y conocerse. El hecho de participar en la escuela ha favorecido esa mejora en la relación entre las familias y la escuela.

Madre: Pues como yo por ejemplo, yo antes reconozco que si venía a hablar con Rafa (director) o con Estefanía, pues yo me sentía más agresiva, me entiendes? Yo... a lo mejor a mi hijo le ha pasado algo y...

Jefa de estudios: Eso sí que es verdad.

Madre: Yo lo reconozco eh, la verdad, me ponía agresiva, porque una vez le mal contesté. (...) A lo mejor he tenido algún problema con una madre en la calle, he entrado aquí dentro, he chillado, a Estefanía le he dicho 4 cosas "ves si quieres al director, me da igual..." o... no sé, me entiendes? Me sentía... para mi como... (...) Yo aprecio a todo el mundo, vale? Porque para mí todos son iguales, pero antes no lo veía igual. Pensaba que le tenían manía a mi hijo y me he dado cuenta de que no.

Maestra de segundo ciclo: ¿Puede ser que el hecho de participar en el colegio te haya hecho tener esa sensación?

Madre: Yo el hecho de participar en el colegio, muy bien. Yo me noto mejor. Yo veo que Estefanía no es mala persona... Además me atienden demasiado bien, porque hay momentos que no pueden, o no deberían de atenderme y me atienden. 
Yo antes eso no lo veía. Sin embargo ahora, si tengo que venir a pedirle perdón a alguien vengo. No me gustaría que mi hijo haga nada malo y antes me daba igual. Tenía el nudo ese ahí (Grupo de discusión del comedor, Referencia 1).

Además, la escuela es vista y sentida con orgullo por las familias que participan en ella y por el profesorado que realmente cree en el cambio y que ve ese cambio en las familias. Estas al mismo tiempo se sienten agradecidas por la ayuda que reciben de la escuela y creen que la educación del alumnado es cosa de dos. Que es fundamental su papel como padres y madres, pero que la escuela también juega una parte importante (diario de la sesión de tutorización para el $2^{\circ}$ CS).

Madre 2: Hay madres que me vienen y dicen, "es que voy a hablar con Rafa (director) y me dice...". Y yo les digo, "a mí no me cuentes eso porque yo hablo con Rafa y hablo normalmente y con educación, y a mi hasta el día de hoy no me han fallado. Yo le he expuesto y él me ha expuesto, y si me ha dado la razón me la ha dado, y si no, no" (Grupo de discusión del comedor. Referencia 2).

Esta cercanía entre unos y otros desemboca en un sentimiento de pertenencia tanto del profesorado como de las familias hacia el centro y la comunidad. Este sentimiento es visto también por las personas que en algún momento dado asisten al centro, aunque no trabajen en él ni sean miembros del barrio. Así mismo, lo explicita la profesional del CEFIRE (Centros de Formación, Innovación y Recursos Educativos) al recordarles que el entusiasmo que desprenden en ese momento no es el que tenían hace unos años $\left(2^{\circ} \mathrm{CS}\right)$.

Ese sentimiento de orgullo e identidad con la escuela no solo lo muestra el profesorado, sino también las familias:

Sí, es importante y el tener un profesorado, yo siempre lo he dicho que el profesorado mío yo no lo cambio por nada del mundo. Y además he dicho más, he dicho que yo no la muevo, la educación de un hijo nuestro con otro que quiera. (...) Yo defiendo mucho este colegio, porque es el colegio de mis hijos. Y mi 
colegio. (...) Además yo hablo mucho del colegio, estoy metido en el AMPA y voy en nombre del colegio por ahí. Y siempre que hablo del colegio hay gente que se queda asombrada y yo digo, es mi colegio. Y creo que eso es importante, ¿no? Que los padres muchas veces también tengamos esa... ese empuje hacia el colegio $\left(2^{\circ} \mathrm{CS}\right.$. Padre).

Además, la buena relación y el sentimiento de grupo establecido en el centro desembocan también en un mayor acercamiento y participación de las familias, que como dice una madre, les hace entrar en la escuela y sentirse "como en casa":

Madre: A parte de que es donde he estudiado y tal, me siento muy bien en el colegio y parece que estoy... cuando entro aqui parece que estoy entrando a casa, ¿no? Que veo a mi familia ¿no? Y la buena noticia es que las madres siempre me están diciendo lo mismo, que cuando entran al colegio se sienten libres se sienten como sifuera...

Profesional del CEFIRE: Que es parte suya.

Madre: Sí, y que no tienen ese miedo de "tengo que hablar con el director pero no sé qué decirle, o no sé cómo" y a veces entraban hacia la puerta y se quedaban, entre "entro, no entro” ¿no?...

Jefa de estudios: Sí, que estaban alli fuera y nos quedábamos, "uy, que pasa que no entran”. Sí, pero ahora ya no. Ahora ya han cambiado un poco las cosas. (Sesión $2^{\circ} \mathrm{CS}$ )

Todos estos cambios despiertan también el agradecimiento del profesorado, que como indicaba anteriormente la profesional del CEFIRE, se refleja en su satisfacción, y que de algún modo el director trata de expresar al decirle al alumnado universitario en una reunión que es muy agradecido trabajar en esa escuela. Aunque fuera del barrio ya no se lo agradece nadie, pero para las personas que trabajan en el centro, ver la satisfacción y la alegría del alumnado y de las familias es muy agradable (sesión de APS).

Estos cambios favorecen la participación de las familias que como expresa el director: 
Hi ha pares que estan ací tantes hores com nosaltres, que estan contínuament fent coses $\left(2^{\circ} \mathrm{CS}\right.$. Director $)$.

Las familias agradecen la entrada y manifiestan que les gusta participar y colaborar con la escuela, además, algunas de ellas creen que esto es fundamental:

Hay que colaborar. Yo creo que para un futuro de nuestros hijos hay que trabajarlo ente todos. Maestros, padres, todos. Yo por ejemplo, mi niña pues todavía tiene tres años, tampoco tiene que hacer exámenes ni nada por el estilo, pero sí que tengo que prepararme tanto yo como ella, ¿no? Y cuando me vea por aquí por el colegio pues que se sienta como si estuviera en casa y que coja confianza con los maestros. También que no lo tenga siempre como "Tengo que ir al colegio (lo dice con pesar)” ¿no?; No, “;Tengo que ir al colegio! (con alegría)”. Y lo bueno es que las madres sienten lo mismo, cuando hablas con ellas dicen lo mismo. Quieren que sus hijos estudien, que estén a gusto ( $2^{\circ}$ CS. Madre).

En el caso de la madre, cuando se refiere a la participación o a los comentarios de las otras madres, se refiere a las madres árabes, ya que en el centro la mayor participación de las familias es de un grupo de unas 10 madres árabes. Además, desde el curso anterior la participación de un padre, de su mujer y de otras cinco madres todos ellos españoles, también ha sido fundamental para introducir mejoras en la escuela e ir cambiando la relación entre las familias y el profesorado. Durante el curso 2012 - 2013, esta mayor participación de las madres árabes es vista con agrado por las familias que ya participaban en el centro, aunque para algunas familias españolas es desconcertante e incluso genera tensiones. En algunos casos, una parte de las familias españolas manifiestan que los cambios parece que se hagan para las familias árabes y no para todas las familias (Sesión de APS).

Por otra parte, aunque la participación de las familias no sea una acción generalizada a todas las familias del centro, sí que hay un hábito y una colaboración con la escuela. Estas, les aportan un gran apoyo y ayuda al profesorado, tanto en su participación como voluntarias en las prácticas de aula 
como en las comisiones u otras acciones del centro. Esta dinámica de trabajo que se ha ido adquiriendo durante los dos cursos parece haber creado un hábito en las familias.

I de les mares també estem aprenent. L'any passat estava ací una mare que, aquest any per altres motius se $n$ 'ha hagut d'anar a una altra escola. Pues ha anat a eixa escola a dir què podia fer ella. Ella vol ajudar. Què els haurà incomodat, perquè supose que hauran dit...! pues ella ha anat a l'escola i els ha dit "jo allí ajudava i jo vull que me digueu coses que puc fer" ( $2^{\circ} \mathrm{CS}$. Director).

La participación y la colaboración no son tan usuales en otras escuelas, sin embargo en esta es un hábito que las familias que lo ejercen valoran como positivo, no solo por ellas mismas sino para contribuir a la educación del alumnado:

Porque yo hasta el otro día, no me veían el pelo, pero últimamente, que te lo digan ellos, yo no me muevo de aquí. Pero todo ¿para qué? (dirigiéndose a un alumno) para beneficio vuestro $\left(2^{\circ}\right.$ CS. Padre $)$.

Finalmente, la valoración de la participación de las familias para una parte del profesorado es muy positiva, aunque como hemos dicho anteriormente, otra parte opina que hay pocas familias implicadas. Así mismo, algunas de las familias que se implican también agradecerían una mayor participación de otros padres y madres.

El padre, me dice que en este colegio las familias se implican poco. Yo le comento que también es el profesorado el que tiene que llamarles a todos para que se impliquen. Él me dice que está en muchas cosas y está agobiado. Que está en la comisión social y en la de estética, además de estar en el AMPA, etc. Que tiene muchas reuniones. (...) Este padre comenta que muchas familias no participan porque no tienen interés. Aunque la madre dice que quizás es por ignorancia y que también es importante insistir. Ella también dice que se consigue contagiar hablando bien de la escuela. Dice que si alguna madre les comenta alguna cosa ella dice que está encantada y que se lo pasa muy bien y es muy divertido participar (Sesión de tutorización a las familias para el $2^{\circ} \mathrm{CS}$ ). 


\subsubsection{Voz del alumnado}

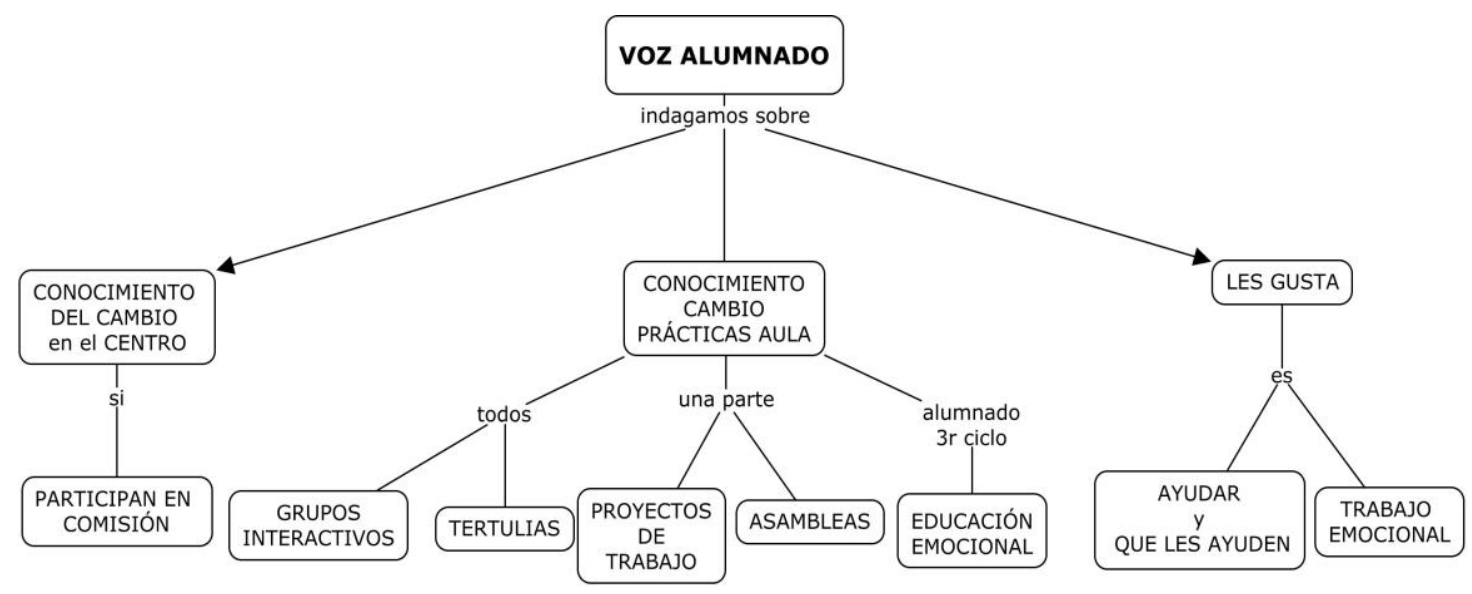

Figura 21. Categorías voz alumnado.

Aunque el alumnado es la razón por la que se plantearon innovar en las aulas y mejorar la relación con las familias, no resulta fácil abrir espacios para su participación. No obstante, obtenemos la mirada de este colectivo, principalmente, a partir de la información de los grupos de discusión realizados durante el curso 2011 - 2012 con el alumnado y con la comisión del comedor, y a partir de la observación de aula y del consejo social del curso 2012 - 2013.

\subsubsection{Conocimiento del cambio}

Durante el curso 2011 - 2012, una parte del alumnado conoce que en la escuela se están realizando acciones que antes no se realizaban. Sin embargo, no saben muy bien a qué son debidos estos cambios ni su propósito. En el caso de aquellas personas que conocen de los cambios es porque participan en los mismos porque forman parte de una comisión de trabajo.

El alumnado que participa en las comisiones se da cuenta de que su papel en la escuela está cambiando. Piensan que los maestros quieren que estén mejor, más 
a gusto, y por eso les hacen participar en las comisiones dando su opinión e intentando cumplir con las propuestas que ellos mismos hacen (Grupo de discusión, comisión del comedor). Sin embargo, su conocimiento sobre la función de las comisiones se restringe al conocimiento sobre la comisión en la que participan.

Por otra parte, aquellas personas que no participan en ninguna de las comisiones desconocen totalmente su existencia y el trabajo que se está haciendo desde ellas. Aunque, todo el alumnado participó en los sueños de la escuela y escribió un papel con aquello que querían mejorar. Tras estos sueños, se han dado cuenta de que hay un mural en la entrada de la escuela con los sueños que escribieron, pero no saben muy bien qué ha ocurrido con ellos.

A partir del curso 2012 - 2013 se pretende llegar más al alumnado, aunque el profesorado sigue encontrando cierta dificultad:

Jo sí que pense que als xiquets ens els estem deixant un poquet pel camí, sense voler. Jo crec que si anem a les classes no sé si ells tots saben el que està passant. (Sesión $1^{\circ}$ CS. Director).

Aunque la visión del profesorado más implicado en los cambios muestra que quizás el proceso no es conocido por el alumnado, indagamos más en la cuestión preguntando directamente al alumnado.

Les empiezo preguntando al alumnado si conocen aquello que se está haciendo en la escuela. Ellos me dicen que es algo del aprendizaje, pero no saben exactamente qué es. Les pregunto también si conocen las comisiones y algunos me dicen que sí y otros que no. Dos niños forman parte de la comisión del comedor y otra de las alumnas que está en la sesión les pregunta si eso que hacen en la comisión es para ayudar (...). Uno de los niños dice que es para ayudar a compañeros que no se saben portar bien. Cuentan que el otro día ayudaron a un niño que tiene mucha rabia y no se lo puede remediar y que también tienen que ayudar a otro niño a quitarse esa palabra que tiene en la boca, que enseguida se “caga en los muertos” (Sesión tutorización al alumnado para el $2^{\circ} \mathrm{CS}$ ). 
Observamos que el alumnado que participa en alguna comisión conoce el funcionamiento de la misma, pero no sabe exactamente para qué se ha creado. Por tanto, aunque es el segundo curso desde que iniciaron el cambio, se sigue observando esta dificultad por llegar a que el alumnado participe.

Alumna de tercer ciclo: Mestra, la comissió què és, opinar alguna cosa, o ajudar als altres?

Alumno de segundo ciclo que participa en una comisión: No, es ir allí y hablar de cosas del comedor para mejorar el comedor, y luego decir ideas que tú quieras que pasen en el comedor, para mejorarlos,... lo ponemos en un papel (Sesión tutorización al alumnado para el $2^{\circ} \mathrm{CS}$ ).

Aunque una parte del alumnado se está quedando fuera, también hay una parte del profesorado que valora mucho la participación del alumnado. En el caso que mostraremos a continuación una maestra resalta el papel del alumnado cuando participa en las comisiones.

Tu veus que quan has creat algun problema $i$ t'hem cridat per a parlar, sempre hem sigut els que estàvem ahi. Però mira que hi ha una feina darrere de tot això. Sempre hi ha algú darrere pensant com fer per a què açò no passe, per a que no hi haja conflictes. Ara teniu la possibilitat vosaltres de dir "anem a buscar una solució per a eixos conflictes". Jo veig que la cosa està funcionant millor $i$ és important que xiquets com tu, estigueu i formeu part $\left(2^{\circ} \mathrm{CS}\right.$. Estefanía).

Su participación es importante, pero no solo para que estén presentes y formen parte de las mejoras que se quieren implementar, sino porque el hecho de estar participando en las comisiones les ayuda a ser más responsables, a aportar un punto de vista desde la madurez. Así mismo, destacan estos cambios en la actitud y el comportamiento de un alumno, que era conocido por sus expulsiones, y desde que participa en la comisión del comedor ha mejorado su comportamiento.

Estefanía: Jo des del meu punt de vista, com a mestra i com a encarregada del menjador t'he de dir que m'agrada molt el teu canvi d'actitud. 
Director: Tu saps que tu i jo hem parlat per desgracia moltes vegades...

Alumno: Moltes!

Director: Açò que estàs fent ací té molt més mèrit que quan perds els nervis $i$ fas... això sap fer-ho qualsevol. Estar ací no, estar ací és tindre ganes, vindre a escoltar. Estar ací sí que té mèrit.

El alumno mira al director y les hace una sonrisa.

Otra maestra que está al lado del alumno le aprieta cariñosamente el brazo y le dice: Felicitats! (con una sonrisa). El alumno con una gran sonrisa responde: Gràcies! (Sesión $2^{\circ} \mathrm{CS}$ ).

\subsubsection{Conocimiento de las prácticas de aula}

En relación a las prácticas realizadas durante el curso 2011 - 2012, la mayor parte de tutores ha implementado algunas prácticas innovadoras en su aula. Es por esto que en el grupo de discusión la mayoría del alumnado conoce los grupos interactivos y las tertulias dialógicas. Una parte conocen también los proyectos de trabajo y las asambleas y finalmente, el alumnado del tercer ciclo destaca el trabajo sobre educación emocional que se ha realizado en su clase.

De todos los aspectos relacionados con las prácticas, el alumnado destaca que le gusta trabajar en equipo y lo que más le gusta es que les ayuden y ayudar. Cabe destacar que un alumno de tercero de primaria comenta que él prefiere realizar el trabajo de manera individual y que no le ayuden ni ayudar, ya que después en el examen estará solo y se tendrá que acostumbrar a trabajar de este modo (Grupos de discusión con el alumnado).

Por otra parte, los aspectos que destaca el alumnado de tercer ciclo en relación al trabajo realizado en el aula tienen que ver con propuestas para trabajar las emociones. En su caso, las maestras de este ciclo trabajaron durante el primer trimestre del curso las tertulias y los grupos interactivos, pero posteriormente se dedicaron a realizar dinámicas más relacionadas con el trabajo emocional. Algunas 
de las actividades que comenta el alumnado es el "Felicite, propose y critique". Otros de los aspectos que comentan también en este ciclo son sobre la resolución de conflictos, que se realiza con mucho diálogo y se basa en la reflexión que hace la maestra, junto el alumnado, sobre aquello que ha ocurrido.

Durante el curso 2012 - 2013, el alumnado que participa en el consejo social destaca que les gusta realizar grupos interactivos. Algunos destacan que realizando otras actividades se aburren y con los grupos interactivos no. Dicen que es divertido y que les gusta ayudar al resto y que les ayuden; además comentan que se mejora la convivencia, o en sus propias palabras: quan li tenim mania a algú, se nos quita (Sesión tutorización al alumnado para el $2^{\circ} \mathrm{CS}$ ). Además, coinciden en que prefieren trabajar en grupo que individualmente, por la misma razón comentada anteriormente, por la ayuda que dan y reciben.

Finalmente, el alumnado también realiza propuestas sobre las prácticas de aula. En primer lugar un alumno de tercer ciclo que recuerda las asambleas de infantil manifiesta que le gustaría volver a hacerlas en su clase $\left(2^{\circ} \mathrm{CS}\right)$.

\subsubsection{Voz de las familias}

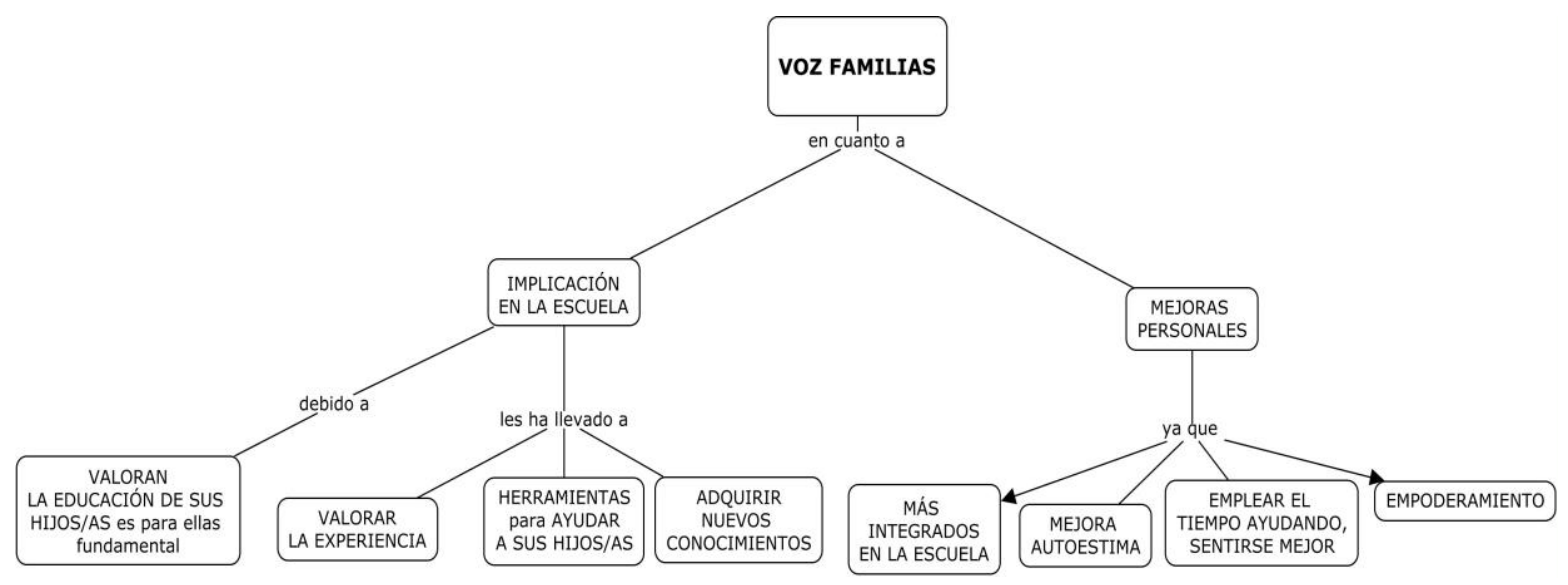

Figura 22. Categorías voz familias. 
Como hemos comentado, las familias que se han implicado en la escuela han sido un pilar a la hora de poner en marcha acciones para mejorar el centro. ¿Pero qué opinan ellas sobre todos estos cambios y su papel en ellos?

En este apartado hablaremos, desde la voz de las familias sobre qué han supuesto para ellas estos cambios. En primer lugar nos centraremos en la entrada de las familias en las aulas y en el centro y posteriormente en algunos cambios que esto ha supuesto a nivel personal.

\subsubsection{Implicación; Entrada en la escuela y en las aulas}

Para las familias que se implican en la escuela, la educación de sus hijos es un aspecto fundamental en la formación de su persona y en el futuro que después estos niños van a tener. Es por esto que las familias manifiestan su agradecimiento al profesorado por tener la oportunidad de participar tanto en el centro como en las aulas. Ellas por su parte, intentan organizarse para poder participar. Como por ejemplo en el caso de una madre árabe, con pocos recursos que paga a una señora para que cuide a su hija pequeña durante la hora que ella está en la escuela como voluntaria. Estas situaciones las valora mucho el profesorado, pero también el resto de familias que se implicaron en la escuela.

Padre: Tú dejas a tu hija para dar un servicio a otra persona que no es tu hijo, eso es mucho de valorar.

Madre que paga a otra señora: A mí, el futuro de mis hijos está aquí. (Grupo de discusión familias. Referencia 8).

En el grupo de discusión con las familias, realizado al final del curso 2011 2012, las familias explican que les ha gustado mucho la experiencia. En los casos en los que han entrado en las clases de sus hijos dicen que han disfrutado mucho viendo cómo aprendían. En los casos en los que no han entrado en la misma clase de sus hijos igualmente valoran la experiencia y explican que les dio herramientas 
para poder ayudar a sus hijos también en casa, cuando van a estudiar o a hacer los deberes.

Como explica un padre, el hecho de ver cómo la maestra explica al alumnado, o incluso cómo se ayudan entre ellos los alumnos, ayuda al padre a saber cómo puede ayudar a su hija a hacer los deberes en casa.

Es que a mí eso me ayudaba mucho porque yo veía como lo explicaba este como lo explicaba el otro y yo más o menos... pues me ayudaba. A mí me ayudaba mucho de cómo lo explicáis vosotros, porque yo vengo de tener, por ejemplo en mi escuela me han enseñado una forma de vivir que eso nunca lo hubierais hecho aquí, seguro..., es una forma muy fácil. Pero bueno, son formas que yo estás cuadriculado, parece que todo lo haga bien, y después viene y te ha salido todo mal. Entonces es una forma que a mí me ayudaba también a la hora de educar a mi hija. De educarla en el sentido ese de enseñar (Sesión ler CS. Padre).

Además, la entrada de las familias en las aulas también les ayuda a refrescar conceptos o a aprenderlos.

Cuando van a repasar las líneas rectas, curvas y poligonales, la madre que ha asistido a la clase se levanta para coger un lápiz y copiar lo que ha escrito la maestra en la pizarra. Entre que ha buscado el lápiz y todo no ha tenido tiempo de copiarlo, pero se aprecia su interés en los aprendizajes instrumentales del aula. Después la maestra se da cuenta de su interés y le deja la pizarra sin borrar para que pueda copiar aquello que ha escrito. Un niño de la misma mesa en la que está la madre mira a otro y le dice sorprendido que la madre también está copiando lo que pone en la pizarra. Para los niños resulta extraño que una persona adulta esté realizando "los mismos aprendizajes" que ellos. En este caso la madre, al ser de otro país, con otra lengua y otro sistema de escritura, aquello que se enseña en la escuela puede ser nuevo también para ella (Diario de $1^{a}$ sesión de proyectos de trabajo). 
La entrada de la madre, que en este caso es una madre árabe, también es una oportunidad para mejorar su adquisición de la lengua, ampliando el vocabulario y concretamente aprendiendo el valenciano que es la lengua vehicular del centro.

Durante el curso 2012 - 2013, debido a que el profesorado se ha organizado para hacer los grupos interactivos entre ellos, la participación de las familias en el aula es menor. Aun así, hay algunas madres que cuando se les invita a entrar lo hacen. Aunque la puerta está abierta y Estefanía también lo comenta en las reuniones de principio de curso, cuando alguna madre le plantea alguna duda concreta sobre su hijo, ella las invita también a que participen en el aula para que entiendan mejor cómo trabajan allí. Es por esto que la predisposición de las madres que entran es buena, al sentirse agradecidas por la oportunidad que se les está brindando.

Además, la maestra que invita a una madre a entrar a su aula también tiene una buena actitud hacia las familias. En el caso de Estefanía hacía partícipe a la madre de la dinámica de la clase, y su entrada favorecía también que se introdujeran en el aula aspectos de su cultura.

\subsubsection{Mejoras personales}

Por otra parte, la entrada de las familias en la escuela es un aporte para las propias familias. En el caso del padre que se implicó en la escuela él explicaba en el grupo de discusión de las familias que antes de participar en el centro se encontraba sin trabajo y el hecho de asistir e implicarse, le ha ayudado a sentirse más integrado en la escuela. Por otra parte, su mujer también asistió como voluntaria. Al principio no quería entrar porque le daba vergüenza, ya que pensaba que no podría ayudar en nada al alumnado. Sin embargo, después de participar en las clases explica que la experiencia le ha ayudado personalmente a sentirse mejor con ella misma, a darse cuenta de que también es una persona válida. 
Madre: Yo antes de entrar a la escuela era cero menos cero. Mi experiencia ha sido más para mí, me he sentido muy útil. (Grupo de discusión familias. Referencia 1).

Además, el mismo padre que se implicó en el curso 2011- 2012 y que volvió a implicarse en el siguiente curso, explica en el consejo social que por su situación de estar sin trabajo el hecho de participar en la escuela le ha ayudado también a sentirse mejor.

Yo sí que lo he pedido porque a mí me ayuda. Primero porque no tienes otra cosa en la cabeza, como estoy en el paro. Y segunda, porque yo puedo ayudar a mi hija, que eso es lo más importante. Y yo siempre lo he dicho que ayudar siempre es importante, estar y... Y yo creo que sí, que mi hija mejora la nota... (Sesión $2^{\circ} \mathrm{CS}$. Padre).

Pero la ayuda prestada favorece también al alumnado así como al profesorado. Al alumnado porque como dice el padre, cree que su hija mejora. Y por otra parte es una ayuda para el profesorado porque la dinámica de la clase es mucho más enriquecedora y tranquila con la ayuda de personas voluntarias en el aula (Notas de campo de la $1^{\mathrm{a}}$ Sesión proyectos de trabajo).

Es por esto que tras las decisiones del profesorado de realizar los grupos interactivos con los refuerzos de los mismos maestros, algunas familias proponen ser ellas las que asistan como voluntarias.

Padre: Es que yo creo, de hecho una de las cosas que dijimos, fue que por qué no entrábamos otra vez los padres. Yo también lo he pedido. ¿Es verdad o no? (...) Que si ahora nos quitaran todo esto, los padres diríamos uy, (pone cara de extrañeza y se echa hacia atrás en la silla) $\left(2^{\circ} \mathrm{CS}\right)$.

Para algunas familias la participación en la escuela les ha llevado también a realizar acciones que no habían realizado anteriormente en su vida. Como por ejemplo el caso de una madre que asistió al despacho del alcalde para comentarle unos aspectos sobre la escuela. 
Madre: Yo es la primera vez en mi vida que había entrado en el despacho del alcalde. Y hablé con una concejal y con el alcalde. Se lo comenté (el tema de que tenían una reja rota), le dije lo de los bancos, que los niños ya está bien de que vayan por el suelo a la hora del patio, que les pongan bancos,... que a ver si pueden arreglar esto mejor, y pintarlo de colores más vivos, no sé parece que esté esto muy apagado! (Grupo de discusión, comisión del comedor. Referencia 1).

El hecho de verse en otros contextos distintos y con un papel distinto en la escuela también ha favorecido a que estas familias se sientan más empoderadas.

\subsection{Las transformaciones en el aula de Estefanía}

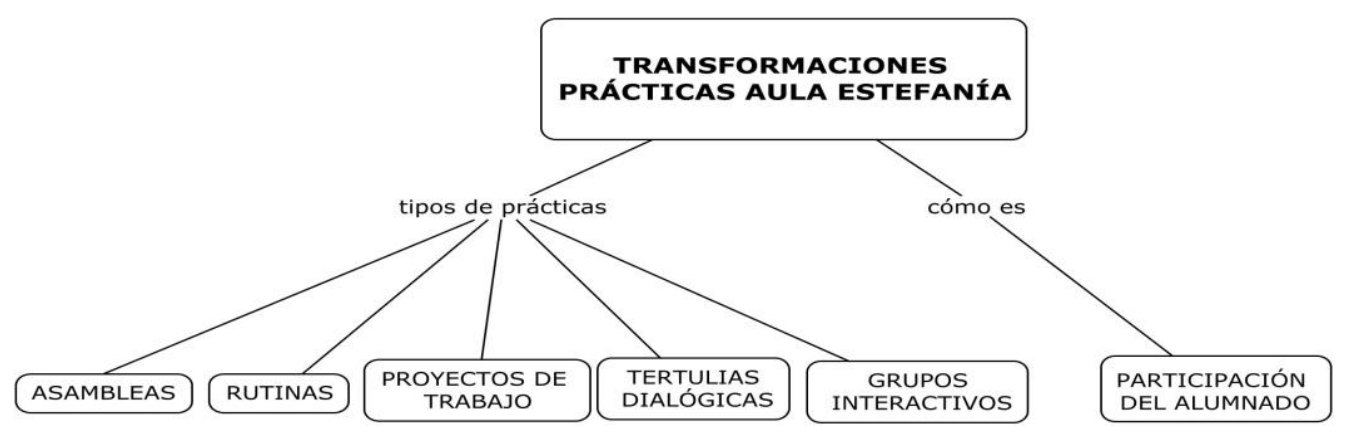

Figura 23. Categorías transformaciones aula Estefanía.

En relación a las transformaciones en el aula de Estefanía, destacaremos el tipo de prácticas realizadas. Entre ellas distinguimos aquellas que han favorecido la atención a la diversidad, que son las asambleas, las tertulias dialógicas y las rutinas, ya que todas estas prácticas se realizaban contando con la participación de todo el alumnado. 
Aquellas que pensamos que no han favorecido la atención a la diversidad son los proyectos de trabajo; por la manera en la que se han realizado y los grupos interactivos, junto con la clase magistral.

Por otra parte, analizamos también cómo es la participación del alumnado en el aula.

\subsubsection{Asambleas}

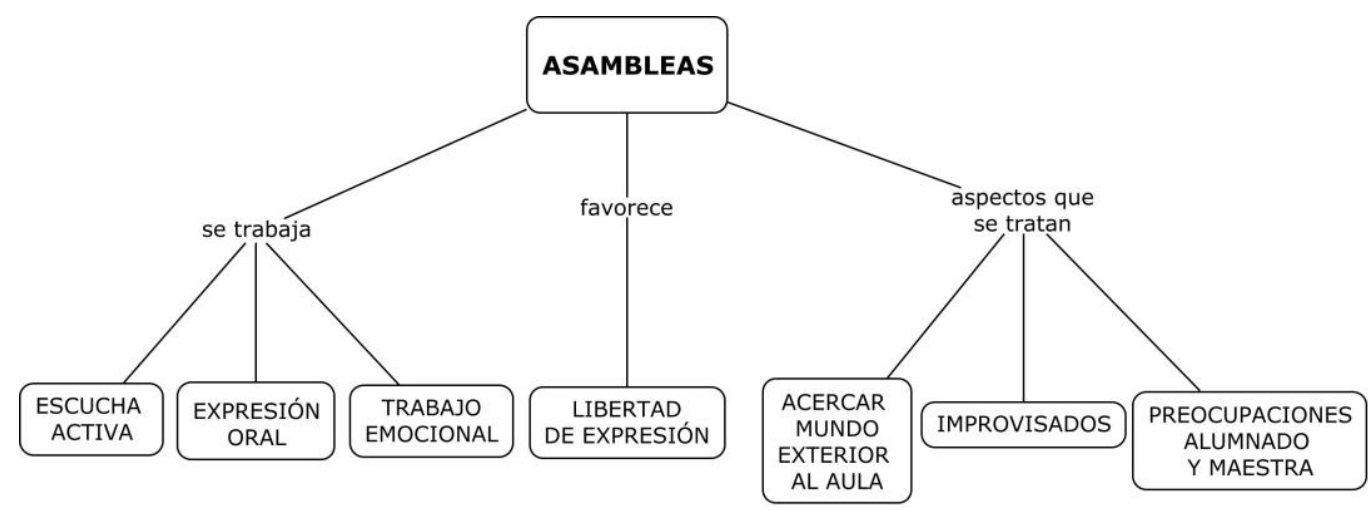

Figura 24. Categorías asambleas.

Las asambleas son la primera práctica que se realiza en el aula. Nada más entrar en la clase, el alumnado se dirige a su mesa y deja su mochila en la silla. También se dirigen al perchero y dejan sus abrigos, bufandas, etc. Directamente, cuando acaban con este ritual acuden al rincón de la asamblea donde se van sentando tal y como van llegando en los bancos que hay preparados en forma circular y esperan a que lleguen todos.

El inicio de la asamblea lo dirige siempre su tutora. Les da la bienvenida y les saluda deseándoles los buenos días. Después de que el alumnado le devuelva el saludo, ella procede preguntándoles qué hicieron el día anterior, o si quieren, antes de empezar pueden decir alguna cosa importante que les pasó; también se realiza un repaso sobre las asignaturas que tienen durante el día y aquello que van a hacer. 
Aunque las temáticas cambian cada día puesto que en función de las aportaciones del alumnado se dedican a hablar sobre unos temas u otros. Intervención a intervención van mostrando sus preocupaciones, aquellas cosas que les emocionan o les inquietan y comparten con el resto de la clase sus experiencias diarias. Todos hablan, o todos los que quieren, puesto que si en algún momento alguien no está dispuesto a hablar tampoco se le obliga, aunque se le ayuda a expresarse.

Estefanía: Bueno, bon dia a tots, una altra vegada, benvinguts.

José María: A veure que hem fet este cap de setmana.

Estefanía (rient): A veure que hem fet este cap de setmana.

Laia: Mos toca matemàtiques,...

Estefanía: Per parts, que ho estem barrejant tot. Primer anem a dir el que ens toca, $i$ després ja parlem del que hem fet este cap de setmana. (2 ${ }^{a}$ Asamblea clase Estefanía).

Parte del alumnado ha interiorizado los temas que se tratan en la asamblea. I antes de que la maestra les pregunte, van diciendo todo aquello sobre lo que tratará la asamblea.

Como hemos dicho, en la asamblea participan todos pero, si alguien no puede participar o no tiene un buen comportamiento también se le invita a quedarse durante un tiempo fuera de la actividad. En el caso de Andrés (alumno con Síndrome de Down), participa muchas veces en la asamblea, pero en algunos momentos necesita salir del círculo o levantarse. El resto de niños le ayudan a que pueda permanecer escuchando a sus compañeros. En los casos en los que sale del círculo, algún alumno también se levanta por si va a beber y necesita ayuda y cuando termina, suelen reconducirlo hacía la actividad. También está pendiente de él alguna de las maestras de apoyo que participan en la asamblea, que suele ser la maestra de PT o en algunos casos la de AL.

Andrés s'alça i se'n ix de l'assemblea. Ningun xiquet/a diu res. La mestra de PT s'alça per anar amb ell $i$ el torna a sentar a la cadira $\left(2^{a}\right.$ Asamblea clase Estefanía). 
En otros momentos, quizás es el comportamiento lo que impide que puedan estar escuchando a sus compañeros y se les corrige para que la asamblea pueda funcionar.

Maestra de PT: Adri, ja està bé; estic fent com si no t'escoltara però encara no has parat. Tu vols estar en l'assemblea? T'agrada estar en l'assemblea? (Adri assenteix). Pues has d'escoltar, perquè una part important de l'assemblea és escoltar als companys. Igual que t'escolten a tu quan parles ( $\sigma^{a}$ Asamblea clase Estefanía).

En relación al comportamiento, es muy importante la escucha activa que practican y que requiere de paciencia y estar presentes en la actividad, respetándose unos a otros. Por eso, en algunos momentos en los que pueden aburrirse o perder la atención, la tendencia es la de hablar con sus compañeros y la maestra les da un toque de atención para que permanezcan escuchando.

Estefanía: En una assemblea podem parlar tots, però si tots parlem alhora no ens aclarim ( $5^{a}$ Asamblea clase Estefanía).

A nivel de contenidos, se practica la expresión oral, y se aprovecha este momento para corregir al alumnado sobre la gramática utilizada, siempre que es necesario. La manera que tiene la maestra de hacerlo es volver a decir la frase pero de la manera correcta. Si dicen "he fet" para referirse a una situación pasada les dice "vaig fer...". Con este trabajo vemos cómo el alumnado mejora día a día su lenguaje.

Quan li toca a Sandra Estefanía la corregeix. Fa el mateix error gramatical que els companys, $i$ en diferents ocasions Estefanía els hi ha corregit. Diu "he fet els deures", per a referir-se a una acció que va fer el dia d'abans. Estefanía els diu que és "vaig fer" (3a Asamblea clase Estefanía).

Pero aquellos temas que más se trabajan en la asamblea están relacionados con las vivencias del alumnado. Podemos decir que a partir de la asamblea el alumnado se abre a contar sus vivencias personales y se posibilita el realizar un trabajo 
emocional con ellos. Uno de los temas que más nos impactaron de los tratados en la asamblea era el expuesto por Davinia, sobre el que nos detendremos más adelante.

La asamblea es una manera de detectar aquellas situaciones en las que el alumnado está pasando por dificultades, para ayudarles a afrontarlas. En este caso a vivirlas como niños.

Estefanía también le pregunta al alumnado por su familia, cuando los conoce o si sabe que tienen alguna circunstancia particular. Por ejemplo, pregunta a Raquel por sus hermanas que van al instituto y que fueron alumnas suyas; a Ivana por su hermano que estuvo en el hospital la semana anterior; a Juan, que estuvo los tres últimos días enfermo y no pudo asistir a la escuela, A Adán por su padre, que lleva un tiempo sin ir a recogerlo y en su lugar lo recoge su madre, etc.

Por otra parte, el alumnado se siente con la libertad de expresarse, no solo Davinia con su historia personal sino también Waldo con la situación de su padre en el trabajo, son ejemplos sobre la confianza y el espacio de libertad que se genera en la asamblea.

Estefanía: Quina paret? Que van entrar a ta casa?

Waldo: ¡No! En el trabajo.

Estefanía: I on treballa ton pare?

Waldo: En cotxes, pintant.

Estefanía: Pintant cotxes? (Waldo assenteix) En un taller de cotxes? I van entrar al taller?

Waldo: Sí. I han fet un...

Elia: Un forat.

Estefanía: Un forat a la paret? Ui, i això ha sigut ací, no ens hem entera't de res. Pues vaja. Pues sí que me sap mal, eh, de veritat. Pues ara has de cuidar molt al papà $i$ donar-li molts besets que el papà ho necessitarà que estarà trist, eh Waldo?

Waldo: I pregunta-ho a mi padre. 
Estefanía: Sí que ho faré. Ho faré per donar-li recolzament. Com li diuen al papà?

Waldo: Asier.

Estefanía: Pues li diré: Asier, si te puc ajudar t'ajudaré (5 $5^{a}$ Asamblea clase Estefanía).

Waldo expresa una situación que le preocupa para que la clase le escuche. Además, quiere que su maestra conozca lo que ha ocurrido y le dice que le pregunte a su padre. Al mismo tiempo la maestra le muestra su apoyo.

Por otra parte, la maestra también aconseja al alumnado en temas de comportamiento que tienen en su casa y pide su colaboración con la familia.

Estefanía li pregunta a Juan com se troba, li recorda que ha estat tres dies sense anar a l'escola perquè estava malalt. Li pregunta si es troba millor i Juan diu que bueno, que es porta mal en casa. Estefanía fa la palmada típica de José María (que ara no està en classe) i Laia la imita. Estefanía. Bueno, i ara això perquè? Per què et portes mal en casa? Tres dies que estàs en casa malalt i ta mare te diu, al cole, que ja està bé de portar-te mal. Sí, no? Juan baixa el cap. Estefanía . Home, i això te fa gràcia? A mi ninguna. Els xiquets es queden mirant a Juan, a veure quina cara fica $\left(5^{a}\right.$ Asamblea clase Estefanía).

Por otra parte, la maestra acerca vivencias de fuera de la clase a su interior y a la inversa.

És el torn d 'Andrés $i$ no vol participar però la mestra va estar amb ell el dissabte - el va veure en falles- i li conta el que va fer. Després Andrés diu que va anar a la fira. Estefanía també li diu que va anar a buscar-lo per ballar el pasdoble però no el va trobar. Li diu que d'ací dos caps de setmana que també hi ha presentació anirà a buscar-lo per ballar amb ell un pasdoble (2 ${ }^{a}$ Asamblea clase Estefanía).

La maestra es del mismo pueblo que el alumnado, y por eso en ocasiones conoce parte de su historia familiar y de sus experiencias fuera de la escuela. Esto 
le ayuda en algunos momentos a comprender las circunstancias familiares y a relacionar aquello trabajado en la clase con su contexto más próximo.

Los temas de las asambleas son improvisados y dependen de los intereses y vivencias del alumnado. La maestra deja fluir lo que va surgiendo, interviniendo junto al resto del alumnado. Por ejemplo, el día que Ivana les contó a la clase que su hermano es un bebé y estaba en el hospital porque tenía muchos mocos y no podía respirar, a partir de ahí la conversación se derivó a hablar sobre la reproducción.

Estefanía aprovecha para preguntarle a Ivana cómo está su hermanito; Estefanía explica que no sabe cómo al final ayer acabaron hablando de cómo se hacen los bebés ( $1^{a}$ Asamblea clase Estefanía).

También, en algunas asambleas Estefanía felicita al alumnado por su buen comportamiento o por sus resultados:

Estefanía s 'incorpora a l'assemblea. És el torn de Juan, Estefanía l'interromp perquè no vol que se li oblide felicitar-lo. Li demana disculpes per interrompre’l però li diu que volia felicitar-lo perquè està treballant més. Tant Estefanía com la mestra de PT feliciten a Juan (6 $\sigma^{a}$ Asamblea classe Estefanía).

\subsubsection{Rutinas}

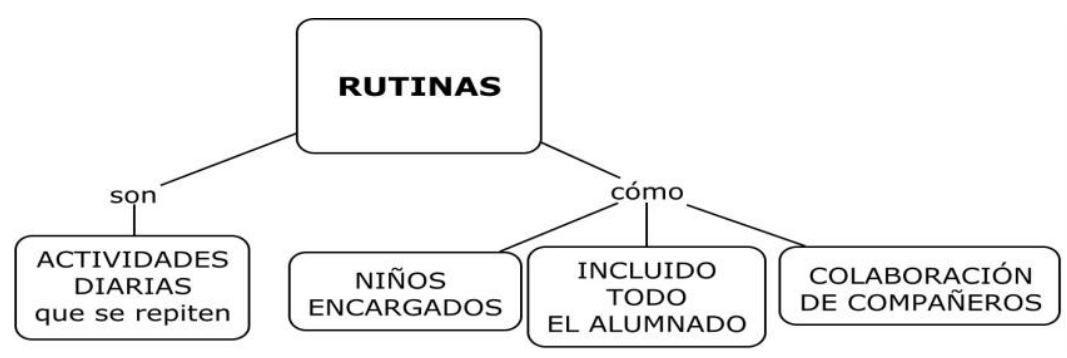

Figura 25. Categorías rutinas. 
Las rutinas de la clase se repiten cada día, y como hemos comentado anteriormente, las actividades que se realizan son pasar lista, realizar el calendario y conocer cómo es el tiempo ese día (nublado, soleado,....).

Estas actividades precisan de la colaboración de unos encargados que cada día nombra la maestra y son quienes se ocupan de repartir el material o de salir a la pizarra para repasar el día de la semana, cambiar la fecha, etc. Son actividades en las que está incluido todo el alumnado y si alguno de los encargados necesita ayuda en la tarea que se le ha asignado, cuenta con la colaboración de sus compañeros y de la maestra.

L'encarregat de passar llista és Andrés. Juan el del calendari, Néstor del material i Raquel baixarà les persianes ( $5^{a}$ sesión rutina clase Estefanía).

Cuando el encargado es Andrés, él participa muy contento en su tarea y la maestra suele ayudarle, en función de las necesidades del niño.

Andrés reconeix als seus companys, sap com es diu cadascú i l'assenyala quan Estefanía pregunta ha vingut... ?(Dice el nombre del niño). Estefanía li diu a Andrés que diga el nom del company i Andrés fa un esforç i ho diu. Estefanía diu, "ha vingut.... Adri?" I Andrés repeteix el nom d'alguns companys $i$ després els companys que ha dit, si estan a classe, li contesten. "Bon dia, estic aci"” (5 sesión rutina clase Estefanía).

Si algún día Andrés no es el encargado pero quiere participar ayudando a sus compañeros, tanto la maestra como el resto del alumnado le dejan hacerlo:

Hui Andrés ajuda més a Estefanía a passar llista. Repeteix el nom d'alguns xiquets per preguntar si han vingut. Pareix que està content d'ajudar-los. No pot estar al mateix lloc tota l'estona però forma part de l'activitat de l'aula (6 $\sigma^{a}$ sesión rutina clase Estefanía). 
Las ayudas de la maestra y del alumnado son siempre una opción, pero tal y como aquellos que tienen más dificultades avanzan, si creen que pueden realizar la actividad sin ayuda también les dejan su espacio.

Ara li toca a Waldo repartir el material. Reparteix les fulles del calendari, per això, ha de llegir el nom dels xiquets per a donar-li a cadascú la seua fulla. S'alcen uns quants xiquets per a ajudar-lo, però Waldo amb les fulles ben agafades els diu que no. Estefanía els diu que Waldo vol fer-ho sol i que el deixen fer. Els xiquets/es que estaven drets es senten ( $6^{a}$ sesión rutina clase Estefanía).

\subsubsection{Proyectos de trabajo}

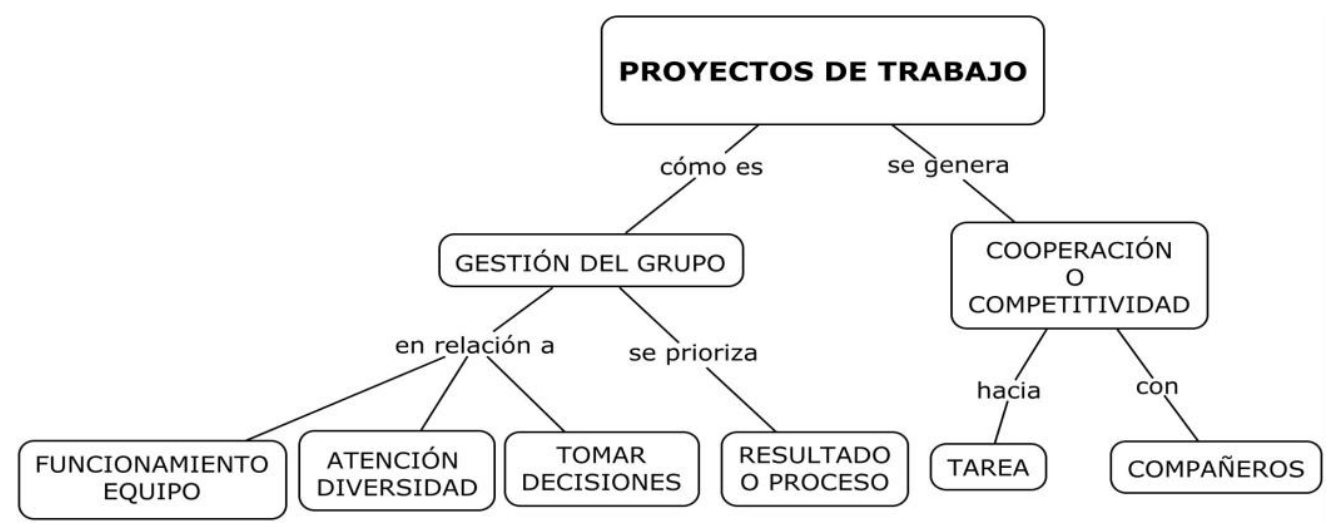

Figura 26. Categorías proyectos de trabajo.

Como hemos comentado en el marco teórico, los proyectos de trabajo son una práctica que facilita la atención a la diversidad, aunque el hecho de que sea una práctica inclusiva o por el contrario que excluya, depende del profesorado. En función de cómo se realice la práctica podrá en mayor o menor medida dar respuesta a la diversidad.

En el caso de esta clase, la práctica de los proyectos no siempre facilita la inclusión. De todas las sesiones, podemos destacar que puede que el alumnado esté en clase realizando el trabajo, pero si los contenidos no están más adaptados a él su 
inclusión resultará dificultosa. A continuación aportamos un dato en el que se ve cómo la maestra trata de incluir a Andrés, un alumno con Síndrome de Down, en la tarea. Aunque, los contenidos en este caso sí que son flexibles, ya que se le dice que comente aspectos de las fallas en general, el alumno más que realizar la actividad está acompañando a la maestra.

Estefanía agafa també a Andrés perquè li ajude a explicar les falles als companys. Estefanía diu que Andrés sap molt de les falles.

La maestra trata de incluir a Andrés en la actividad, pero esta consiste en explicar aspectos de las Fallas y el alumno no dice nada. $\left(3^{a}\right.$ sesión proyectos de trabajo).

En los proyectos de trabajo el alumnado se mantiene más atento en los momentos de trabajo en grupo. Sin embargo, en otros momentos en los que la maestra tiene un rol más activo, se aburren. La finalidad de los proyectos de trabajo es que sea el estudiantado quien construya su aprendizaje. Pero este proyecto es de los primeros que realiza la maestra y el alumnado tampoco está acostumbrado a trabajar de manera cooperativa. Por eso, en las prácticas que observamos sobre el proyecto, el alumnado no siempre tiene el rol activo que se esperaría en este tipo de trabajo.

Estefanía els llig la informació que van ficar dels transports. Encara que estan callats, estan en expressió d'avorrits, recolzats damunt la taula (2a sesión proyectos de trabajo).

Sandra no està pendent de la classe, està jugant amb la carpeta. A Adri també li costa estar atent. Davinia i Waldo estan molestant-se,... En general, l'alumnat pareix que està un poc avorrit, l'activitat els resulta poc dinàmica i s'entretenen amb altres coses ( $2^{a}$ sesión proyectos de trabajo).

La maestra combina estos momentos de explicaciones suyas, con preguntas hacia el alumnado para conocer el conocimiento adquirido durante el proceso. 
Aunque mucha de la información "trabajada" se les ha olvidado. Cabría preguntarnos cómo se ha trabajado esa información ya que no la recuerdan.

Estefanía els diu que eixe dia, enlloc d'avançar, com ja han fet moltes coses del projecte, vol que recorden tot el que han fet fins el moment. Vol saber si entre tots, recorden tot el que han après durant eixe temps. Diu que li queden dos setmanes per acabar el projecte $i$ quan acaben faran un control $i$ després una comunicació. Els diu que per això, han de saber parlar, per fer la comunicació. Estefanía els pregunta què va ser el primer que van fer quan van començar el projecte. ( $2^{a}$ sesión proyectos de trabajo).

En este ejercicio de repaso nos damos cuenta que tan solo una niña en la clase recuerda aquello trabajado en el aula. Por otra parte, la participación del estudiantado a la hora de aportar información tampoco había sido muy alta, como recalca la maestra. Quizás su poca participación desde el inicio es debida a su falta de motivación. En definitiva, aquello que percibimos es que el alumnado no ha hecho suyo el proyecto, sino que más bien parece un proyecto liderado por la maestra.

Entre las acciones realizadas durante el transcurso del mismo aparece la salida para conocer las calles y la arquitectura de la ciudad. En esta parte hay más niñas y niños que recuerdan lo estudiado, aunque la maestra va completando su explicación con aquello que habían olvidado ( $2^{a}$ sesión proyectos de trabajo).

Vos vull dir una cosa. Quan estem fent les parts del projecte vos fiqueu les piles, $i$ vos agrada molt investigar, $i$ vos agrada treballar $i$ parlem molt $i$ parlem molt del tema, però jo veig que ara se vos obliden les coses, i això no pot ser. Hem buscat per Internet, hem anat a l'aula d'informàtica a buscar. Hem llegit llibres, hem eixit pel poble a buscar coses, a fer fotos. I ara no recordeu res? Eixa memòria la teniu molt despistà ( $2^{a}$ sesión proyectos de trabajo).

Por otra parte el alumnado considera las clases de escucha como clases en las que no se trabaja. Realmente, el rol pasivo que mantiene el estudiantado en estas clases no favorece un aprendizaje activo. Es por esto que aquellos niños con una 
motivación intrínseca hacia la tarea perciben las clases magistrales como una pérdida de tiempo.

Ivana s'arrima a la taula d'Estefanía, on està ella, i amb cara de disgust li diu: hui no hem fet res. Estefanía li diu que sí que han treballat, han repassat el projecte. El cert és que no ho recordaven massa bé $i$ ha estat recordant-ho Estefanía, per això els xiquets han perdut l'atenció, ja que no han estat actius $\left(2^{a}\right.$ sesión proyectos de trabajo).

En definitiva la sesión observada no aporta pistas sobre cómo trabaja el alumnado en el proyecto, pero es un buen ejemplo para observar las dificultades que podemos encontrar en la práctica a la hora de realizar actividades en las que el alumnado tiene una mayor autonomía. En la sesión del día 10 de diciembre, en la que trabajan en equipo sobre el proyecto, sí que podemos observar cómo se organiza el alumnado en grupo para poder realizar la tarea. No podemos hablar de que se esté realizando un trabajo cooperativo, puesto que no aparecen los principios mínimos que en toda cooperación deberían estar presentes (responsabilidad individual, interdependencia positiva, interacción cara a cara, habilidades sociales, procesamiento grupal). Sin embargo, sí que se le dan algunas pautas al alumnado para que cooperen.

\subsubsection{Gestión del grupo}

El inicio del trabajo viene de la mano de la maestra que les explica en qué consiste la actividad que van a realizar. Les da una hoja de lectura para cada equipo $\mathrm{y}$ un folio a parte para que apunten aquello que entre todos consideran que es lo más importante de la lectura y les dice que se tienen que ayudar entre todos para hacer la tarea ( $4^{a}$ sesión proyectos de trabajo).

El hecho de que no disponga cada uno de una lectura sino que haya un solo documento a compartir, facilita la cooperación. Sin embargo, las indicaciones aportadas por la maestra no han sido suficientes para que el alumnado comprenda 
cómo proceder para realizar la actividad. Por eso, la maestra va paseando por la clase interviniendo en todos aquellos grupos que considera que necesitan su ayuda para poder empezar a trabajar.

Se trata, el primer pas, que algú de l'equip ho lligca en veu alta perquè la resta s'entere, val?; però és que açò ja ho hem fet més vegades... Cada xiquet ho ha de llegir en veu alta; i l'altre xiquet que ha decidit apuntar, entre tots van dient, pues açò és important, anem a apuntar-ho, pues açò no. No se tracta de copiar, sinó de que allò que cregueu important ho apunteu. Com igual que fem un projecte que decidim el què sabem. En el què sabem no apuntem les coses que sabem? (xiquets, si!) I després en el què volem saber, no apuntem el que sí que volem saber? Pues ací igual. Ho heu entès ara? Xiquets. Sí ( $4^{a}$ sesión proyectos de trabajo. Estefanía ).

A continuación realizaremos un repaso sobre el trabajo realizado en cada uno de los equipos de la clase. En el primero de ellos, el equipo formado por Raquel, Yule, Olivia y Néstor. Aunque Raquel es quien tiene el papel de líder, el trabajo se realiza de manera bastante cooperativa, contando con la opinión de todos los miembros del grupo. Raquel pregunta a cada miembro de su equipo si quieren leer y al responderles todos que no, dice que ella sí que quiere. Sitúa la hoja en el medio para que todos sus compañeros puedan seguir la lectura y ella lee en voz alta. En el equipo de Ivana, Davinia, Waldo y Juan están entre todos pensando cómo van a organizarse, escuchan las aportaciones de Ivana, pero no han decidido el modo de trabajar. En el equipo de Laia, Adri i Adán tienen más dificultades porque es Laia la que va ordenando cómo organizarse y qué tarea realizará cada uno.

Laia els diu el que han de fer a Adri i Adán. Repeteix el que havia dit Estefanía, i reparteix les tasques als companys. Ella comença a llegir. Adri li diu que espere, i Adán es fica a escriure. Laia li repeteix a Adán, "tot no, només les coses importants" ( $4^{a}$ sesión proyectos de trabajo).

En este caso, además observamos que Laia no trata bien a Adán, le dice que no sabe hacer la actividad y prácticamente no le deja participar. Observamos que en este equipo no hay una interdependencia positiva ni tampoco se da la solidaridad 
entre los miembros del grupo, sino que se excluye a un compañero de la tarea porque no sabe cómo hacerla.

Adán mira amb resignació a Laia, que es fica a llegir, i amb un llapis a la mà sap que no pot participar en el treball, mira a Estefanía també que està al seu costat però no li diu res. Fica cara d'estar decebut o disgustat $\left(4^{a}\right.$ sesión proyectos de trabajo).

En este caso la figura de una persona adulta que guie el tipo de interacciones y el trabajo en grupo es fundamental para que pueda intervenir y propiciar que se resuelva el conflicto. Sin embargo, en este caso la maestra está pendiente de más aspectos del aula y no ha detectado lo que sucede.

En el equipo de José María, Sandra y Nayara es Sandra la que dirige el trabajo. Aunque como José María no le hace caso y no le gusta trabajar en equipo, Sandra le da indicaciones únicamente a Nayara. Es un caso curioso, puesto que a diferencia del grupo anterior, en este equipo tiene más dificultades hacia la tarea Sandra que Nayara. Pero Nayara hace solo un par de semanas que ha llegado a la clase y es una niña bastante tímida. Quizás por eso Sandra se impone, aunque tampoco ella tiene claro qué se tiene que hacer.

En el equipo de Raquel, después de un tiempo, están los cuatro miembros atentos a la lectura, desde fuera no se sabe quién de todos está leyendo en voz alta. Me acerco a su grupo y les pregunto cómo están trabajando.

M'expliquen que ho estan llegint tot entre els quatre perquè és un treball en equip. Després en la fulla que tenen van seguint un ordre perquè cadascú apunte el que pensa que és més important. Copien les idees que creuen que són importants del text. Primer comença a copiar Raquel, després Néstor, Olivia i finalment Yule. Raquel és qui lidera el grup i se sap la teoria de que si es fa un treball en equip ho han de fer entre tots. Per això va demanant als companys que prenguen decisions sobre les tasques que han de fer. Aquest és el grup en el que més es comparteix l'activitat (4a sesión proyectos de trabajo). 
En el equipo de Davinia, Waldo, Juan e Ivana, esta última está leyendo con el papel muy cerca de la cara, de manera que el resto no la entienden muy bien y dejan de prestarle atención. En este grupo, también son Ivana y Davinia quienes asumen más tareas que el resto pero de una manera muy poco dialogada. Waldo y Juan no saben qué hacer y ellas de manera individual van realizando la tarea.

En l'equip d'Ivana ho ha llegit tot Ivana $i$ ho ha escrit tot Davinia. Ivana agafa tres fulls en blanc més. Li pregunte perquè tenen tres papers si la resta dels grups ho han de fer tot en el mateix paper. Ella em diu que els ho havia dit Estefanía, i que ho havia de fer tot una persona, però això no és veritat. Els pregunte que han fet Waldo i Juan i no ho saben. Waldo em diu que ho ha fet tot Davinia (4 ${ }^{a}$ sesión proyectos de trabajo).

En definitiva, aunque la maestra ha estado en algún momento supervisando el trabajo de todos los grupos pensamos que serían necesarias más pautas que ayudaran al alumnado a distribuirse las tareas y a trabajar cooperativamente en cada uno de los equipos. Por otra parte, también es cierto que están en el primer trimestre de primero de primaria y es el primer proyecto que realizan de estas características. Puesto que cuando iban a infantil el tratamiento de la información, al no saber la mayoría leer y escribir, era diferente.

Después de un tiempo de trabajo grupal, la maestra les dice que tienen que elegir a una persona del equipo para que lea el trabajo que han realizado. Les dice que la decisión la tienen que tomar entre todos y se les deja un tiempo para que lo discutan.

En el equipo de Raquel ella va preguntando a cada uno si quiere salir a leerlo, como todos dicen que no quieren, dice que saldrá ella. En el de Laia quieren salir ella y Adri, pero ella les dice que ya está claro y que sale ella, aunque Adri le dice que no y por eso Laia acaba proponiéndole que lo hagan entre los dos, aunque finalmente no se sabe qué han decidido. En el equipo de Ivana, Davinia, Juan y Waldo sale Ivana, pero cuando es su turno no sabe qué decir. En el papel hay algunas ideas apuntadas por Davinia. 
Finalmente, aunque el resultado de la tarea no es el que esperaba la maestra, se pueden extraer muchos aprendizajes que ayuden a mejorar la práctica.

Estefanía. A veure, heu apuntat alguna coseta?

Ivana. No.

Estefanía. Com que no?

Davinia. Sí, jo sí!!

Estefanía. A veure alçat! Me pense que Ivana no ho ha tingut clar. Ivana ha funcionat ella sola en el seu equip. Davinia tu has apuntat alguna cosa del teu equip? (Davinia assenteix). I Juan $i$ Waldo també han participat? (Waldo diu que no i Juan baixa el cap i la mirada) No? Pues mal fet! Mal fet per la vostra part, per la vostra i per la de l'equip. A veure, Davinia alça't. Escolte'm a Davinia! Davinia què has apuntat? (Davinia s'alça i es dirigeix cap on està Estefanía en la pissarra, sense el full). Però agafa el que has apuntat! Agafa el paper, si no com ho vas a saber? A veure va (Davinia torna en el paper). ( $4^{a}$ sesión proyectos de trabajo).

A continuación van saliendo a leer otros grupos, pero el resultado es que ninguno ha realizado la tarea como les había indicado la maestra. Estefanía atribuye el mal resultado de la actividad a la pereza del alumnado de no tener ganas de leer. Sin embargo, en mi opinión creo que el alumnado no tenía claro cómo hacer la actividad. Por una parte tenía dificultades para hacer el resumen y por la otra para trabajar cooperativamente.

Por otra parte, tampoco se ha prestado suficiente atención al funcionamiento del equipo. Muchos de los aspectos que pensamos que el alumnado debería saber quizás no se han trabajado suficientemente. Como el hecho de aprender a respetar la diversidad de ritmos, de aprendizajes, de que cada uno tenga una tarea y tomar decisiones entre todos los miembros del equipo. 
En definitiva, aunque pensamos que la idea del trabajo ha sido muy buena y la intención también, creemos que se ha focalizado más en el resultado que en el proceso, siendo realmente importante para el aprendizaje ambas partes.

\subsubsection{Cooperación y competitividad}

Otra de las cuestiones a valorar en los proyectos de trabajo ha sido la competitividad que se ha generado entre el propio alumnado. Esta cuestión pensamos que no está propiciada por la maestra ni por la dinámica, ya que la observamos en el caso de dos grupos y por la relación que existe entre dos niñas: Raquel y Laia. Hay una buena relación entre las dos, pero al mismo tiempo extienden la competitividad que hay entre ellas a su grupo de trabajo. Empieza con esta dinámica Raquel, que le dice a Laia que en su grupo están trabajando en equipo.

Raquel es gira cap a Laia i li diu que ells ho estan fent en equip. Laia li diu a Raquel que ells ja quasi ho han acabat. Laia crida a Adri i li demana que s'espere i que es sente que ho van a fer entre tots. També crida a Adán i es senta. Ella agafa el full i li diu a Adri, ara tu has d'apuntar, vale? I jo llig. I després, Adán ho llig $i$ tu... Es gira Adán i sorprès somriu ( $4^{a}$ sesión proyectos de trabajo).

Después del comentario de Raquel Laia deja participar a Adán, quien se queda algo sorprendido por el cambio de su compañera. En el grupo que ahora están trabajando desde la competitividad es en el de Raquel. En lugar de ayudar a sus compañeros a identificar las partes más importantes, Raquel y Yule que son más rápidos empiezan a decirle a Olivia que se dé prisa en apuntar.

Quan Olivia està acabant Yule li lleva el paper al vol;

Laia, dirigint-se a Adán i Adri: Vale ja, vale ja! No heu escoltat el que jo he dit. (Adán li contesta i Laia s'incorpora per respondre-li). Va! Per favor, ja està bé! L'equip 3 (Laia assenyala el grup de Raquel) ja sabeu que ha acabat, l'equip 3! Ha acabat $i$ ho ha fet! L'equip 3 ja ha acabat, i nosaltres encara no estem! Vamos, vamos, que hay que adelantar al 3! ( $4^{a}$ sesión proyectos de trabajo). 
En el equipo de Laia, ella manifiesta a sus compañeros la necesidad de acabar el trabajo porque en el grupo de Raquel ya están acabando. En el grupo de Raquel que hasta ese momento mantenían una actitud más colaborativa con sus compañeros y se escuchaban las opiniones de todos, también empiezan a competir. La competitividad también la observamos en otras prácticas como en los grupos interactivos, aunque en estos no compiten con miembros de otros grupos, sino que a veces se comparan con otros niños/as de su mismo grupo.

\subsubsection{Tertulias literarias dialógicas.}

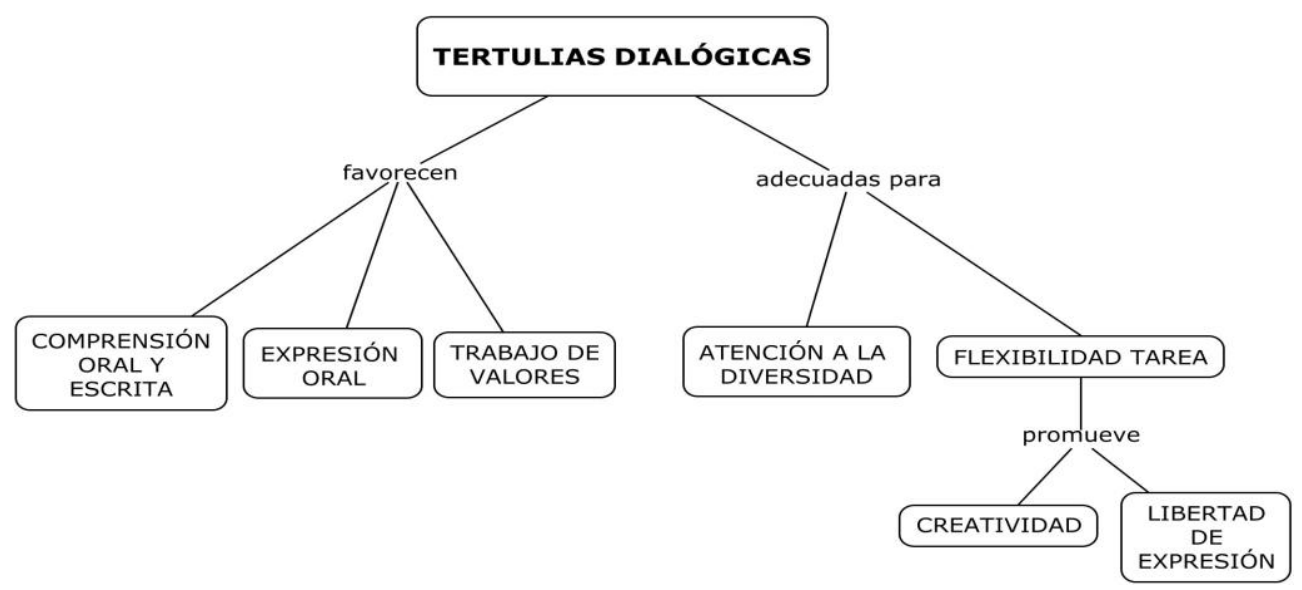

Figura 27. Categorías tertulias dialógicas.

Aunque nos hemos referido en el marco teórico a las tertulias literarias dialógicas, en los resultados hablamos de una aproximación a las mismas. Puesto que no se siguen al pie de la letra las indicaciones sobre su puesta en práctica.

En primer lugar, no se leen los clásicos, sino cuentos infantiles en los que se trabajan igualmente valores y que son lecturas también motivadoras para el alumnado. En segundo lugar, puesto que una parte del alumnado no sabe leer y no siempre cuentan con el apoyo de la familias, las lecturas las realizan en clase, asegurándose de que todo el alumnado puede comprenderlas. En tercer lugar, una 
vez finaliza la lectura del libro con sus correspondientes tertulias, inician en clase un proyecto de investigación, así es como lo llaman. Se trata de un trabajo en el que buscan información sobre aspectos que han aparecido en la lectura y que no entienden, para poder trabajarlos en la siguiente sesión. Finalmente, todas las lecturas acaban con un resultado diferente que elige el alumnado. Algunas con la exposición teatral de la narrativa, otras con la elaboración de un cómic; otras con la propuesta de redactar un final distinto, etc. Los aspectos que sí que conservan son los principios del aprendizaje dialógico.

La tertulia se inicia en el rincón de la asamblea. Sentados en los bancos de manera circular, la maestra invita a que una persona de la clase lea una página del libro. Después suelen seguir el orden en el que están sentados.

Antes de iniciarse en la lectura, prestan atención a la portada y a la contraportada y a partir del título realizan suposiciones sobre aquello que se tratará en la lectura. En el caso de que ya esté empezada recuerdan aquello leído y realizan suposiciones sobre cómo continuará.

Los aprendizajes alcanzados están relacionados con el contenido de la lectura, con los valores que se transmiten, así como con el vocabulario y expresiones de la lengua.

Estefanía. Jo ara em pregunte, què és el que estem treballant en este llibre?

Xiquet. Les tertúlies.

Estefanía. Sí estem fent tertúlies, però què és el que treballem en este llibre.

Sandra. Les dies de la setmana.

Estefanía. Molt bé, Cristina (es el nombre de la protagonista del libro y Sandra interpreta su papel).

Estefanía. I quins són els dies de la setmana?

Alumnat. Dilluns, dimarts, dimecres, dijous, divendres, dissabte i diumenge.

Estefanía comença a preguntar-los què feia Cristina cada dia de la setmana, $i$ els pregunta alguna expressió del llibre: s'avorreix com una petxina. ( $1^{a}$ Tertulia). 
En el ejemplo anterior vemos como el alumnado responde a cada una de las preguntas de la maestra y además recuerda todo el argumento de la historia. La maestra está muy contenta de que lo recuerden y entiendan los aspectos trabajados. Ella atribuye el éxito al trabajo que han realizado y a su motivación hacia la tarea.

\subsubsection{Flexibilidad en la tarea}

Después de hacer un repaso sobre el libro proponen dramatizar la historia. Realizan un teatro en el que todo el alumnado participa interpretando los diferentes personajes que aparecen en la historia. Además, la maestra explica qué es un teatro espontaneo y aquello que significa. Introduce elementos que amplían los contenidos del currículum y se disponen a realizar una actividad de expresión oral y corporal, que también es motivadora para el alumnado ( $1^{a}$ Tertúlia $)$.

En este caso, Estefanía les ayuda a que comprendan qué tienen que hacer, al mismo tiempo que les deja libertad para que sean creativos y les ayuda a expresarse corporalmente. La actividad consiste en que dramaticen lo que aparece en la historia, pero según sus pensamientos. Es decir, en la historia se hace un repaso sobre los días de la semana y cómo se siente la protagonista en cada uno de ellos. Pero la maestra, en lugar de pretender que sigan al pie de la letra la historia, les invita a que dramaticen sus sentimientos. Por eso, en el caso de Laia, que interpretaría el sábado, antes de empezar la maestra le pregunta cómo se siente ella los sábados.

Els pregunta com estan el dissabte. Laia diu que el dissabte és avorrit, Estefanía li diu que per a ella no ho és. Estefanía li diu que a ella no li pareix avorrit però que si a Laia no li agrada que ho manifeste, perquè és ella el dissabte (guia a l'alumnat per ajudar-lo, encara que en tot moment els diu que han d'expressar-se lliurement en funció de les seues idees, els dona llibertat).

Estefanía. En el teatre cadascú s'expressa com vol. El que a mi m'agrada no vol dir que li agrade a Néstor. I el que a Raquel li agrade no vol dir que li agrade 
a Yule. Cadascú ací al mig farà el que voldrà! I ni està millor, Juan, ni està pitjor. Val? Val? Pues, comencem ( $1^{a}$ Tertulia).

Esta actividad que puede parecer sencilla propicia la expresión del alumnado, el que tengan que escucharse interiormente y después mostrar con la expresión corporal aquello que significa para ellos. Es una actividad bastante enriquecedora que ayudará al alumnado a trabajar algunas facetas que la escuela suele olvidar, como la creatividad, la libertad de expresión y el cuerpo como lenguaje. Es cierto que el alumnado no está acostumbrado a este tipo de tareas, al hecho de poder decidir por ellos mismos y salirse del guion. Por eso, vemos que no para todo el alumnado es fácil expresarse.

Laia torna a imitar a Estefanía i ella li diu: jo te parle, jo te done una idea però tu pots dir el que tu vulgues. Laia, de la mà de "Cristina” diu la frase del dissabte. (Se'ls dona llibertat, encara que el model impera i fan una còpia exacta del que diu la mestra) ( $1^{a}$ Tertulia).

Otra propuesta de la maestra fue realizar las tertulias las dos clases de primero. La experiencia fue bien acogida por la otra maestra y por todo el alumnado, además fue una oportunidad para iniciar un trabajo compartido entre las clases de primero. El funcionamiento fue el mismo que con una clase, solo que a la hora de participar se contaba con más niños. También un día Estefanía hizo la propuesta al alumnado de su clase de finalizar las tertulias con la preparación de un baile; escenificando la historia del libro.

Para finalizar, cabe destacar que aquello que realmente le interesa a la maestra es que el alumnado se comunique i se exprese libremente.

Aleshores això. A ells, estos no, l'any passat que estàvem en segon vam acabar fent tres o quatre teatres, però abans vam fer còmics, vam treballar l'escriptura, vam fer canviar el final del compte, inventar-nos un altre títol. Vam treballar l'oral i l'escrit també. Encara que m'interessa molt la lectura, la primera part de les tertúlies; i la segona part és en la que parlen i s'expressen. Per això també que s'expressen mitjançant el teatre és molt bo per a ells ( $1^{a}$ Tertulia). 


\subsubsection{Grupos interactivos}

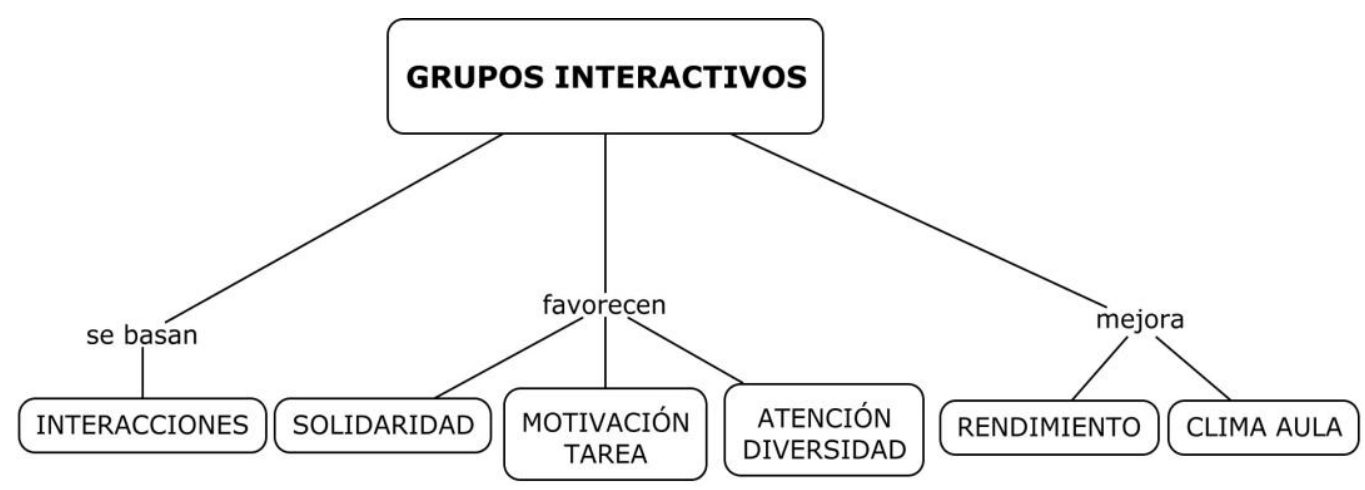

Figura 28. Categorías grupos interactivos.

Sobre los grupos interactivos destacaremos distintos aspectos. Por una parte mencionaremos el tipo de actividades que se suelen preparar; después explicaremos cómo se dan las ayudas y la diferencia entre ayudar y copiar.

En relación al tipo de actividades se intenta que sean tareas que permitan al alumnado interactuar para poder realizarlas. Además, en la clase de Estefanía se preparan actividades sobre conceptos ya explicados en el aula. Así, las personas voluntarias no tienen que explicar en qué consiste la tarea, sino procurar que se den las interacciones entre el alumnado.

En relación a las interacciones entre el alumnado, la ayuda es uno de los aspectos más potentes de la dinámica, ya que la solidaridad de unos compañeros y otros facilita que una parte del alumnado pueda llegar a resolver la tarea y sin esta ayuda le resultaría más costoso hacerlo. En este sentido, aparecen muchas interacciones en las que se observa la ayuda entre unos y otros y por el contrario, algunas situaciones en las que se niega. 


\subsubsection{Ayudar}

En general, el alumnado destaca el hecho de dar o recibir ayuda como un aspecto positivo de la dinámica. A casi todos les gusta poder ayudar a los compañeros y que les ayuden cuando ellos lo necesitan. Además, no siempre son las mismas personas las que dan ayuda y las que la reciben. Hay niños con dificultades de aprendizaje que normalmente necesitan ayuda para acabar su tarea, sin embargo, estos niños también son los que prestan la ayuda en algunos casos. Por ejemplo Waldo, tiene dificultades para realizar la actividad, pero cuando él le explica a su compañero lo que tiene que hacer y se lo explica bien, las maestras se dan cuenta de que Waldo entiende el procedimiento aunque lo que le cuesta es calcular la operación y escribir el resultado ( $3^{\mathrm{a}}$ sesión GI).

Además, observamos cómo en algunos grupos tienen interiorizada la dinámica de ayuda, puesto que en momentos en los que no se les ha acostumbrado a ayudarse siguen dando su ayuda. Como por ejemplo en el caso que mostramos a continuación, donde la ayuda se presta sin que el compañero la haya pedido y para asegurarse de que los dos tienen el mismo resultado. En el caso de no coincidir comprueban cuál sería el resultado correcto:

Ara es fiquen a mirar-ho i entre els dos, cadascú des de la seua fitxa. Laia li diu, este lo tienes mal. I Adri li contesta, no cuatro más uno cuanto son? I li diu un resultat que no és. Laia es queda mirant-lo i jo li pregunte si està segur. Els dos es fiquen a tornar-ho a contar i arriben a la solució correcta de l'operació ( $3^{a}$ sesión GI)

No solo en este caso, sino en otros, la dinámica de la ayuda es algo que el estudiante interioriza como su manera de trabajar. En el caso de estar trabajando en equipo, por ejemplo en el proyecto de trabajo, también saben que pueden ayudarse aunque la maestra no propicia tanto que se dé esta ayuda. También porque solo hay una maestra en clase en lugar de contar con personas voluntarias. 
No obstante, también hay algunos alumnos a los que no les gusta ayudar como a José María o a Ivana. Pero cuando están en grupos interactivos saben que dar o recibir ayuda es una parte más del trabajo.

En la taula que està Estefanía, José María està ajudant a Sandra, li està dient una cosa de l'exercici ( $1^{a}$ sesión GI).

También observamos que la ayuda no solo la dan cuando ya han acabado sus tareas, sino que incluso aquellos que van más avanzados en algún momento pueden no saber cómo seguir y preguntan a sus compañeros, aunque no hayan llegado a esa actividad.

En un moment que Néstor no sap com seguir li allarga la fitxa a Raquel, sense dir-li res. Ella encara no ha arribat a eixa part, però mira la fitxa i li explica el que ella pensa que s'ha de fer ( $3^{a}$ sesión GI).

Normalmente, la ayuda se da en el momento en el que el alumno la necesita. Sin embargo, en algunos grupos en los que las maestras no propician tanto las interacciones entre iguales, las ayudas las da el alumnado una vez ha terminado su tarea.

Maestra voluntaria: Adri, perfecte! Adri, tu que ja has acabat ajuda als teus companys.

Adri està acabant un exercici i fins que no acaba no es disposa a ajudar $\left(2^{a}\right.$ sesión GI).

No obstante, aparecen situaciones en las que el alumnado no se ayuda a resolver la actividad.

Em fique en el grup de José María, Sandra i Nayara. Només repartir-los les fitxes (millor dit, les agafen ells), Sandra em pregunta què han de fer. Li comente que ho pregunte als companys si saben el que s'ha de fer però en eixe moment es queda callada i la resta tampoc li diu res ( $3^{a}$ sesión GI). 
Incluso, aparecen momentos en los que algún compañero le ha pedido ayuda a otro, pero este no quería "perder tiempo" explicándole y no le ayuda. Esto es poco frecuente, pero sí que hay algunos niños que mantienen esta actitud con el resto.

Juan mira a Ivana i li diu, Ivana, cuanto són nou más cinco? Ivana li diu “isuma, suma, suma, con tus dedos!” (Esta alumna no ayuda a su compañero, quiere acabar su tarea).

Juan: es que no sé.

Ivana: Nou més cinc, tens nou més cinc, quinze,... (Ahora le ayuda un poco, pero parece que le molesta porque quiere acabar su tarea y no le dice cómo llegar al resultado, sino que se lo dice ella directamente, aunque tampoco es el correcto). (3 $3^{a}$ sesión GI)

En otra ocasión en la que es una persona adulta la que pide que ayude a su compañero tampoco se muestra dispuesta:

Ivana $i$ Davinia estan fent la fitxa $i$ Juan $i$ Waldo estan parats. Li demane (investigadora) a Ivana que ajude als companys, però ella gira la seua fulla i diu: ja trabajar! (A ella li agrada treballar i prefereix acabar ella la seua fulla abans de poder ajudar. També estan acostumats a fer el treball sols i quan acaben ja poden ajudar) (3 $3^{a}$ sesión GI).

En el caso de Sandra, necesita ayuda, y sin embargo no acepta la ayuda de una compañera que es nueva en la clase y que tiene más habilidad que ella para las matemáticas. Sandra no sabe cómo hacer unos ejercicios pero no pide ayuda. En ese momento estoy yo como voluntaria e intento que interactúen. Sandra le dice a Nayara que no tiene bien un resultado, después de comprobarlo Nayara le dice que sí que lo tiene bien y que es ella la que en lugar de restar ha sumado, pero Sandra no hace caso a Nayara y sigue sin corregir las operaciones. 


\subsubsection{2. ¿Ayudar o copiar?}

Por otra parte, también aparecen algunos conflictos en la manera de dar o recibir la ayuda. En algunos casos es una ayuda basada en una explicación y en otros casos es una "copia”.

Algunas de estas "copias" son un intento de ayudar a un compañero o de encontrar ayuda, pero no se piensa que en lugar de decir el resultado se le tiene que enseñar a pensar. Cuando las maestras hablan de copiar están regañando al alumnado que no sabe muy bien cómo resolver un ejercicio, si este hecho es corregido por las maestras, ellos lo entienden y pueden cambiarlo.

Por norma general, las maestras aluden a la copia y se enfadan, en lugar de reconducir el tema hacia la ayuda:

Maestra voluntaria: Això és copiar eh Davinia, això és copiar... no val copiar (2 $2^{a}$ sesión GI).

Estefanía: Juan, Juan,... Si no ho saps li ho preguntes a ella, però no te copies $\left(1^{a}\right.$ sesión GI).

En el último ejemplo, Juan es un niño que tiene dificultades para realizar el ejercicio. Seguramente no sabe cómo resolverlo y reacciona como suele hacerlo, tratando de copiar si no se siente capaz de hallar la solución al problema. La valoración del diálogo y del trabajo de todos los miembros del grupo son aspectos esenciales para el aprendizaje del alumnado, y especialmente son de ayuda para alcanzar la tarea para aquellas personas que sin ayuda tienen más dificultad. Si no se les explica la diferencia entre copiar y recibir ayuda puede que no sepan cómo enfrentarse a estas situaciones.

Estefanía pasa también por los grupos para ver cómo funcionan, también les da indicaciones a unos y a otros, y en algún momento toques de atención. Suele hacer la función de supervisar el funcionamiento de los grupos. Les recuerda también que no copien y que pidan ayuda. Quizá ese pedir ayuda, el valor de la 
interacción y la valía de los argumentos, son aspectos que aunque se tienen en cuenta no se explicitan para el alumnado. Podría ser interesante que se explicaran para que entendieran por qué se trabaja así.

\subsubsection{Clase magistral: Contraste con la práctica de Grupos Interactivos}

Observamos una clase en la que tenían que hacer grupos interactivos, pero por circunstancias, la mayoría de las maestras que asisten de voluntarias no pueden ir y en lugar de realizar GI resuelven las fichas de matemáticas en su grupo, pero de manera individual. Es decir, sin que haya una voluntaria en cada grupo para propiciar las interacciones.

Este cambio en la dinámica de la clase nos lleva a muchas cambios sustanciales en diferentes aspectos: en el rendimiento, en la distracción, en la dependencia de la maestra y la falta de ayuda entre los compañeros y en la atención a la diversidad.

En relación al rendimiento, el alumnado trabaja más cuando están en GI.

En la sessió de hui podem observar que gairebé han d'estar tota la sessió, uns 40 minuts asseguts. La feina és menor perquè en grup interactiu fan 4 fitxes $i$ ara fan el que equivaldria a una. A banda, al alçar-se cada 15 minuts $i$ canviar d'activitat estan més actius. I a l'haver una altra persona adulta amb ells també ajuda a que es fiquen a la feina. (4 $4^{a}$ sesión, contraste con GI).

Por otra parte, aunque están 40 minutos con una misma actividad (varias fichas de matemáticas), después de los 20 primeros minutos su atención decae y por eso el rendimiento disminuye en relación a los GI en los que de cada 15 minutos cambian de mesa.

No són capaços d'estar treballant sols més de 20 minuts. Ni tampoc de fer durant tota una hora la mateixa tasca. En canvi, en els grups interactius sí que 
poden perquè hi ha un adult dinamitzant que ells interaccionen entre ells sobre la tasca i perquè cada 15 minuts canvien d'activitat ( $4^{a}$ sesión, contraste con GI).

Por estas razones, el alumnado está más distraído y en lugar de dialogar con su compañero para resolver la tarea conversan sobre temas que no están relacionados con la misma.

Davinia i Raquel es fiquen a parlar de coses que no son de la feina; Adri està acabant la fitxa dret $\left(4^{a}\right.$ sesión, contraste con GI).

Estefanía les da un toque de atención, pero para ellos no es suficiente, pues no tienen ninguna motivación hacia la tarea.

Estefanía els diu jo veig una cosa, que hi ha xiquets que van "mangosexant" on no toca i se "liaran" (4 sesión, contraste con GI).

Aunque observamos situaciones en las que se dan ayuda, ahora la manera de proceder es ir a la mesa de la maestra, normalmente para que les corrija la hoja. Esto supone que la maestra tenga más tareas que cuando se ayudan entre ellos y que el alumnado no esté en su mesa. El tiempo que están en la fila hablan unos con otros y además no pueden ayudar a sus compañeros que aún no han acabado.

Adán hui està sol a la seua taula. Els seus companys s'han alçat tots a corregir a la taula de Estefanía. Ell segueix treballant ( $4^{a}$ sesión, contraste con $G I)$.

Encontramos diferencias no solo en el rendimiento, sino también en el clima del aula, respecto de cuando realizan GI. Ahora el clima de trabajo es más distendido, gran parte del estudiantado está en pie y hablan sobre aspectos que no están relacionados con la actividad.

Nayara va a la taula d'Estefanía a corregir els exercicis, Juan acaba d'entrar del bany i també es dirigeix a la taula de Estefanía. Raquel s'alça i també va a la taula de Estefanía a preguntar-li una cosa ( $4^{a}$ sesión, contraste con GI). 
Por otra parte, la atención a la diversidad es menor, en relación al tema de las ayudas, puesto que aquel alumno que necesita más ayuda no tiene el apoyo de sus compañeros ni de la persona voluntaria y demanda de la atención de su maestra al igual que el resto de sus compañeros.

Juan s'arrima a la taula d'Estefanía, fa mala cara, $i$ va pegant voltes al costat de la taula. Estefanía li pregunta si ha llegit l'exercici. A la vegada que està parlant en Juan, s'arrima Yule a preguntar-li una cosa. Estefanía li diu "primer se suma, se suma" ( $4^{a}$ sesión, contraste con GI).

En definitiva, las diferencias entre una clase magistral y la realización de un GI o de cualquier otra de las dinámicas anteriormente citadas son muchas. La más importante la atención a la diversidad que en las clases magistrales resulta muy dificultosa. Por otra parte, tampoco se trabajan toda una serie de competencias que el alumnado de otra manera realiza, como el ser solidarios, etc.

\subsubsection{Participación de todo el alumnado}

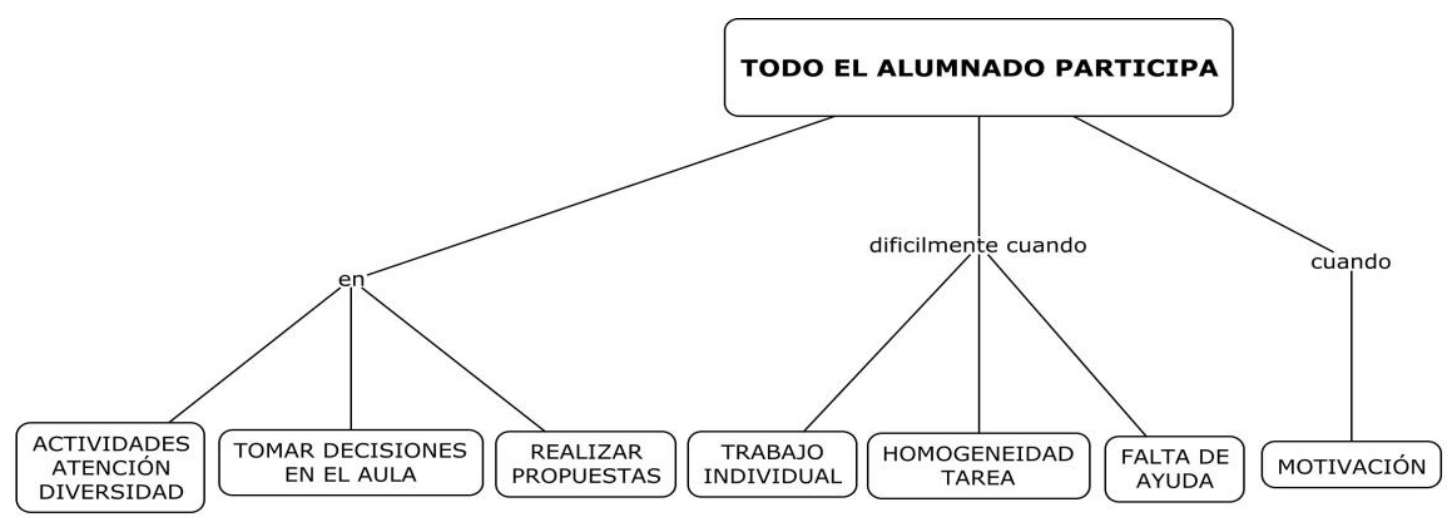

Figura 29. Categorías participación alumnado.

En este apartado nos detendremos en comentar cómo es la participación del alumnado en el aula. En primer lugar hablaremos sobre su participación en función del tipo de práctica realizada. Destacamos las asambleas y las tertulias como las 
prácticas más adecuadas de las realizadas en la clase de Estefanía, para que el alumnado pueda participar y los grupos interactivos como una de las prácticas en las que no todos están incluidos. Con esto no nos referimos a que un grupo interactivo sea una práctica excluyente o que una asamblea sea siempre inclusiva. Nos referimos al modo en el que la realización de la práctica permite o dificulta la participación e inclusión de todo el alumnado en la actividad. Por otra parte, nos detendremos en aquellos momentos en los que la maestra pide la opinión del estudiantado para tomar decisiones, ya que es otra manera en la que el alumnado participa en la clase. Finalmente, hablaremos de aquellas actividades que motivan al alumnado y en las que su participación es más alta.

\subsubsection{Participa en...}

En primer lugar, las asambleas son un contexto idóneo para que todo el alumnado pueda participar en igualdad de condiciones. No se requiere que tengan un gran entendimiento en ninguno de los temas, sino que simplemente se les invita a expresarse y comentan aquello que hicieron el día anterior. Se practica la escucha activa, la empatía, el respeto hacia el otro y la expresión oral. Cada uno se expresa a su manera pero todos lo hacen libremente. Se posibilita que todos adquieran las competencias que se trabajan desde esta práctica.

Además, un aspecto que observamos en la asamblea en relación a la diversidad es que todos escuchan con normalidad a Andrés, un niño con Síndrome de Down, y le hacen caso cuando tiene un buen comportamiento. Cuando empieza a gritar o hacer ruidos y a decirles al resto que se callen, el alumnado de su clase no se ríe de él, sino que entiende que a veces él se expresa de esta manera pero que no hay que prestarle tanta atención porque si no está más tiempo con esta actitud. Un día que la otra clase de primero y su maestra entraron en el aula cuando ellos estaban haciendo la asamblea, nos dimos cuenta de que el estudiantado de la otra clase no 
sabía cómo interpretar las reacciones de Andrés y empezaron a reírse ( $3^{\mathrm{a}}$ asamblea clase Estefanía).

Por otra parte, esta práctica favorece la participación de aquellos alumnos que en otras circunstancias, se mantendrían callados.

És el torn d'Olivia (Estefanía ens diu que és molt callada, però en les tertúlies $i$ les assemblees va soltant-se i parlant més). Hui, quan comença parla molt baixet i Estefanía li diu, “carinyo, des d'ací no t'escolte, vinga, parla un poquet més fort”. Mostra tendresa cap a la xiqueta, li mostra confiança perquè siga capaç d'expressar-se. Com que Olivia no parla molt, Estefanía li fa preguntes perquè conte alguna cosa més del que va fer el cap de setmana (2a asamblea clase Estefanía).

En otras ocasiones vemos como Olivia, además de hacer su aportación, levanta el brazo para añadir más cosas cuando ya ha pasado su turno. Pero también resaltamos que las aportaciones de esta niña son siempre muy bien acogidas por la maestra, que como hemos dicho la anima a participar.

En el caso de otra niña, Nayara, como se incorpora a mediados de noviembre a la clase y proviene de un pueblo de habla castellana, tiene alguna dificultad con el valenciano. Por eso en las primeras asambleas está más callada o en algún caso dice que no entiende alguna expresión. A lo largo de las asambleas observamos su mejora, no solo en el habla, a la hora de expresarse, sino también en el hecho de querer participar y realizar intervenciones bastante completas.

Respecto a las tertulias, también participa todo el alumnado en la actividad. Cabe destacar que este es también el objetivo de la maestra, que estén más activos para que puedan aprender más. Algunos leen, otros que no saben escuchan y tratan de seguir la lectura con la ayuda de alguna persona adulta de la clase. Pero todos participan del comentario de la lectura y de las actividades que se derivan de la misma y que suele proponerle la maestra al alumnado.

A mí me ha gustado mucho, me ha parecido muy divertida y que, lo que tú dices, que todo el mundo participa, nadie se queda sin participar como muchas 
veces pasa en el aula que hay gente más extrovertida y otros pues, están más callados y no participan. De esta forma salen todos ( $1^{a}$ Tertulia. Julia, alumna visitante, estudiante de la universidad).

Tanto en las asambleas como en las tertulias Andrés puede participar.

Andrés representa a la petxina. L'alumnat i les Mestres volen que ell participe també en aquesta ocasió i l'animen, però ell no vol. Al final participa i el fiquen al braç de Sandra, encara que Andrés es tapa els ulls amb les seues mans i els braços (1 $1^{a}$ Tertulia).

Por otra parte, la inclusión de todo el alumnado en el aula genera situaciones de mucho enriquecimiento. Los valores, comportamientos y actitudes que existen en la clase son distintos por el hecho de contar con la diversidad con la que conviven. En concreto, nos referimos a la presencia y participación de Andrés en la clase.

Las interacciones del alumnado con Andrés son distintas a las interacciones que tienen entre ellos. Hacia este niño se genera un cuidado y una estima que no se aprecia del mismo modo con el resto de compañeros. Como veremos en los datos, a Andrés le permiten más que al resto de compañeros. Cuando él no tiene un comportamiento que les gustaría son más pacientes que con el resto y no recurren a la mediación de la maestra para resolver un conflicto, sino que ellos mismos son quienes con dulzura le dicen a Andrés que eso no está bien. Además, aprenden a poner límites de una manera tranquila, sin llegar a enfadarse con él, porque entienden que de algún modo es diferente y no le exigen lo mismo que al resto de sus compañeros. Y por último, con Andrés todas las interacciones acaban con un abrazo o un beso a sus compañeros. Se reconcilia con ellos con esta muestra de amor que a todos les gusta recibir.

La participación del alumnado en el aula se extiende también a algunos momentos puntuales. En una de las ocasiones para decidir entre el estudiantado de las dos clases de primero qué libro escoger, de entre las cuatro opciones que les 
propone Estefanía. En este caso se procede a la elección del libro mediante los resultados de la votación, en lugar de optar por el consenso. Se le explica al alumnado que se tomará la elección que haya escogido la mayoría.

Estefanía: Mireu, anem a començar la votació. Vaig a ensenyar-vos els quatre llibres. Mireu molt bé els quatre llibres perquè cada xiquet n'ha de votar un. Si jo trie un llibre perquè pareix que m'agrade, després no puc tornar a votar un altre, val? Vaig a ensenyar-vos els quatre. (...) Si resulta que després, per majoria, surt que he de llegir un altre que no és el que jo he triat, he de llegir el que jo vull o el que haja decidit la majoria?

Ivana: El que ha decidit la majoria $\left(2^{a}\right.$ Tertulia).

En otra de las ocasiones se les deja escoger qué actividad realizar, porque la maestra no tiene muy claro si vale la pena avanzar el proyecto puesto que han asistido pocos alumnos a clase.

Estefanía vol continuar amb el projecte, però diu que no sap si val la pena perquè son pocs xiquets a la classe, falten tres que estan a casa i Sandra i Andrés que se'n van a religió. Els pregunta als alumnes que es queden què volen fer $\left(3^{a}\right.$ sesión proyecto de trabajo).

También, el alumnado se siente con la libertad de hacer algunas propuestas sobre el trabajo a realizar. Por eso, una alumna propone el día del cumpleaños de la hija de Estefanía, elaborar una tarjeta de felicitación. Otro día la misma niña, que el año anterior estaba en la clase de infantil en la que se realizó el grupo de discusión, propone en clase volver a realizar un grupo de discusión para hablar de aquellas cosas que les han gustado más de las actividades de la clase (Sesión final de trimestre).

\subsubsection{Difícilmente participa en...}

Sin embargo, la inclusión de todo el alumnado en las prácticas de aula no siempre es una tarea fácil, puesto que quizás la propia práctica no lo facilita. En el caso de Andrés, se le excluye principalmente cuando realizan fichas y trabajan de 
manera individual o cuando van a realizar grupos interactivos, aunque contradictoriamente esta última es una práctica definida como inclusiva por la literatura, como hemos visto en el marco teórico. Los motivos por los que pensamos que los grupos interactivos realizados en esta clase, no facilitan la inclusión los encontramos en el tipo de actividades que se realizan. Mientras que estas tengan que ser las mismas para todos los miembros del equipo no tendrá tanto sentido que Andrés participe de la actividad. Podría estar presente, pero eso no significaría que estuviera incluido. Para estarlo, la práctica tendría que ser lo suficientemente flexible como para dar una respuesta a la diversidad de ritmos, de aprendizajes, etc.

A continuación, aportamos algunos datos en los que se observa que los grupos interactivos, a diferencia de otras prácticas, no favorecen la inclusión de todo el alumnado:

El alumnado está en la hora en la que realizan grupos interactivos, cada uno con su equipo realizando las fichas que las maestras han preparado. Pero Andrés no puede resolver esas fichas con la ayuda de sus compañeros, puesto que para realizarlas es necesario comprender mínimamente los contenidos que se están trabajando. Otros compañeros con dificultades sí que pueden seguir la dinámica del grupo y se apoyan en sus compañeros para resolver las actividades, aunque no tengan el mismo éxito que los demás. Es decir, aunque no acaben todos los ejercicios e incluso en algunos casos no se resuelva más que una operación. Sin embargo con Andrés es diferente, directamente está en una mesa jugando a un puzle con la educadora ( $1^{a}$ sesión GI).

Aunque algunas maestras se dirigen a él como si realmente estuviera participando de la actividad, no está ni compartiendo el espacio con el resto de compañeros. Por ejemplo, la maestra de PT le dice que ahora le toca hacer grupos interactivos; pero él no está sentado en ninguno de los equipos. Andrés está en clase, pero en un rincón con la educadora ( $3^{\mathrm{a}}$ sesión GI). 
En una de las sesiones, Andrés se levanta de su mesa y se acerca a un grupo de compañeros. En este caso la educadora coge su silla y se sitúa a su lado y al lado del alumnado de ese equipo. Pero Andrés no puede hacer nada de la tarea que van a resolver sus compañeros.

En otra de las actividades que se excluye a Andrés es en los proyectos de trabajo. Sin embargo, en este caso la técnica en sí podría facilitar la inclusión, puesto que no tienen el porqué, realizar el mismo tipo de tarea todos los miembros del grupo. No obstante, aportamos algunos ejemplos de distintas sesiones en las que se le aparta del resto.

Ha arribat Andrés $i$ se n'ha anat darrere amb la mestra de PT. No participa de l'activitat. (1 ${ }^{a}$ sesión proyecto de trabajo).

Estefanía els diu que guarden l'estoig, com Andrés no el te guardat li demana que ho faça. S'arrima l'educadora, li guarda l'estoig i se l'emporta a un racó. Estefanía no diu res, però s'està tornant a excloure a Andrés de la tasca (2a sesión proyecto de trabajo).

Andrés està a part amb la mestra de PT. (4 ${ }^{a}$ sesión proyecto de trabajo).

En este caso, no solo Andrés está excluido de la tarea, sino que en algunos momentos también lo están otros alumnos como Waldo. En el caso de Waldo, decimos que está excluido de la tarea porque no siempre se propicia la ayuda entre iguales y él la necesita para poder resolver su ficha.

Waldo encara va per la primera frase però ningú l'ajuda. Cadascú està acabant la seua fitxa. No se li sol donar ajuda en activitats que no son grups interactius (Només hi ha 7 xiquets en la classe) ( $3^{a}$ sesión proyecto de trabajo).

En este sentido, aunque la práctica permitiría la diversidad, es la maestra quien busca la homogeneidad en la tarea y por eso algunos alumnos se quedan al margen, y tienen dificultades para realizar su tarea. Además, la falta de solidaridad y de ayuda dificulta la realización de la tarea en el caso de Waldo y también en el de Adán ( $4^{\mathrm{a}}$ sesión proyecto de trabajo), quienes suelen recibir la ayuda de sus compañeros en los grupos interactivos. Aunque para contrastar, también 
encontramos algunos momentos en los que se da esta ayuda, pero no se realiza con la misma sistematización que con los grupos interactivos y no es igualmente aceptada por el profesorado.

Ivana ajuda a Waldo en alguna cosa que no ha fet bé (ficar la data). Estan treballant en silenci. Waldo li va preguntant a Ivana on ha de ficar la data i ella l'ajuda ( $3^{a}$ sesión proyecto de trabajo).

\subsubsection{Motivación del alumnado}

Su participación también está relacionada con aquello que les motiva. De todas las actividades realizadas en el aula existen algunas que les gustan más que otras. A continuación destacaremos qué prácticas nombra el alumnado cómo aquellas que más les gustan, ya que en estas su motivación es más alta y su rendimiento también. Estas prácticas son: las tertulias; los grupos interactivos y el proyecto de trabajo, aunque sobre el proyecto en los datos aparecen algunas sesiones en las que no están motivados. Por otra parte, el alumnado no nombra las asambleas aunque en los datos sí que aparece su motivación por participar y están, la mayor parte del tiempo, atentos.

Sobre las tertulias, una niña destaca que es la práctica que más le gusta, y de todo el trabajo que realizan en las mismas, la parte del trabajo de investigación en la que tienen que buscar aquellas palabras y expresiones que no entienden, o los temas que no acaban de comprender, es la que más le gusta (Sesión final de trimestre). Otra niña comenta también los grupos interactivos, las tertulias y hacer el proyecto (Sesión final de trimestre). En general, los grupos interactivos son los más nombrados, y contrastando con los datos, durante esta práctica están muy atentos y activos. Ellos se dan cuenta de que cuando están en los grupos interactivos las maestras están más contentas del trabajo que ellos realizan y además, sienten que trabajan más ( $3^{a}$ Asamblea clase de Estefanía). También en el caso de alumnos que tienen más dificultades de aprendizaje se les elogia más y las 
maestras voluntarias mantienen una actitud más positiva hacia ellos, al observarlos más participativos y más centrados en la tarea.

Podemos comprobar también cómo cambia la actitud del alumnado cuando su familia entra en el aula. En el caso de Juan, un niño con dificultades de atención, la entrada de su madre en la clase favorece que esté más atento y más motivado hacia la tarea ( $1^{\mathrm{a}}$ sesión proyecto de trabajo).

Por otra parte, tan solo una niña muestra una actividad que no le gusta, la realización de exámenes. No obstante, aparecen algunas prácticas en las que el alumnado muestra su desmotivación. De todas las sesiones observadas, en las que más se percibió su desmotivación fue en dos principalmente, en la sesión de matemáticas del día 12 de diciembre, en la que normalmente realizaban GI pero ese día por cuestiones organizativas no pudieron hacerlos, y en la sesión del 3 de diciembre ( $3^{\mathrm{a}}$ sesión de proyectos de trabajo), en la que estaban realizando proyectos de trabajo. 


\subsection{Estilo docente de Estefanía}

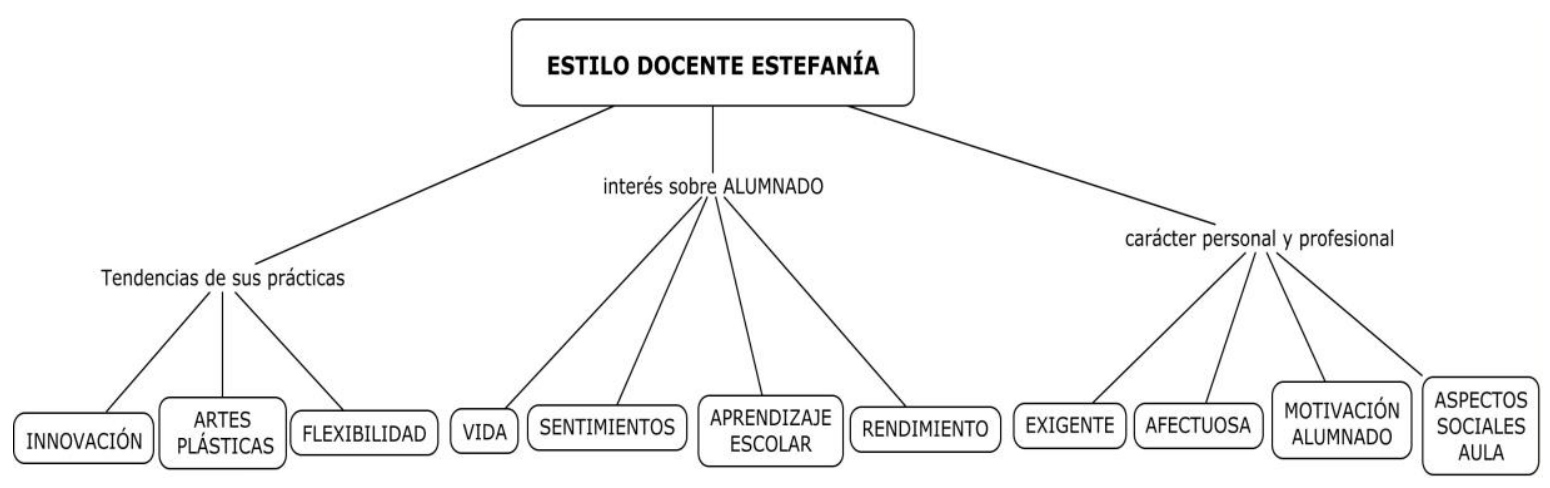

Figura 30. Categorías estilo docente Estefanía.

En esta parte de los resultados nos situamos en la segunda pregunta de investigación. Para tratar de responder al cuarto y el quinto objetivo de la investigación, primero nos detendremos en el estilo docente de Estefanía. Dentro de este apartado, analizaremos los datos en función de si se educa al alumnado para que sepa comportarse, o lo que definiríamos como el saber estar, o si se educa en la faceta más personal y emocional del alumnado relacionada con el ser persona. En esta parte, a partir de los datos, trataremos de comprender mejor como se podría integrar el trabajo personal del alumnado en el aula. En el siguiente apartado, narraremos la historia de vida de Estefanía.

Estefanía es una maestra a la que siempre le ha gustado innovar y probar “cosas nuevas" en el aula (Entrevista a Estefanía). Especialmente le han interesado las artes plásticas, ya que le gusta mucho el teatro y la interpretación. Para Estefanía, realizar en su aula prácticas que le permitieran alejarse del libro de texto era una motivación. Por eso, ella nos explica que el hecho de conocer y probar prácticas distintas le ha ayudado a ir cambiando su estilo docente (Entrevista a Estefanía). 
En su estilo como maestra destaca principalmente su flexibilidad al buscar nuevas maneras de hacer de la técnica una práctica propia. Como por ejemplo, en las tertulias dialógicas, el hecho de decidir con su alumnado nuevas maneras de finalizar el trabajo de la lectura, etc.

Por otra parte, es una maestra a la que le interesa su alumnado, sus vidas, sus sentimientos y su aprendizaje escolar. Es bastante exigente en cuanto a los resultados del alumnado y, aunque sus alumnos tienen un buen rendimiento en clase y en algunas materias incluso mejor que la clase del mismo curso, califica al alumnado con notas bajas, más que las de sus compañeras de ciclo. La mayoría de sus alumnos rozan el aprobado y algunos incluso suspenden algunas asignaturas. No hay demasiados notables y casi ningún sobresaliente (Evaluación final trimestre, clase Estefanía).

$\mathrm{Su}$ interés por el rendimiento del alumnado es el que la ha llevado a implementar grupos interactivos, proyectos de trabajo y tertulias dialógicas en su clase. Es una maestra que se replantea las tareas que realiza el alumnado a diario y plantea actividades que sean motivadoras para ellos y que además, les ayuden a mejorar. Es también una maestra atenta y en algunos casos, adapta sus prácticas a las necesidades que el alumnado tiene en ese momento.

Estefanía: Com veig que esteu una miqueta distrets avui, $i$ no estem avançant res en l'assemblea, anem a repassar un poc el llibre de les nostres tertúlies, per a després començar. Es que vos veig molt nerviosos hui, aleshores anem a fer el teatre ja. Anem a repassar abans el llibre. Qui vol començar a llegir? (1 ${ }^{a}$ Asamblea clase Estefanía).

Por eso mismo, si en algún momento tiene que realizar cambios en el horario, para favorecer el aprendizaje del alumnado, no duda en hacerlo. Siempre que no interfiera en la práctica de otros docentes.

Estefanía: Però a veure, el que hem de tindre clar és que l'horari es pot canviar, mentre no afecte a un especialista. 
Maestra de primer ciclo. Ja ho sé, ja ho sé. Si per exemple tinc valencià esta vesprada m'ho canvie i faig medi i demà puc vindre ací per fer les tertúlies.

Estefanía: A veure, jo el meu horari me'l canvie... llevat dels especialistes. ( $3^{a}$ Reunión de ciclo).

Por otra parte, Estefanía también se preocupa de otras cuestiones más allá de las académicas, como por ejemplo que su alumnado aprenda también aspectos sociales en el aula. De ahí su interés por realizar las asambleas y que pudieran comunicarse sin la necesidad de dinamizarlas ella, sino que el propio alumnado se organizara para hablar y escucharse unos detrás de otros. Pero la realización de las asambleas ha favorecido la entrada de la vida del alumnado en el aula. Desde las asambleas Estefanía conoce mejor a su alumnado, aquello que les preocupa o sus experiencias fuera del aula. En la asamblea Estefanía acompaña al alumnado y trata de ayudarle en aquellos temas que comenta y que están relacionados con su vida fuera del ámbito escolar. Además, la manera de interactuar de Estefanía con su alumnado suele ser bastante afectuosa y ellos se suelen sentir a gusto en la clase.

También, dentro del estilo docente de Estefanía destacamos su carácter emprendedor que en algunos casos lleva a sus compañeras a tratar de implementar mejoras en sus aulas. Como por ejemplo en el caso de su paralela de curso (durante el 2012 - 2013), que también entra en su aula para conocer las tertulias y poder preparar la lectura de un libro juntas.

Dentro de su estilo docente, una de las cuestiones que nos planteamos a partir de los datos es si se educa al alumnado para que sepa comportarse, lo que sería una educación para el estar, o si se educa al alumnado para ser. Es decir, para desarrollar también su dimensión personal. 


\subsection{1. ¿Educar para estar o educar para ser?}

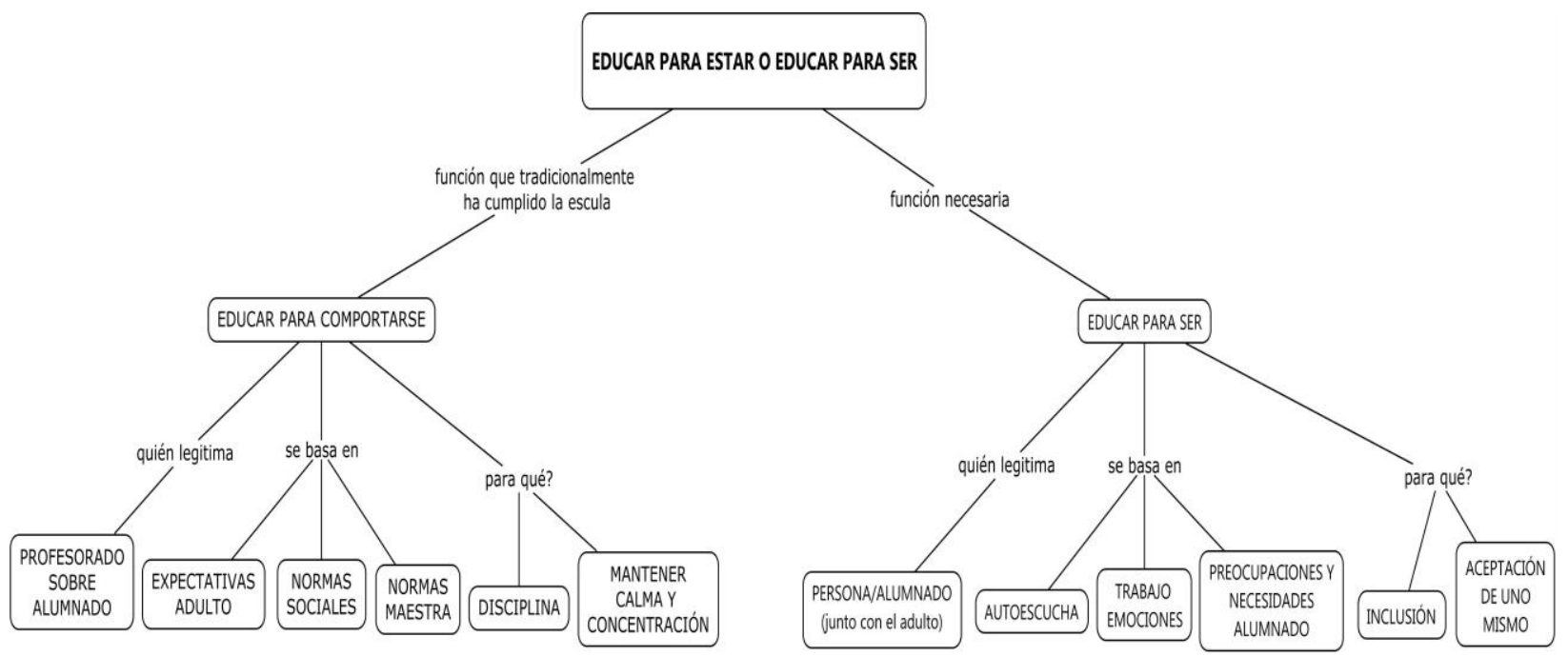

Figura 31. Categorías educar para estar o educar para ser.

Como hemos dicho anteriormente, una de las cuestiones que observamos en el estudio, y en concreto en las prácticas de aula de Estefanía es si se educa al alumnado para que sepa comportarse, o estar, o si se intenta desarrollar una parte más emocional en el alumnado, relacionada con el desarrollo de su ser.

En primer lugar destacamos que se educa al alumnado para que "se comporte". Esto significa que cumpla con las expectativas de los adultos, que sepa mantenerse calmado y centrado; que no se salga de la norma marcada por el adulto, aunque esta haya sido impuesta y quizá no tenga ningún valor para el alumnado. En definitiva, que haga lo que le dice el mayor y "sin rechistar":

Si en algún momento el alumnado no entiende o "no quiere" "portarse bien", puede recibir un castigo. Que tendrá o no relación con la "falta" cometida por el niño/a.

Estefanía. Què vol dir això? Yule, tu ja és la segona vegada que et portes mal, a la tercera no vindràs d'excursió. Has de tindre un càstig i el càstig és que no vindràs. Si un xiquet no sap vindre se queda fins que pense que pot vindre. T'ho pensaràs i quan tu cregues que estàs preparat per a eixir, aleshores podràs vindré. 
Ivana, també és la segona vegada i a la tercera et dic el mateix. Laia, no vindràs $i$ Néstor no vindràs. No sé quina serà, però no vindreu. A mi no m'agradaria arribar a este extrem de que no vingueu quan hi haja una eixida. Però ja veurem ( $7^{a}$ Asamblea clase de Estefanía).

Además, los adultos hemos aprendido que es necesario escuchar al otro y esta disciplina también tratamos de transmitirla a los más pequeños. Todos sabemos que si hablamos todos a la vez no nos entenderemos. Sin embargo, ¿cómo puedo ayudar al alumnado a que se organice en un sistema en el que se puedan comunicar libremente bajo sus normas? Quizás es necesario pasar por un aprendizaje marcado por el tutor, o quizás no... La cuestión es que en las escuelas quien tiene el rol de legitimar lo que toca y lo que no y en el momento y la forma adecuada, suele ser el tutor:

Comença Laia, Estefanía li corregeix en algun moment els temps verbals. Davinia i Sandra estan en el braç alçat. Parlen tots alhora, i Estefanía els recorda que respecten el torn de paraula. Comencen a alçar la mà i Estefanía els diu: no alceu la mà que tots parlareu. Continua Néstor (2 ${ }^{a}$ Asamblea clase Estefanía).

Por otra parte, en la escucha del otro se aprende también a tener paciencia, a respetar las diferencias y a valorar la intervención de los compañeros. Con una educación para el ser, también se fomenta esta parte de escucha activa hacia el otro, pero no deja de lado la autoescucha, que en las escuelas suele ser una olvidada.

También, encontramos dinámicas en las que el alumnado tiene que dialogar e interactuar con sus compañeros, sobre los asuntos que el adulto cree convenientes y en los momentos que el adulto marca para esto. Aunque en las asambleas se deja una puerta abierta a la espontaneidad y a hablar sobre los intereses del estudiantado, igualmente aparecen algunos temas que dejan a la maestra sin palabras. 
Waldo le dice a Estefanía que tiene los ojos muy bonitos, Estefanía se queda un poco descolocada, le da las gracias recordándole que no es lo que "toca”, sino que es momento de estar en el trabajo ( $1^{a}$ Asamblea clase Estefanía).

Por otro lado, si educamos al alumnado para saber estar, se tiene muy en cuenta la disciplina. En este sentido, observamos como la maestra explica algunos matices que ayudan al alumnado a conocer algunas normas de educación. Por ejemplo, que no se tiene que bostezar sin taparse la boca; que al entrar al aula se tiene que llamar a la puerta y preguntar si se puede pasar, etc. Otros valores relacionados con el saber comportarse son aquellos que se tratan de inculcar en general desde la escuela y desde la educación. Por ejemplo, que ayuden a sus familias en las tareas domésticas; etc. Temas así se dialogan en las asambleas, en las que el alumnado expone sus situaciones cotidianas, o las maestras se las preguntan.

Hasta ahora hemos observado en los datos una educación más relacionada con las normas de comportamiento, ¿pero cómo sería una escuela que educa para ser? También basándonos en los datos, rescatamos situaciones que podrían ser una oportunidad para realizar un trabajo emocional con el alumnado. Por ejemplo, podemos observar cómo "duele" aquello que se percibe como "rechazo" a algunos alumnos. En el caso de Yule, cuando observa que a un compañero de su mesa otro compañero distinto le da un papel y a él no, se siente de algún modo rechazado. Pero no sabe cómo gestionar esta emoción. ¿Qué siente rabia o tristeza? ¿Por qué la siente? Estas preguntas que la tutora puede ir trabajando con Yule y con toda la clase son una base para poder hacernos más conscientes de nuestras emociones.

José María s'arrima a la taula de Néstor $i$ li dona un paperet a ell. Yule es queda mirant-ho i li pega a Néstor. Pareix enfadat perquè a ell no li han dit res. (Yule pega a Néstor porque no sabe cómo gestionar la rabia o la tristeza que siente al sentirse separado) ( $4^{a}$ sesión proyectos de trabajo).

En ese momento quizás se necesita de un trabajo comprensivo hacia uno mismo, un camino de autoescucha. En este sentido, no solo estaremos ayudando a un niño sino que estaremos contribuyendo a formar una clase más libre y amorosa. 
No obstante, puede ocurrir que el maestro tampoco sepa qué hacer cuando él, como adulto, se siente así si además, ha sido educado en una educación centrada en las normas de comportamiento, como puede ser la realidad de esta aula. Y quizás por eso mismo, Estefanía le da al botón de avanzar cuando llegan dos canciones tristes del CD de música que están escuchando en clase mientras trabajan.

No obstante, aparecen situaciones que el alumnado puede vivir con tristeza y en estos casos, la maestra les ayuda, dejándoles que se expresen. En el caso de Davinia, es una niña muy expresiva que siente bastante tristeza y preocupación por el divorcio de sus padres. La situación entre ellos no es cordial y la niña se siente en muchos casos con la responsabilidad de "no estropear más las cosas". Por otra parte, la niña que vive con su madre no tiene un hogar físico. No tienen casa y durante el primer trimestre del curso ha pasado por tres viviendas junto con su madre. En primer lugar se alojaban en casa de su abuela materna, pero las discusiones entre su madre y su abuela las llevó a cambiarse de casa. En la segunda de las casas tampoco estuvieron mucho tiempo, según Davinia, ella les molestaba. Por el momento han ido a la casa de otra conocida de su madre y la niña comenta que está a gusto. Sin embargo, la culpa que acarrea Davinia es un aspecto que necesitaría trabajarse. La maestra la ayuda y le dice que no es culpable de la situación que está viviendo, ya que la niña en muchas ocasiones muestra su miedo y también su culpabilidad. El trabajo desde la asamblea es fundamental para dejar este espacio de expresión al alumnado, que lo necesita.

És el torn de Davinia, i abans de començar es gira cap a Estefanía $i$ li diu: açò que te vaig a contar ara no li pots dir a ma mare que t'ho he contat. El dia que vam eixir de classe, açò no li ho pots dir a ma mare que t'ho he contat! -ho diu gesticulant un no en el dit i en el cap-, me vaig mudar. Estefanía assenteix (es queda mirant a la mestra de PT al sentir el que diu Davinia de que no li ho pot dir a sa mare).

Estefanía. A veure, però eixe dia ja t’havies mudat. 
Davinia. Sí, però me vaig tornar a mudar d'eixa casa.

Estefanía. Una altra vegada? Per què?

Davinia. Perquè els molestava. Perquè un dia ma mare li va obligar a dir-li si volia algo pa menjar i després se va enfadar i ens vam tindre que mudar.

Estefanía. I on esteu ara?

Davinia. En el poble del costat.

Estefanía. I com vens tots els dies al cole.

Davinia. En tren.

Estefanía. I de l'estació ací?

Davinia. A peu. (hi ha uns $3 \mathrm{~km}$ des de l'estació fins l'escola $i$ com diu la mestra ella és totes les dies la primera que està a la fila a les 9.00).

Cuando aparecen estas situaciones, las maestras tratan de indagar y de saber si la niña está bien.

Davinia. Només se me cau una gota ja m 'han renyit. I mon pare encara no sap res.

Estefanía. I què passarà quan s'entere?

Davinia. La bronca anirà per a mi.

Estefanía. Per a tu? Per què? Que tu què has fet? Que ta mare decideixca anar-se'n d'una casa no te a veure en tu, crec jo.

Davinia. Ja, però és que després com ma mare no li vol ni parlar ni res a mon pare també perquè s'han divorciat, pues entonces li ho tinc que dir jo tot a ell.

Estefanía. Vale, però Davinia, les coses les pots explicar, que tu ja eres major, com ens ho estàs explicant a nosaltres, que ho estem entenen, i ton pare també és major i també ho entendrà. No té perquè enfadar-se ningú.

Davinia. (Encogiendo los hombros) vale (5a Asamblea clase Estefanía). 
Los maestros en muchas ocasiones son quienes pueden ayudar al alumnado no solo a expresarse, sino también a resituarse en la situación. Pero para ello no es solo importante una reflexión desde la mente, sino un entendimiento desde el corazón. En este caso Estefanía sabe cómo ayudar a que Davinia se sienta mejor y deje de sentirse culpable.

Por otro lado, los complejos del alumnado son otra muestra de sus miedos, normalmente a ser rechazados, a que no les acepten. Por eso, cuando uno se percibe a sí mismo diferente del resto puede pensar que esa diferencia es sinónimo de exclusión y a partir de esa creencia puede iniciar un proceso en el que se separa del resto. Es por esto que pensamos que no es suficiente con trabajar desde la teoría los principios de la diversidad, sino que es necesario vivirlos desde lo humano, desde lo personal.

En este caso, mostramos la actitud de Ivana que un día, al iniciar su intervención en la asamblea porque la maestra se lo pide, lo hace tapándose la cara. Ivana con sus manos está cubriendo una herida que tiene en la nariz y que no quiere que el resto vea. La maestra le pide que se quite las manos de la cara porque se puede hacer daño o infectarse la herida. Pero Ivana no quiere. Finalmente la maestra de PT, se acerca a Ivana y cariñosamente le quita las manos de su cara ( $6^{\mathbf{a}}$ Asamblea clase Estefanía). En esta situación, estamos viendo vergüenza y miedo a la no aprobación. En definitiva estamos viendo una falta de aceptación hacia uno mismo y lo que eso significa, una falta de amor hacia sí mismo.

Existen muchas situaciones que un niño no entiende y no sabe cómo gestionar. También en el caso de Ivana, cuando la maestra le pregunta por su hermano que estuvo unos días ingresado en el hospital, Ivana le responde: El meu germà está muy pesado, al fin y al cabo (6 $6^{\mathbf{a}}$ Asamblea clase Estefanía).

Así como la tristeza, la ira, que quizás en el fondo esconde tristeza, también es una emoción que necesita su espacio en la escuela. En algunas ocasiones en las que 
un alumno no quiere participar porque está enfadado, en esta clase se le invita a que se tranquilice y cuando se le pase, podrá participar.

Por otra parte, vivir la alegría es lo más habitual pero quizás en algunos casos no sabemos cómo exteriorizarla. Como en el siguiente fragmento observamos:

Tant Estefanía com la mestra de PT feliciten a Juan. El xiquet no fa massa cas al principi, però Elia li pregunta si li agrada que el feliciten i ell diu que sí. Les dos mestres li diuen que pot estar content i riure. Ell estava com en ganes de fer un somriure però després el reprimia. A més, li diuen que li ho comente a sa mare perquè s'alegrarà: li has de dir, mamà Estefanía $m$ 'ha felicitat perquè $m$ 'ha dit que estic treballant molt ( $6^{a}$ Asamblea clase Estefanía).

Finalmente, destacamos la importancia de la respiración y de la relajación en las aulas, ya que ayuda al alumnado a centrarse en la tarea y a estar más tranquilo. Ayuda también a conectar con un estado de paz interior. Aunque no tenemos muchas muestras de la realización de estos ejercicios, en algunos casos Estefanía los practicaba en clase cuando notaba al alumnado nervioso y posteriormente, el alumnado emprendía la tarea con más calma y tranquilidad.

Abans d'alçar-se i anar-se'n de l'assemblea Estefanía els diu que estiguen ben asseguts, que tanquen els ulls i que faran tres respiracions. Després dona les indicacions en veu baixa i els diu que poc a poc s'alcen $i$ vagen a la seua cadira. Es nota que estan més tranquils i fan el que ella els diu més tranquil-lament $\left(6^{a}\right.$ Asamblea clase Estefanía).

Estos resultados, sobre si en la escuela se educa al alumnado para saber comportarse o para desarrollarse como un ser humano completo, nos lleva a la subjetividad desde la que educamos en las aulas. Hemos observado cómo en la clase de Estefanía, las emociones se abordan normalmente desde la asamblea. Este hecho, el trabajo emocional del alumnado, también forma parte de lo que sería una educación inclusiva. Pero su manera de abordarlas y de acompañar al alumnado tiene que ver con su manera de vivir su vida y de trabajar sus emociones personalmente. 
A continuación aportamos la historia de vida de Estefanía, como muestra del trabajo biográfico que realizamos con la maestra. El mismo fue una herramienta de autoconocimiento que nos permitió trabajar las emociones. 


\subsection{La historia de vida de Estefanía}

La història d'Estefanía és com la de qualsevol altra persona, i és que com ella sol dir, és una persona molt normal però els pensaments i sentiments la fan ser així, com sols és ella.

Is it getting better, or do you feel the same?

Will it make it easier on you

Now you got someone to blame?

$\mathrm{U} 2$ - One

La infantesa:

"Ací comença la història d'una xiqueta..."

Sóc Estefanía, una mestra d'una escola del meu poble, un poble gran però on tots ens coneixem.

He passat tota la infantesa amb la meua família, però sempre he estat sola. He viscut amb els meus pares $i$ el meu germà, encara que amb ells no he compartit massa temps. Es pot dir que ha sigut una infantesa prou solitària, ja que els meus pares per qüestions de treball no teníem massa temps per a res.

A ma mare no la veia en tot el dia; ella em donava les claus $i$ jo m'encarregava de tot. Amb sis anys me llevava amb el soroll del meu despertador, em feia el desdejuni $i$ em preparava per anar a l'escola. Quan finalitzaven les classes arribava a casa i encara no hi havia ningú. Aleshores era quan m'encarregava de netejar i preparar el sopar, al mateix temps que feia els deures de classe. I "Ai de mi, si no ho feia”, perquè jo era la xica, la que havia de fer-ho tot, no el meu germà; en eixe moment les responsabilitats no eren les mateixes pel fet de ser xic o xica, almenys en ma casa, on la primera masclista sempre ha sigut ma mare. 
Amb el meu germà actualment tinc una relació cordial, només cordial. Però quan érem menuts ell em tenia molta gelosia (vull pensar que ara mateix ja no és tant així), i si alguna nit ens quedàvem a casa sols em feia la vida impossible. Ell és sis anys major que jo i es donava per suposat que quan arribava a casa tornava de treballar $i$, evidentment, era jo la que hauria de fer les feines de la llar, només pel fet de ser la xica. Però aquesta costum va continuar al llarg dels anys, doncs quan jo ja vaig començar estudis universitaris açò va continuar, i aleshores era jo la que arribava a casa ben tard de la universitat, però igualment era jo la que hauria de fer les tasques quotidianes domèstiques. I, novament, "ai de mi si no ho feia”.

Això ha suposat que, forçadament, des de ben menuda he sigut molt responsable en tot. I, per aquest motiu també, es pot dir que vaig haver de madurar molt ràpid. Ma mare no sap el que és seure amb mi i fer els deures o, simplement, manar-me a fer els deures. Tampoc recorde que ella m'haguera acompanyat cap dia a l'escola; açò és l'única cosa que ha reconegut per part seua (de totes les altres coses que a mi em saben greu pel que fa a la meua infantesa, ella no és conscient de cap). Fins fa ben poc estes coses les considerava normals, però ara, tal vegada perquè jo també sóc mare, les considere una part extremadament trista de la meua vida. Un xiquet necessita els seus pares, $i$ jo tinc la certesa de no haver-los tingut al meu costat quan mes falta em feien, a pesar de tindre'ls ben a prop.

Un dels records que tinc més dolents és el fet de tenir la fira al costat de casa $i$ no poder acostar-me. Escoltava eixe soroll característic, veia a les famílies amb els seus fills anar-hi tots els diumenges, mentre jo estava a casa. Les poques vegades que anava era acompanyada de mon pare, però tot i així, quan ara escolte el soroll que fan les atraccions de la fira, em produeix una sensació de tristor. Tenia amb mi als meus pares, però el dia a dia el passava en soledat. 
D’altra banda, guarde molt bon record del món faller. En eixa època, el meu pare era el president d'una falla ${ }^{2} i$ sempre hi havia gent a ma casa. Jo era molt menuda, i per ser la xicoteta de la casa sempre venia gent a saludar-me, a fer-me pessigolles, a alçar-me en braços,... tot això m'agradava molt.

D’aquesta manera van anar passant els anys i per fi vaig arribar a l'època de l'institut.

A l'institut era una persona molt tímida $i$ pensava que passava prou desapercebuda, encara que després em van dir que no era així. De fet, en primer de BUP el xic més popular de l'institut es va fixar en mi. A mi ell també m'agradava, encara que mai se m'haguera passat pel cap poder eixir amb ell. Però la qüestió és que vam acabar eixint junts durant quatre anys, des de primer de BUP fins al meu primer any d'universitat. Pareixiem, m'atreviria a dir, una d'eixes parelles d'adolescents de peli americana...

De tota la meua adolescència el que més recorde és aquella relació. Ell m'agradava molt, estava molt enamorada... al menys això creia jo. Ara puc dir ben fort que aquell xic em tractava malament, doncs era una persona molt possessiva $i$ tota la relació va estar molt marcada per les seues normes.

Els primers anys de BUP no em deixaven eixir per les nits (de fet, vaig poder eixir fins a una hora prudent quan ja estudiava la carrera, a la universitat). Però quan vaig començar a eixir un poc, quedava amb ell els divendres per la nit i els dissabtes ell eixia amb els seus amics; però jo m'havia de quedar a casa, perquè així ho decidia ell. El problema per a mi no és que ell poguera eixir amb els seus amics o no, sinó el fet que jo ho acceptava. Em va absorbir tant, em va dominar tant, em va maltractar tant... que jo feia el que ell me deia.

${ }^{2}$ Falla: es un monumento artístico, satírico y generalmente de grandes dimensiones, en el que aparecen figuras, alrededor de figuras centrales. Estos monumentos se exhiben en la calle durante una semana al año, la semana de las fallas, que finaliza con la "cremà". El día en el que se queman los monumentos que han estado plantados en la calle durante la semana. 
Quan cursava tercer de BUP vaig ser fallera, un somni per a mi fet realitat. Quan aquest xic se va assabentar, se va enfadar moltíssim, doncs això era anar en contra de les seues normes. En eixe temps, me controlava la forma de vestir, les amistats -amics xics no en podia tenir, per suposat-les amigues, $i$ tot el que se li poguera ocórrer. Ara ho pense i sé ben cert que en aquest moment cap persona en faria sentir així, però en aquell moment era una jove totalment dependent $i$ encegada. A més, el fet d'haver-me passat tota la vida tan sola $i$ veure que ara hi havia algú que es fixava en mi, encara que fóra d'eixa manera, em feia sentir viva. D’alguna manera, el fet d'estar amb ell era una oportunitat per eixir de casa $i$ ampliar el meu cercle social.

Quan es va acabar l'any faller, que va ser genial per a mi, una altra falla em va buscar per a que fóra la seua fallera major. Aquest nou canvi va suposar que encara em tractara més malament, si això era possible. Se pot dir que ací va començar el final de la nostra relació....o més bé, el principi d’una nova visió de la vida per a mi, en la que jo era algú per mi mateix. A nivell oral, em va menysprear molt. Em va tractar realment mal.... i jo encara ho vaig aguantar algun temps més. De fet, aquesta relació em va tindre lligada sense estar amb ell encara després d'haver-lo deixat, doncs jo no vaig ser capaç d'entendre el que havia estat passant durant anys. Però, per fi, a la Universitat vaig conèixer a Juanma i és ací quan vaig plantejar-me seriosament la meua relació de parella... i per fi em vaig decidir a deixar-lo jo a ell.

Han passat molts anys d'allò, i encara és un tema que no he acabat de tancar, doncs quan per fi vaig ser valenta i li vaig comentar que volia deixar la relació em va dir una sèrie de coses que em van causar molt de dolor... Em va dir que m'havia enganyat vàries vegades $i$ en més d'una xica. Això, amb la forma en la que em va tractar durant la relació, em va suposar haver d'anar al psicòleg $i$, inclús, al psiquiatra; em van afectar moltíssim les seues paraules. De fet, hui en dia si el veig pel poble, encara tinc sentiments cap a eixa persona. No és amor, per suposat, com el que vaig poder sentir en el seu dia, però alguna cosa sent cap a ell. No sabria 
dir si és ràbia, dolor, rancor,... No sabria dir... tal vegada és una barreja de tots aquests sentiments.

L'any que vaig ser Fallera Major ${ }^{3}$ va ser pèssim. La falla que em va buscar per a exercir aquest càrrec li tenia molt d'afecte a la Fallera Major de l'any anterior $i$ a la meua família $i$ a mi ens feien poc de cas. Durant tot l'any vaig haver de suportar situacions de rebuig per part del president de la Falla i de la Fallera Major de l'any anterior. Per exemple, que aquesta xica es creguera en el dret de posar-se davant de mi en els actes oficials; o que el president es negara a que els meus pares convidaren als músics que venien a arreplegar-me a casa cada vegada que $m$ 'havia de vestir de fallera. I més situacions que ara mateix ni recorde ja. En definitiva, el que va passar és que vaig exercir poc com a Fallera Major en els actes oficials durant aquell any, doncs el president $i$ algunes persones del seu voltant ho van impedir.

La mateixa setmana fallera de l'any 1993 no va ser una setmana gens fàcil $i$ bonica per a mi. Em sentia molt dolguda i ho expressava quan arribava a casa, on no parava de plorar. Un dia, la meua mare se'n va adonar que no estava a gust, $i$ quan em va preguntar el que estava passant li ho vaig contar tot. Els meus pares es van disgustar moltíssim, doncs per a ells eixa setmana també era important $i$ volien que jo m'ho passara d'allò més bé. Tot i així, no va ser tot dolent, doncs la resta de les falleres que formaven la meua cort d'honor em recolzaven $i$ vam fer molt bona relació.

La nit de la Cremà, quan vam acabar de sopar la resta de falleres $i$ jo, vam anar cap a la Falla on estaven tots preparant-se per a la Cremà. Eixa nit és tradició que la Fallera Major encenga la traca que ha de cremar el monument faller, però jo volia donar-los una sorpresa a les falleres de la meua cort $i$ vaig demanar si, per favor, ens podien fer una metja per poder encendre-la totes juntes. Quan va ser el moment, els bombers em van dir que em col-locara sota la falla $i$ des d'allí em vaig dirigir a les falleres per a demanar-los que s'acostaren fins on

\footnotetext{
${ }^{3}$ La fallera Major de una falla, es la persona protagonista de los actos que se realizan esa semana. Es lo que en otras fiestas equivaldría a la reina mayor de las fiestas.
} 
jo estava amb la metja per a totes nosaltres. Tot va ser molt ràpid $i$, abans que pogueren vindre totes, el president va tirar un petard al monument... provocant el que ell volia: que tot se cremara abans que nosaltres pogueren encendre res. A mi em va agafar un atac d'ansietat, doncs jo estava als peus del monument $i$ m'haguera pogut cremar. La sort que vaig tindre és que hi havia molts testimonis presenciant l'acte.

Just a la setmana següent vaig escriure un article d'opinió a un periòdic provincial, denunciant tot allò succeït durant el meu regnat però, sobretot, el que va ocórrer eixa nit. Per la publicació d'aquest article el president i el pare de la Fallera Major de l'any anterior em van denunciar. El juí va durar deu anys $i$, fins $i$ tot, es van plantejar portar el cas al Tribunal de La Haya,....un cas totalment surrealista i fora de lloc. Tots els vaig guanyar.

Per eixe temps, tanmateix, va haver altres aspectes positius en la meua vida. L'any que cursava COU un company em va donar l'oportunitat de formar part d'un grup de teatre que pertanyia a la companyia Visitants, de Vila-Real. Des de la companyia iniciaven als aspirants a actor i actrius per a que, després dels estudis corresponents, pogueren unir-se a la companyia professionalment. En el meu cas, em va ajudar molt tot açò, doncs vaig començar a interpretar (cosa que sempre $m$ 'ha agradat $i$ que actualment he tornat a desenvolupar), però vaig decidir deixar la companyia després d'un temps, donat que el meu desig era estudiar la carrera de Magisteri. Estava convençuda de la meua vocació.

You say one love, one life

When it's one need in the night

One love, we get to share it

Leaves you baby if you don't care for it 
La meua joventut va ser molt bonica. Vaig iniciar els meus estudis de Magisteri a l'escola de Magisteri $i$ allí vaig coincidir amb Juanma...allò va ser “amor a primera vista”.

En realitat, la primera vegada que vam coincidir cara a cara va ser en un gimnàs, anys abans, quan jo m'estava preparant Educació Física per que l'havia suspès. Tots els matins ens trobàvem en el gimnàs i ens miràvem i jo pensava... “Què guapo és, no?” En eixe moment no em plantejava res més amb ell doncs jo estava eixint amb l'altra persona, encara que la relació ja no anara gens bé. Després d'eixe estiu de trobades furtives al gimnàs van passar uns anys en els que si ens trobàvem pel poble no ens quedàvem indiferents, però cadascú seguia amb la seua vida fins que vam arribar a la Universitat.

Juanma estudiava primer de Magisteri d'Educació Física, i jo primer d'Educació Primària. L'escola de Magisteri no era molt gran i tampoc érem massa estudiants, per això era fàcil trobar-nos. Un dia, quan jo anava cap a la parada del bus, ell em va vindre a buscar i em va preguntar: "Eres del meu poble? Vols que te porte?" I, a partir d'eixe moment, vam començar a ser bons amics. Ell sabia que jo estava eixint amb una altra persona, $i$ per això mai va arribar a insinuar-me res, però per a mi el fet de veure com em tractava i com em sentia amb ell, em va fer reaccionar i obrir els ulls. En eixe moment, vaig prendre la decisió de tallar la relació amb l'altre xic. Com he dit abans, després d'aquesta primera relació vaig necessitar ajuda professional per a afrontar tot el que havia viscut amb esta persona. Tot i que no hagués acabat mai sortint amb Juanma, no podia seguir amb una persona que em tractava d'eixa manera.

Entre Juanma i jo l'amistat seguia prenent força, però també era evident que entre els dos havia nascut un fort sentiment d'amor. El dia 1 de juliol de l'any 1994 vam començar oficialment la nostra relació. També va ser un 1 de juliol quan ens vam casar, sis anys després. Ho vam pensar així per què volíem que coincidira 
amb la data d'inici del nostre festeig... Juanma va morir un 7 de juliol. De l'any 2011.

Tornant a la joventut... Un dia que anàvem cap a classe, l'últim any de carrera, Juanma em va comentar que li feia mal el bessó. Vam anar a l'ambulatori $i$ des d'allí ens van fer un volant per a anar al traumatòleg de Vila-Real, d'urgència. Després de tot el mati de proves ens van dir que li havien detectat un tumor maligne. Va ser aquest un dels moments més complicats de la meua vida. Tot va ser molt ràpid, i en qüestió de dies li'l van extirpar. No obstant, va haver de passar per la quimioteràpia, la qual cosa es va allargar durant sis mesos. Cada dues setmanes, una la passava ingressat en La Fe. Durant tot eixe temps jo anava a visitar-lo a l'hospital cada dia. No vaig faltar-ne cap... En tot aquest temps de visites, confidències i d'afiançament d'una relació ja consolidada, Juanma i jo no vam poder estar a soles cap estona. Sempre es quedava amb nosaltres la seua mare. Sembla una tonteria vist ara, però el cas és que tot açò va començar a danyar la relació que tenia amb sa mare, fins eixe moment perfecta.

En aquell moment sa mare em tractava molt bé, però era una persona molt possessiva i sobre protectora amb el seu fill. Jo suposava un perill en aquesta relació marelfill. Un dia, tractant de passar un temps a soles amb Juanma, li vaig comentar que anara tranquil-lament a prendre un cafè $i$ així podríem estar una estona els dos sols. Ella se'n va anar, però em va cridar un moment al passadís. A l'eixir, em vaig trobar amb una xicoteta espenta d'ella i, agafant-me del braç, em va dir que jo allí no pintava res. Aquest va ser el primer incident amb sa mare, encara que davant del fill la seua actitud era totalment diferent. Pel que fa a l'operació del tumor, tot va anar bé, dins de la gravetat, $i$ al finalitzar la quimio $i$ la radioteràpia les revisions periòdiques seguien sent favorables. Un malson per a tots.

Després d'aquest desagradable episodi en les nostres vides, la meua sensació era que sa mare em tenia molt anul.lada. Durant el nostre festeig, va haver alguns desacords o desprecis per la seua part. Un dels que amb més angoixa recorde és el 
moment en el que li vam anunciar que teníem prevista la nostra boda. En ma casa, els meus pares estaven encantats $i$, en canvi, la reacció de sa mare va ser: "Tan prompte? Ni pensar-ho”. Evidentment, açò no va impedir que continuàrem amb els nostres somnis. Un altre despreci per la seua part va ser quan va veure per primera vegada la casa que ens havíem comprat i que anàvem a reformar al nostre gust; evidentment, no li va agradar $i$ així ens ho va manifestar, amb paraules poc afortunades per la seua part. A partir d'ací es podria dir que la nostra relació no era bona, però al menys ens toleràvem; era una relació cordial.

Paral-lelament a la reforma de la nostra futura casa jo em preparava les oposicions. El primer any que em vaig presentar hi havia poques places $i$, per falta de punts d'experiència, em vaig quedar a les portes de tindre plaça. El segon any em vaig preparar moltíssim i vaig traure dos deus (tot un orgull per a mi!), però tampoc vaig traure plaça per qüestions alienes a mi (anem a deixar-ho així). Finalment, al tercer any d'opositar vaig traure la plaça, amb molt bones notes (em costava creure en aquell moment que jo poguera traure eixes notes en una oposició!). Durant els dos anys que vaig treballar d'interina vaig passar per diferents experiències: 15 dies en una escola de Carlet, uns mesos a una escola del Port de Sagunt, i un curs sencer a un poble de la comarca d'Utiel-Requena.

El fet de treballar en aquest poble d'Utiel, em va marcar molt negativament a nivell professional. En primer lloc, perquè era la primera vegada que vivia a soles, lluny de casa, i sense altra companyia que la dels meus apunts de les oposicions. I, en segon lloc, perquè en aquella escola en qüestió, es vivia sota la dictadura de la directora, a l'igual que el poble vivia sota la dictadura del govern municipal. La directora era regidora en l'ajuntament i cosina germana de l'alcaldessa; $i$ una altra mestra i la cap d'estudis també eren regidores. En tot el poble es feia el que deia la alcaldessa, i en l'escola el que deien aquestes tres. La gent del poble els tenia molta temor, i a l'escola ningú parlava per temor a represàlies per part de l'equip directiu. Aquesta situació no podia entendre-la de cap manera $i$, des del primer moment, jo em vaig revelar. 
Quan vaig arribar al poble necessitava una casa per a viure. La directora em va presentar a la seua cosina germana, la qual em va llogar una casa prou confortable. El preu del lloguer de la casa era raonable, encara que hauria d'omplir-me la caldera amb gasolina per a poder passar el gèlid hivern d'aquella zona. Omplir el dipòsit era car, però suposava tindre aigua calenta i calefacció tot el temps que havia d'estar per alli.

A les quinze dies d'estar instal-lada se'm va buidar la caldera perquè hi havia una fuga. Quan ho vaig saber vaig cridar a la propietària, però ella no ho volia arreglar i tampoc deixava que ho arreglara jo passant-li les despeses després. Aquesta situació va suposar un llarg enfrontament amb la propietària, a més de passar una estada en la casa prou desafortunada, doncs el fred allí era insuportable. A mesura que passava el temps, va aparèixer pel poble una altra xica que anava a treballar uns mesos de guarda forestal per la zona $i$ vam decidir compartir la vivenda, pagant el mateix lloguer, doncs aixi m'ho va dir la propietària quan jo vaig llogar primerament la casa. Però després es va retractar $i$ volia que li abonàrem el doble del que havíem acordat. Nosaltres no vam accedir a açò, i vam buscar un altra vivenda pel poble, encara que ningú ens llogava res perquè tots estaven amenaçats que no ho feren. Finalment vam trobar una dona que ens va llogar una casa per a les dos, encara que lluny del poble i en unes condicions prou roïnes. Instal-lades ja en l'altra vivenda, les amenaces cap a les dos per part de diferents persones del poble eren habituals.

A l'escola l'ambient tampoc era molt agradable. A nivell pedagògic l'ensenyament era prou deplorable; era just el contrari del que jo entenia per educació. I no deixaven que cap mestre aplicara la seua pròpia metodologia; era un sistema totalment dictatorial i totalment desfasat. Només tenia bona relació amb una companya, l'educadora, doncs ella parlava en valencià, igual que jo, $i$ açò ens apropava una mica més. Les altres companyes no parlaven aquesta llengua, però tampoc deixaven que nosaltres la parlàrem. La directora ens va prohibir que parlàrem en valencià dins l'escola. Jo no podia amb aquesta 
dictadura, $i$ constantment ho feia saber. Un dia en concret la directora i la cap d'estudis van acudir a la meua aula a amenaçar-me $i$ van tancar la porta en clau per a fer-ho més intimidant.

M'ho vaig passar francament malament fins l'últim dia. L'última setmana de juny, quan tocava desmuntar les classes, li vaig demanar a la meua companya d'Infantil si em podia ajudar a desmuntar-la, doncs jo estava embarassada i no podia fer grans esforços. Ella es va negar... Fins l'últim moment va ser un curs per a oblidar.

Enllaçant tot açò amb l'última dada que he comentat, pel que fa al tema de l'embaràs, he de dir que açò va ser un altre capítol complicat en la meua vida, en la nostra vida. Com que Juanma havia passat per la quimioteràpia, tenir família ens va resultar prou difícil. Tant, que vam haver d'arribar al procés de la fecundació in-vitro, fins que a la cinquena vegada em vaig quedar embarassada. En eixe moment, eixa era la meua gran prioritat. Estava preparant les oposicions, però el meu gran somni era quedar-me embarassada, per davant inclús d'aprovar les oposicions. I clar, cada vegada que un tractament no eixia bé em disgustava moltíssim. Quan per fi em vaig quedar embarassada va ser de bessonada. Un dia fent la migdiada li vaig dir a Juanma que pressentia que alguna cosa no anava bé. Als dos o tres dies teníem la visita amb el ginecòleg $i$, efectivament, un dels fetus havia deixat de respirar. Va ser un colp dur, però recorde perfectament les paraules del ginecòleg al dir-me que deixara d'angoixar-me pel que havia perdut $i$ que lluitara per l'altre que estava en camí. I aixi ho vaig fer.

L'embaràs va anar molt bé fins els 6 mesos. Per eixe temps em vaig posar de part, per la qual cosa vaig tindre que agafar la baixa i quedar-me a casa. Des d'eixe moment fins que va nàixer la xiqueta la mare de Juanma no em va deixar sola, en cap moment. Des de bon matí fins a l'hora de sopar sa mare estava al meu costat; açò em va crear molta ansietat. En eixe moment em podia valdre per mi mateixa, em podia cuidar sola $i$, a més, tenia també a ma mare a prop meu. Però res la feia canviar de parèixer; volia estar amb mi a totes hores per tal de cuidarme. Quan va nàixer la xiqueta la situació, lluny de millorar, es va agreujar més. La 
mare de Juanma ja no cuidava de mi; estava cuidant a la neta totes les hores del dia.

Arribava ben mati a ma casa i no se n'anava fins que no estava a punt d'arribar Juanma, a punt de l'hora de sopar. Durant els primers dies jo ho entenia, donat que era la seua primera neta; després, veient que la situació no canviava en vaig començar a sentir molt malament. Vaig aprimar prou per l'ansietat que em provocava tota la situació. Li ho vaig comentar a Juanma després d'un temps de veure'm així, però com quan ell estava a casa ella ja no hi era, doncs no s'ho acabava de creure i jo em vaig sentir molt sola durant eixos primers mesos de la xiqueta. Per la meua part he de dir que si haguera sabut plantejar-li la situació a sa mare, tal vegada no haguérem arribat tan lluny, però per a mi era molt difícil. Creia que dir-li-ho era faltar-li al respecte, així que m'inventava excuses per no passar tot el dia amb ella i poder eixir sola a passejar amb la xiqueta.

De dilluns a divendres les visites eren diàries, i els caps de setmana havíem de fer la visita al contrari, és a dir, anar en família a sa casa i passar els dies allí. Arribà un dia en què vaig decidir trencar amb açò, però Juanma va continuar sense entendre el motiu.

Arribat aquest punt en aquesta relació insuportable, les coses encara van empitjorar, si és que açò era possible. Després de nàixer la xiqueta vaig tindre una depressió post part prou important, fins al punt d'odiar inclús la casa en la què viviem. No podia suportar estar en aquell lloc, m'ofegava, $i$ va arribar un moment en el que Juanma em va plantejar anar-nos d'allí, i canviar de casa per a viure. A mi em va doldre, perquè, a més de ser una herència dels meus pares, l'haviem construït nosaltres mateixos, era una feina familiar. Finalment, miràrem altres opcions $i$ vam acabar comprant un adossat, on seguisc vivint actualment.

Quan Joana tenia nou mesos vam decidir passar per un altre procés de fecundació. La mare de Juanma em va dir que estàvem bojos perquè la xiqueta 
tenia poc de temps i era massa menuda. Però nosaltres volíem augmentar la família prompte i decidírem que eixe era el moment. Afortunadament, em vaig quedar embarassada d'Óscar de seguida i tot anava perfecte; es va ajuntar l'inici de l'embaràs amb el trasllat de casa, però entre ma mare, Juanma i jo ho vam poder fer tot.

En esta ocasió la mare de Juanma no em va fer gens de cas. Jo havia d'estar en repòs però, així i tot, ajudava en tot el que podia, mentre que ella arribava a ma casa quan tornava Joana de la Llar d'Infants i es quedava tota l'estona amb la xiqueta. No es preocupava de saber com estava jo ni s'oferia per a ajudar en res. Aquesta situació em va tornar a crear ansietat, però ara perillava la vida del fetus que portava dins de mi.

Poc a poc vaig anar cansant-me, física $i$ mentalment, $i$ cada vegada em trobava més abatuda. Una nit em van agafar atacs d'epilèpsia; vaig haver d'estar ingressada $i$, finalment, el diagnòstic va ser ansietat per un fort període d'esgotament psíquic. La mare de Juanma no em va visitar a l'hospital fins l'últim dia que jo romania ingressada. Casualment ho va fer perquè sabia que Joana estaria també allí. Se la volia emportar i jo em vaig negar; necessitava tindre a prop a la meua filla. Ella em va acusar d'estar obsessionada amb la meua pròpia filla. He de reconèixer que la meua negativa de deixar-li a la xiqueta en eixe moment va ser una reacció de ràbia, doncs el fet que no se preocupara pel net que jo portava dins de mi i la vida del qual perillava, va provocar una gran ofensa cap a la meua persona.

Després de tot, arribat el moment va nàixer Óscar. Quan el xiquet tenia dos mesos la meua relació amb la mare de Juanma era molt tirant. Ella seguia venint tots els dies a casa a veure a la xiqueta, però al xiquet no li deia res. Una dia vingué de visita amb la seua germana, tia de Juanma, que vivia fora del nostre poble. En un moment donat jo li vaig passar el xiquet al braç de la germana, doncs aquesta el veia en menys ocasions. La tia de Juanma va aprofitar aquesta situació per a acusar-me de no deixar veure mai el xiquet a la seua àvia i de coses per l'estil. En eixe moment, en què la situació començava a ser realment tensa, va 
arribar Juanma a casa $i$ va poder presenciar l'escena, totalment desafortunada per part d'aquestes dos persones. Jo no acabava d'entendre el fet que al xiquet no li feren el mateix cas que a Joana, ni el fet que no em visitaren a l'hospital quan la seua vida perillava. La mare de Juanma, a açò, em va contestar el que va suposar la fi de la nostra relació: que per la xiqueta ho donaria tot, però pel xiquet no. A partir d'aci tot van ser paraules desafortunades, expressions desagradables $i$ amenaces per la seua part. Jo també vaig aprofitar la situació per a dir-li el que m'havia guardat per a mi durant anys. Finalment, vaig acabar la discussió enviant-les a les dos de ma casa. A Juanma açò no li va semblar massa bé, però les paraules de sa mare li havien afectat considerablement i la seua relació també es va anar gelant, fins que l'últim any de la seua vida Juanma havia tallat completament la relació amb sa mare. Ella anava algunes vegades a veure'l a l'escola on treballava i ell no li negava la paraula, però el ben cert és que la relació era mínima.

Sa mare em culpava del fet que s'haguera trencat la relació amb el fill $i$, per tant, amb la neta. En una ocasió (que encara ara està marcada en la ment de Joana), jo em trobava comprant amb els meus fills $i$ ella $i$ una amiga em van tancar el pas en un passadís del supermercat. Van començar a insultar-me, a dir paraules prou fortes; em vaig dirigir cap a les caixes per a pagar i es van col-locar al meu darrere repetint-me a l'orella eixes paraules. La meua filla estava histèrica de sentir-les $i$ jo vaig aguantar prou tranquil-la fins que vaig arribar a casa $i$ vaig esclatar a plorar amb la meua filla abraçada a mi. Des d'aquell moment, Joana l'anomena "la mala".

Did I disappoint you?

Or leave a bad taste in your mouth?

You act like you never had love

And you want me to go without 
A nivell de parella $i$ a nivell professional ens anava prou bé. Els dos treballàvem al poble, en dos escoles públiques de la localitat. La nostra relació era molt bona i ens sentíem molt feliços amb els fills que haviem tingut. L'única cosa que ens angoixava, i potser a Juanma més que a mi, era la situació amb sa mare, però pel moment les coses estaven així i nosaltres seguíem amb la nostra vida amb tota la normalitat possible.

En abril de l'any 2011 Juanma va anar a la revisió anual pel tumor que havia tingut en el bessó i tot va eixir bé. Ell es trobava una mica cansat, però els resultats de les proves indicaven que tot estava correcte.

Quan vam acabar el curs eixe mateix any, decidírem anar a València el cap de setmana de l'1 de juliol, i així celebrar el nostre aniversari de casament. Vam anar al Circ del Sol $i$, de sobte, Juanma va començar a trobar-se malament. Al dia següent em digué que volia tornar a casa, doncs cada vegada es trobava més cansat. Dinàrem junts abans de tornar a casa... i eixa va ser l'última vegada que ho faríem, doncs al dia següent, diumenge 3 de juliol, Juanma entrava en la UCI, d'on ja no eixiria mai amb vida.

El segon dia d'estar en la UCI em van dir els metges que no hi havia solució a la seua malaltia, que anava a morir en hores o en pocs dies. Ell d'ànim estava bé (com sempre s'havia mostrar des que jo el coneixia), i pensava que seria qüestió d'hores que el baixaren a planta. A les hores de visita sempre entràvem a veure'l el seu germà $i$ jo, tal i com ho va demanar Juanma des del primer moment. També estava el germà amb mi cada vegada que els metges ens parlàvem. El meu cunyat va estar al meu costat en tot moment.

Fins eixe moment Juanma no era conscient que la situació era tan greu, però el dia que va morir, eixa mateixa vesprada -l'última vegada que el vaig veure en vida-, me va demanar que li explicara el que estava passant. Un dels metges no es mostrava a favor que Juanma s'assabentés de la situació, però jo volia dir-li-ho, no volia que morira amb eixe dubte. Abans de fer-ho, li vaig preguntar al metge si 
el fet de donar-li la notícia podia provocar que morira més prompte i em va respondre que no. Juanma tenia un tumor al cor i una vegada aquest li l'oprimira, deixaria de respirar. Quan per fi vaig parlar amb Juanma li vaig dir el que estava passant, encara que disfressant un poc la realitat i la seua gravetat. Va ser l'única vegada que vaig veure plorar el meu home, l'única en tot el temps que havia passat amb ell (17 anys).

I Juanma va morir el 7 de juliol de 2011.

Amb el suport del meu cunyat, vam preparar el millor soterrament per a la millor persona que mai he conegut. Vam decidir deixar les seues cendres en total llibertat; així, una part d'ell està sota la porteria del camp del CD Castelló, el Castàlia, i l'altra part està en alta mar, on Juanma trobava pau interior. Ens van acompanyar molts familiars, amics, coneguts,... Tots volien acomiadar-lo com es mereixia. Va ser un soterrament molt peculiar i diferent, doncs en la seua missa es va escoltar la cançó de U2, One, i es van projectar fotografies de la nostra vida junts. Al finalitzar l'eucaristia vaig convidar a tothom a reunir-nos tots junts $i$ intercanviar els bons records que teniem d'ell. Hi havia moltíssima gent. Sa mare em va criticar molt per esta manera d'actuar (cosa que, d'alguna manera, entenc perfectament), però jo volia fer les coses com a ell li haguera agradat $i$, sobre tot, com es mereixia.

En eixe moment tan dolorós moltíssimes persones em van recolzar, i jo sé que Juanma estaria orgullós de veure com se feren les coses per ell.

Però vaig haver de tornar a casa. Vaig haver de seguir amb la nostra vida amb normalitat. Ara és quan notava el seu buit. Ara i no abans.

Recorde un dia en concret, als pocs dies de la seua mort. Jo em trobava a casa mirant les notícies. Recorde perfectament la notícia: contaven els morts en accidents de circulació que hi havia hagut eixe cap de setmana. I recorde el meu pensament: només prestem atenció a estes dades quan ens afecta personalment. Era tot molt recent; feia pocs dies que m'havia quedat sense la persona amb la que 
volia compartir la meua vida, amb la persona en la que havia compartit 17 anys de la meua vida. Era cruel el fet de poder estar ara amb una persona $i$ en un segon desaparèixer tot pel que havies lluitat. Només t'adones de les coses bones que ens dóna la vida quan pateixes una desgràcia com aquesta.

De moment, et trobes en un pou. Un pou que te va ofegant poc a poc. Però has d'eixir d'aquest pou. Jo ho sabia. Havia d'eixir per mi mateixa. Havia de passar per les fases del dol; em duraria setmanes, mesos, anys,... però eixiria. Anava a lluitar per a que així fóra. Una vegada superades les fases del dol, les quals les vaig superar més apresa del que és normal, vaig començar a viure la vida novament, pels meus fills i també per mi, doncs vida només en tenim una.

Well, it's too late tonight

To drag the past out into the light

We're one, but we're not the same

We get to carry each other

Carry each other... one

"Agafar aire, i respirar"

Al principi, quan va morir, semblava que la meua vida no tenia sentit. Era com si res del que passara estiguera passant en realitat, com si res tinguera a veure amb mi. Un dia, quan encara no feia ni un mes que s'havia mort, vaig anar al cine amb uns amics $i$ amb els meus fills. Estàvem a la cua per a comprar les entrades, quan de sobte em vaig quedar absent, $i$ em va passar la vida a càmera lenta per davant; com quan en una pel-lícula està la persona present però es paralitza el món al seu voltant. Va ser qüestió de segons i quan vaig tornar a reaccionar em vaig parar a analitzar la situació. Veia a tot arreu a persones que estaven gaudint d'un moment d'oci, que es veien feliços i jo dins de mi portava una pena que no em deixava riure. De totes les persones que veia, jo era l'única que no estava rient. I és que no feia ni un més que estava en eixe mateix lloc dinant amb el meu home $i$ proposant-li tenir un altre fill. Al mateix temps que pensava en 
aquestes coses veia als meus fills vivint eixe moment amb naturalitat $i$ va ser en eixe precís instant quan vaig reaccionar $i$ vaig pensar que la vida continua, $i$ que continua per a tots. "Si la vida continua continuaré jo també, millor o pitjor, però seguiré endavant”.

Realment no saps el que tens fins que ho perds. I ja no parle només d'una persona física, com era el meu cas. Parle de la teua pròpia vida. No valorem que la tenim.

Jo no $m$ 'he volgut mai. Mire enrere $i$ veig una infantesa trista, molts problemes personals en la meua joventut i més recentment, a l'edat adulta. Però, així $i$ tot, no he sabut valorar la meua vida, una vida que per a mi ha sigut rö̈na, però que l'he poguda viure. Moltes vegades $m$ 'he donat pena de mi mateixa i no he valorat la vida. Ara em pare a pensar $i$ ho entenc; tinc una vida $i$ he de viure-la, perquè en qüestió de segons se'n va. Viu-la, i viu-la de la millor manera possible! Carpe diem, eixe és el meu lema cada dia.

He tardat anys en entendre-ho així, i ara estic intentant agafar aquesta filosofia de vida. Per aquest motiu, estic en un moment en el que m'apeteix fer moltes activitats. Hi ha gent que açò no ho acaba d'entendre i em diu que m'estic agafant les coses amb molta angoixa, però realment és el que vull fer. Si arriba un dia en el que em lleve i no puc més, deixaré de fer el que siga. Però he decidit fer allò que vull i em dóna igual el que pensen o diguen els altres; faig allò que em naix fer. 
Les circumstàncies són les que et fan veure $i$ viure la vida d'una altra manera. En aquest moment $m$ 'apeteix portar diversos càrrecs a l'escola; també m'apeteix realitzar activitats fora del meu horari laboral. A més, si algun dia m'apeteix eixir amb les meues amigues $i$ deixar els meus fills en companyia d'algú, doncs també ho faig.

Aquesta situació, tanmateix, no em capacita per a dir-li a cap persona com ha de portar a terme la seua vida. Molt probablement el que estic fent ara no ho haguera arribat a fer si les meues circumstàncies no hagueren canviat. La meua vida aniria en línia recta, tal com jo l'havia imaginada. Però eixa vida que jo volia $s$ 'ha vist truncada $i$ ara em trobe cercant el meu cami per un altre costat. Estic cercant-lo, no he arribat encara a trobar-lo, però en aquest procés em trobe còmoda, a gust, en pau.

Ara ja no em lamente per la meua vida, ja no em done llàstima a mi mateixa, doncs sé que jo no sóc la que més ha perdut. Si de vegades plore, no ho faig per mi. Ho faig per Joana i per Óscar, doncs ells s'han quedat sense pare; no han conegut el que és una figura paterna $i$, si ho han conegut, s'han quedat amb ganes de més. Plore per ells, i també per Juanma, doncs ell també s’ha quedat sense poder gaudir del que més volia: els seus fills.

De vegades, mirant com es mouen les branques dels arbres, pense en Juanma. La brisa que les fa moure's no està sentint-la ell. La vida passa, tots podem sentir en la nostra pell eixa brisa; tots, menys ell. Però la vida segueix passant. La meua cosina ha mort recentment, $i$ eixe sentiment, eixa brisa que passa, ho he tornat a experimentar.

Els que estem ací, el xiquet que està jugant a la pilota, la dona que està a la finestra, els que estem, estem sentint eixa brisa. Nosaltres la sentim, ells ja no. On estan? On la senten? Per a mi açò, en aquest moment, és el més dolorós. Tot el que ells ja no senten i també el buit que han deixat.

Des del primer moment que Juanma ens va deixar em vaig quedar sola a casa, amb els meus fills $i$ ells amb mi; però en nostra casa. En cap moment vaig tenir por; tot el contrari, a casa sentia a Juanma més a prop de mi. A vegades tenia la 
sensació que em tocava algú; era una sensació totalment física, i em girava buscant trobar-me amb els seus ulls, però quan mirava no hi havia ningú.

De les sensacions del dia a dia a casa, una de les situacions més doloroses va ser el seure a la taula. El primer dia que ho vam fer després del soterrament es notava massa eixe buit. No vaig dir res, però era una situació difícil per a mi. Óscar, en canvi, $i$ amb la seua innocència característica d'un xiquet de tres anys, $l i$ va proposar a Joana que, com papà ja no estava, es podien seure al seu lloc cada dia un d'ells. Des d'eixe dia, als dinars Joana seu al seu lloc $i$ als sopars seu Óscar. Estes xicotetes coses han fet que em recolze enormement en els meus fills en el dia a dia, i que puga seguir lluitant per tots tres.

Passaven els dies, les setmanes, i la vida continuava per a tots. En agost, de sobte, vaig pensar que havia d'anar de vacances amb els xiquets, com fèiem tots els anys. Així que decidí viatjar a Andorra. Era tot un repte per a mi: el fet de viatjar sola, amb dos xiquets menuts, $i$ un viatge tan llarg, suposava enfrentar-me a tot $i$ demostrar-me a mi mateix que ho podia aconseguir, que no m'anava a rendir. Però les circumstàncies del meu voltant d'alguna manera em paraven o feien que parara forçosament: en Andorra em van destrossar el cotxe en un accident, durant l'hivern següent em van entrar lladres a casa per dues vegades, se van trencar alguns electrodomèstics, les bombetes de casa s'apagaven de sobte,.. presagi d'alguna altra desgràcia material... A més a més, a l'inici del curs em van operar del peu; açò va suposar agafar la baixa laboral durant dos mesos, doncs la meua mobilitat era pràcticament nul.la. Era açò el que em tocava? Em tocava parar eixe ritme frenètic que jo m'havia imposat? Com siga, vaig parar i em va servir per agafar aire, pensar, i continuar cercant eixa pau interior que no arribava.

Poc a poc vaig anar adaptant-me a esta nova realitat $i$ en gener em vaig tornar a incorporar al centre, amb l'esperit fort per a poder seguir endavant. 
Did I ask too much?

More than a lot

You gave me nothing, now it's all I got

"Ho faré per mi, caminaré"

En aquest moment fa un any que Juanma no està $i$ durant aquest temps he tractat d'acomplir totes les seues voluntats. Encara em queden algunes per fer; quan arribe el moment les faré, tal i com a Juanma li haguera agradat.

Enguany Joana serà fallera d'una de les Falles més importants del poble. I ho faig perquè son pare així ho haguera volgut. Fallera de la Falla de son pare, de cap altra.

En relació a la mare de Juanma, els problemes segueixen estan, doncs ella vol seguir veient a la xiqueta, però ja no té al fill per a intentar ensarronar-lo. Em telefona alguna vegada, però no sóc capaç de contestar-li. Va parlar amb el jutge de Pau per aquest motiu, per què vol estar amb la xiqueta (que no amb el xiquet). En aquest moment no puc canviar el que pense, no sóc capaç de perdonar i deixar que estiga amb Joana. Ens va fer molt de mal a tots, inclòs el seu fill, i això tardarà en cicatritzar.

D’altra banda, i com a mare que sóc, no desitge que la mare de Juanma ho passe mal de cap manera, doncs prou de pena ha de tenir per haver perdut un fill. Només espere que algun dia, també com a mare, pense en la situació tan dolorosa en la que ens va fer viure uns mesos abans.

Joana tampoc vol estar amb ella, encara li té temor; així que, com li diu el meu cunyat, el millor que pot fer ara és deixar passar el temps. El pas del temps serà la millor cura per a tot. 
A nivell professional em sent molt afortunada. A l'escola tinc companys $i$ bons amics que m'estan ajudant moltíssim per a poder continuar. M'he volgut involucrar plenament en el procés de transformació del centre $i$, amb açò, estic activant novament la meua vida.

Des de l'inici del procés del canvi, amb les sessions de sensibilització, vaig sentir que aquest és un projecte que dóna frescor a l'escola, dóna aire, ganes de respirar,.. i açò és el que jo necessitava en el meu dia a dia.

Vaig començar a sentir grans expectatives sobre el projecte, $i$ ho traslladava a la meua vida. Com a persona, em va fer pensar en les situacions problemàtiques que cadascun de nosaltres passem al llarg de la nostra vida, doncs és un projecte que apropa plenament a la resta de les persones. Com a docent, les ganes d'aprendre i la preocupació que sentia per a poder formar persones crítiques, la creença en la igualtat d'oportunitats, em van portar a creure que el canvi en l'escola era possible. I jo volia formar part d'aquest canvi.

Aquesta manera d'entendre l'escola la vaig portar a terme a totes les altres facetes de la meua vida, i tot va començar a canviar ràpidament.

Al primer cicle ens vam decidir a treballar algunes de les actuacions que en la sensibilització ens havien explicat. Encara no eren actuacions que la resta del claustre volguera treballar però, així i tot, nosaltres anàvem a intentar-ho.

Començàrem amb el procés de captació de voluntaris amb els familiars dels alumnes del cicle. Però de seguida ens vam trobar en el primer problema: l'aspecte cultural. Seria complicat explicar a les nostres famílies, amb uns interessos i amb unes ideologies diferents, que el que voliem era, precisament, trencar amb eixes diferències, de qualsevol tipus que foren.

Era molt clar el que estava passant: tenien temor a entrar a les aules, a l'escola. Així que vam decidir convidar a les famílies a formar part de les sessions que impartíem. Poc a poc, d'aquesta manera, la participació de les famílies va anar fent-se realitat; i jo em vaig emocionar plenament amb aquesta nova situació. 
A nivell professional em vaig sentir molt realitzada $i$ molt acompanyada. A nivell personal, l'entusiasme que em provocava el canvi que estàvem portant a terme m'ajudava a estar més contenta $i$ a tenir més ganes de fer coses. Vaig acabar sent una de les veus més actives del projecte a l'escola.

Aquest curs ja no estan al centre les companyes de cicle amb les quals vaig començar a somiar. Tanmateix, les ganes d'avançar amb la feina començada fan que no pare de treballar per i amb els meus alumnes.

Pel que fa al centre $i$ a la resta de companys, comence a veure ja major participació $i$ interès pel projecte. També l'equip directiu s'està esforçant per portar-lo endavant.

Encara queda camí per recórrer, doncs no està implicat tot el claustre ni tampoc les actuacions es realitzen correctament; i entenc que és difícil canviar la metodologia d'un centre en poc de temps, però per aquest precís motiu caldrà treballar conjuntament, $i$ ser nosaltres els mestres, els principals agents motivadors del canvi.

A banda de les innovacions portades a terme a l'escola, també $m$ 'he vist molt implicada en donar a conèixer el nostre projecte a altres escoles o a altres centres que així ho han sol-licitat. Estic assistint a diferents seminaris, jornades $i$ xarrades a les quals em conviden per a que explique allò que estem fent al centre $i$ el que faig a la meua classe. Per a mi és un plaer anar a aquests centres i contar-ho, doncs quan et creus el que fas, ho fas a gust $i$ la gent se n'adona. Contagies aquesta emoció que sents.

Poc a poc m'adone que en mi existeix relació entre allò professional $i$ allò personal. És a dir, de la mateixa manera que el projecte m'activa per iniciar aquesta nova etapa de la meua vida, les angoixes que de segur seguiré tenint a nivell emocional també influeixen en la mestra que hi ha en mi.

"Un mestre és un actor en continua representació. Un mestre oblida els seus problemes i s'entrega als seus alumnes. Aquests gaudiran d'aquesta mena 
d'actuació. I aprendran. I seran feliços. El mestre gaudirà ensenyant nous coneixements, aprendrà amb els alumnes. I serà feliç al seu costat”.

You say love is a temple, love, the higher law

Love is a temple, love, the higher law

You ask me to enter, but then you make me crawl

And I can't be holding on to what you got

When all you got is hurt

En las siguientes entrevistas repasaremos cómo se siente Estefanía y cómo nos cuenta su vida del presente, identificaremos el personaje y sentimientos que predominan y llegaremos a su interior para ver dónde está el vacío que ella experimenta y qué le puede devolver al amor incondicional hacia ella misma.

La historia en este caso está narrada a modo de entrevista, con el intento de hacer más entendible el diálogo entre la protagonista y la investigadora. A continuación, la protagonista nos dice cómo vive este proceso de crecimiento:

A nivell professional estic bé, molt motivada $i$ implicada en el projecte del centre. A nivell personal, tanmateix, no estic tan bé com em pensava. El fet d'iniciar aquest procés de treballar la història de vida m'està portant a moments de sofriment. És curiós, però alguns companys del centre, tot i que s'alegraven que la teua tesis es centrara en la meua història de vida i en les meues pràctiques d'aula, ja em van avisar que pot ser trauria qüestions que em farien mal, experiències viscudes que tornarien a ser doloroses a l'hora de reviure-les. Abans d'iniciar aquest treball pensava que em faria bé el fet de parlar amb tu, de contarte la meua vida. Visite al psicòleg una vegada per setmana, i em va bé aquesta teràpia, però pensava que el fet de narrar la meua vida en un altre àmbit i en un projecte com aquest, $m$ 'ajudaria a veure-la d'una altra manera. Tanmateix, amb el treball que estem fent sobre la biografia, amb les converses que tu i jo tenim, tan profundes, me n'adone que tinc un buit enorme en el meu interior, i no només per 
la mort de Juanma; és un buit que no deixa que arribe la felicitat. Mirar dins de mi m'angoixa profundament, doncs descobrisc que hi ha qüestions que creia soterrades però que segueixen ací, sense poder tancar-les, sense deixar passar eixa part de la meua vida. Estic en un procés en el que vaig aprenent a viure d'una altra manera; en aquest procés estic passant per moments d'alegria i pau, però també per moments de conflicte i de lluita interna. Veig que tot forma part d'eixe procés de creixement; d'açò me n'adone ara, a la fi d'aquest treball biogràfic.

A partir de este momento, iniciamos un dialogo hacia el interior de Estefanía. Diálogo en el que las palabras de la protagonista y las de la investigadora acaban llevando a la esencia todo lo que a ambas las mueve por dentro, quizás es esa exigencia y la necesidad de control que comparten y sobre todo, un sentimiento de falta de amor hacia sí mismas. En una conversación entre amigas vemos cómo se va tejiendo una profunda reflexión sobre la vida y un lanzamiento hacia un nuevo despertar.

¿Queréis acompañarnos en este viaje?

One love, one blood, one life

You got to do what you should

"Una Mirada a 1'Interior"

Com et comentava, quan porte una pena dins de mi tracte de deixar-la a un costat per entregar-me als xiquets, però hi ha vegades que em resulta molt difícil. Eixe dilluns vaig arribar al cole sense cap gana d'estar-hi. Em sentia malament, desfeta per dins, i només tenia ganes de tornar a casa, tancar-me i gitar-me.

El conflicte venia des del dissabte al vespre, quan estàvem els tres en la Falla, al casal faller. Joana anava vestida de fallera, després de sopar, va jugar com en qualsevol altre moment. Però eixa dia, enjogassada com estava, va acabar trencant-se el vestit. Ho va fer inconscientment, doncs no deixa de ser una xiqueta, però el meu disgust al veure la destrossa va ser enorme. La vaig castigar $i$ vam 
tornar a casa. Quan vam arribar parlàrem una bona estona sobre el que havia passat. Em vaig emocionar $i$ vaig acabar plorant, doncs li vaig dir que son pare volia eixe vestit per a ella, $i$ jo m'havia esforçat molt per tal d'aconseguir-lo. Aquestes paraules a Joana li van fer mal, i ens vam disgustar les dos. Des d'eixe moment estic malament i necessite el recolzament d'algú.

Al matí següent vaig estar parlant amb un amic que va vindre a casa a intentar consolar-me. També vaig telefonar a ma mare per tal de contar-li-ho, però sabia que ella no m'anava a recolzar. Al veure el vestit li va restar importància. Jo esperava un poc de comprensió per la seua part, una abraçada, unes paraules que em consolaren, però ella em va dir que jo tenia la culpa de tot $i$, en essència, que era una mala mare. Açò em va acabar destrossant.

La veritat és que ella i jo no hem tingut mai una relació cordial de mare i filla, de plena confiança, o de sentir recolzament per part d'ella. Mai m'ha donat una abraçada o un bes. Ni el dia que vaig aprovar les oposicions em va donar l'enhorabona ni molt menys un bes ni una simple felicitació. Res.

En aquest moment ma mare es troba totalment volcada amb Joana i Óscar, sobre tot amb Joana, amb qui es troba molt identificada, doncs les dos van perdre els seus pares a l'edat de cinc anys. Encara que jo no he perdut els meus, el ben cert és que de vegades he sentit que no els tenia a prop, i els necessitava. Els seguisc necessitant. Des que va morir Juanma m'haguera agradat comptar més amb ella, però és evident que no ens comprenem. No para de dir-me que sempre estic enfadada però, lluny de preguntar-me el motiu, no deixa de renyir-me $i$ de desaprovar les decisions que prenc. No accepta el fet que no anàrem a viure a sa casa quan vaig quedar-me vídua. I, per suposat, no li agradarà que jo puga conèixer a cap altre home arribat el moment.

Amb tota aquesta pressió, ha ocorregut un fet vertaderament alarmant. L'altra nit, totalment abatuda per aquesta situació, vaig prendre més pastilles de les que necessitava per a dormir i em vaig quedar inconscient davant l'ordinador. No sé 
quan de temps va passar, però va ser Óscar el que em va despertar. Quan vaig ser conscient del que havia fet vaig telefonar a un amic especial, el qual em va ajudar però, al mateix temps, em va fer veure el problema real del que acaba de passar. Jo creia que ja havia passat tot el pitjor en la meua vida, que ja estava feliç, que començava a tindre una altra vida, eixa que tant busque. Però veig que he tornat a caure. $O$, tal vegada, mai he estat bé. Em sent tan mal amb mi mateixa que jo no sé d'on trauré les forces. No sé si puc continuar fent les coses el millor possible, perquè ja no sé si puc continuar lluitant.

One life with each other

Sisters, brothers

"Relat a dues veus, l'acompanyament"

Anit vaig estar parlant amb un amic, el que sempre està al meu costat per escoltar-me, i ell em deia que és necessari que deixe anar el passat. Però hi ha alguna cosa que no em deixa, sóc jo la que no done el pas. Ho estan notant els meus fills. He estat tant de temps escoltant que havia de ser forta per ells, que havia de lluitar i seguir endavant per ells, que no em preocupe per mi; ningú ho fa. He creat un mur entre nosaltres, sent angoixa, ràbia,... em descarregue ara mateix amb estos sentiments cap a ells. És una de les fases del dol, així m'ho diu el psicòleg, però sé que això no és just per a ningú, i menys per a ells.

Esta persona em va fer veure que la meua vida estava agafant un camí, un camí paral.lel al dels meus fills, però diferent. Ara és hora que comencem a fer eixe camí junts, no puc deixar que la situació seguisca així. Ara és quan me n'adone de la falta que els he pogut fer durant aquest temps, i entenc la necessitat de Joana de cridar la meua atenció, però jo ho interpretava com a que estava trista pel que havia passat amb son pare o pel que passava amb la mare de Juanma; no veia que estava passant poc de temps amb ells, o que el temps que 
passava no l'aprofitava per a ser feliç. Els donava un bes quan es despertaven o quan els replegava de l'escola, però era tot molt mecànic; ara necessite sentir-ho des de l'agraïment $i$ deixar que ixca del meu cor.

Des de hui mateix $m$ 'he proposat canviar les coses. Aquest matí hem estat al llit una bona estona jugant, abraçant-nos $i$ besant-nos. Ja he vist el canvi en les seues caretes (Estefanía).

A mi em sembla molt encertat que veges que la teua relació en els teus fills tal volta no estaves vivint-la com t'agradaria, però pense que potser, això és una conseqüència més d'eixe buit. És a dir, que no veig el buit en una situació externa a tu, sinó que el veig com un sentiment molt profund que està dins teu. Que ara pugues canviar i millorar la relació en els teus fills i que et puga fer sentir millor també és molt important, però si hi ha alguna cosa dins teu segurament et tornarà a eixir. Si no surt en la relació amb els teus fills, doncs d'una altra manera (Investigadora).

És una pena que tinc el fet de veure que els meus fills no són feliços. I és una conseqüència, sí, però l'estic agreujant amb el meu comportament, i si ells no són feliços jo tampoc puc ser-ho (Estefanía).

Quan dius que no pots deixar que aquesta situació segueixi així veig en tu exigència. Com que has d'estar al front sí o sí.

Clar, és que he d'estar-hi, però sense marcar-los tant com feia. He d'estar les 24 hores per ells $i$ això ja ho feia, però ho feia de manera molt mecànica.

Ja, però és que açò que m’estàs dient per a mi també és mecànic. Vull dir que per a mi, el que et fa mal és una part de tu mateixa que ha de viure amb la creença que has de ser la poderosa que ho faça tot. De la mateixa manera que quan et dius que has de fer que els teus fills siguen feliços i que has d'eixir endavant per ells. 
Però no poden ser infeliços per la meua culpa. Tal vegada no seran feliços, cadascú tria la seua vida, però no puc deixar que siguen infeliços perquè no tenen l'amor d'una mare.

És cert, però per poder fer feliços els altres, per poder donar tot eixe amor que ara vols entregar, hauràs de donar-te'l també a tu mateixa. Mentre tu no estigues bé les coses no poden canviar del tot. Sí que pots millorar i estar més a gust quan estàs més temps abraçant-los o quan fas les coses perquè et naix. Però per a mi la qüestió no és que ara "m'ha de nàixer" fer això, sinó per a què? Per a què em vull esforçar tant per ser una bona mare?

Tal volta t'ho estic dient perquè gràcies a tu em veig reflexada i reflexione sobre la meua vida. La teua història resona en mi, tot $\mathrm{i}$ que no hem viscut les mateixes experiències, senc dins meu també una sensació d'ira i de desànim quan les coses no em surten com voldria. Per exemple, quan no faig les coses tan bé, tan perfectes com m'agradaria. En eixa ràbia a voltes me n'adone de que sóc una persona exigent i perfeccionista i això no m'agrada, perquè a voltes em fa també patir. Però d'on me ve eixa por que m'impulsa a ser així? Un dia reflexionant vaig pensar que podia ser por a moltes coses: a no ser acceptada si no feia les coses perfectes, a perdre el control,... Això per a mi només tenia sentit al veure que en el meu interior jo no m'acabava d'acceptar a mi mateixa i que per això no em deixava relaxar-me.

Vaig veure la creença que mantinc sobre que les coses són d'una manera i si se n'ixen dels paràmetres, si no faig el que esperava, doncs em castigue amb pensaments de culpabilitat.

L'adonar-me d'eixa ràbia cap a mi mateixa em va fer sentir una descàrrega, $\mathrm{i}$ el pensar que eixe perfeccionisme que em portava a sentiments de culpabilitat venia per una falta d'acceptació cap a mi mateixa, em va apropar a una espècie d'alliberament interior.

No ho sé, t'ho volia contar perquè les persones que som així en el fons és una falta d'estima cap a nosaltres. No sé si tu... 
T'estic escoltant $i$ pense que em passa el mateix però, una vegada ho reconeixes, què fas?

Doncs no ho sé, supose que seguir treballant i perdonar-nos per tractar-nos així a nosaltres mateixa. Crec que la solució a tot està dins de cadascú de nosaltres. Està clar que podem tindre alts i baixos, però la felicitat plena de ser cada dia feliç jo crec que sí que existeix i crec que es pot aconseguir; no pense que siga una utopia, sinó un camí, un present. (Ahora, años después de aquella entrevista sé lo que significa la felicidad para mí, significa vivir la vida, con mis alegrías y mis miedos, dándome cuenta de que respiro en cada instante y tengo la oportunidad de reinventarme).

No ho sé...no ho tinc clar. Veig que ara em puc preparar per a perdonar-me $i$ així poder ser feliç. Però ho veig ara, que tinc persones al voltant que m'ajudeu a veure-ho. Estic preparada per ser feliç perquè me n'adone que abans no ho era, sempre em faltava alguna cosa; ara veig que el següent pas per aconseguir-ho és saber perdonar-me. Però ara mateix pense que estic en lluita. Vull canviar la meua manera de pensar i de veure les coses, però com que no sé com fer-ho, estic mal. No veig les coses clares.

Eixe estar mal pot ser siga el que et va a permetre créixer, encara que el creixement o l'autodescobriment és un camí constant. No crec que siga que ara et fiques a treballar-te interiorment $i$ en un any estigues perfecta. Jo crec que és com un treball de neteja, per a mi es tracta d'anar perdonant totes aquelles coses que ens han fet mal, o parant atenció a tot allò que estava allí dins de nosaltres i no ens havíem parat a mirar.

Per a mi, ara el més important és canviar la relació amb els meus fills. Tal volta és com dius i això que jo crec que és el més important no és la raó de tot el que m'està passant, però pense que m'ajudarà.

De què tens por? De què creus que pots tindre por? 
Por? Crec que tinc por a tornar a... fracassar; no, fracassar no seria la paraula correcta. Tinc por a que la vida em torne a donar l'espatlla. Estic molt saturada de tot. Són tantes coses que la felicitat me dura dos setmanes, a la tercera ja m'ha passat alguna cosa. Tots tenim problemes, però en el meu cas fa molt de temps que no tinc un període de felicitat plena.

Tinc por al fracàs una altra vegada. En el fons crec que és així. Mire la meua vida $i$ veig una infantesa $i$ una adolescència trista, després ve la situació de Juanma, $i$ veig que predominen més els aspectes negatius que els positius en el meu passat. No vull dir que la meua vida ha sigut un fracàs, però sí que ha sigut trista $i$ solitària.

Seria una por a la soledat?

Pot ser. Però no es tant a una soledat física, doncs em sent envoltada per molts amics $i$ tots ells em recolzen vertaderament. Tanmateix, em continue trobant i sentint sola. Per més gent que tinc al meu costat, més sola sembla que estic. I eixe sentiment de soledat interior és el que em dona por.

T'has de voler. Igual que vols als teus fills i a la gent que t'envolta, t'has de voler a tu. Perquè ells te volen com tu eres, i tu eres la primera que no t'acabes de voler com eres. Tot el que has fet fins ara està bé, és el que havies de fer, i ara és el moment en el que t'has adonat que vols començar a fer les coses d'una altra manera. No perquè estigueren mal, sinó perquè per a la teua felicitat d'ara necessites fer-les d'una altra manera. Acceptant que el que has fet està bé per a eixe moment. I te pots perdonar per tot, i pots estar tranquil.la.

Sembla tan fàcil ara que ho dius!

Pot ser és molt difícil, però tu ho vas a trobar molt fàcil, perquè el més difícil ja ho has fet. El més difícil és portar la vida que portem, així en sofriment. Portar la vida de la felicitat ha de ser molt més fàcil.

Crec que ara no podria fer-ho, hi ha situacions que no sé si estic preparada per a perdonar. 
Bé, eixe camí de perdonar i estimar-nos crec que es fa descobrint-se i atrevintse a mirar en el nostre interior, les nostres creences. Crec que quan estàs disposat a fer-ho vas obrint els ulls i tot va arribant.

Obrir els ulls estic obrint-los; en cas contrari no em plantejaria tantes coses. Tal vegada la solució és perdonar-me, o saber acceptar-me. O les dos coses. Pense que estic en el camí de fer-ho. Encara queda camí, doncs estan afectades diferents facetes de la meua vida. Necessite canviar la relació amb ma mare, i saber perdonar-la a ella. No crec que açò em resulte fàcil.

Però estàs en el camí.

La veritat és que me fa profit parlar de tot açò. És dolorós obrir els ulls $i$ veure des d'una altra perspectiva la teua vida passada, la present, i voler construir un futur des del canvi, sempre per a millorar el que creus que no has fet bé.

Quan vam començar a treballar la meua història de vida alguns companys que m'estimen em van assegurar que tot açò em faria mal. Jo pensava que pot ser em faria mal pel fet de parlar de Juanma, però me n'adone que no és això el que m'està afectant o el que està canviant. És...

Sí, el meu cor. Ja m’has entès. (Expressió amb les mans dirigida al cor).

One life, but we're not the same

We get to carry each other

Carry each other

One, one 
"I la meua vida continua"

Vols que continuem amb la història de vida?

Com tu vulgues. En aquest moment estic eufòrica $i$ molt feliç perquè està canviant la relació amb els meus fills i veig que en ells també s'estan produint molts canvis! No me puc creure com està arribant a canviar Joana: està molt més responsable, en casa ho fa tot de seguida, no discutim, em fa cas i fa més del que li demane. Estic encantada.

Pel que fa a ma mare, he tractat d'aproximar-me a ella. L'altre dia els hi vaig portar berenar $i$, sense esperar cap tipus d'agraïment, igualment em vaig sentir bé pel fet d'apropar-me a ells amb aquest gest.

I sobre el treball interior, com ho portes?

La veritat és que com ara tot va bé només puc dir que el que faig és analitzarme, analitzar les situacions i pensar que sóc capaç de fer les coses que em preocupen.

Estic esperant que arribe alguna situació fora de l'habitual per a veure com reaccione, si sóc capaç de donar una altra resposta o si torne a ofegar-me. M'agradaria afrontar-la de manera més positiva i arribar a pensar: "Estefanía, para, respira; açò està ací per a superar-ho, no per a bloquejar-te”.

El fet d'apropar-me l'altre dia als meus pares, a ma mare, sense esperar res a canvi, i sentir-me tan bé amb mi mateixa, és un pas molt gran el que ja comence a donar. Crec que ací radica una gran veritat, el fer les coses de cor sense esperar res a canvi. Això és l'essència, encara que arribar-hi no és gens fàcil. Per això, si em preguntes com estic, doncs estic molt bé! Perquè no sé si estic fent les coses bé o malament, però estic molt tranquil-la en totes les accions que he pres en aquests últims dies. Estic fent allò que m'ix del cor. Fa dues setmanes no haguera sigut capaç de fer-ho.

Doncs sí que hi ha canvi. No només en aquests tipus d'accions sinó en com les veus. M'ha agradat molt la teua afirmació "no sé si estic fent les coses bé o 
malament, però em sent bé fent-les". Per a mi això és un canvi d'actitud també pel que fa al perfeccionisme. Ja no t'importa tant que les coses hagen de ser d'una manera i que siguen correctes així; tampoc t'importa tant equivocar-te, les fas com tu creus i ja està.

Sí, però m'estic adonant ara, en això no $m$ 'havia assabentat. En la meua vida han coincidit una sèrie de fets, $i$ d'ells he d'aprendre alguna cosa, com el fet que heu arribat fins a mi moltes persones que m'esteu ajudant a obrir els ulls, $i$ tots alhora. No pot ser casualitat, és una conjunció de fets i de persones que heu arribat per algun motiu.

I ara, de la vida esperes coses bones? Sense tindre expectatives, sense tindre por de dir “No sé què m’espera en el futur però sé que vaig a estar bé”.

Tots voldríem coses bones, però no saps el que et pot passar demà ni ací a dos minuts. No espere coses bones, espere que tot passe. Coses bones! Jo espere actuar sentint-me a gust, eixe és el meu objectiu, actuar,... actuar sentint-me a gust. I fent sentir a gust a la gent que m'envolta: els meus fills, la mena família, els meus amics; en eixe ordre, eixes són les prioritats en la meua vida.

Coses bones? Espere que les coses passen, que passen simplement. I jo m'esforçaré per a actuar de manera que eixes coses no em perjudiquen. A mi, als meus fills, a la meua família, als meus amics. Jo la primera, doncs si jo no estic bé, aquest fet podrà afectar a totes les persones que van darrere de mi. He d'estar bé amb mi mateixa; la primera, això és el que estic aprenent ara. Després cadascú té la seua vida en paral-lel, clar, però pel que a mi respecta intentaré actuar de la millor manera possible per a que tots estiguem bé. Coses bones,... no ho definiria així.

Estefanía, estàs dient un fum de coses que...

T'he dit que hui estava positiva. 
Ja, però per a dir això ho has de sentir. Vull dir... jo sí que veig canvis en tu. És veritat el que dius, que estàs en un procés, però ja no estàs en eixe procés en por. Estàs en eixe procés en ganes de viure'l.

Això no m'ha faltat mai. Però, tot i que sempre he tingut ganes de viure, certes coses de la meua vida m'havien bloquejat. Tenia un mur al davant $i$ no veia més enllà. Les persones que en aquest moment esteu al meu voltant $m$ 'heu ajudat a trencar-lo i he avançat un pas, ara em queda tota la resta. I això, metafòricament, és tota la història de la meua vida.

Bé, les persones que estem ací no hem obert els teus ulls, això ho has fet tu. I nosaltres, a través teu també hem pogut aprendre altres coses nostres. En el meu cas tu m'has ajudat a mi. Per a nosaltres estar ací també té un sentit; per a mi, estar ací amb tu té molt de sentit. I l'objectiu de les dos crec que és el mateix, el d'estar bé en tu mateixa i aconseguir més pau interior.

Clar. Ara que parles de pau, pau en el meu interior, saps el que vaig fer l'altre dia inconscientment? Vingué una fotògrafa a casa a ensenyar-me les fotos de tot l'any faller de Joana, i em digué: "Han vingut a la tenda les dos àvies de la xiqueta, ta mare i la teua sogra”. "És la mare de Juanma, la meua sogra no”. Això encara no puc... Tornant al tema, em digué que les dos li havien demanat còpies de les fotos de la xiqueta i que necessitava el meu consentiment per a donar-los eixes còpies. En un altre moment de la meua vida la meua resposta haguera sigut un “No, no done el meu consentiment per a eixes dos persones", però, parant-me a analitzar açò, quin problema trobe realment? Cap, realment no hi ha problema, el problema el crearia jo al negar-me.

No estic preparada per a perdonar-la, però sí que veig que hi ha un canvi. En aquests moments estic en procés de canvi, i eixe canvi també afecta a la relació amb ella. D’altra banda, també ella està veient $i$ valorant coses meues. Per exemple, l'altre dia va parlar amb ma tia i esta li va dir que estic fent moltes coses per complir amb la voluntat del seu fill. Ella no ho sabia i ara ho està valorant. Tal vegada per a perdonar-la necessite que ens perdonem les dos. 
La meua actitud ara mateix va en positiu, però encara no estic preparada per a perdonar-la, no puc fer-ho. He començat ara a obrir els ulls i seria una hipocresia per la meua part dir que tot va perfecte.

Però està anant molt bé.

Sí, però encara queda camí.

Bé, a tots. Tota la vida.

Tota la vida... doncs això.

Pense que quan una persona està bé interiorment és quan està en coherència amb ella mateixa, fa el que pensa que ha de fer i es sent bé fent-ho.

Eixe equilibri és el que tots hauríem d'aprendre a trobar. I això és difícil. Necessitem ajuda per a aconseguir-ho. Jo no haguera pogut si no haguéreu estat ací per a ajudar-me.

O tal vegada si et passa alguna cosa en la vida que et fa canviar.

Però encara que et passe alguna cosa en la vida, com a mi, sempre te fa falta algú que te diga les coses pel seu nom. Ara, després d'aquestes ajudes, estic aprenent a viure en pau interior, i a saber-me perdonar. Aquests són pensaments sans $i$ així és com vull continuar... I com sempre t'he dit: tornarà a eixir el Sol. 


\section{Testimonio de Estefanía tres años después de las entrevistas:}

I la vida continua. Tot ha canviat, però el temps no ha deixat d'avançar. Lentament de vegades, $i$ altres massa ràpid.

En aquest moment ja no necessite mirar cap arrere per a veure la meua vida passar. No té cap sentit. Ara mire el present. Visc el present. Doncs el present és el que ens queda a tots; el hui, el ara després. Veure cada dia la careta de Joana $i$ d'Óscar, raonar amb ells per a decidir el que anem a fer “ara després”, els tres junts; aprofitaré aquest temps que ens queda als tres d'estar junts, doncs el temps passa massa ràpid per a mi en aquest sentit, $i$ ells prompte tindran altres reflexions per ells mateixos, altres expectatives, altres desitjos. I jo ho entendré, perquè eixe serà el seu temps.

Però quan açò arribe, jo també hauré seguit avançant en el temps, com faig ara mateix, cada dia. I això serà el futur. I del futur no parle. Per què vull viure el present. I en el present estic. Feliç. Feliç en el present.

El passat queda lluny. El present està ací, hui, ara... Està ací per a fer-nos la vida fàcil. I serà fàcil si nosaltres volem que ho siga. Açò és el que he aprés del passat. Jo vull un present fàcil, sense rancúnies, sense dubtes, sense penes,... I només ho aconseguiré si sóc jo la que ho desitja. I vull. I ho estic aconseguint. Tinc el present que vull.

El futur? El futur està per vindre. Per a què pensar en un futur incert?

Des d'aci vull agrair a la persona que ha fet possible que hui en dia pense d'aquesta manera. Eixa persona em va ajudar en molts aspectes de la meua vida, $i$ mai tindré prou paraules per a donar-li les gràcies. Amb ella he compartit moments dolorosos que, ara ho veig clarament, eren necessaris per a seguir avançant. Les dos ho hem fet. Hem avançat juntes, $i$ cadascuna ara té el seu camí en la vida. Espere i desitje que eixos camins algun dia es tornen a creuar. Te vull Paula.

Estefanía. 


\section{Discusiones}

Lo amenazado por el olvido sale a flote en la memoria más despierta y minuciosa que nunca hayamos conocido; el pasado en todas sus formas, el inmediato y aquellos tiempos remotos que las épocas de madurez ni sospechaban, son el pasto de la atención del hombre de hoy. (María Zambrano, 1973, p. 183)

Este capítulo está dividido en tres partes. En la primera, las conclusiones, destacamos los principales aspectos relacionadas con el cambio en el centro, las prácticas de aula y el trabajo personal del profesorado. A continuación, basándonos en referentes de la literatura y en algunos de los autores nombrados en el marco teórico, realizamos las discusiones. En primer lugar, examinaremos distintos aspectos relacionados con el cambio educativo. Nos detendremos en la dificultad que encuentran las instituciones educativas para cambiar cuando el cambio en lugar de ser un proceso reflexivo se basa en la adopción de una serie de estrategias. Por otra parte, hablaremos sobre la fuerza de las creencias y las concepciones pedagógicas como una parte fundamental para que las transformaciones escolares lleguen a realizarse.

En segundo lugar, analizaremos las prácticas de aula, en concreto aquellos aspectos que determinan que una práctica sea o no inclusiva. Por otra parte, nos 
detendremos en el informe de Delors, para entrar en una vertiente más profunda de la educación, centrada en el aprender a ser.

En el tercer apartado, hablaremos sobre la historia de vida de Estefanía y la potencialidad que vemos en ella basándonos en la importancia de realizar un trabajo personal con el profesorado.

El capítulo finaliza con un apartado dedicado a las limitaciones, aportaciones del estudio y futuras líneas de investigación. 


\section{Conclusiones...}

Hemos resumido las principales conclusiones de este trabajo en seis ideas. A partir de estas, realizamos un repaso sobre los cambios en el centro, las prácticas de aula, la importancia de las emociones y la necesidad de realizar un trabajo personal por parte del profesorado, para trabajar estos temas.

Estas ideas son las siguientes:

1. No es suficiente implicarnos y realizar cambios, sino que el cambio tiene que ser sentido y coincidir con los valores del modelo al que pretendemos acercarnos.

La primera conclusión que destacamos es que los cambios educativos para ser reales tienen que ser sentidos por sus gentes. Con esto nos referimos a que no es suficiente implicarse en los cambios educativos del centro, sino que además tenemos que creer en ellos para que las actuaciones realizadas coincidan, o se aproximen, a los valores del modelo educativo que perseguimos.

Basándonos en los datos, nos referimos a que hay docentes que participan en las comisiones mixtas e incluso realizan cambios en sus aulas, pero al mismo tiempo expresan sus bajas expectativas hacia el alumnado y sus prejuicios hacia las familias. En estos casos, aunque estos maestros realizan acciones coincidentes con el modelo educativo intercultural inclusivo, sus creencias, que están presentes en sus prácticas y en la manera de relacionarse con otros agentes, no coinciden con un modelo que apuesta por la equidad. Por tanto, no pueden aportar respuestas interculturales e inclusivas. 
2. Los mayores cambios observados en el centro se realizan desde las altas expectativas.

Con esta conclusión nos referimos a que los valores de la interculturalidad y la inclusión, han estado presentes a lo largo del estudio, en todas aquellas relaciones, acciones y situaciones, en las que las personas implicadas creían en el modelo educativo intercultural inclusivo y en sus valores.

Por ejemplo, destacamos la participación de las familias en las comisiones, en las prácticas de aula y en el consejo social, como acciones favorecedoras de un modelo intercultural inclusivo. Las familias que se implicaron lo hicieron porque empezaron a confiar en el profesorado y a creer que su participación podía ayudar a todo el alumnado. Así mismo, manifestaron su cambio de actitud en relación al centro y redefinieron su posicionamiento en él. La escuela empezó a ser importante para estas familias.

Además, destacamos el caso de una madre con pocos recursos que contrató a una persona durante unas horas, para que pudiera cuidar de su hija de dos años y así ella, poder asistir como voluntaria al centro para ayudar a otros niños. En este sentido, valores como la solidaridad se pusieron de manifiesto, y el ejemplo de esta madre fue muy valorado tanto por una parte del profesorado, como por una parte de las familias.

También la ayuda del profesorado en la realización del taller para las familias, para aprender el idioma español, y la predisposición de algunos docentes a que entraran las familias en el centro y en las aulas, fueron acciones que impulsaron aquellos docentes que creían en la necesidad de una escuela intercultural e inclusiva y que conllevaron cambios importantes.

Cabe señalar también, la participación activa del alumnado en las comisiones de las que formaba parte y del consejo social. Posibilitar espacios en los que se escuchara su voz, dotó de sentido al cambio educativo. 
3. Realizar prácticas definidas por la literatura como inclusivas, no determina que lo sean.

Como hemos visto en los resultados, es la manera en la que se realiza la práctica, en su complejidad, y no la técnica en sí, la que nos acerca hacia un modelo intercultural inclusivo, o por el contrario, hacia prácticas exclusoras.

En este sentido, a nivel de centro, el seminario de formación fue un espacio que posibilitó la colaboración docente y la reflexión compartida sobre cuestiones pedagógicas. Sin embargo, aunque algunos docentes "probaron" algunas de las técnicas presentadas en el seminario, no creían en ellas y por eso, a la hora de realizarlas no favorecían la participación de todo el alumnado.

Por otra parte, también destacamos la práctica de los proyectos de trabajo en la clase de Estefanía. Aunque los proyectos, facilitan la participación de todos y respetan la diversidad de ritmos, no en todas las sesiones se favorecieron estos aspectos, por el modo en el que se realizó la práctica por parte de la maestra.

Por el contrario, en el caso de prácticas que por su estructura puede que no faciliten la atención a la diversidad, como las tertulias, la puesta en práctica de Estefanía la favoreció.

4. La realización de las asambleas en la clase de Estefanía ha sido fundamental para acercarnos a una educación más centrada en el ser.

El espacio de las asambleas en esta clase ha facilitado la expresión de temas que no se mencionaban en otras prácticas. Ha permitido acercarnos a las emociones de algunos alumnos y conocerles mejor.

Por ejemplo, en el caso de Davinia, le ha permitido compartir una situación que le provocaba angustia y tristeza. El hecho de expresarla y que Estefanía le aconsejara, le ayudó a estar más tranquila y a sentir "menos culpa" por la situación. Del mismo modo, para Estefanía también fue positivo conocer qué le pasaba a la niña y comprender mejor el motivo por el que se sentía así. 
5. El alumnado que ha trabajado las emociones en su aula expresa que este trabajo es muy importante para ellos y les ayuda a sentirse mejor en clase.

El alumnado de tercer ciclo nos sitúa en un tipo de educación más comprometida con las emociones. Aunque en el grupo de discusión en el que realizan esta afirmación no se les preguntaba por este trabajo en concreto, sino que se les pedía que dijeran qué prácticas del aula les habían gustado más, ellos expresaron que el trabajo emocional. Se trataba de alumnos que durante todo un trimestre y por iniciativa de las maestras (antes de iniciar el seminario de formación), habían realizado grupos interactivos y tertulias dialógicas. Sin embargo, aquello que valoraban era precisamente sentirse bien y queridos en clase. Era un aula con muchos problemas de convivencia, pero que durante ese curso, gracias al trabajo realizado por esa maestra, funcionó mejor.

El alumnado expresó que el trabajo emocional les ayudó a relacionarse de una manera más dialogante con sus compañeros, a discutir menos y a llevarse mejor los unos con los otros. Del mismo modo, destacaron que aquello que menos les gustaba de su clase era cuando en ocasiones, entre compañeros, se faltaban al respeto.

6. Un maestro no entra en el aula, únicamente, desde su rol como docente, sino como persona.

Es precisamente en esta parte en la que también tiene sentido el trabajo personal del profesorado. Por eso nos planteamos que para trabajar con el alumnado el "aprender a ser", es necesario que el profesorado también realice un trabajo interior consigo mismo.

Pensamos que las bajas expectativas o los prejuicios hacia el alumnado o hacia las familias, no son una cuestión puramente profesional, en caso de serlo, sería más fácil transformar esta visión. De hecho, algunos docentes expresaban en las entrevistas una visión más cercana al modelo intercultural inclusivo, sin embargo, era en las prácticas de aula, en las reuniones y en las sesiones del seminario, en las que aparecían los prejuicios y las bajas expectativas. 
Pensamos que estas creencias tienen que ver con los valores personales y con las experiencias vitales. Es por esto que afirmamos que un docente que no haya realizado un trabajo interior sobre sus emociones, difícilmente podrá ayudar a su alumnado a gestionarlas.

En nuestro estudio, conocer y trabajar la historia de vida de Estefanía nos acercó a sus emociones, a su manera de sentir y vivir la vida, que en muchos casos estaba conectada con su manera de ser maestra y con aquello que esperaba de su alumnado.

\subsection{El cambio educativo: más allá del rol docente}

Para empezar, contrastaremos nuestros resultados con la teoría del cambio educativo. Basándonos en Fullan (2002), encontramos que realmente aunque se dispone de cantidad de estrategias y recursos como en el caso de esta escuela, se produce muy poco cambio en educación. El cambio educativo orientado hacia la mejora escolar, desde sus orígenes ha sido planteado como un cambio en las formas, en la estructura e inclusive en las prácticas, pero no se ha visto como un cambio en las concepciones pedagógicas y en las creencias de quienes participaban del mismo; y es precisamente en este aspecto, en el que encontramos las dificultades en nuestro caso, para que el cambio sea real.

Cabe destacar que, los cambios que se realizaban a principios y mediados del siglo $\mathrm{XX}$, no eran los mismos que las innovaciones realizadas en las últimas décadas. Actualmente, los cambios miran hacia un modelo educativo de igualdad. 
Son cambios orientados hacia una mejora educativa, pero desde referentes sociales (Traver, Sales y Moliner, 2010). Por eso, muchas escuelas tratan de transformarse hacia prácticas y maneras de construirse como escuela y como institución, que tengan en cuenta la diversidad y la interculturalidad. Pero, para llevar a cabo estos cambios, es necesario tener en cuenta las creencias del profesorado.

Como hemos dicho en el marco teórico, Domingo (2001); Carreres y Arnáiz (2010), muestran el tema de las creencias y las actitudes como un pilar básico a trabajar para poder acercarnos a la interculturalidad y la inclusión. También GilJaurena (2012, p. 106), sitúa a la práctica educativa como fruto de los pensamientos y creencias del profesorado y Fernández Batanero (2013) explica que el éxito de poner en marcha cualquier política educativa sobre atención a la diversidad depende de muchos factores, pero en concreto la formación del profesorado y la actitud, son elementos claves.

Contrastando lo que muestran los autores con nuestros resultados, coincidimos en que las creencias y la actitud del profesorado son aspectos determinantes a la hora de plantear transformaciones en los centros. Por eso, pensamos que la revisión de creencias es un punto inicial y también un elemento recurrente en la práctica docente (Aguado, Gil-Jaurena y Mata, 2008).

Como hemos visto en nuestro estudio, las creencias favorecen o dificultan el cambio en función de si coinciden con el nuevo modelo de escuela hacia el que se pretende avanzar. Por eso, para llevar a cabo transformaciones en toda la escuela, y no solo en algunas aulas, son necesarios procesos de reflexión. Aun así aparecen dificultades. Para Escudero (2002) estas dificultades se explican porque la escuela todavía no se ha replanteado su función como institución para todos los ciudadanos y sigue sin cuestionar las estructuras socioeconómicas en las que se tratan de llevar a cabo las reformas educativas. Para nosotros, que coincidimos con este planteamiento, estas dificultades se sitúan en las creencias y las concepciones pedagógicas del profesorado.

En este sentido, también nos replanteamos el proceso de cambio, en función de aquello que hemos constatado en nuestro estudio. Algunos autores, al explicar el 
proceso de cambio hablan de la realización de un diagnóstico tras la primera fase más reflexiva y después de haber decidido iniciar el cambio. Este diagnóstico nos aportará las dificultades y los elementos favorecedores del cambio. En este caso, Murillo y Krichesky (2012), nos explican que el diagnóstico tiene que centrarse en tres dimensiones: el desarrollo de los estudiantes, la calidad del centro y la adecuación de los procesos de enseñanza en el aula. Para nosotros, este diagnóstico puede resultar importante para que se desarrolle el cambio. Sin embargo, planteamos que las creencias del profesorado y sus valores tanto personales como profesionales van a ser uno de los elementos más determinantes para que el cambio se realice.

Pensamos que en última instancia, las creencias del profesorado serán el elemento que determine la dirección del cambio. Cabe destacar que, incluso cuando abordamos de una manera teórica el tema de las creencias, posteriormente podemos encontrar contradicciones entre la teoría y la práctica (Freire, 1979; Traver, Sales y Moliner, 2010). Esta contradicción puede ser debida también al hecho de no reconocer como docentes algunas actitudes discriminatorias que aunque seamos maestros o profesores podemos tener como personas. En definitiva, en nuestro estudio observamos que el cambio no puede ser real si las personas no creen en él. Si, por ejemplo, su manera de entender la educación y también la vida, no coincide con la ideología que se defiende desde una escuela intercultural e inclusiva.

En esta escuela, incluso aparecen algunas de las condiciones que favorecen la realización de transformaciones. Por ejemplo, algunos docentes en un primer momento manifestaban sus resistencias al cambio y posteriormente implementaron innovaciones en sus clases. En este sentido, podríamos decir que la escuela se transforma $\mathrm{y}$, estas transformaciones aparecen a partir del seminario que realiza el profesorado. Por tanto, vemos que la reflexión compartida sobre la práctica y la colaboración docente, son factores que facilitan la realización de cambios en los centros y en las aulas (Essomba, 2006). Sin embargo, incluso en estos casos en los 
que se acaban realizando prácticas definidas por la literatura como prácticas inclusivas, pensamos que el cambio no siempre es real.

En los resultados mostrábamos cómo algunos docentes, que no creían en el cambio ni en la participación de las familias, acababan realizando prácticas más inclusivas. Para una parte del profesorado esto no era suficiente y propusieron establecer una serie de compromisos que aseguraran la incorporación de estas técnicas en todos los cursos. Todo el profesorado aceptó, e incluyeron estas técnicas en su programación, pero en el fondo no creían en ellas. En este sentido, volvemos a situarnos en un modelo de adoptantes (Fullan, 2002), y comprobamos que no siempre el hecho de realizar una práctica puede ir transformando tu estilo docente, sino que el estilo docente depende de tus concepciones pedagógicas. En el caso de Estefanía, ella explica que el hecho de realizar nuevas prácticas en su aula la impulsaron a ir transformando su estilo docente. Sin embargo, ella ya tenía esta predisposición sobre el cambio, tenía unas concepciones pedagógicas que coincidían con los valores de la interculturalidad y la inclusión.

Por tanto, en relación a si una práctica es o no inclusiva, pensamos que el análisis aislado de la técnica por sí sola, carece de sentido. Este, lo aportan los valores y las creencias del profesorado que se explicitan en la práctica. Autores como Sales, Ferrández, Traver y Moliner (2012), afirman que las transformaciones se convierten en alternativas vacías en la medida en que no coinciden con los valores de los actores que las llevan a cabo. Quizás este problema ya viene de la "fase de arranque", cuando se decide iniciar el proceso de cambio, si esta decisión ha sido impuesta (Sales, Traver y García, 2011; Sales, Ferrández y Moliner, 2012).

Es por esto que aunque coincidimos con la afirmación de Fink (2000), que expresa que cuantos más profesores y otros agentes educativos se involucren en el cambio de la escuela, mayor será su potencial para conseguir mejoras, pensamos que la implicación en acciones del profesorado o de otros agentes, no determina que se "crea" realmente en estas acciones, y por tanto, que la interculturalidad y la inclusión sean reales. Por ejemplo, comprobamos que no por el hecho de realizar grupos interactivos o tertulias dialógicas, el profesorado tiene una actitud más 
positiva hacia la diversidad. Para que haya un cambio en cuanto a la visión de la diversidad, tendríamos que indagar no sólo en las creencias y los valores pedagógicos del profesorado, sino en sus valores más personales y sus experiencias vitales. Porque es desde nuestra complejidad como personas, desde la que entramos en las aulas (Gallegos, 2001).

Para conseguir la sostenibilidad del cambio no sólo tendremos que basarnos en los compromisos sobre la acción, sino también en los valores profundos de las necesidades humanas. Como dice Fullan (2002), la sostenibilidad del cambio es la capacidad que tiene el sistema de comprometerse para resolver las complejidades que resultan de la mejora y que es compatible con los valores profundos derivados de las necesidades humanas. Es por esto que, autores como Gather, (2004); Tedesco, (2004) y Essomba, (2006), coinciden en la importancia de invertir en procesos innovadores fundamentados en el cambio del profesorado, más que en la inversión de recursos o la transformación de las estructuras.

Por eso, pensamos que son necesarias las dos partes, tanto la individualidad del profesor, como la cultura escolar del centro para que la transformación sea real y se institucionalice el cambio. Pero, sin una necesidad individual y sentida no se puede dar un cambio real, aunque la cultura escolar lo facilite. Por otro lado, si el docente siente la necesidad de cambio, podrá realizar transformaciones en su clase. Pero, esto no asegura que haya una transformación de la cultura escolar, aunque a la larga, por el contagio y otros elementos abordados anteriormente como la colaboración docente, el cambio podría iniciarse a nivel de centro.

Aun así, nos quedamos con la idea de Fullan y Hargreaves (1996), en la que expresan que, aquello primordial es entender al docente en su totalidad, no sólo en su rol como maestro o profesor.

Este aspecto, el personal, es fundamental. Por ejemplo, aunque pensemos "que no tenemos que ser racistas", si por mis vivencias o mis creencias no tengo una visión "adecuada" sobre la diversidad, como maestro no podré transmitir esto a mis 
alumnos. Muchas veces, el tono de voz, la manera de relacionarse de la maestra con el alumnado, las expectativas sobre sus alumnos, etc. son aspectos más sutiles que determinarán que una práctica pueda ser más o menos inclusiva, y que nos muestran cómo es nuestra manera de entender la diversidad.

Pero los cambios no sólo los observamos en la realización de prácticas inclusivas en las aulas, sino que observamos otras cuestiones que también están relacionadas con las transformaciones del centro hacia un modelo más intercultural e inclusivo, como son, el liderazgo compartido y la democratización del proceso. En este sentido, destacamos precisamente la falta de democratización en los procesos de participación y de toma de decisiones, que en nuestro estudio aparece de la mano del equipo directivo.

El equipo directivo se siente responsable de realizar cambios en el centro y se siente comprometido con la comunidad educativa. Por esa razón, aunque quieren una escuela de todos y todas, al principio les cuesta dejar que el liderazgo sea compartido, en concreto, con las familias y el alumnado. Su afán por empezar y dar una respuesta al proceso de cambio, les hace entrar en la contradicción de fomentar que el proceso sea más del profesorado que de toda la comunidad. Se propicia lo que llamamos una cultura profesionalista (Imbernon, 2007; Escobedo, Traver, Ortells, 2013). No obstante, tal y como se van implicando las familias en la mejora de la escuela, el profesorado va transformando su manera de verlas. Aunque no acaban de fomentar la participación de todas las familias en la escuela, sí que hay un cambio en la confianza que depositan en las familias que se implican.

Por tanto, la escuela está cambiando, ¿pero este movimiento y transformación se dirige hacia un modelo intercultural e inclusivo? Para responder a esta pregunta, realizaremos un repaso sobre los elementos que tienen que estar presentes para avanzar hacia la construcción de la escuela intercultural inclusiva. Por ejemplo, coincidimos con la importancia de las siete acciones estratégicas que nombra Essomba (2006): la creación de un consejo de actualización curricular; la participación del alumnado en la planificación de actividades; la participación de las organizaciones y asociaciones sociales en la vida del centro; el establecimiento 
de un currículum creado por todos; la acción comunitaria como una acción de servicio y la creación de una red de centros y el observatorio local de la educación. Algunas de estas acciones, también se llevaron a cabo en esta escuela. Como por ejemplo, la creación de un consejo de actualización curricular, que sería la formación del profesorado en el seminario de formación; la participación del alumnado en la planificación de actividades, en el caso de la clase de Estefanía y otras clases de infantil y de primaria; la participación de asociaciones del barrio en el centro, etc. Sin embargo, pensamos que la parte más personal del cambio también debería contemplarse en la construcción de la escuela intercultural inclusiva. Con esto nos referimos a la importancia de la dimensión personal del profesorado y de todas las personas que forman parte de la comunidad educativa. A esta dimensión personal podemos llegar conociendo las experiencias de vida, y de este modo acercarnos a la comprensión de distintas creencias y valores más personales que profesionales.

Para concluir este apartado, haremos un recorrido por las implicaciones que tiene la educación intercultural desde la perspectiva de Gil-Jaurena (2012) nombradas en el marco teórico-, y compararemos estas implicaciones interculturales e inclusivas con el proceso de transformación llevado a cabo en la escuela.

La primera de ellas es que tanto la interculturalidad como la inclusión son un enfoque educativo, una manera de entender la educación, y suponen un proceso continuo (no un programa o una acción ocasional). En este sentido, en nuestro estudio nos encontramos con tres posibilidades: una parte del profesorado antes de iniciar el proyecto ya entendía la educación desde estos parámetros, aunque no le pusieran el nombre de intercultural e inclusivo. En estos casos, aunque tuvieran una sensibilidad hacia el alumnado y hacia la diversidad, sus planteamientos y sus prácticas de aula no siempre daban cabida a la inclusión. Sin embargo, sí que existía una actitud adecuada hacia todas las familias y el alumnado en general. Para estos docentes, la formación realizada al inicio del curso, el acompañamiento del 
profesorado en el seminario de formación y las acciones que ellos mismos emprendieron, sí que les acercaron a un posicionamiento intercultural e inclusivo, como sería el caso de Estefanía. Por otro lado, existe otra parte del profesorado con una actitud negativa hacia la diversidad, con prejuicios hacia las familias inmigrantes o hacia el estudiantado con diversidad funcional. En estos casos para que las acciones introducidas respondan a un modelo intercultural inclusivo se tendría que llegar a un replanteamiento de las creencias. Pero no únicamente limitado a su acción como docentes, sino que cabría adentrarnos en su historia de vida y realizar un trabajo personal con este profesorado, que por distintos motivos se mantiene distante y con bajas expectativas hacia las familias y el alumnado.

El segundo de los elementos está directamente relacionado con el anterior: Como enfoque holístico, afecta a todas las dimensiones educativas (no solo al currículo). Puesto que nuestra manera de pensar no puede parcializarse, la educación que impartimos tampoco puede verse separada de aquello que pensamos. Por eso, una educación intercultural e inclusiva necesita de un enfoque holístico que vaya más allá de las asignaturas instrumentales y que trascienda el aula.

En relación al término intercultural, como enfoque inclusivo, supone la educación de todos (no la de minorías o inmigrantes). Este aspecto es visto con naturalidad en la escuela que estudiamos, quizás si contaran con una parte importante de personas de la misma cultura dominante y además con un ritmo de aprendizaje normal (en el caso del estudio el ritmo es durante los primeros años bajo, por su desconocimiento de la cultura dominante) se propondrían adaptaciones para una parte de la clase, en lugar de entender la diversidad como la totalidad. Es en esta cuestión, en la comprensión de la diversidad, en la que encontramos la dificultad. Pues para una parte del profesorado y de las familias, tanto inmigrantes como no, la diversidad es vista como lo diferente a mí.

Por eso la diversidad también comprende la relación con las familias y el hecho de no tener miedo a que un padre, al que por sus comportamientos anteriores se le encasilló como "maleducado" en la escuela, -o que simplemente, por 
cuestiones de afinidad no les parecía agradable a algunos docentes-, pudiera entrar en las clases. En este sentido la diversidad es vista como una revolución hacia nuestras creencias personales que pueden ser limitadoras, como un eje que nos impulsa a observar desde la confianza en uno mismo y en el otro, la realidad. Una observación de lo exterior expectante a aquello que ocurre sin tener la necesidad de juzgarlo. Más allá del juicio se puede dar una comprensión del otro, de su situación, de su comportamiento, pero para ello necesito conocerle. Como vemos, estas no son creencias que puedo mantener como maestro/a; sino que son creencias que tengo que trabajar como persona. En los resultados de nuestro estudio, hemos resaltado también el conocimiento del otro como un aspecto importante a la hora de comprender la diversidad. En concreto, una de las madres destacaba la importancia de conocer al otro para romper muros, y un padre que al inicio manifestaba actitudes racistas, poco a poco fue mostrando una relación distinta y colaborativa con las madres árabes.

En este sentido, el siguiente elemento se centra precisamente en la percepción de la diversidad, como un valor, no como una deficiencia. La diversidad en su sentido más amplio. La necesidad de conocer a nuestro alumnado con sus características personales, con sus habilidades, etc. En definitiva, la diversidad sintiéndose desde la propia diversidad como característica de la naturaleza.

Por otra parte, la interculturalidad tiene cuatro objetivos generales: la equidad, el antirracismo, la competencia intercultural y la transformación social. Todos y cada uno de ellos dependen de las creencias. Aunque algunos de estos objetivos tienen más elementos que influyen. Como por ejemplo, el hecho de que haya una transformación social depende de más aspectos a parte de las creencias. No obstante, la transformación social tendría también su origen en las creencias, pero esta vez compartidas, entre las personas implicadas en el cambio. La equidad y el antirracismo son aspectos que si no vivimos desde nuestra propia vida no podremos valorar en el otro. Si no me trato con dignidad, con justicia y me valoro como al resto, difícilmente podré darles esa equidad en mis interacciones con los otros. Con 
el antirracismo ocurre lo mismo, si hay partes de mí que no acepto, quizás algunas de estas se pueden proyectar con una visión racista de la realidad.

El último de los elementos que destaca Gil-Jaurena (2012), es que la interculturalidad pretende reformar la escuela para conseguir una educación de calidad para todos los estudiantes. Este hecho, como destaca la autora es un enfoque transformador. Pero que una escuela que parte de modelos positivistas, centrados en la eficiencia, basados en la industrialización, etc., se plantee que este modelo no sirve y que necesita transformar su realidad para dar una respuesta adecuada a la diversidad, es un planteamiento radical, inclusivo e intercultural. Para que este planteamiento sea real, todos sus integrantes deben comprenderlo y sentir la necesidad de cambio desde los mismos principios de igualdad de oportunidades.

En la escuela de este estudio, es aquí donde encontramos las primeras dificultades, debido a creencias que no vienen a coincidir con estas necesidades. A creencias de separación y de exclusión, de miedo y de desconfianza. Si algo nos dice el modelo intercultural es que el cambio hacia una mayor apertura, solo se produce cuando se da el mestizaje entre distintos grupos, como comentamos en el marco teórico. Por eso, Gil-Jaurena (2012) coincide con Abdallah-Pretceille (2001) al afirmar que la interculturalidad sería más fácil de entender si en lugar de darle tanta importancia a aquello que nos diferencia y separa, se la diéramos a aquello que nos une. O como decíamos anteriormente con palabras de Osuna (2012), si los estudiantes en lugar de ser marroquíes, españoles o chinos fueran Mohamed, Pepe, Andrea, Abel...

\subsection{Aprender a ser}

El segundo pilar de este estudio son las prácticas de aula, en concreto, las interculturales e inclusivas. En el marco teórico ya hemos definido qué entendemos 
por prácticas y hemos encontrado algunos indicadores para identificar cuando una práctica es intercultural e inclusiva.

En la guía para el análisis, reflexión y valoración sobre las prácticas inclusivas, Durán, Giné y Marchesi (2010) proponen una serie de indicadores que nos pueden ayudar a identificar si la práctica es o no inclusiva. En este caso pensamos que los indicadores son un acierto para medir pedagógicamente si la técnica es adecuada para dar una respuesta a la diversidad. El primer indicador "En el aula se trabaja deliberadamente la comprensión de las diferencias", nos ayuda a reflexionar sobre si la práctica facilita la atención a la diversidad desde la comprensión de las diferencias. Pensamos que es un indicador que mide de algún modo, las concepciones pedagógicas en la práctica. Es decir, si el tipo de respuesta del profesorado es adecuado para dar cabida a la diversidad en las aulas.

En el caso del segundo indicador "Las actividades que se hacen en el aula recorren sistemáticamente el aprendizaje cooperativo", se nos plantean algunas dudas. Entendemos que los autores se refieren a si en la práctica, están presentes los componentes básicos del aprendizaje cooperativo que son: la interdependencia positiva, responsabilidad individual, interacción promotora cara a cara, desarrollo de habilidades sociales y procesamiento grupal (Johnson, Johnson y Holubec, 1999). Para nosotros estos indicadores facilitan la atención a la diversidad, pero pensamos que es necesario -más allá de que se tengan en cuenta estos factores-, favorecer la inclusión del alumnado desde un ámbito más relacionado con el desarrollo de sus potencialidades y su integración e inclusión radical en el aula. Es decir, que puedan participar de la actividad y que puedan desarrollar sus capacidades, que se sientan queridos, integrados y aceptados.

Continuamos con el tercer indicador "El profesorado facilita que el alumnado que ayuda a sus compañeros tome consciencia de que también está aprendiendo". En este caso seguimos observando que la inclusión está relacionada con el aprender a conocer y aprender a hacer. Puesto que no se especifica que es lo que está 
aprendiendo, entendemos que se aprende sobre los contenidos de las asignaturas instrumentales.

El último indicador "El profesorado colabora, los unos con los otros, en las prácticas inclusivas", tampoco pensamos que nos ayude a medir aspectos básicos para poder comentar si se trata de una técnica intercultural e inclusiva o no. Aunque es un elemento importante de la acción docente creemos que está más orientado a las relaciones que se generan entre el profesorado, que a la relación entre profesorado y alumnado o, al clima que se genera en el aula, que también sería otro elemento importante a medir en el caso de las prácticas interculturales e inclusivas.

Para nosotros, la inclusión tiene un carácter más profundo. La inclusión real de todas y todos la situamos en la aceptación radical del otro, y por consiguiente de mí mismo, ya que como hemos dicho en el marco teórico, para aceptar al otro me tengo que aceptar también a mí. Desde el modelo intercultural e inclusivo se debería llegar más allá de la participación de todos y del desarrollo de sus capacidades orientadas al conocer y al hacer. Para nosotros la interculturalidad y la inclusión en la práctica está relacionada con la equidad y la justicia, pero también con que el alumnado se sienta integrado y aceptado. Además, precisamente estos aspectos son los que destaca el alumnado de tercer ciclo en el grupo de discusión. Para ellos, lo más importante es sentirse bien en el aula, por eso, el trabajo emocional tiene sentido y es aquello que más valoran, de los aspectos trabajados en clase.

Para nosotros, es imprescindible realizar esta conexión entre la inclusión y el amor hacia uno mismo y hacia el otro. Como decía Pérez de Lara (1998), situaríamos la inclusión en la relación amorosa de aceptación plena junto a mí del otro. Esa relación amorosa, como indica la autora, es la única que puede mediar saber y convivencia, conocimiento y vida.

Además de centrar el planteamiento en las relaciones humanas, Pérez Gómez (1985), basándose en Doyle, comenta que aquello que se aprende en la escuela 
proviene más del contexto y de que haya un clima emotivo, que de los propios programas.

Por tanto, las técnicas pueden facilitar que la acción docente sea más o menos inclusiva, sin embargo, acaba siendo siempre la propia acción la que se orienta hacia un modelo u otro, y lo hace a partir de las creencias y valores que tiene ese profesor o maestro, como persona (Aguado, Gil-Jaurena y Mata, 2008; Gil-Jaurena, 2012). Este aspecto también lo hemos comentado en el apartado anterior, resaltando el valor de las concepciones pedagógicas del profesorado. En nuestro estudio, hemos podido comprobar que la implementación de técnicas definidas como interculturales e inclusivas (INCLUD-ED Consortium, 2011), no siempre generan prácticas de este tipo. Por ejemplo, hemos encontrado dificultades a la hora de promover la participación de todo el alumnado en los GI. En concreto, con Andrés que es un niño con Síndrome de Down y tiene un nivel educativo inferior al resto de niños de su clase. No sabe hablar, tan sólo emite algunas palabras, y por supuesto no sabe leer y escribir o realizar operaciones matemáticas; contenidos que se trabajan en los GI al ser los propios de primero de Educación Primaria. Su presencia en el aula es un regalo, no sólo para este niño sino para todos sus compañeros, por todos los aspectos afectivos y sociales que el alumnado aprende y que formarían parte también de los valores de la inclusión. Aunque estos no quedan reflejados en parte de la literatura al definir lo que significa una práctica intercultural inclusiva.

Por eso, a nivel académico resulta difícil incluir a Andrés en algunas prácticas y hacerle participar como al resto. Su participación, si se ciñe a tener que realizar exactamente la misma tarea que sus compañeros como se indica en los GI, es dificultosa por no decir imposible.

La inclusión en los GI en el caso de Waldo, Juan o Adán, que tienen un ritmo más lento que sus compañeros y una mayor dificultad para realizar las tareas, sí que es posible. Para ellos, la realización de los GI es positiva y pueden "más o menos" seguir el ritmo de sus compañeros. Pero, como entendemos la inclusión y 
la diversidad desde la totalidad del alumnado, si sacamos a Andrés de la dinámica ya no es una práctica inclusiva. Por tanto, coincidimos con Muntaner, Piña y De la Iglesia, (2015) al afirmar que los GI no siempre son una práctica que favorece la atención de toda la diversidad.

De todas las prácticas observadas pensamos que las tertulias dialógicas y las asambleas, son aquellas que más han favorecido la inclusión en la clase de Estefanía. Aunque tenemos que tener en cuenta algunas consideraciones previas.

En el caso de las tertulias realizadas por Estefanía, todo el alumnado participa de la sesión, incluido Andrés, desde sus posibilidades. Además, tras la realización de la lectura y comprensión del libro, se realizan otras actividades para seguir trabajando los valores y distintos temas que han aparecido en el mismo. Estas actividades las decide el alumnado junto con la maestra y en algunos casos les permite al propio alumnado realizar aprendizajes sobre aspectos que normalmente no suelen trabajarse desde el currículum escolar. Como por ejemplo, la realización de teatros, en los que además de todo el trabajo anterior, el alumnado aprende a expresarse también corporalmente.

No obstante, si analizamos las TLD (Tertulias literarias dialógicas) tal y como se definen por las comunidades de aprendizaje, nos encontramos con el mismo dilema que en los GI. No todo el alumnado puede estar incluido en la práctica si para ello tiene que saber leer, por ejemplo. En este caso, a diferencia de otras prácticas como los proyectos de trabajo o las asambleas, las TLD no podrían realizarse en la etapa de educación infantil o con todo el alumnado del primer curso de primaria. Aunque entre las características de las TLD se dice que se pueden llevar a cabo con estudiantes desde educación infantil, también dicen que las personas participantes en la tertulia asisten al aula con la lectura hecha de las páginas que se hayan acordado. Quizás se refieren a que en Educación Infantil son los padres los que tienen que realizar la lectura, en casa, con sus hijos y estos conversar y argumentar sobre las mismas en la clase. No obstante, en el caso de la escuela en la que realizamos el estudio, las familias del alumnado no saben leer y no entienden el idioma por lo que esta tarea resultaría dificultosa. 
En el aula de Estefanía, en la que está Andrés, quizás él no aprende a leer en toda la etapa de primaria y su participación en las tertulias sería de nuevo imposible. A no ser que habláramos de adaptaciones sobre la práctica, como las que realiza Estefanía con el fin de flexibilizarla, para que en última instancia se favorezca la inclusión. En las tertulias que realizan en la clase de Estefanía, pueden participar todos los alumnos, sepan leer o no. Además de Andrés hay otros niños que no saben leer y no por ello se les excluye o se deja de potenciar este trabajo en clase.

El trabajo que realizan es la lectura compartida en el aula, no tienen que leerlo en su casa, porque además de que no todos saben leer, como hemos dicho, tampoco sus familias entienden el idioma. Otro aspecto por el que diríamos que Estefanía no realiza TLD, es que no se leen los clásicos. Aunque pensamos que estos son adecuados para los niños, también creemos que el trabajo de valores se puede realizar con distintos libros de la literatura infantil y juvenil. Los libros leídos en la clase han sido una ayuda para trabajar los miedos del alumnado sobre temas que les preocupaban, algunos de estos han sido Mare bracet, sobre la celosía infantil; No tinc por, sobre los miedos de los niños a la hora de irse a dormir, etc. En todos los libros, las aportaciones e interés del alumnado; las temáticas y los valores trabajados han sido amplios y relacionados con las experiencias del estudiantado de la clase.

Algunas de las cuestiones que sí que aparecen en las tertulias realizadas por Estefanía y que se definen en las TLD, son que prima la validez del argumento en lugar de las pretensiones de poder; se favorece la participación igualitaria de todos los miembros $\mathrm{y}$, en algunos casos, se han realizado con familias $\mathrm{u}$ otros miembros de la comunidad.

En definitiva, pensamos que las tertulias realizadas en la clase de Estefanía sí que serían prácticas inclusivas: se favorece la participación de todo el alumnado de la clase, y además, se favorecen las relaciones sociales, el respeto y la comprensión de las diferencias. 
Coincidimos con Aguilar, Alonso, Padrós y Pulido (2010), en que las tertulias favorecen la transformación de las personas, en el sentido de que, personas que en otras circunstancias no se hubieran atrevido a hablar, en las tertulias lo hacen. Pero, destacamos que lo hacen igualmente en las asambleas. Creemos que, debido al espacio de confianza que se crea entre las personas asistentes.

En relación a las asambleas, aunque no se centran en el trabajo de una asignatura instrumental, en ellas el alumnado aprende a expresarse mejor, a compartir sus experiencias, aprenden a respetarse desde la comprensión de diferencias. Como dice Gómez Rosado (2007), el hecho de expresarse en público les ayuda a desinhibirse y pierden el miedo escénico. Además, aportan gran cantidad de información al profesorado sobre aspectos que influyen en el alumnado y sobre temas que les preocupan, más allá de las cuestiones académicas (Monfort y Juárez, 1996). Pensamos que la asamblea construye el contexto idóneo para conocer mejor al otro, y por tanto, para poder aprender a respetarnos y a empatizar con las situaciones de nuestros compañeros. Aspectos que también favorecen la inclusión del alumnado y que se puedan sentir a gusto y queridos por la maestra y por sus compañeros.

Por otra parte, los proyectos de trabajo tienen un planteamiento flexible y abierto desde el inicio. Es por esto que favorecen la inclusión de todas las personas independientemente de sus capacidades, habilidades o ritmo de aprendizaje (Sales, 2004). No obstante, en el caso de Estefanía, algunas sesiones dedicadas al trabajo del proyecto por parte del alumnado, no se diferenciaban de lo que sería una clase magistral en la que la maestra explica y el alumnado escucha. Esta no es la finalidad de un proyecto, pero en determinadas ocasiones, la maestra, con la intención de repasar los temas abordados e indagar en los conocimientos adquiridos por el alumnado, acababa realizando ella, prácticamente sin la ayuda del alumnado, la explicación de todo aquello estudiado durante el proceso.

En definitiva, lo que venimos a destacar desde la reflexión de las distintas prácticas, es que finalmente es el docente quien consigue favorecer la diversidad o por el contrario, quien realiza prácticas exclusoras en el aula. A veces puede que 
sin ser consciente de ello. Por eso, destacamos la importancia del profesorado no sólo como maestros y/o profesores, sino como personas que pueden favorecer la creación de una sociedad más justa.

Como hemos comentado, el maestro entra en la escuela con su mochila compuesta por todas sus experiencias de vida, que le hacen ver la realidad del aula y las situaciones del alumnado de un modo determinado. Es precisamente la mirada, aquello que podemos transformar para conseguir la inclusión, más que formación centrada en técnicas pedagógicas (Domingo, 2001; Jordán, 2004; Carreres y Arnáiz, 2010).

Desde esta perspectiva, poco a poco se va trasladando el concepto de educación intercultural e inclusiva hacia una educación más centrada en la persona. Las bases de este concepto demandan de una educación que nos dirija hacia el encuentro con el otro desde la aceptación de uno mismo. Por eso, existen autoras que sitúan la educación intercultural inclusiva no sólo hacia perspectivas del saber y del saber hacer, sino también hacia la dimensión más personal del alumnado, del desarrollo de su ser (Aguado, Gil-Jaurena y Mata, 2008).

Como hemos nombrado en el marco teórico, ya en 1972 en el informe de Edgar Faure para la UNESCO se apuntaba a la importancia del aprender a ser. Posteriormente en el informe de Delors (1996), también se hace mención a una educación para aprender a ser, destacando otros aprendizajes más habituales en el ámbito escolar como el aprender a conocer o el aprender a hacer. Tanto el aprender a ser como el aprender a convivir son dos retos para la educación del siglo XXI, y es el profesorado y también las familias las que necesariamente tienen que liderar este proceso.

En este trabajo apostamos por un replanteamiento del modelo intercultural e inclusivo y de las prácticas que desde él se realizan. Este replanteamiento lo dirigimos hacia una mirada más profunda del docente, del alumnado y de la sociedad. Apostamos por una educación intercultural e inclusiva que dirija la 
atención a la diversidad hacia un posicionamiento más inclusivo. A la inclusión de las personas desde el corazón. Es decir, una educación centrada en la persona desde su complejidad.

Es aquí donde nos posicionamos como educadores preocupados por la educación intercultural e inclusiva y por su necesaria transformación hacia una educación más radicalmente abierta a la diversidad y a la transformación personal. Una educación en la que el alumnado aprenda a ser, a desarrollar sus potencialidades, a conocerse interiormente y a poder ser más comprensivo y respetuoso con los demás.

En esta dirección, otras teorías que pensamos que tienen que estar presentes desde el modelo intercultural inclusivo son la educación holística y la educación emocional. En relación a esta última, aunque hemos visto en el marco teórico la importancia que las emociones tienen en nuestra vida, en la de los educandos y los maestros, todavía no hemos tratado de integrar esta perspectiva en las escuelas actuales (Bisquerra, 2009). Los motivos quizás son los que hemos nombrado en el marco teórico, que aquellos quienes pueden hacerlo, el profesorado y las familias, no se sienten preparados o con la necesidad de hacerlo.

También es verdad que el tema de la educación emocional es bastante reciente y las políticas educativas no facilitan su introducción en las escuelas, ni la formación necesaria para que el profesorado se plantee estas cuestiones.

Por ejemplo, en la anterior ley de educación, la LOE (Ley orgánica 2/2006, de 3 de mayo, de Educación, BOE de 4 de mayo), se decía en el preámbulo que se trataría de conseguir que todos los ciudadanos alcanzasen el máximo desarrollo posible de todas sus capacidades individuales y sociales, intelectuales, culturales y emocionales. Se hacía mención en algunos momentos de la Ley, sobre la inclusión del alumnado y en algunas ocasiones, sobre el trabajo emocional. Aunque a efectos prácticos no se proporcionaron los medios para facilitar que esto fuera posible en todas las escuelas.

Más adelante, con la LOMCE (Ley Orgánica 8/2013, de 9 de diciembre, para la mejora de la calidad educativa) la atención a la diversidad y el trabajo emocional 408 
tiene menor presencia. En este caso, se hace mención a una educación basada en la mejora económica como uno de los objetivos de la educación y a la competitividad como un elemento favorecedor para conseguirlo. En esta ley se sitúa el desarrollo social de la mano de la economía y lejos de una visión humanista. Aunque en algunos momentos aparecen declaraciones que hacen un guiño a la atención a la diversidad, parecen ideas contrarias a las que se pueden entender en el trasfondo de la mencionada ley.

Lo que venimos a destacar es que este tipo de educación centrada en el aprender a ser, tiene que sentirse como una necesidad para el profesorado. Puesto que como hemos comentado, en última instancia la inclusión y la interculturalidad tienen que ver con los valores personales.

A la conclusión a la que queríamos llegar después de este recorrido es a la distancia entre lo que aporta la educación holística y la educación emocional y la realidad en la que nos encontramos. Como hemos dicho, ante esta situación la administración está bastante por detrás de lo que los teóricos y profesionales de la educación declaran. Podemos decir, que existe una falta de conciencia social sobre estos temas, que son aspectos clave para la educación y el avance social.

Sin embargo, aquellos maestros, profesores y alumnos que de algún modo ya han iniciado esta tarea, destacan su alta potencialidad y la necesidad de que este trabajo más relacionado con una educación integral, sea la base del aprendizaje en las escuelas (Gallegos, 2001; Yus Ramos, 2001; Toro, 2005; González, 2014).

En nuestro estudio, aquellos que coinciden con esta visión son algunos docentes -que realizan un trabajo centrado en la educación emocional- y su alumnado. Como hemos comentado, el alumnado de tercer ciclo que realizó técnicas definidas por la literatura como interculturales e inclusivas y que además trabajó las emociones en su aula, destacaba en los grupos de discusión, su interés y la importancia precisamente, de las emociones y de las relaciones sociales con sus compañeros. Aunque desde el estudio nuestra pretensión inicial era observar las 
prácticas interculturales e inclusivas y nuestra mirada todavía no se centraba en el trabajo de las emociones, pudimos constatar, tanto en las prácticas de Estefanía como en los comentarios del alumnado de tercer ciclo, que las necesidades del alumnado -y pensamos que, también de los adultos-, no eran aprender contenidos específicos, sino aprender a sentirse bien, queridos y respetados por ellos mismos y por el resto de personas.

En los resultados de la clase de Estefanía, nos aporta mucha información al respecto el alumnado en las asambleas. Es en estas prácticas en las que conocemos sus situaciones personales y a partir de ahí les podemos entender mejor. En muchos casos, el profesorado que conoce la situación de un niño le trata con mayor comprensión si sabe que está pasando por un momento difícil. Sin embargo, aunque somos conscientes de la importancia que tienen los acontecimientos en nuestra vida y la manera de interpretarlos, no siempre dejamos suficiente espacio en las aulas para trabajar estos temas.

Estos datos nos acercan a aspectos definidos desde el marco teórico como fundamentales en el trabajo desde las aulas. La necesidad de que la educación se centre en el desarrollo integral del alumnado y en competencias sociales y emocionales. En definitiva, la necesidad de una educación conectada con la vida y con el corazón.

Esta propuesta no es contradictoria con el modelo intercultural e inclusivo, sino que pensamos que es necesaria la integración de esta parte, para que la inclusión pueda ser real. Como diría José María Toro (2005): “El corazón no está reñido con la razón sino que la contiene. Plantear una «educación con co-razón» es proponer la recuperación del componente emotivo o emocional de la racionalidad" (p.20).

Según este maestro y escritor, a la escuela todavía le resulta arriesgado acoger al niño por entero y sobre todo, acoger la vida que trae con él. La escuela suele quedarse con la dimensión de aprendiz e implícitamente, considera al alumno como un ser "inacabado" y en proceso de aprendizaje y socialización. No obstante, el niño al igual que el adulto es un ser en permanente desarrollo, pero completo. Así 
mismo, destacamos las palabras del autor que nos hacen reflexionar sobre la escuela actual y sobre su distancia respecto a temas esenciales para vivir la vida.

A veces me pregunto si «entrar» en la escuela no implica «salir» de la vida (...). Es como si traspasado el umbral de la puerta del colegio quedase atrás todo lo que «habitualmente» vive, le ocupa e incluso preocupa. Los latidos de su sentir, su pensar, de su sencillo vivir, se detienen y son sustituidos por las palpitaciones de las lecciones, los «deberes», las explicaciones, los ejercicios, las correcciones, los exámenes... (Toro, 2005, p. 24).

En los resultados del estudio, apuntábamos hacia una educación para ser, que se base precisamente en el desarrollo integral del alumnado. En la clase de Estefanía, la vida del alumnado le acompaña en su entrada en el aula. Por ejemplo, cuando en el caso de Davinia expresa su sentimiento de culpabilidad por la situación que está viviendo; o cuando Ivana se tapa la cara para que no vean la herida que tiene en la nariz. Sin embargo, el profesorado no siempre se siente con herramientas suficientes para actuar, o para saber cómo ayudarles a gestionar sus emociones.

En el caso de Ivana, podemos observar también que se siente poco atendida, cuando reacciona con enfado ante la pregunta de la maestra sobre el estado de salud de su hermano. Quizás porque sus padres ahora están preocupados por él, ella se siente así. Esta situación que racionalmente comprendemos como adultos, si la hemos vivido como niños quizás ha dejado meya en nosotros. Un niño puede aceptar que su hermano necesite más a sus padres que a él en ese momento, pero en su interior puede que no lo comprenda, puesto que ése mismo niño también necesita el cariño de su familia. Por eso, es importante un trabajo con esas emociones que van surgiendo. Este trabajo puede ayudar al alumnado a crecer en amor hacia sí mismo.

En la clase también se invita al alumnado a retirarse de la actividad si no se "comporta bien". Sin embargo, puede que fuera más saludable en algún momento abordar a qué se debe ese comportamiento. Ayudarle a expresar su emoción, 
sentirla y posteriormente, que pudiera soltarla y que poco a poco fueran cada vez más capaces de escucharse y reconocer cómo se sienten. A muchos adultos nos sorprendería ver cómo los niños aprenden a gestionar las emociones más rápido que nosotros, pero también necesitan que se les eduque para ello.

Sin darnos cuenta, somos educados desde parámetros que nos pueden limitar. Por ejemplo, desde bien pequeños, al interpretar el mundo desde la visión que nos han aportado los adultos de referencia, aprendemos que nos tienen que amar y que hay cosas en nosotros mismos que el resto no aceptará. Sutilmente vamos cada vez construyendo un personaje desde lo que pensamos que los mayores "esperan" de nosotros y eso nos crea sufrimiento cada vez que el personaje que creamos se aleja de nuestra manera de ser (Escudero, 2015). El mayor sufrimiento es que no nos quieran y este sentimiento se repite en la mayoría de niños y lo arrastramos hasta que somos adultos. Desde una edad más madura podemos empezar a perdonar y a comprender que nos podemos amar incondicionalmente por aquello que somos, $\mathrm{y}$ no por lo que hacemos. Pero esto puede que no sea tan fácil como se escribe. La cuestión es que, como hemos dicho, este trabajo sería necesario realizarlo desde el inicio de nuestras vidas, y la escuela es un lugar preferente para hacerlo, por todo el tiempo que el alumnado pasa allí y porque la educación también significa ayudar a crecer.

\subsection{Educar para ser: el trabajo personal y la historia de vida}

La educación que queremos para nuestros hijos y alumnos no es que todos lleguen a ejercer como abogados, presidentes, profesores, etc., sino que se sientan felices con aquello que hacen. Para llegar a este punto pensamos que es importante que el alumnado se conozca interiormente, que sepa cómo trabajar sus emociones y 
pueda desarrollar sus talentos desde la escuela, para que posteriormente, se pueda sentir realizado en su vida de adulto.

Para ello, necesitamos realizar un trabajo personal con el alumnado. Pero, el profesorado tiene que tener esa predisposición y saber también, cómo trabajar consigo mismo estos temas, sus emociones.

En nuestro caso, el encuentro con la biografía nos ha posibilitado realizar este crecimiento personal y acercarnos a nuestras emociones y a las de Estefanía. En su relato, hemos podido conocer cómo es ella y cómo ha vivido su vida. En su historia podemos entrever a una niña que se sentía poco escuchada, poco atendida y quizás poco amada. En todos nosotros existe esa historia de vida que vamos construyendo a lo largo de nuestra existencia y que va marcando nuestro presente.

Conocer nuestra historia de vida es una manera de llegar a nuestros sentimientos más profundos, de conocer de qué manera estamos viviendo ese presente y qué nos impulsa a seguir viviéndolo así o a cambiar nuestra manera de estar en la vida (Escudero, 2015).

En la historia de Estefanía reconocemos el perfeccionismo y la exigencia como personajes que aparecen en el discurso. Quizás los reconocemos porque al mirar el relato dejamos ver en él nuestras sombras, aquello que también nos cuesta ver en nosotros mismos.

La identificación del personaje, una de las puertas para su liberación, y el trabajo compasivo con nosotros mismos, son dos aspectos fundamentales que aparecen en las últimas entrevistas con Estefanía.

Ella, aunque no había tenido una vida fácil, siempre había salido hacia delante, mirando el futuro iba pasando de puntillas por su presente. Sin embargo, tras la muerte de su marido nace en ella una nueva persona, más necesitada que nunca de vida, de alegrías y de consciencia. No obstante, un hecho como este no siempre es suficiente para permitirnos mirar en nuestro interior. Pero Estefanía es valiente y atrevida. Tras sus primeros miedos se esconde el valor de una guerrera en busca de 
su felicidad, para finalmente descubrir que esta nunca la había abandonado, aunque en ocasiones, en largas ocasiones, se había mantenido a la espera de un encuentro verdadero con su presencia.

El darse cuenta del vacío interior y de la falta de amor hacia sí misma es finalmente la llave que le devuelve a un nuevo estado, el de responsabilidad hacia su vida, hacia los actos que ve en ella. Pero también el de sentir un gran amor y agradecimiento hacia su persona.

En el relato de Estefanía podemos ver su evolución a partir de un camino de autoconocimiento, basado en la autoescucha y en un trabajo emocional para comprender mejor sus emociones y sus acciones. Su historia, su vida, también influye en su manera de ser maestra, en su mirada sobre el alumnado y en su posicionamiento, día a día en el aula. Por eso, su testimonio es una muestra más para hacernos reflexionar sobre la importancia del trabajo personal y sobre la influencia que este tiene en uno mismo, y si eres docente, en la escuela.

El trabajo interior nos conecta con nosotros mismos y aporta sentido a nuestras vivencias. Nos acerca también a una mayor consciencia espiritual y en el plano educativo, a ser educadores con más presencia (Toro, 2005). Por eso, este camino de autoconocimiento no puede ser una opción si queremos trasladar a las aulas otra manera de educar. 


\section{Limitaciones, aportación del estudio y futuras líneas de investigación}

En relación a las limitaciones del estudio, cabe destacar que la gran predisposición de esta escuela, pasando por el alumnado, las familias, el personal de servicios, el profesorado y entre ellos, el equipo directivo, ha facilitado mucho la realización del trabajo. Desde el primer momento todo han sido ayudas.

No obstante, durante el primer curso de la transformación encontramos algunas dificultades. Una de ellas fue la imposibilidad de realizar la entrevista con la maestra de PT. En este caso nos interesaba su perspectiva como maestra especialista, que asistía al aula para atender generalmente, al alumnado con diversidad funcional. Aunque se insistió en distintas ocasiones, incluso la maestra el último día del curso nos pidió que le enviáramos las preguntas vía Internet, no llegó a responderlas. El siguiente curso esta maestra tenía asignada otra destinación y ya no pudimos volver a contactar con ella.

En algunos casos, hemos considerado también una limitación los silencios en algunas reuniones. Aunque, incluso antes de iniciar las sesiones del seminario de formación casi todo el profesorado había expresado su opinión positiva o negativa, en relación al cambio. No obstante, en el caso de una docente, aunque expresaba sus opiniones en las distintas reuniones y sesiones de formación, en la entrevista, si bien no se negó a realizarla no expuso las mismas valoraciones que manifestaba en las sesiones anteriores. Como hemos mencionado, fue una vez apagada la grabadora y pidiendo que la información no se mostrara, cuando dio su punto de vista. 
Otra de las limitaciones fue el cambio en la plantilla del profesorado al inicio del segundo curso de transformación. No obstante, este hecho favoreció que el trabajo se reorientara hacia el caso de una maestra en particular.

En cuanto a la aportación de nuestro trabajo al campo de la educación, se concreta en nuestro intento de conectar el modelo educativo intercultural inclusivo con otros modelos educativos dirigidos hacia el trabajo emocional o la educación holística y también, a reconocer la necesidad de realizar un trabajo de autoconocimiento con el profesorado. Otra de las aportaciones, la atribuimos al uso que se ha realizado de la historia de vida, en este caso hacia una mirada personal del cambio.

En cuanto a futuras líneas de investigación, apuntamos precisamente el uso que se le ha dado a la historia de vida, como una posibilidad para futuras investigaciones. Es decir, contribuir al crecimiento personal del profesorado a partir del trabajo sobre su biografía. Aunque como dice Krishnananda (2012), se puede llegar a un mayor conocimiento de uno mismo a partir de otras estrategias:

Estoy convencido, de acuerdo con mi propia experiencia, que cuando llevamos la energía dentro y empezamos sinceramente a observarnos a nosotros mismos sucede la transformación. Ni siquiera tenemos que preocuparnos de desenterrar recuerdos del pasado o de la niñez, pues nuestras relaciones importantes traen consigo todos los patrones, todas las heridas, todo el material que necesitamos trabajar (p.84).

Por otra parte, también señalamos futuras líneas de investigación sobre el tema de "educar para ser en la escuela intercultural inclusiva". Aunque la literatura acerca de la educación holística y la educación emocional nos aporta algunas experiencias, podría ser interesante enfocar esta mirada también desde el modelo intercultural inclusivo y conocer más experiencias con esta orientación. Pensamos que futuras investigaciones pueden seguir acercándonos a la integración entre estos modelos, para que se conviertan en una realidad en la educación pública.

Pero, la universidad no puede quedarse indiferente ante estos cambios. Pensamos que una futura línea de investigación podría centrarse en la formación inicial del alumnado de magisterio, en relación a la educación emocional. En 
favorecer el trabajo emocional desde los grados de maestro, y concienciar sobre la importancia de este trabajo en las escuelas y en las aulas de educación infantil y primaria.

Finalmente, si continuáramos nuestra investigación, la mirada la enfocaríamos hacia el mundo interior del alumnado de la clase de Estefanía. Nos centraríamos en conocer cómo gestionan sus emociones, a partir del trabajo que la maestra realiza con ellos, en las asambleas u otras prácticas del aula. También, en observar cambios en las prácticas de Estefanía fruto de un camino de crecimiento personal que ya ha emprendido esta maestra. 
Para finalizar, queremos dedicar unas palabras a esa persona que ha hecho posible encontrar esta nueva mirada en nuestra investigación:

Gracias Estefanía por tu gran sabiduría, por dejarme caminar a tu lado para encontrarme y descubrir que las cosas se pueden ver de otra manera. Que la educación es amor y amando decido vivir este camino. FIN. 


\section{Referencias}

Abdallah-Pretceille, M. (2001). La educación intercultural. Barcelona: IdeaBooks.

Aguado, T. (coord.). (2010). Diversidad cultural y logros de los estudiantes en educación obligatoria. Lo que sucede en las escuelas. Madrid: MECUNED. Estudios del CREADE $n^{\circ} 4$.

Aguado, T. y Ballesteros, B. (2012). Equidad y diversidad en la Educación obligatoria. Revista de Educación, 358, 12-16.

Aguado, T., Gil-Jaurena, I., Mata, P. (2008). El enfoque intercultural en la formación del profesorado; Dilemas y propuestas. Revista complutense de educación, 19(2), 275-292.

Aguilar, C., Alonso, J., Padrós, M. \& Pulido, M. (2010). Lectura dialógica y transformación en las comunidades de aprendizaje. Revista Interuniversitaria de Formación del Profesorado, 67 (24), 31-44.

Aguirre, A.; Sales, A.; Escobedo, P. (2014). Construyendo la escuela intercultural inclusiva desde el diagnóstico social participativo. XI Congreso Internacional, XXXI Jornadas de Universidades y Educación Inclusiva: La Escuela Excluida. Quaderns digitals. NET.

Ainscow, M.; Booth, T.; Dyson, A., Farrell; P., Frankham, J.; Gallannaugh, F.; Howes, A. and Smith, R. (2006). Improving schools, developing inclusion. London: Routledge.

Ainscow, M. (2002). Rutas para el desarrollo de prácticas inclusivas en los sistemas educativos. Revista de Educación, 327, 69-82.

Albert, M. (2007). La Investigación Educativa. Claves Teóricas. Madrid: Mc Graw Hill.

Álvarez-Gayou, J.L. (2005). Cómo hacer investigación cualitativa. 
Fundamentos y metodología. México: Paidós.

Apple, M.W. y Beane, J.A. (2005). Escuelas democráticas. Madrid: Morata.

Argyris, C. and Schön, D. (1996). Organizational learning II: Theory, method and practice, Reading, Mass: Addison Wesley.

Atkinson, R. (1998). The life story interview. London: Sage Publications.

Aubert A.; Duque E.; Fisas M.; Valls, R. (2004). Dialogar y transformar. Pedagogía crítica del siglo XXI. Barcelona: Graó.

Aubert, A.; Flecha, A.; García, C.; Flecha, R.; Racionero, S. (2008). Aprendizaje dialógico en la sociedad de la información. Barcelona: Hipatia Editorial.

Aubert, A.; Garcia, C. y Racionero, S. (2009). El aprendizaje dialógico. Cultura y Educación, 21 (2), 129-139.

Bach, E.; Darder, P. (2002). Sedúcete para seducir. Vivir y educar las emociones. Barcelona: Paidós.

Banks, J. A. (1995). Multicultural education and curriculum transformation. Journal of Negro Education, 390-400.

Bar-On, R., y Parker, J. D. A. (2000). The Bar-On Emotional Quotient Inventory EQ-I: YV: Technical manual. Toronto, Canadá: Multi-Health Systems.

Bartolomé, M. (1992). Diseños y metodología de investigación desde la perspectiva de la educación intercultural. En Educación Intercultural en la Perspectiva de la Europa Unida. (Tomo II. pp. 646-670). X Congreso Nacional de Pedagogía. Salamanca: Imprenta Provincial.

Barton, L. (Comp.) (1998). Discapacidad y sociedad. Madrid: Morata/Fundación Paideia. [Original en inglés en 1998: Disabiliy and society: emerging issues and insights. London: Addison Wesley Longman]

Beck, U. (1998). La sociedad del riesgo. Paidós: Barcelona.

Becker, H.S. (1953). The teacher in the authority system of the public school. Journal of the Educational Sociology, 27, 128-141.

Besalú, X. (2002). Diversidad cultural y educación. Madrid: Síntesis.

Bisquerra, R. (2000). Educación emocional y bienestar. Barcelona: Praxis.

Bisquerra, R. (2003). Educación emocional y competencias básicas para la vida. 
Revista de Investigación Educativa, Vol. 21, nº 1, 7-43.

Bisquerra, R. (2009). Metodología de la investigación educativa. Madrid: La Muralla.

Bisquerra, R. (2011). Educación emocional y bienestar (2ª reimpresión de la 6a ed.). Madrid: CISS Praxis.

Bisquerra, R. y Pérez, N. (2007). Las competencias emocionales. Educación XXI, 10, 61-82.

Blanco, R. (1999). Hacia una escuela para todos y con todos. Boletín del Proyecto principal de educación en América Latina y el Caribe, 48, 55 72.

Bolívar, A. (1997). Liderazgo, mejora y centros educativos. En Medina, A. (coord.): El liderazgo en educación, p. 25 - 46. Madrid: UNED.

Bolívar, A. (1999). Cómo mejorar los centros educativos. Madrid, Síntesis.

Bolívar, A. (2000). Los centros educativos como organizaciones que aprenden. Promesa y realidades. Madrid: La Muralla Colección Aula Abierta.

Bolívar, A. (2010). ¿Cómo un liderazgo pedagógico y distribuido mejora los logros académicos? Revisión de la investigación y propuesta. Magis, Revista Internacional de Investigación en Educación, 3 (5), 79-106.

Bolívar, A., Domingo, J. y Fernández, M. (2001) La investigación biográfico narrativa en educación. Enfoque y metodología. España: La muralla.

Bolívar, A., Moya, J., \& Luengo, F. (2008). Aportaciones teóricas para una educación democrática. En F. y. Luengo, Escuela, familia, comunidad. Claves para la acción (págs. 19 - 80). Madrid: Wolters Kluwer.

Booth, T. y Ainscow, M. (2000). Guía para la evaluación y mejora de la educación inclusiva. Desarrollando el aprendizaje y la participación en las escuelas. Traducido y adaptado por traducción y adaptación: Ana Luisa López, David Durán, Gerardo Echeita, Climent Giné, Esther Miquel, Sebastián Moratalla y Marta Sandoval. Madrid: CSIE y consorcio Interuniversitario para la Educación Inclusiva 
Brisebois, R. (1997). Sobre la confianza. Cuadernos de Empresa y Humanismo, $65,19-31$.

Bruner, J. (1996). The Culture of Education. Cambridge: Harvard University Press.

Bucknall, S. (2009). Children as researchers: exploring issues and barriers in English primary schools. $\mathrm{PhD}$ thesis, The Open University, University of Warwick, UK.

Burkhard, G., (2009) Buscando el hilo de la vida.Madrid: Rudolf Steiner

Cagigal, V. (2005). Trabajar con familias en el contexto escolar. En V. Cagigal (Eds.), Construyendo puentes (pp. 9-24). Madrid: PPC.

Calvo, A., Rodríguez-Hoyos, C., y García, M. (2012). Lo mejor de todo es que nos escucháis. Investigar el aumento de la participación de los estudiantes en los programas de diversificación y de cualificación profesional inicial. Revista de Educación, 359, 164-183.

Carbonell, F. (coord.) (2000): Educació i immigració. Els reptes educatius de la diversitat cultural i l'exclusió social. Barcelona: Mediterrània.

Carreres, A.Ll. y Arnaiz, P. (2010).Evaluación de las Prácticas Educativas del Profesorado de los Centros Escolares: Indicadores de Mejora desde la Educación Inclusiva. REICE. Revista Iberoamericana sobre Calidad, Eficacia y Cambio en Educación, 8 (5), 96-109.

Clark, C. M. y Peterson, P.L. (1990). Procesos de pensamiento de los docentes. En M. C. Witttrock (Eds.). La investigación de la enseñanza, Vol. III. Profesores y alumnos. Madrid: Paidós-MEC.

Cohen, J. (Ed). (1999). Educationg minds and hearts. Social emotional learning and ther passage into adolescence. Nueva York: Teachers College Columbia University.

Cohen, L. y Manion, L. (1990): Métodos de investigación educativa. Madrid: Editorial La Muralla.

Cortés, P. y Núñez, C. (2012). El sujeto que investiga el sujeto investigado. En Rivas, J. I., Hernández, F., Sancho, J. M., Núñez, C. (Eds.), Historias de 
vida en educación: Sujeto, Diálogo, Experiencia. (pp.227-231) Barcelona: Dipòsit Digital UB.

Creemers, B.; Chrispeels, J.; Mortimore, P.; Murphy, J.; Reynolds, D.; Stringfield, S.; Stoll, L.; and Townsend, T. (1998). The future of School Effectiveness and Improvement. School Effectiveness and School Improvement, 9 (2), 125-134.

Damasio, A. (2001). La sensación de lo que ocurre. Cuerpo y emoción en la construcción de la conciencia. Madrid: Debate.

Del Rincón, D. (1997). Metodologies qualitatives orientades a la comprensió. Barcelona: Ediuoc.

Delors, J. (1996). La educación encierra un tesoro. Madrid: Santillana/Unesco.

Dewey, J. (1995). Democracia y educación: una introducción a la filosofía de la educación. Madrid: Ediciones Morata.

Domingo, J. (coord.) (2001). Asesoramiento al centro educativo. Colaboración y cambio en la institución. Barcelona: Octaedro.

Dorio I, Sabariego M, Massot I. (2009). Características generales de la metodología cualitativa, En Bisquerra. (Eds) Metodología de la Investigación Educativa. (pp. 275-292) Barcelona: La Muralla (2ª ed).

Dunst, C.J., and Dempsey, I. (2007). Family/professional partnerships and parenting competence, confidence and enjoyment. International Journal of Disability, Development and Education, 54, 305-318.

Durán, D.; Giné, C. i Marchesi, A. (2010). Guia per a l'anàlisi, la reflexió i la valoració de pràctiques inclusives. Barcelona: Departament d'Educació.

Dyson, A. (1999) Inclusion and inclusions: theories and discourses in inclusive education, in: H. Daniels \& P. Garner (Eds.) World yearbook of education. Inclusive Education. (pp. 36-53) London: Kogan Page.

Dyson, A., Howes, A. and Roberts, B. (2004). What do we really know about inclusive schools? A systematic review of the research evidence, in: D. Mitchell (Ed.). Special educational needs and inclusive education: 
major themes in education. London, Routledge Falmer.

Echeíta, G. (2005): Perspectivas y dimensiones críticas en las políticas de atención a la diversidad. Alambique, Didáctica de las Ciencias Experimentales, 44. 7-16.

Echeíta, G. (2011). El proceso de inclusión educativa en España. ¡Quien bien te quiere te hará llorar! CEE Participación Educativa, 18, 117 - 128.

Echeíta, G., Sandoval, M., Illán, N., Domingo, J., Soler, M., Melero, N. y Luengo, F. (Coord.), (2010). Inclusión y educación democrática: éxito para todos a lo largo de la vida. Madrid: Proyecto Atlántida.

Elboj, C., Puigdellívol, I., Soler, M. y Valls, R. (2002). Comunidades de Aprendizaje. Transformar la educación. Barcelona: Graó.

Elias, M. J., Tobias, S. E., and Friedlander, B. S. (2000). Emotionally intelligent parenting: How to raise a self-disciplined, responsible, socially skilled child. New York: Random House/Three Rivers Press.

Elias, M. J., Zins, J. E., Weissberg, R. P., Frey, K. S., Greenberg, M. T., Haynes, N. M., et al. (1997). Promoting social and emotional learning: Guidelines for educators. Alexandria, VA: Association for Supervision and Curriculum Development.

Elliot, J. (1990). La investigación - acción en educación. Madrid: Ediciones Morata.

Elmore, R. (1996). La reestructuración de las escuelas. Buenos Aires/México:FCE.

Epstein, J. L. (2001). School, family, and community partnerships: Preparing educators and improving schools. Boulder, CO: Westview Press.

Escobedo, P., Traver, J., \& Ortells, M. (2013). Desde la cultura profesionalista hacia una escuela intercultural inclusiva. En M. N. Rodríguez, \& A. Barraza Macías (Eds.), Dirección, liderazgo, modelos y procesos de gestión: claves hacia la transformación (pp. 283-318). México: Red Durango de Investigadores Educativos A. C. 
Escobedo, P.; Sales, A.; Traver, J. (2011). La cultura del profesorado en el cambio hacia la escuela inclusiva intercultural. Congreso Mejora Educativa y Ciudadanía Crítica. Universitat Jaume I, Castellón.

Escudero, J. M. (2002) La reforma de la reforma: ¿qué calidad para quiénes? Barcelona: Ariel.

Escudero, J. M. (2006). Educación para la ciudadanía democrática: Currículo, organización de centros y profesorado. En Revilla, F. (coord.) (Eds.). Educación y ciudadanía. Valores para una sociedad democrática. (pp. 19-53), Madrid: Biblioteca Nueva.

Essomba, M.A. (2006). Liderar escuelas interculturales e inclusivas. Equipos directivos y profesorado ante la diversidad cultural y la inmigración. Barcelona: Graó.

Extremera, N. y Fernández-Berrocal, P. (2004). La importancia de desarrollar la inteligencia emocional en el profesorado. Revista Iberoamericana de Educación, 33, 1-9.

Faure, E.; Herrera, F.; Kaddoura, A.R.; Lopes, H.; Petrovski, A.V.; Rahnema, M.; Champion Ward, F. (1973). Aprender a ser, la educación del futuro. Madrid: Alianza Editorial.

Fernández Batanero, F. (2013). Competencias Docentes y Educación Inclusiva. En: Revista Electrónica de Investigación Educativa, 15, (2), 82-99.

Fernández Enguita, M. y Terrén, E. (2008) Presentación. De inmigrantes a minorías: temas y problemas de la multiculturalidad. Revista de Educación, 345, 15-21 1.

Fernández Núñez, L. (2006). ¿Cómo analizar datos cualitativos? Butlletí La Recerca, Ficha 7, pp. 1- 13. Barcelona: Universidad de Barcelona.

Fielding, M. (2001): Students as radical agents of change. Journal of Educational Change, 2, (2), 123-141.

Fielding, M. (2011). La voz del alumnado y la inclusión educativa: una aproximación democrática radical para el aprendizaje intergeneracional. 
Revista Interuniversitaria de Formación del Profesorado, 70 (25, 1), 3161.

Fielding, M. (2012). Beyond Student Voice: Patterns of Partnership and the Demands of Deep Democracy. Revista de Educación, 359, 45-65.

Fink, D. (2000). Good Schools/Real Schools: Why school reform doesn't last. New York: Teachers' College Press.

Flecha, R. (2006-2011). INCLUD-ED. Strategies for inclusion and social cohesion in Europe from education, FP6 028603-2. Sixth Framework Program of Research of the European Commission. Priority 7 Citizens and governance in a knowledge-based society. European Commission

Flecha, R. y Puigvert, L. (2002). Las comunidades de aprendizaje: una apuesta por la igualdad educativa. REXE: Revista de Estudios y Experiencia Educativas, I, Vol. I, pp. 11-20.

Flecha, R., I. Tortajada (1999). Retos y salidas educativas en la entrada del siglo XXI. Los retos del futuro inmediato. Barcelona: Biblioteca de Aula.

Flecha, R., Padrós, M., \& Puigdellívol, I. (2003). Comunidades de Aprendizaje: transformar la organización escolar al servicio de la comunidad. Organización y gestión educativa, 5, 4-8.

Flecha, R.; Gómez, J.; Puigvert, L. (2001). Teoría sociológica contemporánea. Barcelona, Paidós

Flecha, R. (1997). Compartiendo palabras. El aprendizaje de las personas adultas a través del diálogo. Barcelona: Paidós.

Flick, U. (2007). Designing qualitative research (Book one of the SAGE Qualitative Research Kit). London: Sage.

Flutter, J. and Rudduck, J. (2004). Consulting Pupils: What's in it for Schools? London: Routledge Falmer.

Freinet, C. (1972). Por una escuela del pueblo. Barcelona: Fontanella.

Freire, P. (1975). Pedagogía del Oprimido. Madrid: Siglo XXI.

Freire, P. (1979). La conciencia y la historia: la praxis educativa de Paulo Freire (antología). Sao Paulo: Loyola. 
Freire, P. (1996). Educación y participación comunitaria. Experiencias educativas, 29 - 33.

Fullan, M. (1972). Overwiew of innovative process and the use. Interchange, 3, 1-46.

Fullan, M. (1993). Change forces: Probing the depths of educational reform. Londres: Falmer. [Ed. esp.: Las fuerzas del cambio. Explorando las profundidades de la reforma educativa. Madrid: Akal, 2002].

Fullan, M. (2002). El significado del cambio educativo: un cuarto de siglo de aprendizaje. Profesorado, revista de currículum y formación del profesorado, 6 (1-2), 1 - 14.

Fullan, M. y Hargreaves, A. (1996). What's worth fightin for in your school? Nueva York: Teachers College Press. [Ed. española: ¿Hay algo por lo que merezca la pena luchar en la escuela? Trabajar unidos para mejorar. Sevilla: Publicaciones M.C.E.P]

Gairín, J. (2004). La dirección escolar como promotora de los planteamientos institucionales. En Enseñanza, 22, 159-191.

Gale, T., \& Densmore, K. (2007). La implicación del profesorado. Una agenda de democracia radical para la escuela. Barcelona: Octaedro.

Gallegos, R. (2001). Educación Holística. Pedagogía del amor universal. Guadalejara, México: Fundación Internacional para la Educación Holista.

Gardner, H. (1993). Multiple Intelligences: The Theory in Practice. Nueva York: Basic Books.

Gather, M. (2004). Innovar en el seno de la institución escolar. Barcelona: Graó.

Giddens, A. (1995). La constitución de la Sociedad: bases para la teoría de la estructuración. Buenos Aires: Amorrortu editores.

Gil-Jaurena, I. (2012). Observación de procesos didácticos y organizativos de aula en Educación Primaria desde un enfoque intercultural. Revista de Educación, 358., 85-110. 
Gil Jaurena, I. (2009). Diversidad cultural en educación obligatoria. ¿Qué sucede en las escuelas?, En Fernández Montes, Matilde y Mullauer-Seichter, Waltraud (coords.). La integración escolar a debate, (pp. 143-169) Madrid: Pearson / Prentice Hall.

Gillis, R. M. (2007). Cooperative learning: Integrating theory and practice. London: Sage Publications

Giné, C. (2000). Las necesidades de la familia a lo largo del ciclo vital. En Verdugo, M.A. (Eds.), Familias y discapacidad individual, (pp. 19-40). Madrid: FEAPS.

Giné, N.; Parcerisa, A. (2003). Planificación y análisis de la práctica educativa. La secuencia formativa: fundamentos y aplicación. Barcelona: Graó

Goetz, J.P. y Lecompte, M.D. (1988). Etnografía y diseño cualitativo en investigación educativa. Madrid: Morata.

Goleman, D. (1995). Inteligencia emocional. Barcelona: Kairós

Goleman, D. (1998). La práctica de la inteligencia emocional. Barcelona: Kairós

Gómez Mendoza, M. A. (1999). No solo tiza y tablero: epistemología de la pedagogía y de la educación. Mesa redonda magisterio, n. ${ }^{\circ} 48$, Bogotá.

Gómez Rosado, P. (2007). Las asambleas escolares. P@K-EN-REDES Revista Digital del Centro de Profesores de Alcalá de Guadaíra, I, (2). Recuperado de http://pakenredes.cepalcala.org/upload/file_aj14_05_09_7_02_54.pdf.

González, C. (2014). 23 maestros de corazón. Un Salto Cuántico En La Enseñanza (Aprender a ser). Madrid: Desclée.

González, M., y Escudero, J. (1987). Innovación educativa: Teorías y procesos de desarrollo. Barcelona: Humanitas

Goodlad, J., Klein, M. (1970). Behind the classroom door. Worthington, OH: Charles A. Jones

Gozálvez, V., García, R., Traver, J. (2011). El aprendizaje cooperativo desde una perspectiva ética. Estudios sobre Educación, 21, 181-197.

Gross, N., Giacqunita, J. and Bernstein, M. (1971). Implementing organizational 
innovations: A sociological analysis of planned educational change. New York: Harper \& Row, Publishing, Inc.

Guarro, A. (2005). La transformación democrática de la cultura escolar: Una respuesta justa a las necesidades del alumnado de zonas desfavorecidas. Profesorado, revista de currículum y formación del profesorado, 9 (1), $1-48$.

Guerrero, A. (2007). El análisis sociológico del profesorado: categoría social y agente educativo. Educación y futuro, 17, 43 - 70.

Guba, E.G. y Lincoln, Y.S. (1985). Naturalistic Inquiry, Beverly Hills, LA, CA: Sage.

Gutiérrez, J. (2008). Dinámica del grupo de discusión. Madrid: CIS (Colección Cuadernos Metodológicos $\mathrm{n}^{\circ}$ 41).

Habermas, J. (1987) Teoría de la acción comunicativa. I. Racionalidad de la acción y racionalización social. II. Crítica de la razón funcinalista. Madrid: Taurus.

Hargreaves, A. (2003). Enseñar en la sociedad del conocimiento. Barcelona: Octaedro.

Hargreaves, A.; Goodson, I. (2006). Educational change over time? The sustainability and non-sustainability of three decades of secondary school change and continuity. Educational Administration Quarterly 42 (1), 3-41.

Hargreaves, A. \& Fink, D. (2006). El Liderazgo Sostenible. Siete Principios para el Liderazgo en Centros Educativos Innovadores. Madrid: MINEDUC / Ediciones Morata.

Hargreaves, A., \& Fink, D. (2008). El Liderazgo Sostenible. Siete principios para el liderazgo en centros educativos innovadores. Madrid: Morata.

Hargreaves, A. y Fullan, M. (1997). What's worth fighting for out there? Toronto: Ontario Public Schools Teacher Federation.

Hargreaves, A. y Fullan, M. (2014). Capital profesional. Transformar la 
enseñanza en cada escuela. Madrid: Ediciones Morata.

Harris, A. (2004). Distributed leadership and school improvement. Educational Management Administration \& Leadership, 32 (1), 11-24.

Hart, R. (1992). Children's participation: from tokenism to citizenship. Florence: UNICEF/International Child Development Centre.

Hawkins, D. (2014). Dejar ir. El camino de la entrega. Barcelona: El grano de mostaza.

Hernández, F.; Ventura, M. (1992). La organización del currículum por proyectos de trabajo. El conocimiento es un calidoscopio. Barcelona: Graó/Ice de la Universitat de Barcelona.

Hink, P. (2005). Supporting the Development of more Inclusive Practices Using the Index for Inclusion. Educational Psychology in Practice, 21 (2), 117122.

Imbernón, F. (2007). Diez ideas clave. La formación permanente del profesorado. Nuevas ideas para formar en la innovación y el cambio. Barcelona: Graó.

INCLUD-ED. Strategies for inclusion and social cohesion in Europe from education (2006-2011). FP6, Priority 7 (Social Sciences and Humanities), European Commission. www.ub.edu/includ-ed

Jiménez, J. y Pozuelos, F. (2001). Una escuela pública abierta a la comunidad. Investigación en la escuela, 44, pp. 5 - 17.

Jiménez, P., y Vilá, M. (1999). De educación especial a educación en la diversidad. Málaga: Aljibe.

Johnson, D. W., Johnson, R.T. y Holubec. E.J. (1999). El aprendizaje cooperativo en el aula. Buenos Aires: Paidós.

Johnson, D.W. y Johnson, R. (1987). Learning together and alone. New Jersey: Prentice Hall Englewood Cliffs.

Jordán, J. A. (2004). Introducción: la formación permanente del profesorado en educación intercultural. En J. A. Jordán, X. Besalú, M. Bartolomé, M. T. 
Aguado, C. Moreno y M. Sanz (Eds.), La formación del profesorado en educación intercultural (pp. 11-48). Madrid: Catarata

Kagan, S. (1994). Cooperative Learning. San Juan Capistrano, California: Kagan Publishing.

Krishnananda, T. (2012). De la codependencia a la libertad. Cara a cara con el miedo. Madrid: Artes Gráficas COFÁS, S.A.

Lara, S. (2001). Una estrategia eficaz para fomentar la cooperación. Estudios sobre Educación, 1 (99-110).

Lara, L. (2002). Cuando el alumnado toma la palabra. Cuadernos de Pedagogía, (317), 14-19.

Latorre, A. (2007). La investigación- acción. Conocer y cambiar la práctica educativa. Barcelona, España: Grao

Leave, J. y Wenger, E. (1991). Situated learning. Legitimate peripheral participation. Cambridge, United Kingdom: Cambridge University Press.

Leithwood, K. y Louis, K. (1998). Organizational learning in schools. Lisse (Holanda): Swets \& Zeitlinger.

Ley orgánica de educación (LOE) (Ley orgánica 2/2006, de 3 de mayo). Boletín Oficial del Estado, $n^{o}$, 106, 2006, 4 de mayo.

Ley orgánica para la mejora de la calidad educativa (LOMCE) (Ley Orgánica 8/2013, 9 de diciembre). Boletín Oficial del Estado, $n^{o}$ 295, 2013, 10 diciembre.

Lieberman, A. \& Miller, L. (2004). Teacher leadership. San Francisco, CA: Jossey-Bass.

Lipman, P. (1997). Restructuring in context: a case study of teacher participation and the dynamics of ideology, race and power. American Educational Research Journal, 34 (1), 3-37.

Lluch, X. (2003). Multiculturalidad: invisible en los libros de texto. Cuadernos de Pedagogía, 328, 82-86. 
Lobato, X. (2001). Importancia de la cultura escolar para el desarrollo de las escuelas inclusivas. (Tesis Doctoral), Salamanca, España.

López Melero, M. (1997). Escuela pública y atención a la diversidad. La Educación Intercultural: la diferencia como valor. En VVAA (Eds.). Escuela pública y sociedad neoliberal. (pp. 115 - 150). Málaga: Aula Libre.

Mac Gilchrist, B., Myers, K. y Reed, J. (2004). The Intelligent School. Londres: Sage.

Marcelo, C. (1987). El pensamiento del profesor. Barcelona: CEAC.

Marcelo, C. y Estebaranz, A. (1999). Cultura escolar y cultura profesional: los dilemas del cambio. Educar, 24, 47-69.

Martínez Bonafé, J. (1999). Trabajar en la Escuela. Profesorado y Reformas en el umbral del Siglo XXI. Buenos Aires: Miño y Dávila.

Mata, P. y Ballesteros, B. (2012). Diversidad cultural, eficacia escolar y mejora de la escuela: encuentros y desencuentros. Revista de Educación, 358, 17-37.

McCrae, R.R. (2000). Emotional intelligence from the perspective of the fivefactor model of personality. In Bar-On, R. and Parker, J.D.A. (Eds.), The Handbook of Emotional Intelligence (pp.263-276). New York, USA: Jossey-Bass.

Mead, H. (1973). Espíritu, persona y sociedad. Barcelona: Paidós.

Messiou, K. (2013). El compromiso con la voz del alumnado: uso de un marco de trabajo para abordar la marginación en las escuelas. Revista de Investigación en Educación, 11 (3), 97-108.

Miles, M. B. y Huberman, A.M. (1994). Qualitative data analysis: An expanded sourcebook ( $2 \mathrm{a}$ ed.). Thousand Oaks, CA: Sage.

Miller, J. (1996). The Holistic Teacher. Toronto: OISE Press

Mir, C. (1997). ¿Diversidad o heterogeneidad? Cuadernos de Pedagogía, 263, 44- 50.

Molina, S. (2007). Los grupos interactivos: Una práctica de las comunidades de aprendizaje para la inclusión del alumnado con discapacidad. (Tesis 
doctoral), Universitat de Barcelona, Barcelona, España.

Mora, F. (2013). Neuroeducación. Solo se puede aprender aquello que se ama. Madrid: Alianza Editorial.

Moriña, A. (2008). La escuela de la diversidad: materiales de formación para el profesorado. Madrid: Síntesis

Moriña, A. (2011). Aprendizaje cooperativo para una educación inclusiva. Estudios sobre Educación, (21), 199 - 216.

Moriña, A.; Perera, V.H.; Molina, V.M. (2013). Sobre el uso de la Historia de Vida para narrar las trayectorias universitarias del alumnado con diversidad funcional. En: Histórias de Vida em Educação: A Construção do Conhecimento a partir de Histórias de Vida. (pp. 139-146), Universitat de Barcelona.

Mucchielli, R. (1988): L'analyse de contenu de documents et des communications. Connaissance du problem et applications pratiques. Paris: Editions ESF.

Muntaner, J., Pinya, C., y De la Iglesia, B. (2015). Evaluación de los grupos interactivos desde el paradigma de la educación inclusiva. Revista Electrónica Interuniversitaria de Formación del Profesorado, 18 (1), 141-159.

Muñoz-Repiso, M. (1996). La calidad como meta. Cuadernos de Pedagogía, 246, 52-57.

Murillo, F.J. (2002). El clima como factor de eficacia escolar. Organización y Gestión Educativa, 4, 3-7.

Murillo, F.J. (2004). La investigación sobre eficacia escolar a debate. Análisis de las críticas y aportaciones. Tendencias Pedagógicas, 9, 111-131.

Murillo, F. J. (2006). Una dirección escolar para el cambio: del liderazgo transformacional al liderazgo distribuido. Revista Electrónica Iberoamericana sobre Calidad, Eficacia y Cambio en Educación, 4 (4e), 11-24. Recuperado en: http://www.rinace.net/arts/vol4num4e/art2.pdf 
Murillo, F.J. (Coord.) (2001). Mejora de la Eficacia Escolar. Tema del mes de Cuadernos de Pedagogía, 300, 47-74.

Murillo, F.J. y Krichesky, G.J. (2012). El Proceso del Cambio Escolar. Una Guía para Impulsar y Sostener la Mejora de las Escuelas. REICE. Revista Iberoamericana sobre Calidad, Eficacia y Cambio en Educación, 10 (1), 26-43.

O’Connor, U. (2008). Meeting in the middle? A study of parent-professional partnerships. European Journal of Special Needs Education, 23 (3), 253268.

Offir, N. (2012). La pedagogía de proyectos en la escuela: una revisión de sus fundamentos filosóficos y psicológicos. Magis, 685 - 707.

Oliger, E., \& Gatt, S. (2010). De los actos comunicativos de poder a los actos comunicativos dialógicos en las aulas organizadas en grupos interactivos. Special Issue: Communicative acts for social inclusion, Signos, 43 (2), 279-294.

Ortiz, M. y Lobato, X. (2003). Escuela inclusiva y cultura escolar: algunas evidencias empíricas. Bordón, 55 (1), 27-39.

Osuna, C. (2012). En torno a la educación intercultural. Una revisión crítica. Revista de educación, (358), 38-58

Parrilla, A. (2002). Acerca del origen y sentido de la educación inclusiva. Revista de Educación, 327, 11- 29.

Peinado, J.M., Gutiérrez, J. (1994). Métodos y técnicas cualitativas de investigación en ciencias sociales. Madrid: Síntesis Psicología.

Pérez de Lara, N. (1998). La capacidad de ser sujeto. Más allá de las técnicas en educación especial. Barcelona: Editorial Leartes.

Pérez Gómez, A. (1987). El pensamiento del profesor, vínculo entre la teoría y la práctica. Revista de Educación, 284, 213-215.

Pérez Gómez, A. (1985). La comunicación didáctica. Málaga: Servicio de Publicaciones.

Petrou, A.; Angelides, P. y Leigh, J. (2009). Beyond the Differences: from Margins to Inclusion. International Journal of Inclusive Education, 13, 
(5), 439-448.

Piaget, J. (1969). Psicología y pedagogía. Barcelona: Ariel.

Pinkus, S. (2003). All talk and no action: transforming the rhetoric of parentprofessional partnership into practice. Journal of Research in Special Educational Needs, 3 (2), 128 - 241.

Porter, G. L. (Productor). (1994). Teachers Helping Teachers: Problem Solving Teams That Work. [vídeo]. Toronto: The Roeher Institute \& School District 12.

Poveda, D; Sebastián, E. y Moreno, A. (2003). 'La ronda' como evento para la constitución social del grupo en una clase de educación infantil. Infancia y Aprendizaje, 26 (2), 131-146.

Pujadas, J. (2000). El método biográfico y los géneros de la memoria. Revista de Antropología Social, 9, 127 -158.

Pujolàs, P. (2008). 9 ideas clave. El aprendizaje cooperativo. Barcelona: Graó.

Pujolàs, P. (2009). La calidad en los equipos de aprendizaje cooperativo. Algunas consideraciones para el cálculo del grado de cooperatividad. Revista de Educación, 349, 225-239.

Pulido, C. y Zepa, B. (2010). La interpretación interactiva de los textos a través de las tertulias literarias dialógicas. Signos, 43 (2), 279-294.

Renard, G. (2009). La desaparición del universo. California: Hay House.

Reparaz, C., \& Naval, C. (2014). Capítulo 1. Bases conceptuales de la participación de las familias. En C. y. Ministerio de Educación (Eds.), La participación de las familias en la educación escolar (pp. 21 - 34). Madrid: Secretaría General Técnica.

Repetto, E., Pena, M., Mudarra, M.J. \& Uribarri, M. (2007). Guidance in the area of socio-emocional competencies for secondary students in multicultural contexts. Electronic Journal of Research in Educational Psychology, 11(5), 159-178.

Reynolds, D. y otros (1997). Las escuelas eficaces. Claves para mejorar la 
enseñanza. Madrid: Santillana.

Rockwell, E. (2008). Del campo al texto: dilemas del trabajo etnográfico. En: Ma. Isabel Jociles y Adela Franzé (Eds.) ¿Es la escuela el problema? Perspectivas socio-antropológicas de etnografía y educación, (pp. 90103). Madrid: Editorial Trotta.

Rodríguez, C.; Lorenzo, O.; Herrera, L. (2005). Teoría y práctica del análisis de datos cualitativos. Proceso general y criterios de calidad. Revista Internacional de Ciencias Sociales y Humanidades, SOCIOTAM, XV, (2), 133-154.

Rogoff, B. (1993). Aprendices del pensamiento: El desarrollo cognitivo en el contexto social. Madrid: Paidós.

Rojas, S., Haya, I., \& Lázaro, S. (2012). La voz del alumnado en la mejora escolar: niños y niñas como investigadores en Educación Primaria. Revista de Educación, 359, 81 - 101.

Romero, C. (2003). El cambio educativo y la mejora escolar como procesos de democratización. Una experiencia en escuelas secundarias públicas de la ciudad de Buenos Aires. Revista Electrónica Iberoamericana sobre Calidad, Eficacia y Cambio en Educación, 1 (1). Recuperado de file://C:/Users/Administrador/Downloads/Dialnet-

\section{ElCambioEducativoYLaMejoraEscolarComoProcesosDeDem-} $638735 \% 20(1) . p d f$.

Romero, J., Luis, A., García, F. F. y Rozada, J. M. (2006). Formación crítica del profesorado y profesionalidad democrática. Conciencia social, (10), 1368.

Rubin, H.J. y Rubin, I.S. (1995). Qualitative interviewing. The art of hearing data. Thousand Oaks, CA: Sage.

Rudduck, J y Flutter, J. (2007). Cómo mejorar tu centro escolar dando la voz al alumnado. Madrid: Morata.

Rudduck, J. y Fielding, M. (2006). Students voice and the perils of popularity. Education Review, 58 (2), 219-231.

Saarni, C. (2000). Emotional Competence. A Developmental Perspective. En R. 
Bar-On y J. D. A. Parker (Eds.), The Handbook of Emotional Intelligence. Theory, Development, Assessment, and Application at Home, School, and in the Workplace (pp. 68-91). San Francisco, Ca: Jossey-Bass

Sales, A. (2004). Hacia una escuela inclusiva e intercultural: los proyectos de trabajo como propuesta curricular y formativa. XXI. Revista de Educación, 6, 139-153.

Sales, A. (2007). Diversidad en el ámbito escolar: por una educación intercultural inclusiva. Congreso Orientación Educativa y Profesional. Universitat Jaume I, Castellón.

Sales, A; Ferrández, R. y Moliner, O. (2012). Educación intercultural inclusiva: estudio de caso de un proceso de autoevaluación. Revista de Educación, 358, pp. 153-173.

Sales, A.; Traver, A. y García, R. (2011). Action research as a school-based strategy in intercultural professional development for teachers. Teaching and Teacher Education, 27 (5), 911-919.

Salovey, P. y Mayer, J.D. (1990). Emotional intelligence. Imagination, Cognition, and Personality, 9, 185-211.

Sanders, M. G.; Epstein, J. L. (1998). School-family-community partnerships and educational change: International perspectives. En A. Hargreaves, A. Lieberman, M. Fullan, D. Hopkins (Eds.). International Handbook of Educational Change. (482-502). Hingham MA: Kluwer.

Sandín. M.P. (2003). Investigación Cualitativa en Educación. Fundamentos y Tradiciones. Madrid: McGraw Hill.

Santos Guerra, M. A. (2010). Una pretensión problemática: educar para los valores y preparar para la vida. Revista de Educación, 351, 23-47.

Sarason, S. (1971). The culture of the school and the problem of change. Boston: Allyn \& Bacon.

Schön, D. (1983). El profesional reflexivo: Cómo piensan los profesores cuando 
actúan. Barcelona: Paidós.

Scribner, S. (1986). Thinking in action: Some characteristics of practical thought. En Sternberg, J. y Wagner, R.K., (Eds.). Practical intelligence: Nature and origins of competence in the everyday World. (pp. 13-30). Cambridge: Cambridge University Press.

Senge, P. (1992). La quinta disciplina en la práctica. Barcelona: Granica.

Senge, P.; Cambrón-Mc Cabe, N.; Lucas, T.; Smith, B.; Dutton, J.; Kleiner, A. (2002). Escuelas que Aprenden, Un manual de la quinta disciplina para educadores, padres de familia y todos los que se interesen en la educación. Bogotá, Colombia: Editorial Norma.

Slavin, R. E. (1983). Cooperative Learning. New York: Longman

Smith, L. y Keith, P. (1971). Anatomy of educational innovations: An organization analysis of an elementary school. Nueva York. Wiley.

Soler, M. (2001). Dialogic reading. A new understanding of the reading event. (Tesis doctoral), Harvard University, England.

Soodack, L., \& Erwin, E. (2000). Valued member or tolerated participant: parents'experiences in inclusive early childhood settings. Journal of the Association for Person with Severe Handicaps, 25 (1), 29-41.

Stainback, S. y Stainback, W. (1999). Aulas Inclusivas. Madrid: Narcea.

Stake, R. (2007). Investigación con estudio de casos. Madrid: Ediciones Morata.

Stoll, L. y Fink, D. (1999): Para cambiar nuestras escuelas: reunir la eficacia y la mejora. Barcelona: Octaedro.

Susinos, T. (2012). Las posibilidades de la voz del alumnado para el cambio y la mejora educativa. Revista de Educación, 359, 16-23.

Susinos, T. (2013). Desde el mismo lugar no vemos lo mismo. Investigar la participación de los estudiantes como un proceso multivocal. Revista de Investigación en Educación, 11 (3), 120-132

Susinos, T. y Ceballos, N. (2012). Voz del alumnado y presencia participativa en la vida escolar. Apuntes para una cartografía de la voz del alumnado en la mejora educativa. Revista de Educación, 359, 24-44.

Susinos, T. y Parrilla, A. (2008). Dar la voz en la investigación inclusiva. 
Debates sobre inclusión y exclusión desde un enfoque biográficonarrativo. REICE - Revista Electrónica Iberoamericana sobre Calidad, Eficacia y Cambio en Educación, 6, (2), 157-171.

Tedesco, J.C. (2004). Educació i igualtat d'oportunitats en els sistemes educatius. En Bonal, X., Essomba, M.A., Ferrer, F. (Eds.): Política educativa i igualtat d'oportunitats. Prioritats i propostes. (pp. 141-175). Barcelona: Mediterrània/ Fundació Jaume Bofill.

Thomson, P. (2007). Making it Real: Engaging Students in Active Citizenship Projects. En D. Thiessen y A. Cook-Sather (Eds.), International Handbook of Student Experience in Elementary and Secondary School (pp. 775-804). Dordrecht: Springer.

Toro, J. M. (2005). Educar con "Co-razón" (5ª edic.) Bilbao. Desclée de Brouwer.

Torres, J. (2007). Centros escolares y familias en las sociedades multiculturales. Revista Andalucía Educativa, 60, 24 - 27.

Traver, J. (2009). Igualtat i diferència en educació: el difícil equilibri de la inclusió. En AAVV. Una escola per a saber i per a viure sense exclusions (IX Jornades educatives de Cullera), Ajuntament de CulleraCEFIRE-Bromera, Benifaió (Valencia).

Traver, J. y Rodríguez, M. (2010). Los cuadernos de aprendizaje en grupo. Una herramienta para favorecer el aprendizaje cooperativo. Valencia: La Xara-Novadors.

Traver, J.; Sales, A.; Moliner, O. (2010). Ampliando el territorio: algunas claves sobre la participación de la comunidad educativa. REICE (Revista Iberoamericana sobre calidad, eficiencia y cambio en educación) 8, (3), 96-119.

Trujillo, M. y Rivas, L. (2005). Orígenes, evolución y modelos de inteligencia emocional. Revista de ciencias administrativas $y$ sociales, INNOVAR. 15, (25), 9-24. 
Uribe, M. (2005). El liderazgo docente en la construcción de la cultura escolar de calidad: un desafío de orden superior. Revista PREALC 1, 109 - 195.

Valderrama, R. (2012). Los procesos de participación como un espacio educativo de desarrollo de la pedagogía. Cuestiones Pedagógicas, 22, $351-376$.

Velasco, H. y Díaz, A. (1997). La lógica de la investigación etnográfica. Un modelo de trabajo para etnógrafos de la escuela. Madrid: Editorial Trotta.

Vera, M.M. (2009). Aprendizaje cooperativo. Revista digital innovación y experiencias, 14, 1-11.

Vygotsky, L. S. (1996). A formação social da mente: o desenvolvimento dos processos psicológicos superiores. 5.ed. Rio de Janeiro: Martins Fontes.

Waller, W. (1932). The Sociology of teaching. New York: Wiley.

Wells, G. (2001). Indagación dialógica. Hacia una teoría y una práctica sociocultural de la educación. Barcelona: Paidós.

Wenger, E. (1988). Communities of practice: learning, meaning, and identity. Cambridge, MA: Cambridge University Press [Trad. cast.: Comunidades de Práctica. Barcelona: Paidós, 2001].

Wenger, E. (2001). Comunidades de práctica. Barcelona: Paidós

Wilber, K. (1982). La naturaleza de la conciencia. En Walsh, R. y Vaughan, F. (Eds.). Más allá del ego. Textos de psicología transpersonal, (pp. 101174). Barcelona: Kairós.

Wilber, K. (1991). Los Tres Ojos del Conocimiento. La búsqueda de un nuevo paradigma. Barcelona: Editorial Kairós.

Woods, P. (1987). La Escuela por Dentro: La Etnografía en la Investigación Educativa. Buenos Aires: Editorial Paidós.

Yus Ramos, R. (2001). Educación Integral. Una educación holística para el siglo XXI (II). Bilbao: Ed. Desclée De Brouwer

Zabalza, M.A. (2004). Diarios de clase. Un instrumento de investigación y desarrollo profesional. Madrid: Narcea. 
Zambrano, M. (1973). El hombre y lo divino. México, DF: Fondo de Cultura Económica, S.A. 

Anexo

\begin{tabular}{|c|c|}
\hline Referencia en los resultados & Código de la fuente \\
\hline \multicolumn{2}{|c|}{$1^{a} F A S E$ ETNOGRAFÍA } \\
\hline \multicolumn{2}{|c|}{ REUNIONES CLAUSTRO } \\
\hline $1^{\mathrm{a}}$ Reunión & $1^{\mathrm{a}} .20 .1 .12$. Contacto tesis. \\
\hline $2^{\mathrm{a}}$ Reunión & $2^{\mathrm{a}} \cdot 10.2 .12$. Sueños equipo directivo. \\
\hline $3^{\mathrm{a}}$ Reunión & $3^{\text {a }}$ 15.2.12. Sueños comisión del proyecto. \\
\hline $4^{\mathrm{a}}$ Reunión & $\begin{array}{l}4^{\mathrm{a}} \text {. 24.2.12. Reunión comisión proyecto y } \\
\text { familias sueños. }\end{array}$ \\
\hline $5^{\mathrm{a}}$ Reunión & $5^{\mathrm{a}}$. 29.2.12. Información al claustro. \\
\hline $6^{\text {a Reunión }}$ & $6^{\mathrm{a}}$. 06.3.12. Claustro, comisiones. \\
\hline $7^{\mathrm{a}}$ Reunión & $7^{\mathrm{a}}$. 3.4.12. Claustro proyecto tesis. \\
\hline $8^{a}$ Reunión & $\begin{array}{l}8^{\text {a }} .18 .5 .12 \text {. Reunión equipo directivo. Balance } \\
\text { y organización sesiones. }\end{array}$ \\
\hline $9^{a}$ Reunión & $\begin{array}{l}\text { 9a. 08.06.12. Preparación sesión de DSP. } \\
\text { Equipo directivo. }\end{array}$ \\
\hline \multicolumn{2}{|c|}{ SEMINARIO DE FORMACIÓN } \\
\hline Sesión 1 , seminario de formación. & 25.04.12.1 ${ }^{\mathrm{a}}$ Sesión. Proyectos de trabajo. \\
\hline Sesión 2, seminario de formación. & 2.5.12. $2^{\mathrm{a}}$ Sesión. Proyectos de trabajo (II). \\
\hline Sesión 3, seminario de formación. & $\begin{array}{l}\text { 9.5.12. } 3^{\text {a }} \text { Sesión. Grupos interactivos, lectura } \\
\text { en pareja y tertulias. }\end{array}$ \\
\hline
\end{tabular}




\begin{tabular}{|c|c|}
\hline Referencia en los resultados & Código de la fuente \\
\hline Sesión 4, seminario de formación. & $\begin{array}{l}4^{\mathrm{a}} .23 .5 .12 .4^{\mathrm{a}} \text { Sesión. Reflexiones, dudas, } \\
\text { sesión de trabajo, planifican acciones. }\end{array}$ \\
\hline Sesión 5, seminario de formación. & $\begin{array}{l}\text { 6.6.12. } 5^{\mathrm{a}} \text { Sesión. Compartir experiencia } \\
\text { realización de acciones. Compromisos curso } \\
2012-2013 \text {. }\end{array}$ \\
\hline \multicolumn{2}{|c|}{ GRUPOS DE DISCUSIÓN } \\
\hline Grupo de discusión familias & 19.6.12. Grupo de discusión familias \\
\hline $\begin{array}{l}\text { Grupos de discusión con el } \\
\text { alumnado }\end{array}$ & 18.6.12. Alumnado de $1^{\circ}$ a $3^{\circ}$. \\
\hline $\begin{array}{l}\text { Grupos de discusión con el } \\
\text { alumnado }\end{array}$ & 15.6.12. Alumnado de $4^{\mathrm{o}}$ a $6^{\mathrm{o}}$. \\
\hline Grupo de discusión del comedor & 20.6.12. Grupo de discusión del comedor \\
\hline \multicolumn{2}{|c|}{ ENTREVISTAS A DOCENTES } \\
\hline Entrevista a maestras de infantil & 26.6.12 Entrevista \\
\hline Entrevista a primer ciclo & 26.6.12 Entrevista a primer ciclo \\
\hline Entrevista a Estefanía & 26.6.12 Entrevista a Estefanía \\
\hline Entrevista a segundo ciclo & 27.6.12 Entrevista a segundo ciclo \\
\hline $\begin{array}{l}\text { Entrevista a maestro de segundo } \\
\text { ciclo }\end{array}$ & 26.6.12 Entrevista a maestro de segundo ciclo \\
\hline $\begin{array}{l}\text { Entrevista a maestra de tercer } \\
\text { ciclo }\end{array}$ & 27.6.12 Entrevista a maestra de tercer ciclo \\
\hline Entrevista a maestra especialista 1 & 27.6.12 Entrevista a maestra especialista \\
\hline
\end{tabular}




\begin{tabular}{|c|c|}
\hline Referencia en los resultados & Código de la fuente \\
\hline Entrevista a maestro especialista 2 & 27.6.12 Entrevista a maestro especialista \\
\hline Entrevista equipo directivo & 3.7.12 Entrevista equipo directivo \\
\hline \multicolumn{2}{|c|}{$2^{a}$ FASE ETNOGRAFIA E HISTORIA DE VIDA } \\
\hline Sesión de APS & APS.21.11.12. \\
\hline COCOPE & COCOPE 10.12.12. \\
\hline Sesión Sant Nicolau & DSN (DINAR SANT NICOLAU) 05.12.12. \\
\hline $\begin{array}{l}\text { Evaluación final trimestre, clase } \\
\text { Estefanía }\end{array}$ & Av. 12.12.12. \\
\hline Sesión final de trimestre & 21.12 .12 \\
\hline $\begin{array}{l}\text { Reunión claustro, segundo curso } \\
\text { transformación }\end{array}$ & Claustre. 4.12.12. \\
\hline Comisión comedor & CM.29.11.12. \\
\hline \multicolumn{2}{|c|}{ REUNIÓN CICLO } \\
\hline $1^{\mathrm{a}}$ Reunión ciclo & $\mathrm{RC} 1.14 .11 .12$ \\
\hline $2^{a}$ Reunión ciclo & RC2. 23.11.12. \\
\hline $3^{\mathrm{a}}$ Reunión de ciclo & RC3. 28.11.12. \\
\hline \multicolumn{2}{|c|}{ CONSEJO SOCIAL } \\
\hline 1er CS & $1^{\circ} \mathrm{CS}$. \\
\hline
\end{tabular}




\begin{tabular}{|c|c|}
\hline Referencia en los resultados & Código de la fuente \\
\hline $\begin{array}{l}\text { Sesión tutorización a las familias } \\
\text { para el } 2^{\circ} \mathrm{CS}\end{array}$ & $\begin{array}{l}\text { 17.12.12. (Nombre de informante, en cada } \\
\text { caso). }\end{array}$ \\
\hline $\begin{array}{l}\text { Sesión tutorización al alumnado } \\
\text { para el } 2^{\circ} \mathrm{CS}\end{array}$ & $\begin{array}{l}\text { 17.12.12. (Nombre de informante, en cada } \\
\text { caso). }\end{array}$ \\
\hline $2^{\circ} \mathrm{CS}$ & $2^{\circ} \mathrm{CS}$ \\
\hline \multicolumn{2}{|c|}{ PRÁCTICAS DE AULA } \\
\hline $1^{\mathrm{a}}$ Asamblea clase Estefanía & AR. 23.11.12. \\
\hline $2^{a}$ Asamblea clase Estefanía & AR. 26.11.12. \\
\hline $3^{\mathrm{a}}$ Asamblea clase Estefanía & AR. 29.11.12. \\
\hline $4^{\mathrm{a}}$ Asamblea clase Estefanía & AR. 3.12.12. \\
\hline $5^{\mathrm{a}}$ Asamblea clase Estefanía & AR. 10.12.12. \\
\hline $6^{a}$ Asamblea clase Estefanía & AR. 12.12.12. \\
\hline $7^{a}$ Asamblea clase Estefanía & AR. 19.12.12. \\
\hline $1^{\text {a }}$ Sesión proyectos de trabajo & AR. 23.11.12. \\
\hline $2^{\text {a }}$ Sesión proyectos de trabajo & AR. 26.11.12. \\
\hline $3^{\text {a }}$ Sesión proyectos de trabajo & AR. 29.11.12. \\
\hline $4^{\mathrm{a}}$ Sesión proyectos de trabajo & AR. 3.12.12. \\
\hline $1^{\mathrm{a}}$ sesión rutina clase Estefanía & AR. 10.12.12. \\
\hline $2^{\mathrm{a}}$ sesión rutina clase Estefanía & AR. 12.12.12. \\
\hline $3^{\mathrm{a}}$ sesión rutina clase Estefanía & AR. 19.12.12. \\
\hline $4^{\mathrm{a}}$ sesión rutina clase Estefanía & AR. 23.11.12. \\
\hline
\end{tabular}




\begin{tabular}{|c|c|}
\hline Referencia en los resultados & Código de la fuente \\
\hline $5^{\mathrm{a}}$ sesión rutina clase Estefanía & AR. 26.11.12. \\
\hline $6^{\mathrm{a}}$ sesión rutina clase Estefanía & AR. 29.11.12. \\
\hline $7^{a}$ sesión rutina clase Estefanía & AR. 3.12.12. \\
\hline $1^{\mathrm{a}}$ Tertulia & T. 23.11.12. \\
\hline $2^{\mathrm{a}}$ Tertulia & T. 29.11.12. \\
\hline $1^{\mathrm{a}}$ sesión GI & P.GI.21.11.12. \\
\hline $2^{\mathrm{a}}$ sesión GI & GI (2) 28.11.12. \\
\hline $3^{\mathrm{a}}$ sesión GI & GI (3) 12.12.12. \\
\hline $4^{\mathrm{a}}$ sesión, contraste con GI & PCGI (4) 19.12.12. \\
\hline $1^{\mathrm{a}}$ sesión, proyecto de Trabajo & PT. 23.11.12. \\
\hline $2^{\mathrm{a}}$ sesión, proyecto de Trabajo & PT. 26.11.12. \\
\hline $3^{\mathrm{a}}$ sesión, proyecto de Trabajo & PT. 3.12.12. \\
\hline $4^{\mathrm{a}}$ sesión, proyecto de Trabajo & PT. 10.12.12. \\
\hline \multicolumn{2}{|c|}{ HISTORIA DE VIDA } \\
\hline $\begin{array}{l}\text { Primera entrevista historia de vida } \\
\text { (Pasado). }\end{array}$ & 3.11 .12 . \\
\hline $\begin{array}{l}\text { Segunda entrevista historia de } \\
\text { vida (Pasado). }\end{array}$ & 8.11 .12 \\
\hline $\begin{array}{l}\text { Tercera entrevista, historia de } \\
\text { vida investigadora. }\end{array}$ & 14.11.12. \\
\hline $\begin{array}{l}\text { Cuarta entrevista, historia de vida } \\
\text { (Presente). }\end{array}$ & 26.11 .12$. \\
\hline $\begin{array}{l}\text { Quinta entrevista, historia de vida } \\
\text { (Presente y futuro). }\end{array}$ & 28.11 .12 \\
\hline
\end{tabular}




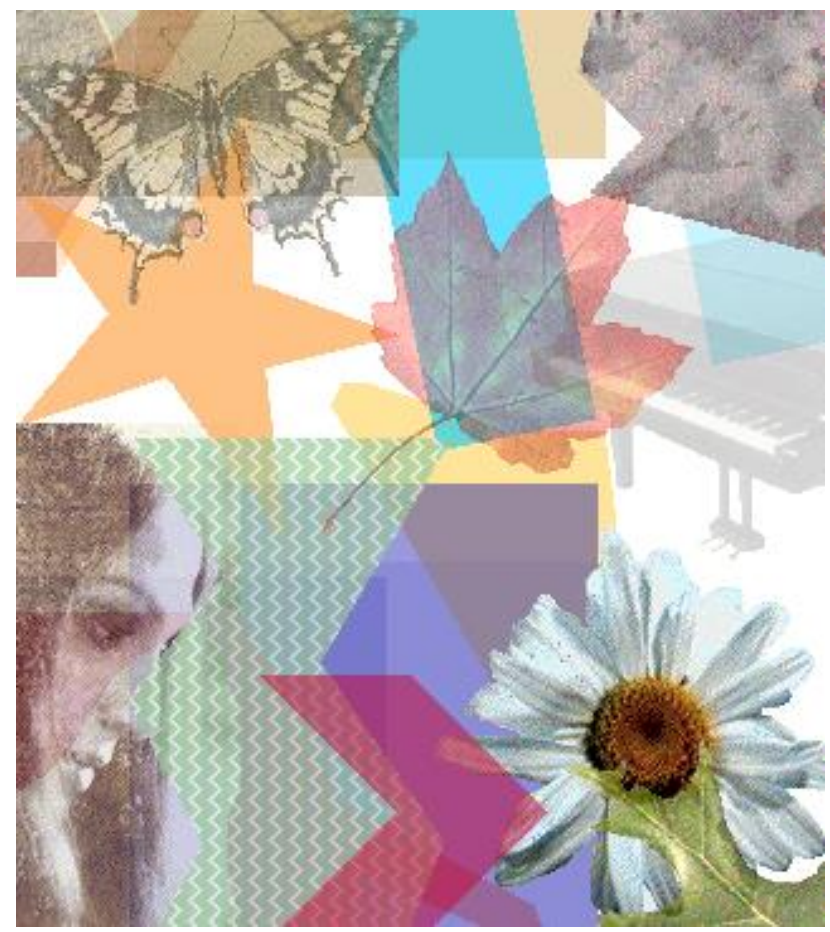

"I... tornarà a eixir el sol". 